\title{
Development of a Design Tool for Modern Gas \\ Turbine Combustors and Commissioning of a Gas Turbine Combustion Research Laboratory
}

\author{
by \\ Michele Capurro \\ B. Eng, Carleton, 2004 \\ A thesis submitted to the Faculty of Graduate Studies and Research \\ In partial fulfillment of the requirements for the degree of
}

\section{Master of Applied Science}

Ottawa-Carleton Institute for Mechanical and Aerospace Engineering

\author{
Department of Mechanical and Aerospace Engineering \\ Carleton University \\ Ottawa, Ontario \\ Canada
}

April 2008

(C) Copyright by Michele Capurro, 2008 


$\begin{array}{ll}\begin{array}{l}\text { Library and } \\ \text { Archives Canada }\end{array} & \begin{array}{l}\text { Bibliothèque et } \\ \text { Archives Canada }\end{array} \\ \begin{array}{l}\text { Published Heritage } \\ \text { Branch }\end{array} & \begin{array}{l}\text { Direction du } \\ \text { Patrimoine de l'édition }\end{array} \\ \begin{array}{l}\text { 395 Wellington Street } \\ \text { Ottawa ON K1A 0N4 } \\ \text { Canada }\end{array} & \begin{array}{l}\text { 395, rue Wellington } \\ \text { Ottawa ON K1A 0N4 } \\ \text { Canada }\end{array}\end{array}$

Your file Votre référence ISBN: 978-0-494-40634-2

Ourfile Notre référence

ISBN: 978-0-494-40634-2

NOTICE:

The author has granted a nonexclusive license allowing Library and Archives Canada to reproduce, publish, archive, preserve, conserve, communicate to the public by telecommunication or on the Internet, loan, distribute and sell theses worldwide, for commercial or noncommercial purposes, in microform, paper, electronic and/or any other formats.

The author retains copyright ownership and moral rights in this thesis. Neither the thesis nor substantial extracts from it may be printed or otherwise reproduced without the author's permission.
AVIS:

L'auteur a accordé une licence non exclusive permettant à la Bibliothèque et Archives Canada de reproduire, publier, archiver, sauvegarder, conserver, transmettre au public par télécommunication ou par l'Internet, prêter, distribuer et vendre des thèses partout dans le monde, à des fins commerciales ou autres, sur support microforme, papier, électronique et/ou autres formats.

L'auteur conserve la propriété du droit d'auteur et des droits moraux qui protège cette thèse. $\mathrm{Ni}$ la thèse ni des extraits substantiels de celle-ci ne doivent être imprimés ou autrement reproduits sans son autorisation.
In compliance with the Canadian Privacy Act some supporting forms may have been removed from this thesis.

While these forms may be included in the document page count, their removal does not represent any loss of content from the thesis.
Conformément à la loi canadienne sur la protection de la vie privée, quelques formulaires secondaires ont été enlevés de cette thèse.

Bien que ces formulaires aient inclus dans la pagination, il n'y aura aucun contenu manquant.

\section{Canada}




\begin{abstract}
In response to rising environmental concerns, Natural Resources Canada contracted the Mechanical and Aerospace Engineering Department of Carleton University to develop a preliminary design for a $50 \mathrm{~kW}$ zero-emission power plant. The work presented in this thesis focuses on the microturbine combustor for this particular type of power plant.

The first major task was the development of a design tool for the design of gas turbine combustors. The design methodology is largely based on established empirical and semiempirical correlations for conventional gas turbine combustors. The methodology was updated and supplemented by recent correlations to address the particular issues of modern lean premixed combustor. The preliminary design of a lean premixed gas turbine combustor was generated using the new design tool. The new combustor was manufactured and instrumented, and is ready for testing.

The second major task was the commissioning of a gas turbine combustion research laboratory. The laboratory was designed and constructed so that the performance of the new gas turbine combustor and the accuracy of the design tool could be evaluated at a later time.
\end{abstract}




\section{ACKNOWLEDGEMENTS}

I am especially grateful to Dr. Donald Gauthier for giving me the opportunity to work on such an interesting and challenging research project. Thank you whole-heartedly for all the supervision, guidance and professional advice you have given me throughout this thesis.

My gratitude goes out as well to the staff at Environment Canada. A special thank you is expressed to Jim Fearn, Guy Bracewell, Peter Barton and Fred Hendren for their support during this effort.

I would also like to acknowledge the Mechanical and Aerospace Department at Carleton University. Many thanks goes to Ms. Christie Egbert and Ms. Nancy Powell for all the administrative support and Mr. Alex Proctor and Kevin Sangster for letting me use the mechanical workshop and, more importantly, for the valuable assistance and expertise.

A special thank you goes out to Mr. Get Nuñez for supporting my enrolment in the Master's program and for providing parts needed for the research laboratory.

I would like to acknowledge and express my deep gratitude to Dr. Ali Mahallati for all his generous assistance.

A much felt thank you goes to Mr. Carlo Rea and Scanivalve Corporation who donated an expensive piece of equipment to the research laboratory.

My utmost respect and gratitude is expressed to a true gentleman, my father-in-law David Emery. I whole-heartedly thank you for all the unconditional support and love given to me over the years.

Words can not express the gratitude and appreciation I feel towards my wife, Audrey, who sacrificed so much through the years so that I could fulfil my ambitions. I also thank you for your time and patience in editing my thesis.

I would like to thank my family in Italy for the wisdom, guidance and help provided to me throughout the years.

Finally, I would like to thank everybody who contributed to the successful realization of this thesis, while expressing at the same time my apologies for not being able to mention you personally one by one. 


\section{TABLE OF CONTENTS}

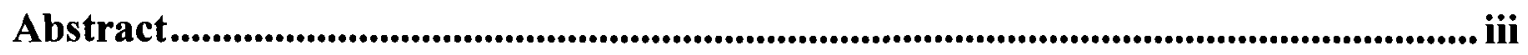

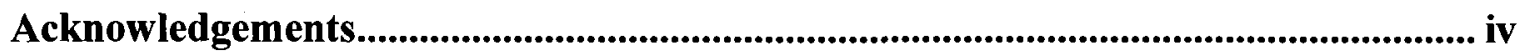

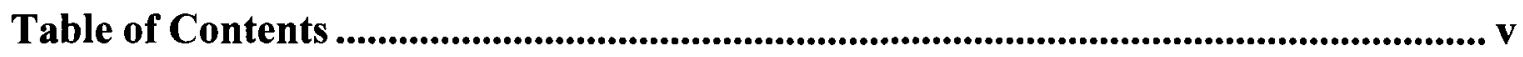

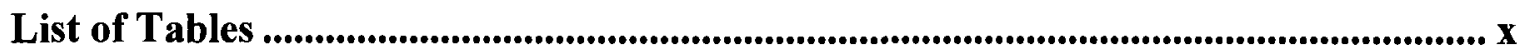

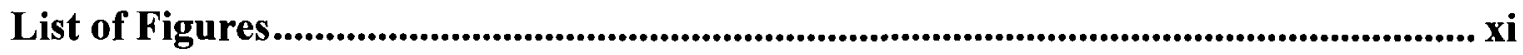

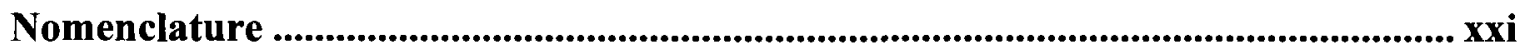

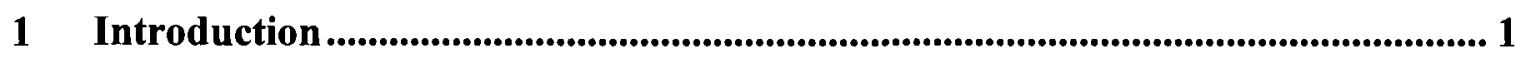

1.1 Research Project Overview ................................................................. 1

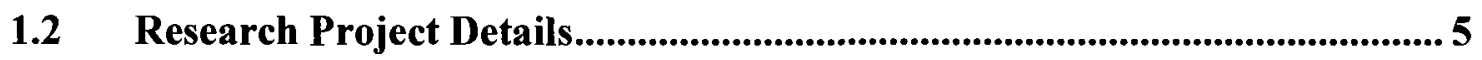

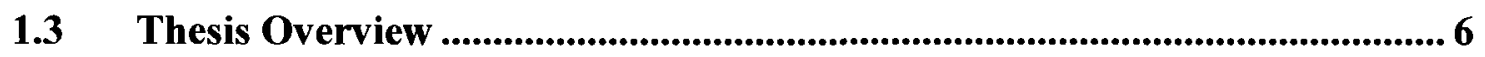

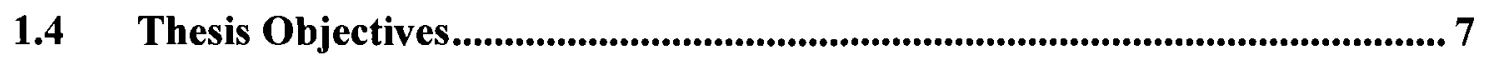

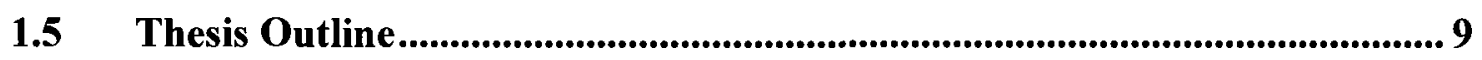

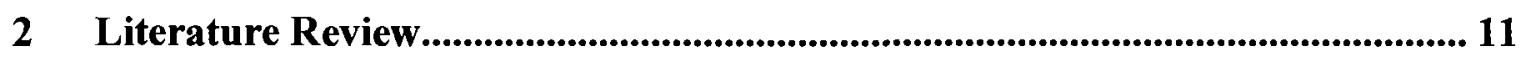

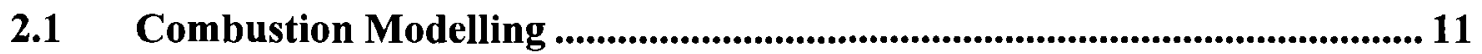

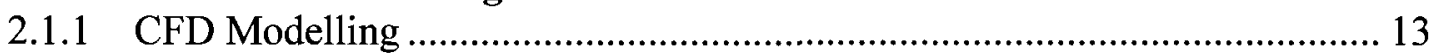

2.1.2 Reactor Theory Modelling ............................................................... 18

2.1.3 Empirical and Semi-empirical Design Methodology ................................. 22

2.2 Manufacturing of Combustor and Gas Turbine Combustion Research

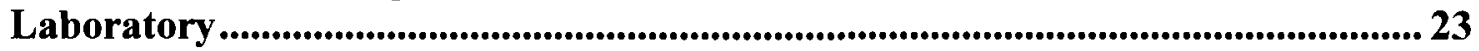

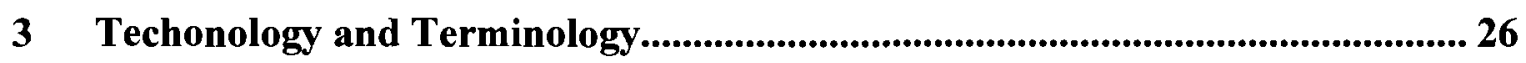

3.1 Gas Turbine Layout and Cycle Analysis .................................................. 26

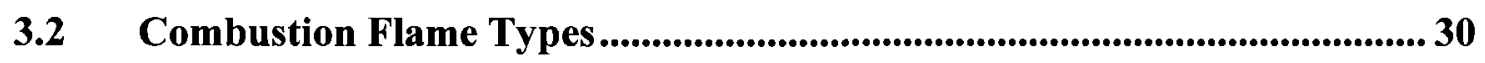

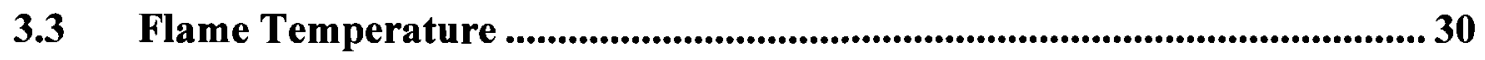

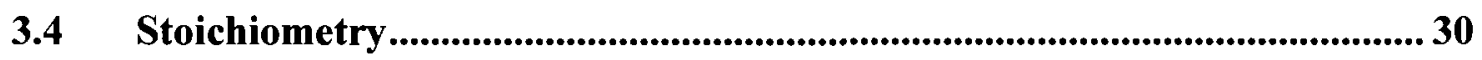

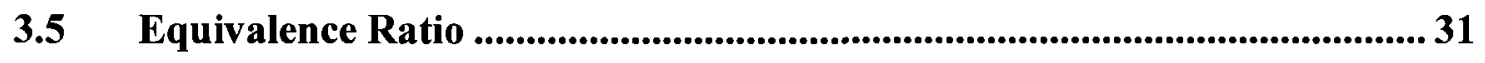




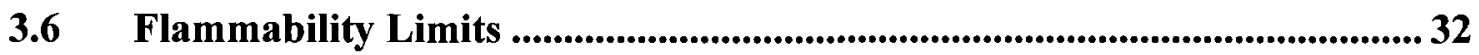

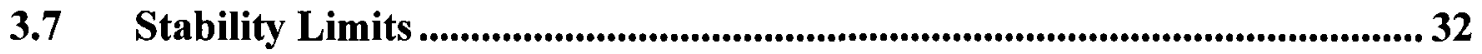

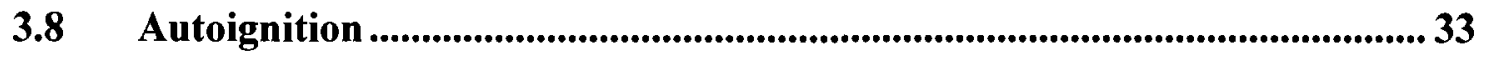

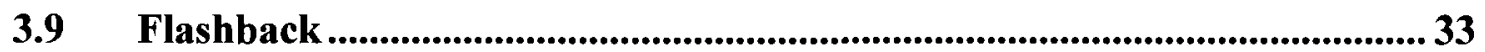

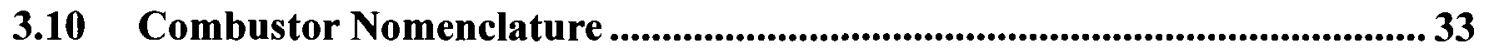

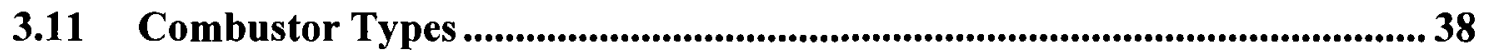

4 Design Methodology for the Preliminary Design of a Gas Turbine Combustor40

4.1 Combustor Preliminary Design Approach ............................................. 42

4.2 Equivalence Ratio Estimation........................................................................ 44

4.3 Adiabatic Flame Temperature and Mixture Mole Fractions .................... 45

4.4 Liner Air Mass Flow Rate Distribution .............................................52

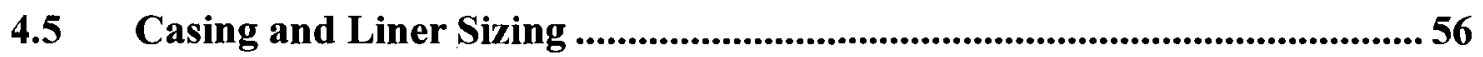

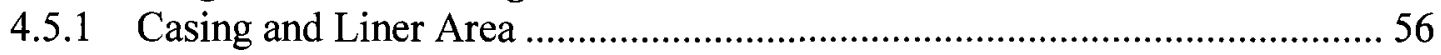

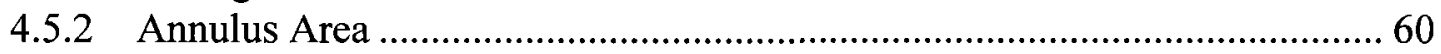

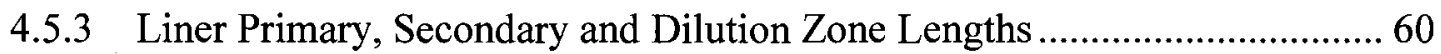

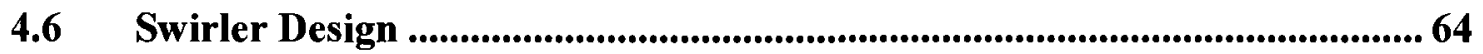

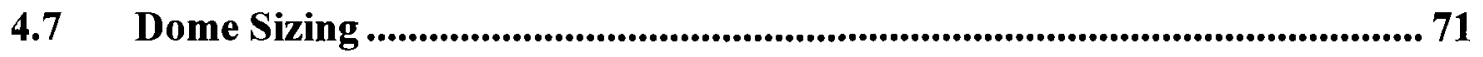

4.8 Combustor Resizing for Lean Premixed Combustion ................................ 74

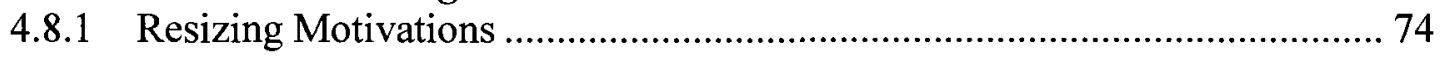

4.8.2 Resizing Approach for Lean Premixed Combustors................................ 76

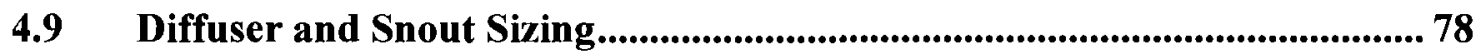

4.10 Liner Cooling Mechanism ................................................................... 84

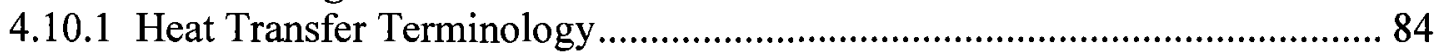

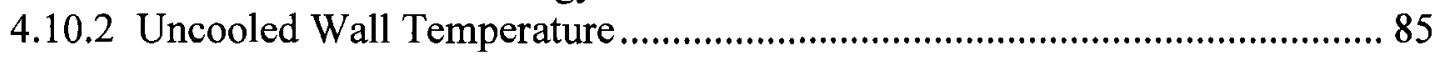

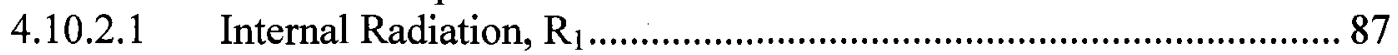

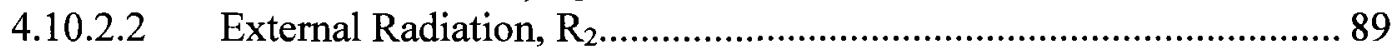

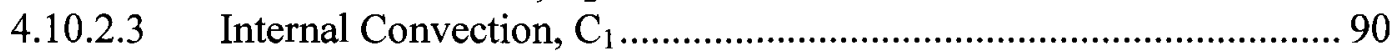

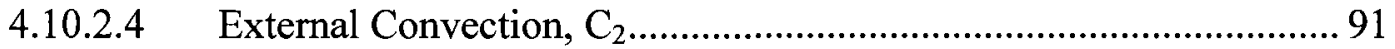

4.10.2.5 Calculation of Uncooled Liner Wall Temperature .......................... 92

4.10.3 Calculation of Cooled Liner Wall Temperature and Cooling Mass Flow .... 93

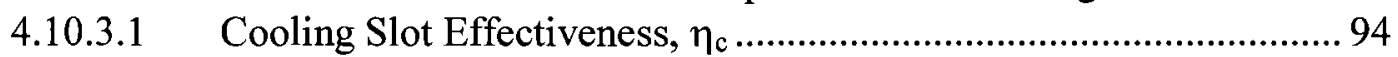

4.10.3.2 Equivalent Hot Gas Temperature, $\mathrm{T}_{\mathrm{g}}{ }^{\prime}$.............................................. 95 


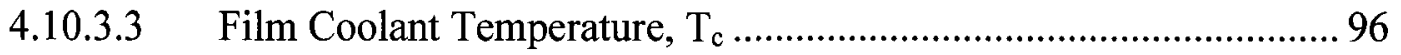

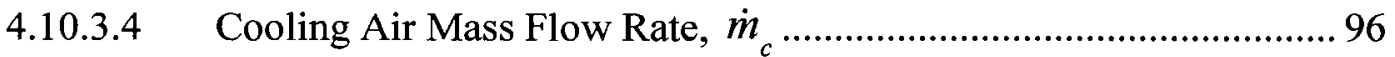

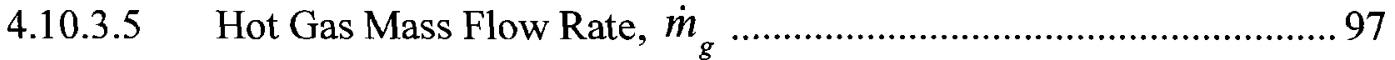

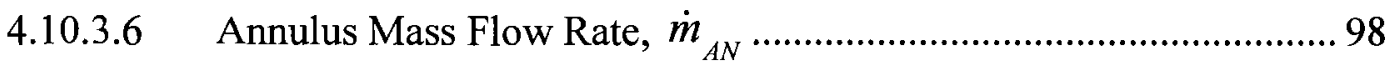

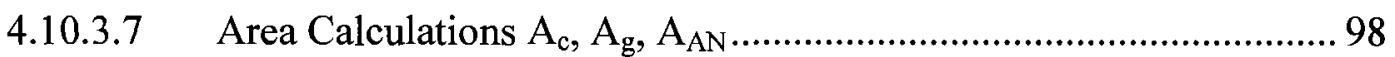

4.10.3.8 Calculation of Cooled Wall Temperature ………………….............. 98

4.11 Injection Hole Sizing.................................................................................. 99

4.12 Fuel Injection Theory …........................................................................ 106

4.12.1 Fuel Atomization Process .......................................................................... 107

4.12.2 Droplet Evaporation Process and Evaporation Model.................................. 111

4.12.3 Droplet Motion.................................................................................. 118

4.12.4 Ignition Process and Ignition Model......................................................... 120

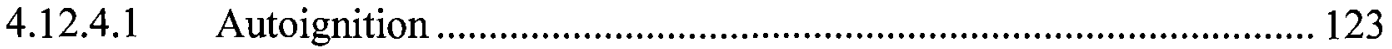

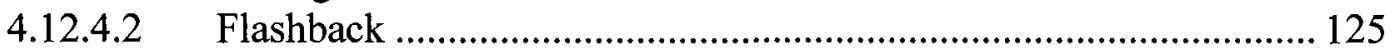

4.13 Pollutant Emissions Prediction ........................................................................... 125

4.14 Combustor Structural Considerations........................................................... 127

5 Combustor Preliminary Design Geometry ............................................................... 131

5.1 Preliminary Geometry of Lean Premixed Combustor .................................... 131

5.1.1 Design Considerations ............................................................................. 133

5.1.2 Overview of Combustor Dimensions.......................................................... 134

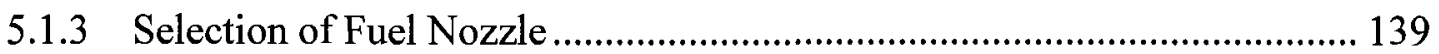

5.1.4 Selection of Ignition System ................................................................. 140

6 Premixed Combustor Manufacturing Process ............................................................ 142

6.1 Material Overview for Engine Hot Section Components............................. 142

6.2 Selection of Combustor Liner Material .......................................................... 145

6.3 Overview of Superalloys Manufacturing Processes......................................... 146

6.4 Overview of Superalloys Joining Processes ...................................................... 147

6.5 Selection of the Combustor Liner Manufacturing Method ........................ 150

6.6 Combustor Casing Material Selection .......................................................................... 157

6.7 Selection of Combustor Casing Manufacturing Method............................... 159

$6.8 \quad$ Liner Casing Assembly ..................................................................................... 161 
6.9 Premixer Manufacturing Process............................................................ 164

6.10 Fuel Nozzle Modifications .......................................................................... 166

7 Gas Turbine Combustion Research Laboratory.................................................... 170

7.1 Gas Turbine Combustion Research Laboratory Layout and Location... 170

7.2 Gas Turbine Room ..................................................................................173

7.2.1 Allison 250-C20B Overview ………………….................................. 173

7.2.2 Allison 250-C20B Air Flow Path.......................................................... 175

7.2.3 Allison 250-C20B Engine Modifications …………............................... 176

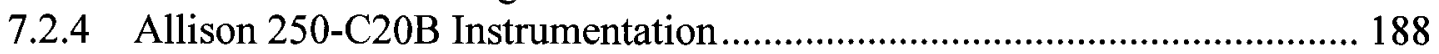

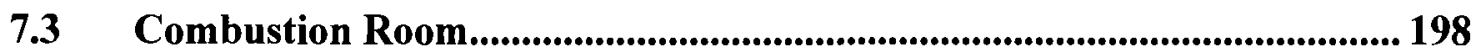

7.3.1 High Pressure Air Delivery System ......................................................... 199

7.3.2 Air Delivery System Design and Flow ...................................................... 199

7.3.3 Air Delivery System Components ............................................................. 211

7.3.4 Air Delivery System Instrumentation ...................................................... 219

7.3.4.1 Microturbine Combustor Instrumentation ......................................... 219

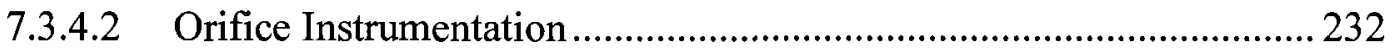

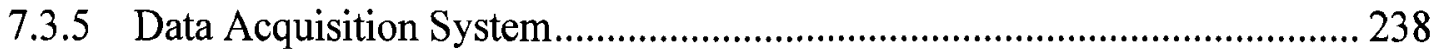

7.3.6 Atmospheric Pressure Air Delivery System ............................................... 240

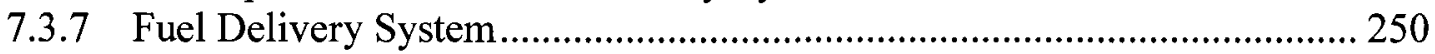

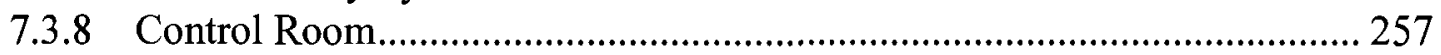

8 Instrument Calibration Process and Shakedown Tests........................................ 266

8.1 Thermocouples Calibration .............................................................................. 266

8.2 Pressure Transducers Calibration ....................................................................... 268

8.3 Pressure Probes Calibration ..................................................................... 271

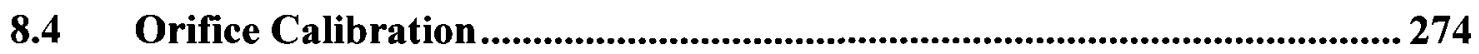

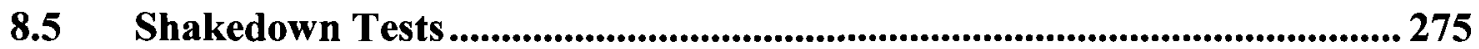

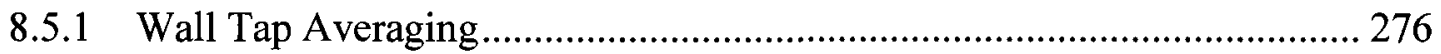

8.5.2 Leak Tests of Instrumentation Pressure Lines ........................................ 277

8.5.3 Air Delivery System Pressure Leak Tests................................................ 279

8.5.4 Air Delivery System Shakedown Tests ............................................. 280

8.5.5 Repeatability Shakedown Tests ....................................................... 282

8.5.6 Fuel Delivery System Shakedown Tests.................................................. 284

8.5.7 Allison 250-C20B Shakedown Tests ................................................... 287

8.5.8 Bleed Shakedown Tests ............................................................................... 289

9 Conclusions and Recommendations ............................................................ 294 


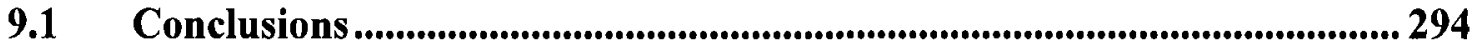

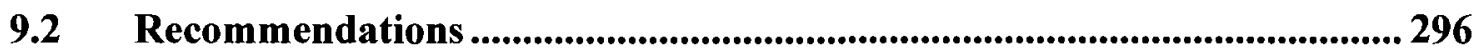

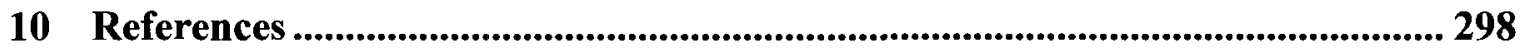

Appendix A : Example of Microturbine Combustor Technical Drawing ................. 305

Appendix B : Materials Properties.......................................................................................................... 307

Appendix C : BETE PJ Model Information .................................................................. 310

Appendix D : Stainless Steel Pipe Diameters....................................................................316

Appendix E : Piping Guide ASME B31.3 .............................................................................. 317

Appendix F : Instrument Calibration Curves....................................................................... 318

Appendix G : Allison 250-C20B Limits and Operating Procedure.............................. 346 


\section{LIST OF TABLES}

Table 1.1 Zero-emission power plant specifications ........................................ 3

Table 4.1 Pressure loss terms for aircraft and industrial engine combustors.......... 58

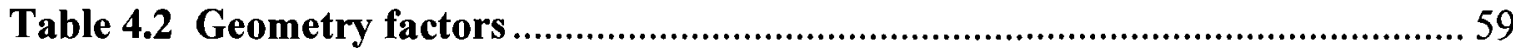

Table 4.3 Emissions index (EI) of modern aircrafts during cruise (Cumpsty,

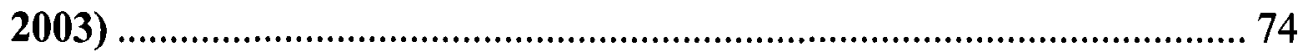

Table 4.4 Summary of empirical constants used in diesel autoignition correlations

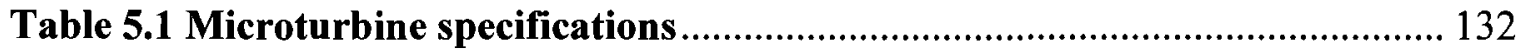

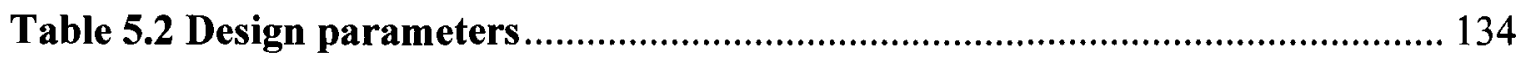

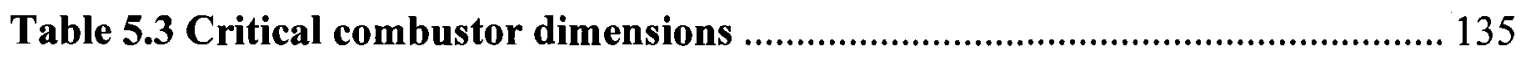

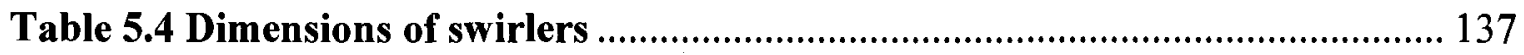

Table 6.1 Operation and maintenance life for typical industrial combustor liner (Adapted from Boyce, 2006)......................................................... 144

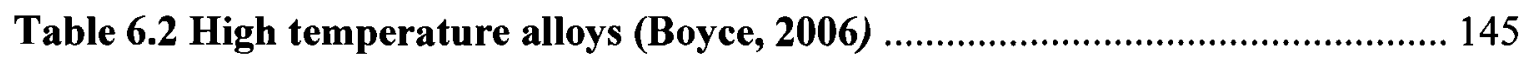

Table 7.1 Air delivery system non-recoverable coefficients ................................. 205

Table 7.2 Predicted thermodynamic performance of T63-A-700 (Haas, 1996) ...... 215

Table 7.3 Calculated thermodynamic performance of Allison 250-C20B .............. 215

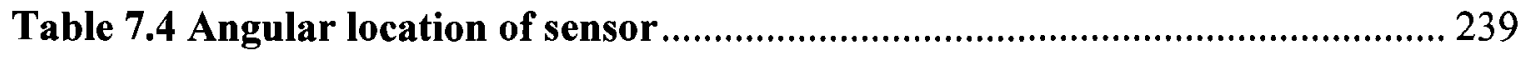




\section{LIST OF FIGURES}

Figure 1.1 Zero-emission power plant cycle schematic .......................................... 4

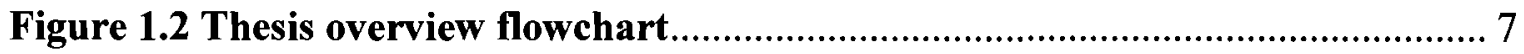

Figure 2.1 CFD modelling process outline (Hansen et al., 2005) ............................ 13

Figure 2.2 Combustor liner unstructured surface mesh (Chok, 2003) .................... 15

Figure 2.3 Bragg combustor, simplest form of an idealized gas turbine combustor (Mattingly et al., 2002) ................................................. 19

Figure 2.4 Idealized gas turbine combustor (Adapted from Allaire, 2006) ............. 20

Figure 3.1 T-s diagram for simple cycle gas turbine used for electrical power generation (Top: Adapted from Rolls-Royce plc, 1996; Bottom:

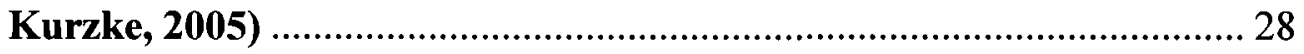

Figure 3.2 Effect of pressure ratio and TIT on cycle thermal efficiency ................. 29

Figure 3.3 Effect of pressure ratio and TIT on specific fuel consumption ............... 29

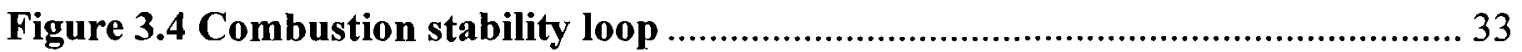

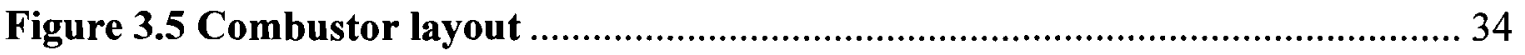

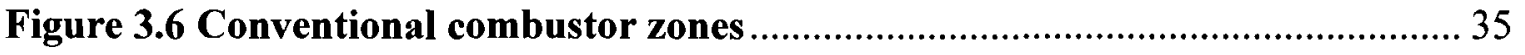

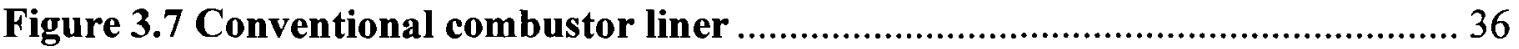

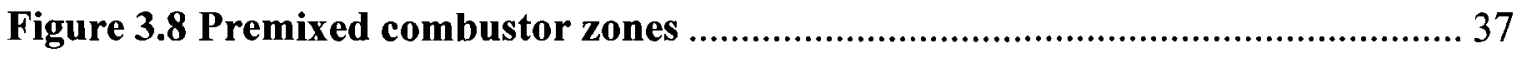

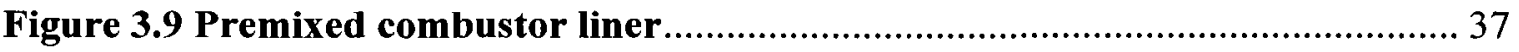

Figure 3.10 Common combustor configurations (Adapted from Rolls-Royce,

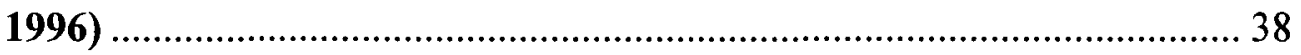

Figure 4.1 Combustor preliminary design algorithm ...................................... 41 
Figure 4.2 Adiabatic flame temperature algorithm .......................................... 48

Figure 4.3 Effect of equivalence ratio on adiabatic flame temperature................... 51

Figure 4.4 Combustor design evolution (Adapted from Cumpsty, 2003) ................ 52

Figure 4.5 Typical conventional combustor air flow distribution ........................... 54

Figure 4.6 Effect of PZ temperature on formation of pollutants for conventional combustor (Adapted from Mattingly, 2002) .................................. 55

Figure 4.7 Premixed combustor air flow distribution .................................... 56

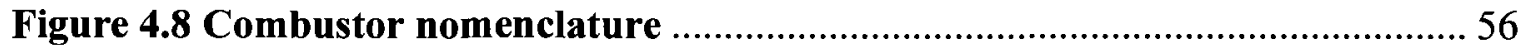

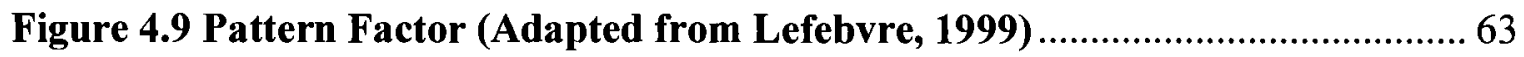

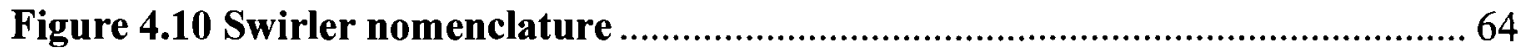

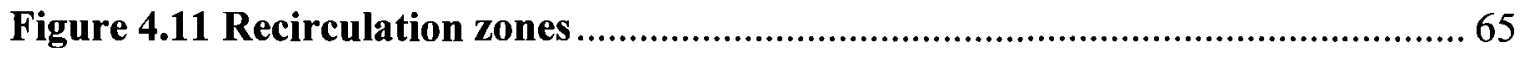

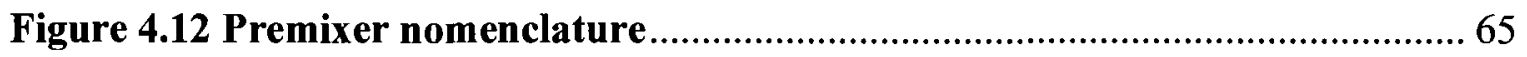

Figure 4.13 Size of recirculation zone as function of swirl number (Adapted

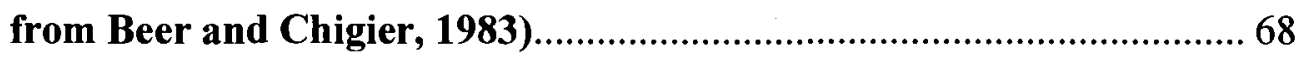

Figure 4.14 Entrainment ratio versus swirl number (Lefebvre, 1999) ................... 70

Figure 4.15 Swirl angle versus solidity (Kilik, 1976) .......................................... 71

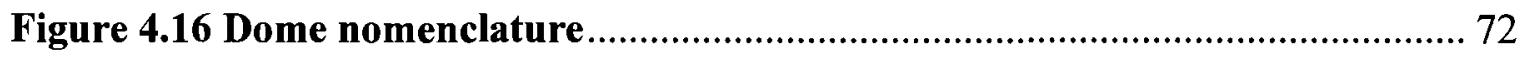

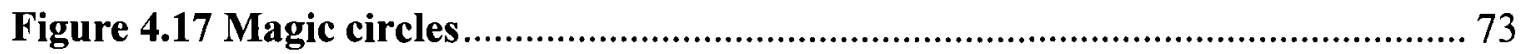

Figure 4.18 Effect of temperature on forward rate coefficient ............................. 76

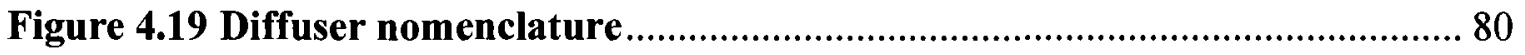

Figure 4.20 Performance chart for conical diffusers (Adapted from Lefebvre,

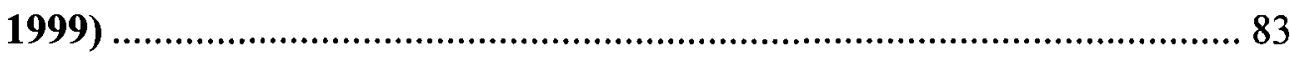

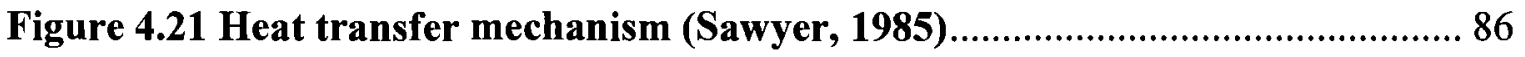


Figure 4.22 Cooling schemes (Rolls-Royce plc, 1996)

Figure 4.23 Effect of hole pressure drop coefficient on discharge coefficient (Adapted from Kaddah, 1964) 104

Figure 4.24 Effects of hole pressure loss factor and hole geometry on discharge coefficient (Freeman, 1965) 104

Figure 4.25 Injection hole nomenclature (Adapted from Lefebvre, 1999) ............... 105

Figure 4.26 Program algorithm for single droplet evaporation ............................ 113

Figure 4.27 $\mathrm{D}^{2}$ law for droplet evaporation using simplified analysis..................... 118

Figure 4.28 Droplet particle trajectory (Charest, 2005) ........................................... 119

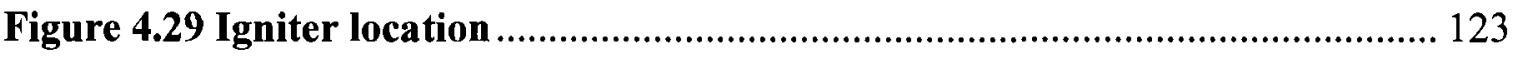

Figure 4.30 Force diagram of thin walled pressure vessel (Adapted from

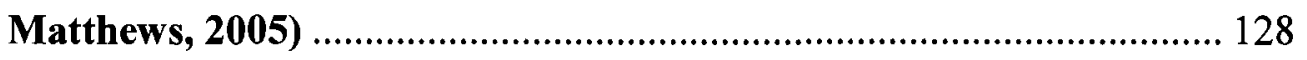

Figure 4.31 Material principle stresses (Adapted from Matthews, 2005)................ 130

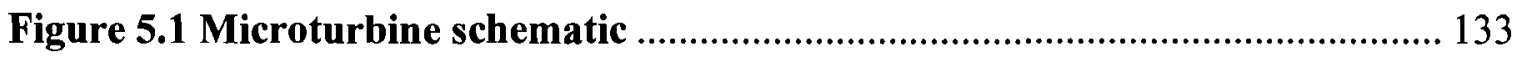

Figure 5.2 Combustor key dimensions............................................................... 134

Figure 5.3 Liner mass flow distribution................................................................... 135

Figure 5.4 Premixer dimensions ........................................................................... 136

Figure 5.5 Diesel fuel premixer ............................................................................. 137

Figure 5.6 Effect of blade turning angle on swirl number ........................................ 138

Figure 5.7 Effect of blade turning angle on pressure loss across swirler................. 138

Figure 5.8 BETE impingement nozzle (model PJ) (Adapted from BETE, 2007).... 140

Figure 5.9 Ignition system and spark igniter (Adapted from Allison Engine

Company, 1999). 141 
Figure 6.1 Evolution of turbine blades with firing temperature (Boyce, 2006) ...... 143

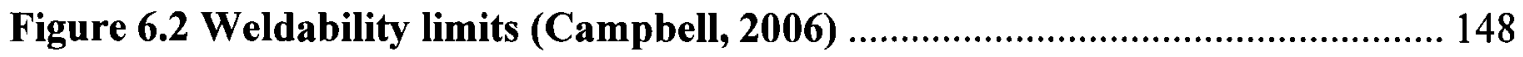

Figure 6.3 Welding techniques schematics (Campbell, 2006) ................................ 149

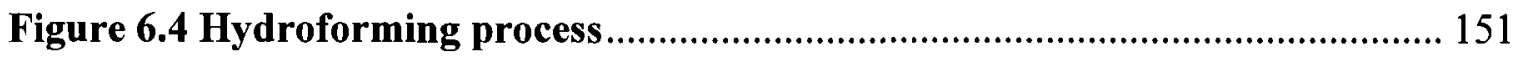

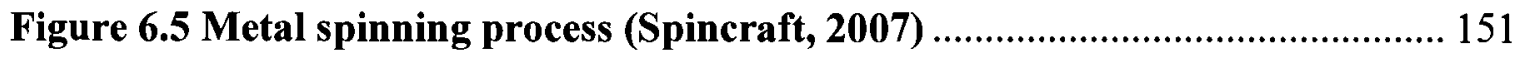

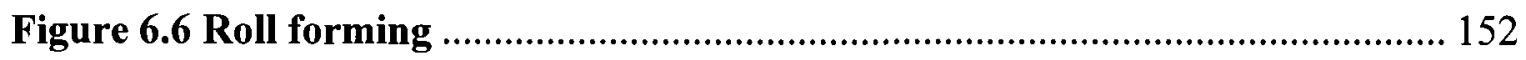

Figure 6.7 Combustor liner manufacturing process......................................... 153

Figure 6.8 Liner exploded view (top) and actual parts (bottom) after roll

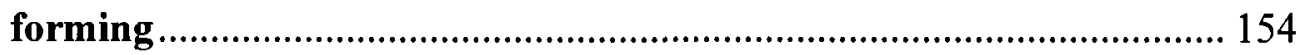

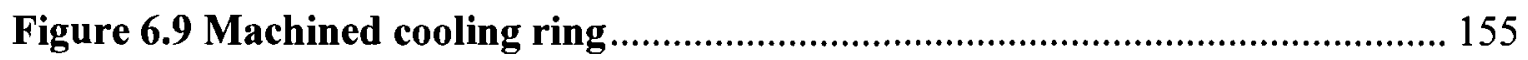

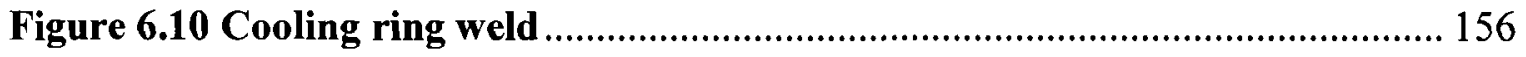

Figure 6.11 Liner solid model and final product............................................. 156

Figure 6.12 Combustor casing manufacturing process ….................................. 160

Figure 6.13 Casing exploded view (top), cross-section (middle) and final product

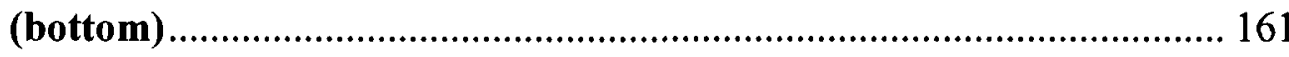

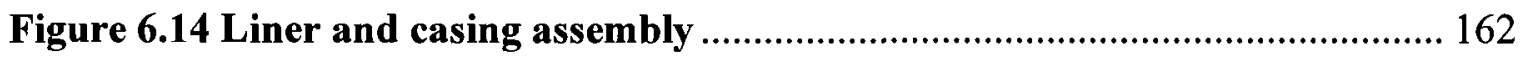

Figure 6.15 Liner and casing final assembly ............................................... 164

Figure 6.16 Premixer parts before final assembly ........................................ 165

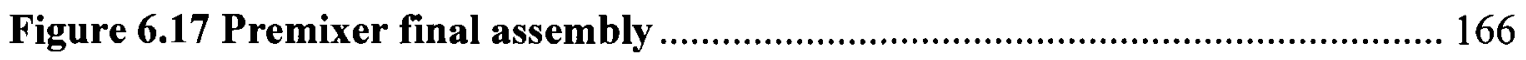

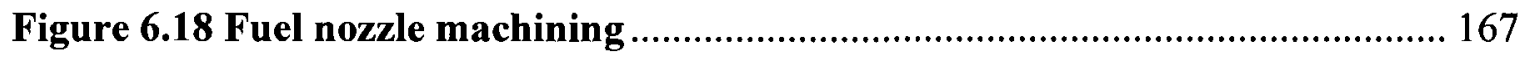

Figure 6.19 Fuel nozzle after machining with fuel line welded............................ 167

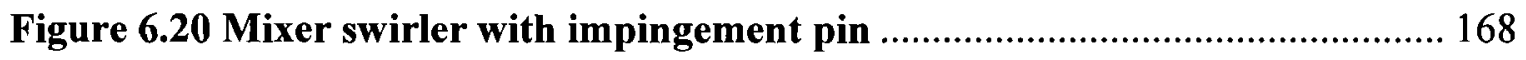

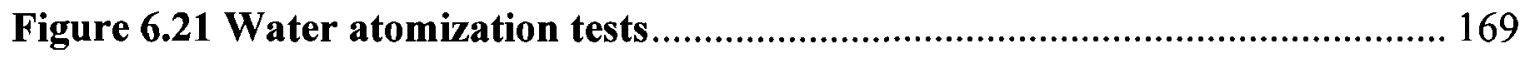


Figure 7.1 Gas turbine combustion research laboratory layout

Figure 7.2 Allison 250-C20B configuration and air flow (Adapted from Anonymous, 2008) 174

Figure 7.3 Allison 250-C20B isometric view and air flow path (Adapted from

Allison Engine Company, 1999) 175

Figure 7.4 Allison 250-C20B and dynamometer 177

Figure 7.5 Partial disassembly of Allison 250-C20B engine..................................... 178

Figure 7.6 Example of tool used for engine disassembly ......................................... 179

Figure 7.7 Third stage low pressure turbine wheel before and after machining .... 179

Figure 7.8 Exploded view of low pressure turbine section ........................................ 180

Figure 7.9 Low pressure turbine section reassembly ............................................. 181

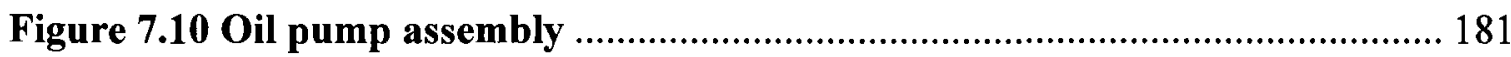

Figure 7.11 Allison 250-C20B final assembly after modification ............................. 182

Figure 7.12 Allison 250-C20B discharge air tube (Adapted from Allison Engine Company, 1999). 182

Figure 7.13 Air bleed system assembly (Murphy, 2004) ……................................. 183

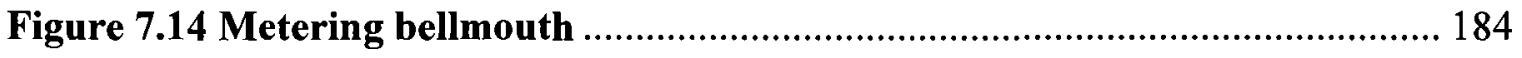

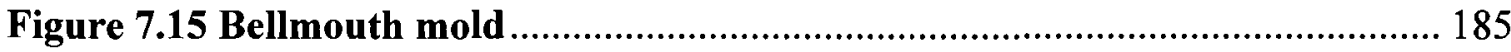

Figure 7.16 Inlet protective screen …….......................................................... 186

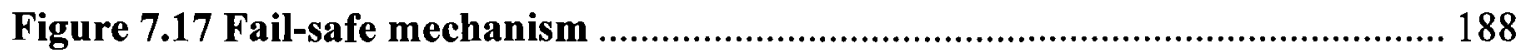

Figure 7.18 Metering bellmouth principle ............................................................. 189

Figure 7.19 Averaging manifold ........................................................................ 192

Figure 7.20 Thermocouple working principle (Omega Engineering, 2004) ............ 193 
Figure 7.21 Type $K$ thermocouple nomenclature (Adapted from Omega Engineering, 2004)

Figure 7.22 Accelerometer working principle and actual ACC101 accelerometer (Adapted from Omega Engineering, 2000)

Figure 7.23 Accelerometer installation points (Adapted from Allison Engine Company, 1999).

Figure 7.24 Gearbox accelerometer installation 196

Figure 7.25 Test cell instrumentation.

Figure 7.26 Gas turbine combustion research laboratory layout 198

Figure 7.27 Air delivery system layout in Gas Turbine Room 200

Figure 7.28 Air delivery system layout in Combustion Room 200

Figure 7.29 Jamesbury $815 \mathrm{~W}$ flow coefficient as a function of valve aperture...... 204

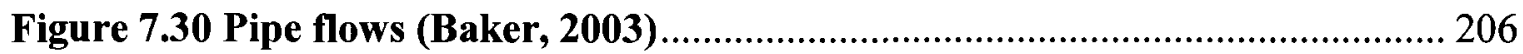

Figure 7.31 Air delivery system total length .................................................. 206

Figure 7.32 Maximum operating conditions of sch. 40S stainless steel (316L) pipes 207

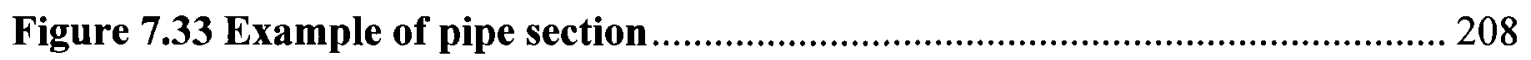

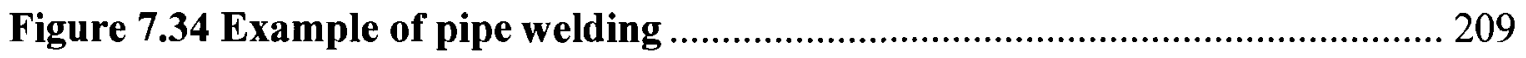

Figure 7.35 Breaking load of fine versus coarse threads (Nayyar, 2000) .............. 210

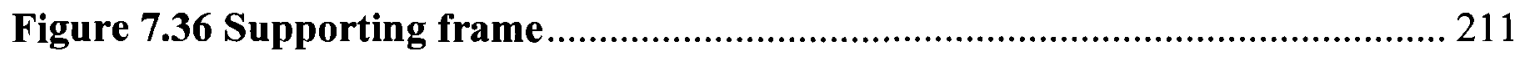

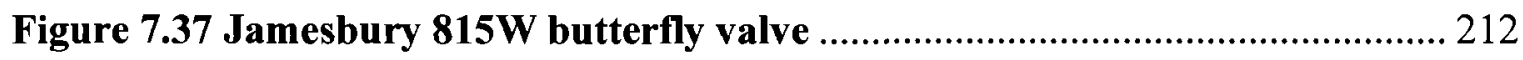

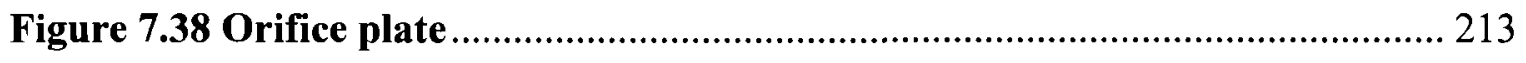

Figure 7.39 Program algorithm for simple gas turbine thermodynamic cycle ....... 214 
Figure 7.40 Effects of bleed mass flow rate and engine operating point on EGT ... 216

Figure 7.41 Pressure switch location in air delivery system (Adapted from

Omega Engineering, 2000)

Figure 7.42 PSW-108 pressure switch details (Adapted from Omega

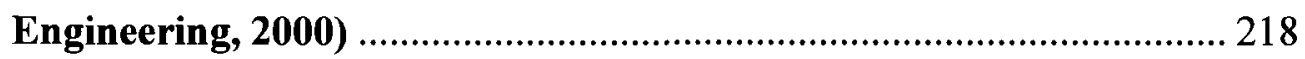

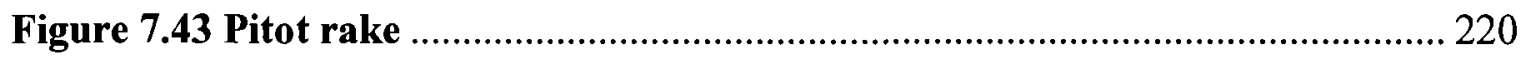

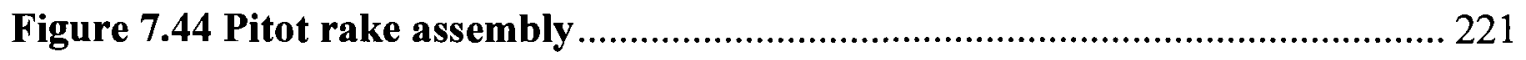

Figure 7.45 Instrumentation upstream of microturbine combustor .................... 221

Figure 7.46 Wall tap manufacturing process .................................................. 222

Figure 7.47 Microturbine air inlet temperature thermocouple .......................... 223

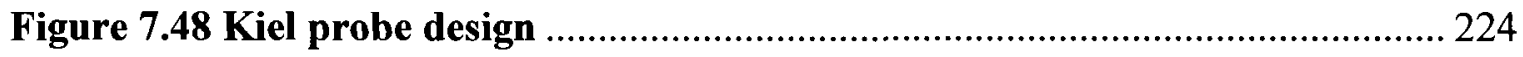

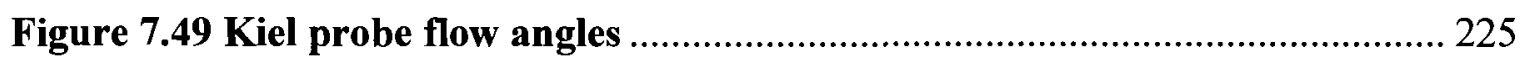

Figure 7.50 Instrumentation downstream of microturbine combustor ............... 226

Figure 7.51 Thermocouple assembly for measuring combustor outlet

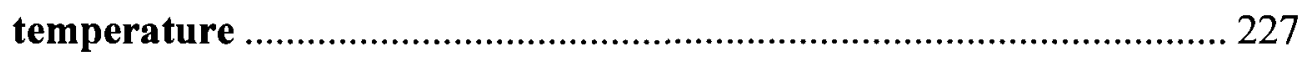

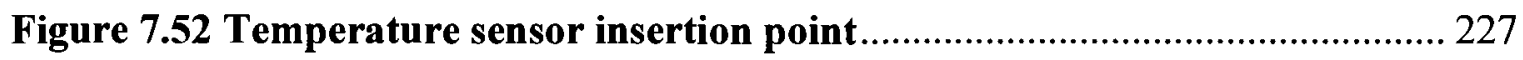

Figure 7.53 Thermocouple wire stripper (Omega Engineering, 2004) .................. 228

Figure 7.54 Type $K$ thermocouple nomenclature (Adapted from Omega

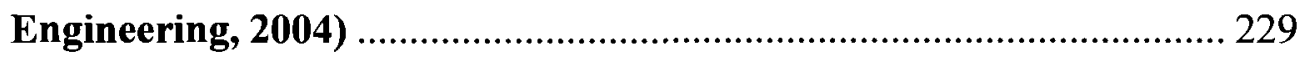

Figure 7.55 Thermocouple connectors (Adapted from Omega Engineering,

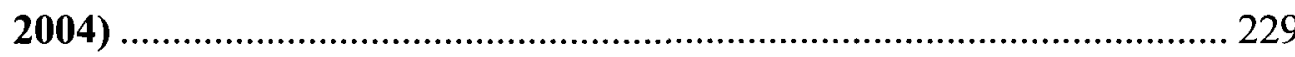

Figure 7.56 Views of liner instrumentation through a $270^{\circ}$ rotation .................... 231

Figure 7.57 Thermocouples spot welds detailed view .................................... 231 
Figure 7.58 Orifice plate with 1-D and $\frac{1}{2}-D$ wall taps

Figure 7.59 Orifice plate wall taps (upstream)

Figure 7.60 Wall tap and pitot rake pressure lines............................................. 235

Figure 7.61 Scanivalve pressure scanner and solenoid controller............................ 235

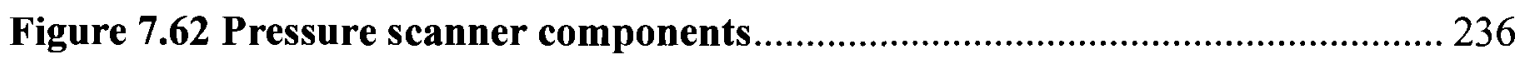

Figure 7.63 Keithley 2700 data acquisition system ............................................. 238

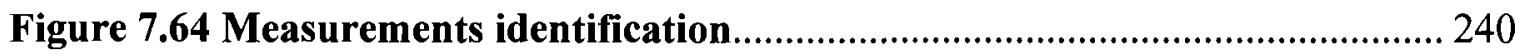

Figure 7.65 Layout top view of atmospheric pressure air delivery system ............. 241

Figure 7.66 Atmospheric configuration set-up...................................................... 242

Figure 7.67 Spencer Turbine Company blower model 30104A3 .............................. 243

Figure 7.68 Blower performance curve and hose pressure losses ............................ 243

Figure 7.69 Atmospheric and high pressure configurations of air delivery

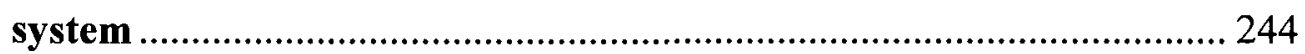

Figure 7.70 Close-up of air and fuel delivery systems ........................................... 244

Figure 7.71 Liner preparation for discharge coefficient type tests ......................... 246

Figure 7.72 Laminar flow element assembly ...................................................... 248

Figure 7.73 Laminar flow element instrumentation ............................................. 249

Figure 7.74 Fuel delivery system layout top view ……………………………….... 250

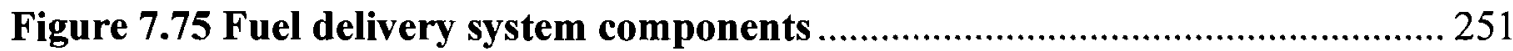

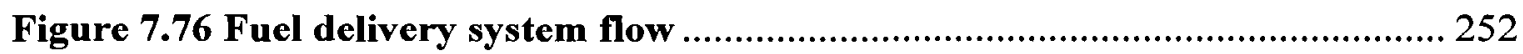

Figure 7.77 Hydra-Cell C62 pressure regulator valve (Adapted from Wanner,

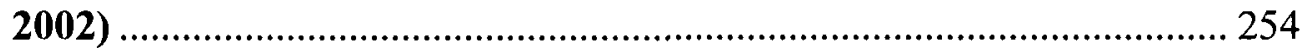

Figure 7.78 Fuel delivery systems close-up ..................................................... 257 
Figure 7.79 Control Room layout top view 257

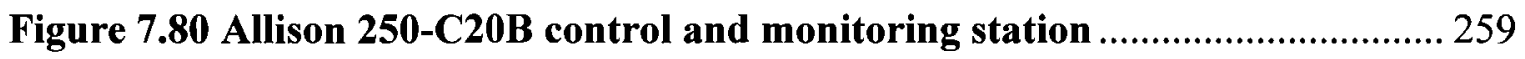

Figure 7.81 Fractional flow control valve actuation system............................. 261

Figure 7.82 Operating console wiring details ................................................. 261

Figure 7.83 Operating console top panel and monitors...................................... 262

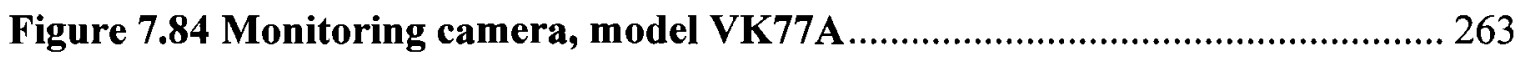

Figure 7.85 LabView program fragment with detailed transducer subroutine...... 264

Figure 7.86 LabView front panels as displayed by monitors ............................... 265

Figure 8.1 CL 122-2 block calibrator and Allison 250-C20B inlet thermocouple... 267

Figure 8.2 EGT thermocouple calibration...................................................... 268

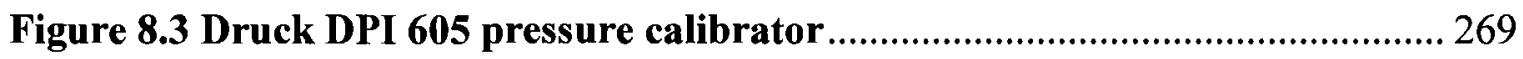

Figure 8.4 PX243A-1 pressure transducer calibration curves............................ 271

Figure 8.5 Kiel probe calibration rig (Adapted from Mahallati, 2003) ................. 272

Figure 8.6 Effect of Kiel probe pitch angle on total pressure coefficient............... 272

Figure 8.7 Calibration rig sensor location (Adapted from Mahallati, 2003).......... 273

Figure 8.8 Viscosity and wall proximity correction for pitot tubes (Ower and

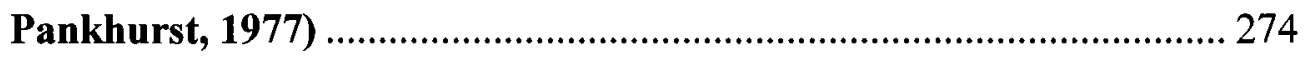

Figure 8.9 Atmospheric blower instrumented with metering bellmouth .............. 275

Figure 8.10 Performance assessment of metering bellmouth wall taps ................ 276

Figure 8.11 Performance assessment of metering bellmouth wall taps ................ 277

Figure 8.12 Pressure leak test for S30B01 pressure line .............................. 278

Figure 8.13 Pressure leak test for air delivery system; pressure regulator details . 280

Figure 8.14 Pressure leak test for air delivery system; sealing plate details .......... 280 
Figure 8.15 Repeatability tests

283

Figure 8.16 Effect of differential pressure across PJ12 nozzle on water flow rate. 286

Figure 8.17 Effect of differential pressure across PJ12 nozzle on diesel flow rate . 287

Figure 8.18 Effect of gas generator rotational speed on Allison 250-C20B

vibrations

Figure 8.19 Allison 250-C20B bleed shakedown test

290

Figure 8.20 Effect of testing time on Gas Turbine Room temperature 291

Figure 8.21 Effect of testing time on gas turbine exhaust temperature 292 


\begin{tabular}{|c|c|}
\hline$A$ & Area or empirical constant, Equation (4.126) \\
\hline$A_{o}$ & Cooling slot outlet area \\
\hline$A_{\text {eff }}$ & Cooling slot overall effective area \\
\hline$A R$ & Casing area to combustor inlet area ratio \\
\hline$B_{c}$ & Cooling slot blockage factor \\
\hline$B_{\text {stoich }}$ & Stoichiometric fuel mass transfer number \\
\hline$B_{T}$ & Spalding number \\
\hline$C$ & Convection heat transfer \\
\hline$C_{d}$ & Discharge coefficient or drag coefficient \\
\hline$c_{p}$ & Specific heat \\
\hline$C_{p}$ & Pressure recovery coefficient \\
\hline$C_{s}$ & Flameholder shape factor \\
\hline$d$ & Diameter \\
\hline$d_{h}$ & Hydraulic diameter \\
\hline$d_{q}$ & Quenching distance \\
\hline$D$ & Diameter \\
\hline$D_{c}$ & Flameholder characteristic dimension \\
\hline
\end{tabular}




\begin{tabular}{|c|c|}
\hline$D_{o}$ & Orifice diameter \\
\hline$D_{32}$ & Sauter mean diameter (SMD) \\
\hline e & Electrical charge \\
\hline$E$ & Dynamic Young's modulus \\
\hline$E_{a}$ & Activation energy \\
\hline$E_{\min }$ & Minimum ignition energy \\
\hline$G F$ & Geometry factor \\
\hline $\bar{g}_{f}^{0}$ & Standard Gibbs free energy of formation \\
\hline$G_{m}$ & Axial flux of angular momentum \\
\hline$G_{t}$ & Axial thrust \\
\hline$\Delta G_{T}^{0}$ & Standard Gibbs free energy change \\
\hline$H$ & Molar based absolute enthalpy \\
\hline$k$ & Thermal conductivity or proportionality constant, Equation (4.45) \\
\hline$k_{f}$ & Forward rate coefficient, Equation (4.40) \\
\hline$k_{o p t}$ & Optimum parameter, Equation (4.26) \\
\hline$K$ & $\begin{array}{l}\text { Conduction heat transfer or pressure loss factor or constant, Equation } \\
(4.120)\end{array}$ \\
\hline$K_{p}$ & Equilibrium constant, Equation (4.15) \\
\hline$K_{S W}$ & Swirler vane geometry factor \\
\hline$J$ & Momentum flux ratio \\
\hline
\end{tabular}




\begin{tabular}{|c|c|}
\hline$l_{b}$ & Beam length \\
\hline$L$ & Length or luminosity factor \\
\hline$M$ & Molecular weight \\
\hline$\dot{m}$ & Mass flow rate \\
\hline$n$ & Empirical constant, Equation (4.126) \\
\hline$n_{v}$ & Number of vanes \\
\hline$n_{h}$ & Number of holes \\
\hline$N$ & Casing diffuser length \\
\hline$N u$ & Nusselt number \\
\hline$p$ & Static pressure \\
\hline$P$ & Pressure or partial pressure \\
\hline$P_{\text {sat }}$ & Saturation pressure \\
\hline $\bar{P}$ & Mass flow weighted pressure \\
\hline $\operatorname{Pr}$ & Prandtl number \\
\hline$q$ & $\begin{array}{l}\text { Dynamic pressure or fuel/air ratio by mass or empirical constant, Equation } \\
(4.100)\end{array}$ \\
\hline $\bar{q}$ & Mass flow weighted dynamic pressure or bulk mean turbulent fluctuation \\
\hline$Q$ & Pattern factor or liquid fuel total volume fraction \\
\hline$r$ & Radius \\
\hline$R$ & Radius or radiation heat transfer \\
\hline$R_{a}$ & Air gas constant \\
\hline
\end{tabular}




\begin{tabular}{|c|c|}
\hline$R_{\text {gas }}$ & Gas constant \\
\hline $\bar{R}$ & Universal gas constant \\
\hline $\operatorname{Re}$ & Reynolds number \\
\hline$s$ & Slot depth \\
\hline$S$ & Vane spacing or stress \\
\hline$S_{L}$ & Laminar flame speed \\
\hline$S_{N}$ & Swirl number \\
\hline$t$ & Thickness or time \\
\hline$T$ & Temperature \\
\hline$T_{g}^{\prime}$ & Equivalent gas temperature \\
\hline$u$ & Particle velocity component in $\mathrm{x}$ direction \\
\hline$\overline{u^{\prime}}$ & Mean bulk fluctuation in $\mathrm{x}$ direction \\
\hline$v$ & Particle velocity component in $\mathrm{x}$ direction \\
\hline$\overline{v^{\prime}}$ & Mean bulk fluctuation in y direction \\
\hline V & Voltage \\
\hline$V$ & Velocity \\
\hline$V_{B O}$ & Lean blowout velocity \\
\hline Vol & Volume \\
\hline$\overline{w^{\prime}}$ & Mean bulk fluctuation in $\mathrm{z}$ direction \\
\hline$W e$ & Weber number \\
\hline
\end{tabular}




\begin{tabular}{|c|c|}
\hline$x_{p}$ & Potential core length \\
\hline$X$ & Jet axial length or empirical constant, Equation (4.100) \\
\hline$\chi$ & Mole fraction \\
\hline$w$ & Cooling slot width or particle velocity component $\mathrm{z}$ direction \\
\hline$Y$ & Jet radial length \\
\hline$Y_{F}$ & Fuel mass fraction \\
\hline$Y_{R}$ & Fuel mass fraction at droplet surface \\
\hline$Y_{\infty}$ & Fuel mass fraction far from droplet \\
\hline$\Delta P$ & Pressure drop \\
\hline$\alpha$ & Hole area ratio or coefficient of thermal expansion \\
\hline$\alpha_{0}$ & Thermal diffusivity \\
\hline$\beta$ & Hole bleed ratio \\
\hline$\delta$ & Thermal expansion \\
\hline$\varepsilon$ & Emissivity or strain \\
\hline$\varepsilon_{T}$ & Thermal strain \\
\hline$\lambda$ & Pressure loss coefficient \\
\hline$\lambda_{e v}$ & Evaporation constant \\
\hline$\eta_{\text {Comb }}$ & Combustion efficiency \\
\hline$\eta$ & Efficiency or effectiveness \\
\hline$\mu$ & Dynamic viscosity or velocity area ratio \\
\hline$\phi$ & Equivalence ratio \\
\hline
\end{tabular}




$\begin{array}{ll}\Phi & \text { Jet angle } \\ \psi & \text { Diffuser angle } \\ \varphi & \text { Casing diffuser angle } \\ \theta & \text { Angle } \\ \Delta & \text { Difference } \\ \rho & \text { Density } \\ \sigma & \text { Stephan-Boltzmann constant or surface tension or yield stress } \\ \tau & \text { Time constant } \\ \tau & \\ v & \text { Autoignition delay time } \\ v & \text { Kinematic viscosity }\end{array}$

\section{Subscripts}

$0 \quad$ Initial

1 Conventional combustor or inner liner wall

$2 \quad$ Premixed combustor or outer liner wall

$3 \quad$ Combustor inlet

$4 \quad$ Combustor outlet

$a \quad$ Air

ad Adiabatic

amb Ambient

axial Axial

AN Annulus

b Bulk or boiling 


\begin{tabular}{|c|c|}
\hline bleed & Bleed \\
\hline$c$ & Cooling \\
\hline casing & Casing \\
\hline crit & Critical \\
\hline Comb & Combustor \\
\hline comp & Compressor \\
\hline$D$ & Dome \\
\hline diff & Diffuser \\
\hline$D Z$ & Dilution zone \\
\hline eff & Effective \\
\hline$e v$ & Evaporation \\
\hline$f$ & Fuel \\
\hline$g$ & Flame or hot gasses \\
\hline gas & Gas \\
\hline global & Global \\
\hline$h$ & Hole \\
\hline hot & Hot gasses \\
\hline$h u b$ & Hub \\
\hline ideal & Ideal \\
\hline ig & Ignition \\
\hline in & Inlet \\
\hline$j$ & Jet \\
\hline$l$ & Liquid fuel \\
\hline
\end{tabular}




\begin{tabular}{|c|c|}
\hline$L$ & Liner \\
\hline$m$ & Mechanical \\
\hline $\max$ & Maximum \\
\hline meas & Measured \\
\hline out & Outlet \\
\hline$p$ & Particle \\
\hline premixer & Premixer \\
\hline prod & Products \\
\hline$P Z$ & Primary zone \\
\hline$r$ & Recirculation \\
\hline radial & Radial \\
\hline react & Reactants \\
\hline ref & Reference \\
\hline rel & Relative \\
\hline$R Z$ & Recirculation zone \\
\hline$s n$ & Snout \\
\hline Stoich & Stoichiometric \\
\hline$S W$ & Swirler \\
\hline$S Z$ & Secondary zone \\
\hline turb & Turbine \\
\hline$T$ & Temperature \\
\hline$u$ & Unburned gasses \\
\hline$v$ & Vane \\
\hline
\end{tabular}




\begin{tabular}{ll} 
yield & Yield \\
$w$ & Wall or droplet surface \\
Acronyms & \\
CAD & Canadian \\
CFD & Computational fluid dynamics \\
CNC & Computer numerical control \\
CPU & Central processing unit \\
CRM & Chemical reactor model \\
DES & Detached eddy simulation \\
DNS & Direct numerical simulation \\
EDM & Electrical discharge machining \\
EI & Emissions index \\
ERMD & Emissions Research and Measurements Department \\
FNPT & Female national pipe thread \\
GE & General Electric \\
GF & Geometry factor \\
GMAW & Gas metal arc welding \\
GTAW & Gas tungsten arc welding \\
HAZ & Heat affected zone \\
HVV & Higher heating value \\
LES & Large eddy simulations \\
LHV & Lower heating value \\
LPP & Lean premixed prevaporized \\
\hline
\end{tabular}

xxix 


\begin{tabular}{ll} 
MNPT & Male national pipe thread \\
NRCan & Natural Resources Canada \\
PDR & Pressure drop ratio \\
PFR & Plug flow reactor \\
PLF & Pressure loss factor \\
ppmv & Parts per million volume \\
PSR & Perfectly stirred reactor \\
RANS & Reynolds-average Navier-Stokes equations \\
RQL & Rich-burn, quick-quench and lean burn \\
RSM & Reynolds stress model \\
SFC & Specific fuel consumption \\
SMD & Sauter mean diameter \\
TBC & Thermal barrier coating \\
TI & Turbulence intensity \\
TIT & Turbine inlet temperature \\
UHC & Unburned hydrocarbons \\
VAC & Voltage alternating current \\
VDC & Voltage direct current \\
WSR & Well stirred reactor \\
\hline
\end{tabular}




\section{INTRODUCTION}

This chapter first gives an overview of a zero-emission power plant which has been developed by Carleton University under a contract given by Natural Resources Canada (NRCan). This research project has been the basis for the work presented in this thesis. The chapter then elaborates on the motivations for the work and the approach used to meet the research project objectives. It concludes by giving a chronological outline and a brief explanation of the various chapters making up this thesis.

\subsection{Research Project Overview}

In response to rising environmental concerns, NRCan contracted Carleton University, more specifically the Mechanical and Aerospace Engineering Department, to develop the preliminary design for a zero-emission power plant.

The deregulation of utilities and the increase in costs of bringing electrical power to the buying public favoured the introduction of a number of new technologies for distributed power generation, especially in the $30 \mathrm{~kW}$ to $300 \mathrm{~kW}$ electrical output range (Kolanowsky, 2004). Consequently, NRCan requested the preliminary design of a $50 \mathrm{~kW}$ zero-emissions microturbine and then to scale the technology to a conceptual design of a 100 MW power plant.

When burning hydrocarbon fuels, the reduction of pollutants such as carbon dioxide $\left(\mathrm{CO}_{2}\right)$ and water vapour $\left(\mathrm{H}_{2} \mathrm{O}_{\mathrm{g}}\right)$ can only be achieved through a decrease in fuel consumption since these two products are an inescapable outcome of the combustion process. On the other hand, oxides of nitrogen $\left(\mathrm{NO}_{\mathrm{x}}=\mathrm{NO}+\mathrm{NO}_{2}\right)$, carbon monoxide (CO), unburned hydrocarbons (UHC) and particulates, also known as soot (unburned 
carbon), are directly related to the type of fuel and oxidizer used, as well as to the gas turbine combustor design and performance.

The development of a semi-closed, recuperated cycle, combusting natural gas and oxygen $\left(\mathrm{O}_{2}\right)$, and using the resulting $\mathrm{CO}_{2}$ combustion product as the primary working fluid for the turbine engine, addressed the zero-emissions and $50 \mathrm{~kW}$ electrical power output requirements.

By assuming complete combustion and a combustion efficiency $\left(\eta_{\text {Comb }}\right)$ of $100 \%$, the burning of methane $\left(\mathrm{CH}_{4}\right)$ with pure oxygen would lead to the formation of carbon dioxide and water vapour, as can be seen by the following chemical reaction:

$$
\mathrm{CH}_{4}+2\left(\mathrm{O}_{2}+\mathrm{CO}_{2}\right) \Rightarrow 3 \mathrm{CO}_{2}+2\left(\mathrm{H}_{2} \mathrm{O}\right)_{\mathrm{g}}+\text { Heat }
$$

As can be seen from the above reaction, using an oxidizer and a fuel that do not contain nitrogen eliminates $\mathrm{NO}_{\mathrm{x}}$ formation during the combustion process. Oxides of nitrogen $\left(\mathrm{NO}_{\mathrm{x}}\right)$, which are obtained from combustion processes that use air as the oxidizer, are responsible for chemical smog, depletion of stratospheric ozone, acid rain and, to a lesser degree than $\mathrm{CO}_{2}$, greenhouse effects.

In addition to using $\mathrm{CH}_{4}$ and $\mathrm{O}_{2}$, a semi-closed, recuperated cycle enables to capture the pollutant responsible for most greenhouse effects, namely $\mathrm{CO}_{2}$.

Table 1.1 and Figure 1.1 show the power plant specifications given by NRCan and the cycle schematic developed by Carleton University. 
Table 1.1 Zero-emission power plant specifications

1. Release zero $\mathrm{CO}_{2}, \mathrm{NO}_{\mathrm{x}}, \mathrm{SO}_{\mathrm{x}}$ emissions to surroundings

2. Fuelled by natural gas (assumed to have the following composition on a volume basis; $95.60 \% \mathrm{CH}_{4}, 1.75 \% \mathrm{C}_{2} \mathrm{H}_{6}, 0.10 \% \mathrm{C}_{3} \mathrm{H}_{8}, 1.75 \% \mathrm{~N}_{2}$ and $0.8 \% \mathrm{CO}_{2}$ )

3. Use high purity oxygen ( $99 \%$ by volume) from liquid storage vessel with evaporator able to generate gaseous oxygen at pressure needed to combustor

4. Use high-purity propane as test fuel

5. Have a net electrical output of $50 \mathrm{~kW}$ at $480 \mathrm{VAC}, 60 \mathrm{~Hz}$ (ISO conditions, unistalled)

6. Have an efficiency of $25 \%$ (thermal to electric), accounting for $\mathrm{CO}_{2}$ compression by the plant to its discharge value, but not the $\mathrm{O}_{2}$ supply

7. Maintain a high efficiency at part load

8. Be continually pressurized to eliminate air infiltration

9. Use an air cooled indirect contact condenser to cool the recycled steam

10. Store $\mathrm{CO}_{2}$ with purity of $98 \%$, at a pressure of 80 bar in liquid phase

11. Have zero oil contamination in $\mathrm{CO}_{2}$

12. Vent water and steam for disposal (small quantity of $\mathrm{CO}_{2}$ in water permitted)

13. Be capable of safe start-up, operation and shut-down under automatic control

14. Be able of operating between $-40^{\circ} \mathrm{C}$ and $+40^{\circ} \mathrm{C}$

15. Have a casing capable of containing a rotor failure assuming a worst case scenario of one third (1/3) rotor loss

16. Be instrumented for test purposes

17. Have low maintenance and capital costs 


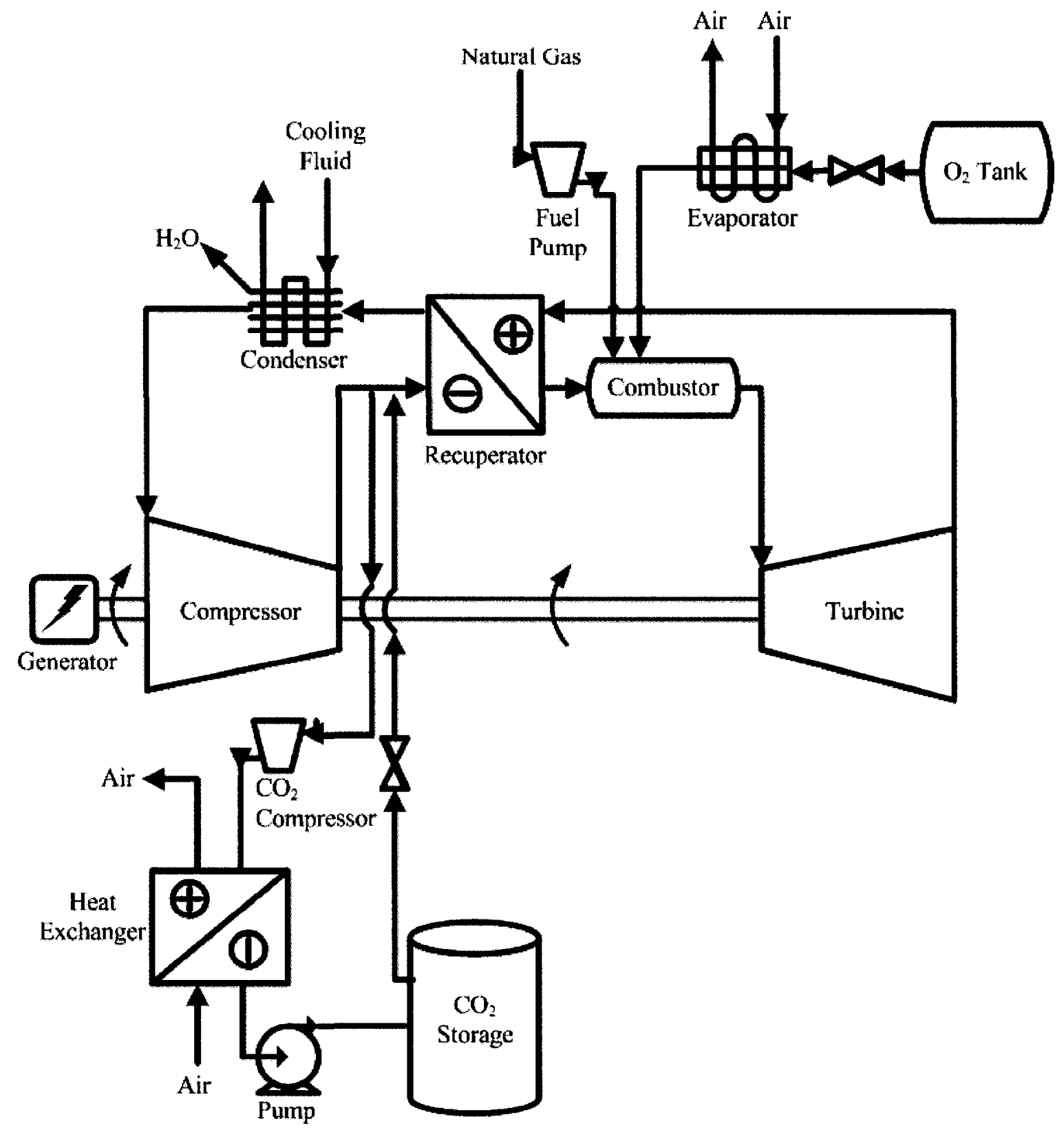

Figure 1.1 Zero-emission power plant cycle schematic

Figure 1.1 shows the flow path analysis of the plant. The cycle working fluid is $\mathrm{CO}_{2}$ that, during engine start-up, comes from a storage tank where it was previously captured and accumulated. 
The $\mathrm{CO}_{2}$ gas enters the compressor where it is pressurised from 3 bar to 21 bar. The fluid then flows into the recuperator where it is preheated, from an inlet temperature of $485 \mathrm{~K}$ to an outlet temperature of $875 \mathrm{~K}$, by the hot gasses exhausted from the turbine.

In the combustor, natural gas is mixed with just enough $\mathrm{O}_{2}$ for all the fuel to completely burn, technically referred to as stoichiometric combustion. The $\mathrm{CO}_{2}$ entering the combustor promotes mixing of the $\mathrm{CH}_{4}$ and $\mathrm{O}_{2}$ prior to combustion, cools the combustor walls for structural integrity purposes and lowers, through a dilution process, the exhaust gas temperature to $1200 \mathrm{~K}$. The dilution process, as will be discussed in more detail later, extends the life of components downstream of the combustor.

The hot gasses, now including $\mathrm{CO}_{2}$, water vapour, and the $\mathrm{CO}_{2}$ produced by the combustion process, enter the turbine where they are expanded to approximately 3 bar. The hot exhaust gasses then enter the recuperator where, as mentioned before, they are used to preheat the incoming $\mathrm{CO}_{2}$.

The last plant component encountered by the working fluid, before the cycle is repeated, is the condenser. The condenser, not only lowers the $\mathrm{CO}_{2}$ temperature before it re-enters the compressor, but it also condenses the unwanted water vapour, created in the combustion process, into liquid which is then expelled from the plant.

\subsection{Research Project Details}

The main focus of this thesis is the microturbine combustor of the previously presented power plant. The combustor specifications are as follows:

- provide a turbine inlet temperature (TIT) of $1200 \mathrm{~K}$;

- sustain a pressure loss across the combustor not higher than $3 \%$ of the combustor inlet pressure; 
- ensure $99 \%$ combustion efficiency $\left(\eta_{C o m b}\right)$;

- ensure combustor wall temperatures below $1300 \mathrm{~K}$; and

- operate at a working pressure of 21 bar.

The work contained in this thesis is built upon initial efforts done on the combustor. More specifically, preliminary combustor design work, carried out by senior mechanical and aerospace engineering students at Carleton University, was used as basis for the thesis objectives presented next.

\subsection{Thesis Overview}

The scope of the work presented in this thesis, summarized in Figure 1.2, was to:

- carefully scrutinize a design methodology that had been developed before the start of this research project;

- manufacture a combustor whose preliminary geometry came from the above mentioned design methodology;

- update and further develop the methodology; and

- design and construct a gas turbine combustion research laboratory. 


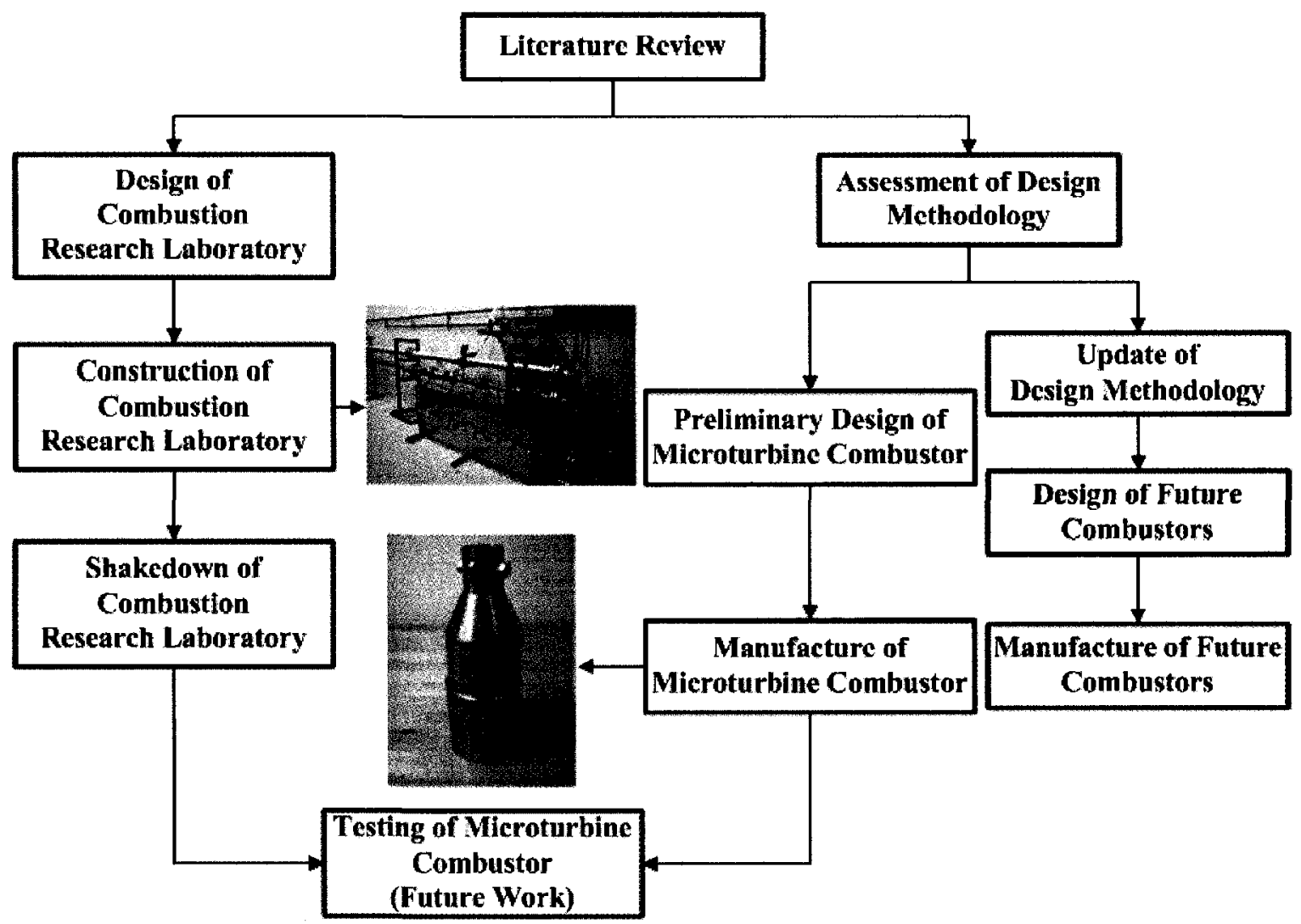

Figure 1.2 Thesis overview flowchart

\subsection{Thesis Objectives}

To carry out the thesis objectives in a timely fashion, an initial concurrent approach, addressing all major project aspects simultaneously, had to be taken. Furthermore, executive decisions, in the early phases of the project, had to be made because of manufacturing lead times and costs. In particular, the prohibitive costs in building a laboratory that could operate with natural gas, oxygen and carbon dioxide at 21 bar required essential decisions to be made promptly.

Two of these crucial decisions were to:

- manufacture the lean premixed combustor, even though no computer modelling work was carried out; and 
- construct a gas turbine combustion research laboratory that, as one of the many goals, could be used as a "calibration tool" for future modelling work on the microturbine combustor under investigation.

In particular, a gas turbine combustion research laboratory using pressurized air (7 bar) and diesel fuel had to be designed, constructed and equipped with instrumentation so that experimental work on the microturbine combustor could later be conducted. The experimental data, obtained from future combustor testing, would then be used as inputs for upcoming computer simulations as well as serving as a validation tool for the outputs of the simulations.

Additional computer simulations, after having validated and obtained confidence in the outputs of the combustor computational models, would then replicate intended combustor operating parameters (natural gas, oxygen and carbon dioxide at a working pressure of 21 bar) so that the combustor geometry and performance could be reassessed.

In addition to serving as a validation tool, the gas turbine combustion research laboratory was designed and constructed to allow for:

- testing of future gas turbine combustor designs, which are operating on air and liquid fuels;

- development of new empirical and semi-empirical correlations derived from combustion tests;

- possible testing of new alternative fuels, through minor fuel delivery system modifications; and

- testing of gas turbine hot section component materials and coatings through the addition of a material test rig downstream of the combustor. 
Prior to proceeding with the manufacturing of the microturbine combustor, careful examination of the previously developed design methodology was undertaken. The assessed methodology was deemed adequate. However, as part of the thesis objectives, obsolete empirical and semi-empirical correlations were updated. New research findings were incorporated and liquid fuel correlations, as well as expressions that can predict gas turbine pollutant emissions were added to the design methodology.

\subsection{Thesis Outline}

This thesis was written to provide as much information as possible on the developed design methodology as well as on the processes used and decisions made when manufacturing the microturbine combustor and commissioning the gas turbine combustion research laboratory. The extensive details presented in this thesis were given so that future individuals involved in using the design methodology and/or the research laboratory can quickly and easily understand key factors related to this research.

The development of the design methodology, the manufacture of the combustor and the commissioning of the research laboratory were the objectives of this project. Although, these objectives were interlinked in that one led to the achievement of the next, they had fundamental differences. The design methodology was developed from science of gas turbine combustion, while the combustor manufacturing and the research laboratory commissioning were based on applied knowledge from various fields. Because of this, the literature review pertaining to this research project was presented in three different chapters. Therefore, Chapter 4 outlines the design methodology, Chapter 6 describes the microturbine combustor manufacturing process and Chapter 7 covers the commissioning of the gas turbine combustion research laboratory. 
In total, this thesis is composed of 9 Chapters as follows:

- Chapter 1 gives an overview of and specifications for a zero-emission power plant which was the basis for the work presented in this thesis. This chapter also presents the thesis objectives.

- Chapter 2 outlines different computational approaches that can be used as tools to design a gas turbine combustor and builds a case for the necessity of a design methodology based on proven empirical and semi-empirical correlations.

- Chapter 3 gives an overview of technology and terminology used in the gas turbine field with particular emphasis on the combustor.

- Chapter 4 gives details of the design methodology used to design a lean premixed, prevaporized microturbine combustor.

- Chapter 5 presents design details of the microturbine combustor which has been developed from the methodology described in Chapter 4

- Chapter 6 focuses on the combustor manufacturing process.

- Chapter 7 centres on the commissioning of the gas turbine combustion research laboratory.

- Chapter 8 presents instrumentation calibration and shakedown test results.

- Chapter 9 gives the thesis conclusions and recommendations. 


\section{LITERATURE REVIEW}

This chapter first gives a general overview of different computational approaches that can be used as design tools for the development of gas turbine combustors. After having reviewed the various approaches, the author emphasizes the need for the development of a computationally efficient design methodology for the preliminary sizing of a gas turbine combustor. The chapter then gives reasons for the necessity of developing and constructing a gas turbine combustion research laboratory. In conclusion, the chapter summarizes sources considered during the design of the above mentioned gas turbine combustion research laboratory.

\subsection{Combustion Modelling}

Until recent years, the gas turbine combustor was the least understood engine component in comparison to other engine parts, namely the compressor and turbine. This was due to the fact that students and engineers did not have the opportunity to study all the relevant engineering courses to understand and design a gas turbine combustor. In the past, combustor design has been referred to as a "black art" (Mattingly, 2002) since new combustor designs were developed from previously established combustor geometries through a trial-and-error approach (Dodds and Bahr, 1990).

Presently, combustion theory and gas turbine combustor design have greatly progressed thanks to years of research which translated into a better understanding of the subject, and the availability and affordability of computers and software which allow to conduct "numerical experiments" without incurring exorbitant developmental and testing costs. Furthermore, constant pressure in meeting more stringent emissions regulations 
compelled engine manufacturers to constantly develop leading edge technologies and to persistently evolve the combustor design.

Recently published gas turbine combustion papers show that computer modelling and experimental work play a crucial role in the development of new combustor designs.

Computer models, dealing with reacting flows, are based on the following four fundamental principles; 1) conservation of fluid momentum, 2) mass conservation, 3) energy conservation and 4) conservation of number of moles of each of the elements present in the initial reacting mixture. In theory, these physical principles are expressed through integral equations or partial differential equations whose solutions are an infinite continuum of values throughout some domain.

To numerically solve these expressions through the use of computers, the governing equations are converted, through the introduction of some simplifying assumptions, into algebraic equations that can be numerically solved. This conversion process is also known as discretization. The discretized equations are solved by the computer and provide a finite number of discrete points or volumes within the domain. Graphically, the discretization process can be regarded as a geometrical grid, also called a mesh, which has been shaped by the solution of each discrete point or volume (Anderson, 1995).

Discretization techniques can be carried out by using a finite difference, a finite volume and a finite element method. For more detailed information on the topic, the reader is encouraged to look at work published by Anderson (1995) and Hansen et al. (2005).

There are various commercially available software which employ the above mentioned techniques and which can be used as design tools for combustor modelling. 
Depending on the modelling approach, these software can be divided into two categories;

1) computational fluid dynamics (CFD) models or 2) chemical reactor models (CRM).

The following sections will briefly present an overview of recently published CFD and CRM work, focusing particularly on turbulent reacting flows which are the foundation of gas turbine combustors.

\subsubsection{CFD Modelling}

Gas turbine combustion is characterized by turbulent flow behaviour due to the high Reynolds numbers at which the process occurs. Therefore, CFD simulations must predict turbulent flows by modelling turbulent transport (diffusion) and the interaction between chemical reactions and turbulent fluctuations. Two commercially available software that can do this are FLUENT ${ }^{1}$ and ANSYS CFX ${ }^{2}$. However, regardless of the software used, the process to solve CFD problems is shown in Figure 2.1.

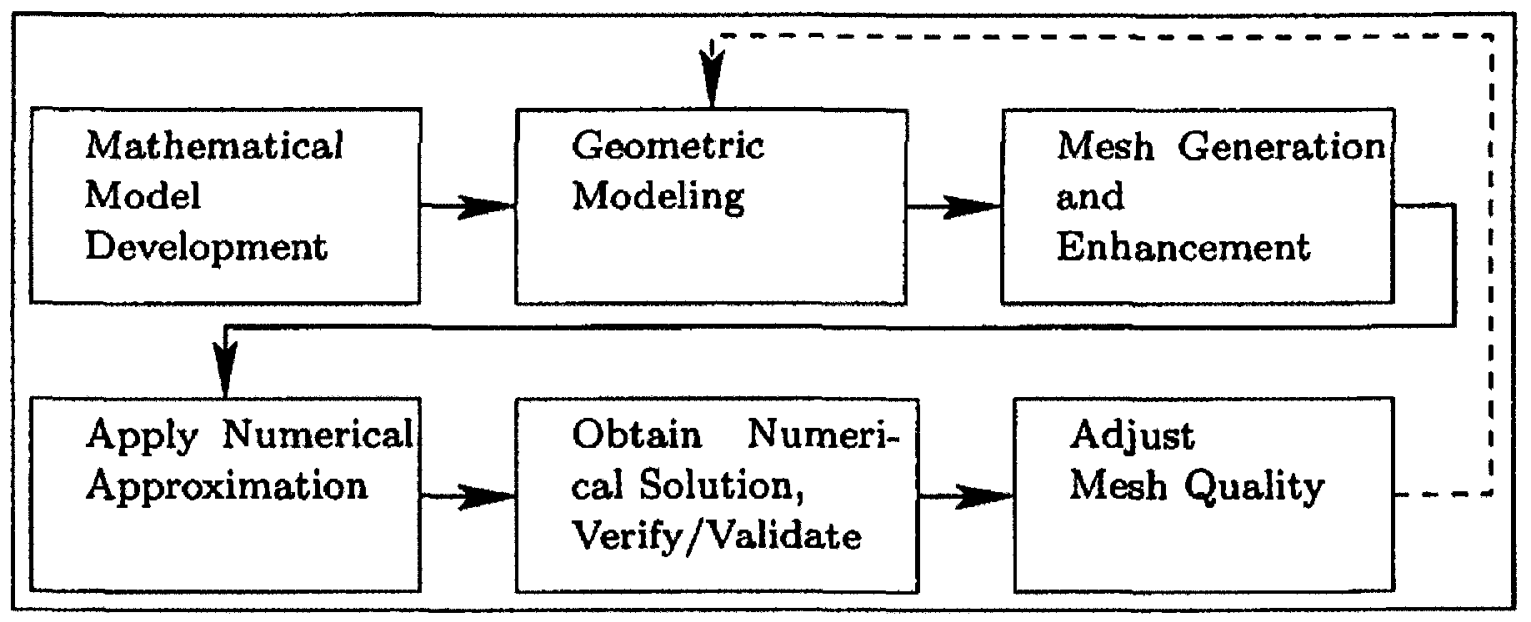

Figure 2.1 CFD modelling process outline (Hansen et al., 2005)

\footnotetext{
${ }^{1}$ ANSYS, Inc. 10 Cavendish Court Lebanon, NH 03766 U.S.A

${ }^{2}$ ANSYS, Inc. Southpointe 275 Technology Drive, Canonsburg, PA 15317 U.S.A
} 
In Figure 2.1, two factors that greatly influence the outcome of a CFD simulation are the quality of the mesh generated and the numerical technique used. Recently published CFD work focuses on the trade-offs between mesh enhancement, adequacy of the numerical technique used and computational costs. A typical example of this type of studies is published by Schneider et al. (2007).

Mesh enhancement deals with the improvement of computability and numerical accuracy of the numerical simulation. The term computability, also referred to as robustness, usually relates undesirable mesh characteristics to the ability of a particular simulation to proceed to completion.

Mesh enhancement is handled through the type of discretization method used. Gas turbine combustor simulations, which must describe complex physical processes that evolve in a turbulent and unsteady manner, use mainly the finite volume method and, more recently (Anderson, 1995), the finite element method as discretization techniques. The finite volume and finite element methods, as opposed to the finite difference method, are more readily utilized since they do not require a uniform, rectangular grid (structured grid) for computation (Anderson, 1995). Unstructured meshes allow for maximum flexibility in combining mesh cell with combustor surface boundaries (Figure 2.2). Furthermore, as can be seen from Figure 2.2, unstructured meshes allow cells to be put in locations that are deemed critical. This is a very important aspect of unstructured grids since the fluid dynamics of combustors is a combination of confined swirled flows with multiple recirculation zones and reattachments points. 


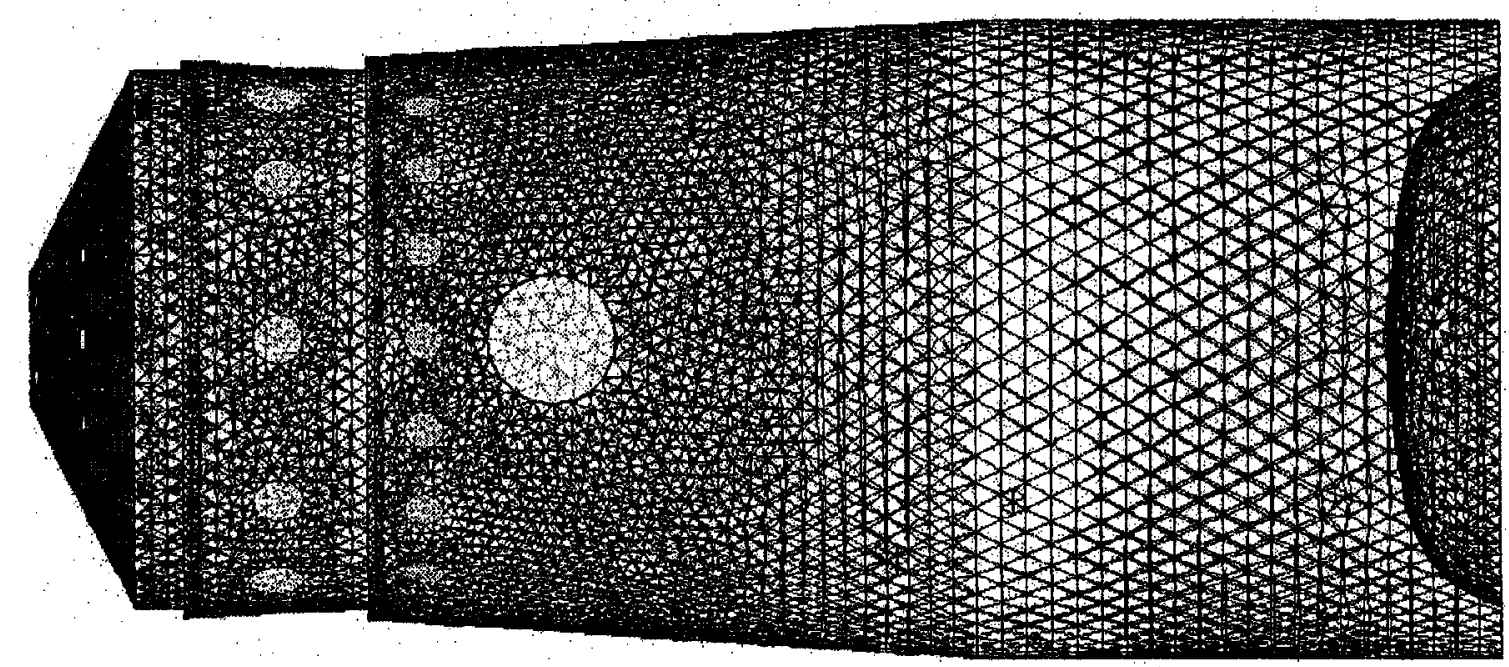

Figure 2.2 Combustor liner unstructured surface mesh (Chok, 2003)

Another aspect of interest in CFD simulations is the numerical technique used and the effect of the model on computational time. There is an ample selection of such models outlined in literature. In particular, books written by Fox (2003) and Hewitt and Vassilicos (2005) give detailed explanations on models currently used in turbulent reacting flows.

The following paragraphs introduce only some of the main classes of numerical techniques dealing with turbulent reacting flows, since covering the large variety of such numerical approaches described in the literature would require a thesis of its own.

The first numerical technique presented, namely direct numerical simulation (DNS), can be used to solve turbulent combusting flows. When high accuracy is required (above the $10^{\text {th }}$ order) (Hewitt and Vassilicos, 2005), DNS methods are usually discretized through the finite difference method. However, DNS simulations are often limited to simplified studies due to its extensive computational time. The computational costs are related to the fact that the DNS approach captures all of the relevant scales of turbulent motion. As mentioned by Hewitt and Vassilicos (2005), simulation of a turbulent flame 
by DNS would require an order of $10^{6}$ grid nodes per $\mathrm{mm}^{3}$ of flame, since the orientation and position of the flame is a random function of time with respect to any fixed grid. These extremely fine computational grid cells translate into prohibitive computational costs, even with today's great enhancement in computer power and memory storage.

Another numerical technique is large eddy simulations (LES). In LES, the smaller eddies are filtered and are modeled using a sub-grid scale model, while the larger energycarrying eddies are simulated. This method generally requires a more refined mesh than the Reynolds-average Navier-Stokes (RANS) model, presented next, but has a far coarser mesh than a DNS solution.

The oldest approach to turbulence modelling is the Reynolds-average Navier-Stokes equations. Reynolds averaging is used to separate the Navier-Stokes equations into mean (time averaged) and fluctuating components. This allows for the creation of a time averaged (also known as ensemble averaged) version of the governing equations that can be numerically solved. Detailed description of this computational method is beyond the scope of this thesis and more information on the topic can be found in Poinsot and Veynante, 2001.

The reader should be aware, however, that RANS models are divided into two broad approaches, namely the Boussinesq hypothesis and the Reynolds stress model (RSM). Work carried out by Jiang and Campbell (2005 and 2007) indicates that RSM models have superior performance when compared to models founded upon the Boussinesq hypothesis, in particular the k- $\varepsilon$ model. The higher accuracy of RSM comes from the fact that this model accounts for the anisotropic effect of turbulent flow, whereas the k- $\varepsilon$ model considers the turbulent viscosity as an isotropic scalar quantity (Chok, 2003, 
FLUENT, 1998). Since, for highly swirled flow situations, the anisotropy of turbulence is the dominant effect, the Reynolds stress model would be the preferred solving technique for gas turbine combustor CFD work. Nevertheless, the drawbacks to this model, as mentioned in the FLUENT 5 manual, are that RSM requires $50 \%$ to $60 \%$ more CPU (central processing unit) time per iteration and needs $15 \%$ to $20 \%$ more memory compared to the $\mathrm{k}-\varepsilon$ models (FLUENT, 1998).

The last type of numerical technique to be considered here is the hybrid model. Hybrid models are researched and developed to achieve an optimal compromise between robustness, numerical costs and physical accuracy. An example of one such model is the detached eddy simulation (DES). DES is a modification of the RANS model. With this modification, the DES technique switches to a subgrid scale formulation in regions fine enough for LES calculations. Regions near solid boundaries and where the turbulent length scale is less than the maximum grid dimension are assigned the RANS mode of solution. The ability to switch between LES and RANS allows for a grid resolution which is not as demanding as pure LES, thereby considerably cutting down on the cost of the computation.

In conclusion, the challenges to overcome when using CFD as a design tool are selecting the adequate mesh as well as choosing the best numerical technique for the type of application at hand. In addition, a compromise between robustness, computational costs and physical accuracy must also be attained. A way to avoid the aforementioned constraints is by using chemical reactor model (CRM) as the design tool for developing a gas turbine combustor, as will be discussed in the next section. 


\subsubsection{Reactor Theory Modelling}

As previously mentioned, solving combustion flows in detail through CFD can be computationally costly. Therefore, since there are stringent emission regulations on the formation of pollutants, such as oxides of nitrogen $\left(\mathrm{NO}_{\mathrm{x}}=\mathrm{NO}+\mathrm{NO}_{2}\right)$, carbon monoxide (CO) and carbon dioxide $\left(\mathrm{CO}_{2}\right)$, another modelling method, chemical reactor model (CRM) which is based on reactor theory, can be employed. Using CRM, reactor theory can predict emissions, through simplified versions of physics and chemistry governing equations, without solving combustion flow dynamics. Hence, computational time is drastically reduced. In other words, reactor theory can decouple fluid dynamics from detailed chemical kinetics analysis, therefore, cutting down greatly on computational costs.

Chemkin $^{3}$, a commercially available software, has been developed on the basis of reactor theory, and can be used as a design tool for gas turbine combustors. Another software based on reactor theory, which also could be used as a design tool for combustion design purposes is Cantera ${ }^{4}$. However, Cantera, unlike Chemkin, is available at no cost to the public.

The simplest idealized form of a gas turbine combustor, using reactor theory, is the Bragg combustor (Mattingly et al., 2002). The Bragg combustor (Figure 2.3) is composed of a well stirred reactor (WSR), also referred to as a perfectly stirred reactor (PSR), in which inflowing reactants are vigorously mixed together and come into contact with previously burned gasses. The Bragg combustor is also made up of a plug flow reactor

\footnotetext{
${ }^{3}$ Reaction Design, 6440 Lusk Boulevard, Suite D-205, San Diego, CA 92121, U.S.A

${ }^{4} \mathrm{http} / / /$ sourceforge.net/projects/cantera/
} 
(PFR) which is sized to allow for complete combustion to occur before the burning products exit the combustor.

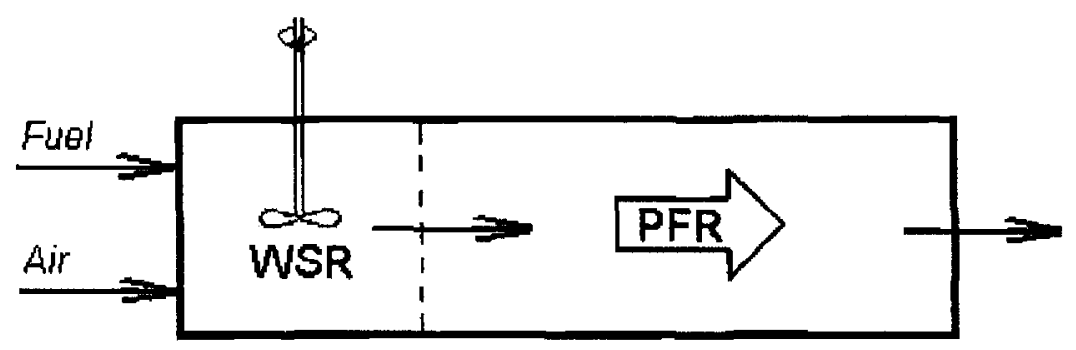

Figure 2.3 Bragg combustor, simplest form of an idealized gas turbine combustor (Mattingly et al., 2002)

However, reactor models can be far more complicated than that represented by the Bragg combustor. The number of reactors used and their linkage complexity must reflect the combustor geometry and must be optimized for meaningful outputs to be produced.

Work carried out by Allaire (2006) is a perfect example of the trade-off between combustor geometry accuracy and simulation outputs. Specifically, the objective of the study conducted by Allaire was to use reactor theory as a policy making tool to predict emissions of potential future gas turbine combustors rather than a design tool. Hence, the CRM was deemed successful if general trends in the emission levels from different combustor designs, operating at various regimes, were in agreement with values of $\mathrm{NO}_{\mathrm{x}}$ predicted by empirical models and $\mathrm{CO}$ levels found in literature.

Figure 2.4 shows the final reactor model used by Allaire for the estimation of gas turbine combustor emissions levels. 


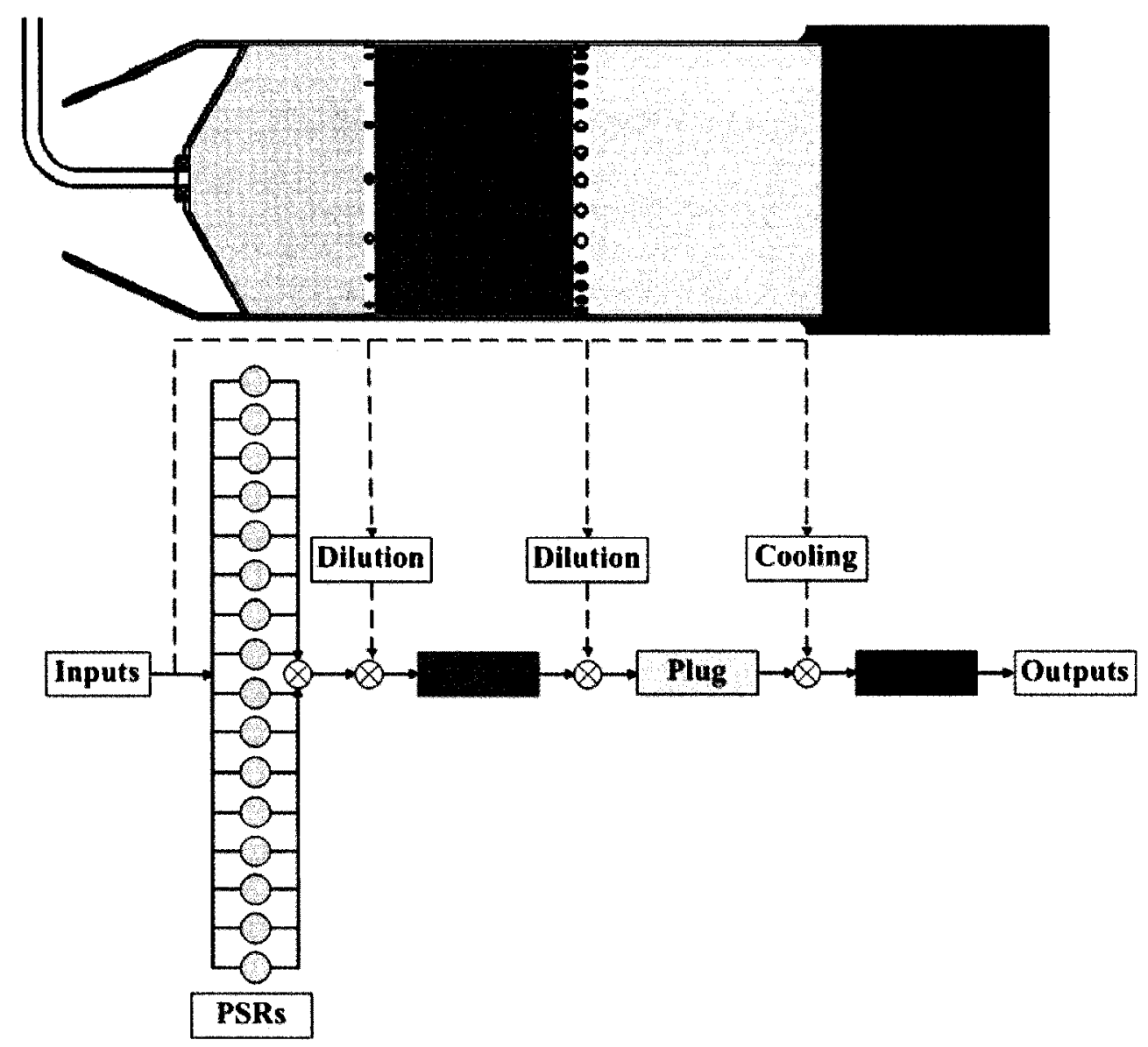

Figure 2.4 Idealized gas turbine combustor (Adapted from Allaire, 2006)

Even though in Allaire's study the reactors' configuration is not combustor specific, the model still had to represent a generic gas turbine combustor geometry to better predict the emissions levels. As can be seen, the complexity of the reactors in Figure 2.4 is far greater than that of the Bragg combustor. This intricacy would further increase if the model had to investigate a specific combustor geometry.

In addition, the model inputs had to represent parameters and operating conditions corresponding to present gas turbine engines and had to be able to be modified for projecting future technology. The reactor model inputs are the combustor inlet temperature and pressure, the mass flow rate into the combustor and its partitioning (i.e., percentage of combustor inlet flow rate going into dilution and cooling holes), the fuel 
flow rate, the combustor volumes, and how well mixed the fuel and air are before burning.

The extent of mixing of the fuel and air prior to burning, also referred to as unmixedness, depends on how vigorously the reactants are mixed and the physical phase of the fuel used, namely liquid versus gaseous. In general, liquid fuels require longer mixing times since the liquid fuel droplets have to evaporate before burning can take place.

Unmixedness has a significant effect on pollutant emissions. The emissions of $\mathrm{NO}_{\mathrm{x}}$ and $\mathrm{CO}$, which are dependent on flame temperature, are highly sensitive to the local fuelto-air ratio. As will be explained in more detail in Chapter 4, the fuel-to-air ratio determines the temperature of the flame, which in turns establishes the amount of pollutant formation during the combustion process.

Within the volume occupied by the PSRs, which represent the primary zone of a combustor, the fuel-to-air ratio varies from point to point (hence the use of multiple PSRs). Some areas of the primary zone will contain more fuel than air (fuel-rich zones), others will have less fuel than air (fuel-lean zones) and some zones will have stoichiometric fuel-to-air ratios where a sufficient amount of air is present for all the fuel to completely burn. The variation in the fuel-to-air ratios is due to the fact that in a conventional gas turbine combustor, as was in the case of Allaire, the fuel is sprayed and mixed, in the combustor primary zone, with air under highly turbulent and random conditions.

In reactor theory, the unmixedness in the primary zone can be approximated by a normal distribution about some mean equivalence ratio (Rizk et al., 2002) where, by 
definition, the equivalence ratio is the fuel-to-air ratio at stoichiometric conditions divided by the fuel-to-air ratio that is actually burned (see Section 3.5 for details).

In the study, Allaire determined that 16 PSRs represented adequately the unmixedness distribution of the primary zone and that a further increase in number of PSRs used in the model had no significant impact on the emissions of $\mathrm{NO}_{\mathrm{x}}$ and $\mathrm{CO}$.

The remainder of the reactor model was comprised of plug flow reactors which were sized to allow for completion of the burning process while taking into consideration dilution and cooling.

The output of the model, as previously mentioned, is to predict pollutant emissions of potential future gas turbine combustors. More precisely, the model estimates the ratio of grams of a particular pollutant to kilograms of fuel burned. These ratios are known as the emissions index (EI). Therefore, even for a detailed reactor model, the outputs of CRM simulations do not provide any fluid dynamics information. Furthermore, these outputs are greatly influenced by combustor geometry (reactors volume) and by the presumed fluid dynamics (dilution and cooling flow rates). For these reasons, studies like that of Russo et al. (2007) combined both CFD and CRM computational tools to create an acceptable compromise between computational time efforts and accuracy of results that satisfy both the fluid dynamics and the chemical kinetics aspects.

\subsubsection{Empirical and Semi-empirical Design Methodology}

As can be deduced from the above brief introduction of current computational models, whether using CFD or CRM simulations, a preliminary knowledge on the design of the gas turbine combustor under investigation is indispensable. Regarding CFD simulations, as seen in Figure 2.1, the final combustor design is achieved through an 
iterative process. Hence, starting with an accurate preliminary combustor design can therefore reduce the amount of CFD iterations needed in meeting the design specifications, thus minimizing the overall computational time of this already expensive process. The appropriate combustor design is even more critical in CRM simulations. As was seen from Allaire's work, the outputs of CRM models can only give meaningful predictions if the proper combustor geometry is investigated.

Therefore, the above shows the need for a design methodology based on established empirical and semi-empirical correlations that, without prohibitive computational costs, permits designing a gas turbine combustor that meets specific engine requirements.

\subsection{Manufacturing of Combustor and Gas Turbine Combustion Research Laboratory}

The manufacturing of the combustor, developed from the above mentioned methodology, and the design and construction of the gas turbine combustion research laboratory required knowledge in various engineering fields based on aerodynamic, thermodynamic, metallurgical, manufacturing and electrical knowledge.

Safety considerations also played a large role in the manufacturing of the combustor and gas turbine combustion research laboratory.

The selection of high temperature materials for the construction of the combustor and the gas turbine combustion research laboratory were aided by material science books like Nickel, Cobalt, and Their Alloys by Davis (2000) as well as previous work experience of the author.

The manufacturing techniques used in the building of the combustor and the research laboratory were determined by the author's background experience, manufacturing 
process books (Campbell, 2006; Tschaetsch, 2006 and Weman, 2003) as well as research project funds.

The design for the combustor and combustion test rig instrumentation was based on recommended practices for pressure and temperature measurements of gas turbine engines and components (Saravanamuttoo, 1990), books such as that written by Blevins (1984) and Ower and Pankhurst (1977) as well as theses like the one published by Haas and Murphy (2004), to name a few. In addition, reference to literature such as that published by companies like Omega Engineering, was crucial for the selection of the appropriate measuring instrument for the specific application.

The design and material selections for the components making up the fuel delivery apparatus were based on the author's previous experience in working with pyrolytic fuels.

The selection of suitable fuel delivery parts was aided by books like that edited by Smith and Zappe (2004), and by extensive online searches to find products that met design specifications while remaining within the project budget and without compromising apparatus reliability and safety.

The open loop control scheme of the various systems that make up the laboratory utilized the commercially available software, LabView, as well as low and high voltage electrical wiring. Furthermore, the electrical wiring was implemented according to electrical codes and was subjected to verification and approval.

The data acquisition process was carried out through the usage of a Keithley data acquisition system, the LabView software for data manipulation and a desktop computer for data display and storage. 
The design of the gas turbine combustion research laboratory was aided greatly by the theoretical knowledge gained on gas turbine engines through courses like those offered by Carleton University and books such as those of Saravanamuttoo (2001) and Boyce (2006). In addition, the design modification and safe operation of the gas turbine engine (Allison 250-C20B) present in the laboratory was aided by operational and maintenance manuals specific to the just mentioned engine.

In conclusion, the design and construction of the combustor and gas turbine combustion research laboratory were based on knowledge gained from various engineering fields and, in particular, on the investigation of current gas turbine combustion research.

The successful completion of the entire research project relied ultimately on careful planning, attention to details and hours of shakedown testing. 


\section{TECHONOLOGY AND TERMINOLOGY}

The first section of this chapter gives an overview of a gas turbine engine used for electrical power generation. More specifically, it describes how a gas turbine works and the major components that comprise such an engine. The chapter then focuses on the combustor, one of the major components making up a gas turbine engine. The chapter introduces terminology used to describe combustors and the combustion process.

\subsection{Gas Turbine Layout and Cycle Analysis}

This section will give an overview of a gas turbine engine used for electrical power generation, with particular emphasis on the combustor. Figure 3.1 shows the layout of the engine as well as the temperature versus entropy diagram (T-s diagram) of the gas turbine cycle (Brayton cycle) (Gauthier, 2005).

In a simple cycle gas turbine engine, the air enters the engine through the intake ( 1 in Figure 3.1) and it then travels through the compressor where the air gets pressurized ( 2 to 3 in Figure 3.1). The pressurized air is then discharged via a diffuser into the combustor ( 3 in Figure 3.1). The combustion section is made up of a casing (outer shell) and a liner. The air enters the combustion liner through a series of holes. Once in the liner, the air is mixed with fuel which is sprayed via a fuel nozzle and ignited by a spark igniter. The combustion products then leave the combustor to enter the turbine section (4 in Figure 3.1) where they are expanded and useful work is extracted. This useful work is then converted into electrical power by a generator. After the combustion products are fully expanded, they exit the engine through an exhaust (5 in Figure 3.1). 
In the T-s diagram, the compression process is represented by the curve going from Station 2 to Station 3. Combustion, at nearly constant pressure, corresponds to the curve delimited by Stations 3 and 4 and finally, the expansion process is shown by the curve between Stations 4 and 5 . The temperature increase, going from the combustor inlet temperature (Station 3) to the turbine inlet temperature (TIT) (Station 4), is due to the fact that combustion is an exothermic process where the chemical energy contained in the flammable mixture is released in form of thermal energy (heat). In particular, when looking at Figure 3.2 and Figure 3.3, it can be seen that the engine efficiency and fuel consumption are dependent on TIT and engine pressure ratio. The rise in TIT is limited by the materials and type of cooling techniques used in the engine hot section components, such as the combustor liner, nozzle guide vanes and turbine blades.

As previously mentioned, the combustion process occurs at almost constant pressure. One of the aims in the design of a combustor is to minimize its parasitic pressure loss. A high combustor pressure loss would translate in a loss of useful work that could be extracted by the turbine.

In addition to the above, other combustor design requirements are (Lefebvre, 1999):

- High combustion efficiency

- Wide stability limits

- Low emissions

- Durability (of combustor as well as components downstream of combustor such as high pressure nozzle guide vanes and high pressure turbine blades)

- Manufacturability

- Maintainability 
- Low cost

- Multifuel capability

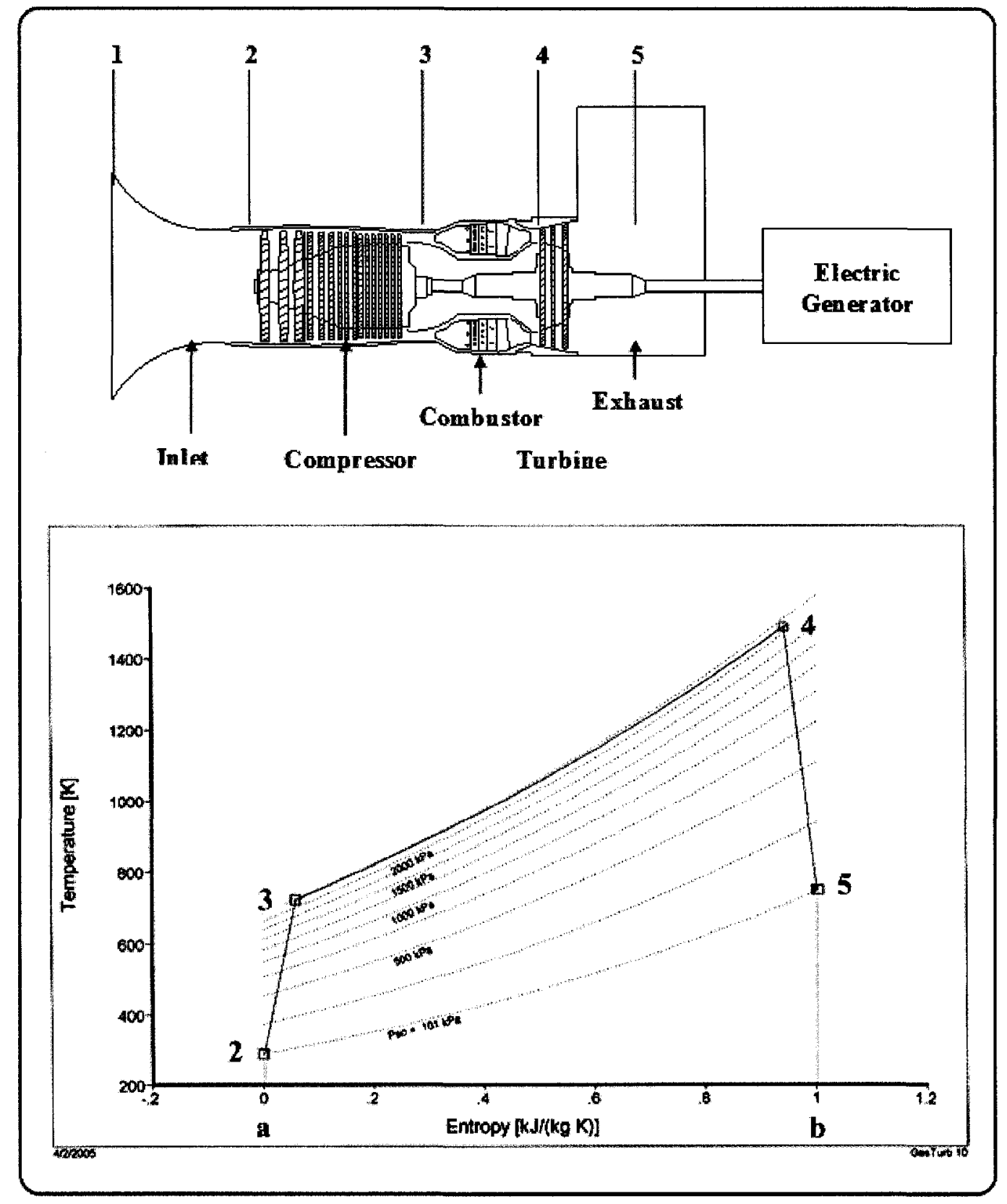

Figure 3.1 T-s diagram for simple cycle gas turbine used for electrical power generation (Top: Adapted from Rolls-Royce ple, 1996; Bottom: Kurzke, 2005) 


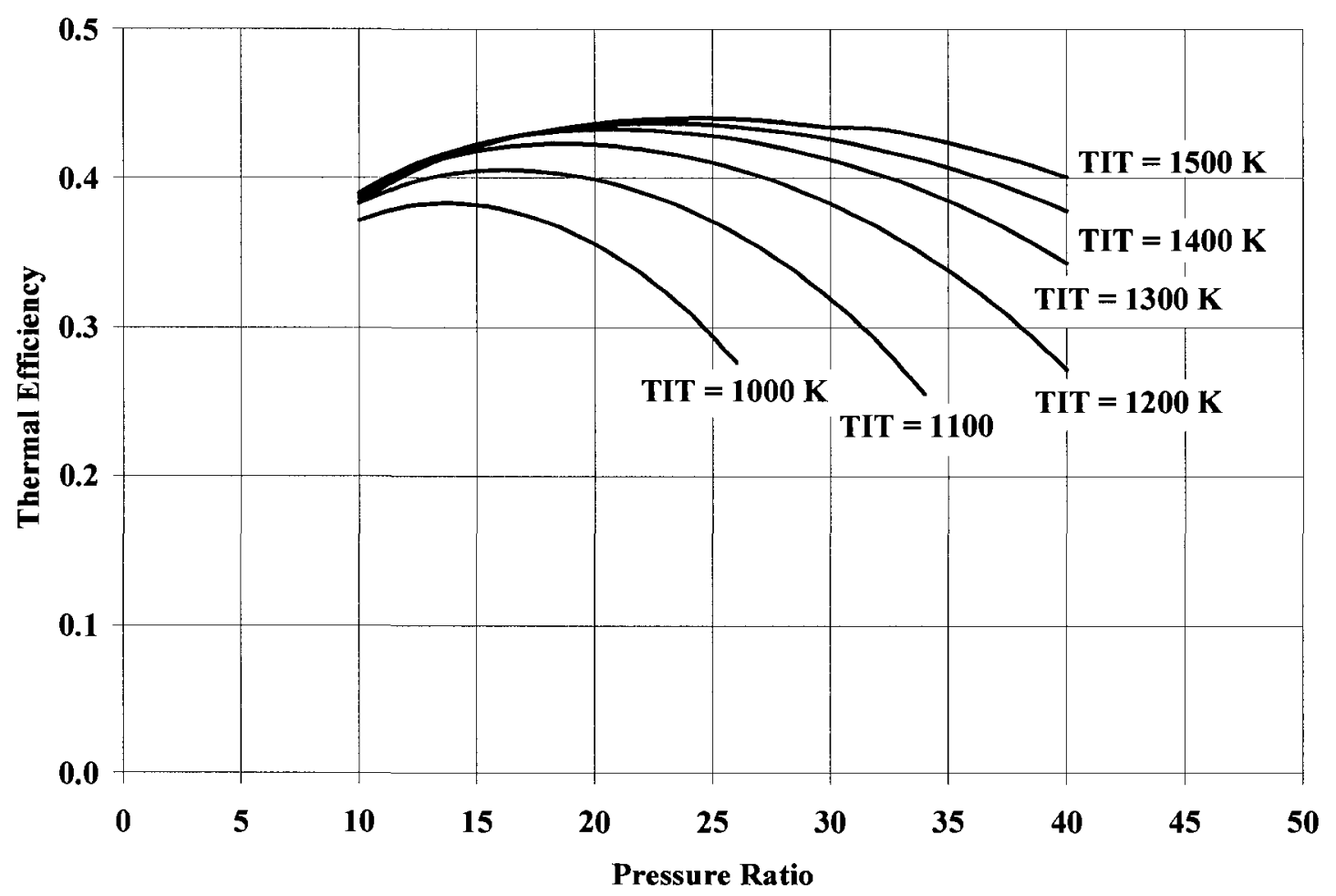

Figure 3.2 Effect of pressure ratio and TIT on cycle thermal efficiency

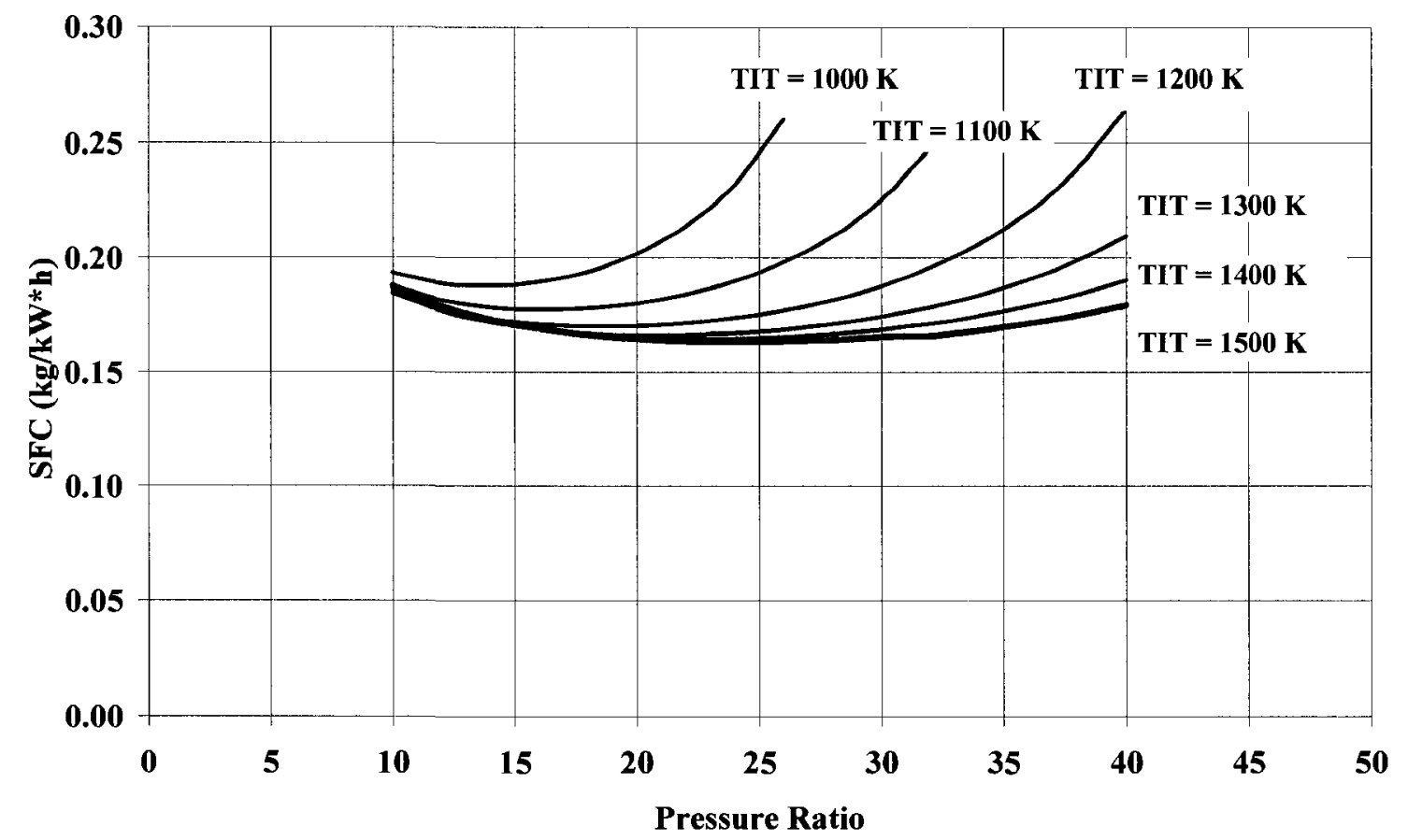

Figure 3.3 Effect of pressure ratio and TIT on specific fuel consumption 


\subsection{Combustion Flame Types}

To achieve combustion, a gaseous or prevaporized fuel must be mixed with an oxidizer as shown in the following chemical reaction (Gauthier, 2005).

Fuel + Oxidizer $\Rightarrow$ Combustion Products + Heat

Flames can be defined as premixed flames or diffusion flames depending on whether the fuel and oxidizer are mixed prior to entering the combustor or are mixed by diffusion within the combustor. Furthermore, depending on the burning velocities, i.e., the rate at which a plane combustion wave will propagate through a gaseous flammable mixture (Lefebvre 1999), the above mentioned flames can be additionally classified as laminar or turbulent.

\subsection{Flame Temperature}

Depending on the context, the flame temperature is the actual measured temperature of the flame or a value which as been calculated through mathematical expressions (Lefebvre, 1999). When calculated, the flame temperature is usually referred to as adiabatic flame temperature $\left(T_{a d}\right)$. The term adiabatic (no heat transfer to the surroundings) implies that the chemical energy contained in the flammable mixture is released as thermal energy (exothermic reaction) which is completely used in heating the combustion products.

\subsection{Stoichiometry}

For a generic hydrocarbon fuel mixed with an oxidizer such as air (C-H-O-N system), the stoichiometric chemical equation is given by (Turns, 2000): 
$\mathrm{C}_{\mathrm{x}} \mathrm{H}_{\mathrm{y}}+a\left(\mathrm{O}_{2}+3.76 \mathrm{~N}_{2}\right) \Rightarrow x \mathrm{CO}_{2}+\left(\frac{y}{2}\right) \mathrm{H}_{2} \mathrm{O}+3.76 a \mathrm{~N}_{2}$

The above chemical reaction assumes that air is composed of $21 \%$ oxygen and $79 \%$ nitrogen (Turns, 2000) and $a$ is defined as,

$a=x+\left(\frac{y}{4}\right)$

Stoichiometry is achieved when a sufficient amount of oxidizer is present for all the fuel to completely burn. The stoichiometric fuel-to-air ratio can be expressed as (Turns, 2000):

$\left(\frac{\text { Air }}{\text { Fuel }}\right)_{\text {Stoich }}=4.76 a \frac{M_{a}}{M_{f}}$

where $M_{a}$ is the molecular weight of air

$M_{f}$ is the molecular weight of fuel

\subsection{Equivalence Ratio}

By definition the equivalence ratio is the ratio of fuel-to-air at stoichiometric conditions divided by the ratio of fuel-to-air that is actually burned (Turns, 2000).

$$
\phi=\frac{\left(\frac{\text { Air }}{\text { Fuel }}\right)_{\text {Stoich }}}{\left(\frac{\text { Air }}{\text { Fuel }}\right)_{\text {Actual }}}
$$

Fuel-lean mixtures have equivalence ratios less than unity $(\phi<1)$. Fuel-rich mixtures have equivalence ratios higher than unity $(\phi>1)$. An equivalence ratio equal to one indicates a stoichiometric mixture $(\phi=1)$. 


\subsection{Flammability Limits}

The lower flammability limit, also known as the weak or lean limit, corresponds to the minimum amount of fuel which will make the mixture flammable. At the other extreme, the point at which the reactive mixture will stop burning is called the upper flammability limit or rich limit. This is reached when too much fuel is added to the oxidizer. For many fuels, the weak limit corresponds to an equivalence ratio of approximately 0.5 , whereas the rich limit corresponds to an equivalence ratio of 3 (Lefebvre, 1999).

\subsection{Stability Limits}

Stability, in gas turbine combustion terminology, is frequently used either to describe the range of fuel-to-air ratios over which stable combustion can be achieved, or as a measure of the maximum air velocity the combustor can tolerate before flame extinction occurs (Lefebvre, 1999). For example (see Figure 3.4), for a fixed air flow rate, the equivalence ratio can be increased or decreased to reach points which can extend beyond the stability loop. At the points beyond the stability loop, along the vertical axis A, the mixture can no longer react and flame blowout will occur. Similarly, with a fixed equivalence ratio, an increase in air flow rate would move the combustor operating point horizontally along axis B. In this case, a point outside the stability loop would indicate that the flame has been swept downstream and blowoff has occurred. Lastly, as can be seen by Figure 3.4, the most stable point (Point C) will occur close to stoichiometric conditions. This point corresponds to maximum flame temperature, maximum burning velocity and incipient blowoff (maximum flow rate) (Lefebvre, 1999). 


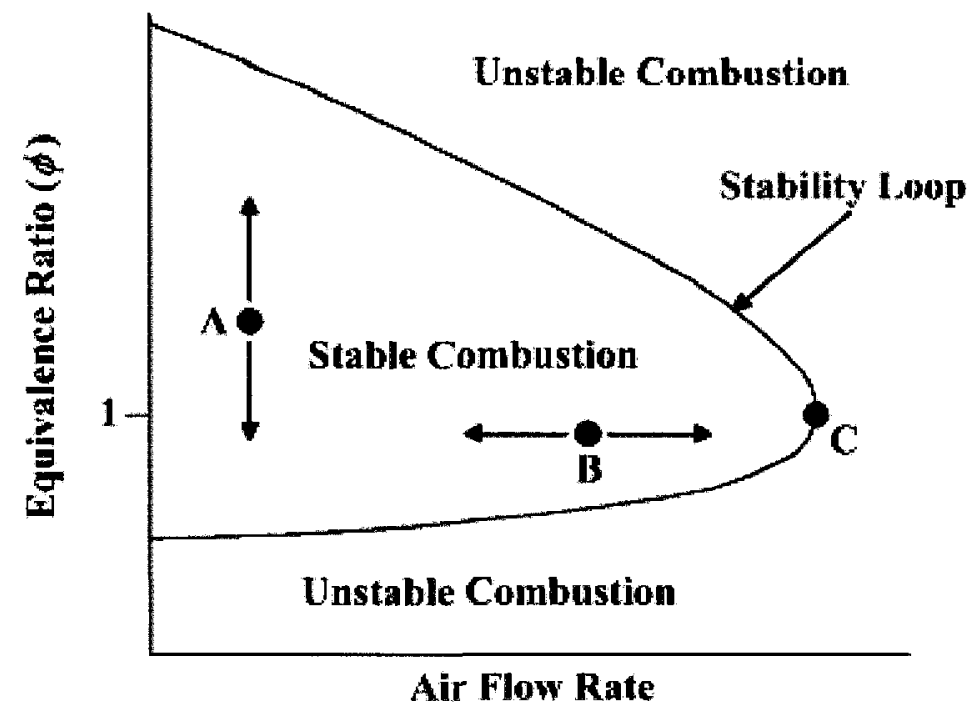

Figure 3.4 Combustion stability loop

\subsection{Autoignition}

Autoignition, also known as spontaneous ignition, takes place when a combustible mixture begins to burn in the absence of a concentrated ignition energy source such as a spark or flame.

\subsection{Flashback}

Flashback occurs when the burning velocity, also known as flame speed, exceeds the approach flow velocity of the gaseous flammable mixture and upstream propagation of the flame occurs.

\subsection{Combustor Nomenclature}

The objective of a gas turbine combustor is to convert chemical energy to thermal energy while meeting the previously mentioned design requirements.

The combustor is made up of a casing and a liner, the latter also referred to as a flame tube (Figure 3.5). The casing may be considered a pressure vessel that encloses the liner 
and all the fluids pertaining to the combustion process. Furthermore, the casing must reduce high compressor outlet velocities to levels where flame blowoff will not occur. This is done by introducing a diffuser, upstream of the liner, in which the flow is decelerated. The velocity reduction through the diverging passage, namely the diffuser, not only will provide for stable combustion but will also decrease combustor pressure losses since, in a gas turbine combustor, the pressure losses are proportional to the square of the velocity entering the combustor (see Section 4.1 for a detailed explanation) (Lefebvre, 1999).

$\Delta P_{\text {Comb }} \propto V_{3}^{2}$

where $\Delta P_{\text {Comb }}$ is the combustor pressure drop

$V_{3}$ is the air velocity at the combustor inlet

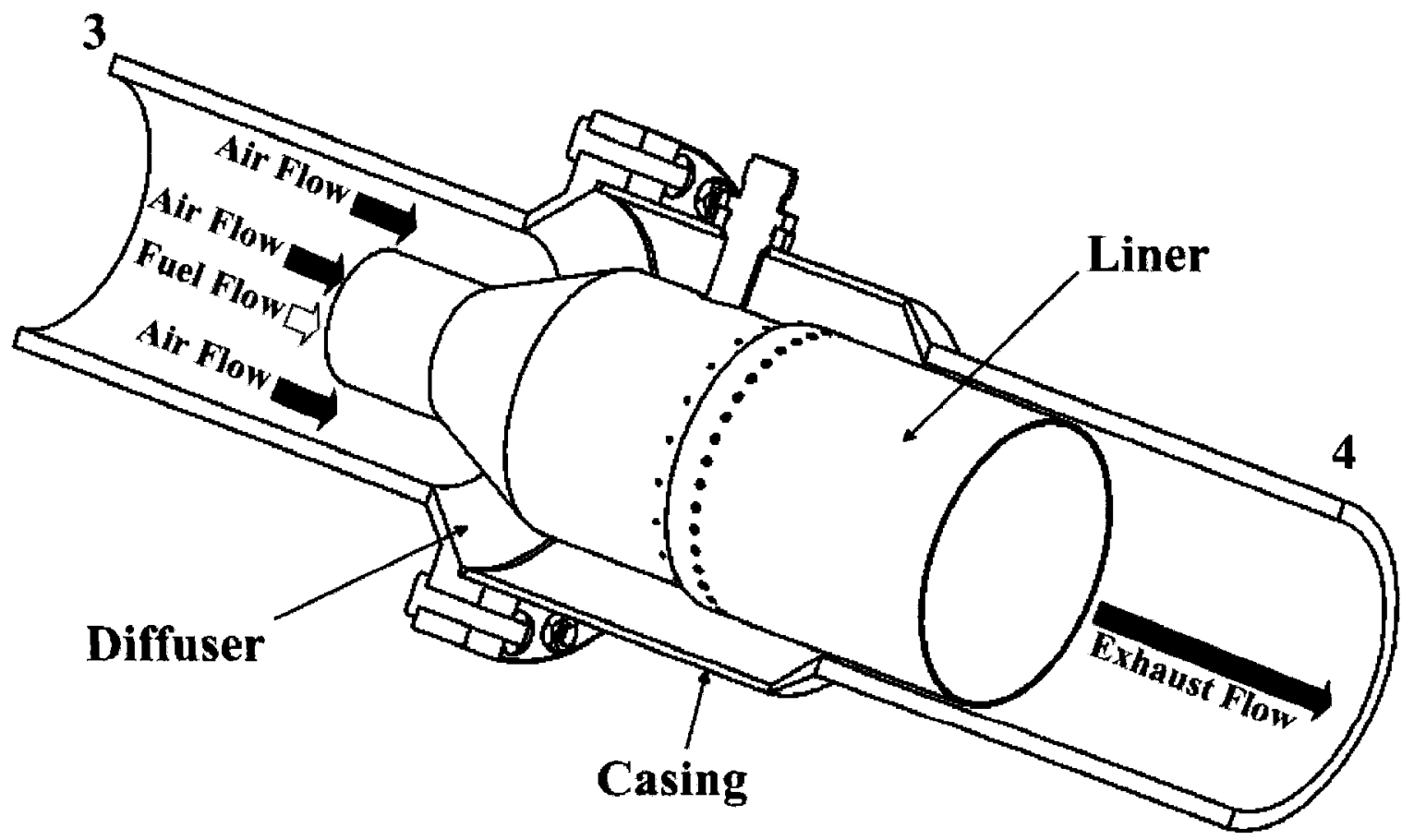

Figure 3.5 Combustor layout 


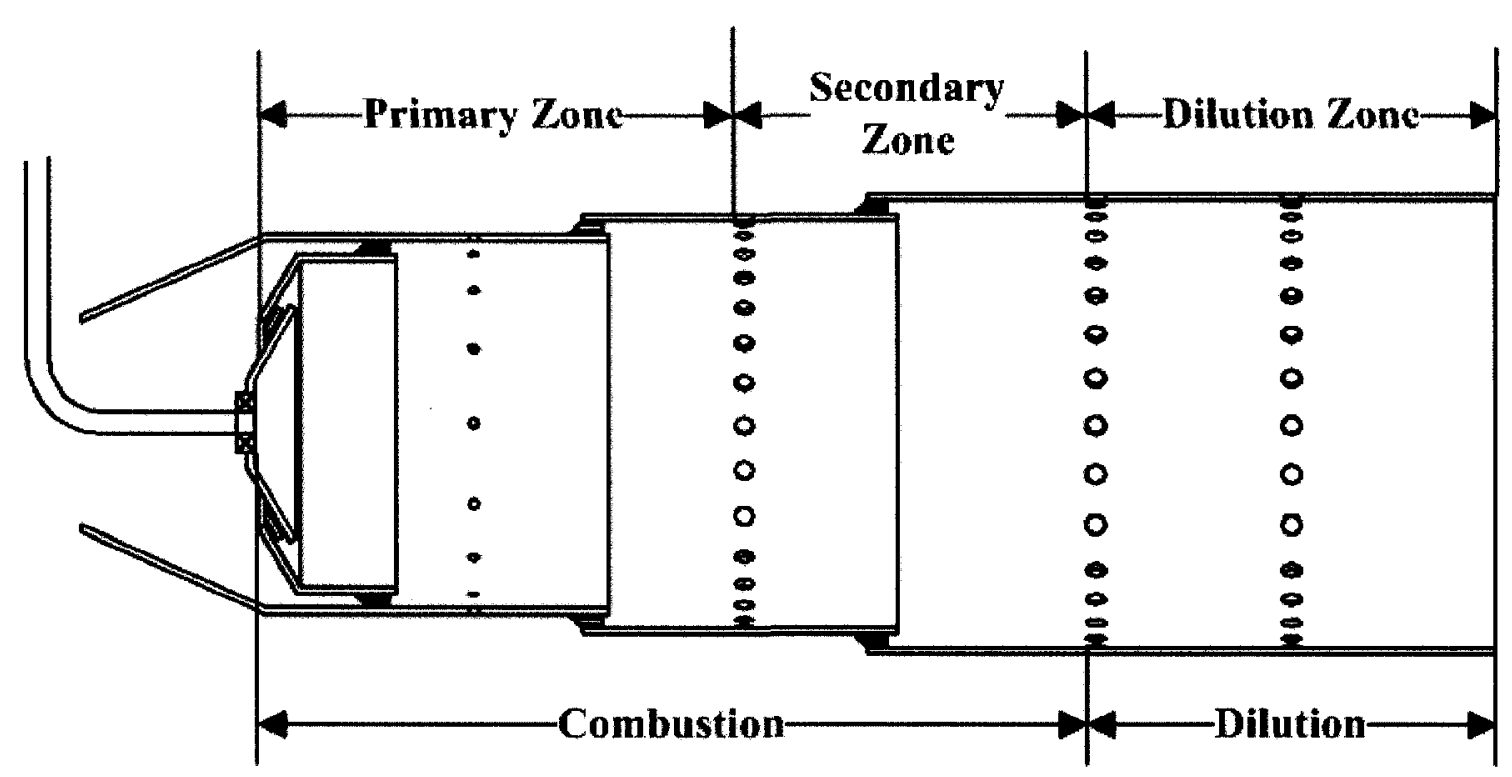

Figure 3.6 Conventional combustor zones

The role of the liner is to facilitate combustion and to contain hot combustion products.

In a conventional combustor the liner, is comprised of three areas called primary, secondary and dilution zones (Figure 3.6). By design the primary zone must anchor the flame and provide enough time, turbulence and temperature for the combustible mixture to efficiently burn. The secondary or intermediate zone allows for the combustion process to terminate. The scope of the dilution zone, also known as the tertiary zone, is to ensure that the combustion exhaust gasses have a temperature distribution that is satisfactory for the turbine (see Section 4.5.3 for more dilution details).

In a conventional combustor, the liner (Figure 3.7) is made up of a snout, dome, swirler, injection holes, cooling devices and a fuel nozzle(s) which injects fuel directly into the primary zone. 


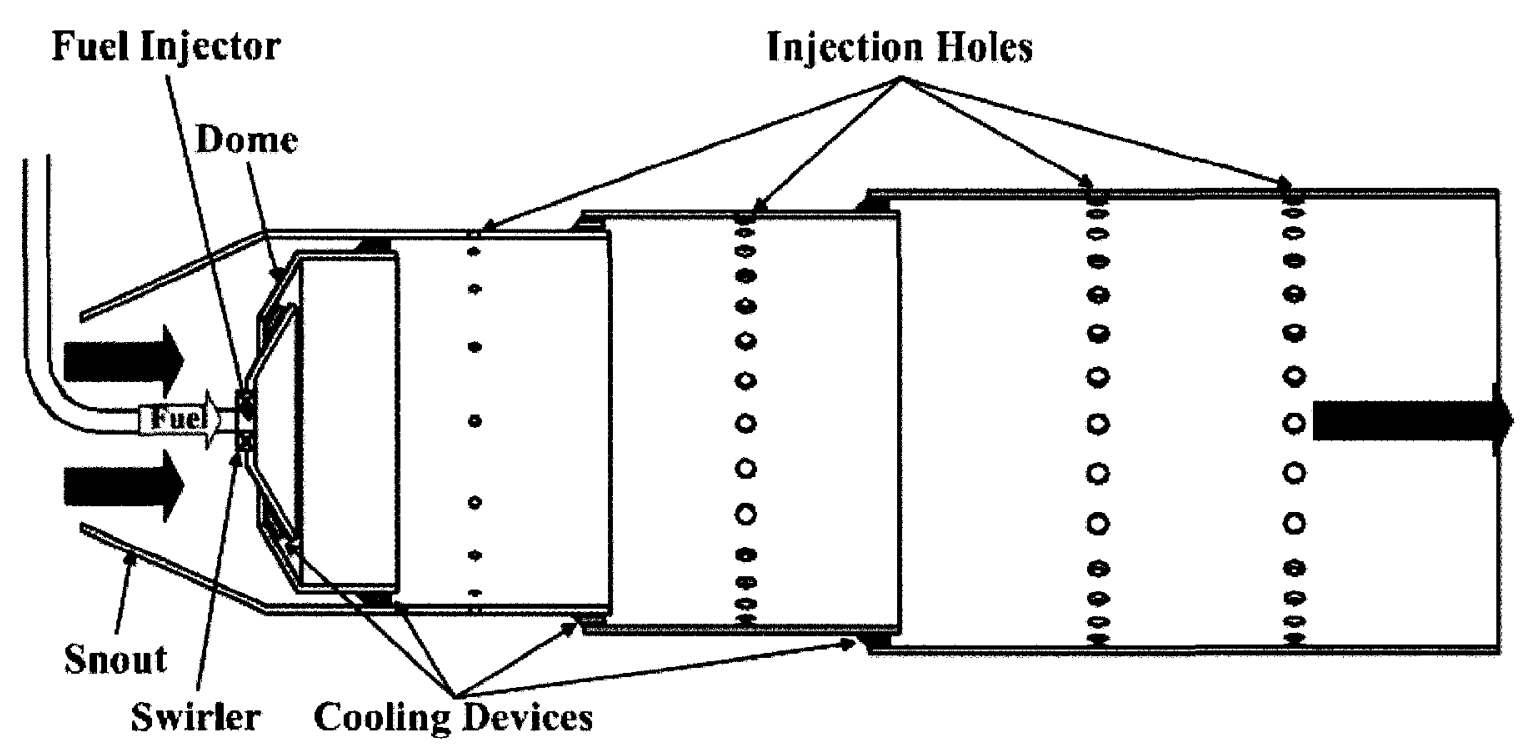

Figure 3.7 Conventional combustor liner

In a lean-premixed combustor, hereafter referred to as a premixed combustor, fuel is injected and mixed with air within a premixer fitted to the liner prior to entering the primary zone (Figure 3.9). Since the mixing of fuel and air is begun before entering the primary zone, the combustion process terminates within the primary zone. Hence, when compared to a conventional combustor, a premixed combustor has only two areas, namely the primary and the dilution zones (Figure 3.8 ). The primary zone must anchor the flame and provide enough time, turbulence and temperature for the combustible mixture to efficiently and completely burn. The dilution zone must ensure that the combustion exhaust gasses have a temperature distribution that is satisfactory for the turbine. 


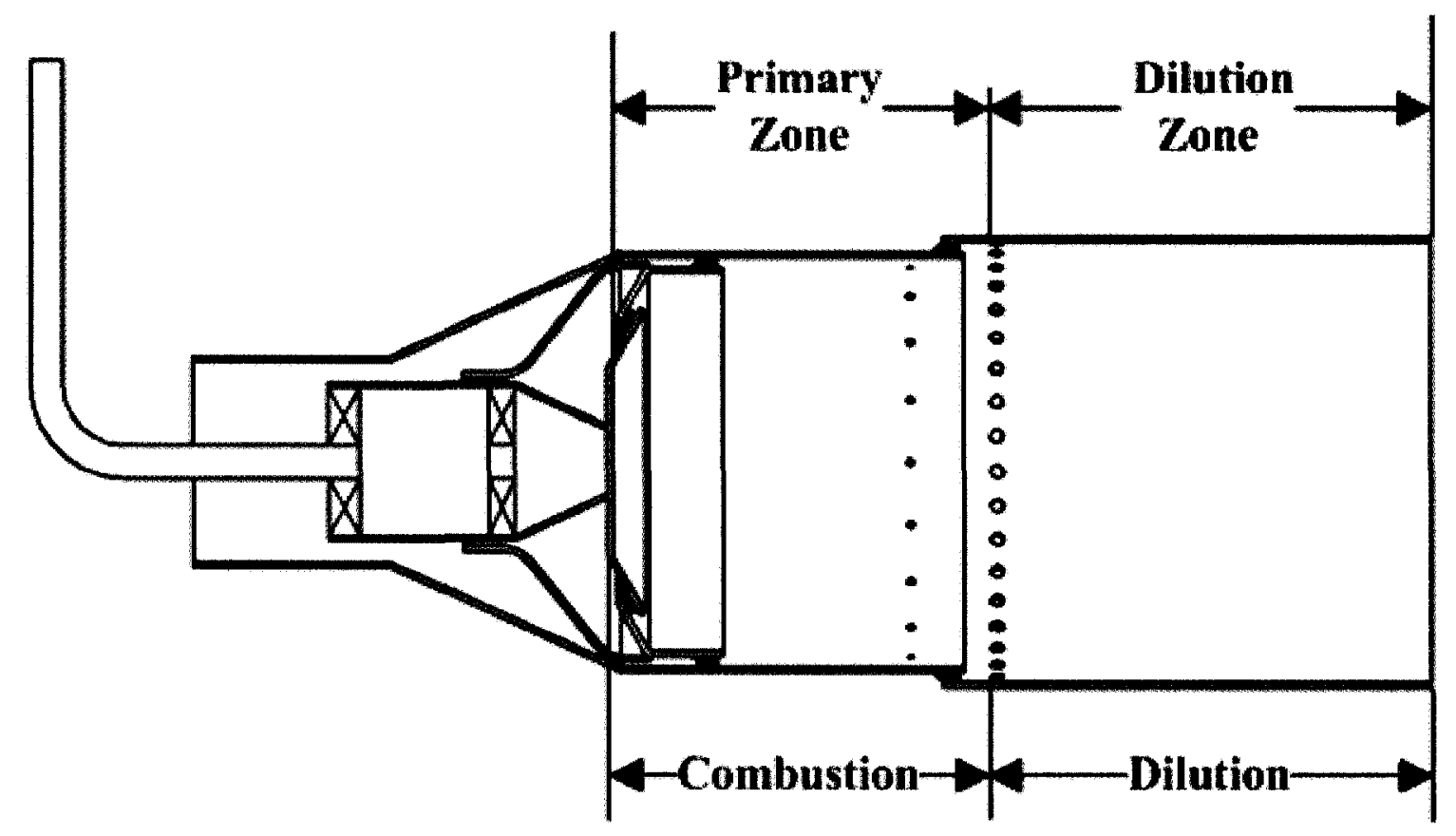

Figure 3.8 Premixed combustor zones

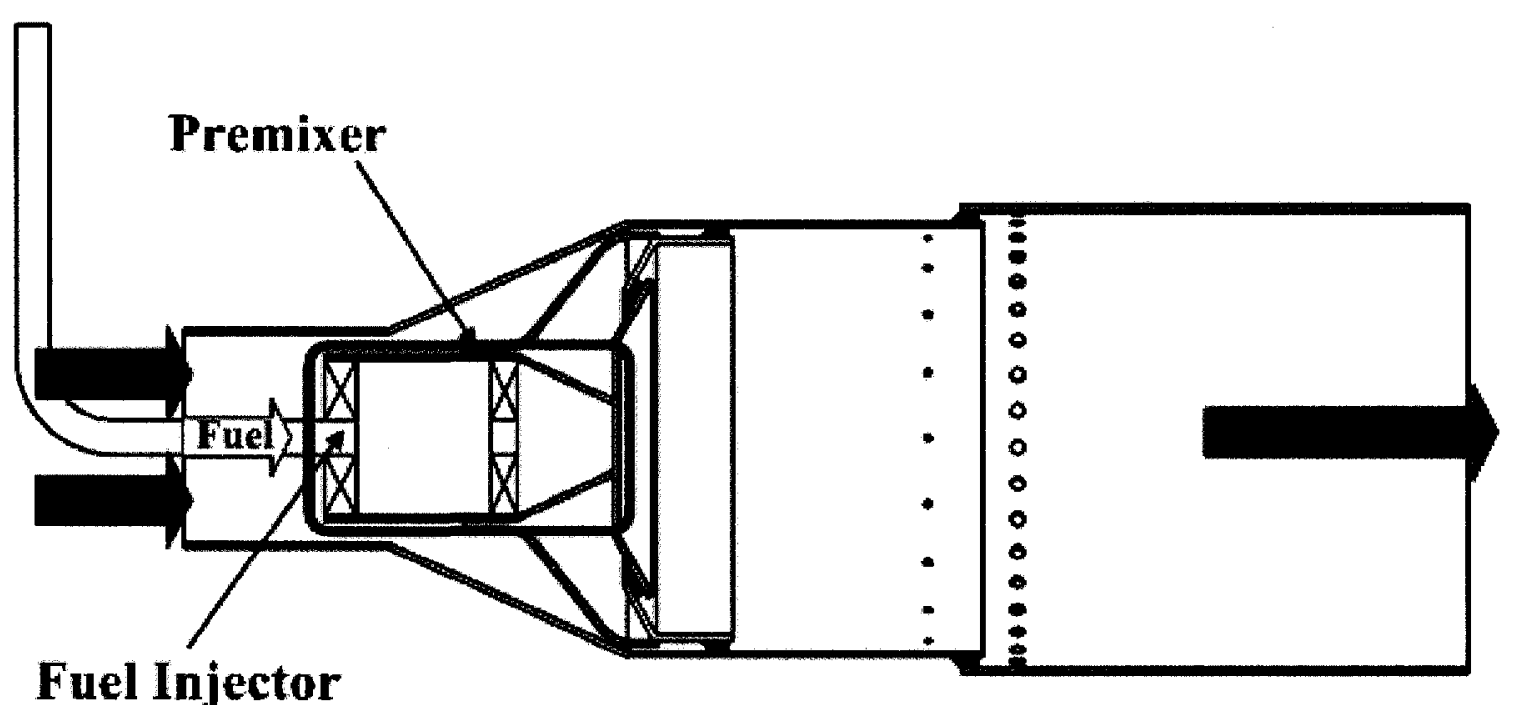

Figure 3.9 Premixed combustor liner 


\subsection{Combustor Types}

When taking into consideration the geometry of the combustor, the four most common designs are; 1) the can, 2) multi-can, 3) can-annular and 4) annular configurations (Figure 3.10) (Rolls-Royce, 1996). Can combustors, also known as tubular combustors, have cylindrical liners and casings. A gas turbine engine can contain one can combustor or multiple can combustors (multi-can). Annular combustors have a single annular liner and a concentric annular casing. Can-annular combustors are a combination of the two designs described above. This type of combustor, also called a tuboannular combustor, has a series of cylindrical liners enclosed within an annular casing.
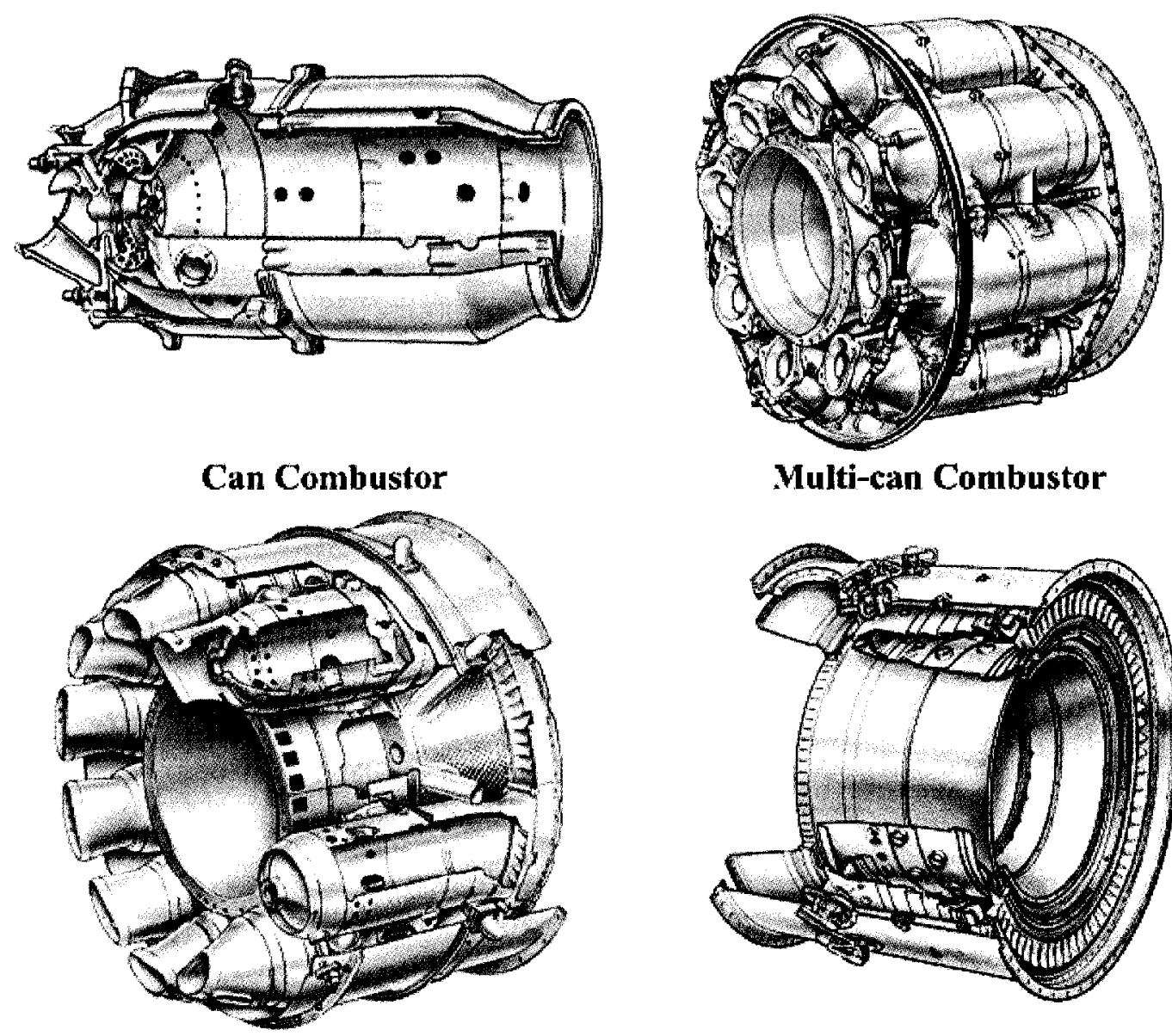

Can-annular Combustor

Multi-can Combustor

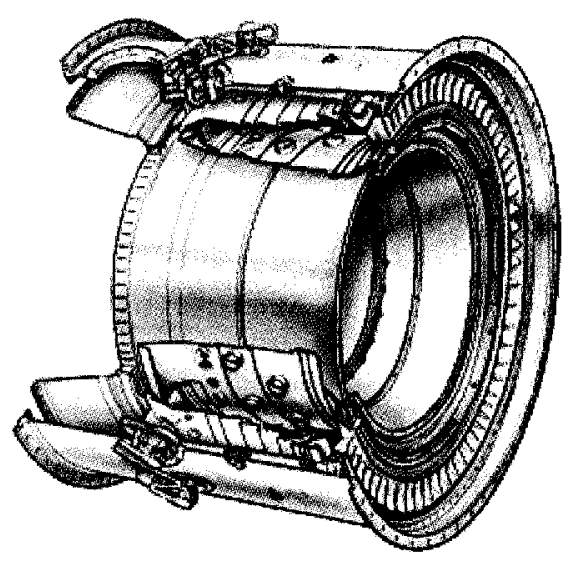

Annular Combustor

Figure 3.10 Common combustor configurations (Adapted from Rolls-Royce, 1996) 
Aerodynamically, combustors are divided as (Peters and Hammond, 1990):

- diffusion flame combustors, also called conventional combustors, where the fuel and oxidizer are injected and mixed within the primary zone;

- premixed combustors where the fuel and oxidizer are injected and mixed before they enter the combustor primary zone;

- $\quad$ staged combustors where, in addition to the primary fuel injector (main stage), supplementary fuel nozzles (pilot stage) are employed to provide better combustion stability and lower pollutant emissions throughout the various engine power settings; and

- catalytic combustors where combustor stability, in very lean fuel mixtures, is improved by the inclusion of a catalytic stabilizer whose main function is to reduce the concentrations of carbon monoxide $(\mathrm{CO})$ and unburned hydrocarbons (UHC).

The nature of the gas turbine engine application (aerospace, industrial, or vehicular) will determine the type of combustor to be used. For example, the main concerns in an aircraft engine are weight and reliability. The selection of an annular combustor will ensure a low engine cross sectional area and therefore, minimize airplane weight (Saravanamuttoo, 2001). The reliability of this combustor will be achieved by designing it to operate well within the stability loop (Figure 3.4) at all operating conditions (i.e., from ground to high altitudes). 


\section{DESIGN METHODOLOGY FOR THE PRELIMINARY DESIGN OF A GAS TURBINE COMBUSTOR}

The following chapter will focus on the theory used to develop a methodology (computer program) to preliminary design a gas turbine combustor to meet given engine specifications. The program, which is composed of many interlinked subroutines, allows the user to design a conventional or a premixed (or premixed prevaporized, LPP, for liquid fuel) combustor that meets engine requirements.

Figure 4.1 shows the design methodology algorithm. The various subroutines of the program, symbolized by the rectangular boxes, will be described in more detail in the following sections.

The programming was carried out using the computer software, Mathcad ${ }^{5}$.

\footnotetext{
${ }^{5}$ PTC Corporate Headquarters, 140 Kendrick Street, Needham, MA 02494, U.S.A
} 


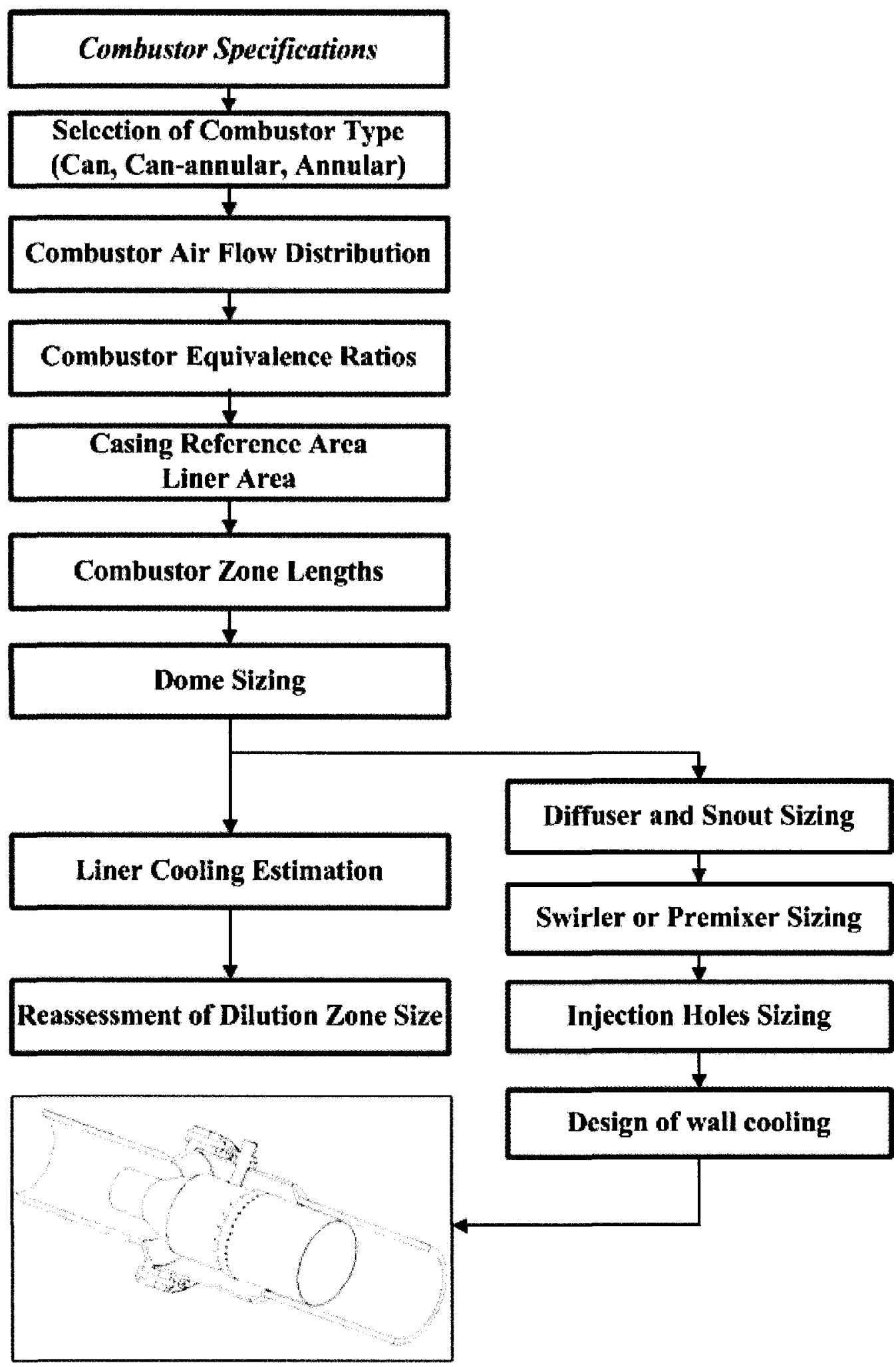

Combustor Preliminary Design

Figure 4.1 Combustor preliminary design algorithm 


\subsection{Combustor Preliminary Design Approach}

The initial dimensions of a combustor can be determined using either an aerodynamic approach or a reaction rate (chemical kinetics) approach. The design methodology presented in this work sizes the combustor implementing the former. This means that the combustor will be sized to meet a specified pressure loss across it.

The overall combustor pressure drop is comprised of two components; 1) "hot loss", also known as fundamental loss, and 2) cold loss as shown in the following equation (Lefebvre, 1999):

$$
\Delta P_{\text {Comb }}=\Delta P_{h o t}+\Delta P_{3-4}
$$

The hot loss is defined as:

$$
\Delta P_{h o t} \approx \frac{\rho_{3} V_{3}^{2}}{2}\left(\frac{T_{4}}{T_{3}}-1\right)
$$

where $\rho_{3}$ is the air density at the combustor inlet

$V_{3}$ is the air velocity at the combustor inlet

$T_{3}$ is the total temperature at the combustor inlet

$T_{4}$ is the total temperature at the combustor outlet

The cold loss is defined as:

$$
\Delta P_{3-4}=\Delta P_{d i f f}+\Delta P_{L}=\Delta P_{d i f f}+\frac{\rho_{3} V_{3}^{2}}{2}
$$

where $\Delta P_{\text {diff }}$ is the pressure drop in the diffuser

$$
\Delta P_{L} \text { is the pressure drop across the liner }
$$


The "hot loss" $\left(\Delta P_{\text {hot }}\right)$ represents the loss of the combustor stagnation pressure associated with the momentum change produced by the rapid release of energy during the combustion process (exothermic reaction process) (Saravanamuttoo, 2001).

The cold loss $\left(\Delta P_{3-4}\right)$ consists of the pressure drop in the diffuser $\left(\Delta P_{\text {diff }}\right)$ and the pressure drop across the liner $\left(\Delta P_{L}\right)$. Since the pressure drop in the diffuser is a parasitic loss, which means that it does not contribute to combustion, it should be minimized. The pressure loss across the liner, on the other hand, aids combustion in the primary zone, preserves the combustor structural integrity and ensures that a suitable exhaust temperature profile is seen by components downstream of the combustor. Combustion in the primary zone is aided by vigorous mixing of the fuel and the oxidizer. To mix these reactants, turbulence must be created which in turn results in liner pressure losses. To ensure combustor structural integrity cooling devices are strategically located throughout the liner. These devices create drag and therefore additional liner pressure losses. Finally, dilution holes are also present in the liner. The purpose of these holes is to allow for some of the air to enter the liner and mix with the hot combustion products to ensure that a suitable exhaust temperature profile is seen by the nozzle guide vanes and the turbine, which are located downstream of the combustor. The high velocity and expansion process as the air flowing through the dilution holes as well as the mixing process with the hot gasses is the last pressure drop component of the liner. However, even though a liner pressure drop is vital to the combustion process, it should also be minimized so that, as explained in Section 3.1, the useful work done by the turbine can be maximized and engine performance is not compromised. 
The importance of the diffuser in minimizing the combustor pressure losses can be appreciated by looking at Equations (4.2) and (4.3). As can be seen, the combustor pressure loss is proportional to the square of the compressor exit velocity $\left(V_{3}\right)$. Therefore, as mentioned in Section 3.10, the reduction of high compressor outlet velocities, through the combustor diffuser, will greatly diminish the combustor pressure losses.

The preliminary sizing of a combustor using the aerodynamic design approach will yield a combustor volume that is bigger than the volume given by a chemical kinetic design. This is because the turbulent mixing rate, which is based on aerodynamic fundamentals, is not fast when compared to the chemical kinetics rates related to a combustion system (Sawyer, 1985; Chemkin, 2006).

\subsection{Equivalence Ratio Estimation}

From previously established engine performance parameters (i.e., power output, specific fuel consumption, turbine inlet temperature, air and fuel mass flow rates, etc.) the global equivalence ratio, which is the ratio of fuel-to-air at stoichiometric conditions divided by the ratio of air entering the combustor to fuel used by the gas turbine, can be calculated from Equation (3.5) as follows (Turns, 2000):

$$
\phi_{\text {global }}=\frac{\left(\frac{\text { Air }}{\text { Fuel }}\right)_{\text {Stoich }}}{\left(\frac{\dot{m}_{3}}{\dot{m}_{f}}\right)_{\text {Actual }}}
$$

where $\dot{m}_{3}$ is the air mass flow entering the combustor 
$\dot{m}_{f}$ is the fuel mass flow entering the combustor

The primary zone equivalence ratio, Equation (4.5), which is the ratio of fuel-to-air at stoichiometric conditions divided by the ratio of air entering the combustor primary zone to fuel used by the gas turbine, can be expressed, through mathematical manipulation, as follows:

$$
\phi_{P Z}=\phi_{P Z}\left(T_{g}\right)=\phi_{\text {global }} \frac{\dot{m}_{3}}{\dot{m}_{P Z}}
$$

However, as can be see from Equation (4.5), the amount of air entering the primary zone is determined by the combustor flame temperature $\left(T_{g}\right)$. The methodology used to estimate the combustor flame temperature is given in the following section.

Similarly, the secondary and dilution zone equivalence ratios can be calculated as:

$$
\begin{aligned}
& \phi_{S Z}=\phi_{\text {global }} \frac{\dot{m}_{3}}{\dot{m}_{S Z}} \\
& \phi_{D Z}=\phi_{\text {global }} \frac{\dot{m}_{3}}{\dot{m}_{D Z}}
\end{aligned}
$$

However, prior to calculating these two ratios, the air flow distribution for the whole combustor $\left(\dot{m}_{P Z}, \dot{m}_{S Z}\right.$ and $\left.\dot{m}_{D Z}\right)$ must be determined (Section 4.4).

\subsection{Adiabatic Flame Temperature and Mixture Mole Fractions}

The following section presents the methodology used for obtaining the combustor flame temperature and the mole fractions of major combustion product species. The program is based on theory found in work published by Turns (2000). 
Since gas turbine combustion occurs at approximately constant pressure and heat loss is negligible compared to the energy added by the fuel, the flame temperature can be estimated by the constant pressure adiabatic flame temperature. For an accurate estimation of this temperature, the dissociation of major species involved in the combustion process should be taken into account. In high temperature combustion processes, as found in gas turbines, major species, such as $\mathrm{CO}_{2}, \mathrm{H}_{2} \mathrm{O}, \mathrm{O}_{2}$ and $\mathrm{N}_{2}$ dissociate to produce $\mathrm{H}_{2}, \mathrm{OH}, \mathrm{CO}, \mathrm{H}, \mathrm{O}, \mathrm{N}$ and $\mathrm{NO}$. The dissociation process uses energy to break molecule bonds and to form new molecules. Therefore, omission of the dissociation process would lead to an overestimation of the constant pressure adiabatic flame temperature, since the calculations would not take into account the energy loss due to dissociation.

The program (see Figure 4.2 for algorithm), which is used as a subroutine in the combustor design methodology, assumes that the $\mathrm{C}-\mathrm{H}-\mathrm{O}-\mathrm{N}$ system is a mixture of ideal gasses, that the air is composed of $21 \%$ oxygen and $79 \%$ nitrogen and that the fuel is in its vapour state.

The programming aspect was simplified by assuming that heat release reactions occur much more quickly than those which form NO, that the concentrations of NO, N and $\mathrm{O}$ are very small (parts per million, ppm) and that the concentration of $\mathrm{N}_{2}$ changes very little. By making these assumptions, the chemical equilibrium composition could be solved in two steps. The first part of the program calculates the dissociation of the C-H-O system (no $\mathrm{N}_{2}$ dissociation) and the heat released by the reaction $\left(T_{a d}\right)$. The second part of the program uses the above outputs to solve for the dissociation of nitrogen $\left(\mathrm{N}_{2}\right)$ to 
form NO, $\mathrm{N}$ and $\mathrm{O}$. The following chemical reactions illustrate the two-step method approach (Gauthier, 2005):

$\underline{\text { STEP } 1}$

$\mathrm{C}_{\alpha} \mathrm{H}_{\beta} \mathrm{O}_{\gamma}+\frac{\mathrm{x}_{\mathrm{s}}}{\phi}\left(\mathrm{O}_{2}+3.76 \mathrm{~N}_{2}\right) \Rightarrow \mathrm{N}_{\mathrm{CO}_{2}}^{\prime} \mathrm{CO}_{2}+\mathrm{N}_{\mathrm{CO}}^{\prime} \mathrm{CO}+\mathrm{N}_{\mathrm{H}_{2} \mathrm{O}}^{\prime} \mathrm{H}_{2} \mathrm{O}+\ldots$

$\ldots+\mathrm{N}_{\mathrm{H}_{2}}^{\prime} \mathrm{H}_{2}+\mathrm{N}_{\mathrm{O}_{2}}^{\prime} \mathrm{O}_{2}+\mathrm{N}_{\mathrm{OH}}^{\prime} \mathrm{OH}+3.76 \cdot \frac{\mathrm{X}_{\mathrm{s}}}{\phi} \cdot \mathrm{N}_{2} \quad$ for $\phi \leq 1$

where $\mathrm{N}^{\prime}$ represents the coefficients of product species

$$
x_{s}=\alpha+\left(\frac{\beta}{4}\right)-\left(\frac{\gamma}{2}\right)
$$

An iterative process, described later, is used to simultaneously solve for $\mathrm{N}_{\mathrm{CO}}^{\prime}, \mathrm{N}_{\mathrm{H}_{2}}^{\prime}$, $\mathrm{N}_{\mathrm{OH}}^{\prime}$ and adiabatic flame temperature $\left(T_{a d}\right)$.

\section{$\underline{\text { STEP } 2}$}

$\mathrm{C}_{\alpha} \mathrm{H}_{\beta} \mathrm{O}_{\gamma}+\frac{\mathrm{x}_{\mathrm{s}}}{\phi}\left(\mathrm{O}_{2}+3.76 \mathrm{~N}_{2}\right) \Rightarrow \mathrm{N}_{\mathrm{CO}_{2}}^{\prime} \mathrm{CO}_{2}+\mathrm{N}_{\mathrm{CO}}^{\prime} \mathrm{CO}+\mathrm{N}_{\mathrm{H}_{2} \mathrm{O}}^{\prime} \mathrm{H}_{2} \mathrm{O}+\mathrm{N}_{\mathrm{H}_{2}}^{\prime} \mathrm{H}_{2}+\ldots$

$\ldots+\mathrm{N}_{\mathrm{O}_{2}}^{\prime} \mathrm{O}_{2}+\mathrm{N}_{\mathrm{OH}}^{\prime} \mathrm{OH}+\mathrm{N}_{\mathrm{NO}}^{\prime} \mathrm{NO}+\mathrm{N}_{\mathrm{N}}^{\prime} \mathrm{N}+\mathrm{N}_{\mathrm{O}}^{\prime} \mathrm{O}+\mathrm{N}_{\mathrm{N}_{2}}^{\prime} \mathrm{N}_{2} \quad$ for $\phi \leq 1$

Solving for $\mathrm{N}_{\mathrm{NO}}^{\prime}, \mathrm{N}_{\mathrm{N}}^{\prime}, \mathrm{N}_{\mathrm{O}}^{\prime}$ 


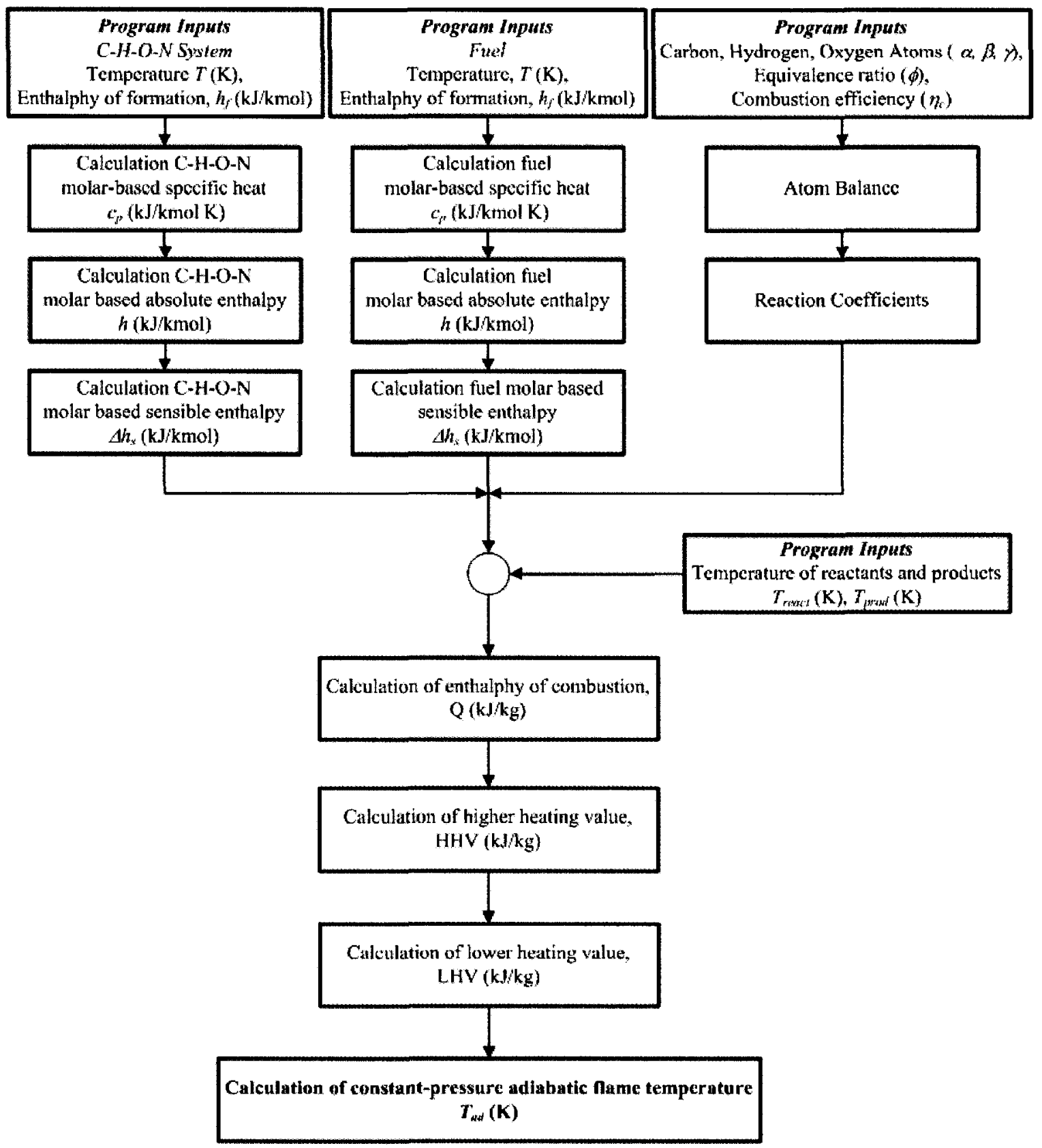

Figure 4.2 Adiabatic flame temperature algorithm

The calculation of the adiabatic flame temperature, $\left(T_{a d}\right)$, is based on energy conservation theory which dictates that the absolute enthalpy of the reactants at their initial states must equal the absolute enthalpy of the products at their final states as shown below (Turns, 2000): 
$H_{\text {react }}\left(T_{i}, P\right)=H_{\text {prod }}\left(T_{a d}, P\right)$

where $H$ is the enthalpy, $\mathrm{J}$

$T$ is the temperature, $\mathrm{K}$

$P$ is the pressure, $\mathrm{Pa}$

The second law of thermodynamics, and in particular, the standard Gibbs free energy change $\Delta G_{T}^{0}$, allows the calculation of the mixture equilibrium composition for a given reactant temperature, pressure and equivalence ratio.

$$
\Delta G_{T}^{0}=-\bar{R} T \ln \left(K_{p}\right)
$$

where $\bar{R}$ is the universal gas constant $(8.3144 \mathrm{~J} / \mathrm{mol} \mathrm{K})$

$K_{p}$ is the equilibrium constant, calculated in Equation (4.15).

For a general chemical system, as shown below,

$$
a A+b B+\ldots \leftrightarrow e E+f F+\ldots
$$

the standard-state Gibbs function change $\left(\Delta G_{T}^{0}\right)$ is determined as (Turns, 2000):

$$
\Delta G_{T}^{0}=e \bar{g}_{f, E}^{0}+f \bar{g}_{f, F}^{0}+\ldots-a \bar{g}_{f, A}^{0}-b \bar{g}_{f, B}^{0}-\ldots
$$

where $\bar{g}_{f, i}^{0}$ is the standard Gibbs free energy of formation for the $i$ th species.

The equilibrium constant $K_{p}$ is calculated as (Turns, 2000):

$$
K_{p}=\frac{\left(\frac{P_{E}}{P^{0}}\right)^{e}\left(\frac{P_{F}}{P^{0}}\right)^{f} \cdots}{\left(\frac{P_{A}}{P^{0}}\right)^{a}\left(\frac{P_{B}}{P^{0}}\right)^{b} \cdots} \quad i=A, B, \ldots E, F \ldots
$$

where $P_{i}$ is the partial pressure of the $i$ th species 
$P^{0}$ is the standard state pressure, $1 \mathrm{~atm}$.

By noting that the partial pressure $\left(P_{i}\right)$ can be expressed in terms of mole fractions, $\chi_{i}$

$$
P_{i}=\chi_{i} P
$$

and by substituting Equation (4.15) into Equation (4.12), the equation below can be yielded (Turns, 2000):

$$
\frac{\chi_{E}^{e} \cdot \chi_{F}^{f} \cdot e t c}{\chi_{A}^{a} \cdot \chi_{B}^{b} \cdot e t c} \cdot\left(\frac{P}{P^{0}}\right)^{(e+f+\ldots-a-b-\ldots)}=\exp \left[\frac{\Delta G_{T}^{0}}{\bar{R} T}\right]
$$

Lastly, conservation of elements, Equation (4.13) imposes that the summation of the mole fractions must equal unity (4.18) (Turns, 2000):

$$
\sum_{i} \chi_{i}=1
$$

In summary, the solution of Equation (4.11) determines the constant pressure adiabatic flame temperature and the simultaneous solution of Equations (4.13), (4.17) and (4.18) solves for the mixture equilibrium composition (i.e., the mixture mole fractions).

Confidence in the program outputs was obtained through a verification process. The subroutine verification was carried out by comparing its results with outputs obtained from HPFLAME, a FORTRAN program developed by Olikara and Borman (1975) which also calculates the adiabatic constant pressure flame temperature and the mixture mole fractions. As can be seen from Figure 4.3 the Mathcad and HPFLAME program results are in very good agreement. 


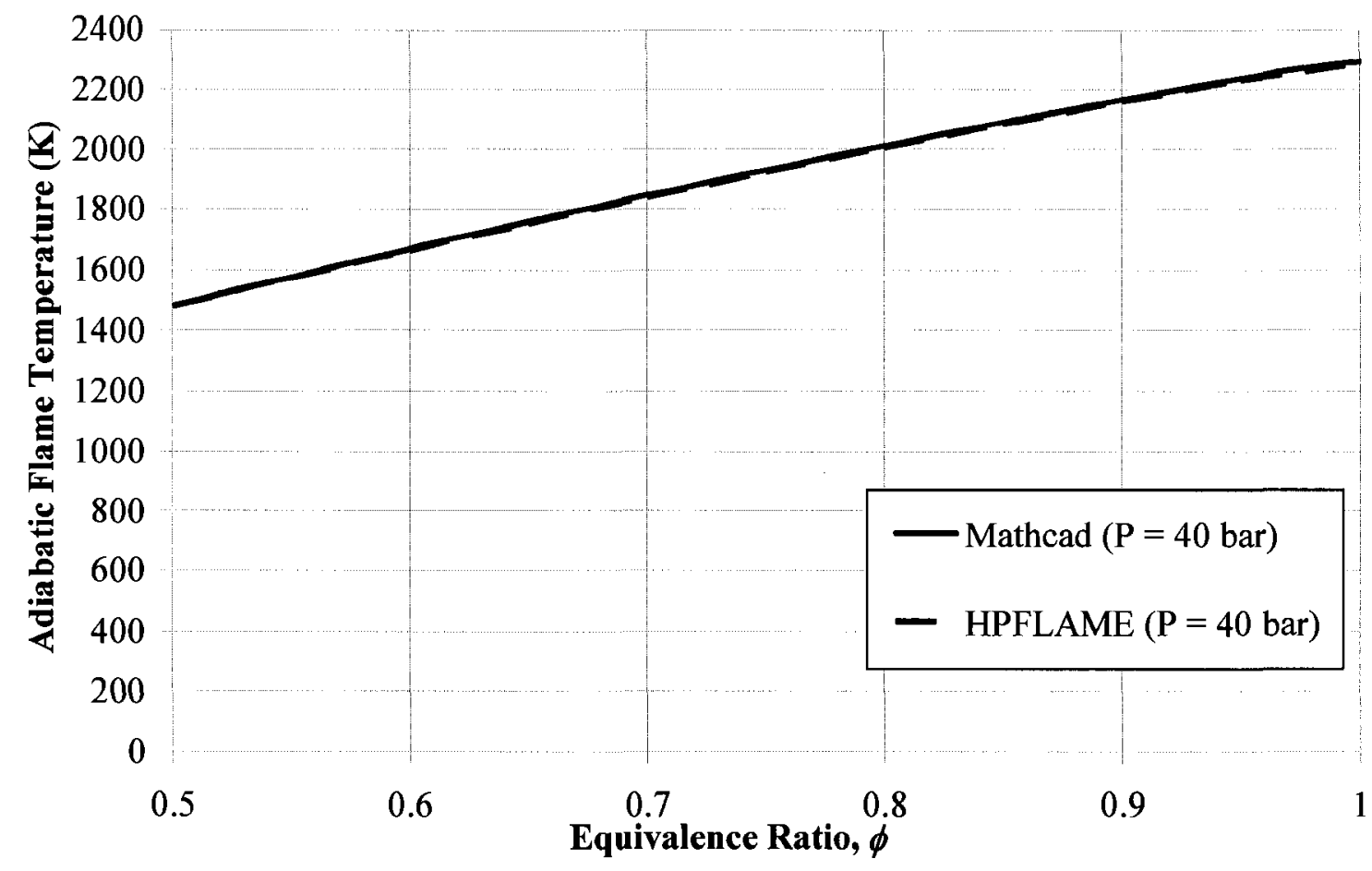

\section{Figure 4.3 Effect of equivalence ratio on adiabatic flame temperature}

As can be seen from the algorithm (Figure 4.2) and the theory described above, the calculation of the adiabatic flame temperature and the mixture mole fractions requires a lengthy program that has to solve many equations simultaneously. A simpler approach, based on work presented by Gülder (1986), could be found useful for users who are solely interested in the adiabatic flame temperature or when the combustion work requires a large amount of program iterations, making the computational time too expensive. In the publication, Gülder presents empirical correlations that can estimate the adiabatic flame temperature through the implementation of a simple formula. Although not as accurate as the results obtained from chemical equilibrium programs $(0.4$ to $0.8 \%$ error) (Gülder, 1986), the correlations take into account reactants pressure, temperature, equivalence ratio, and it can be applied to diesel, gasoline, pure alkanes, aromatics as 
well as jet fuel. The simplicity and good estimation of this approach makes it very suitable for preliminary design work.

\subsection{Liner Air Mass Flow Rate Distribution}

The drive to reach higher gas turbine performance levels and the adherence to stringent emissions regulations have caused the design of the combustor to evolve over the past few decades.

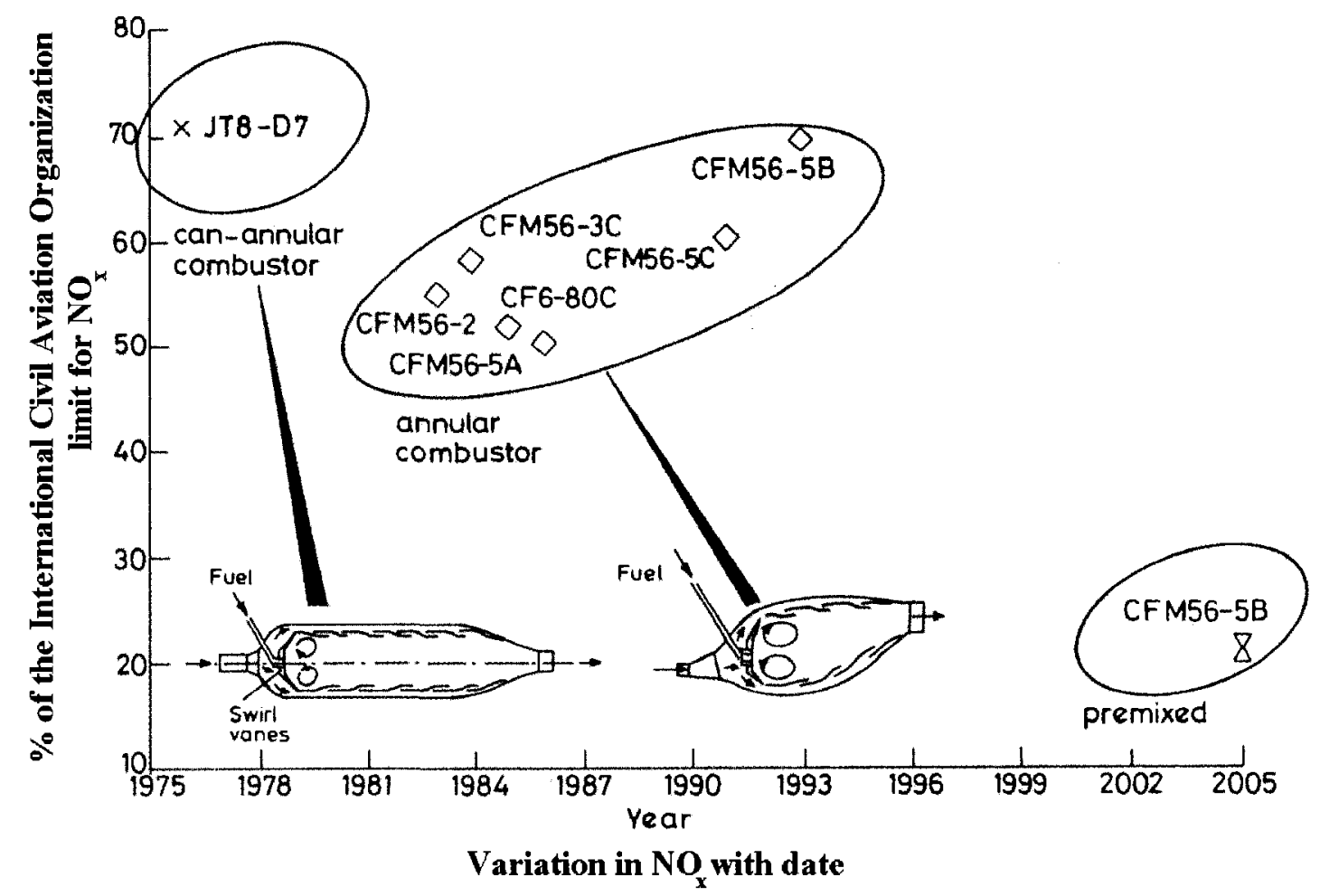

Figure 4.4 Combustor design evolution (Adapted from Cumpsty, 2003)

Figure 4.4 shows the progression of combustor design for gas turbine engines used in aircraft applications. The fact that premixed combustors for aerospace usage are still at an early service stage when compared to gas turbine combustors designed for land-based power generation is of particular interest. Premixed combustors for aircraft engine 
applications have still practical difficulties (engine reliability from ground to high altitude operations as well as engine relight problems at high altitude) that need to be addressed before premixing becomes viable for the aerospace industry (Cumpsty, 2003).

Combustor design evolution was further investigated by the author by reviewing combustor design guidelines published in the last 20 years. Revision of design guidelines published by Sawyer (1985), Kretschmer (2000), Saravanamuttoo (2001), Lefebvre (1999), Mellor (1990) and Gauthier (2007), not only illustrated how the gas turbine combustor has evolved, but also provides useful information, like the combustor air flow distribution, that has been the foundation upon which the design methodology has been developed.

The air flow distribution of past and more recent combustors, based on the above references, is presented next.

As a general guideline, for a conventional combustor, Saravanamuttoo (2001) suggests that approximately 15 to $20 \%$ of the total air entering the combustor should be introduced in the primary zone around the fuel nozzle. Roughly $30 \%$ of the total air should be admitted in the secondary zone and between 50 and $55 \%$ should be admitted in the dilution zone. Similarly, Sawyer (1985) and Kretschmer (2000) indicated that $25 \%$ of the total air entering the combustor should be admitted within the primary zone, $20 \%$ in the secondary zone and 55\% (which includes film cooling) in the dilution zone (Figure 4.5). Lefebvre (1999) and Rolls-Royce (1996) indicated that the need for larger quantities of liner cooling air, to keep up with progressively higher gas turbine pressure ratios, resulted in amount of air available for the dilution zone ranging between $20 \%$ and $40 \%$ of the total air entering the combustor. 


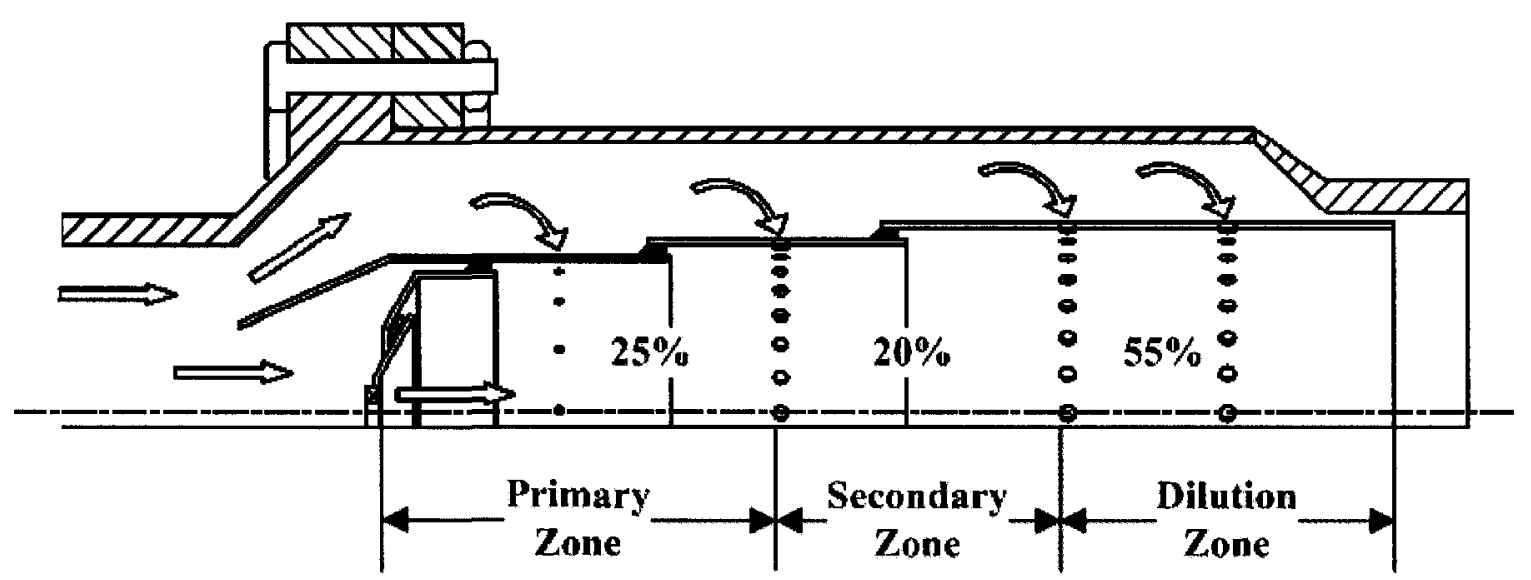

Figure 4.5 Typical conventional combustor air flow distribution

More recent gas turbine combustion work on conventional combustors, published by Mattingly (2002), shows that typical primary zone equivalence ratios take into consideration the formation of pollutants. In fact, the increase in combustor entry and exit temperatures and pressures allowed reaching combustion stability with lower primary zone equivalence ratios. In particular, more recent combustors operate with an equivalence ratio in the primary zone in the order of $\phi_{P z}=0.8$ or with a target flame temperature in the range of $1700 \mathrm{~K}$ to $1900 \mathrm{~K}$ (Mattingly, 2002). As can be seen in Figure 4.6, within this temperature range the formation of air pollutants such as carbon monoxide $(\mathrm{CO})$ and nitrogen oxides $\left(\mathrm{NO}_{\mathrm{x}}\right)$ can be minimized.

The above work is in accordance with work published by Lefebvre (1999) which suggests that the flame temperature should be kept below $2000 \mathrm{~K}$. 


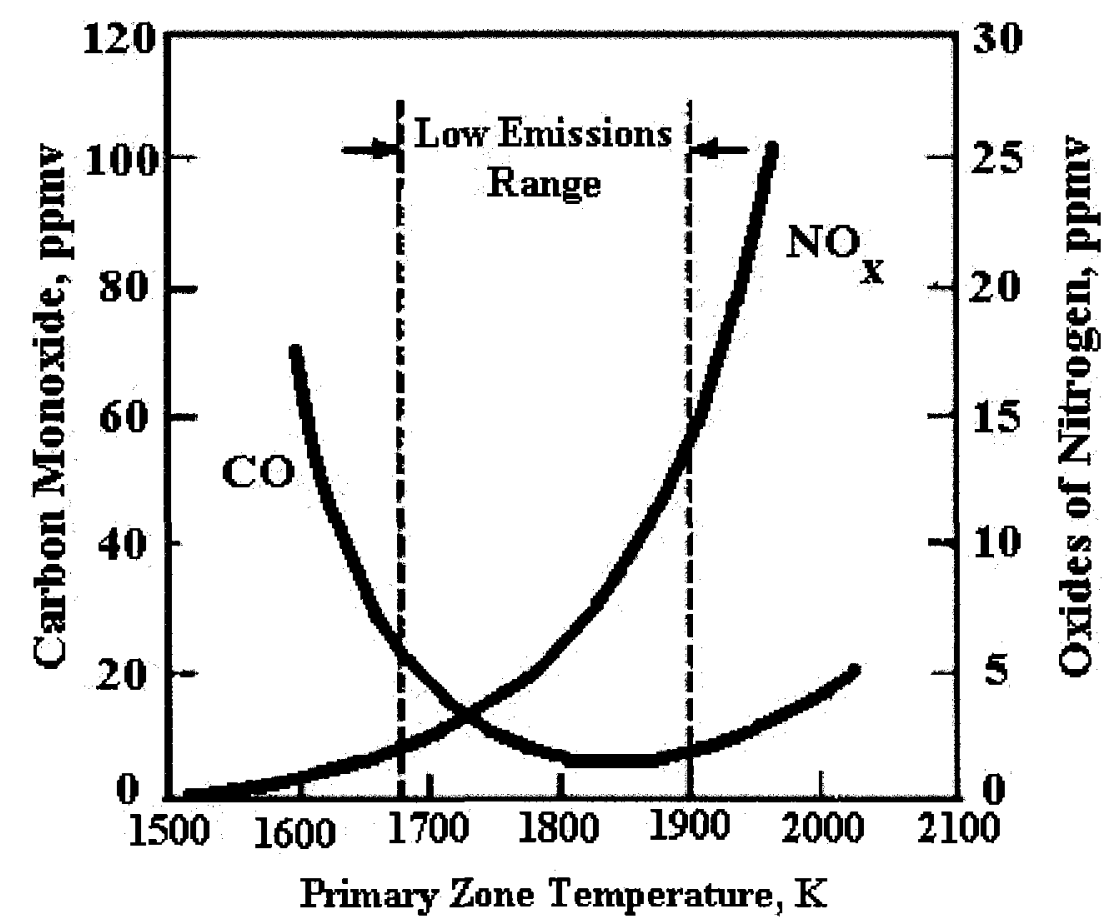

Figure 4.6 Effect of $\mathrm{PZ}$ temperature on formation of pollutants for conventional combustor (Adapted from Mattingly, 2002)

The air flow distribution for premixed combustors is shown in Figure 4.7. As a general guideline, for a premixed combustor, Gauthier (2007) suggests that approximately 60 to $80 \%$ of the total air entering the combustor should be introduced in the primary zone through the premixer. Between 0 to $20 \%$ of the total air should be admitted in the primary zone via injection holes and between 10 to $20 \%$ of the total air should be admitted in the dilution zone. 


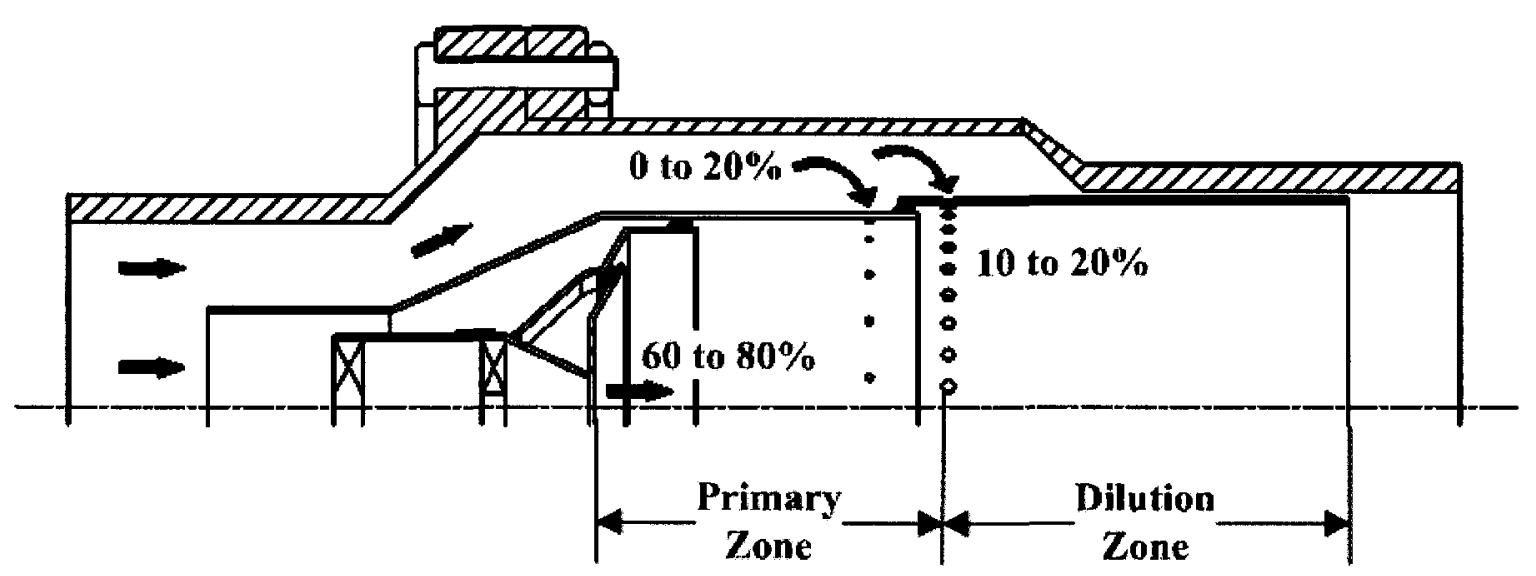

Figure 4.7 Premixed combustor air flow distribution

\subsection{Casing and Liner Sizing}

\subsubsection{Casing and Liner Area}

The first objective in the sizing of a combustor (see Figure 4.8 for nomenclature) is the determination of the reference area.

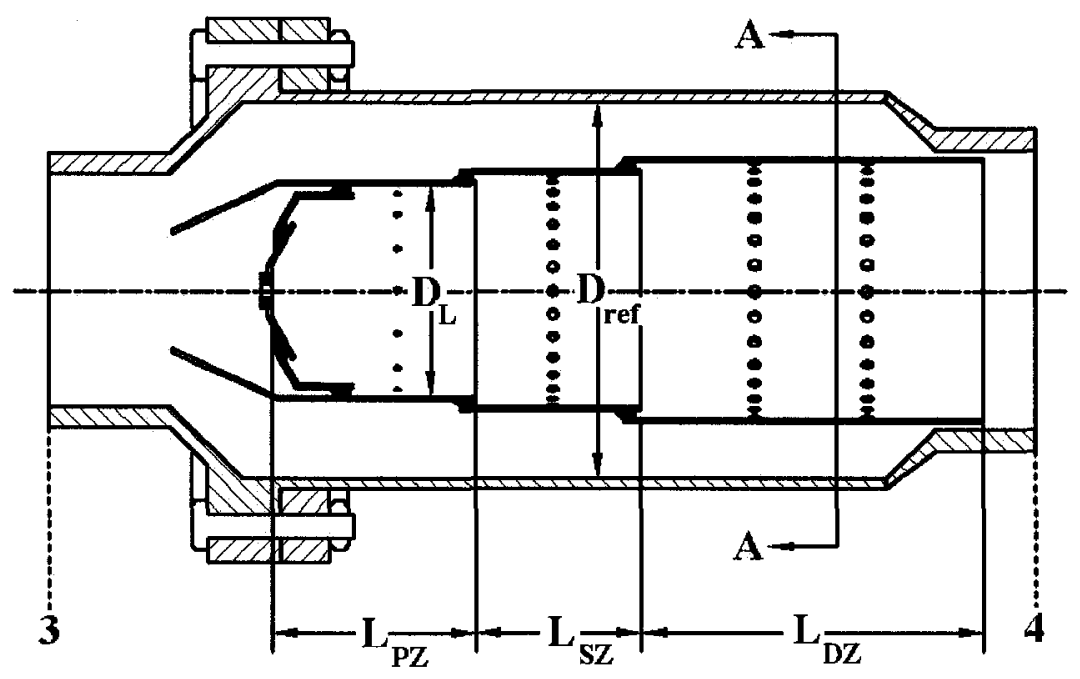

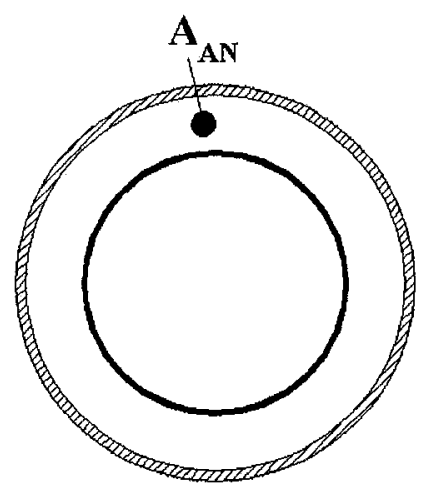

Section A-A

Figure 4.8 Combustor nomenclature

The reference area, $A_{r e f}$, which defines the maximum casing area, is calculated by (Sawyer, 1985; Lefebvre, 1999; Kretschmer, 2000): 
$A_{r e f}=\left[\frac{R_{a}}{2}\left(\frac{\dot{m}_{3} T_{3}^{0.5}}{P_{3}}\right)^{2}\left(\frac{\Delta P_{3-4}}{q_{r e f}}\right)\left(\frac{\Delta P_{3-4}}{P_{3}}\right)^{-1}\right]^{0.5}$

where $A_{\text {ref }}$ is the reference area, $\mathrm{m}^{2}$

$R_{a}$ is the air gas constant, $286.9 \frac{\mathrm{Nm}}{\mathrm{kg} \mathrm{K}}$

$\dot{m}_{3}$ is the mass flow rate at the combustor inlet, $\frac{\mathrm{kg}}{\mathrm{s}}$

$P_{3}$ is the total pressure at the combustor inlet, $\mathrm{Pa}$

$T_{3}$ is the total temperature at the combustor inlet, $\mathrm{K}$

$\Delta P_{3-4}$ is the cold pressure loss, $\mathrm{Pa}$

$q_{r e f}$ is the reference dynamic pressure Equation (4.20), $\mathrm{Pa}$

Equation (4.19) contains two important aerodynamic dimensionless parameters.

These parameters are the pressure drop ratio (PDR) and the pressure loss factor (PLF).

The PDR $\left(\Delta P_{3-4} / P_{3}\right)$ is the ratio of the total pressure drop across the combustor $\left(\Delta P_{3-4}\right)$

to the combustor inlet total pressure $\left(P_{3}\right)$. The PLF $\left(\Delta P_{3-4} / q_{r e f}\right)$ is the ratio of the total

pressure drop across the combustor to the reference dynamic pressure $\left(q_{\text {ref }}\right)$.

$q_{r e f}=\frac{1}{2} \rho_{3} V_{r e f}^{2}$

where $\rho_{3}$ is the air density at the combustor inlet

$V_{r e f}$ is the reference velocity, Equation (4.21) 
$V_{r e f}=\frac{\dot{m}_{3}}{\rho_{3} A_{r e f}}$

From an aerodynamic point of view, the PLF measures the flow resistance introduced into the air flow by the combustor and can be defined as the combustor drag coefficient. Since the PLF is dependent solely on the combustor design and manufacturing process, each combustor will have its unique pressure loss factor which will be independent from engine operating conditions. Table 4.1 gives a summary of typical values for PDR and PLF found in literature.

Table 4.1 Pressure loss terms for aircraft and industrial engine combustors

\begin{tabular}{|c|c|c|c|c|}
\hline Author & \multicolumn{2}{|c|}{ Sawyer (1985) } & \multicolumn{2}{|c|}{ Kretschmer (2000) } \\
\hline $\begin{array}{c}\text { Pressure Loss } \\
\text { Terms }\end{array}$ & $\begin{array}{c}\Delta P_{3-4} / P_{3} \% \\
\text { (PDR) }\end{array}$ & $\begin{array}{c}\Delta P_{3-4} / q_{\text {ref }} \\
\text { (PLF) }\end{array}$ & $\begin{array}{c}\Delta P_{3-4} / P_{3} \% \\
\text { (PDR) }\end{array}$ & $\begin{array}{c}\Delta P_{3-4} / q_{r e f} \\
\quad(\mathrm{PLF})\end{array}$ \\
\hline Multi-can & $\overline{5.3}$ & 40 & $\overline{5.3}$ & 40 \\
\hline Annular & 6.0 & 20 & 6.0 & 20 \\
\hline Can-annular & 5.4 & 30 & 5.4 & 30 \\
\hline Industrial & - & - & 3.0 & - \\
\hline Author & \multicolumn{2}{|c|}{ Lefebvre (1999) } & \multicolumn{2}{|c|}{ Saravanamuttoo (2001) } \\
\hline $\begin{array}{l}\text { Pressure Loss } \\
\text { Terms }\end{array}$ & $\begin{array}{c}\Delta P_{3-4} / P_{3} \% \\
\text { (PDR) }\end{array}$ & $\begin{array}{c}\Delta P_{3-4} / q_{\text {ref }} \\
\text { (PLF) }\end{array}$ & $\begin{array}{c}\Delta P_{3-4} / P_{3} \% \\
\text { (PDR) }\end{array}$ & $\begin{array}{c}\Delta P_{3-4} / q_{\text {ref }} \\
(\mathrm{PLF})\end{array}$ \\
\hline Multi-can & 7.0 & 37 & \multirow{3}{*}{4.0 to 7.0} & 35 \\
\hline Annular & 6.0 & 20 & & 18 \\
\hline Can-annular & 6.0 & 28 & & 25 \\
\hline Industrial & - & - & 2.0 to 3.0 & - \\
\hline
\end{tabular}

After having estimated the reference area, at the design engine operating condition, the geometry factor $(G F)$, defined next, can be calculated and compared to typical values found in literature (Table 4.2). 
$G F=\frac{\dot{m}_{3} \sqrt{T_{3}}}{P_{3} A_{r e f}}$

Table 4.2 Geometry factors

\begin{tabular}{|c|c|c|c|}
\hline Author & Sawyer (1985) & Kretschmer (2000) & Lefebvre (1999) \\
\hline \multirow{2}{*}{ Geometry Factor } & $\frac{\dot{m}_{3} \sqrt{T_{3}}}{P_{3} A_{r e f}}$ & $\frac{\dot{m}_{3} \sqrt{T_{3}}}{P_{3} A_{r e f}}$ & $\frac{\dot{m}_{3} \sqrt{T_{3}}}{P_{3} A_{r e f}}$ \\
\hline \hline Multi-can & $3.0 \times 10^{-3}$ & $3.0 \times 10^{-3}$ & $3.6 \times 10^{-3}$ \\
\hline \hline Annular & $4.5 \times 10^{-3}$ & $4.5 \times 10^{-3}$ & $4.6 \times 10^{-3}$ \\
\hline \hline Can-annular & $3.5 \times 10^{-3}$ & $3.5 \times 10^{-3}$ & $3.9 \times 10^{-3}$ \\
\hline
\end{tabular}

With the reference area (maximum casing area) calculated, the liner area $\left(A_{L}\right)$ can now be estimated, using the following guidelines:

Sawyer (1985) suggests that the liner area should be in the following range:

$$
0.6 A_{\text {ref }} \leq A_{L} \leq 0.72 A_{\text {ref }}
$$

The above is in agreement with Kretschmer (2000) which presented the liner area to be,

$$
A_{L}=0.7 A_{r e f}
$$

where $A_{L}$ is the liner area, $\mathrm{m}^{2}$

Lefebvre (1999) proposes the following expression:

$$
A_{L}=k_{o p t} A_{r e f}
$$

where $k_{\text {opt }}$ is the optimal value determined from Equation (4.26) 
$k_{o p t}=1-\left[\frac{\left(1-m_{s n}\right)^{2}-\lambda_{\text {diff }}}{\frac{\Delta P_{3-4}}{q_{r e f}}-\lambda_{\text {diff }} A R^{2}}\right]^{\frac{1}{3}}$

where $m_{s n}$ is the ratio of air entering snout to total combustor air flow

$\lambda_{\text {diff }}$ is the diffuser pressure loss coefficient

$A R$ is the ratio of the outlet to inlet areas of the diffuser

However, usage of Equation (4.26) requires more detailed knowledge on diffuser and snout geometry. More specifically, the ratio of air entering the snout to total combustor air flow $\left(\frac{\dot{m}_{s n}}{\dot{m}_{3}}\right)$, the diffuser pressure loss coefficient $\left(\lambda_{\text {diff }}\right)$ and the ratio of casing area to combustor inlet area ( $A R$ ) must be known or estimated. Therefore, for the combustor design, the methodology used Equation (4.24) due to its simplicity.

\subsubsection{Annulus Area}

The annulus area $\left(A_{A N}\right)$ is the region confined by the casing inner wall and the liner outer wall (Figure 4.8). With the casing reference area and liner area determined, the annulus area is calculated as,

$$
A_{A N}=A_{r e f}-A_{L}
$$

\subsubsection{Liner Primary, Secondary and Dilution Zone Lengths}

The next step in the design process is the calculation of the three zone lengths which make up the combustor liner. 
For the primary zone, the length $\left(L_{P Z}\right)$ is usually found between the following range (Sawyer, 1985):

$\frac{2}{3} D_{L} \leq L_{P Z} \leq \frac{3}{4} D_{L}$

where $D_{L}$ is the liner diameter

Noting that a longer primary zone length would give more residence time to the reacting mixture, and that a longer residence time will in turn lead to higher combustion efficiency, the primary zone length should be a compromise between combustor efficiency and engine costs incurred due to a longer combustor.

Lefebvre (1999) proposes two correlations for sizing the volume of the primary zone. However, upon review of the suggested expressions, the following conclusions were drawn:

- for combustors burning heterogeneous mixtures (mixtures which contain fuel in both gaseous and liquid phases), the correlation was dependent on geometry and mixing characteristics which were too combustor specific, and

- the correlation given for the lean premixed prevaporized (LPP) combustor (i.e. a premixed combustor which uses liquid fuel, hence the term prevaporized) depends on a constant which, due to scarce data availability, has to be determined experimentally. Thus, this made the correlation unusable at the present time.

The secondary zone, $L_{S Z}$, should be estimated to be $50 \%$ of the liner diameter (Sawyer, 1985; Kretschmer, 2000):

$$
L_{S Z}=\frac{1}{2} D_{L}
$$


The last zone to be sized is the dilution zone. The goal of the dilution zone is to "shape" the temperature profile of the hot combustion products into an acceptable and consistent temperature distribution as they are discharged into the high pressure turbine. The temperature profile of the hot gasses is contoured by the injection and mixing of cooler air, entering from the dilution holes, with the hot gasses contained within the liner. The length of the dilution zone, $L_{D Z}$, is greatly dependent on the pattern factor $(Q)$ defined by Equation (4.30), which is sometimes also named as the transverse quality (Lefebvre, 1999):

$Q=\frac{T_{\max }-T_{4}}{T_{4}-T_{3}}$

where $T_{\max }$ is the maximum total temperature value at the combustor outlet

$T_{4}$ is the total temperature at the combustor outlet

$T_{3}$ is the total temperature at the combustor inlet

The pattern factor has a great impact on the life of the stationary nozzle guide vanes and on the life of the rotating first stage turbine blades. To prolong the life of these components, the combustor designer must create a combustor that will not have "hot spots" (localized high gas temperatures) and that will deliver a reasonable variation of gas temperature profiles in both the radial and circumferential directions. Figure 4.9 and correlation expressed by Equation (4.31) show how the pattern factor of can and canannular combustors is influenced by the liner pressure loss factor and by the liner length and diameter. 


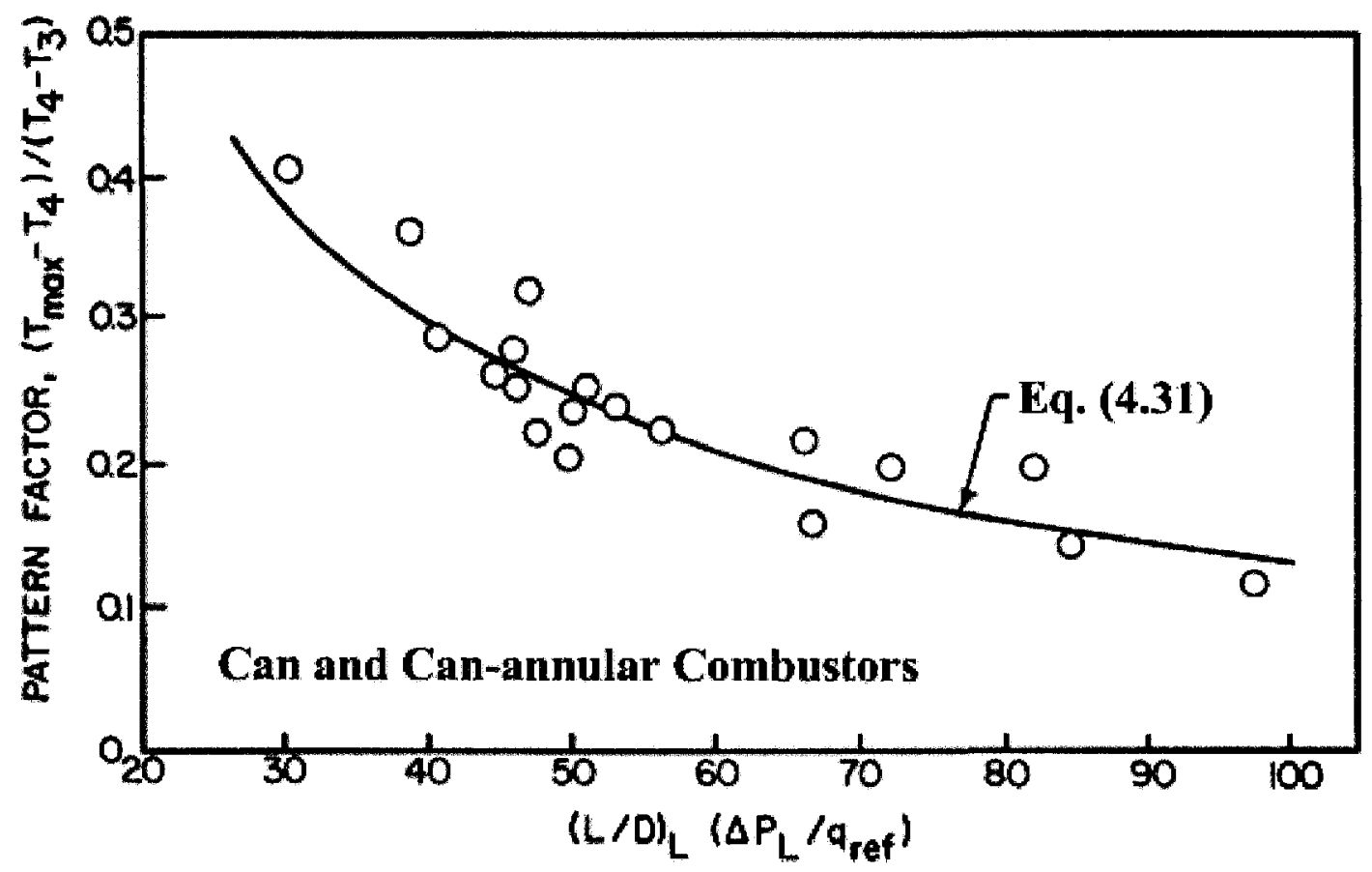

Figure 4.9 Pattern Factor (Adapted from Lefebvre, 1999)

$$
Q=1-\exp \left(-0.070 \frac{L_{L}}{D_{L}} \frac{\Delta P_{L}}{q_{r e f}}\right)^{-1}
$$

where $L_{L}$ is the liner length, $\mathrm{m}$

$D_{L}$ is the liner diameter, $\mathrm{m}$

$\Delta P_{L}$ is the liner pressure loss, $\mathrm{Pa}$

$q_{r e f}$ is the reference dynamic pressure, $\mathrm{Pa}$

In general, the review of published work suggests that the selection of $Q=0.2$ will lead to an adequate dilution length (Sawyer, 1985, Kretschmer, 2000) and that dilution zones less than one and half times the liner diameter will have poor mixing and therefore undesirable hot gas temperature profiles (Mattingly, 2002; Lefebvre, 1999). Hence, the length of the dilution zone $\left(L_{D Z}\right)$ can be estimated to be: 


$$
L_{D Z} \approx 1.5 D_{L}
$$

\subsection{Swirler Design}

During engine start-up, initial ignition of the fuel/oxidizer mixture is achieved with the help of an igniter which produces a concentrated source of energy, namely a spark. However, after the engine start-up procedure is successfully completed, the igniter is disengaged and combustion is now a self-sustaining process. This self-sustaining mechanism is achieved through the swirler (Figure 4.10) whose design is primarily influenced by aerodynamics.

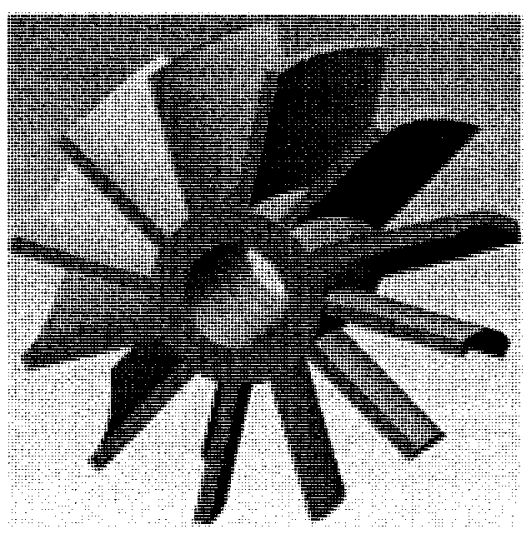

Solid Model

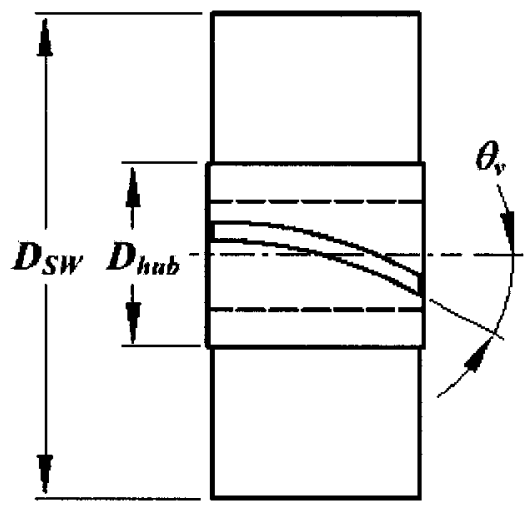

Side View

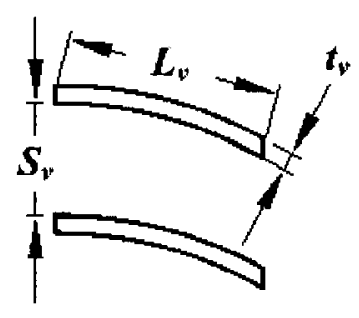

Simplified

Top View

Figure 4.10 Swirler nomenclature

In a conventional combustor, the scope of the swirler is to generate a recirculation bubble in the primary zone by creating a toroidal flow reversal that allows for some of the hot combustion products to get entrained, to recirculate and to come in contact with the fresh mixture of fuel and oxidizer. In a typical combustor, the swirl induced recirculation zone is also augmented by air flow entering through injection holes strategically placed in the primary zone (Figure 4.11). 


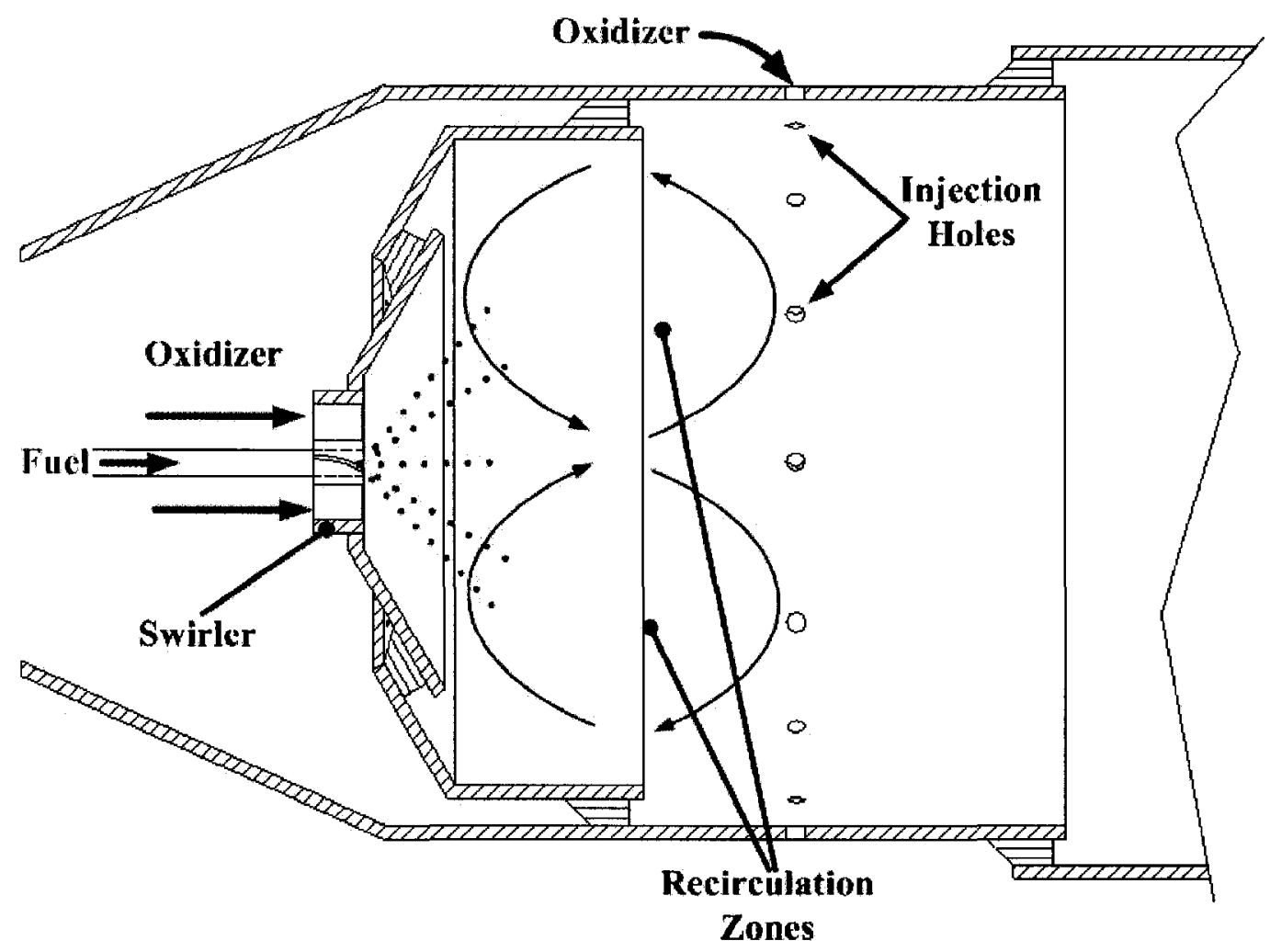

Figure 4.11 Recirculation zones

In a premixed combustor, a set of swirlers are located within the mixer tube to form a premixer (Figure 4.12).

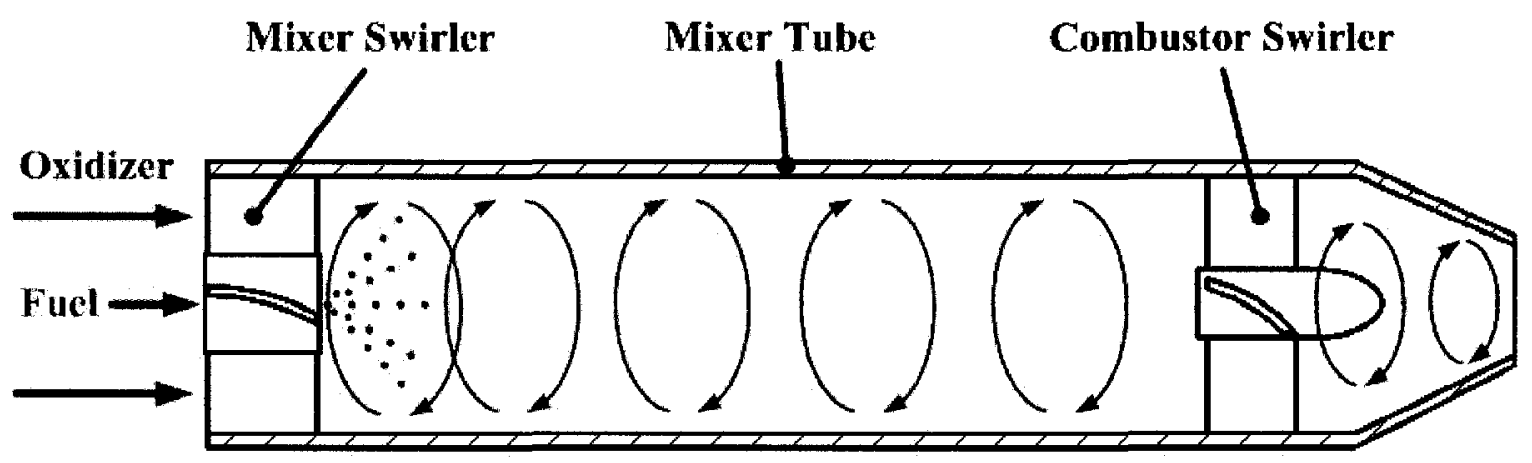

Figure 4.12 Premixer nomenclature

The premixer is designed to fulfil three main objectives; 1) to facilitate fuel evaporation (if liquid fuel is used), 2) to favour mixing of the fuel with the oxidizer and 3) to induce flow recirculation in the primary zone so that combustion can be sustained. 
The evaporation and mixing processes occur downstream of the first swirler, the mixer swirler. Flow recirculation in the primary zone is dependent on the design of the second swirler, the combustor swirler. There has been extensive work conducted on premixer and swirler designs. This work led to general guidelines which are presented next.

The unmixedness (Section 2.1.2) and fuel evaporation determine the length of the mixer tube. When sizing the premixer, the spontaneous ignition phenomena must be taken into consideration. Spontaneous ignition occurs when the residence time of the combustible mixture, flowing through the premixer, is more than the mixture autoignition delay time for these conditions (see Section 4.12.4.1 for details). Therefore, to prevent autoignition, the premixer length must be less than the length traveled by the mixture before autoignition occurs. Furthermore, no flow recirculation must be present downstream of the mixer swirler. A recirculation zone within the premixer would translate into an increase in the combustible mixture residence time, which could therefore cause autoignition to occur. To obtain thorough mixing, but still avoid the formation of a recirculation zone within the premixer, the usage of a co-axial swirler is suggested. If space and manufacturing costs are an issue, as they were in this research project, a single swirler with a swirl number (defined next) less than 0.4 should be employed (Lefebvre, 1999).

The swirl number $\left(S_{N}\right)$, defined in Equation (4.33), is a nondimensional parameter that characterizes the amount of swirl impaired to the axial flow.

$$
S_{N}=\frac{2 G_{m}}{D_{S W} G_{t}}
$$

where $G_{m}$ is the axial flux of angular momentum 
$G_{t}$ is the axial thrust

$D_{S W}$ is the swirler outer diameter (Figure 4.10)

The swirl number can be calculated as (Lefebvre, 1999):

$S_{N}=\frac{2}{3}\left[\frac{1-\left(\frac{D_{h u b}}{D_{S W}}\right)^{3}}{1-\left(\frac{D_{h u b}}{D_{S W}}\right)^{2}}\right] \tan \left(\theta_{v}\right)$

where $D_{S W}$ is the swirler outer diameter (Figure 4.10)

$D_{h u b}$ is the swirler inner (hub) diameter (Figure 4.10)

$\theta_{v}$ is the blade turning angle (Figure 4.10)

Lefebvre (1999), gives the following guidelines for the design of a combustor swirler. Generally, the amount of oxidizer entering the swirler varies from 3 to $12 \%$ of the total flow rate entering the combustor $\left(\dot{m}_{3}\right)$ and the pressure drop across the swirler $\left(\Delta P_{S W}\right)$ can be estimated to be 3 to $4 \%$ of the combustor inlet pressure $\left(P_{3}\right)$. To create a recirculation zone, strong swirl conditions corresponding to swirl numbers higher than $0.6\left(S_{N}>0.6\right)$, are needed (Lefebvre, 1999). Figure 4.13 shows how the size of the recirculation zone is affected by the swirl number.

The swirl number and the pressure drop across the swirler, $\Delta P_{S W}$, calculated next, are interlinked by the blade turning angle $\left(\theta_{v}\right)$. A swirler is designed to meet a specific pressure drop, which as previously mentioned is between 3 to $4 \%$ of the combustor inlet pressure $\left(P_{3}\right)$. 


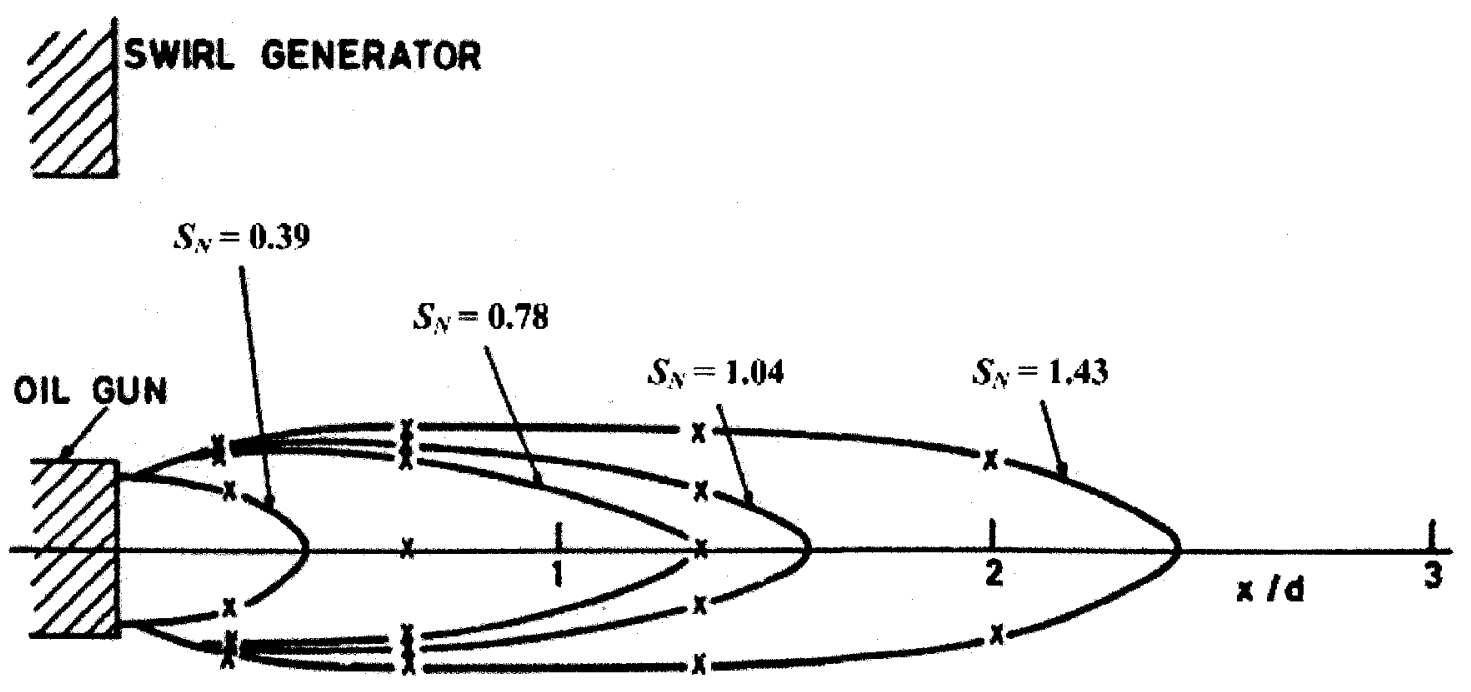

Figure 4.13 Size of recirculation zone as function of swirl number (Adapted from Beer and Chigier, 1983)

The pressure drop across the swirler is calculated as (Sawyer, 1985; Kretschmer, 2000 and Lefebvre, 1999):

$\Delta P_{S W}=q_{r e f} K_{S W}\left[\left(\frac{A_{r e f}}{A_{S W}}\right)^{2} \sec ^{2}\left(\theta_{v}\right)-\left(\frac{A_{r e f}}{A_{L}}\right)^{2}\right]\left(\frac{\dot{m}_{S W}}{\dot{m}_{3}}\right)^{2}$

where $K_{S W}$ is 1.3 for flat vanes and 1.15 for curved vanes

$\dot{m}_{S W}$ is the swirler mass flow rate

$A_{S W}$ is the swirler frontal area, calculated as (Lefebvre, 1999):

$A_{S W}=\left(\frac{\pi}{4}\right)\left(\frac{D_{S W}^{2}}{D_{h u b}^{2}}\right)-0.5 n_{v} t_{v}\left(D_{S W}-D_{h u b}\right)$

where $n_{v}$ is the number of vanes

$t_{v}$ is the vane thickness 
As a general rule, combustor swirlers are designed for swirl numbers above 0.6 , they are made up of eight to 16 blades equally spaced and the blades turning angle, $\theta_{v}$, is usually set between $30^{\circ}$ and $70^{\circ}$ (Lefebvre, 1999 and Mellor, 1990). The shape of the blades (curved versus flat) also has an effect on the recirculation zone size. Curved vanes induce larger reverse mass flows $\left(\dot{m}_{r}\right)$ with respect to flat vanes for the same swirl number (Figure 4.14). Furthermore, as can be seen in Figure 4.14, for very strong swirl conditions $\left(\mathrm{S}_{\mathrm{N}}>2\right.$ for curved vanes and $\mathrm{S}_{\mathrm{N}}>2.5$ for flat vanes $)$, which corresponds to blades turning angles above $65^{\circ}$, the amount of entrained flow exceeds that of the swirler flow $\left(\frac{\dot{m}_{r}}{\dot{m}_{S W}}>1\right)$. This suggests that some of the oxidizer entering through the primary injection holes will be part of the recirculation bubble. Mattingly (2002) proposes the following expression for the approximation of the entrainment ratio.

$$
\frac{\dot{m}_{r}}{\dot{m}_{S W}}=0.1\left(S_{N}\right)^{3} \quad \text { for } \quad S_{N}<2.5
$$

where $\dot{m}_{r}$ is the maximum reverse mass flow rate 


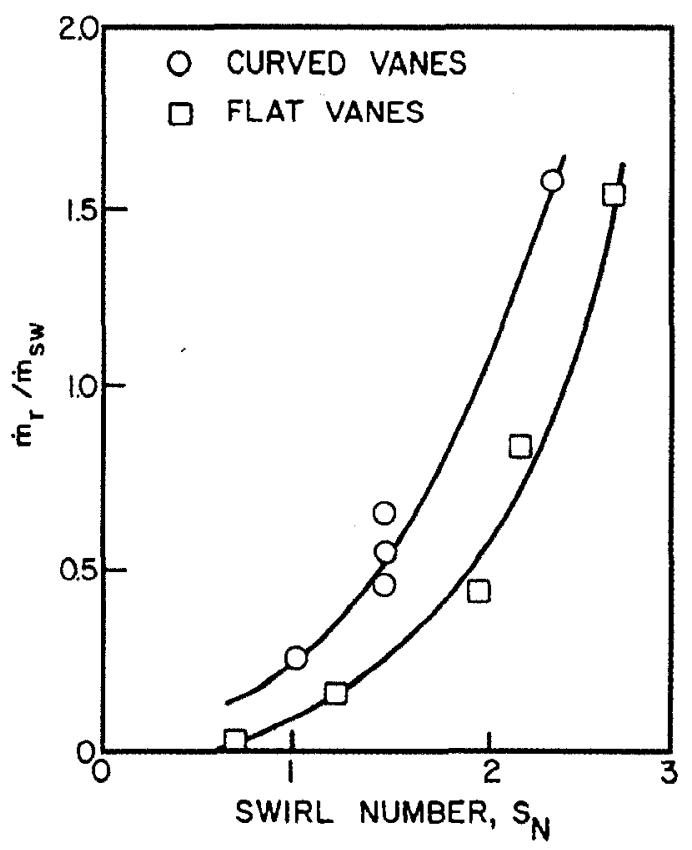

Figure 4.14 Entrainment ratio versus swirl number (Lefebvre, 1999)

In addition, the combustor swirler should be designed with a solidity equal or greater than one at the tip of the swirler vane $\left(D_{S W}\right)$, where the vane solidity is defined as the ratio of the vane length $\left(L_{v}\right)$ to the vane spacing $\left(S_{v}\right)$ (see Figure 4.10 for nomenclature).

An explanation for the above design guideline can be found in work published by Kilik (1976). This author conducted experiments for various swirler designs. The study results showed that in swirlers having solidity values greater than one, the swirl angle matched the blade turning angle $\left(\theta_{v}\right)$, even when swirl angles were high (Figure 4.15). 


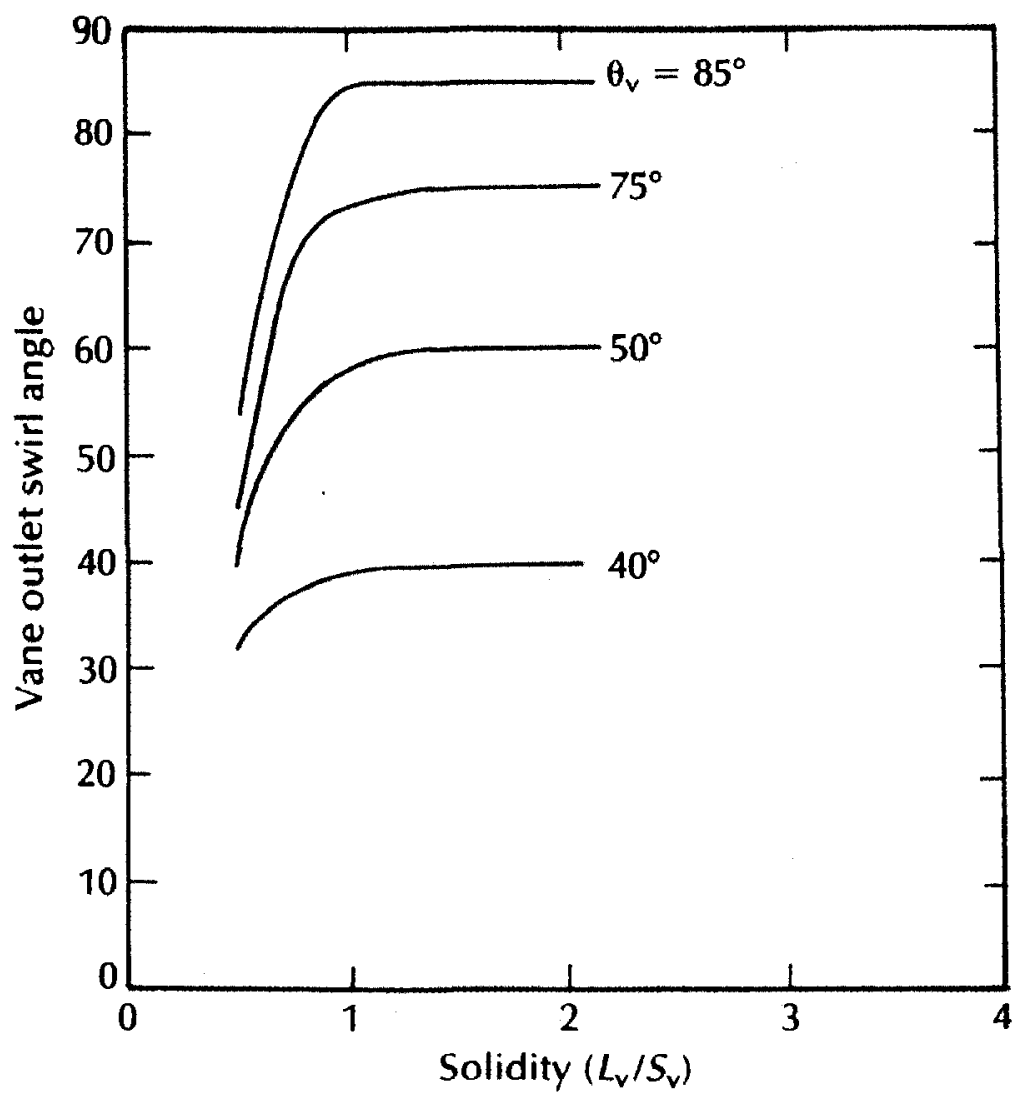

Figure 4.15 Swirl angle versus solidity (Kilik, 1976)

The reason for these findings relies on swirler aerodynamics. As previously mentioned, swirl is induce to the flow entering the swirler by having vanes arranged at a determined angle. Due to this angle, the swirler vanes, whether flat or curved, will cause the flow to separate at their leading edges. To ensure that the flow will exit at the desired swirl angle $\left(\theta_{v}\right)$ the passage length $\left(L_{v}\right)$ should be long enough to allow for the flow to reattach within the vane passage (Kilik, 1976).

\subsection{Dome Sizing}

As a general guideline, the combustor dome is shaped so that most of the swirling air is captured in the recirculation eddy (Mattingly, 2002). To achieve this, authors like 
Sawyer (1985) and Kretschmer (2000) suggest wall angles $\left(\theta_{D}\right)$ between $45^{\circ}$ and $60^{\circ}$ (see Figure 4.16 for nomenclature).

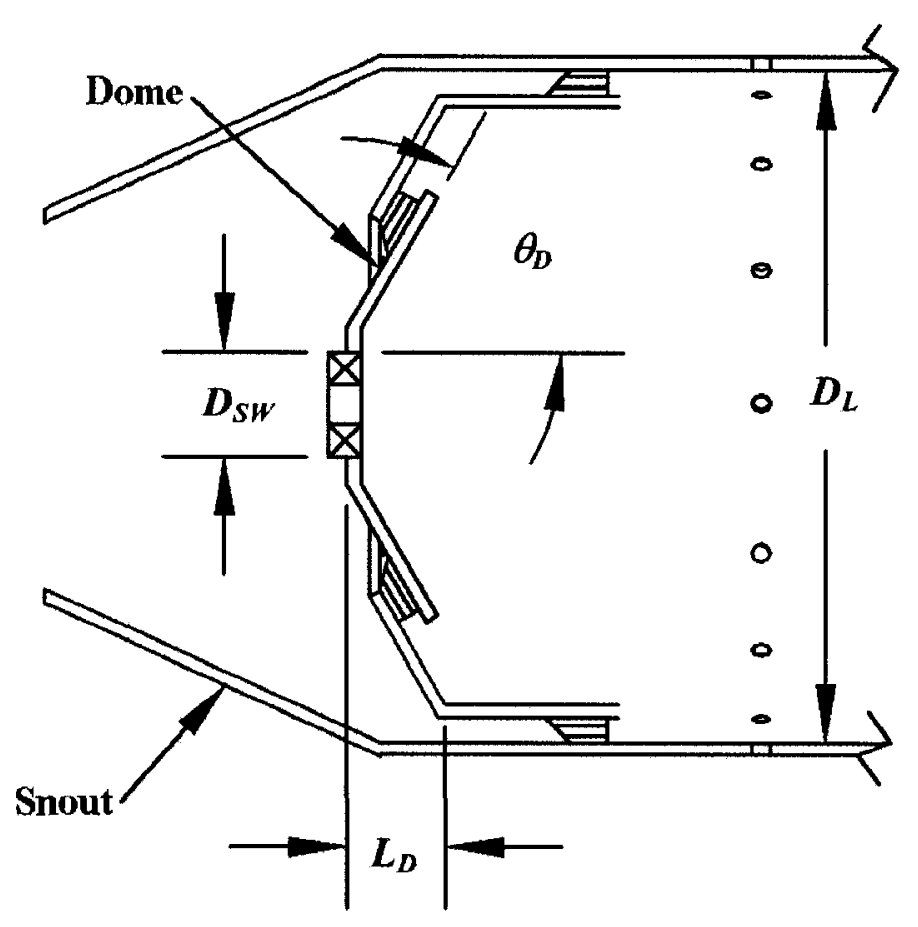

Figure 4.16 Dome nomenclature

The length of the dome depends on the wall angle used. Once a wall angle is selected, the dome length can be calculated as:

$$
L_{D}=\left(D_{L}-\frac{D_{S W}}{2}\right) \tan \left(\theta_{D}\right)
$$

With the completion of the dome design, the length of the recirculation zone, which is based on the principle of "magic circles", can be obtained (Figure 4.17). The idea behind this principle is to represent the flow behaviour within the recirculation zone by two imaginary circles whose diameters are half that of the liner. These circles are placed so that the dome and liner walls function as borders to the circles (Sawyer, 1985). 


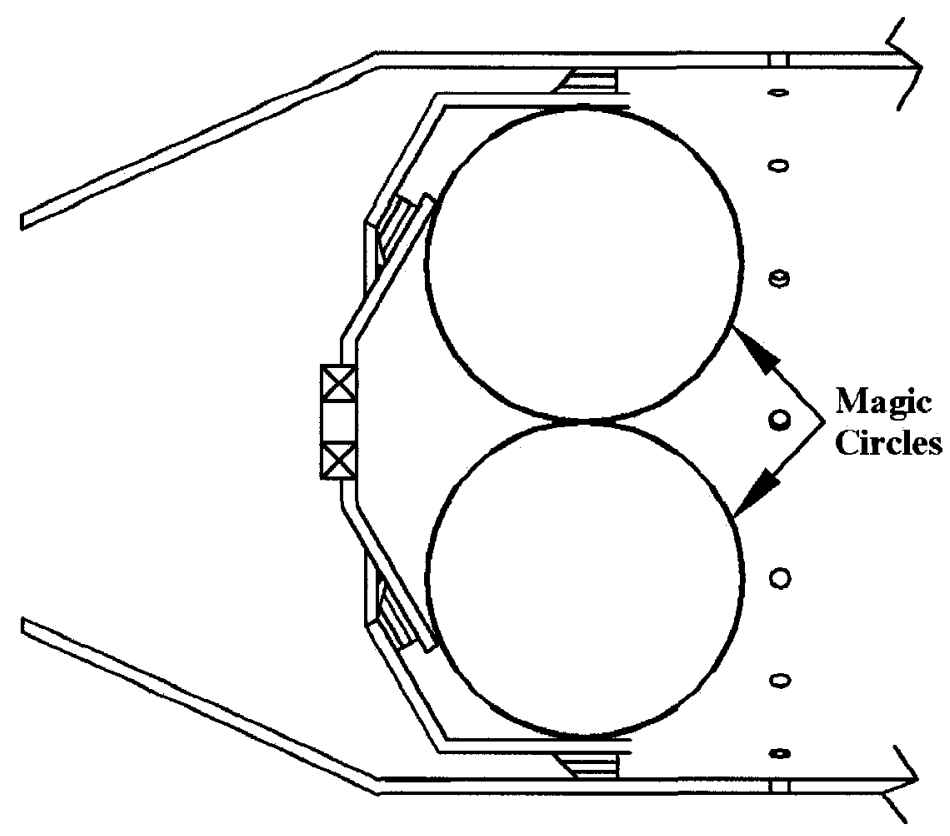

Figure 4.17 Magic circles

However, as previously mentioned, experimental work shows that the size of the recirculation zone is affected by the swirler geometry (Figure 4.13). Therefore, upon completion of the swirler design, comparison of the axial length estimation of the recirculation zone obtained form the "magic circles" method to the estimation given by the following equation, which takes into consideration the swirler design by introducing the swirl number, $S_{N}$ (Mattingly, 2002), is suggested.

$L_{R Z} \approx 2 S_{N} r_{t}$

where $r_{t}$ is the tip radius of the swirler vanes

In particular, it was found that an increase in the size of the recirculation zone was directly linked to one or more of the following factors (Lefebvre, 1999):

- an increase in vane angle

- an increase in number of vanes

- a decrease in aspect ratio 
- a change from flat to curved vanes.

\subsection{Combustor Resizing for Lean Premixed Combustion}

\subsubsection{Resizing Motivations}

In recent years, stringent emissions regulations forced the combustor design to evolve to meet current and future emissions targets.

Reduction of pollutants such as $\mathrm{CO}_{2}$ and $\mathrm{H}_{2} \mathrm{O}_{\mathrm{g}}$ (vapour phase) can only be achieved through a decrease in hydrocarbon fuel consumption, since these two products are an inescapable outcome of combustion (Lefebvre, 1999). Oxides of nitrogen $\left(\mathrm{NO}_{\mathrm{x}}=\mathrm{NO}+\right.$ $\mathrm{NO}_{2}$ ), carbon monoxide (CO), unburned hydrocarbons (UHC) and particulates, also known as soot (unburned carbon), are directly related to the combustor design and its performance. The following table shows the emissions index (EI) of modern aircraft gas turbine engines during cruise.

Table 4.3 Emissions index (EI) of modern aircrafts during cruise (Cumpsty, 2003)

\begin{tabular}{|c|c|c|c|c|c|c|c|}
\hline Species & $\mathrm{CO}_{2}$ & $\mathrm{H}_{2} \mathrm{O}_{\mathrm{g}}$ & $\mathrm{NO}_{\mathrm{x}}$ & $\mathrm{SO}_{\mathrm{x}}$ & $\mathrm{CO}$ & $\mathrm{UHC}$ & Particulate \\
\hline $\begin{array}{c}\text { EI } \\
\text { (g per kg of fuel) }\end{array}$ & 3200 & 1300 & $9-15$ & $0.3-0.8$ & $0.2-0.6$ & $0-0.1$ & $0.01-0.05$ \\
\hline
\end{tabular}

As can be seen from the table, the highest emission which can be addressed by combustor design is that of the oxides of nitrogen. However, the needs for the alteration in the combustor design can only be understood by first exploring how oxides of nitrogen are formed.

When fuel, which contains no nitrogen, and air are mixed and combusted, three chemical mechanisms take place and nitric oxide (NO) is formed. Once in the atmosphere NO oxidizes to form nitrogen dioxide $\left(\mathrm{NO}_{2}\right)$ which is responsible for acid rain and 
photochemical smog. Some $\mathrm{NO}_{2}$ is also produced during the combustion process when the $\mathrm{HO}_{2}$ radicals, formed in relatively low temperature regions, mix with $\mathrm{NO}$ molecules, present in the high temperature regions.

The chemical mechanisms involved in NO formation are the thermal or Zeldovich mechanism, the Fenimore or prompt mechanism and the $\mathrm{N}_{2} \mathrm{O}$-intermediate mechanism (Turns, 2000 and Lefebvre, 1999). The Zeldovich mechanism is typical in high temperature combustion over a wide spectrum of equivalence ratios. The prompt mechanism is prevalent in rich combustion whereas the $\mathrm{N}_{2} \mathrm{O}$-intermediate mechanism is common in low temperature conditions where equivalence ratios are lower than 0.8 (Turns, 2000).

In the Zeldovich mechanism the concentration rate of NO is derived to be (Turns, 2000):

$$
\frac{d[\mathrm{NO}]}{d t}=2 k_{f}[\mathrm{O}]_{e q}\left[\mathrm{~N}_{2}\right]_{e q}
$$

where $[\mathrm{O}]$ and $\left[\mathrm{N}_{2}\right]$ are the equilibrium concentrations of the oxygen atom and of nitrogen respectively $k_{f}$ is the forward rate coefficient of the following chemical reaction:

$$
\mathrm{O}+\mathrm{N}_{2} \leftrightarrow \mathrm{NO}+\mathrm{N}
$$

The forward rate coefficient is defined as (Turns, 2000):

$$
k_{f}=1.8 \cdot 10^{11} \exp \left[-\frac{38370}{T(K)}\right]\left(\frac{\mathrm{cm}^{3}}{\mathrm{gmols}}\right)
$$

As can be seen in Figure 4.18, the above chemical reaction has strong dependence on temperature. 


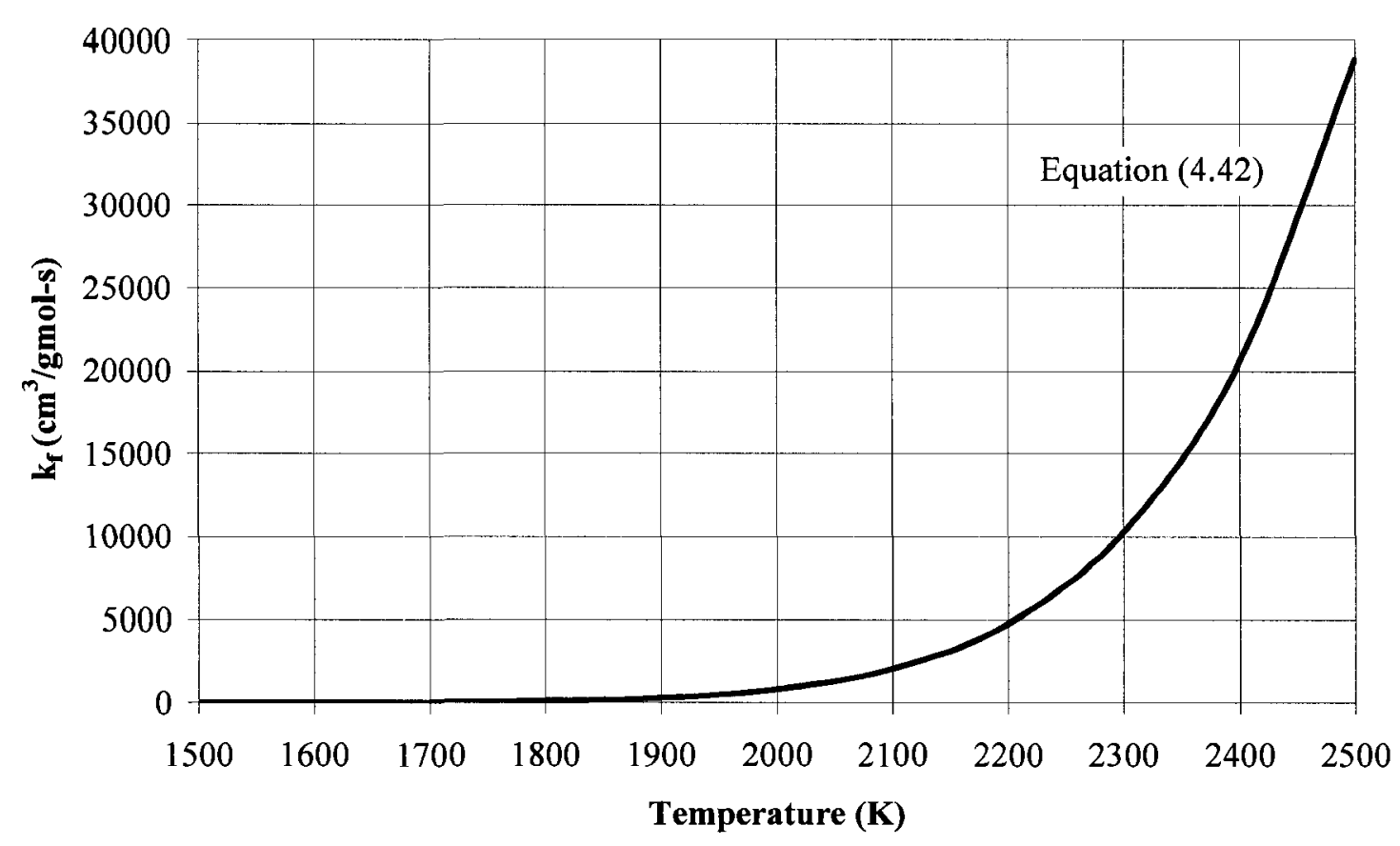

Figure 4.18 Effect of temperature on forward rate coefficient

One of the various methods for restraining the primary zone flame temperature is premixing. Premixing allows combustion to take place at leaner equivalence ratios and therefore, produces cooler flame temperatures. The conventional combustor resizing to account for premixing will be discussed in the following section.

\subsubsection{Resizing Approach for Lean Premixed Combustors}

The following conventional combustor resizing approach, to include premixing, has been reported by Charest (2005). The resizing process is based on maintaining an equivalent flame stability when converting a conventional combustor configuration to a premixed combustor design. The scaling parameter used, to maintain this equivalent flame stability, is the lean blowout velocity, $V_{B O}$ (Ballal and Lefebvre, 1981), 
$V_{B O}=C_{s}\left(\frac{D_{c} S_{L}^{2}}{\alpha_{0}}\right)$

where $C_{s}$ is the flameholder shape factor (dependent on flameholder geometry)

$D_{c}$ is the flameholder characteristic dimension, $\mathrm{m}$

$\alpha_{0}=\lambda / c_{p} \rho$ is the thermal diffusivity upstream of the flameholder, $\frac{\mathrm{m}^{2}}{\mathrm{~s}}$

$S_{L}$ is the laminar flame speed, $\frac{\mathrm{m}}{\mathrm{s}}$

By non-dimensionalizing and through some simple assumptions, given in more detail in Charest's work, Equation (4.43) can be manipulated into Equation (4.44) and the resizing, from a conventional combustor to a premixed combustor, can be carried out as follows:

$D_{L_{2}}=D_{L_{1}} \times\left(\frac{\phi_{P Z_{2}}}{\phi_{P Z_{1}}}\right)^{\frac{1}{3}} \times\left(\frac{S_{L_{1}}}{S_{L_{2}}}\right)^{\frac{2}{3}}$

where the subscripts 1 and 2 refer to the conventional and premixed combustors respectively.

Based on work published by Mattingly (2002), the equivalence ratio of the primary zone of the conventional combustor $\left(\phi_{P Z_{1}}\right)$ can be set to 0.8 .

The laminar flame speed, which is the maximum homogeneous burning velocity, is calculated from the modified Semenov equation (Gauthier et al, 1996): 
$S_{L}=\sqrt{\frac{k T_{u}^{2} T_{g}^{5} \exp \left[-\frac{E_{a}}{\bar{R} T_{g}}\right]}{\left(T_{g}-T_{u}\right)^{3}}}$

where $k$ is the proportionality constant

$T_{u}$ is the reactant temperature

$T_{g}$ is the flame temperature

$E_{a}$ is the activation energy

$\bar{R}$ is the universal gas constant

The proportionality constant $k$, if not known, can be calculated at normal ambient conditions $(T=293 \mathrm{~K}$ and $P=1 \mathrm{~atm})$ with a flame temperature $\left(T_{g}\right)$ estimated at an equivalence ratio of 1.05 , an activation energy $\left(E_{a}\right)$ of $92 \mathrm{~kJ} / \mathrm{mole}$ and a maximum homogeneous burning velocity $\left(S_{L}\right.$ ), for alkanes, of approximately $43 \mathrm{~cm} / \mathrm{s}$ (Gauthier et al., 1996). After having calculated the constant $k$, the laminar flame speeds for the conventional $\left(S_{L_{1}}\right)$ and premixed $\left(S_{L_{2}}\right)$ cases can be determined and sizing of the premixed combustor can be undertaken.

\subsection{Diffuser and Snout Sizing}

With the combustor resizing completed, the diffuser and snout sizing can be initiated. As mentioned in Section 4.1, the combustor design includes parasitic pressure losses that need to be minimized. An example of these parasitic losses is the pressure loss across the diffuser, $\Delta P_{\text {diff }}$. 
$\Delta P_{\text {diff }}=P_{i n, d i f f}-P_{o u t, d i f f}$

The purpose of the diffuser (see Figure 4.19 for nomenclature) is to reduce high compressor outlet velocities, which can be higher than $170 \mathrm{~m} / \mathrm{s}$ (Saravanamuttoo, 2001), to values where flame blowoff will not occur. In general, the compressor outlet velocity must be reduced to a velocity within the range of 30 to $60 \mathrm{~m} / \mathrm{s}$ (Saravanamuttoo, 2001). This is in agreement with Lefebvre (1999) who indicates that the compressor outlet velocity (higher than $170 \mathrm{~m} / \mathrm{s}$ ) must be decreased to about one fifth for combustion to take place. The diffuser consists of a diverging passage through which the compressor outlet velocity is decreased. A good diffuser design will minimize pressure loss, will maximize static pressure recovery, will be fairly insensitive to engine operating conditions and will minimize engine production costs by being as short as possible (Klein, 1995). According to Sawyer (1985) the pressure loss across the diffuser is usually limited to $1 \%$ of the total pressure at the combustor inlet $\left(\Delta P_{\text {diff }}=0.01 P_{3}\right)$.

After having estimated the percentage of oxidizer needed in the primary zone, about half of this quantity will enter the snout $(\sim 20 \%)$ while the remaining amount will flow through the annulus and will enter the primary zone via strategically located injection holes. At the snout inlet, most of the air $(\sim 80 \%)$ is subjected to a change in direction as it enters the diffusing passage. To minimize the possibility of flow separation, the change in flow direction should be carried out at a constant velocity. Therefore, the location of the snout inlet $\left(L_{o}\right)$ should be placed where the velocity of the flow entering the combustor is equal to the velocity of the flow entering the annulus as shown by the following equation (Sawyer, 1985): 
$\frac{A_{o}}{A_{A N}}=\frac{\dot{m}_{3}}{\dot{m}_{A N}}=\frac{V_{3}}{V_{A N}}$

where $A_{o}$ is the area where the velocity of the flow entering the combustor is equal to the velocity of the flow entering the annulus $A_{A N}$ is the annulus area $\dot{m}_{3}$ is the air mass flow entering the combustor $\dot{m}_{A N}$ is the air mass flow entering the annulus

$V_{3}$ is the air velocity at the combustor inlet

$V_{A N}$ is the air velocity at the annulus inlet

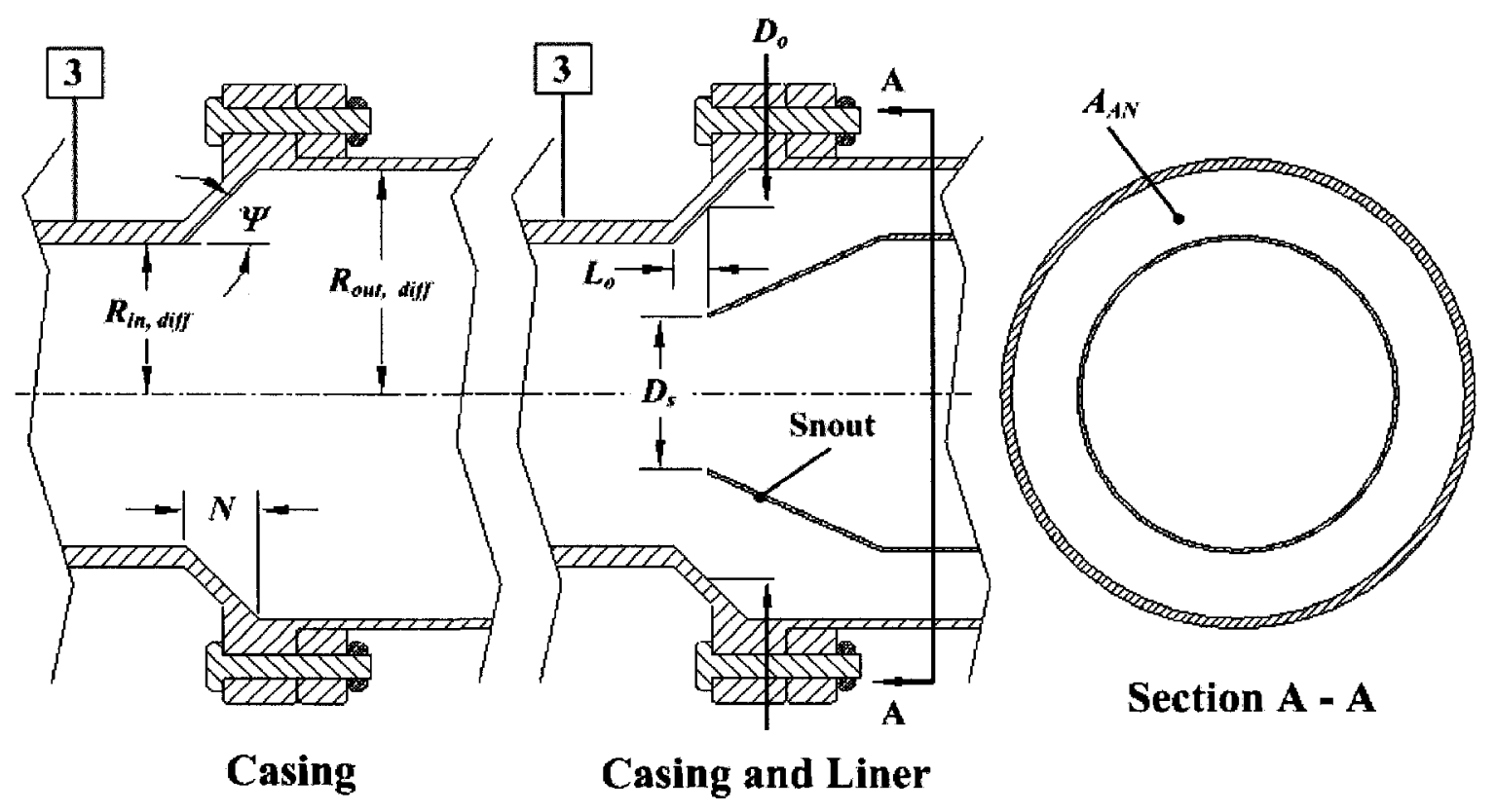

Figure 4.19 Diffuser nomenclature

With the snout location established, the diffuser area ratio can be calculated. The diffuser area ratio can be estimated by first calculating the diffuser divergence angle $(\psi)$, using 
Equation (4.48), and then guaranteeing that the effect of the calculated angle will still ensure that the pressure loss across the diffuser $\left(\Delta P_{\text {diff }}\right)$ is met (Sawyer, 1985).

$\frac{\Delta P_{\text {diff }}}{P_{3}}=1.75 R_{a}\left(\frac{\dot{m}_{3} \sqrt{T_{3}}}{P_{3}}\right)^{2} \tan (\psi)^{1.22} \frac{1}{A_{3}^{2}}\left(1-\frac{A_{3}}{A_{o}}\right)^{2}$

where $\psi$ is the diffuser divergence angle, degrees

$P_{3}$ is the combustor inlet pressure, $\mathrm{Pa}$

$T_{3}$ is the combustor inlet temperature, $\mathrm{K}$

$\dot{m}_{3}$ is the air mass flow entering the combustor, $\frac{\mathrm{kg}}{\mathrm{s}}$

$A_{3}$ is the combustor inlet area, $\mathrm{m}^{2}$

$A_{o}$ is the area where the velocity of the flow entering the combustor is equal to the velocity of the flow entering the annulus, $\mathrm{m}^{2}$

$R_{a}$ is the is the air gas constant, $287 \frac{\mathrm{J}}{\mathrm{mol} \mathrm{K}}$

By applying the continuity equation and Bernoulli's equation to the control volume around the diffuser, the area ratio $(A R)$ and the rise in static pressure (static pressure recovery) can be calculated as follows (Lefebvre, 1999):

$$
\begin{aligned}
& A R=\frac{A_{\text {out }, \text { diff }}}{A_{\text {in,diff }}}=\frac{V_{\text {in,diff }}}{V_{\text {out }, \text { diff }}}=\frac{V_{3}}{V_{\text {out,diff }}} \\
& p_{\text {out }, \text { diff }}-p_{\text {in,diff }}=q_{\text {in,diff }}\left(1-\frac{1}{A R^{2}}\right)-\Delta P_{\text {diff }}
\end{aligned}
$$

where $A$ is the area at the inlet (in,diff) and outlet (out,diff) of the diffuser, $\mathrm{m}^{2}$ 
$V$ is the air velocity at the inlet (in,diff) and outlet (out,diff) of the diffuser, $\frac{\mathrm{m}}{\mathrm{s}}$

$V_{3}$ is the air velocity at the combustor inlet, $\frac{\mathrm{m}}{\mathrm{s}}$

$p$ is the static pressure at the inlet (in, diff) and outlet (out,diff) of the diffuser, $\mathrm{Pa}$

$q$ is the inlet (in,diff) and outlet (out,diff) dynamic pressure of the diffuser, $\mathrm{Pa}$

The diffuser pressure recovery coefficient $\left(C_{p, \text { diff }}\right)$ and the ideal diffuser pressure recovery coefficient $C_{p \text {-ideal,diff }}$ are calculated as (Lefebvre, 1999):

$$
\begin{aligned}
& C_{p, \text { diff }}=\frac{p_{o u t, d i f f}-p_{i n, \text { diff }}}{q_{i n, \text { diff }}} \\
& C_{p-\text { ideal }, \text { diff }}=1-\frac{1}{A R^{2}}
\end{aligned}
$$

To understand if the diffuser is well designed, its performance must be assessed. The performance of the diffuser is evaluated by the overall effectiveness $\left(\eta_{d i f f}\right)$, which is typically found to be between 0.5 and 0.9 (Mattingly, 2002), or by the loss coefficient ( $\lambda_{\text {diff }}$ ) which is usually found to be in the range of 0.15 to 0.45 (Lefebvre, 1999) depending on the diffuser design (i.e., faired versus dump).

The overall effectiveness is given by (Lefebvre, 1999):

$\eta_{\text {diff }}=\frac{C_{p-\text { meas }}}{C_{p-\text { idealdiff }}}$

where $C_{p-\text { meas }}$ is the diffuser pressure recovery coefficient calculated from experimental results.

The loss coefficient is found as (Lefebvre, 1999): 
$\lambda_{\text {diff }}=\frac{\bar{P}_{\text {in,diff }}-\bar{P}_{\text {out }, \text { diff }}}{\bar{q}_{\text {in,diff }}}$

where the overbar indicates a mass flow weighted value derived from a detailed transverse across the duct.

With the selection of the divergence angle, the diffuser performance can be compared against characteristic curves found in literature such as the one shown in Figure 4.20.

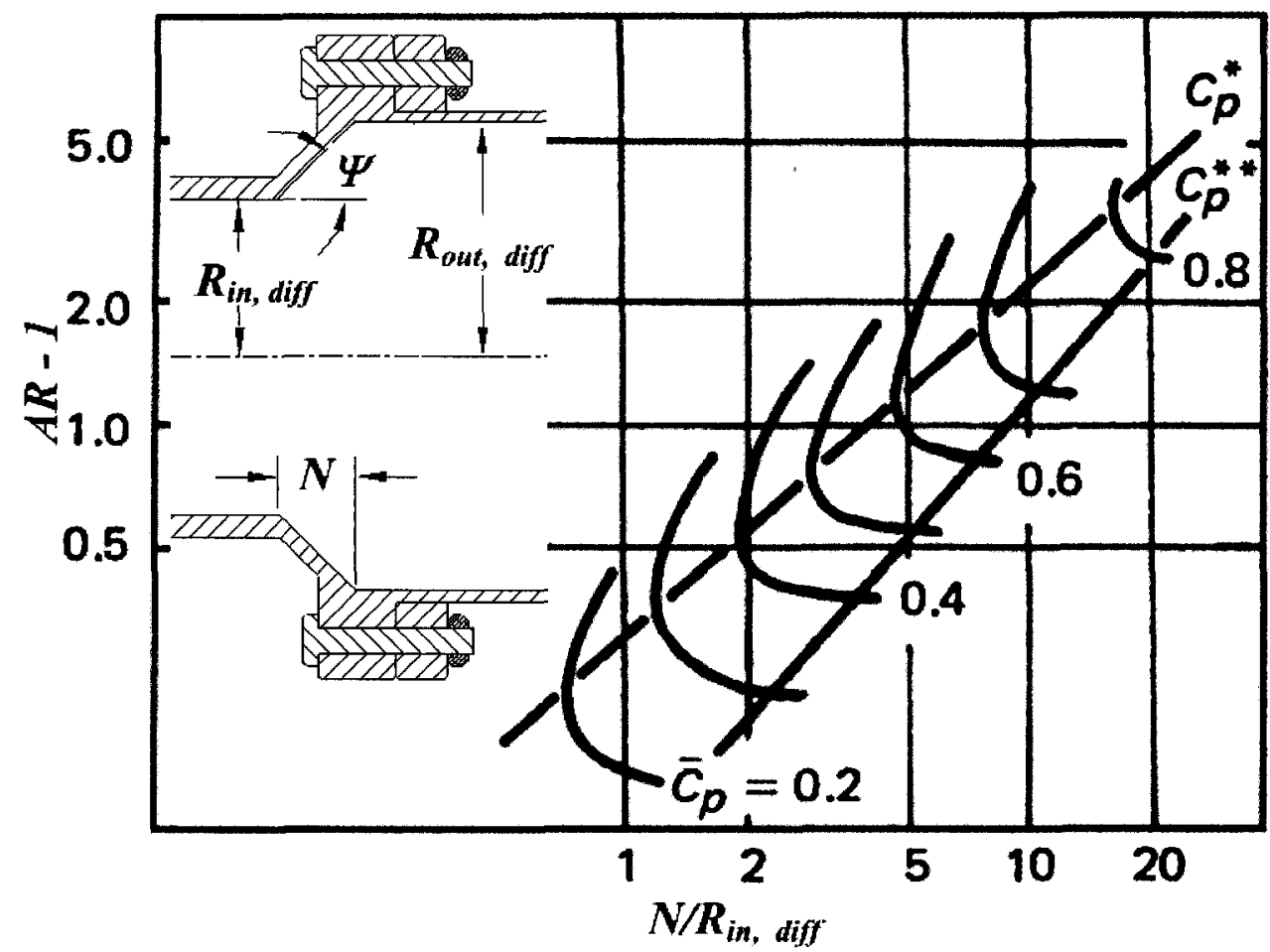

Figure 4.20 Performance chart for conical diffusers (Adapted from Lefebvre, 1999)

In particular, when looking at Figure 4.20 , it should be noted that the maximum static pressure recovery and therefore, the optimum diffuser geometry is found between the two lines named $C_{p}^{*}$ and $C_{p}^{* *}$.

The last step in the diffuser design is the calculation of the snout area, $A_{s n}$. 
$\frac{A_{s n}}{A_{o}}=\frac{\dot{m}_{s n}}{\dot{m}_{3}} \cdot \frac{1}{C_{d, s n}}$

where $\dot{m}_{s n}$ is the air mass flow entering the snout

$C_{d, s n}$ is the snout discharge coefficient and can be assumed to be one (Sawyer, 1985).

\subsection{Liner Cooling Mechanism}

The following section will review gas turbine heat transfer work published by Sawyer (1985), Kretschmer (2000) and Lefebvre (1999). The estimation of the amount of cooling flow required to maintain the liner structural integrity is based on heat transfer science. Some familiarization with heat transfer terminology, related to gas turbine combustion, is needed and is presented next.

\subsubsection{Heat Transfer Terminology}

A gas turbine combustor will gain and loose heat via conduction, convection and radiation (Sawyer, 1985).

Conduction heat transfer occurs when a temperature difference within a material exists. Through conduction, heat from one area is transferred to another by random molecular motion or by diffusion in the absence of a velocity gradient (Çengel, 1997). Usually conduction is associated with solid materials but it also applies to liquids and gasses (Çengel, 1997).

Convection occurs when a solid surface transfers energy to an adjacent moving fluid (Çengel, 1997). 
Radiation is the transfer of energy as photons. The sun heating up earth is an example of heat transfer via radiation. Radiation can be transferred through a transparent substance, such as air, or even through a perfect vacuum. All surfaces emit and absorb radiation energy to and from the surroundings. The ratio of the radiation emitted by a surface at a given temperature to the radiation emitted by a blackbody at the same temperature is known as emissivity, $\varepsilon$. A blackbody, which is defined as a perfect emitter and absorber of radiation $(\varepsilon=1)$, emits radiation energy uniformly in all directions per unit area normal to direction of emission and absorbs all incident radiation, regardless of wavelength and direction (Çengel, 1997).

\subsubsection{Uncooled Wall Temperature}

The methodology to calculate the amount of liner cooling needed entails, first calculating the uncooled wall temperature, and then re-evaluating the wall temperature after having selected a cooling technique.

When looking at Figure 4.21, it can be seen that the liner wall receives heat by convection and radiation from the hot gasses contained within the liner and loses heat by convection to the flow traveling through the annulus and by radiation from the liner wall to the casing wall. Conduction heat transfer is also present due to a temperature gradient along and through the combustor wall. At steady state, the rate of heat transfer into the wall element must be equal to the rate of heat transfer out. Equation (4.56) shows the mathematical formulation of this phenomenon (Sawyer, 1985). 


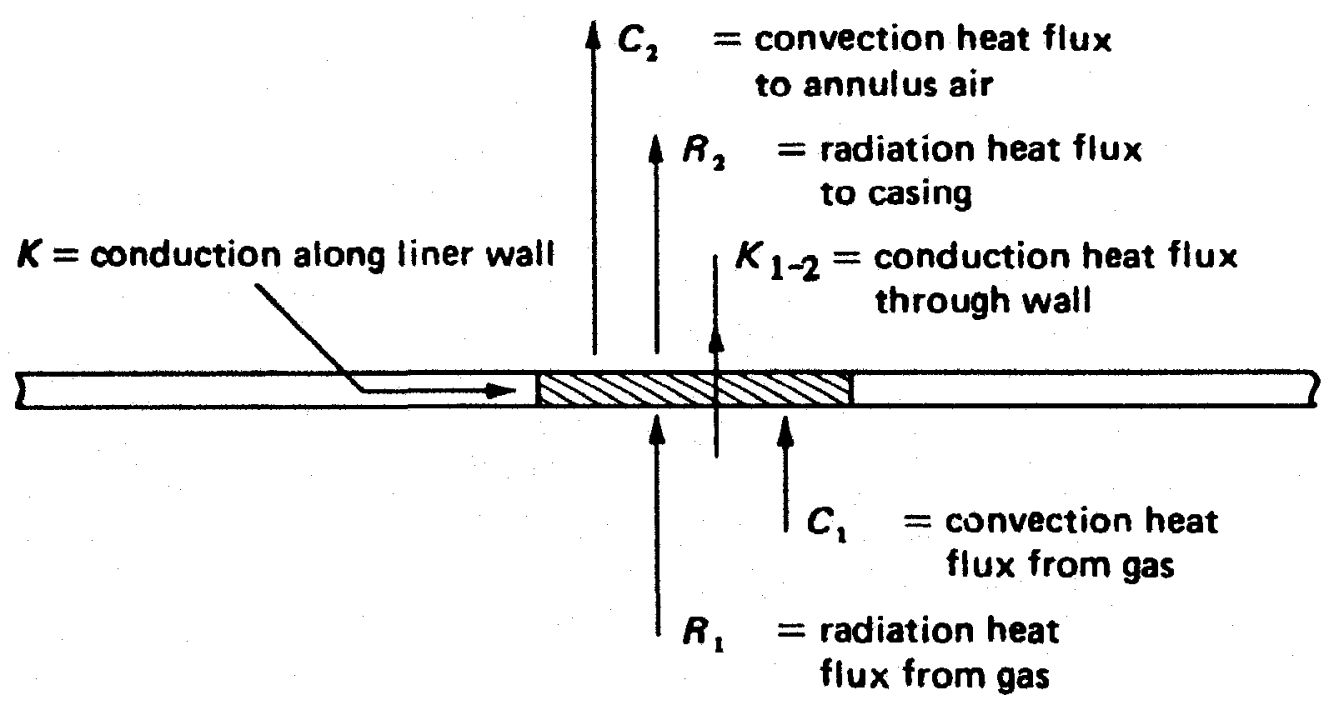

Figure 4.21 Heat transfer mechanism (Sawyer, 1985)

$\left(R_{1}+C_{1}+K\right) \Delta A_{w 1}=\left(R_{2}+C_{2}\right) \Delta A_{w 2}=K_{1-2} \Delta A_{w 1}$

where $R_{1}$ is the heat transfer by radiation to inner surface of liner wall

$C_{1}$ is the heat transfer by convection to inner surface of liner wall

$K$ is the heat transfer by conduction along the wall

$R_{2}$ is the heat loss through radiation from outer surface of liner wall

$C_{2}$ is the heat abstracted by convection from outer surface of liner wall

$K_{1-2}$ is the heat transfer by conduction across the liner wall

$\Delta A_{w}$ is the wall element surface area

Since the conduction heat transfer $(K)$ along the wall is small when compared to convection and radiation heat transfer, it can be omitted from the above equation.

Furthermore, since the thickness of liner walls is usually thin, the following assumption can be made: 
$\Delta A_{w 1}=\Delta A_{w 2}$

Hence, Equation (4.56) can be simplified to

$R_{1}+C_{1}=R_{2}+C_{2}=K_{1-2}$

where the conduction heat transfer through the wall $\left(K_{1-2}\right)$ due to a temperature gradient is defined as (Sawyer, 1985):

$K_{1-2}=\frac{k_{w}}{t_{w}}\left(T_{w 1}-T_{w 2}\right)$

where $k_{w}$ is the thermal conductivity

$t_{w}$ is the material thickness

$T_{w 1}$ is the liner inner wall temperature

$T_{w 2}$ is the liner outer wall temperature

The coefficient of thermal conductivity, $k_{w}$, is dependent on the material used to fabricate the combustor liner and $t_{w}$, is the material thickness.

The various terms of the governing heat transfer equation can now be defined.

\subsubsection{Internal Radiation, $R_{1}$}

Radiation heat transfer from the flame $\left(T_{g}\right)$ to the liner inner wall $\left(T_{w 1}\right)$ is comprised of two terms; 1) the nonluminous and 2) the luminous radiation terms. Nonluminous radiation is emanated by combustion products like carbon dioxide and water vapour. Luminous radiation depends on the fuel combusted, and, in particular, on the number and 
size of particles contained within the flame. The formula for estimating internal radiation is given by Equation (4.60) (Sawyer, 1985):

$$
R_{1}=0.5 \sigma\left(1+\varepsilon_{w}\right) \varepsilon_{g} T_{g}^{1.5}\left(T_{g}^{2.5}-T_{w 1}^{2.5}\right)
$$

where $\sigma=5.67 \times 10^{-8} \mathrm{~W} / \mathrm{m}^{2} \mathrm{~K}^{4}$ is the Stephan-Boltzmann constant

$\varepsilon_{w}$ is the liner wall emissivity (Nimonic $=0.7$; Sawyer, 1985)

$\varepsilon_{g}$ is the hot gas emissivity

The gas emissivity for luminous gasses is estimated by (Lefebvre, 1999)

$$
\varepsilon_{g}=1-\exp \left[-290 P L\left(q l_{b}\right)^{0.5} T_{g}^{-1.5}\right]
$$

where $P$ is the gas pressure, $\mathrm{kPa}$

$L$ is the luminosity factor

$q$ is the fuel-to-air ratio by mass

$l_{b}$ is the beam length, $\mathrm{m}$

The luminosity factor, $L$, can be calculated from the correlation published by Kretschmer (2000) and Odger (1978):

$$
L=0.0691\left(\frac{\mathrm{C}}{\mathrm{H}}-1.82\right)^{2.71}
$$

where $\frac{\mathrm{C}}{\mathrm{H}}$ is the fuel carbon to hydrogen carbon ratio by mass.

Typically, the beam length $\left(l_{b}\right)$ can be estimated as (Lefebvre, 1999):

$$
l_{b}=3.4 \frac{\text { gas volume }}{\text { gas surface area }}
$$


For can and can-annular combustors, the beam length ranges from $0.6 D_{L}$ to $0.9 D_{L}$ (Lefebvre, 1999).

\subsubsection{External Radiation, $R_{2}$}

The expression for the estimation of the external radiation $R_{2}$, from the liner wall to the casing, is given by Equation (4.64). This formula assumes that the liner and casing walls behave as gray surfaces with emissivities $\varepsilon_{w}$ and $\varepsilon_{\text {casing }}$ respectively. In addition, the outer wall and the casing temperatures are assumed to be uniform in the axial direction. Furthermore, the annulus air temperature $\left(T_{3}\right)$ is used in the estimation of the external radiation because of lack of accurate knowledge of the casing temperature ( $\left.T_{\text {casing }}\right)$ (Lefebvre, 1999).

Given the above, the expression for the net radiation flux is given by (Lefebvre, 1999),

$$
R_{2}=\sigma \frac{\varepsilon_{w} \varepsilon_{\text {casing }}}{\varepsilon_{\text {casing }}+\varepsilon_{w}\left(1-\varepsilon_{\text {casing }}\right)\left(\frac{A_{w}}{A_{\text {casing }}}\right)}\left(T_{w 2}^{4}-T_{3}^{4}\right)
$$

where $\varepsilon_{\text {casing }}$ is the casing wall emissivity (Stainless steel $=0.7-0.8$; Çengel, 1997)

$\varepsilon_{w}$ is the liner wall emissivity (Nimonic $=0.7$; Sawyer, 1985)

$A_{\mathrm{w}}$ is the liner wall surface area

$A_{\text {casing }}$ is the casing surface area

$T_{w 2}$ is the liner outer wall temperature 
where, in the case of tubular chambers, the ratio of the liner wall surface area to the casing surface area equal to the liner-casing diameter ratio, $\frac{D_{L}}{D_{\text {ref }}}$.

\subsubsection{Internal Convection, $C_{1}$}

The rapid physical changes and chemical reaction rates make the estimation of internal convection very challenging, especially in the primary zone. Conventional heat transfer theory used for straight pipes is applied here with the understanding that the Reynolds number is consistent with that of very high turbulence intensity (Lefebvre, 1999).

$C_{1}=0.020 \frac{k_{g}}{d_{h L}^{0.2}}\left(\frac{\dot{m}_{g}}{A_{L} \mu_{g}}\right)^{0.8}\left(T_{g}-T_{w 1}\right)$

where $k_{g}$ is the hot gas thermal conductivity, $\frac{\mathrm{W}}{\mathrm{mK}}$

$\dot{m}_{g}$ is the hot gas mass flow rate, $\frac{\mathrm{kg}}{\mathrm{s}}$

$A_{L}$ is the liner area, $\mathrm{m}^{2}$

$\mu_{g}$ is the hot gas dynamic viscosity, $\frac{\mathrm{kg}}{\mathrm{ms}}$

$T_{g}$ is the flame temperature, $\mathrm{K}$

$T_{w 1}$ is the liner inner wall temperature, $\mathrm{K}$

$d_{h L}$ is the hydraulic diameter $(\mathrm{m})$ of the liner is calculated as: 


$$
d_{h L}=4 \frac{\text { cross sectional flow area }}{\text { wetted perimeter }}=D_{L}
$$

\subsubsection{External Convection, $C_{2}$}

External convection (Equation (4.68)) is calculated using the approach outlined in Section 4.10.2.3. However, the Reynolds number for this expression is based on the annulus hydraulic mean diameter.

$$
D_{A N}=D_{r e f}-D_{L}
$$

The air flowing through the annulus is assumed to be adequately stirred in order that turbulent heat transfer theory can be applied, giving (Lefebvre, 1999),

$$
C_{2}=0.020 \frac{k_{a}}{D_{A N}^{0.2}}\left(\frac{\dot{m}_{A N}}{A_{A N} \mu_{a}}\right)^{0.8}\left(T_{w 2}-T_{3}\right)
$$

where $k_{a}$ is the air thermal conductivity, $\frac{\mathrm{W}}{\mathrm{mK}}$

$\mu_{a}$ is the air dynamic viscosity, $\frac{\mathrm{kg}}{\mathrm{ms}}$

$\dot{m}_{A N}$ is the air mass flow rate in the annulus, $\frac{\mathrm{kg}}{\mathrm{s}}$

$A_{A N}$ is the annulus area, $\mathrm{m}^{2}$

$D_{A N}$ is the annulus diameter, $\mathrm{m}$

$\mu_{g}$ is the hot gas dynamic viscosity, $\frac{\mathrm{kg}}{\mathrm{ms}}$

$T_{w 2}$ is the liner outer wall temperature, $\mathrm{K}$ 


\subsubsection{Calculation of Uncooled Liner Wall Temperature}

The following section outlines the methodology to iteratively solve Equation (4.58) and estimate the liner wall temperature when cooling techniques are not present. The procedure is as follows (Lefebvre, 1999):

1) Estimate the mean fuel-to-air ratio for the zone under investigation. Within the primary zone, stoichiometric conditions should be assumed if a maximum value for the wall temperature is required;

2) Calculate the gas emissivity from Equation (4.61);

3) Calculate the net internal radiation heat flux (Equation (4.60)) as a function of the internal wall temperature;

4) Calculate the net external radiation heat flux (Equation (4.64)) as a function of the external wall temperature;

5) Calculate the net internal convection heat flux (Equation (4.65)) as a function of the internal wall temperature making sure that the coefficient of thermal conductivity and the dynamic viscosity are evaluated at the hot gas temperature;

6) Calculate the net external convection heat flux (Equation (4.68)) as a function of the external wall temperature making sure that the coefficient of thermal conductivity and the dynamic viscosity are evaluated at the combustor inlet temperature.

With the estimation of the uncooled liner wall temperature completed; the selection of a cooling scheme and the evaluation of its performance on the liner wall temperature can be undertaken. 


\subsubsection{Calculation of Cooled Liner Wall Temperature and Cooling Mass Flow}

Innovative technologies as well as new material and coating developments give an array of choices when selecting a cooling scheme and the amount of coolant needed. Performance versus costs and manufacturing feasibility are usually the determining factors when deciding on a cooling scheme.

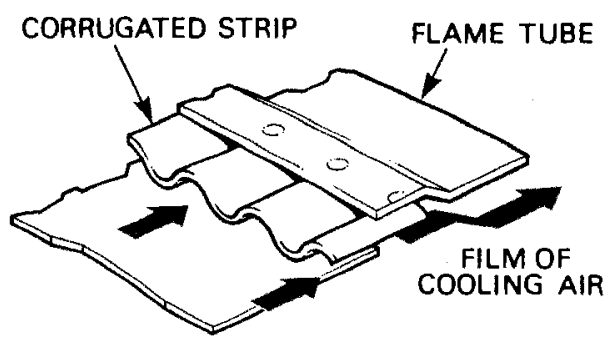

CORRUGATED STRIP COOLING

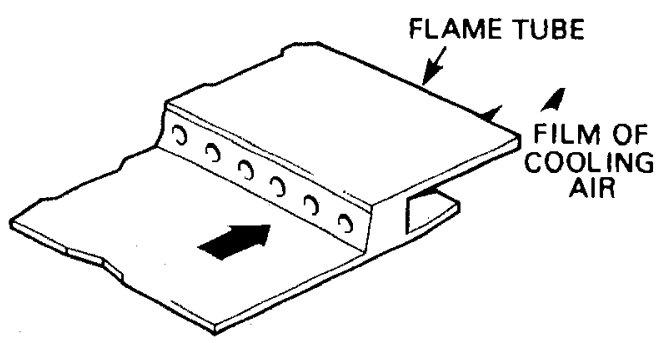

MACHINED COOLING RING

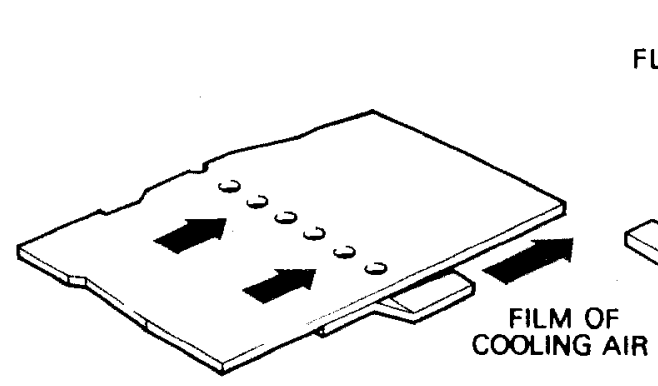

SPLASH COOLING STRIP

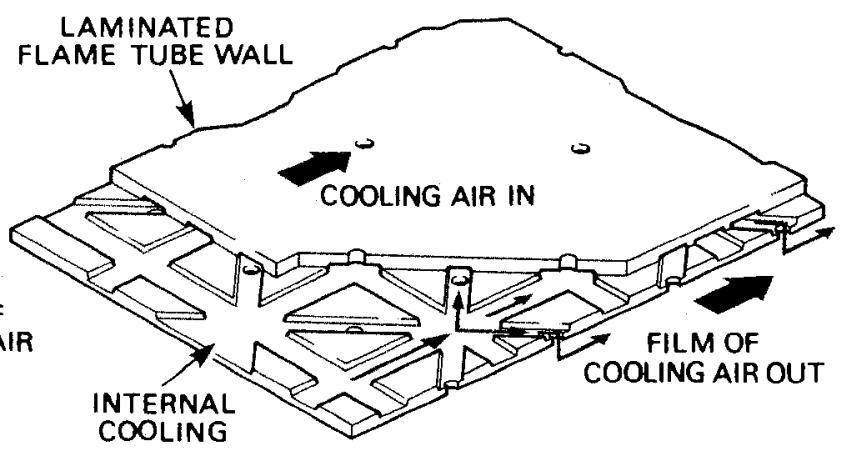

TRANSPIRATION COOLING

\section{Figure 4.22 Cooling schemes (Rolls-Royce plc, 1996)}

Figure 4.22 shows various cooling techniques used in gas turbine combustors. Each design has its pros and cons. However, they all have the same function, which is to provide a cooling flow that runs between the liner wall and the hot gasses so that a barrier is formed to protect the liner wall from the heat of the combustion process. As the film cooling and hot gasses travel downstream together, they mix and the effectiveness of the coolant depreciates. Prior to reaching the maximum operating temperature of the liner wall material, another cooling film must be introduced. 
The heat transfer theory presented next is based on work published by Sawyer (1985). The expressions for the film cooling theory are derived with the following assumptions in mind:

- The hot gas is assumed to be of uniform temperature and velocity and that it does not transfer heat by radiation;

- The film cooling is thought to completely occupy the cooling slot, to be uniform in velocity and temperature and to not transfer heat by radiation;

- The liner wall temperature is taken to be that of the cooling film adjacent to it and is governed by the adiabatic process.

With these simplifications the film cooling equations are presented next.

\subsubsection{Cooling Slot Effectiveness, $\eta_{c}$}

This section presents formulations for the estimation of the cooling slot effectiveness, $\eta_{c}$. The expression for the cooling slot effectiveness, $\eta_{c}$, was derived from wall jet model theory, which states that when in close proximity to the cooling device, the flow emerging from the cooling slot behaves like a jet (Sawyer, 1985).

$\eta_{c}=\left(\frac{\dot{m}_{g} A_{c}}{\dot{m}_{c} A_{g}}\right)^{0.8}\left(\frac{T_{g}^{\prime}}{T_{a}}\right)^{0.6}\left(\frac{x^{0.8}}{w}\right) \cdot K$

where

1) The calculation of the equivalent hot gas temperature, $T_{g}^{\prime}$, is given in Section 4.10.3.2.

2) The calculation of the cooling mass flow rate, $\dot{m}_{c}$, is presented in Section 4.10.3.4. 
3) The hot gas mass flow rate $\left(\dot{m}_{g}\right)$ calculation, is defined in Section 4.10.3.5.

4) The coolant and hot gas areas are calculated in Section 4.10.3.6.

5) $x$ and $w$ are the distance $(\mathrm{m})$ from the dome to the cooling slot and the slot gap dimension respectively and

6) where the constant $K$ is defined as follows:

$$
\begin{aligned}
& K=1 \text { for } \frac{V_{g}}{V_{c}} \geq 0.8 \\
& K=\left(\frac{V_{g}}{V_{c}}+0.2\right)^{-\frac{5}{4}} \text { for } 0<\frac{V_{g}}{V_{c}}<0.8
\end{aligned}
$$

where $V_{g}$ is the hot gas velocity

$$
V_{c} \text { is the coolant velocity }
$$

\subsubsection{Equivalent Hot Gas Temperature, $T_{g}$}

The change in the local hot gas temperature due to film cooling must be taken into account when evaluating the film cooling effectiveness. This is done by introducing the “equivalent" hot gas temperature, $T_{g}^{\prime}$, which represents the average hot gas temperature encountered by the film cooling span. The mean value from the area under the curve $T_{g}$ versus x gives $T_{g}^{\prime}$ (Sawyer, 1985).

$$
T_{g}^{\prime}=\frac{1}{x} \int_{0}^{x} T_{g} d x
$$




\subsubsection{Film Coolant Temperature, $T_{c}$}

Assuming that the film coolant is not subjected to heat transfer, the adiabatic film effectiveness can be calculated as (Sawyer, 1985):

$\eta_{c}=\frac{T_{g}^{\prime}-T_{w, a d}}{T_{g}^{\prime}-T_{c}}$

where $T_{g}^{\prime}$ is the equivalent hot gas temperature

$T_{w, a d}$ is the adiabatic wall temperature

$T_{c}$ is the film coolant temperature

Hence, the film coolant temperature as a function of liner length can be calculated as:

$T_{c}=T_{g}^{\prime}-\frac{1}{\eta_{c}}\left(T_{g}^{\prime}-T_{w, a d}\right)$

\subsubsection{Cooling Air Mass Flow Rate, $\dot{m}_{c}$}

The methodology for the estimation of the cooling air mass flow rate is shown next. The calculation is identical for each cooling device but, factors such as geometry and location of the cooling device must be taken into consideration. For example, the pressure loss across the dome cooling slot will be dependent upon the pressure drop of the snout, since this cooling device takes its flow from the snout, and the type of cooling geometry used (i.e., corrugated strip or machined rings, etc.). The cooling air mass flow rate is calculated as (Sawyer, 1985):

$$
\dot{m}_{c}=\sqrt{\frac{\Delta P_{c, i}}{P_{3}} \frac{P_{3}^{2} A_{e f f}^{2}}{k T_{3}}}
$$


where $\Delta P_{c, l}$ is the pressure drop across the cooling device under consideration, $\mathrm{Pa}$

$$
k=143.5 \text { (SI units) }
$$

$A_{\text {eff }}$ is the cooling slot effective area $\left(\mathrm{m}^{2}\right)$ and it is calculated as follows:

$$
A_{e f f}=A_{c}\left(1-B_{c}\right) C_{d}
$$

where $B_{c}$ is the cooling slot blockage factor

$C_{d}$ is the discharge coefficient ( 0.85 for total head or 0.65 for splash) (Sawyer, 1985)

$A_{c}$ is the cooling slot area (calculated in Section 4.10.3.7), $\mathrm{m}^{2}$

\subsubsection{Hot Gas Mass Flow Rate, $\dot{m}_{g}$}

To determine the cooling slot effectiveness, Equation (4.69), the hot gas mass flow rate must be estimated. For the recirculation zone, since a precise amount of the hot gas mass flow rate is not known at this stage, it is possible to approximate it with the following expression (Sawyer, 1985):

$$
\dot{m}_{g}=\dot{m}_{S W}+\dot{m}_{c, f}+\frac{1}{2} n_{h, P Z} \dot{m}_{h, P Z}
$$

where $\dot{m}_{S W}$ is the swirler mass flow rate

$$
\dot{m}_{c, f} \text { can be estimated to be } \dot{m}_{c, f}=0.03 \dot{m}_{3}
$$

$n_{h, P Z}$ is the number of injection holes in the primary zone $\dot{m}_{h, P Z}$ is the air mass flow rate flowing through the injection holes 


\subsubsection{Annulus Mass Flow Rate, $\dot{m}_{A N}$}

The annulus mass flow rate, along the liner, is simply the mathematical subtraction of the flow rate entering the liner from the total mass flow rate entering the combustor inlet.

\subsubsection{Area Calculations $A_{c}, A_{g}, A_{A N}$}

The cooling device area is calculated as

$$
A_{c}=\pi \cdot D_{c} \cdot w
$$

where $D_{c}$ is the arithmetic diameter of the cooling slot gap $w$ is the slot gap width

The hot gas area, $A_{g}$, is the area of the liner without the cooling film thickness (which thickness is estimated to be equal to the slot gap width $w$ ). Note that, as more cooling devices are introduced, this area will be altered to reflect the changes.

The annulus area, $A_{A N}$, is the area enclosed by the outer liner wall and the casing inner wall. This area decreases as more cooling devices are introduced.

\subsubsection{Calculation of Cooled Wall Temperature}

The heat transfer Equations (4.58) derived in Section 4.10.2 still hold true and can be applied to calculate the liner wall temperature when cooling devices are introduced. However, the internal convection expression (Equation (4.65)) must now take into consideration that the film cooling changes the temperature and velocity of the hot gas in proximity to the wall.

When using Sawyer's approach, this change is taken into account by evaluating the expression using cooling film properties. This is shown next: 
$C_{1}=0.017 \frac{k_{c}}{d_{h c}^{0.2}} T_{c}\left(\frac{\dot{m}_{c}}{A_{c} \mu_{c}}\right)^{0.8}\left(T_{c}-T_{w 1}\right)$

where $k_{c}$ is the coolant thermal conductivity, $\frac{\mathrm{W}}{\mathrm{mK}}$

$d_{h c}$ is the hydraulic diameter of the coolant, $\mathrm{m}$

$T_{c}$ is the film coolant temperature, $\mathrm{K}$

$T_{w 1}$ is the liner inner wall temperature, $\mathrm{K}$

$A_{c}$ is the cooling device area, $\mathrm{m}^{2}$

$\dot{m}_{c}$ is the coolant mass flow rate, $\frac{\mathrm{kg}}{\mathrm{s}}$

$\mu_{c}$ is the coolant dynamic viscosity, $\frac{\mathrm{kg}}{\mathrm{m} \mathrm{s}}$

With $C_{1}$ defined, the cooled liner wall temperature can be undertaken using the methodology reported in Section 4.10.2.5. Equation (4.58) can now be solved iteratively making sure that the internal convection component is defined by Equation (4.79).

\subsection{Injection Hole Sizing}

The last step in the preliminary design of a gas turbine combustor is the sizing of the injection holes (see Figure 4.25 for nomenclature). The following section will present work which has been published by Sawyer (1985) and Lefebvre (1999) on the subject. Both authors recognize that the injection hole geometry, the liner pressure loss, the liner geometry and the injection hole bleed ratio (shown next) have an effect on injection hole performance. 
The governing equation, given by Sawyer (1985), for the pressure loss through a hole (assuming incompressible flow) is the following:

$$
\frac{\Delta P_{h}}{P_{3}}=\frac{143.5 \dot{m}_{h}^{2} T_{3}}{P_{3}^{2} C_{d}^{2} A_{h}^{2}}
$$

where $\Delta P_{h}$ is the pressure loss across the hole, $\mathrm{Pa}$

$$
\dot{m}_{h} \text { is the mass flow rate through the hole, } \frac{\mathrm{kg}}{\mathrm{s}}
$$

$A_{h}$ is the area of the hole, $\mathrm{m}^{2}$

$C_{d}$ is the hole discharge coefficient whose calculation is shown next.

According to Sawyer, depending on the design of the injection hole, whether plain or plunged, the discharge coefficient is calculated as follows:

For plain holes the equation is:

$$
C_{d}=\frac{K-1}{0.8\left[4 K^{2}-K(2-\beta)^{2}\right]^{0.5}}
$$

where the hole pressure loss factor $K$ is calculated as:

$$
K=\frac{P_{A N}-p_{j}}{q_{A N}}=1+0.64\left\{2 \mu^{2}+\left[4 \mu^{4}+1.56 \mu^{2}\left(4 \beta-\beta^{2}\right)\right]^{0.5}\right\}
$$

where $P_{A N}$ is the annulus total pressure, $\mathrm{Pa}$

$p_{j}$ is the jet static pressure, $\mathrm{Pa}$

$q_{A N}$ is the annulus dynamic pressure, $\mathrm{Pa}$

However, before solving Equation (4.82) the following parameters need to be identified: the hole area ratio, $\alpha$ 
$\alpha=\frac{A_{h}}{A_{A N}}$

where $A_{h}$ is the hole area

$A_{A N}$ is the annulus area

the hole bleed ratio, $\beta$

$\beta=\frac{\dot{m}_{h}}{\dot{m}_{A N}}$

where $\dot{m}_{h}$ is the air mass flow rate through the hole

$\dot{m}_{A N}$ is the air mass flow rate through the annulus

and the velocity area ratio, $\mu$

$\mu=\frac{\beta}{\alpha}$

The jet angle $(\Phi)$ is given by:

$\sin \Phi=\frac{1}{1.6 C_{d}} \frac{K-1}{K}$

For plunged holes, the discharge coefficient is calculated as:

$$
C_{d}=\frac{K-1}{0.6\left[4 K^{2}-K(2-\beta)^{2}\right]^{0.5}}
$$

with the hole pressure loss factor expressed as:

$$
K=1+0.36\left\{2 \mu^{2}+\left[4 \mu^{4}+2.77 \mu^{2}\left(4 \beta-\beta^{2}\right)\right]^{0.5}\right\}
$$

and the jet angle defined as: 
$\sin \Phi=\frac{1}{1.2 C_{d}} \frac{K-1}{K}$

When looking at Lefebvre's work, the following formulations can be found (Lefebvre, 1999):

$\dot{m}_{h}=C_{d} A_{h}\left[2 \rho_{3}\left(P_{3}-p_{j}\right)\right]^{0.5}$

where $C_{d}$ is the hole discharge coefficient

$A_{h}$ is the hole area

$\rho_{3}$ is the air density upstream of the hole

$P_{3}$ is the total pressure upstream of the hole

$p_{j}$ is the static pressure downstream of the hole

The discharge coefficient for plain holes, according to Lefebvre (1999), can be calculated as follows:

$C_{d}=\frac{1.25(K-1)}{\left[4 K^{2}-K(2-\beta)^{2}\right]^{0.5}}$

where $\beta$ is the hole bleed ratio, Equation (4.84)

$K$, the hole pressure loss factor, calculated as:

$K=\frac{q_{j}}{q_{A N}}$

where $q_{j}$ is the jet dynamic pressure

$q_{A N}$ is the annulus dynamic pressure upstream of the hole 
For plunged holes, the discharge coefficient and the initial jet angle equations, given by Lefebvre, are respectively

$$
\begin{aligned}
& C_{d}=\frac{1.65(K-1)}{\left[4 K^{2}-K(2-\beta)^{2}\right]^{0.5}} \\
& \sin ^{2} \Phi=\frac{C_{d}}{C_{d, \infty}}
\end{aligned}
$$

where $C_{d, \infty}$ is the asymptotic value as the hole bleed ratio $(\beta)$ tends to infinity (i.e. $\left.C_{d, \infty}=1\right)$

Figure 4.23 and Figure 4.24 show results of experimental work carried out by Kaddah (1964) and Freeman (1965) on discharge coefficient for various hole geometry configurations. In particular, as can be seen in Figure 4.23, Equation (4.91) has a good level of agreement with the experimental data.

By analyzing the above mentioned figures, the following can be concluded. High ratio values of the jet dynamic pressure to the annulus dynamic pressure upstream of the hole $(K)$ ensure high discharge coefficients which are insensitive to small changes in the hole pressure loss factor. This is important since high $K$ values will make the injection hole insensitive to manufacturing tolerances, circumferential variations in combustor inlet velocity profile and small changes in air flow distribution during the development of the combustor (Lefebvre, 1999). The expense of this advantage, however, will be an increased diffuser area ratio. 


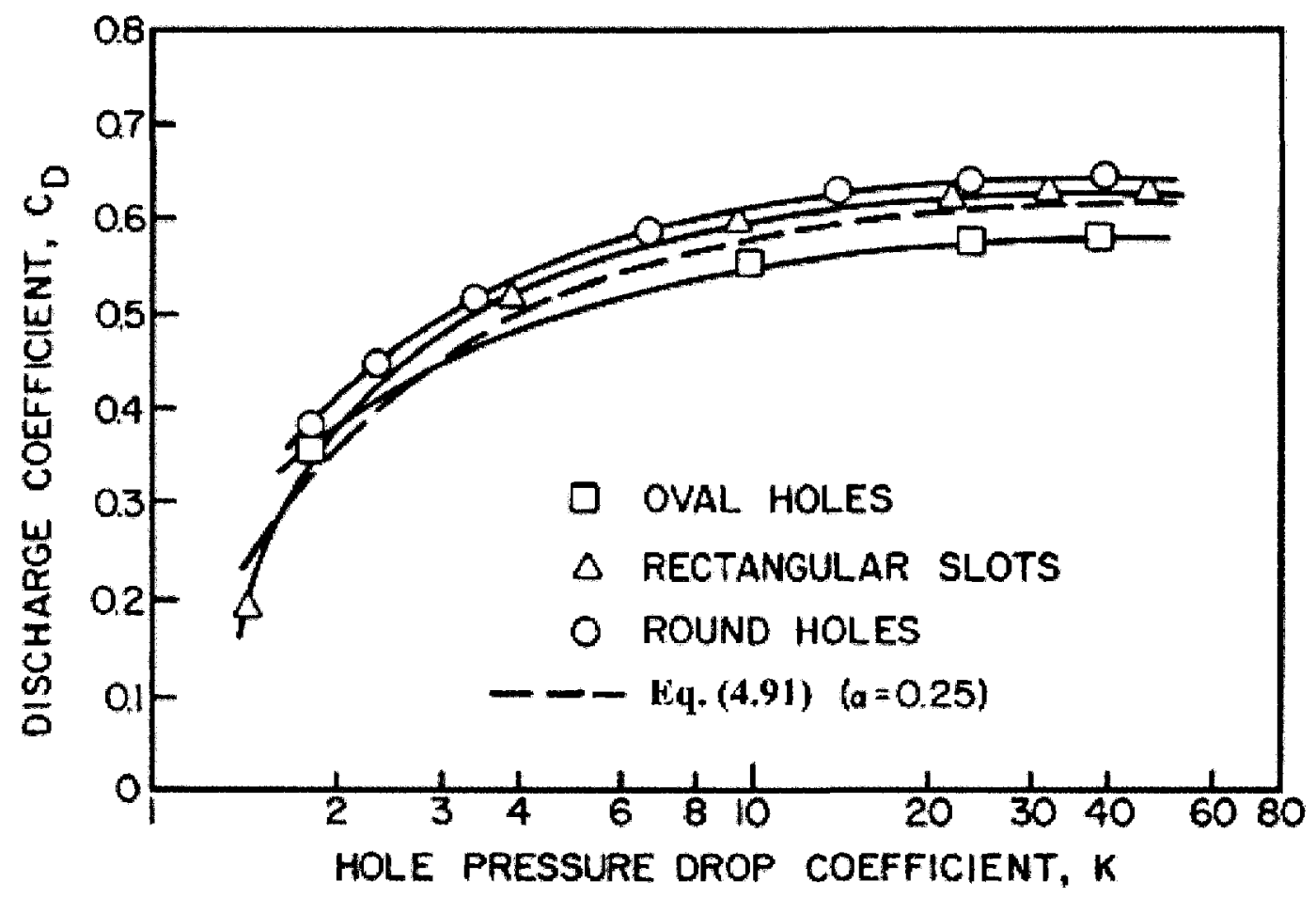

Figure 4.23 Effect of hole pressure drop coefficient on discharge coefficient (Adapted from Kaddah, 1964)

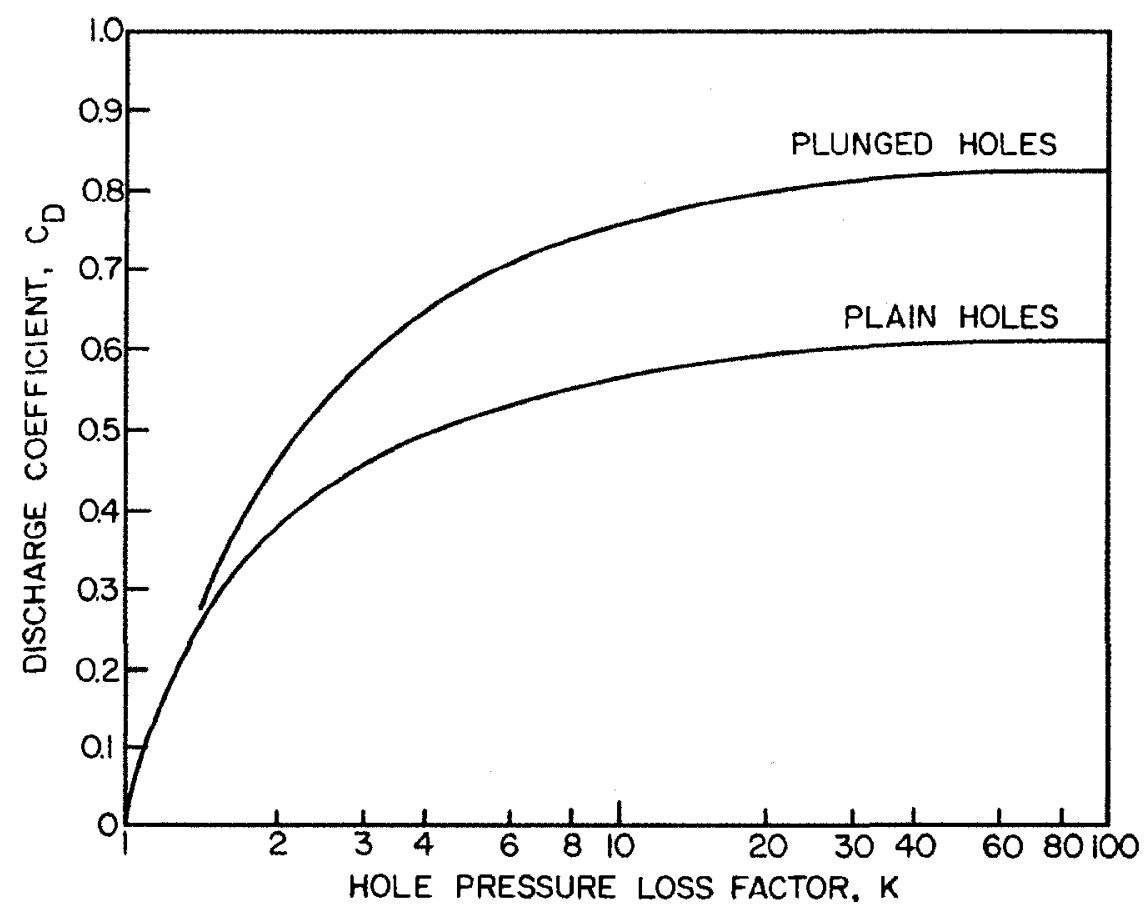

Figure 4.24 Effects of hole pressure loss factor and hole geometry on discharge coefficient (Freeman, 1965) 
For primary injection holes, Lefebvre suggests that the hole pressure loss factor $(K)$ should not be less than six due to poor combustor inlet flow conditions.

The dilution injection holes, as mentioned in Sections 3.10 and 4.5.3, have the critical job of injecting cold air into hot combustion products to ensure an outlet temperature profile which is satisfactory for the components directly downstream of the combustor. Therefore, jet penetration and mixing are of primary importance when designing dilution injection holes.

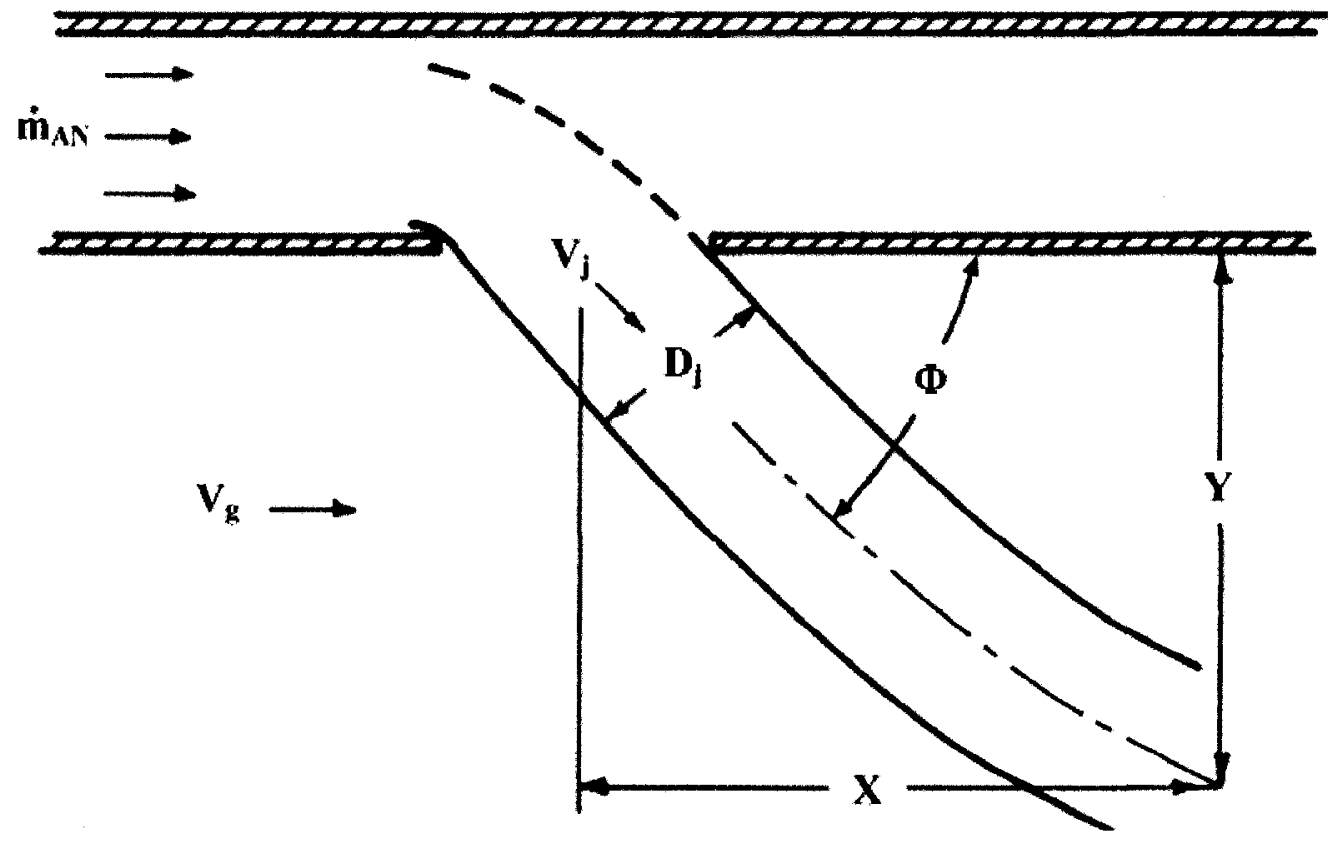

Figure 4.25 Injection hole nomenclature (Adapted from Lefebvre, 1999)

Based on single jet experiments, Lefebvre (1999) concluded that the trajectory of a jet in a crossflow (see Figure 4.25 for nomenclature) can be represented by (Figure 4.25)

$$
\frac{Y}{D_{j}}=0.82 J^{0.5}\left(\frac{X}{D_{j}}\right)^{0.33}
$$

where $X$ and $Y$ are the jet axial and radial lengths respectively, $\mathrm{m}$ 
$D_{j}$ is the jet diameter, $\mathrm{m}$

$J$ is the momentum flux ratio, is defined as:

$J=\frac{\rho_{j} V_{j}^{2}}{\rho_{g} V_{g}^{2}}$

where $\rho_{j}$ is the density of the air jet flowing trough the hole

$V_{j}$ is the jet velocity

$\rho_{g}$ is the hot gas density

$V_{g}$ is the hot gas velocity

For a single round jet introduced into a circular duct, the maximum jet penetration $\left(Y_{\max }\right)$ is given by the following equation (Lefebvre, 1999)

$Y_{\max }=1.15 D_{j} J^{0.5} \sin \Phi$

In the case of multiple round jets (Lefebvre, 1999) injected into a can liner, the maximum jet penetration is given by

$$
Y_{\max }=1.25 D_{j} J^{0.5} \frac{\dot{m}_{g}}{\left(\dot{m}_{g}+\dot{m}_{j}\right)}
$$

\subsection{Fuel Injection Theory}

This chapter discussed, thus far, how to carry out a preliminary design of a conventional or premixed combustor via the usage of a design methodology based on empirical and semi-empirical correlations. In addition to this, however, another important combustion aspect, fuel injection, needs to be addressed. Particularly, since the fuel used 
in the laboratory is liquid diesel the theory reported in the following sections will expand on liquid fuel injection.

Specifically, the next sections will present correlations of the various interacting mechanisms related to the injection process, such as fuel atomization, fuel evaporation and fuel ignition processes. The following models will aid in the design of the premixer, will assist in the selection of suitable fuel nozzle, and will quantify the igniter requirements. The premixer design as well as the selected fuel nozzle and the ignition system will be further discussed in Chapter 5 .

\subsubsection{Fuel Atomization Process}

The atomization process facilitates combustion since it converts bulk fuel into small drops which subsequently evaporate, mix (essential for combustion) and burn. These droplets form when the disruptive forces created by the atomization process exceed the consolidating surface tension of the liquid fuel (Lefebvre, 1999).

Atomization is achieved through the use of pressure atomizers which can be of different types as reported by Lefebvre (1999). Depending on the type of atomizer used, the mechanisms of atomization can be divided into either classical or prompt. In the classical mechanism, fuel drops are formed from a fuel jet or sheet which interacts with the surrounding air. The interaction between the fuel jet or sheet with the air creates disturbances which lead to the formation of waves then change into ligaments which ultimately turn into drops (Lefebvre, 1999).

The prompt mechanism is based on the same principles as the classical mechanism, but the jet or sheet brake-up occurs very rapidly. Atomization processes are referred to as 
prompt when fuel is discharged at very high velocities into stagnant air or, conversely, when high velocity air jets are used to break-up the fuel jet or sheet (Lefebvre, 1999).

Independent of the mechanism used, the most important atomization parameter is the Weber number, $W e$. The Weber number, defined next, is the ratio of inertial forces to surface tension forces (Winterfeld et al., 1990). For the same liquid (i.e., same $\sigma_{l}$ and $\left.\rho_{l}\right)$, the higher the Weber number, the smaller the droplet diameter. This is due to the higher interacting forces between the fuel jet or sheet and the air.

$W e=\frac{\rho_{l} V_{l}^{2} D_{l}}{\sigma_{l}}$

where $\rho_{l}$ is the density of the liquid fuel

$V_{1}$ is the velocity of the liquid jet

$D_{l}$ is the liquid jet diameter

$\sigma_{1}$ is the surface tension of the liquid fuel

Fuel atomization being random and chaotic in nature creates droplets whose diameters vary widely. The drop size distribution has been investigated by many researchers. However, the most well known empirical correlations of drop size distributions are those by Rosin and Rammler (1933), and by Nukiyama and Tanasawa (1939), the former being the most widely used (Lefebvre, 1999). Through experimentation, Rosin and Rammler (1933) derived that the drop size distribution can be expressed as:

$$
1-Q=\exp -\left(\frac{D}{X}\right)^{q}
$$


where $Q$ is the fraction of the total volume contained in drops of diameter less than $D$ $X$ and $q$ are constants that are determined experimentally

In Equation (4.100), the exponent $q$ represents the spread of drop sizes, which, for most practical purposes, lies between 1.8 and 3.0 (Lefebvre, 1999), and $X$ is the drop diameter such that $63.2 \%$ of the total liquid volume is in drops of smaller diameter than D.

When investigating the evaporation process, working with the entire drop size distribution is not practical. For this reason, evaporation calculations deal with mean or average drop diameters.

For gas turbine combustion calculations, the Sauter mean diameter (SMD or $\left.\mathrm{D}_{32}\right)$ is the most important representative fuel drop diameter of the many possible choices given in literature (Lefebvre, 1999). The SMD represents the diameter of a drop within the spray whose volume to surface area ratio is the same as that of the whole spray (Lefebvre, 1999). The estimation of SMD, which ranges between 50 and 100 microns in gas turbine combustion (Saravanamuttoo, 2001), can be carried out through the use of purely empirical correlations. Winterfed (1990) and Lefebvre (1999) give a number of SMD correlations. These correlations take into account the type of pressure atomizer used, its size, geometry and operating conditions as well as the fuel properties and the properties of the gas surrounding the atomizer. The simplest geometry presented by Lefebvre (1999) is a simple circular orifice which injects at high velocity a fuel jet into the surrounding gas. The corresponding SMD correlation is given as (Elkotb, 1982):

$$
S M D=3.08 v_{l}^{0.385}\left(\sigma_{l} \rho_{l}\right)^{0.737} \rho_{a}^{0.06} \Delta P_{l}^{-0.54}
$$


where $v_{l}$ is the kinematic viscosity of the fuel, $\frac{\mathrm{m}^{2}}{\mathrm{~s}}$

$\sigma_{l}$ is the fuel surface tension, $\frac{\mathrm{kg}}{\mathrm{s}^{2}}$

$\rho_{l}$ is the liquid fuel density, $\frac{\mathrm{kg}}{\mathrm{m}^{3}}$

$\rho_{a}$ is the air density, $\frac{\mathrm{kg}}{\mathrm{m}^{3}}$

$\Delta P_{l}$ is the pressure differential across the orifice, $\mathrm{Pa}$

Another important aspect of the atomization process is the spray cone angle which indicates the spread of the scattered drops. A spray cone angle permits the formation of a symmetrical and well distributed spray which improves the atomization quality by increasing the contact volume between the fuel spray and the surrounding gas or air. The spray angle is defined as that angle formed by two straight lines starting from the discharge orifice and ending downstream at a distance of 60 discharge orifice diameters $\left(D_{o}\right)$ (Lefebvre, 1999). The simplest expression for spray angles $\left(\theta_{l}\right)$ is that of the simple circular orifice. This expression is presented by Abramovich (1963) as:

$\tan \theta_{l}=0.13\left(1+\frac{\rho_{a}}{\rho_{l}}\right)$

where $\rho_{a}$ is the air density, $\frac{\mathrm{kg}}{\mathrm{m}^{3}}$

$\rho_{l}$ is the liquid fuel density, $\frac{\mathrm{kg}}{\mathrm{m}^{3}}$ 
Having done a brief overview of the atomization process, the next important aspect of fuel injection theory is the evaporation process where, through mass and heat transfer, the liquid fuel droplets evaporate.

\subsubsection{Droplet Evaporation Process and Evaporation Model}

As previously mentioned, combustion can only occur if the fuel burnt is in its vapour phase and it is mixed with air at a molecular level. Therefore, a simple model for estimating droplet evaporation is presented below. The theory discussed in this section gives a general overview of the model. For more details, work published by Turns (2000) should be consulted.

The evaporation process occurs through mass and heat transfer. In other words, the heat surrounding the liquid droplet supplies the energy needed for evaporation to take place. Initially, the higher heat from the surroundings increases the droplet temperature through a conduction and convection heat transfer process. Once the droplet temperature reached steady state, the heat transfer acts solely towards the evaporation process. The vapour which is formed, cool the droplet by transporting away some of the heat, then diffuses from the droplet surface to the surroundings. The loss of mass causes the droplet diameter to decrease until it is completely evaporated.

The model presented next is applied to a single droplet of liquid fuel and contains many simplifying assumptions to avoid dealing with mass transfer aspects of the evaporation process. However, as mentioned by Turns (2000), the model still agrees reasonably well with experimental results. The model main assumptions are:

- the evaporation process is quasi-steady and occurs at constant pressure; 
- the single droplet evaporates in quiescent, infinite surroundings, is spherical in shape, and has a constant, uniform temperature equal to the fuel boiling temperature;

- the fuel is a single component liquid with zero solubility for gasses and with constant thermo-physical properties;

- the fuel molar and thermal diffusivities $\left(\alpha_{0}=\lambda / c_{p} \rho\right)$ are considered equal;

- the liquid and the vapour are at equilibrium at the droplet surface, and no heat transfer through radiation is considered.

The model algorithm is shown in Figure 4.26. 


\section{Inputs}

Boiling Temperature, $T_{n h}(\mathrm{~K})$, Ambient Temperature, $T_{s c}(\mathrm{~K})$, Fuel Temperature, $T_{F R}(\mathrm{~K})$, Initial Droplet Diameter $\left(D_{0}, \mu \mathrm{m}\right)$, Relative Velocity $\left(V_{r e t}, \mathrm{~m} / \mathrm{s}\right)$, Ambient Pressure $(P, \mathrm{~Pa})$

Fucl Mass Fraction Inside Droplet $\left(Y_{F R}\right)$, Fucl Mass Fraction Far From Droplet $\left(Y_{\infty}\right)$

Fuels Critical Pressures $\left(P_{\mathrm{o}}, \mathrm{Pa}\right)$, Fuels Heats of Vaporization $\left(h_{f \mathrm{~g}}, \mathrm{~kJ} / \mathrm{kg}\right)$

Molecular Weights (air, octane, dodecane) $(M, \mathrm{~kg} / \mathrm{kmol})$, Densities (air, octane, dodecane) $\left(\rho, \mathrm{kg} / \mathrm{m}^{3}\right)$

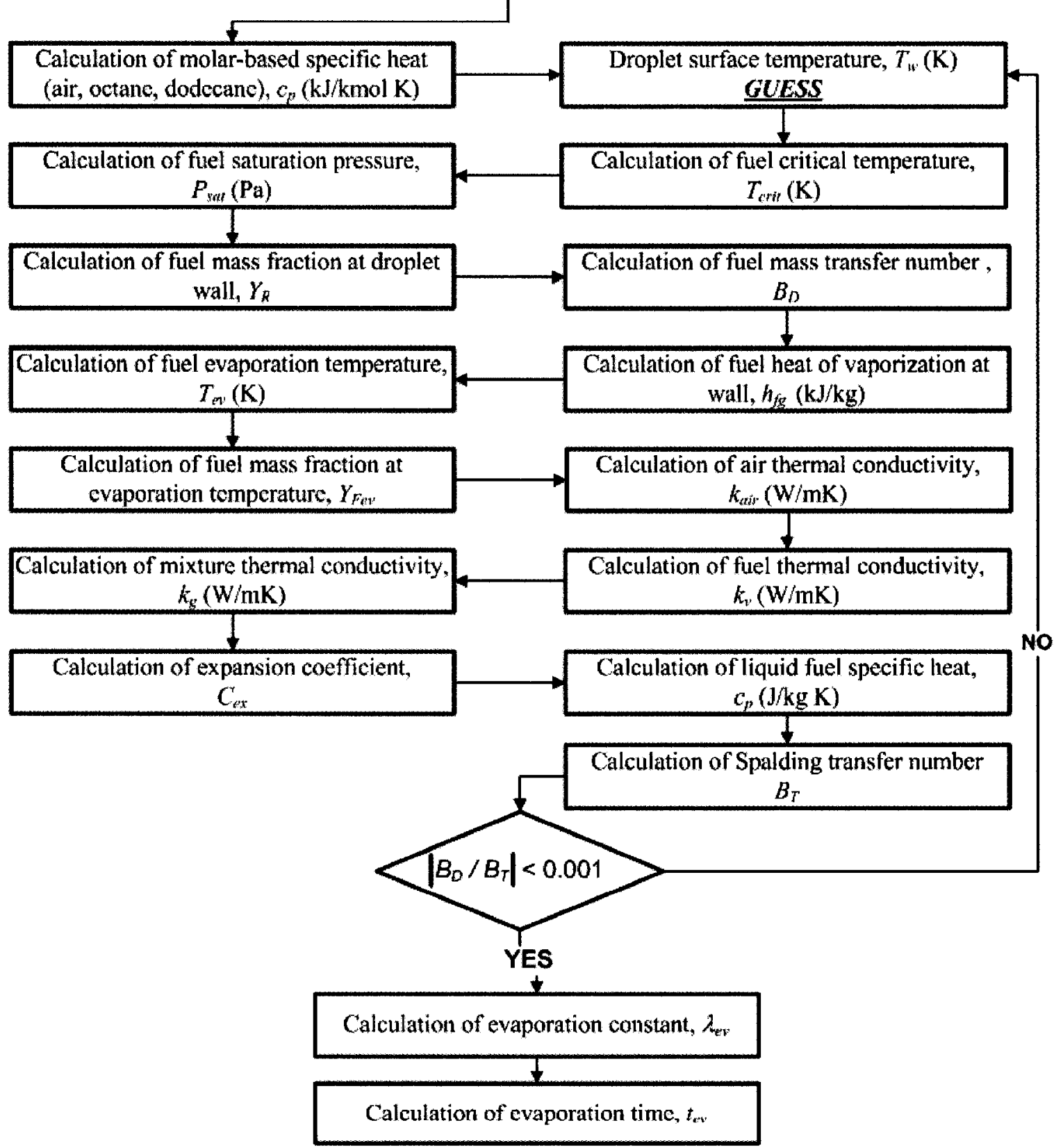

Figure 4.26 Program algorithm for single droplet evaporation

Through mass and energy conservation, and by solving the droplet surface energy balance, the evaporation rate is derived to be: 
$\dot{m}_{e v}=\frac{4 \pi k r}{c_{p}} N u \ln \left(B_{T}+1\right)$

where $k$ is the mixture thermal conductivity, $\frac{\mathrm{W}}{\mathrm{mK}}$

$r$ is the droplet radius from centre to surface, $m$

$c_{p}$ is the mixture specific heat, $\frac{\mathrm{kJ}}{\mathrm{kmolK}}$

$N u$ is the Nusselt number defined by Equation (4.104)

$B_{T}$ is the Spalding number also called the transfer number and is defined by Equation (4.110).

The Nusselt number $(N u)$ takes into consideration heat transfer through forced convection in the evaporation process and it can. This forced convection is due to the fact that the fuel droplet might have a relative velocity with respect to the mixture. For a still mixture, the evaporation process would only account for the conduction heat transfer and the Nusselt number would be set to 2 (i.e., $R e_{r e l}=0$ ). The Nusselt number, which is estimated using the Ranz-Marshall correlation for the convective heat transfer to a sphere, is shown next (Ranz and Marshall, 1952):

$N u=2\left(1+0.3 \operatorname{Re}_{r e l}^{\frac{1}{2}} \operatorname{Pr}^{\frac{1}{3}}\right)$

where $\operatorname{Pr}$ is the Prandtl number

$R e_{r e l}$ is the Reynolds number calculated using the droplet relative velocity

These numbers are defined in Equations (4.105) and (4.106). The Prandtl number can be expressed as (White, 1999): 
$\operatorname{Pr}=\frac{\mu c_{p}}{k}$

where $\mu$ is the mixture dynamic viscosity, $\frac{\mathrm{kg}}{\mathrm{ms}}$

$c_{p}$ is the mixture specific heat, $\frac{\mathrm{kJ}}{\mathrm{kmolK}}$

$k$ is the mixture thermal conductivity, $\frac{\mathrm{W}}{\mathrm{mK}}$

The Reynolds number, which is calculated from the relative velocity of the fuel droplet with respect to the mixture, is defined as (White, 1999):

$R e_{r e l}=\frac{\rho V_{r e l} D}{\mu}$

where $\rho$ is the mixture density, $\frac{\mathrm{kg}}{\mathrm{m}^{3}}$

$V_{r e l}$ is the relative velocity of the fuel droplet with respect to the mixture, $\frac{\mathrm{m}}{\mathrm{s}}$

$D$ is the droplet diameter, $\mathrm{m}$

However, Equation (4.106) should take into consideration that gas turbine combustion is a turbulent process. This turbulent process increases the rate of convective heat and mass transfer. Therefore, the above equation is modified to be (Charest, 2005):

$R e_{r e l}^{\prime}=\frac{\rho \bar{q} D}{\mu}$

where $\bar{q}$ is the mean turbulent fluctuation of the bulk flow and is calculated from White (1999) as: 
$\bar{q}=\sqrt{\frac{1}{3}\left(\overline{u^{\prime 2}}+\overline{v^{\prime 2}}+\overline{w^{\prime 2}}\right)}$

where $\overline{u^{\prime 2}}, \overline{v^{\prime 2}}$, and $\overline{w^{\prime 2}}$ are the mean bulk fluctuations in the $x, \mathrm{y}, \mathrm{z}$ directions.

In practice, these fluctuations are presented as percentage of the free stream velocity and are named turbulence intensity, $T I$. For gas turbine combustors, the turbulence intensities range between $10 \%$ to $15 \%$ (Taylor, 1978; Dodds and Bahr, 1990) and are calculated as follows,

$T I=\frac{\bar{q}}{V_{b}}$

where $V_{b}$ is the bulk flow velocity.

The last parameter in Equation (4.103) that must be addressed is the Spalding number $\left(B_{T}\right)$ which is expressed as,

$$
B_{T}=\frac{Y_{R}-Y_{\infty}}{Y_{F}-Y_{R}}
$$

where $Y_{\infty}$ is the fuel mass fraction far from the droplet, which, as a simplifying assumption, can be assumed to be zero

$Y_{F}$ is the fuel mass fraction inside the droplet and is set to unity

$Y_{R}$ is the fuel mass fraction at the surface of the droplet and is calculated as:

$$
\frac{1}{Y_{R}}=1+\left(\frac{P_{\infty}}{P_{s a t}}-1\right) \frac{M_{\infty}}{M_{f}}
$$

where $P_{\infty}$ is the surrounding pressure 
$M_{\infty}$ and $M_{f}$ are the molecular weights of the surrounding gas or air and fuel respectively

$P_{\text {sat }}$ is the fuel saturation pressure and can be calculated as (Gauthier, 2005):

$P_{\text {sat }}=1 \mathrm{~atm}\left(\frac{1 \mathrm{~atm}}{P_{\text {crit }}}\right)^{-\left(\frac{T_{\text {crit }}}{T_{w w}}\right)\left(\frac{T_{w}-T_{b}}{T_{c r i t}-T_{b}}\right)}$

where $P_{c r t}$ is the fuel critical pressure, atm

$T_{\text {crit }}$ are the fuel critical pressure and temperature respectively, $\mathrm{K}$

$T_{w}$ is the fuel droplet surface (wall) temperature, $\mathrm{K}$

$T_{b}$ is the fuel boiling temperature, $\mathrm{K}$

By noting that the evaporation rate, $\dot{m}_{e v}$ (Equation (4.103)), is directly related to the rate at which the mass of the droplet decreases $\left(-\frac{d D}{d t}\right)$, the droplet lifetime can be derived as (Gauthier, 2005):

$\frac{d D^{2}}{d t}=-\frac{8 k}{\rho_{l} c_{p}} N u \ln \left(B_{T}+1\right)$

where the right-hand side of Equation (4.113) is the evaporation constant, $\lambda_{e v}$, thus,

$\lambda_{e v}=\frac{8 k}{\rho_{l} c_{p}} N u \ln \left(B_{T}+1\right)$

By integrating Equation (4.113), the $\mathrm{D}^{2}$ law for droplet evaporation can be evaluated to be (Turns, 2000),

$D^{2}(t)=D_{0}^{2}-\lambda_{e v} t$ 
where $D_{o}$ is the initial droplet diameter

For a given initial droplet diameter, the evaporation time (i.e., $D^{2}\left(t_{e v}\right)=0$ ) is calculated as:

$t_{e v}=\frac{D_{0}^{2}}{\lambda_{e v}}$

The graphical solution of Equation (4.115) is shown in Figure 4.27.

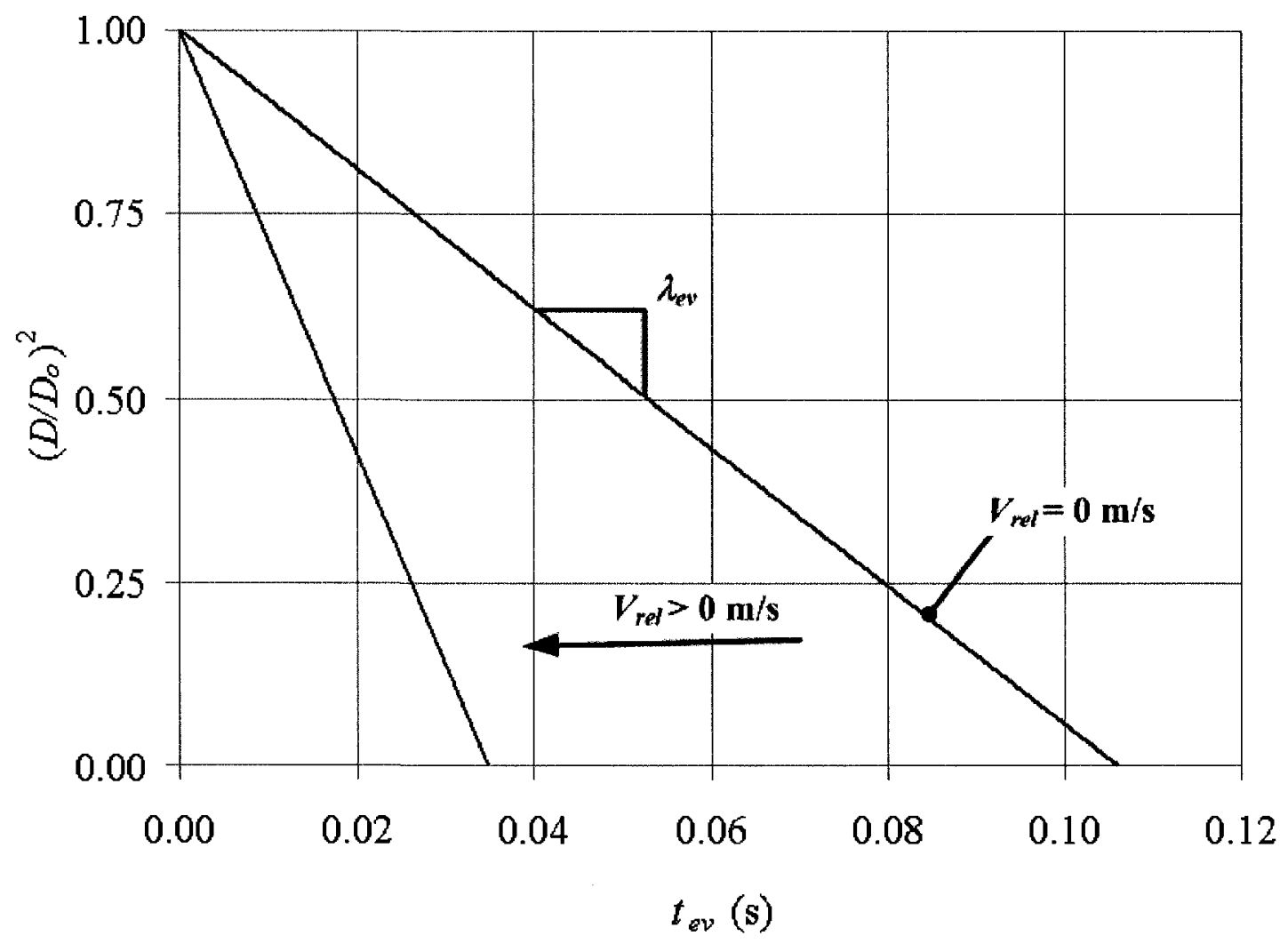

Figure 4.27 $\mathrm{D}^{2}$ law for droplet evaporation using simplified analysis

\subsubsection{Droplet Motion}

The work presented in this section models the mean particle trajectory inside a premixer. Particularly, the theory permits to estimate the premixer length required by 
relating mean particle trajectory to the evaporation process. The theory presented is based on Charest's (2005) work.

As can be seen in Figure 4.28, the motion of a droplet particle is three-dimensional.

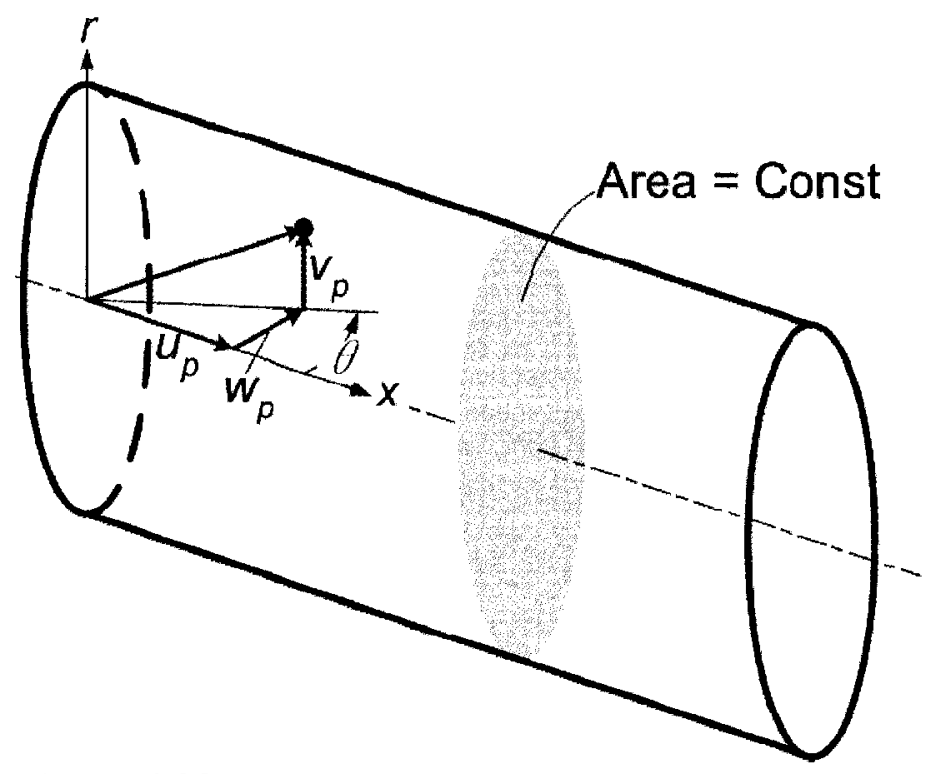

Figure 4.28 Droplet particle trajectory (Charest, 2005)

The motion or velocity of the droplet particle is described by Newton's second law. In cylindrical coordinates, the components of the particle velocity are given as (Hallett, 2003):

$\frac{d u_{p}}{d t}=-\frac{1}{\tau}\left(u_{p}-u_{b}\right)$

$\frac{d v_{p}}{d t}=-\frac{1}{\tau}\left(v_{p}-v_{b}\right)-\frac{w_{p}^{2}}{r}$

$\frac{d w_{p}}{d t}=-\frac{1}{\tau}\left(w_{p}-w_{b}\right)-\frac{v_{p} w_{p}}{r}$

where the subscripts $p$ and $b$ are for the particle and bulk fuel respectively.

The time constant for particle motion, $\tau$, is defined as (Hallett, 2003): 
$\tau=\frac{4}{3} \frac{D_{l}}{C_{d}} \frac{\rho_{l}}{\rho} \frac{1}{V_{r e l}}$

where $C_{d}$ is the particle drag coefficient and is calculated in Equation (4.121)

$\rho_{1}$ and $\rho$ are the densities of the fuel and mixture respectively

$V_{r e l}$ is the relative velocity of the fuel particle with respect to the fuel bulk velocity and is defined by Equation (4.122)

The particle drag coefficient is calculated as (Hallett, 2003):

$C_{d}=\frac{24}{R e}\left(1+0.15 R e^{0.687}\right) \frac{1}{1+B_{T}}$

where $B_{T}$ is the Spalding number

$R e$ is the droplet Reynolds number

The particle relative velocity with respect to the bulk velocity is expressed as,

$V_{r e l}=\sqrt{\left(u_{p}-u_{b}\right)^{2}+\left(v_{p}-v_{b}\right)^{2}+\left(w_{p}-w_{b}\right)^{2}}$

where $u, v, w$ are the components of the particle velocity in the $\mathrm{x}, \mathrm{y}$ and $\mathrm{z}$ directions respectively and the subscripts $p$ and $b$ are for the particle and bulk fuel respectively

The particle location in the premixer can, therefore, be obtained by evaluating Equation (4.120) and by integrating Equations (4.117), (4.118) and (4.119) with respect to time.

\subsubsection{Ignition Process and Ignition Model}

This section focuses on the minimum ignition energy needed to ignite a critical spherical volume in a reactant mixture. 
In the absence of a flame, the ignition process of a reactant mixture is carried out through the use of electrical sparks. Ignition occurs if the kernel energy of the spark is sufficient to increase the temperature of a critical mixture volume from its initial state to the flame temperature $\left(T_{a d}\right)$ (Lefebvre, 1999).

The minimum ignition energy is defined as the smallest amount of energy needed to heat the smallest volume of the reactant mixture to its adiabatic flame temperature. The smallest volume of reactant mixture is determined by the minimum quenching distance (Lefebvre, 1999) as explained below. The quenching distance of a quiescent or slow moving multidroplet mist is given by (Lefebvre, 1999):

$d_{q}=\left[\frac{\rho_{l} D_{l}^{2}}{\rho_{a} \phi_{P Z} \ln \left(1+B_{\text {stoich }}\right)}\right]^{0.5}$

where $\rho_{l}$ and $\rho_{a}$ are the liquid fuel and air density respectively

$D_{l}$ is the droplet diameter

$\phi_{P Z}$ is the primary zone equivalence ratio

$B_{\text {stoich }}$ is the stoichiometric fuel mass transfer number calculated as (Gauthier, 2005):

$B_{\text {stoich }}=\frac{c_{p a}\left(T_{\text {stoich }}-T_{w}\right)}{h_{f g}+c_{l}\left(T_{w}-T_{R}\right)}$

where $c_{p a}$ is the air specific heat, $\frac{\mathrm{kJ}}{\mathrm{kmol} \mathrm{K}}$

$c_{l}$ is the fuel specific heat, $\frac{\mathrm{kJ}}{\mathrm{kmolK}}$

$T_{\text {stoich }}$ is the free stream stoichiometric temperature (far from droplet), $\mathrm{K}$ 
$T_{w}$ is the temperature of the droplet surface (wall), $\mathrm{K}$

$T_{R}$ is the reservoir temperature (inside droplet), $\mathrm{K}$

$h_{f g}$ is the fuel heat of vaporization, $\frac{\mathrm{kJ}}{\mathrm{K}}$

The minimum energy needed to ignite the smallest spherical volume of a mixture is therefore calculated as (Lefebvre, 1999):

$E_{\min }=c_{p a} \rho_{a} \Delta T_{\text {stoich }}\left(\frac{\pi}{6}\right) d_{q}^{3}$

where $c_{p a}$ is the air specific heat, $\frac{\mathrm{kJ}}{\mathrm{kmolK}}$

$\rho_{a}$ is the air density, $\frac{\mathrm{kg}}{\mathrm{m}^{3}}$

$\Delta T_{\text {stoich }}$ is the rise from the reactant temperature to the flame temperature for a primary zone equivalence ratio of unity $\left(\phi_{P Z}=1\right), \mathrm{K}$

$d_{q}$ is the quenching distance, $\mathrm{m}$

By estimating the minimum energy needed for ignition, a suitable igniter can be selected for engine start-up, or, in the case of this research project, test combustor startup. The location of the igniter is determined by following guidelines given by Sawyer (1986) and Kretschmer (2000). The authors suggest that the igniter location should be based on the principles of the "magic circles", which have been presented in Section 4.7. Hence, the igniter should be inserted where the circle touches the liner wall, as shown in Figure 4.29, since high mixture concentrations of reactants are expected at this location. 


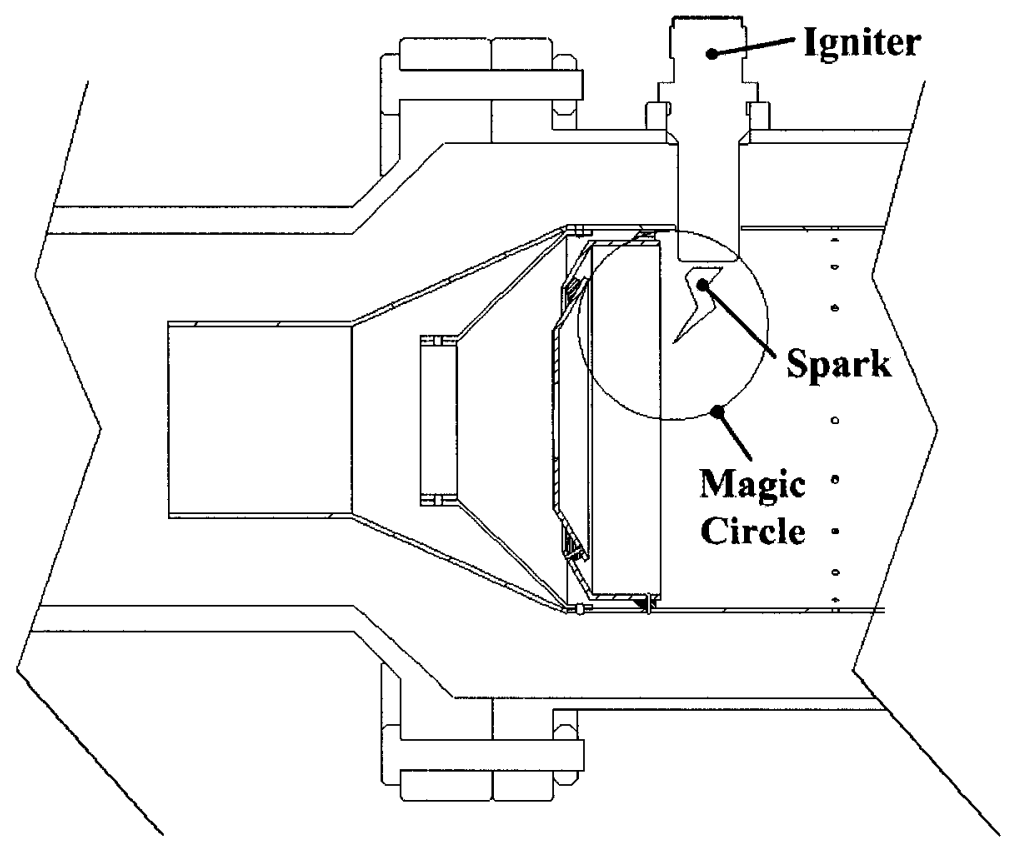

\section{Figure 4.29 Igniter location}

The following sub-sections will discuss autoignition and flashback, two phenomena that must be avoided to ensure safe combustor operation.

\subsubsection{Autoignition}

Autoignition is a process by which a reactant mixture ignites spontaneously. This phenomenon, if occurring within the premixer, can have catastrophic results and therefore, must be addressed.

Autoignition has been studied for many years. This fact is evident in a published work by Assanis et al. (2003) where the author lists a number of references on the topic and, more specifically, on the autoignition delay time $\left(\tau_{i d}\right)$ of diesel. The article focuses on experimental work whose correlations use the Arrhenius expression given below.

$\tau_{i d}=A P^{-n} e^{\left(\frac{E_{a}}{\bar{R} T}\right)}$

where $A$ and $n$ are empirical constants 
$P$ is the operating pressure, bar

$E_{a}$ is the activation energy, $\frac{\mathrm{J}}{\mathrm{mol}}$

$\bar{R}$ is the universal gas constant, $8.3144 \frac{\mathrm{J}}{\mathrm{mol} \mathrm{K}}$

$T$ is the operating temperature, $\mathrm{K}$

Table 4.4 lists empirical constants fitted to Equation (4.126) as well as the researchers who conducted the study (Assanis et al., 2003).

Table 4.4 Summary of empirical constants used in diesel autoignition correlations

\begin{tabular}{|c|c|c|c|c|c|}
\hline Correlation & $\begin{array}{c}\text { Test } \\
\text { Apparatus }\end{array}$ & Fuel & $A$ & $n$ & $\frac{E_{a}}{\bar{R}}$ \\
\hline Wolfer & C.V. bomb & Cetane No.> 50 & 0.44 & 1.19 & 4650 \\
\hline Kadota & single droplet & n-dodecane & 6.58 & 0.52 & 4400 \\
\hline Spadaccini & steady flow & diesel No. 2 & $4.00 \times 10^{-10}$ & 1 & 20080 \\
\hline Stringer & steady flow & $\begin{array}{c}\text { diesel } \\
\text { Cetane No. }=49\end{array}$ & 0.0409 & 0.757 & 5473 \\
\hline Hiroyasu & C.V. bomb & diesel & $0.01 \times \phi^{-1.04}$ & 2.5 & 6000 \\
\hline Fujimoto & $\begin{array}{c}\text { C.V. bomb p } \\
<40 \text { bar }\end{array}$ & $\begin{array}{c}\text { Heavy oil } \\
\text { Cetane No. 52.5 }\end{array}$ & 0.134 & 1.06 & 5130 \\
\hline Pischinger & steady flow & $\begin{array}{c}\text { diesel } \\
\text { Cetane No. 50 }\end{array}$ & 0.0081 & 1.14 & 7813 \\
\hline Watson & diesel engine & diesel & 3.45 & 1.02 & 2100 \\
\hline C.V. = Calorific Value & \multicolumn{5}{|l}{} \\
\hline
\end{tabular}

Using the appropriate operating pressure and temperature, the estimation of the premixer length before spontaneous ignition occurs can be assessed as:

$$
L_{i g}=V_{\text {premixer }} \tau_{i d}
$$


Therefore, the premixer length must be shorter than the autoignition length, $L_{i g}$.

\subsubsection{Flashback}

Flashback occurs when the flow velocity of the reactant mixture falls below the flame speed, which causes the flame to propagate upstream. This phenomenon, if not addressed, can result in significant damage to the fuel nozzles and combustor liner. Flashback within the premixer should not be a problem as long as the reactant mixture velocity is higher than $20 \frac{\mathrm{m}}{\mathrm{s}}$ (Poeschl et al., 1994).

\subsection{Pollutant Emissions Prediction}

As previously mentioned, pollutants emissions cannot be ignored when designing a combustor. Therefore, the design methodology should include correlations that predict the emissions of pollutants such as $\mathrm{NO}_{\mathrm{x}}$ and $\mathrm{CO}$.

Review of published work (e.g., Lefebvre, 1999; Derr and Mellor, 1990; Mongia, 2003; and Allaire, 2006) revealed a number of empirical and semi-empirical correlations for estimating pollutant emissions from gas turbine engines. In particular, Tsague et al. (2007) give very simple empirical correlations that relate $\mathrm{NO}_{\mathrm{x}}$ formation to gas turbine operating conditions such as, for example; fuel flow rate versus $\mathrm{EI}_{\mathrm{NOx}}$ (where $\mathrm{EI}$ is the pollutant emission index), output power versus $\mathrm{EI}_{\mathrm{NOx}}$, compression ratio versus $\mathrm{EI}_{\mathrm{NOx}}$, to name a few.

The correlations presented below, however, were selected because they are directly related to the combustion process and, in particular, factors comprising the expressions have been already calculated by the design methodology or can be easily estimated. 
Furthermore, the correlations simplicity keeps the complexity of the design methodology to a minimum, while giving insightful information on emissions of pollutants.

The correlations presented below come from work published by Lefebvre (1999). $\mathrm{NO}_{\mathrm{x}}$ and $\mathrm{CO}$ emissions can be estimated with Equations (4.128) and (4.129) respectively.

$$
\mathrm{NO}_{\mathrm{x}}=9 \times 10^{-8} P_{3}^{1.25} \operatorname{Vol}_{\text {Comb }} e^{\frac{0.01 T_{\text {stoich }}}{\dot{m}_{a} T_{P Z}}}(\mathrm{~g} / \mathrm{kg} \text { fuel })
$$

$$
\mathrm{CO}=86 \dot{m}_{a} T_{P Z} e^{-\left[\frac{0.00345 T_{P Z}}{\left(V o l_{C o m b}-V o l_{e v}\right)\left(\frac{\Delta P_{3-4}}{P_{3}}\right)^{0.5} P_{3}^{1.5}}\right]}(\mathrm{g} / \mathrm{kg} \text { fuel })
$$

where $P_{3}$ is the combustor inlet pressure, $\mathrm{kPa}$

$T_{\text {stoich }}$ is the stoichiometric flame temperature (i.e., $\phi_{P Z}=1$ ), $\mathrm{K}$

$T_{P Z}$ is the primary zone temperature, Equation (4.130), $\mathrm{K}$

$\dot{m}_{a}$ is the combustor mass flow rate, $\frac{\mathrm{kg}}{\mathrm{s}}$

$V o l_{\text {Comb }}$ is the combustion volume $=\operatorname{Vol}_{P Z}, \mathrm{~m}^{3}$

$\mathrm{Vol}_{e v}$ is the volume occupied in evaporation, Equation (4.132), $\mathrm{m}^{3}$

The primary zone temperature can be estimated using guidelines given by Sawyer (1985) and Kretschmer (2000) as follows,

$$
T_{P Z}=T_{3}\left[\eta_{P Z}\left(T_{a d}-T_{3}\right)\right]
$$

where $\eta_{P Z}$ is the primary zone efficiency and is calculated as:

$$
\eta_{P Z}=0.71+0.29 \tanh \left\{1.5475 \times 10^{-3}\left[T_{3}+108 \ln \left(P_{3}-1863\right)\right]\right\}
$$


where $P_{3}$ is the combustor inlet pressure, $\mathrm{Pa}$

$T_{3}$ is the combustor inlet temperature, $\mathrm{K}$

From Lefebvre (1999), the volume occupied in evaporation is calculated as,

$V_{e v}=0.55 \dot{m}_{P Z} \frac{D_{0}^{2}}{\rho_{P Z} \lambda_{e v}}$

where $\dot{m}_{P Z}$ is the mass flow rate in the primary zone, $\frac{\mathrm{kg}}{\mathrm{s}}$

$D_{0}$ is the SMD droplet diameter, $\mathrm{m}$

$\rho_{P Z}$ is the density in the primary zone, $\frac{\mathrm{kg}}{\mathrm{m}^{3}}$

$\lambda_{e v}$ is the evaporation constant calculated by Equation (4.114)

The estimation of pollutant formation during the combustion process concludes the design methodology analysis. However, prior to introducing the combustor design, a brief overview on combustor structural considerations, which need to be addressed to ensure mechanical integrity during combustor operation, will be given in the next section.

\subsection{Combustor Structural Considerations}

This section focuses on the combustor structural design. In particular, the following section elaborates on the theory that was consulted to determine the thickness of the material used for the combustor liner and casing.

Since the diameter to wall thickness ratios for the combustor casing and liner were estimated to be higher than 20 , mechanics of materials theory for thin cylinders could be used to estimate the strain and stresses seen by the casing and liner during operation (Matthews, 2005) (Figure 4.30). 


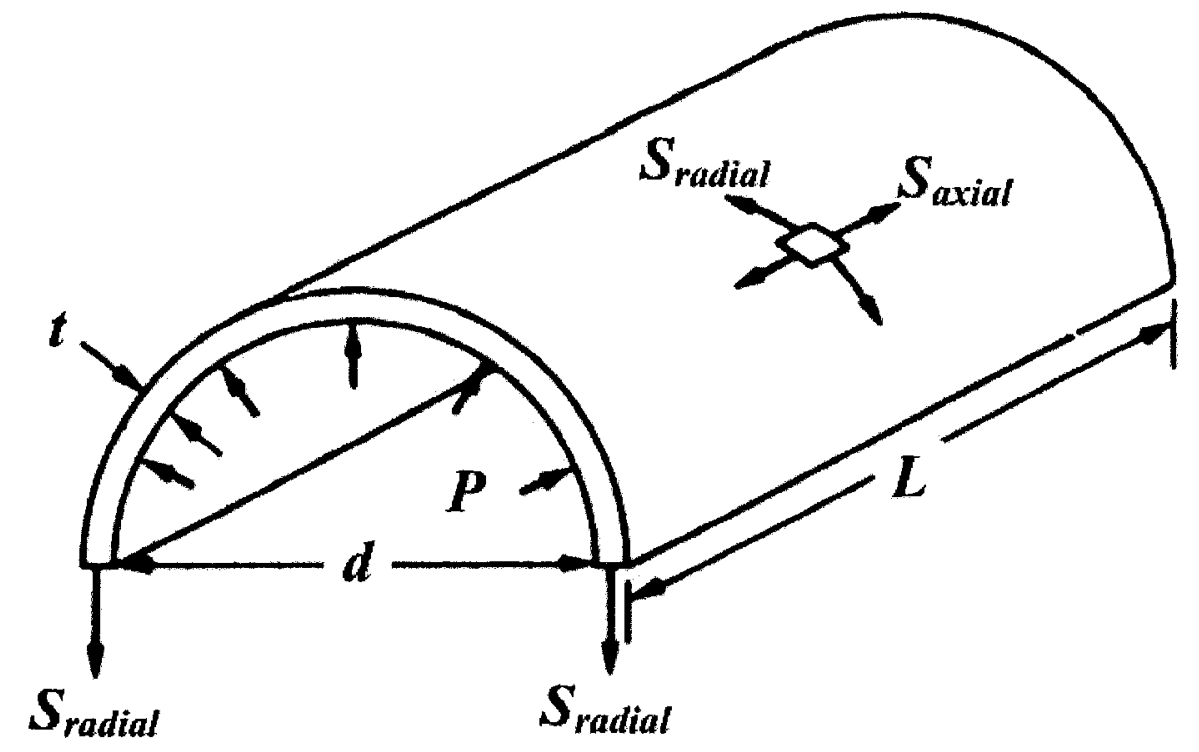

Figure 4.30 Force diagram of thin walled pressure vessel (Adapted from Matthews, 2005)

The fundamental stress and strain equations, which are the basis for all pressure vessel codes and standards, are as follows; 1) the circumferential hoop stress, Equation $(4.133), 2)$ the hoop strain, Equation $(4.134), 3)$ the longitudinal (axial) stress, Equation (4.135) and 4) longitudinal strain, Equation (4.136) (Matthews, 2005).

$$
\begin{aligned}
& S_{\text {radial }}=\frac{\Delta P d}{2 t} \\
& \varepsilon_{\text {radial }}=\frac{1}{E}\left(S_{\text {radial }}-v S_{\text {axial }}\right)+\varepsilon_{T} \\
& S_{\text {axial }}=\frac{\Delta P d}{4 t} \\
& \varepsilon_{\text {axial }}=\frac{1}{E}\left(S_{\text {axial }}-v S_{\text {radial }}\right)+\varepsilon_{T}
\end{aligned}
$$

where $\Delta P$ is the pressure difference between cylinder's internal and external pressure $d$ is the cylinder diameter 
$t$ is the cylinder wall thickness

$E$ is the dynamic Young's modulus of the material used

$v$ is the Poisson's ratio for the material used

$\varepsilon_{T}$ is the thermal strain and is calculated as,

$$
\varepsilon_{T}=\alpha(T)\left(T-T_{0}\right)
$$

where $\alpha(T)$ is the coefficient of thermal expansion, as a function of temperature, for the material used $T_{0}$ and $T$ are the initial and operating temperatures of the material respectively Another important factor to consider in the structural design of a combustor is the thermal expansion due to high combustion temperatures. The axial $\left(\delta_{\text {axial }}\right)$ and radial $\delta_{\text {radial }}$ thermal expansions can be calculated as,

$$
\delta_{\text {axial }}=\varepsilon_{T} L
$$

$$
\delta_{\text {radial }}=\varepsilon_{T} d
$$

where $L$ is the cylinder length

$\mathrm{d}$ is the cylinder diameter

$\varepsilon_{T}$ is the thermal strain

Once the equations are defined, both the casing and liner must be designed to sustain maximum operating conditions. More specifically, they must withstand plastic deformation (yielding) at these conditions.

At high temperatures many materials become very ductile. Therefore, the von Mises yield criterion is used to estimate material failure. The criterion states that material failure 
(yield) occurs as a function of the difference between principal stresses $\left(S_{1}, S_{2}\right.$ and $\left.S_{3}\right)$ as shown by Figure 4.31 and expressed in Equation (4.140) (Matthews, 2005).

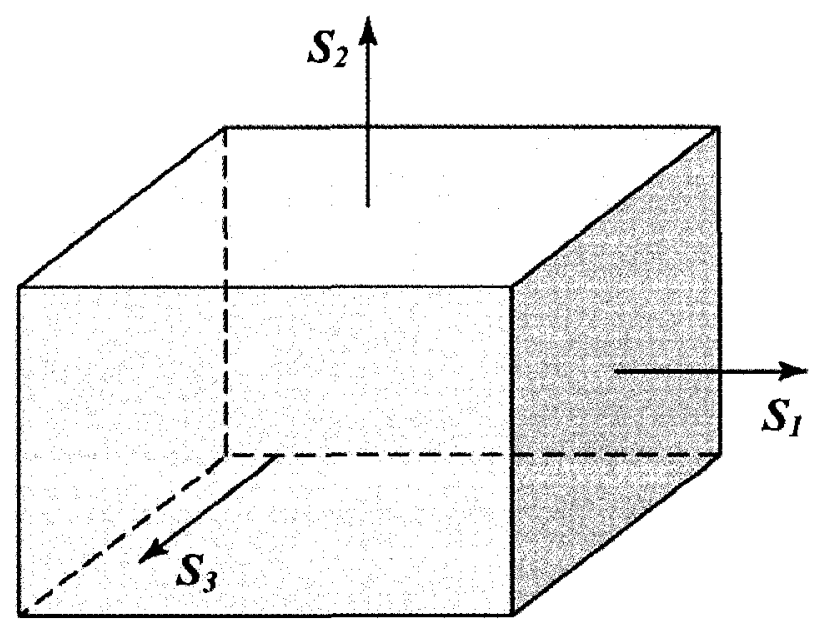

Figure 4.31 Material principle stresses (Adapted from Matthews, 2005)

$\frac{1}{\sqrt{2}} \sqrt{\left(S_{1}-S_{2}\right)^{2}+\left(S_{2}-S_{3}\right)^{2}+\left(S_{3}-S_{1}\right)^{2}} \leq \sigma_{\text {yield }}$

Noting that the thin cylindrical case is a two-dimensional case (i.e., $S_{3}=0$ ) with $S_{1}=S_{\text {axial }}$ and $S_{2}=S_{\text {radial }}$, the above equation becomes,

$\sqrt{S_{\text {axial }}^{2}+S_{\text {radial }}^{2}-S_{\text {axial }} S_{\text {radial }}} \leq \sigma_{\text {yield }}$

For the liner, Equations (4.133) to (4.141) are solved with $\Delta P \approx \Delta P_{L} \approx 0.03 P_{3}$. For the casing, the same equations are solved using $\Delta P \approx P_{3}-P_{a m b}$. The material properties used in solving Equations (4.133) to (4.141) have to reflect those of the materials selected for the liner and casing respectively. 


\section{COMBUSTOR PRELIMINARY DESIGN GEOMETRY}

The following chapter presents the combustor liner, casing and premixer designs and discusses the selection of a suitable fuel nozzle and igniter.

A preliminary design of the combustor was done by senior mechanical and aerospace engineering students at Carleton University using an earlier version of the methodology described in Chapter 4. Since the manufacturing had already been initiated by the undergraduate students (combustor casing), completion of the construction of the combustor for future testing was undertaken. Given that the algorithm presented in Chapter 4 has evolved significantly from the undergraduate version, its performance will be assessed indirectly by changing its structure, but not its content, to analyse the existing combustor. Therefore, when experimental results become available, possibly supplemented by CFD simulations, assessing the accuracy of the preliminary design methodology will be feasible.

The premixer, fuel nozzle and igniter were sized taking into consideration combustion laboratory requirements. More specifically, they were designed (premixer) and selected (fuel nozzle and igniter) for liquid fuel applications since the gas turbine combustion laboratory at Environment Canada is presently not equipped to burn gaseous fuels.

\subsection{Preliminary Geometry of Lean Premixed Combustor}

The combustor liner and casing geometries were sized to meet the microturbine engine specifications as shown in Table 5.1 and Figure 5.1. Specifically, the combustor was designed to burn natural gas and oxygen in a carbon dioxide environment. Other requirements for the combustor were: 
- to provide a turbine inlet temperature (TIT) of $1200 \mathrm{~K}$;

- to maintain a pressure loss of, at most $3 \%$, across the combustor;

- to ensure $99 \%$ combustion efficiency;

- to ensure that the liner wall temperature remains below $1300 \mathrm{~K}$; and

- to operate at a working pressure of 21 bar.

With the above engine specifications in mind, the combustor geometry evolved from a series of design parameter selections. Some of these design choices are presented below.

Table 5.1 Microturbine specifications

\begin{tabular}{|c|c|c|c|}
\hline & $\begin{array}{c}\text { Pressure } \\
\text { (bar) }\end{array}$ & $\begin{array}{c}\text { Temperature } \\
\text { (K) }\end{array}$ & $\begin{array}{c}\text { Mass Flow } \\
(\mathrm{kg} / \mathrm{s})\end{array}$ \\
\hline Compressor Inlet & 3.00 & 298 & 0.444 \\
\hline Compressor Outlet & 21.00 & 482.15 & 0.444 \\
\hline $\begin{array}{c}\text { Recuperator Inlet } \\
\text { (Cold Side) }\end{array}$ & 20.995 & 482.15 & 0.444 \\
\hline $\begin{array}{c}\text { Recuperator Outlet } \\
\text { (Cold Side) }\end{array}$ & 20.58 & 893.05 & 0.444 \\
\hline Combustor Inlet & 20.58 & 893.05 & 0.444 \\
\hline Combustor Outlet & 19.96 & 1200 & 0.463 \\
\hline Turbine Inlet & 19.50 & 1200 & 0.463 \\
\hline Turbine Outlet & 3.15 & 949.08 & 0.463 \\
\hline Fuel Inlet & 22.53 & 654 & 0.0038 \\
\hline Oxygen Inlet & 22.53 & 298 & 0.015 \\
\hline Thermal Efficiency & $25.7 \%$ & & \\
\hline
\end{tabular}




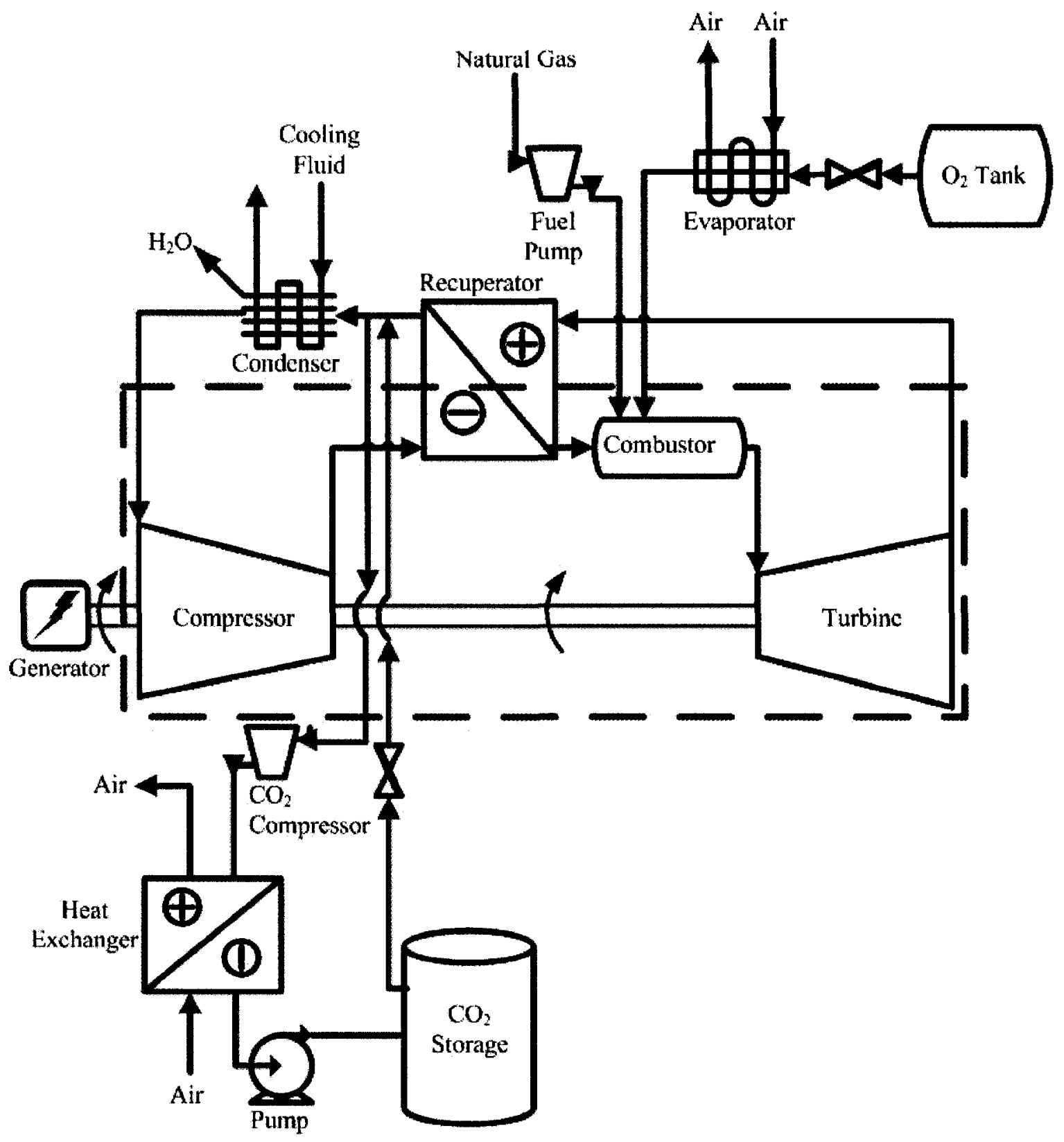

Figure 5.1 Microturbine schematic

\subsubsection{Design Considerations}

The developed combustor design was shaped by the engine specifications and by the use of correlations and guidelines outlined in Chapter 4. The following (Table 5.2) are some of the critical parameters that created the final combustor geometry. 
Table 5.2 Design parameters

\begin{tabular}{|l|c|c|}
\hline \multicolumn{1}{|c|}{ Description } & Symbol and Value & Equation \\
\hline Combustor Efficiency & $\eta_{C}=0.99$ & Specifications \\
\hline Turbine Inlet Temperature & $T I T=1200 \mathrm{~K}$ & Specifications \\
\hline Global Fuel Ratio & $\phi_{\text {global }}=0.126$ & $(4.4)$ \\
\hline Primary Zone Equivalence Ratio & $\phi_{P Z}=0.79$ & $(4.5)$ \\
\hline Pressure Drop Ratio & $P D R=0.03 P_{3}$ & $(4.19)$ \\
\hline Pressure Loss Factor & $P L F=37$ & $(4.19)$ \\
\hline Geometric Factor & $G F=3.0 \times 10^{-3}$ & $(4.22)$ \\
\hline Liner Area Factor & $k_{o p t}=0.7$ & $(4.25)$ \\
\hline Patter Factor & $Q^{-1}=0.2$ & $(4.31)$ \\
\hline Dome Wall Angle & $\theta_{D}=60^{0}$ & $(4.38)$ \\
\hline Diffuser Pressure Loss & $\Delta P_{\text {diff }}=0.01 P_{3}$ & $(4.48)$ \\
\hline
\end{tabular}

\subsubsection{Overview of Combustor Dimensions}

Important casing and liner dimensions are summarized in Figure 5.2 and Table 5.3. An example of the many combustor technical drawings, provided to companies for quotations and manufacturing purposes, can be found in Appendix A. Figure 5.3 shows the mass flow distribution of the combustor.
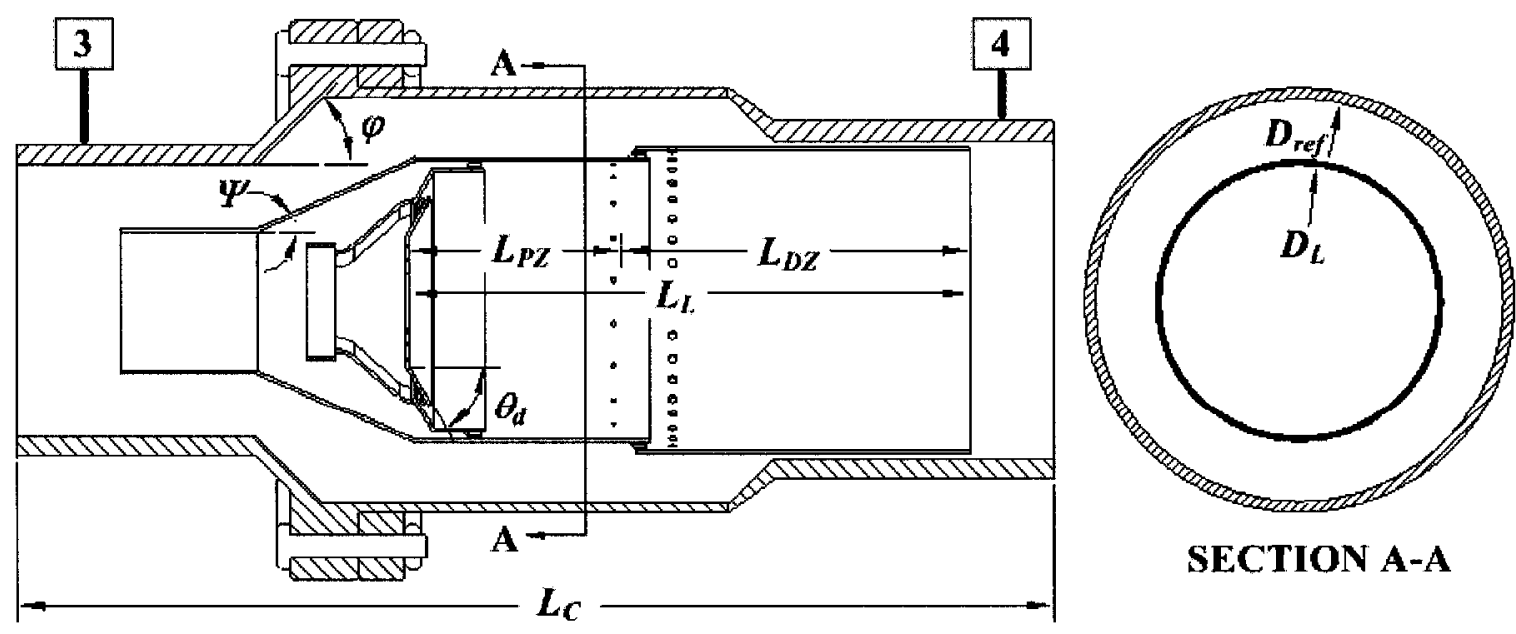

SECTION A-A

Figure 5.2 Combustor key dimensions 
Table 5.3 Critical combustor dimensions

\begin{tabular}{|c|c|c|}
\hline Description & Symbol & Dimension mm (in) \\
\hline Combustor Length & $L_{C o m b}$ & $290(11.4)$ \\
\hline Liner Length & $L_{L}$ & $157(6.18)$ \\
\hline Primary Zone Length & $L_{P Z}$ & $59.7(2.35)$ \\
\hline Dilution Zone Length & $L_{D Z}$ & $97.5(3.84)$ \\
\hline Maximum Casing Diameter & $D_{r e f}$ & $115(4.53)$ \\
\hline Liner Diameter & $D_{L}$ & $78.9(3.15)$ \\
\hline Dome Wall Angle & $\theta_{\mathrm{D}}$ & $60^{\circ}$ \\
\hline Liner Diffuser Wall Angle & $\psi$ & $24^{\circ}$ \\
\hline Casing Diffuser Wall Angle & $\varphi$ & $45^{\circ}$ \\
\hline
\end{tabular}

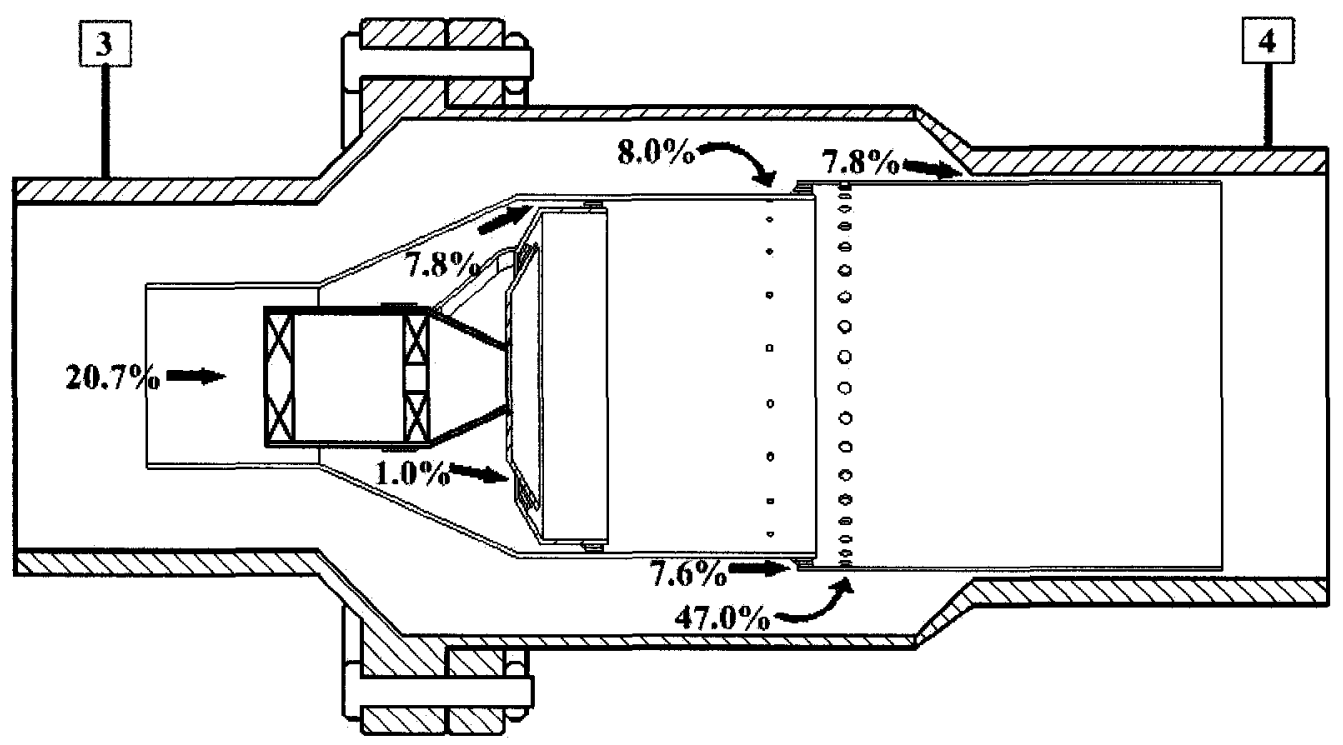

Figure 5.3 Liner mass flow distribution

The location of the cooling rings and the amount of the cooling flows were estimated by employing the design methodology reported in Section 4.10 using a maximum liner wall temperature $\left(T_{w 1}\right)$ of $1200 \mathrm{~K}$ (upper limit of usefulness for Hastelloy X; Davis, 2000). As the wall temperature approached the maximum material temperature, a cooling ring was inserted to bring the material temperature down to acceptable levels. The material properties used in the calculations presented in Section 4.10 were those of Hastelloy X (Appendix B). The calculations also used a material wall thickness of $1 \mathrm{~mm}$. 
The premixer was sized to allow the same mass flow rate (20.7\%) as the original liner design to flow through. However, the premixer design had to take into consideration that liquid fuel is used in the research laboratory contrary to the microturbine which has been developed to burn natural gas. Therefore, a longer premixer length, when compared to the original design (Figure 5.3), was designed to permit some of the evaporation and mixing processes to occur within the premixer. The premixer length was resized using theory described in Section 4.12. Particular attention was given to the autoignition delay time to ensure that it was longer than the evaporation time for diesel fuel, thus avoiding spontaneous ignition within the premixer. Furthermore, to prevent possible flashback problems, a conical section was introduced at the premixer outlet. This ensured that the reactant mixture velocities were higher than $20 \mathrm{~m} / \mathrm{s}$ as was suggested in Section 4.12.4.2. Figure 5.4 shows some of the principal details of the premixer.

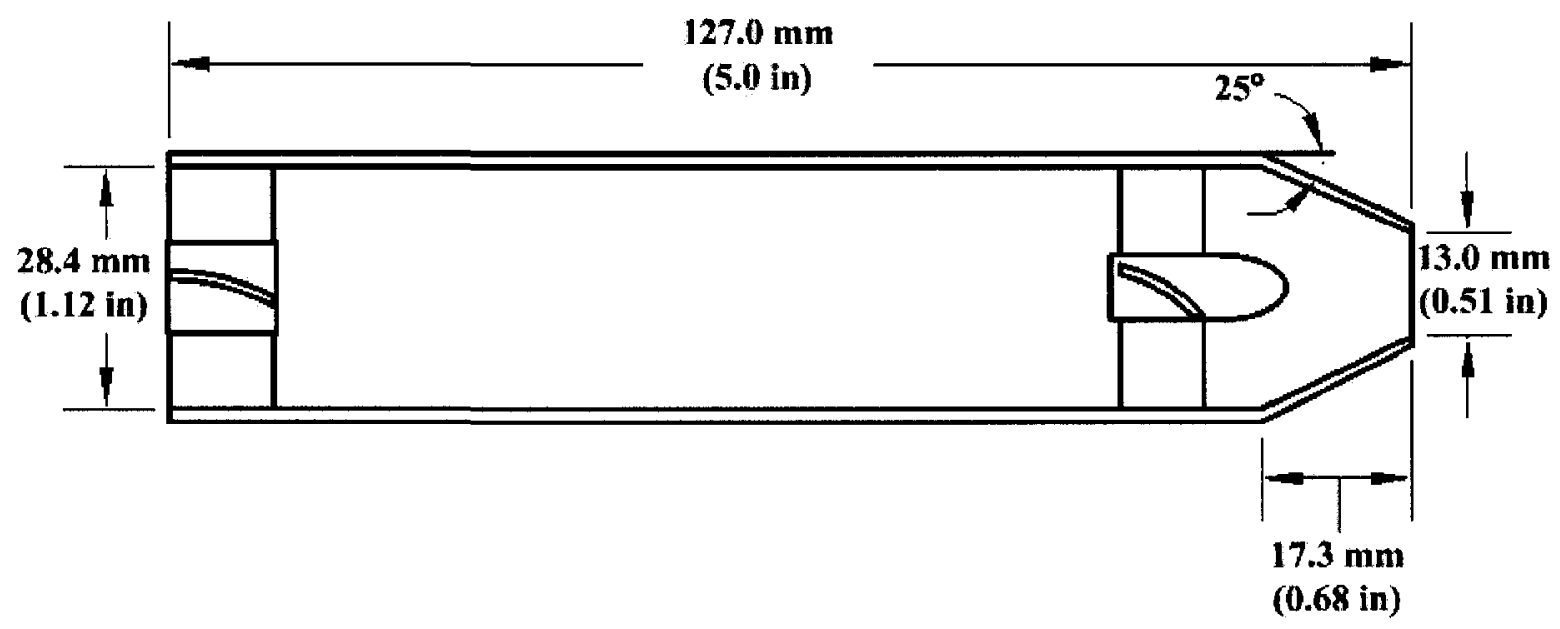

Figure 5.4 Premixer dimensions

As can be seen in Figure 5.5, the premixer is composed of a mixer tube and two swirlers, namely the mixer swirler and the combustor swirler with dimensions presented below. 

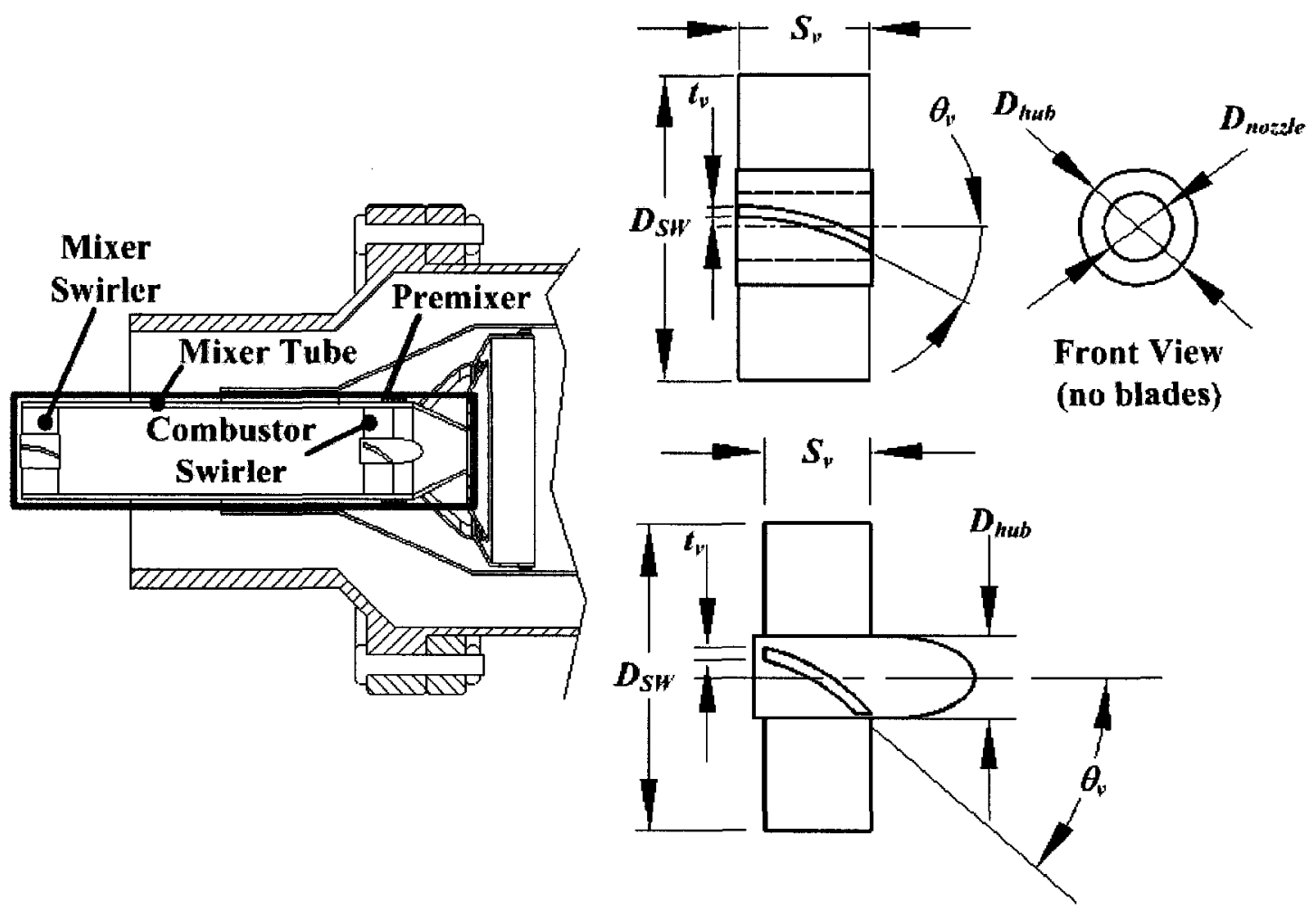

Figure 5.5 Diesel fuel premixer

The sizing of the swirlers followed the methodology reported in Section 4.6. Table 5.4 as well as Figure 5.6 and Figure 5.7 show the results of the calculations.

Table 5.4 Dimensions of swirlers

\begin{tabular}{|c|c|c|c|}
\hline & & Mixer & Combustor \\
\hline Description & Symbol & $\begin{array}{l}\text { Dimensions } \\
\text { mm (in) }\end{array}$ & $\begin{array}{c}\text { Dimension } \\
\text { mm (in) }\end{array}$ \\
\hline Swirler Diameter & $D_{S W}$ & $28.5(1.12)$ & $28.5(1.12)$ \\
\hline Hub Diameter & $D_{h u b}$ & $10.7(0.42)$ & $7.6(0.30)$ \\
\hline Vane Angle & $\theta_{v}$ & $30^{\circ}$ & $44^{\circ}$ \\
\hline Vane Length & $L_{v}$ & $12.5(0.49)$ & $10.7(0.42)$ \\
\hline Vane Thickness & $t_{v}$ & $1.0(0.04)$ & $1.0(0.04)$ \\
\hline Vane Spacing & $S_{v}$ & $5.0(0.20)$ & $7.0(0.28)$ \\
\hline Solidity & & 2.5 & 1.5 \\
\hline Swirl Number & $S_{N}$ & 0.4 & 0.72 \\
\hline Swirler Pressure Drop & $\Delta P_{S W} \%$ & 0.42 & 0.52 \\
\hline
\end{tabular}




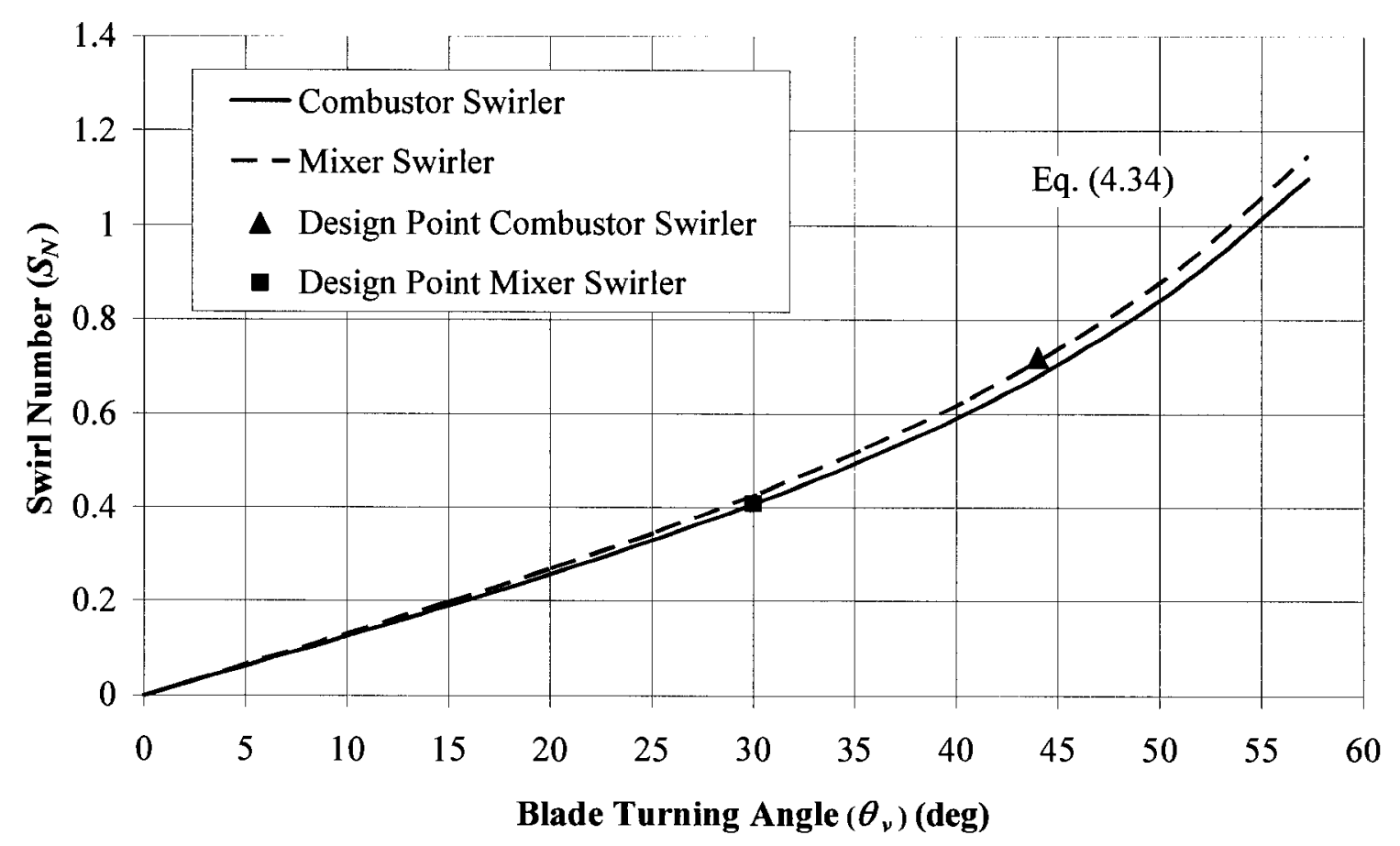

Figure 5.6 Effect of blade turning angle on swirl number

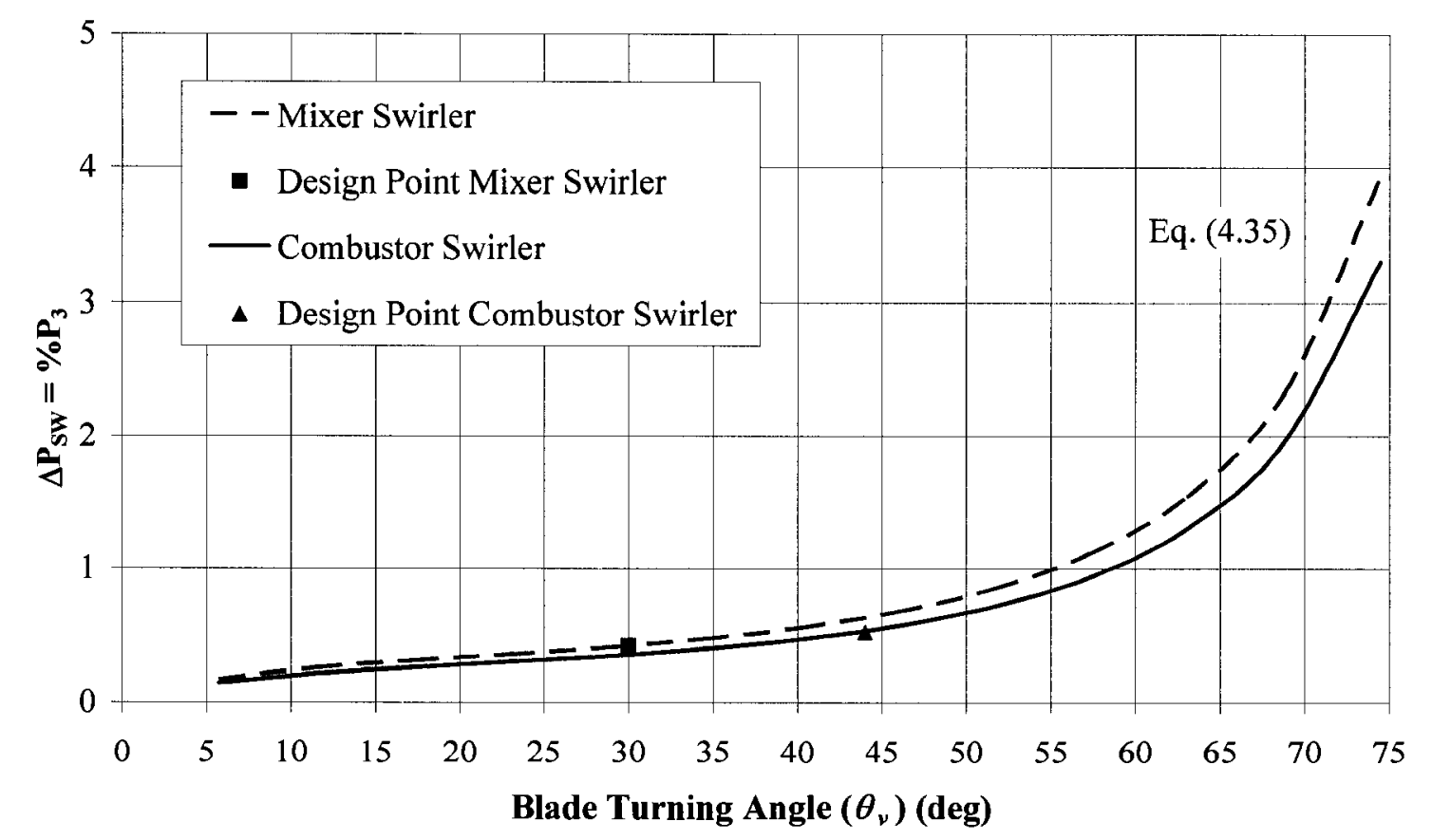

Figure 5.7 Effect of blade turning angle on pressure loss across swirler 
Figure 5.6 shows that the swirl number for the mixer swirler was selected to be 0.4 . This value corresponded to weak swirl conditions which permitted good mixing of the reactants while avoiding the formation of a recirculation zone within the mixer tube. For the combustor swirler, on the other hand, to create a recirculation zone within the primary zone, a swirl numbers of 0.72 was selected. The pressure losses across the mixer and combustor swirlers were estimated to be $0.42 \%$ and $0.52 \%$ of the combustor inlet pressure respectively (Figure 5.7).

\subsubsection{Selection of Fuel Nozzle}

The fuel nozzle selection was constrained by many factors. The nozzle had to be small enough to fit within the mixer swirler $\left(D_{\text {nozzle }}=6.4 \mathrm{~mm}(0.25 \mathrm{in})\right.$; Figure 5.5). It also had to be inexpensive and had to produce SMD droplets between 50 and 100 microns.

An impingement nozzle (model PJ), produced by $\mathrm{BETE}^{6}$, was found to be suitable for the lean premixed prevaporized combustor configuration to be tested. The impingement nozzle, as shown in Figure 5.8, has a spray angle of $90^{\circ}$ and produces the finest fog of any direct pressure nozzle sold by the company, with a high percentage of SMD droplets under 50 microns (Appendix $\mathrm{C}$ for droplet diameter distribution and nozzle information). Furthermore, the nozzle can operate at pressures as high as 70 bar and flow rates between 0.043 to $5.34 \frac{\mathrm{L}}{\min }$ (BETE, 2007).

\footnotetext{
${ }^{6}$ BETE Fog Nozzle, Inc. 50 Greenfield Street, Greenfield, MA 01301U.S.A
} 


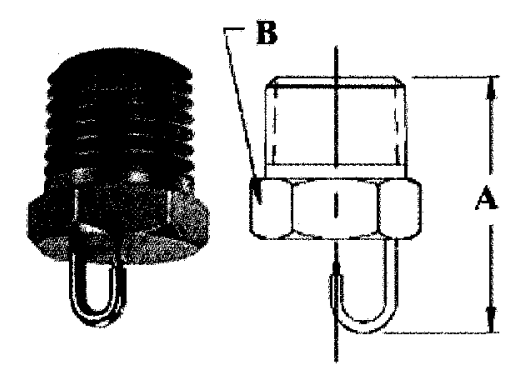

Figure 5.8 BETE impingement nozzle (model PJ) (Adapted from BETE, 2007)

The principal nozzle dimensions A and B, as shown in Figure 5.8, are $24.6 \mathrm{~mm}(0.97$ in) and $14.2 \mathrm{~mm}(0.56 \mathrm{in})$ respectively. As can be seen, dimension B is more than double the diameter of the mixer swirler bore $\left(D_{\text {nozzle }}=6.4 \mathrm{~mm}(0.25\right.$ in); Figure 5.5). Therefore, before being able to utilize the nozzle, modifications had to be made to its geometry as presented in Section 6.10 .

The nozzle selection (i.e., nozzle model number) took into consideration the properties of the fuel used (diesel) as well as the operating pressures and temperatures of the fuel and air delivery systems. The fuel nozzle was also sized to deliver fuel flow rates that would achieve, in the combustor primary zone, equivalence ratios covering a lean to rich spectrum. These nozzle models, namely the PJ10, PJ12 and PJ15, were purchased from BETE so that various ranges of fuel flows could be achieved. Three nozzles of each model were acquired in case of possible machining problems during the modification process.

\subsubsection{Selection of Ignition System}

The ignition system is a high energy, capacitor type ignition system that produces a high voltage and an exceptionally hot spark which covers a large area. The exciter box is powered by a 28 VDC power supply. The energy supplied is stored into a capacitor located within the exciter box. During test start-up, the exciter box is triggered (push 
button type switch) and current begins to flow through the lead to the spark igniter. This current is then discharged by the igniter as a high voltage and high temperature. This spark is created by an arc which forms between the centre electrode and the grounded electrode (igniter body) as seen in Figure 5.9.

The ignition system used in the laboratory had been previously acquired by Murphy (2004). The exciter box, lead and spark igniter purchased are those used by the Allison 250-C20B ignition system. The exciter box, lead and spark igniter part numbers are 6870885,6870097 and 6877518 respectively.

Since the ignition system in Murphy's work successfully ignited diesel fuel, it was also used in this research project, so that laboratory construction costs could be minimized. Furthermore, since Murphy's test conditions (i.e., pressure and temperature) were similar to those of this research project, the ignition system was deemed suitable.

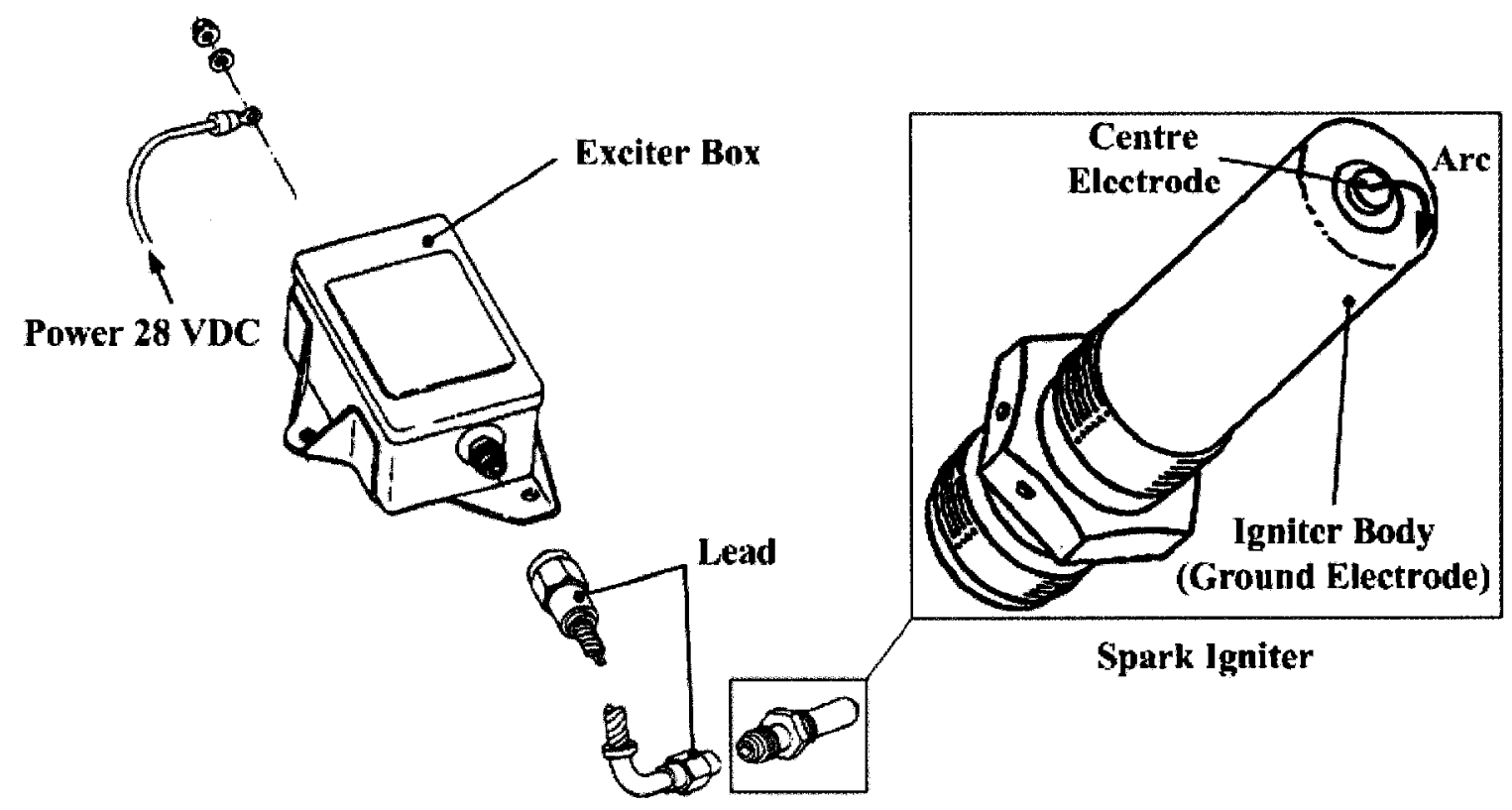

Figure 5.9 Ignition system and spark igniter (Adapted from Allison Engine Company, 1999) 


\section{PREMIXED COMBUSTOR MANUFACTURING PROCESS}

The following chapter focuses on the combustor manufacturing process. It first gives an overview of nickel based superalloy materials found in gas turbine hot section components (i.e., combustor, nozzle guide vanes and turbine). Following this, the chapter focuses on specific superalloys used in gas turbine combustors and then lists the superalloys chosen for the developed combustor liner. With the material selection undertaken, the chapter then gives an overview of the manufacturing processes of the chosen superalloys after which the casing material and the casing manufacturing process are discussed. Finally, the chapter elaborates on the manufacturing of the premixer and concludes by showing the fuel nozzle modification.

\subsection{Material Overview for Engine Hot Section Components}

Nickel based superalloys are the materials used for gas turbine hot section components, such as the combustor, the nozzle guide vanes and the turbine. These components use nickel based superalloys because they have to withstand high combustion temperatures, high temperature corrosion as well as mechanical and thermal stresses.

As mentioned in Section 3.1, the material operating temperature is the limiting factor for the efficiency of a gas turbine engine. Having a high TIT allows for a decrease in specific fuel consumption. However, a high engine TIT has a direct effect on the life of the combustor liner, the nozzle guide vanes and the turbine blades. As a general guideline, at high temperature conditions encountered inside gas turbine hot sections, a $50^{\circ} \mathrm{C}$ increase in temperature reduces components lives by $50 \%$ (Gauthier, 2005). 
Gas turbine blades are the most affected by high TITs since the blade material has to sustain high combustion temperatures, high temperature corrosion, and extreme conditions of stress, due to blades rotation. In particular, Figure 6.1 shows how the increase in combustor firing temperature has caused the blade materials, manufacturing processes and cooling techniques to evolve. As can be seen from the figure, the properties of blade materials have been enhanced by the use of new nickel based superalloys 500, RENE 77, IN 733 and GTD 111). Changing the manufacturing processes from conventional investment casting to single crystal casting and advancements in cooling techniques also have allowed to sustain the constant increase in combustor firing temperatures.

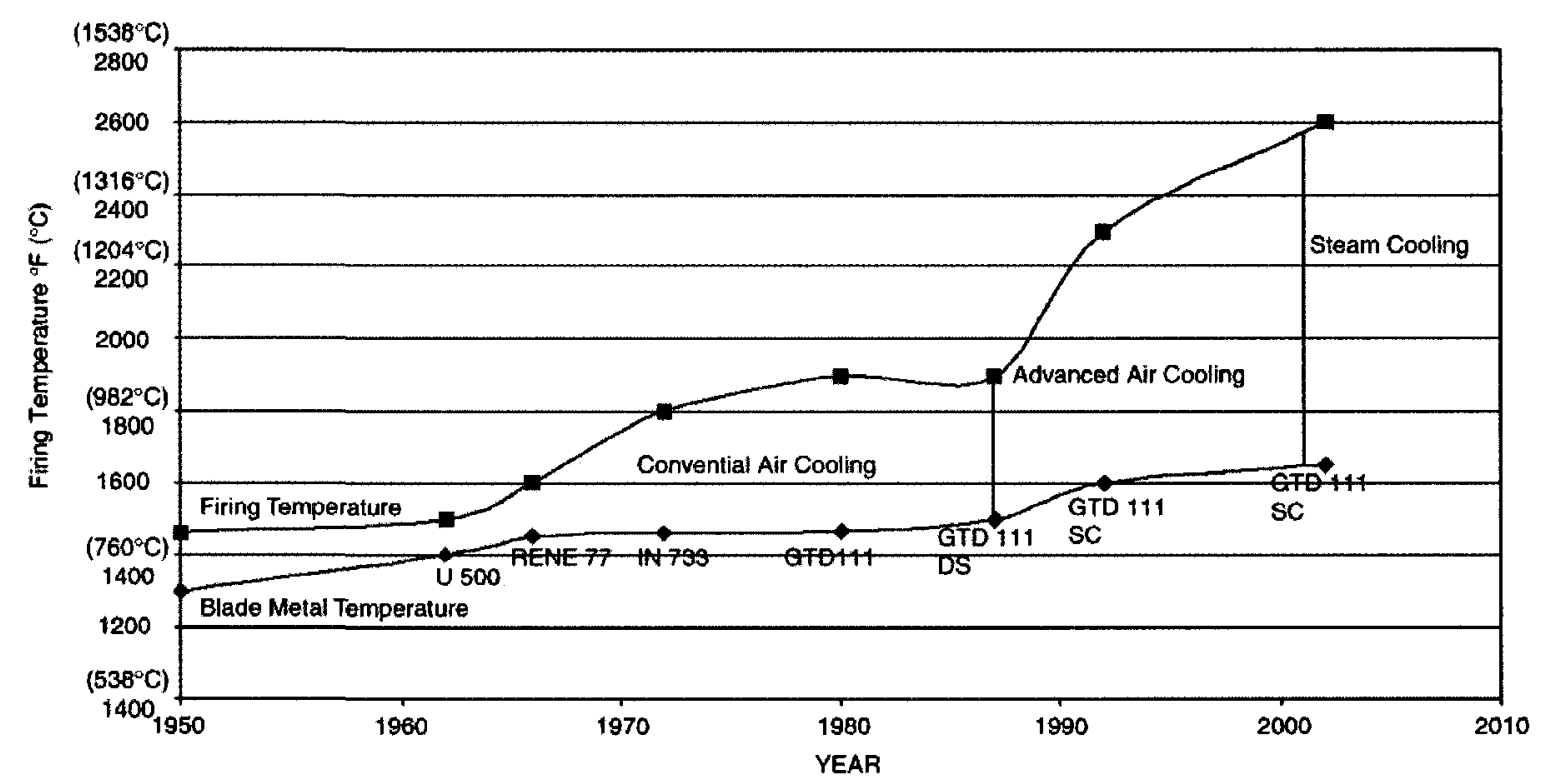

Figure 6.1 Evolution of turbine blades with firing temperature (Boyce, 2006)

High firing temperatures also affect the performance of combustor materials, but in a different way than that of turbine blades. When compared to turbine blades, a combustor operates in low mechanical stress conditions since it is a stationary component. Nevertheless, its life is affected by high temperature gradients during engine start-up and shut-down, by buckling problems if thermal expansion is not taken into consideration 
during the design phase, and by potential melting problems if the liner cooling is not addressed properly.

The life of the combustor is also affected by the type of application and fuel used. Table 6.1 shows the effect of these on the life of industrial gas turbine combustor liners. As can be seen from the table, one engine start-up sequence every 1000 operating hours can consume the equivalent of 30,000 hours of combustor service before maintenance is performed (Boyce, 2006). The long life of the combustor liner is greatly dependent on the selection of suitable nickel based superalloys and the implementation of effective cooling techniques.

Table 6.1 Operation and maintenance life for typical industrial combustor liner (Adapted from Boyce, 2006)

\begin{tabular}{|c|c|c|c|}
\hline $\begin{array}{c}\text { Type of Application and } \\
\text { Fuel }\end{array}$ & Starts/hr & $\begin{array}{c}\text { Firing Temperature } \\
\text { below } 1200 \mathrm{~K}\left(927^{\circ} \mathrm{C}\right) \\
\text { Maintenance Life }(\mathrm{hr})\end{array}$ & $\begin{array}{r}\text { Firing Temperature } \\
\text { above } 1200 \mathrm{~K}\left(927^{\circ} \mathrm{C}\right) \\
\text { Maintenance Life }(\mathrm{hr})\end{array}$ \\
\hline \multicolumn{4}{|l|}{ BASE LOAD } \\
\hline Natural gas & $1 / 1000$ & 30,000 & 15,000 \\
\hline Natural gas & $1 / 10$ & 7,500 & 3,750 \\
\hline Distillate oil & $1 / 1000$ & 22,000 & 11,250 \\
\hline Distillate oil & $1 / 10$ & 6,000 & 3,000 \\
\hline Residual & $1 / 1000$ & 3,500 & 2,500 \\
\hline \multicolumn{4}{|c|}{ SYSTEM PEAKING (Normal maximum load of short duration and daily starts) } \\
\hline Natural gas & $1 / 10$ & 7,500 & $\overline{5,000}$ \\
\hline Natural gas & $1 / 5$ & 3,800 & 3,000 \\
\hline Distillate & $1 / 10$ & 6,000 & 4,000 \\
\hline Distillate & $1 / 5$ & 3,000 & 2,500 \\
\hline TURBINE PEAKING (Opera & ng above 2 & $3 \mathrm{~K}-311 \mathrm{~K}\left(28^{\circ} \mathrm{C}-56^{\circ} \mathrm{C}\right)$ & ring temperature) \\
\hline Natural gas & $1 / 5$ & 2,000 & 2,000 \\
\hline Natural gas & $1 / 1$ & 400 & 400 \\
\hline Distillate & $1 / 5$ & 1,600 & 1,700 \\
\hline Distillate & $1 / 1$ & 400 & 400 \\
\hline
\end{tabular}

Depending on the engine application and the engine capital cost, the combustor life is further aided by additional protective thermal barrier coatings (TBC) which are plasma sprayed on the inner walls of the combustor liner. The high thermal resistance and low 
emissivity of TBCs greatly reduce the liner metal temperature. These coatings are particularly effective in reducing liner thermal stresses during engine start-up and shutdown procedures.

Table 6.2 shows an array of suitable nickel based superalloys, with their respective chemical compositions, used for the manufacturing of combustors. Particularly, the superalloys presented in Table 6.2 are those used in General Electric (GE) industrial gas turbine engines.

Table 6.2 High temperature alloys (Boyce, 2006)

\begin{tabular}{|c|c|c|c|c|c|c|c|c|c|c|c|c|c|}
\hline \begin{tabular}{|l|} 
Component \\
\end{tabular} & $\mathbf{C r}$ & $\mathbf{N i}$ & Co & $\mathrm{Fe}$ & W & Mo & $\mathbf{T i}$ & $\mathbf{A l}$ & $\mathbf{C b}$ & $\mathrm{V}$ & C & B & $\mathbf{T a}$ \\
\hline \multicolumn{14}{|l|}{ Combustors } \\
\hline SS309 & 23 & 13 & - & BAL & - & - & - & - & - & - & 0.1 & - & - \\
\hline HAST X & 22 & BAL & 1.5 & 1.9 & 0.7 & 9 & - & - & - & - & 0.07 & 0.005 & - \\
\hline $\mathrm{N}-263$ & 20 & BAL & 20 & 0.4 & - & 6 & 2.1 & 0.4 & - & - & 0.06 & - & - \\
\hline HA-188 & 22 & 22 & BAL & 1.5 & 14 & - & - & - & - & - & 0.05 & 0.01 & - \\
\hline
\end{tabular}

Of the materials presented above, Hastelloy $\mathrm{X}$ is readily available in sheet, strips, rods and discs. Furthermore, the exceptional strength and oxidation resistance (up to $1473 \mathrm{~K}$ or $1200^{\circ} \mathrm{C}$ ) of Hastelloy X (Davis, 2000) made it an ideal material for the manufacturing of the combustor liner developed in this research project.

\subsection{Selection of Combustor Liner Material}

After having investigated the metallurgy of superalloys and considered potential manufacturing processes, discussed below, two sheet metal pieces of Hastelloy X, conforming to AMS $5536 \mathrm{~L}$ specifications were purchased from Rolled Alloys. A (305 $\mathrm{mm}$ by $610 \mathrm{~mm} ; 12$ in by $24 \mathrm{in}$ ) piece of sheet metal with a thickness of approximately 1 $\mathrm{mm}$ ( $0.04 \mathrm{in})$ was dedicated for the liner walls. A second piece $(152 \mathrm{~mm}$ by $305 \mathrm{~mm}$ by 6 $\mathrm{mm}, 6$ in by 12 in by 0.25 in) was purchased for the cooling rings. 


\subsection{Overview of Superalloys Manufacturing Processes}

The selection of a satisfactory manufacturing process to build the combustor liner was undertaken after having obtained proper fabrication knowledge on superalloys.

Superalloys can be found in cast, rolled, extruded, forged and powder forms. Wrought alloy forms, such as rolled, extruded and forged, have better fatigue properties, due to the alloy finer grain sizes resulting from the fabrication process. Even though superalloys can be formed in many ways, there are some restrictions to certain production processes.

One such fabrication process that is restricted is forging. The excellent high temperature strength of superalloys, makes forging a difficult process to perform when compared to other materials used in gas turbine engines.

Superalloys hot forming is also a difficult process since it can only be performed within a narrow temperature range of $1200 \mathrm{~K}$ to $1500 \mathrm{~K}$ (Campbell, 2006). At temperatures higher than $1500 \mathrm{~K}$, the alloy microstructure starts to coarsen (grain growth) which leads to poor mechanical properties of the metal. For this reason, cold forming, followed by anneal treatments, is a preferred approach.

The cold forming process, for wrought superalloys, is similar to that used for stainless steel. The same stainless steel forming presses can be used to cold work superalloys. However, due to their higher strength, the forming process of superalloys requires $50 \%$ to $100 \%$ more power when compared to that needed for stainless steel (Campbell, 2006). One superalloy that responds well to the cold working process is Hastelloy X since it can be reduced by as much as $90 \%$ before annealing is required (Campbell, 2006), thus reducing manufacturing costs. Annealing is a heat treatment process which relieves 
internal stresses caused by the cold working process and which improves the mechanical properties of alloys.

In conclusion, of all the metals used in gas turbine engines, superalloys are considered the most difficult metal to machine. The superalloys retention of high strength properties at elevated temperatures put the machining tools under extreme stress. The excessive heat, pressure and abrasion conditions make the nose of the cutting tool wear away rapidly or break off, thus making machining a problematic process.

\subsection{Overview of Superalloys Joining Processes}

Superalloys can be joined by one of the following methods: fusion welding, diffusion bonding, brazing/soldering, adhesive bonding, or mechanical fasteners (Campbell, 2006).

However, of the above mentioned processes, the combustors intricate geometries combined with very thin wall thicknesses make the fusion welding process to be the most flexible and cost effective of all joining techniques. Nevertheless, when considering fusion welding as a joining process, close attention must be given to the aluminum and titanium contents making up the superalloy. As can be seen in Figure 6.2, there is a clear line which demarks the materials that are readily weldable from those which are difficult to weld. Specifically, Figure 6.2 shows that for determined percent weight contents of aluminum and titanium, the superalloys can be susceptible to hot cracking during welding or to delay cracking after welding. For more details on the causes of these phenomena the reader is encouraged to look at Reed (2006) for information on superalloy microstructures and Campbell (2006) for crack causes and welding guidelines. 


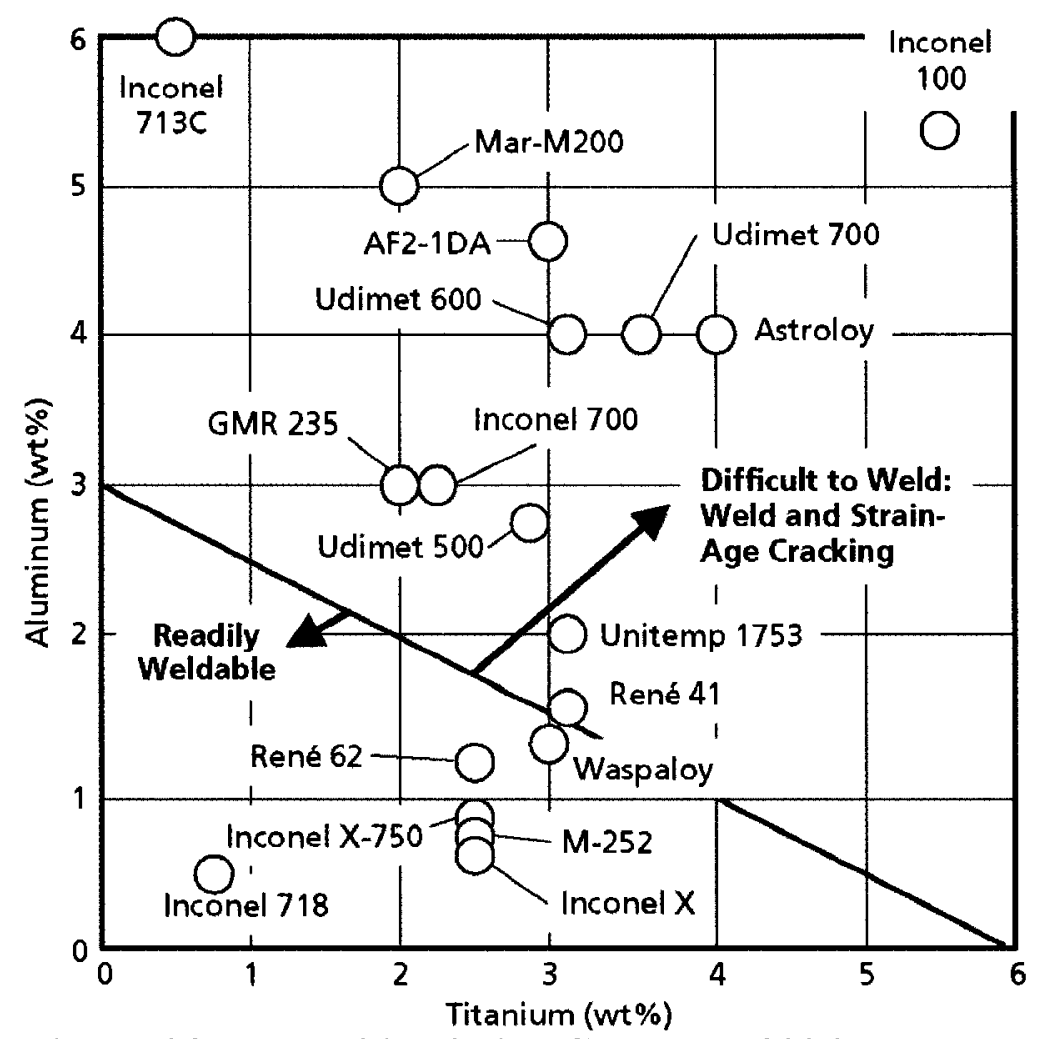

Figure 6.2 Weldability limits (Campbell, 2006)

When looking at the composition (Table 6.2) of the selected liner material, namely Hastelloy X, neither the presence of aluminum nor titanium can be seen. This, therefore, makes the alloy readily weldable by fusion arc welding processes such as Gas Tungsten Arc Welding (GTAW) and Gas Metal Arc Welding (GMAW)

Figure 6.3 shows the schematics of the above mentioned welding processes. In gas tungsten arc welding, the fusion heat is provided by an arc maintained between a nonconsumable tungsten electrode, the cathode, and the workpiece, the anode. The negative tungsten electrode, which has a melting temperature of $3665 \mathrm{~K}\left(3392^{\circ} \mathrm{C}\right)$ (Campbell, 2006), can carry a large amount of current which is then discharged, via the arc, to the positive charged workpiece. The extreme heat produced by the arc results in the melting of the workpiece. Furthermore, since the heat is very localized, by keeping the gap 
distance between the electrode and workpiece to a minimum, it allows for deep weld penetration with a narrow weld width, also known as a weld bead.

In gas metal arc welding, in contrast to GTAW, the roles of the electrode (anode) and workpiece (cathode) are reversed. The electrical potential difference between the electrode and workpiece still generates an arc. However, in GMAW the heat produced by the arc melts the consumable electrode which is then fused with the workpiece resulting in a strong weld joint.

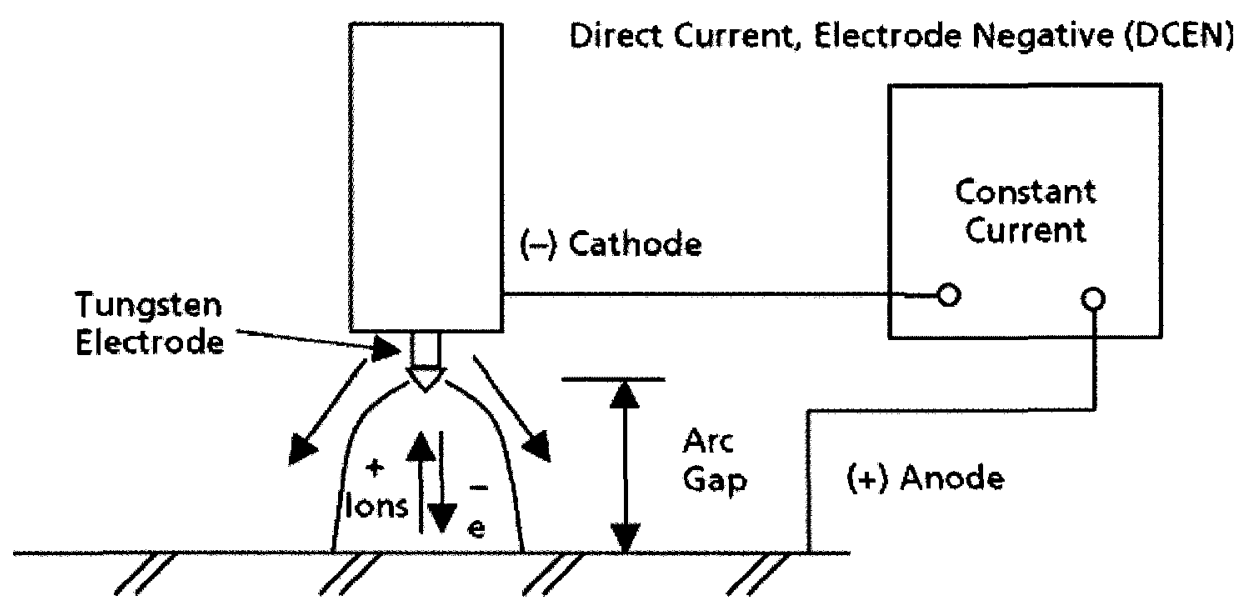

Workpiece

Gas Tungsten Arc Welding

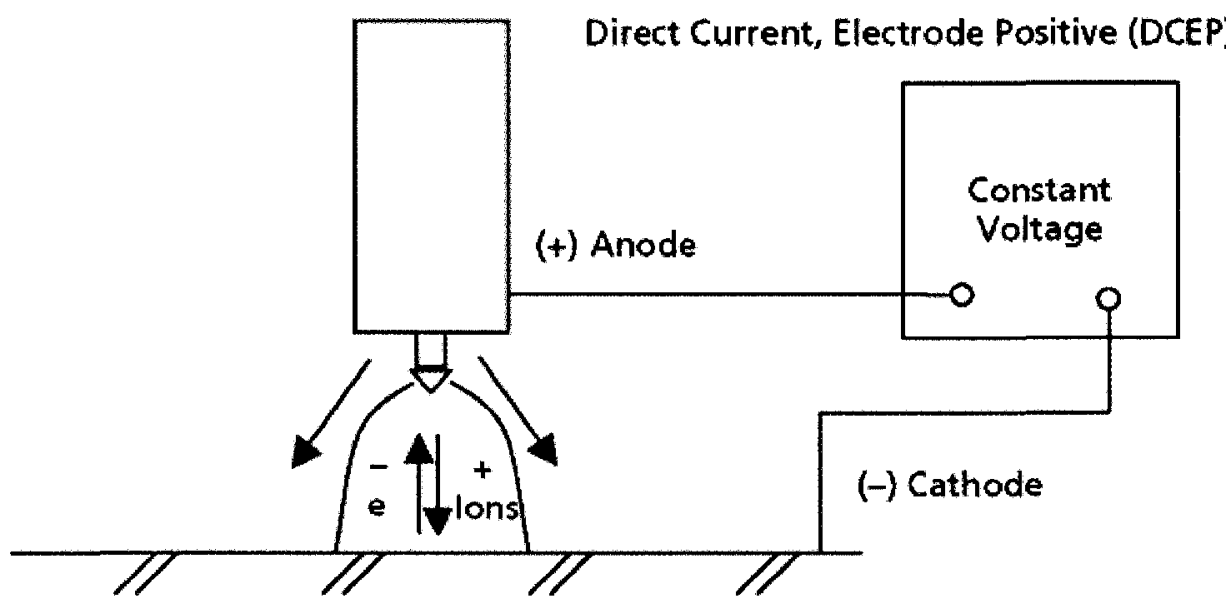

Workpiece $(-)$

Gas Metal Are Welding

Figure 6.3 Welding techniques schematics (Campbell, 2006) 
Furthermore, when comparing GMAW with GTAW, the latter technique has a better ability to control welding process variables such joint design, joint position, weld speed, electrode type, electrode size, filler metal type and its size to name a few. Therefore, GTAW was the preferred joining method for joining the combustor liner.

After choosing the combustor liner material and after gaining a better understanding of the manufacturing processes of superalloys the production method of the liner was selected and is presented below.

\subsection{Selection of the Combustor Liner Manufacturing Method}

The geometry (i.e., long thin walls) of the combustor liner and the fact that only one liner was going to be manufactured, made cold forming the most appealing manufacturing process for the research project. Three cold forming methods were explored in more detail. These methods were hydroforming, metal spinning and roll forming.

In hydroforming (Figure 6.4), a tubular, metal, starting stock is contained within a completely sealed die. The die has been previously machined to be the negative geometry of the part being manufactured. The desired geometry of the part is achieved by permanently deforming (plastic deformation) the metal stock via high internal pressure created by a fluid (typically water or oil) injected into the inner area of the stock. The plastic expansion of the metal stock is completed when the part geometry is delimited by the die walls. 


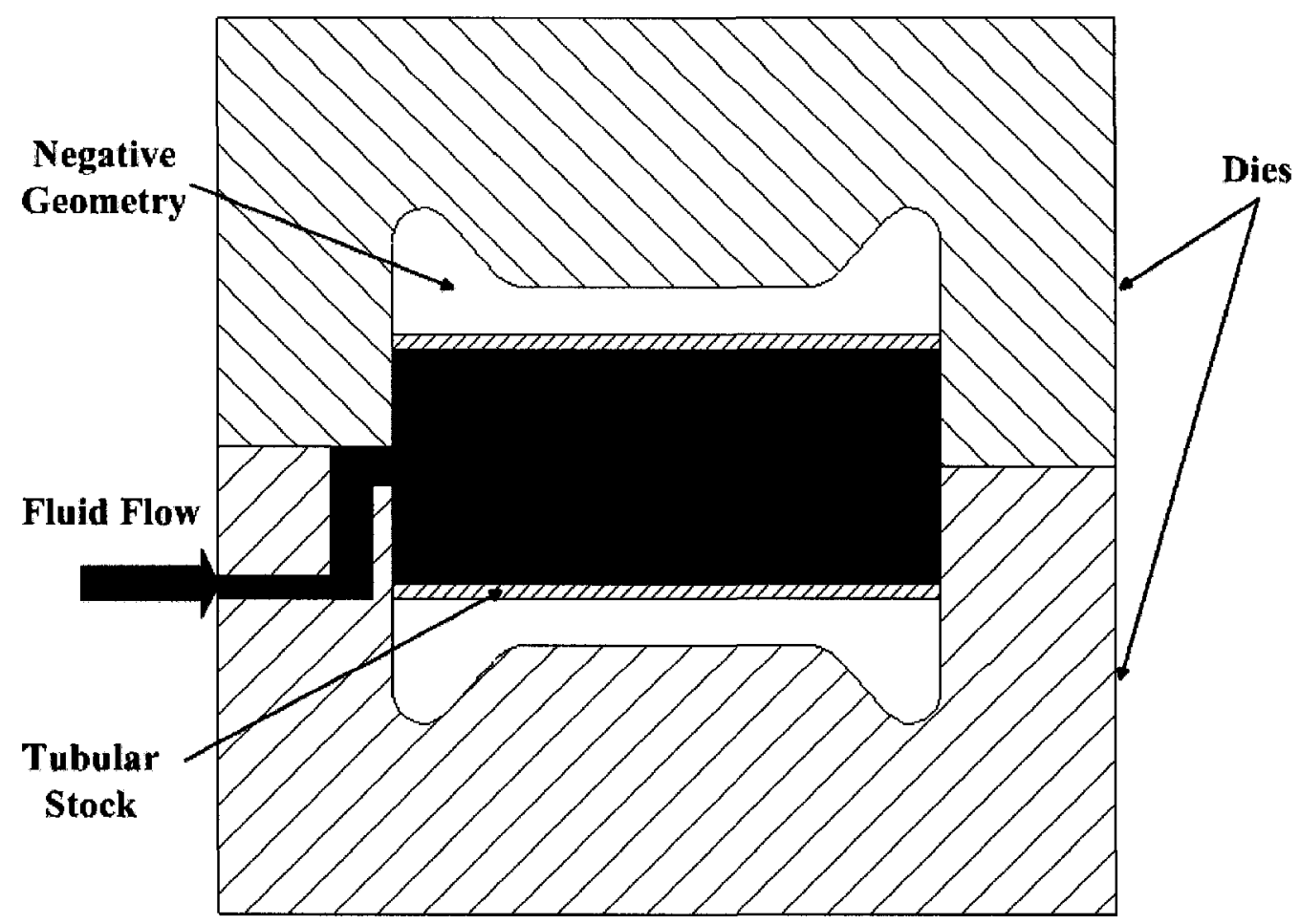

Figure 6.4 Hydroforming process

Another cold forming method is metal spinning. Metal spinning (Figure 6.5) is when tensile and compressive forces are used to form pre-cut, round sections of sheet or hollow blanks into axisymmetric (rotationally symmetric) hollow parts with various kinds of outlines. This is done with roller tools which indent points, or occasionally lines, on workpieces which are rotating (Tschaetsch, 2006).

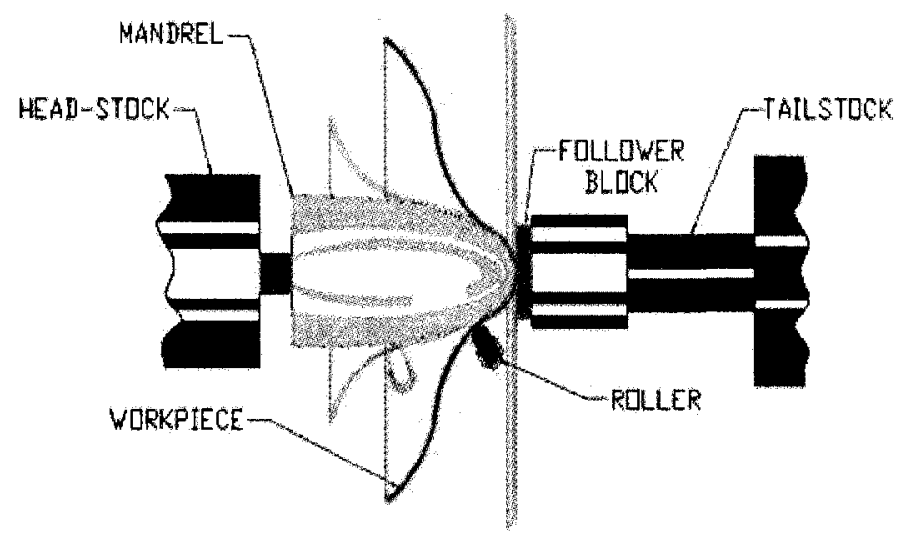

Figure 6.5 Metal spinning process (Spincraft, 2007) 
The third technique, roll forming, is the cheapest and fastest method since extra tooling costs (material and machining costs as well as machining time costs associated with the making of dies or mandrels) are not incurred by this process. Because of these reasons, roll forming was the selected process for shaping the combustor liner. As can be seen in Figure 6.6, almost any diameter can be achieved by roll forming. The smallest diameter is limited by the size of the bending rolls while the largest diameter is limited by the properties and, in particular, the plasticity of the metal.

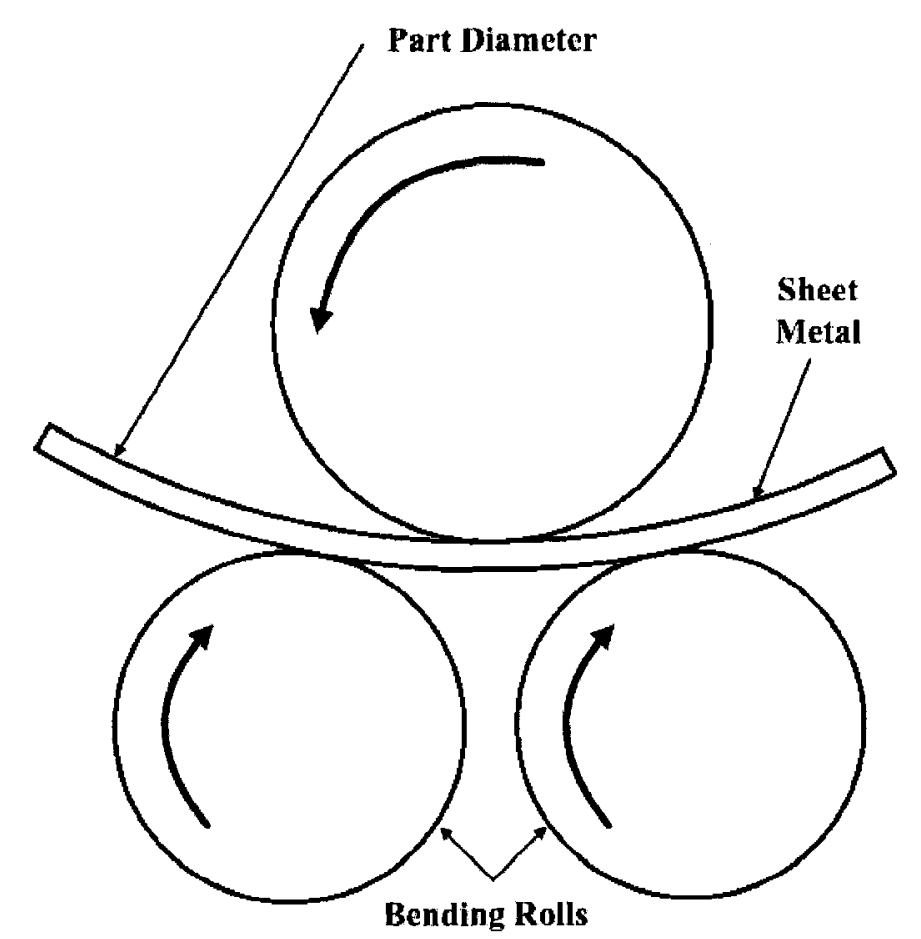

Figure 6.6 Roll forming

Based on the gained knowledge, a liner manufacturing process scheme was developed and it is presented in Figure 6.7. 


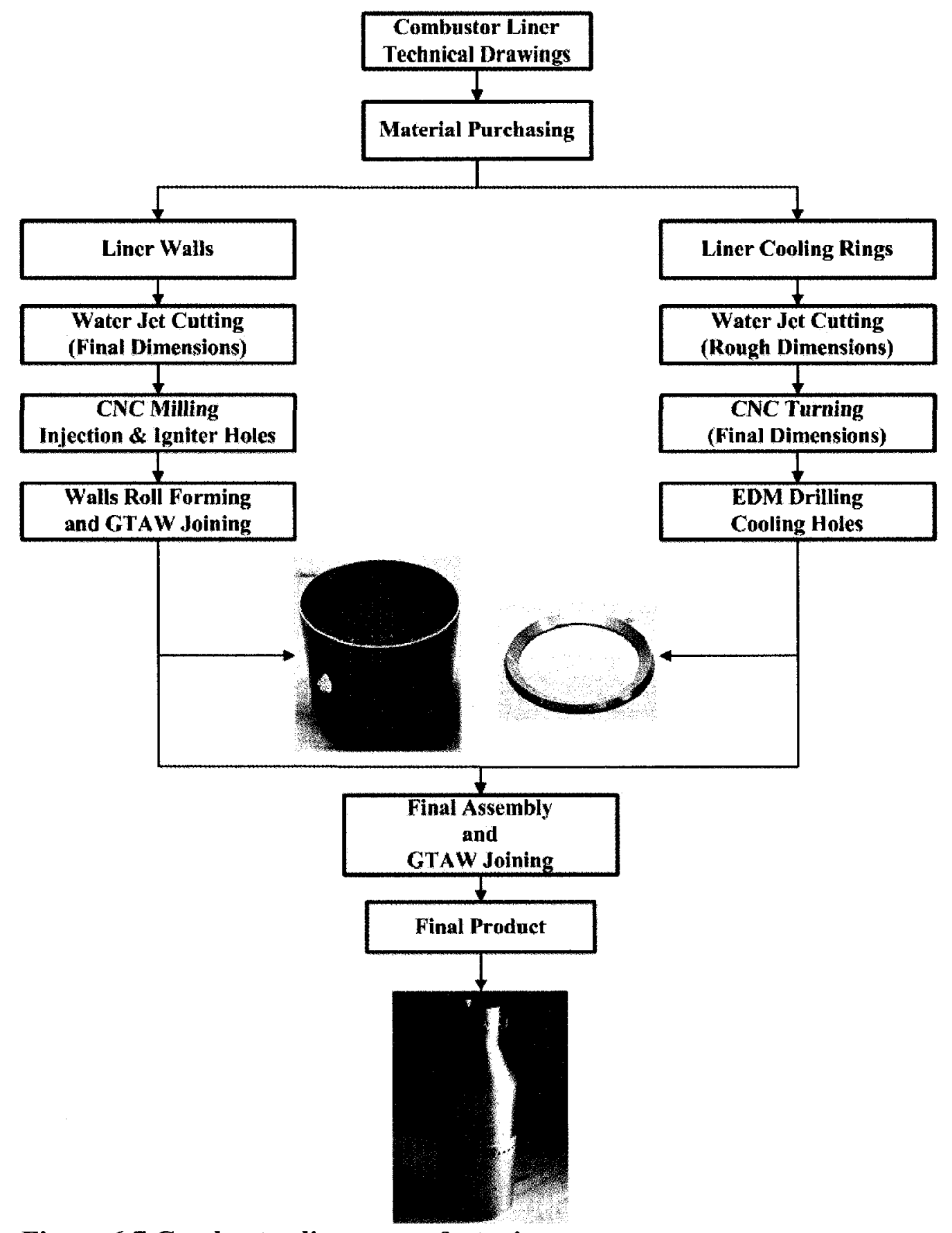

Figure 6.7 Combustor liner manufacturing process

To manufacture the combustor liner out of sheet metal, the unfolded view of the various parts making up the liner walls had to be drawn.

Once the above was accomplished, the outlines of the various combustor liner parts needed to be cut. Two methods were considered, namely abrasive water jet cutting and 
electrical discharge machining (EDM). The simplicity of the liner outlines made abrasive water jet cutting the ideal choice. This process is fast (about $10-30 \mathrm{~cm}^{2} / \mathrm{min}$ ), cheap, can maintain high tolerances (thicknesses up to about $100 \mathrm{~mm}$ ) and, contrary to EDM, does not produce a heat affected zone (HAZ) where material properties are changed, since water jet cutting is a cold process (Weman, 2003).

After having cut the outlines of the various combustor liner parts, the dilution and igniter holes were drilled out using a computer numerical control (CNC) milling machine.

Upon completion of the holes, the various parts making up the liner walls were roll formed, as can be seen in Figure 6.8, and then butt welded to create hollow cones and cylinders.

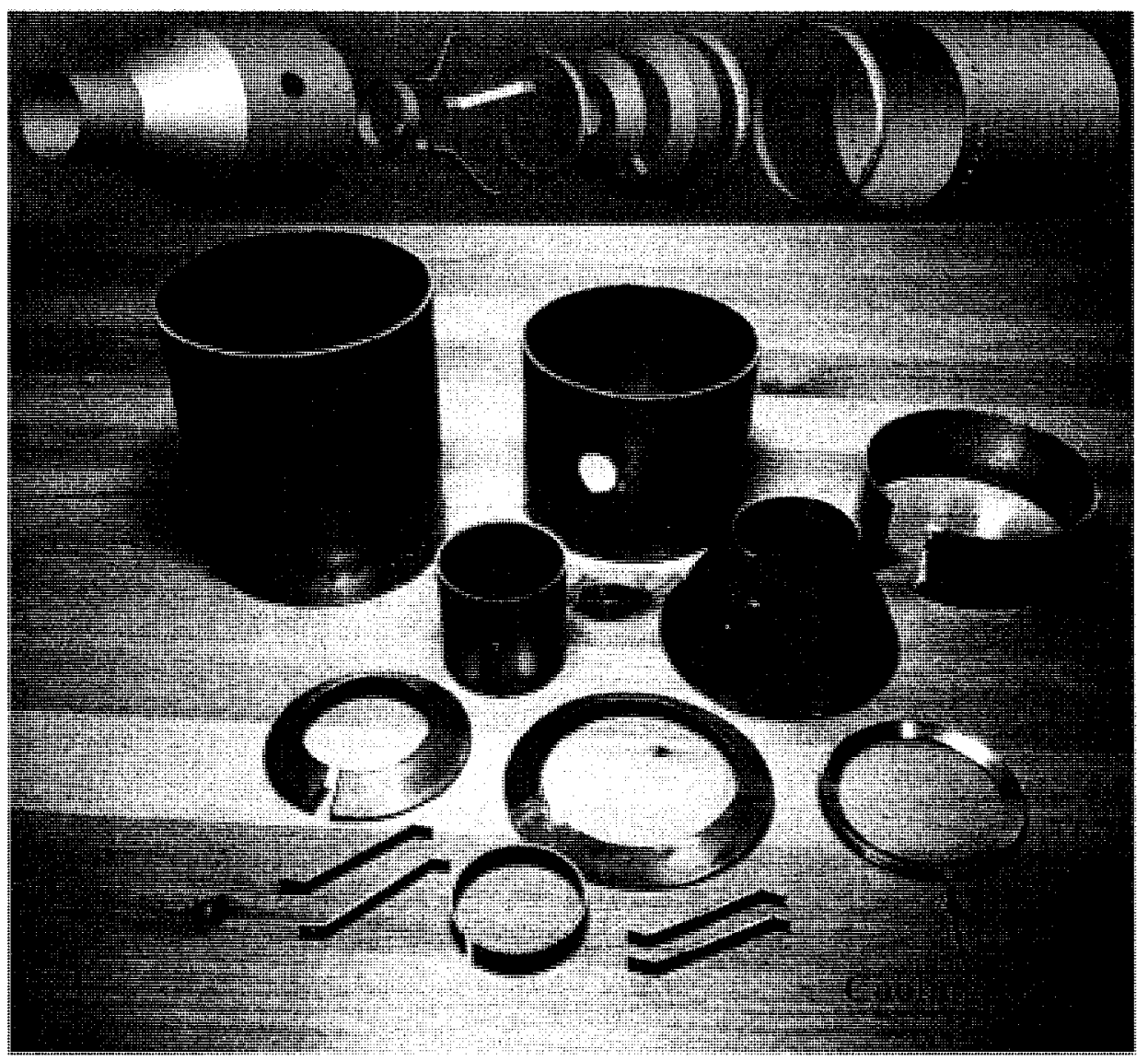

Figure 6.8 Liner exploded view (top) and actual parts (bottom) after roll forming 
Figure 6.8 also shows one of the three cooling rings (dome cooling ring) present in the liner. The cooling rings were first cut from the thicker sheet metal by water jet to rough dimensions and then machined to their final dimensions through turning. Due to small diameter dimensions $(0.8 \mathrm{~mm})$ the cooling holes were EDM drilled. The final machining for the dome cooling ring is shown in Figure 6.9.

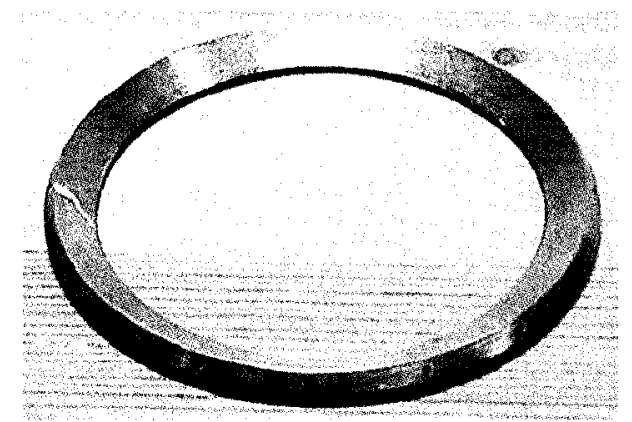

\section{Figure 6.9 Machined cooling ring}

With all the liner components completed, the final step of the manufacturing process was the joining process.

As previously mentioned, the GTAW process was found to be the most flexible and cost effective of all fusion welding techniques investigated. The suitability of the selected GTAW process as the joining method for the developed combustor liner can be fully appreciated when looking at Figure 6.10. Figure 6.10 shows a partially sectioned view of the combustor liner solid model as well as a detailed view of an actual cooling ring weld. As can be seen from the figure, in order not to damage, distort or even plug the small cooling ring holes $(0.8 \mathrm{~mm}$ in diameter), the weld beads had to be less than $1.5 \mathrm{~mm}$ thick. The proper selection of the tungsten electrode diameter, which is commercially available in diameters from $0.25 \mathrm{~mm}$ to $6.4 \mathrm{~mm}$, combined with a suitable operating current allowed to carefully control the weld penetration depth and bead width resulting in very successful welds with negligible liner distortion. 


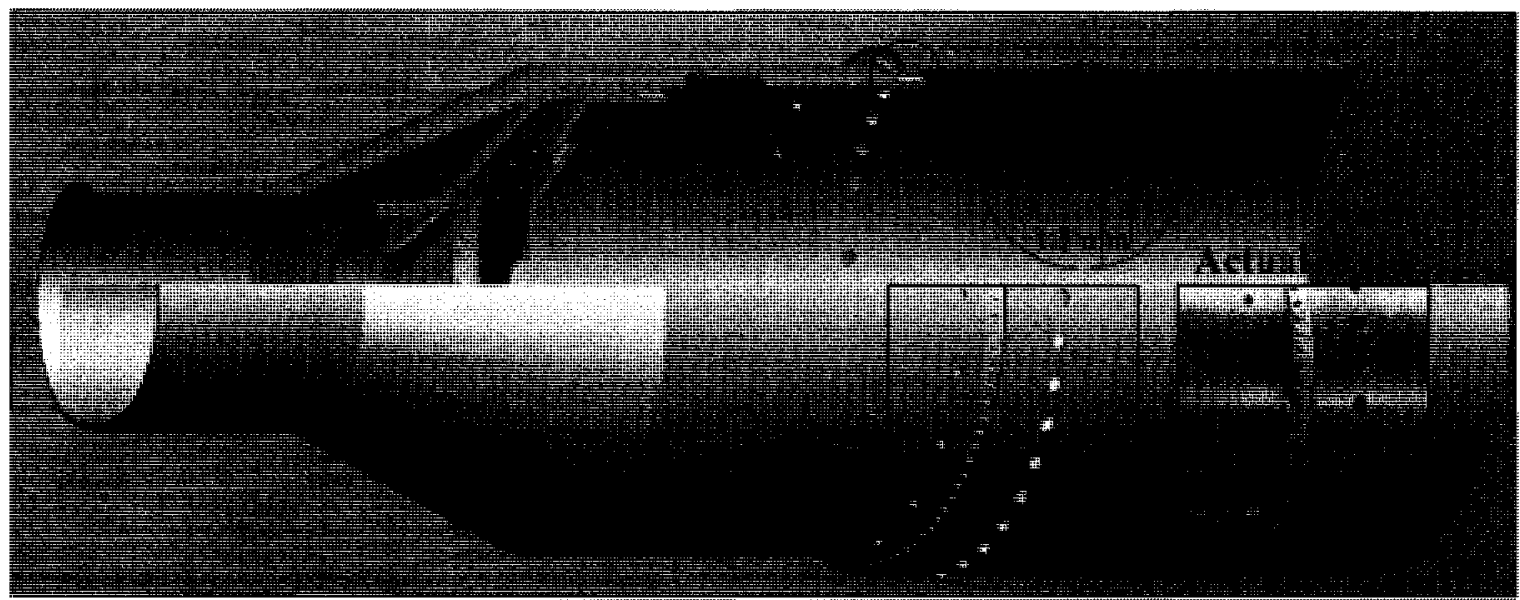

Figure 6.10 Cooling ring weld

The machining process was carried out by A-Line ${ }^{7}$. The welds were produced by FullFusion Welding ${ }^{8}$. Figure 6.11 shows the liner after having completed the manufacturing process.

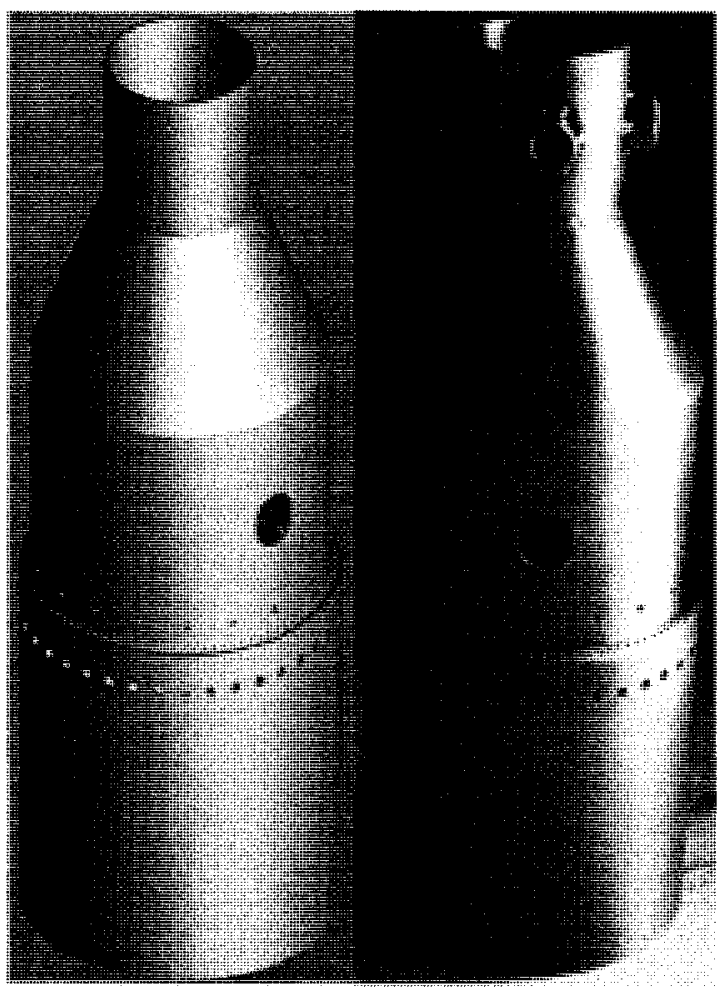

\section{Solid Model Actual Part}

\section{Figure 6.11 Liner solid model and final product}

\footnotetext{
${ }^{7} 51$ McCormack St, YORK, Ontario M6N 1X8, Canada

${ }^{8} 345$ Wyecroft Rd, Unit 4B, Oakville, Ontario L6K 2H2, Canada
} 


\subsection{Combustor Casing Material Selection}

Like the liner, the combustor casing operates at low-stress conditions. However, when compared to the liner, the casing functions at lower operating temperatures since some of the heat is removed by the cool air flowing between the casing and liner walls, as it was previously introduced in Section 4.10.

Due to the low stress conditions and cooler operating temperatures, austenitic steel (stainless steel) with a $316 \mathrm{~L}$ grade was considered as the casing material. In addition, research on high temperature materials revealed that, not only austenitic stainless steels had very good properties for hot environments, but it was also considerably cheaper than superalloys materials, thus, making austenitic steel $316 \mathrm{~L}$ the selected candidate for the casing material.

Austenitic steels are iron based alloys that contain at least $16 \%$ chromium and $10 \%$ nickel (Bhadeshia and Honeycombe, 2006). To make them suitable for high temperature and corrosion resistant applications some austenitic alloy compositions also contain elements like molybdenum (see Appendix B for further metallurgical information). In general, austenitic steels have high corrosion resistance, and very high ductility, weldability and resistance to high temperature environments. However, when operating in high temperature conditions austenitic steels are susceptible to intergranular corrosion.

Intergranular corrosion is a localized corrosion phenomenon associated with carbide precipitation. Carbide particles precipitation occurs when the chromium and carbon contained in the alloy combine due to long periods of exposure to high temperatures (700 $\mathrm{K}$ to $1125 \mathrm{~K}$ or $425^{\circ} \mathrm{C}$ to $850^{\circ} \mathrm{C}$ ) (Bhadeshia and Honeycombe, 2006). The formation of carbide particles in the grain boundaries results in the depletion of chromium in areas 
adjacent to the carbide particles. This chromium depletion allows the alloy to be less resistant to corrosion, particularly along the grain boundaries. This phenomenon is also known as sensitization (Bhadeshia and Honeycombe, 2006).

To make austenitic steel less susceptible to intergranular corrosion, extra low carbon content alloys have been developed. Particularly, 304L and 316L grades have high temperature strengths, attributed to the chromium content, and good resistance to corrosion due to the low carbon content (less than 0.03 weight \%) (Bhadeshia and Honeycombe, 2006). 304L and 316L grades can be used up to $1200 \mathrm{~K}\left(925^{\circ} \mathrm{C}\right)$ for continuous temperature operations and up to $1140 \mathrm{~K}\left(870^{\circ} \mathrm{C}\right)$ for intermitted temperature operations (Bhadeshia and Honeycombe, 2006).

The capability of using standard fabrication techniques made austenitic stainless steels an appealing option for use in this research project. The very high ductility of these alloys allows them to be heavily cold worked despite their high strengths. However, cold working austenitic steels translates into work hardening, thus making these alloys a more difficult metal to machine.

When considering joining methods, austenitic grades are readily weldable. GMAW and GTAW are examples of standard welding processes that can be readily used. When the component manufacturing process includes extensive welding, as was the case with this research project, then the use of low carbon content grades (304L and 316L) should be considered to prevent intergranular corrosion problems, as was previously discussed. Furthermore, since 304L and 316L grades do not require post weld heat treatments, since sensitization is not a problem, the manufacturing costs are minimized (Bhadeshia and Honeycombe, 2006). 
After considering the above, the casing material chosen was austenitic steel with a 316L grade.

\subsection{Selection of Combustor Casing Manufacturing Method}

Like superalloys, austenitic steels can be found in cast, rolled, extruded, forged and powder forms. The same manufacturing and joining processes presented for the superalloys can be applied to austenitic steels and thus are not repeated here. The casing manufacturing process scheme is outlined in Figure 6.12.

For ease of manufacturing and low fabrication costs, the casing was designed to be composed of five different parts. Figure 6.13 shows the parts making up the casing which, depending on the shape, were either $\mathrm{CNC}$ turned or $\mathrm{CNC}$ turned and milled. Once the machining process was completed, the different components were joined using GTAW to produce the front and aft casing sections (Figure 6.13). The casing manufacturing process was carried out by the Science Technology Centre ${ }^{9}$. The final product can be seen in Figure 6.12.

\footnotetext{
${ }^{9}$ Carleton University Science Technology Centre, 1125 Colonel By Drive, Ottawa, ON K1S 5B6, Canada
} 


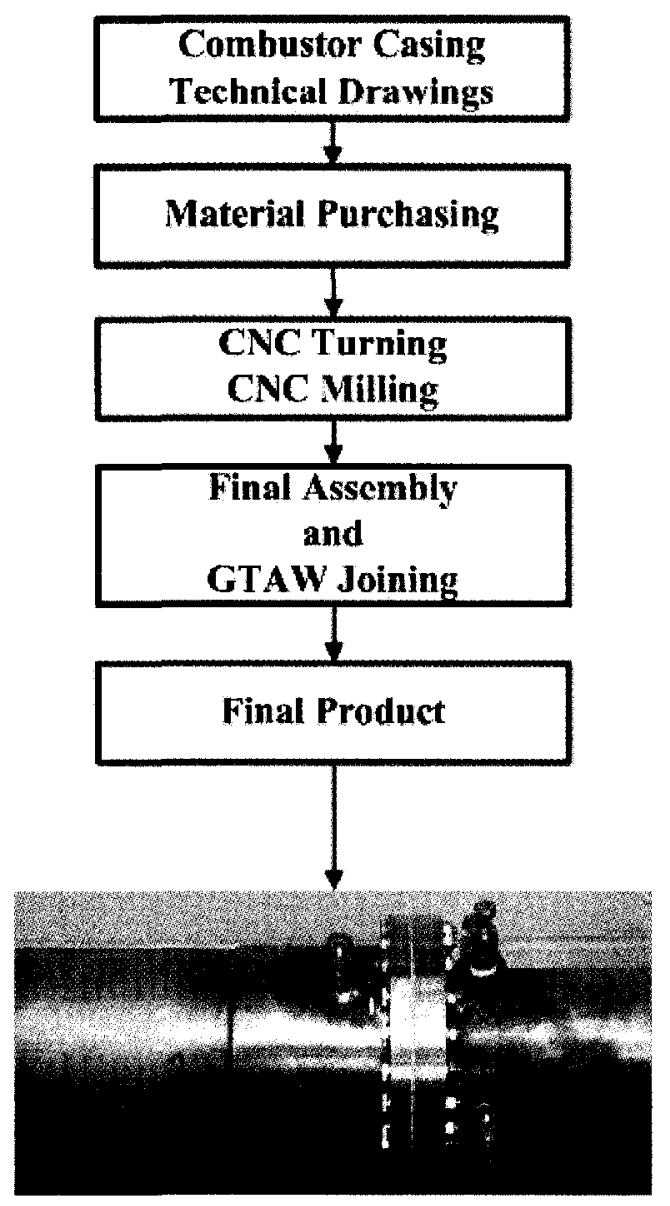

Figure 6.12 Combustor casing manufacturing process

Enclosure of the liner within the casing was accomplished by first assembling the liner to the front section of the casing (discussed in the next section) and by then assembling and securing the front and aft casing sections through the use of $20(1 / 4-28$ UNF-2A X 2) hexagon bolts and corresponding washers and nuts, which were also made of stainless steel (316). 

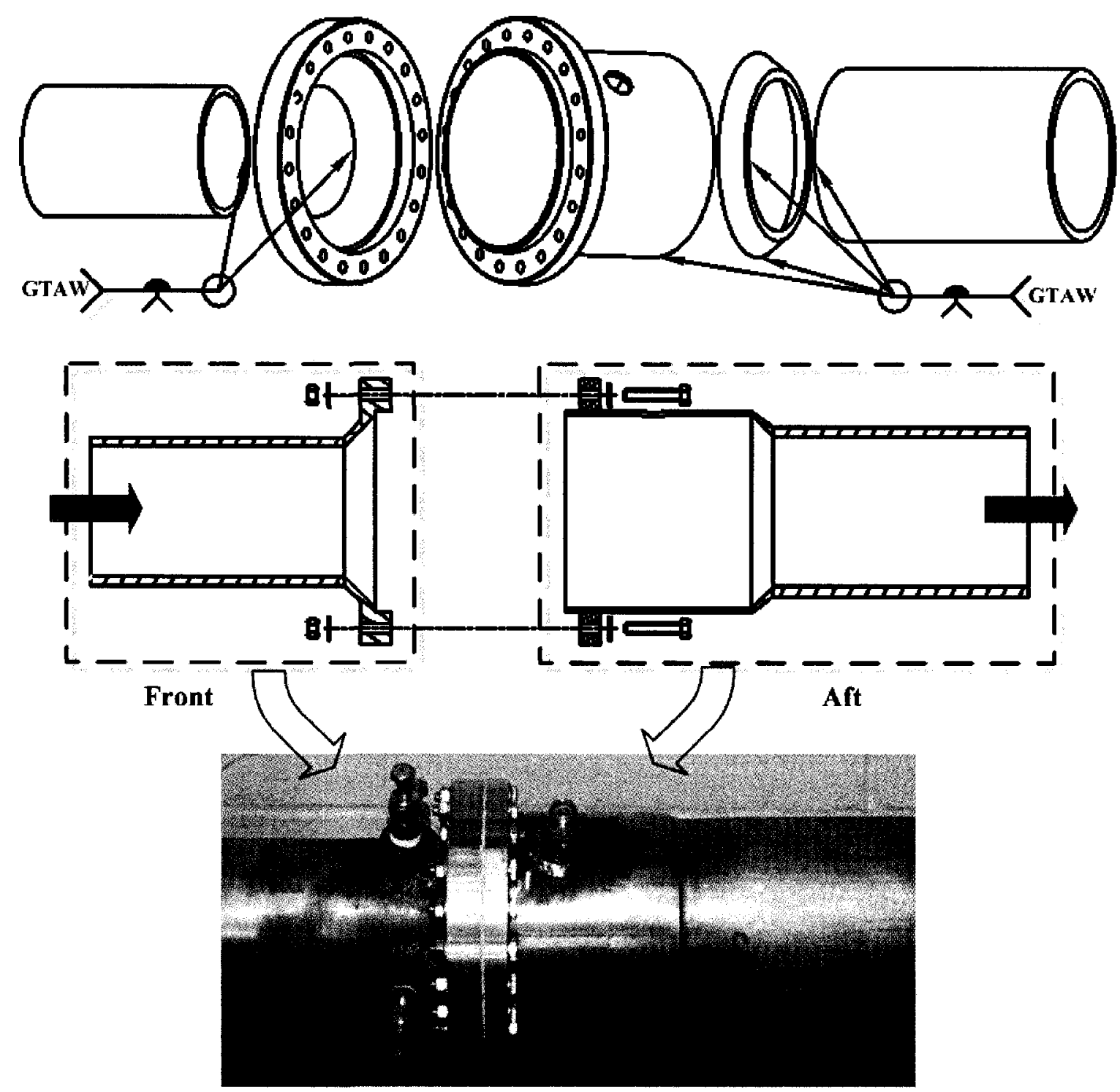

Figure 6.13 Casing exploded view (top), cross-section (middle) and final product (bottom)

\subsection{Liner Casing Assembly}

The liner-casing coupling mechanism was designed for ease of manufacturing. The design also had to ensure effortless assembly and repeatability. Here, repeatability means that every time that the liner had to be disassembled and then reassembled, the coupling mechanism had to consistently guarantee liner alignment and concentricity with respect 
to the casing, as well as maintain excellent gas-tight sealing properties. Through the inventive usage of tube fittings, readily available from companies such as Swagelok or Parker, all the above mentioned conditions could be met.

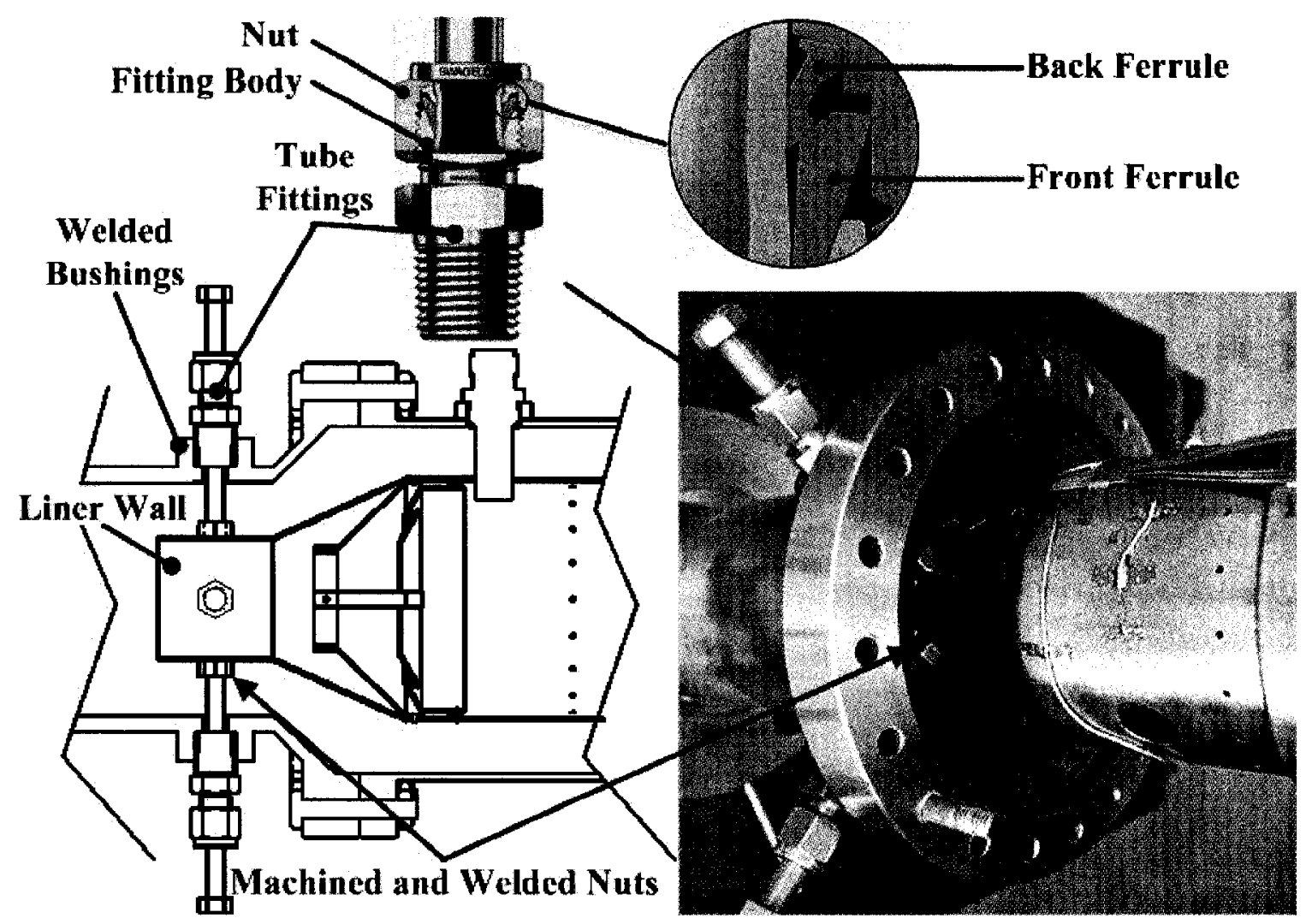

Figure 6.14 Liner and casing assembly

Tube fittings, such as the one shown in Figure 6.14, are used in a wide variety of markets such as alternative fuels, oil and gas, food, beverage and dairy, to name a few, where advanced fluid system designs are present. These fittings, which come in many sizes, materials and configurations, offer leak-tight tube connections, even at high fluid working pressures. The liner-casing assembly, through the usage of tube fittings, took advantage of the patented two-ferrule mechanical grip design, but used stainless steel bolts instead of the intended tubing, as it will be further explained next. 
To be able to assemble the liner and casing, four bushings and four nuts had to be welded onto the casing and liner walls respectively. The bushings and nuts, made of stainless steel (316), were welded at $90^{\circ}$ intervals and they had to be carefully aligned (see Figure 6.13 and Figure 6.14). The bushings were machined to have female national pipe threads (FNPT) whereas the nuts' threads were removed to simplify liner assembly. NPT threads, namely the FNPT and MNPT, are tapered threads which flanks (thread walls) compress against each other when torqued assuring a leak tight connection. Hence, the FNPT bushing threads permitted fastening of four MNPT tube fitting connectors (see Figure 6.13 and Figure 6.14) providing a gas-tight assembly that could be used to couple the liner with the casing.

After having assured liner alignment and concentricity, with respect to the casing, four stainless steel (316) bolts were carefully inserted through the tube fitting until they were constrained by the machined nut walls and by the liner wall (Figure 6.14). With the four bolts in their proper position, the fitting nuts were then torqued according to company specifications, wedging the front and back ferrules onto the stainless steel bolts. The ferrules plastic deformation created a perfectly sealed surface while the ferrules permanent grip assured liner casing assembly repeatability. Figure 6.15 shows the liner and front casing coupling assembly. Final combustor assembly was completed by lining up the front and aft casing sections and fastening them together through the use of 20 hexagon bolts and corresponding washers and nuts as previously mentioned. 


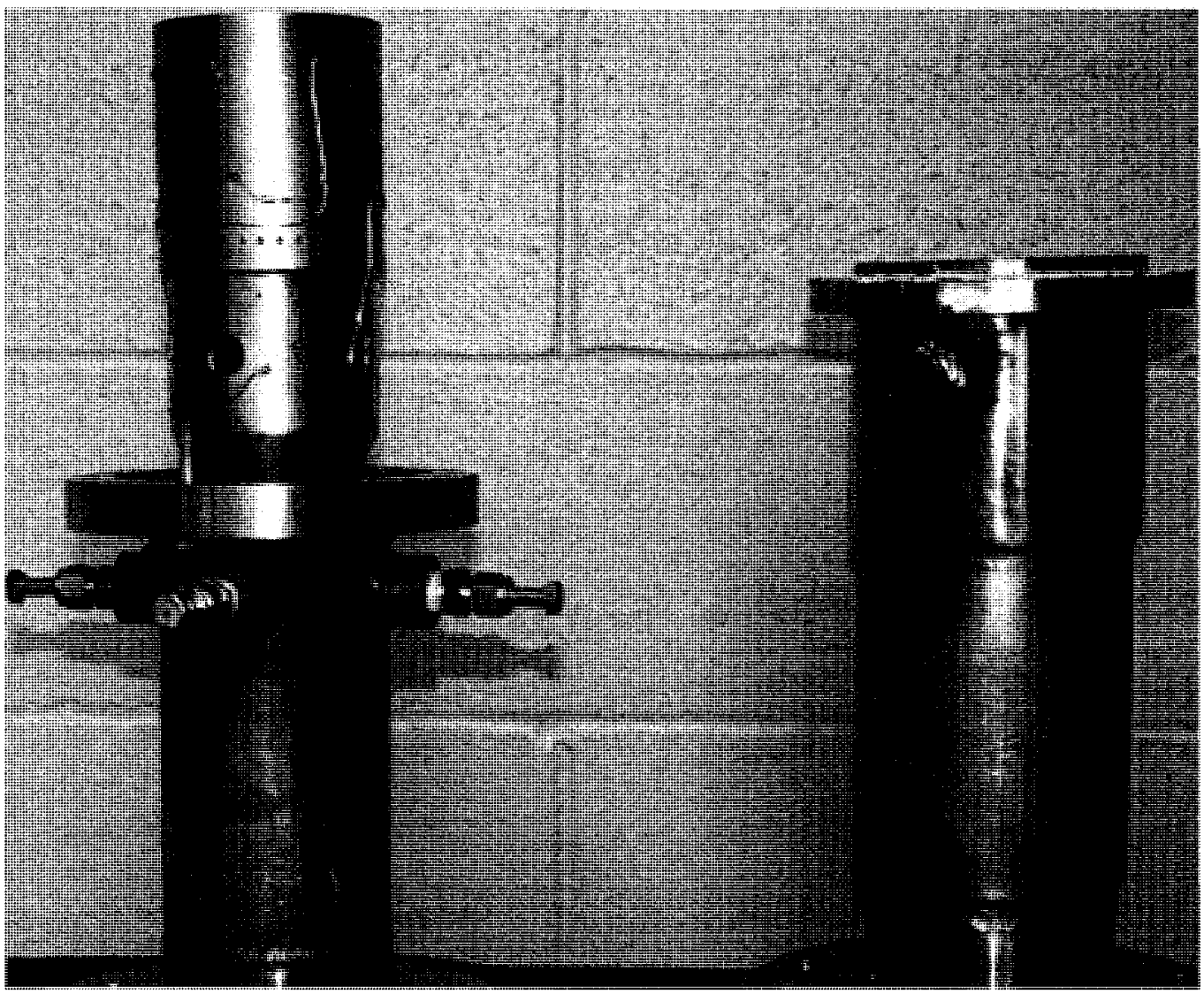

Figure 6.15 Liner and casing final assembly

\subsection{Premixer Manufacturing Process}

The premixer manufacturing process adopted readily available techniques and its production was carried out by the machine shop at the National Research Council in Ottawa, Canada.

The premixer outline is made up of a cylindrical tube followed by a conical contraction. Within the mixer tube there are two swirlers whose geometries were presented before in Section 4.6. All the parts forming the premixer are made out of stainless steel (316) and were manufactured using computer numerical control (CNC) turning and milling machines. 
The swirlers and conical contractions were machined from a rod, whereas the cylindrical tube was readily available and, except for cutting the proper length, further turning was not required. Figure 6.19 shows the final machined parts before assembly and welding took place.

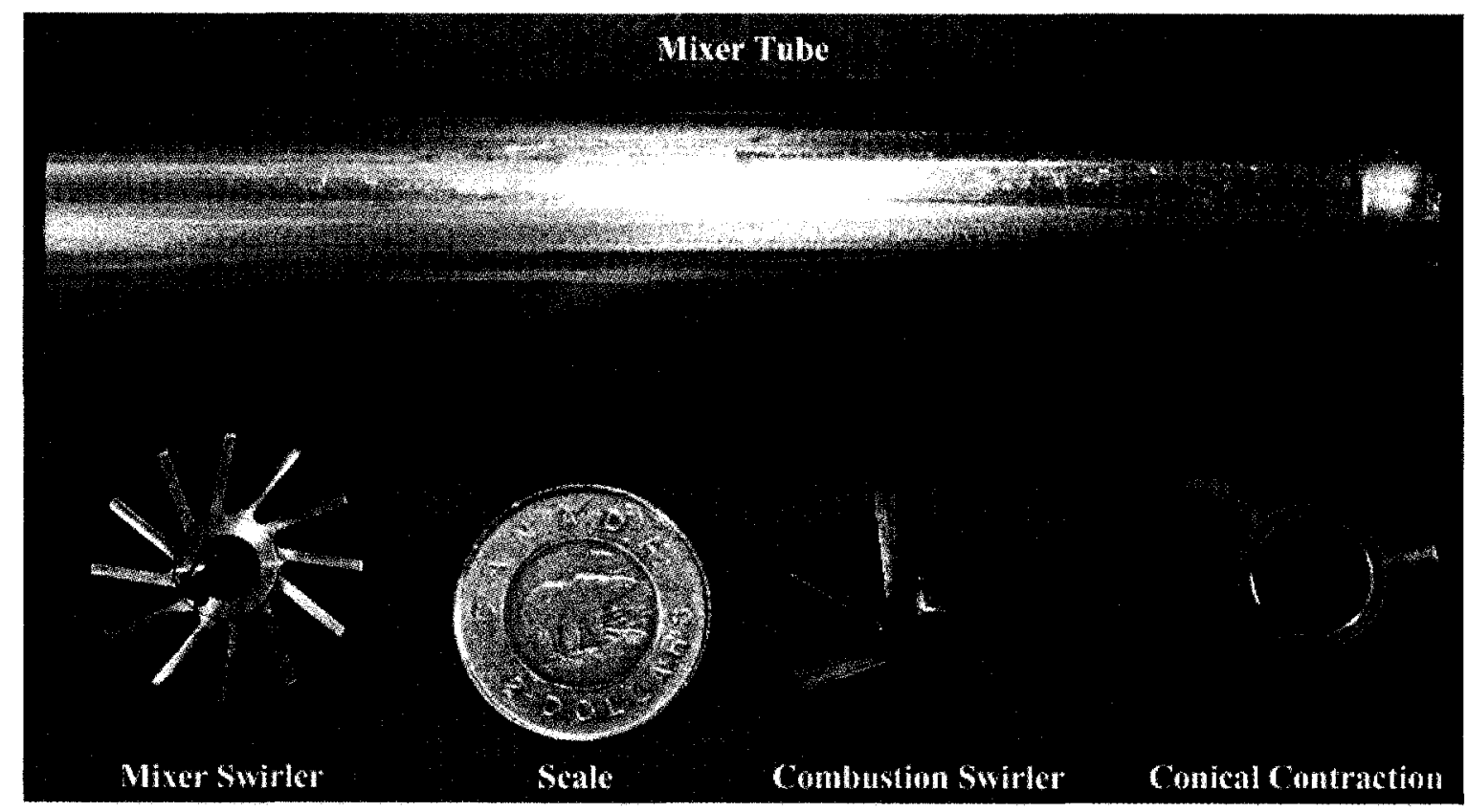

Figure 6.16 Premixer parts before final assembly

The joining process was carried out in steps using the GTAW technique. First, the combustor swirler was placed into position and was spot welded onto the cylindrical tube wall. Next, the cylindrical tube and conical contraction were butt welded. Lastly, the mixer swirler was placed into position and firmly fastened by four stainless steel set screws equally spaced at a $90^{\circ}$ interval. This non-permanent fastening method of the mixer swirler, as opposed to a more permanent method such as welding, was chosen to have more flexibility during installation of the fuel nozzle within the mixer swirler.

The completed premixer was press fitted into the premixer holder to obtain a firm assembly between the combustor liner and the premixer. The accurate mating of the 
swirler with the dome wall was ensured by the previously machined lip at the conical contraction outlet (Figure 6.17).

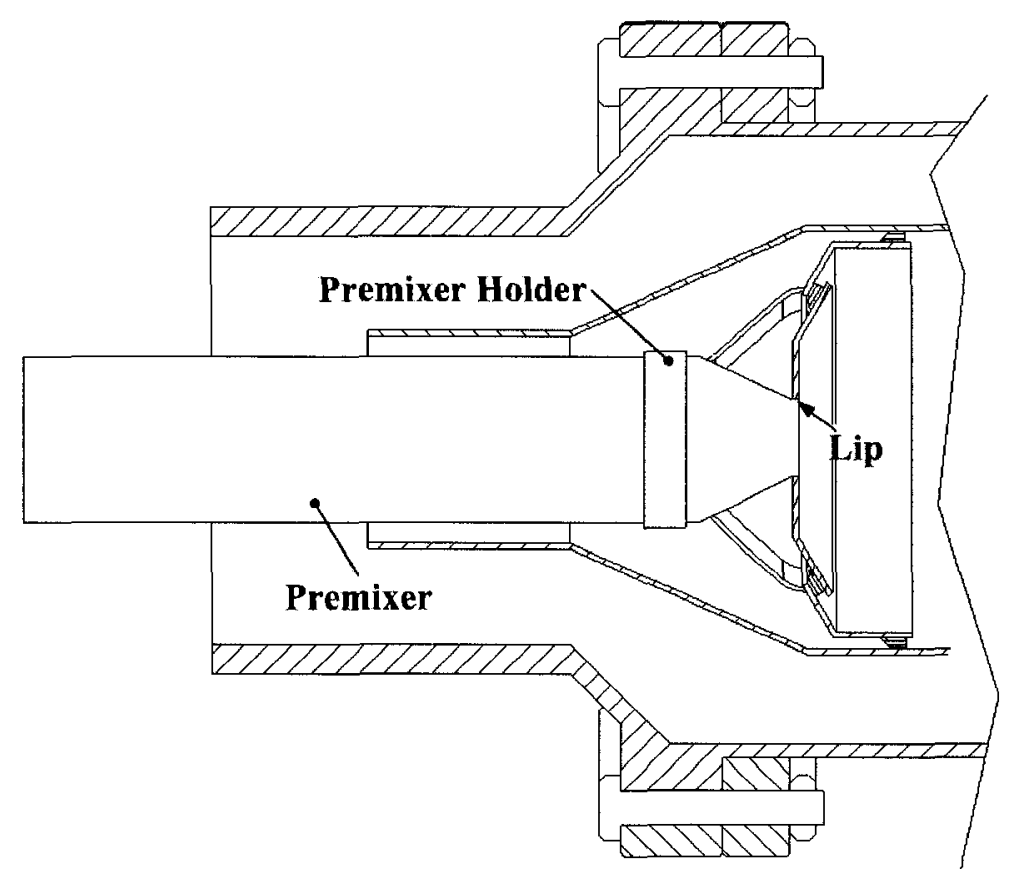

Figure 6.17 Premixer final assembly

\subsection{Fuel Nozzle Modifications}

As mentioned in Section 5.1.3, the fuel atomization process is carried out by an impingement type nozzle; in particular, the PJ model was selected and purchased from BETE. The discussion below outlines the modifications that needed to be done to the nozzle before it could be coupled with the premixer.

The PJ nozzle met all the required laboratory specifications for proper fuel atomization to take place, however, its dimensions were more than double than that permitted by the bore in the mixer swirler. Nevertheless, the low nozzle cost ( $\$ 63 \mathrm{CAD}$ ) and good performance characteristics outweighed the major modifications needed to assemble the nozzle within the mixer swirler. 
The scope of the PJ nozzle modifications was to reduce the nozzle original dimensions to a nozzle outer diameter of $6.3 \mathrm{~mm}(\sim 0.25 \mathrm{in})$ so that it could be inserted inside the mixer swirler while maintaining the atomization properties of the original design. To meet this objective, the nozzle was carefully machined until the press fitted impingement pin could be safely removed (Figure 6.18).

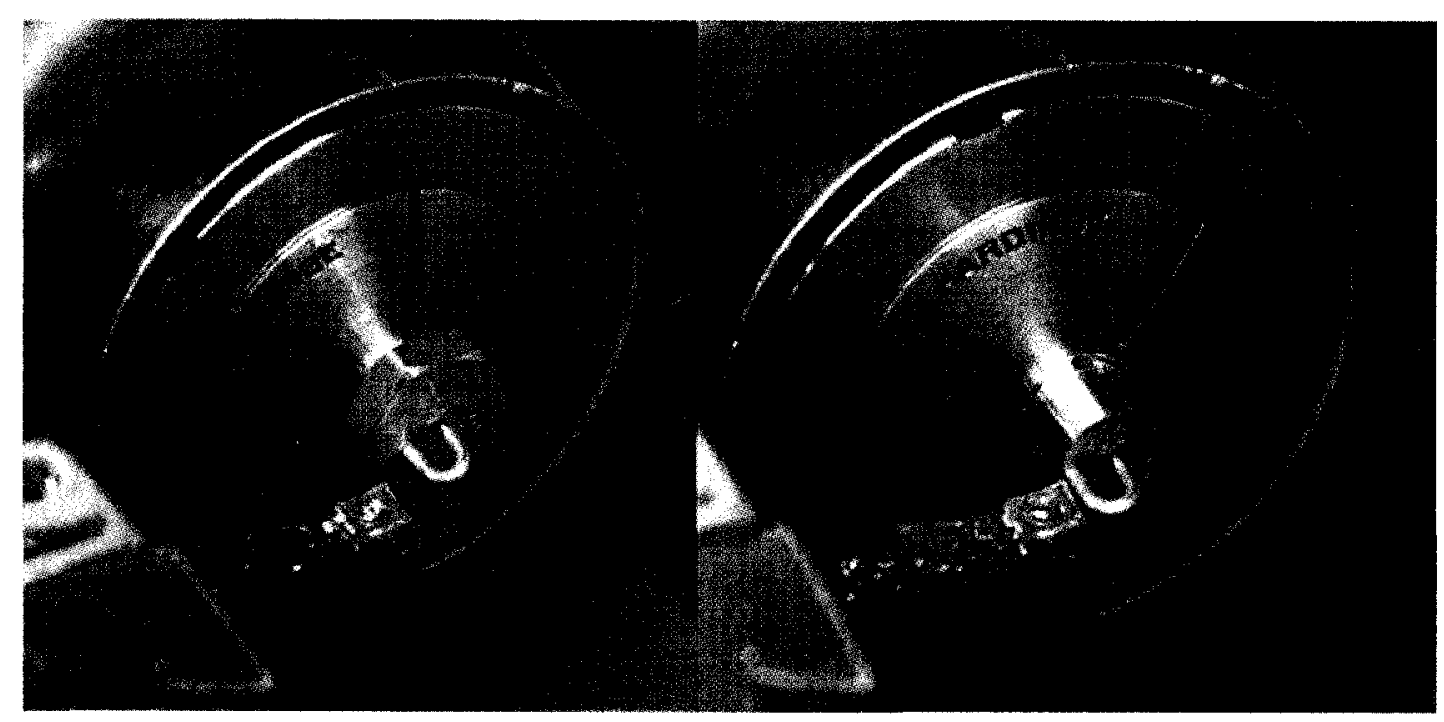

As Received

Before Removing Impingement Pin

Figure 6.18 Fuel nozzle machining

Once the pin was removed, the nozzle was turned to the final dimensions shown in Figure 6.19 .
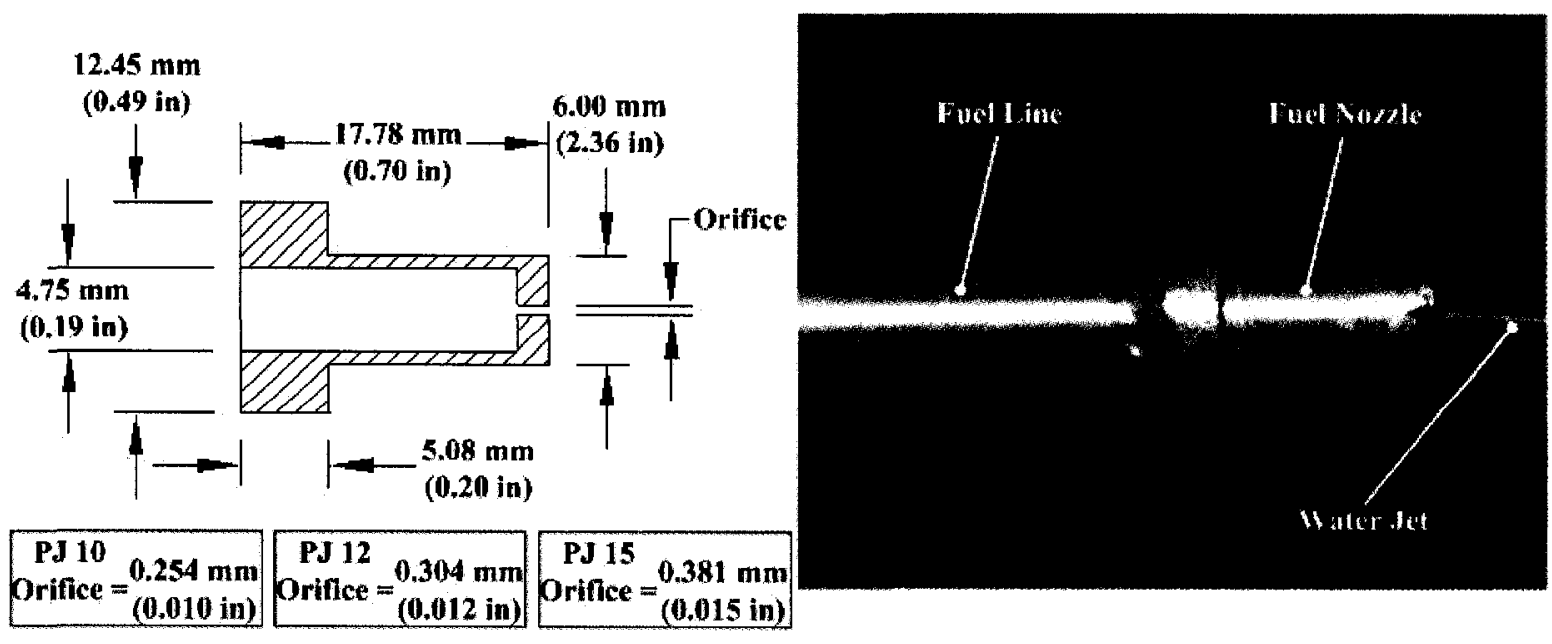

Figure 6.19 Fuel nozzle after machining with fuel line welded 
Once the machining process was completed, a fuel line (details given in Section 7.3.7) was directly welded onto the nozzle (Figure 6.19). The removed impingement pin was then carefully press fitted into the hole present on the mixer swirler wall (Figure 6.20).

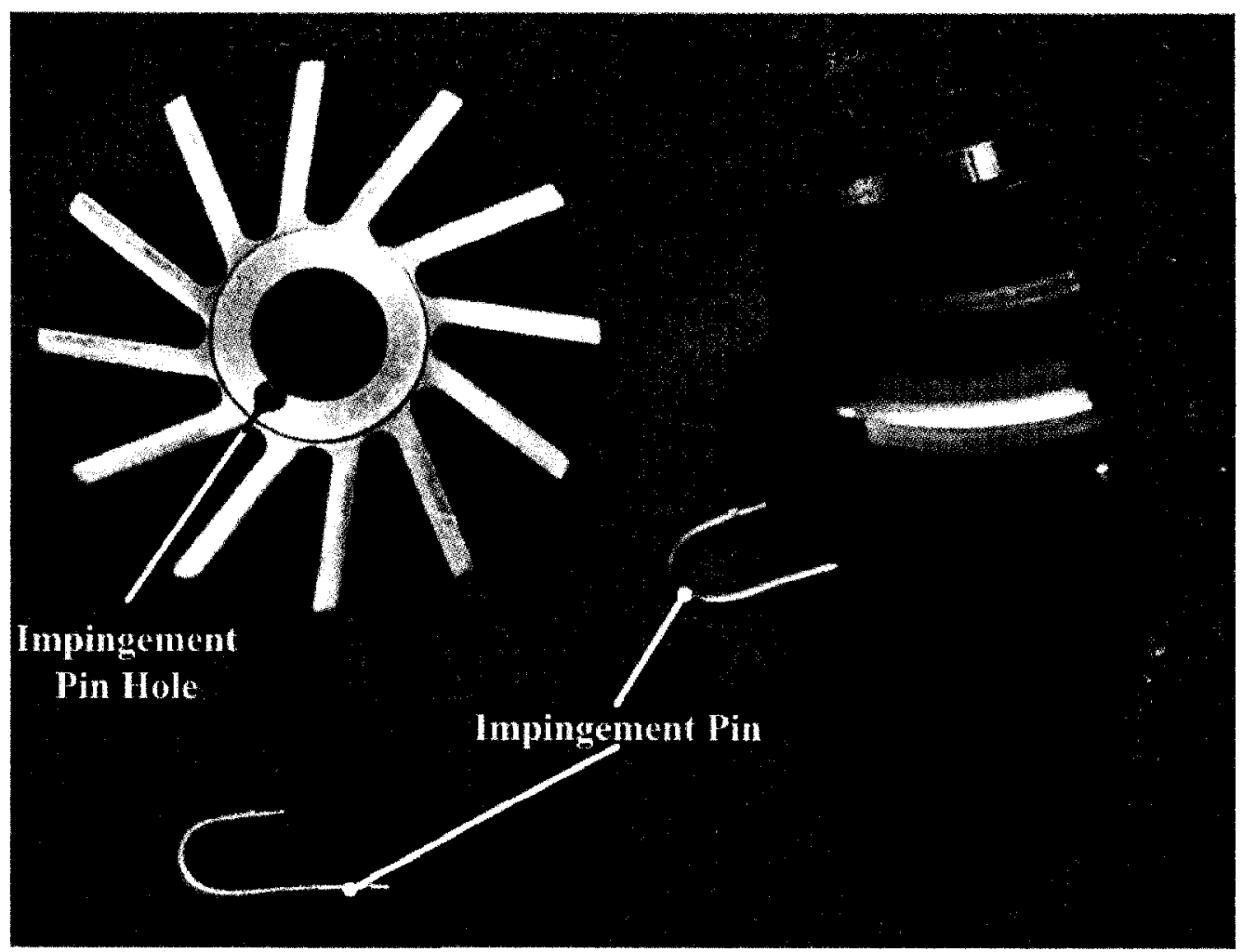

\section{Figure 6.20 Mixer swirler with impingement pin}

As an increased safety measure in the locking technique, the pre-established hole was also filled with high temperature epoxy (Loctite $\mathbb{B}-H y s o l \circledast 9492$ A\&B). Particular attention was given to the pin assembly process to ensure that, once the fuel nozzle was inserted within the mixer swirler, the distance between the impact pin and the nozzle orifice was the same as that of the original design. Another critical assembly aspect was to guarantee that the nozzle orifice and impact pin were perfectly aligned after assembly.

To guarantee that the modification process was carried out successfully, a series of atomization tests, using water, were executed. Figure 6.21 shows one of such tests. 


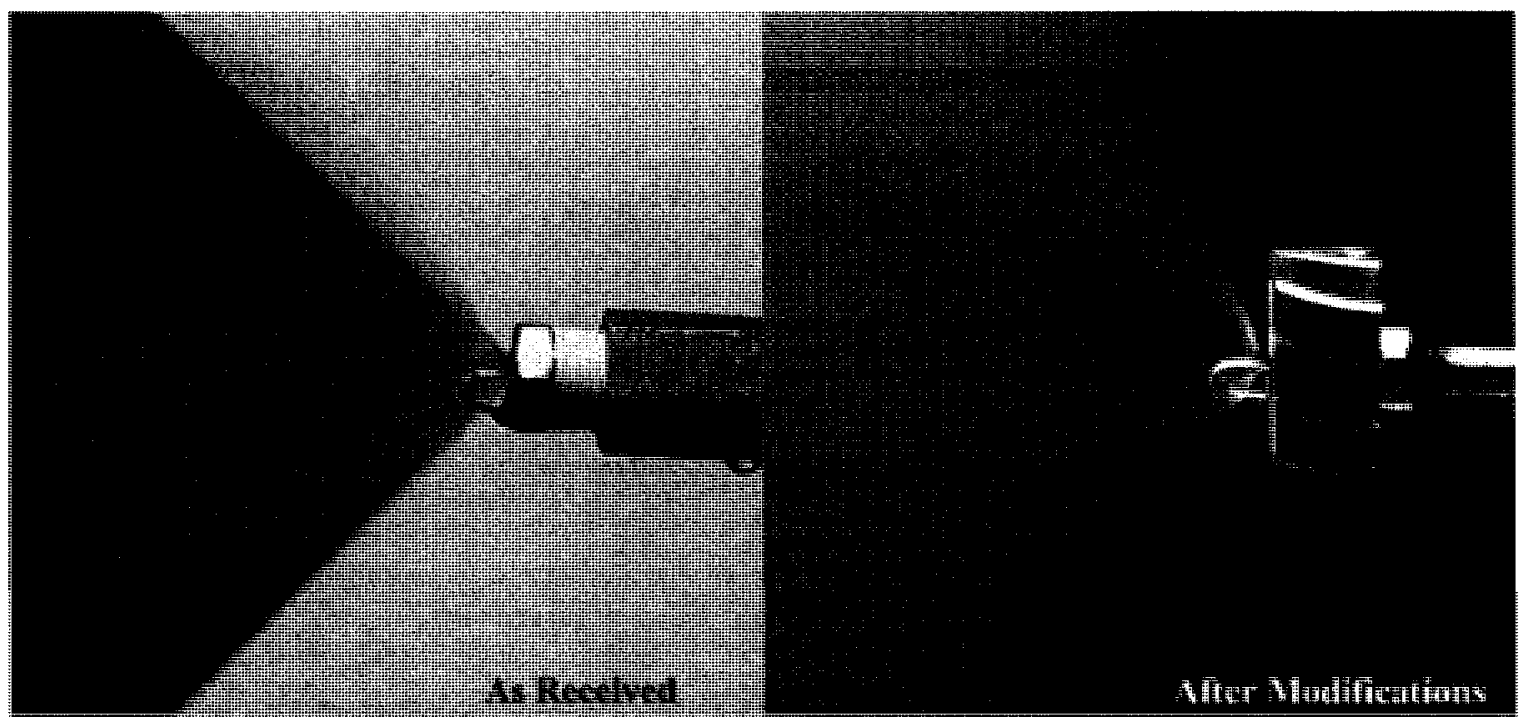

Figure 6.21 Water atomization tests

Once the validation process was concluded and deemed successful, the stainless steel fuel line was connected to the fuel delivery system through the usage of tube fittings as it will be presented in Section 7.3.7. 


\section{GAS TURBINE COMBUSTION RESEARCH LABORATORY}

This chapter first gives a general overview of the gas turbine combustion research laboratory that has been designed and constructed by the author so that experimental work on the microturbine combustor could later be conducted. After giving the layout of the laboratory, the chapter will provide details on the various systems that make up the gas turbine combustion research laboratory. More precisely, the following sections will introduce the components making up the laboratory apparatus and will then expand on the present instrumentation in the facility.

\subsection{Gas Turbine Combustion Research Laboratory Layout and Location}

The gas turbine combustion research laboratory is situated at Environment Canada's River Road facility in Ottawa. The laboratory is jointly operated by Carleton University and the Emissions Research and Measurement Department (ERMD).

Figure 7.1 shows the laboratory layout. The various rooms and systems making up the gas turbine combustion research laboratory will be identified and discussed below. 


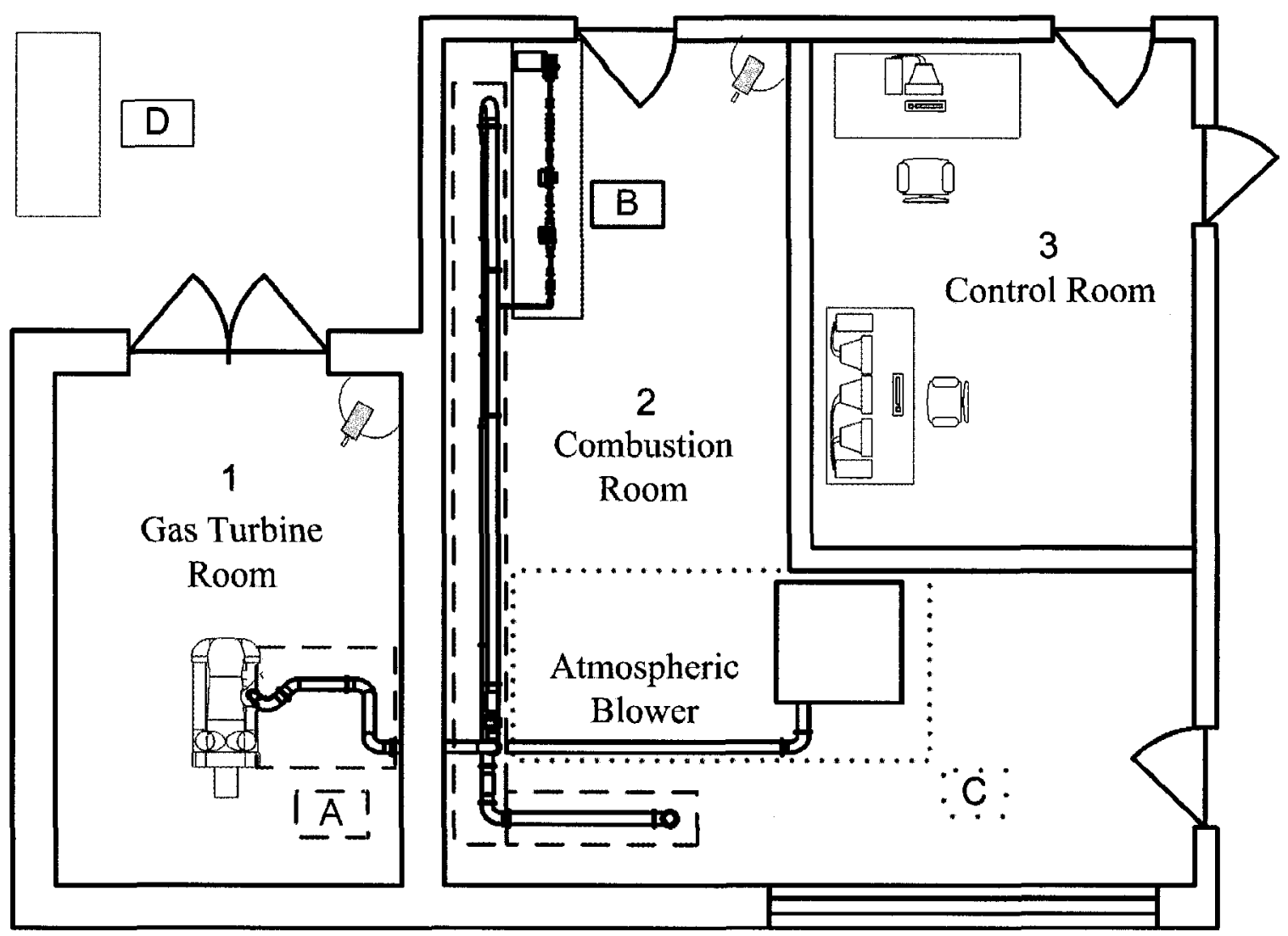

Figure 7.1 Gas turbine combustion research laboratory layout

The gas turbine combustion research laboratory is composed of three rooms. These rooms are the Gas Turbine Room (1), the Combustion Room (2) and the Control Room (3). The Gas Turbine Room, as the name implies, is an engine test cell which has been allocated to an Allison 250-C20B gas turbine engine. The purpose of this engine is to deliver pressurized ( 7 bar) air to the microturbine combustor under investigation, which resides in the adjacent room, the Combustion Room. The Combustion Room is where experimentations take place and where all test data pertaining to the combustor are acquired. The third area is the Control Room. Within this area, two control and monitoring stations are present. One station is for controlling and monitoring the gas turbine engine, and the second station is for controlling and monitoring the various systems residing in the Combustion Room. In other words, the latter station controls and 
monitors the air delivery system (A in Figure 7.1) and the fuel delivery system (B in Figure 7.1).

The air delivery system can be coupled either to the gas turbine engine, to deliver air at high pressures, or to an "atmospheric" blower, to deliver air at near-atmospheric pressures. Coupling it to the gas turbine more closely represents the gas turbine operating conditions of full engine tests without incurring the related costs. Coupling it to an atmospheric blower, on the other hand, permits tests on combustion parameters that are independent from engine operating conditions, such as the discharge coefficients of the injection and cooling holes, to be carried out. The use of an atmospheric blower in this case enables useful information to be collected while minimizing experimental costs. The costs are reduced by the elimination of extra personnel needed to operate the gas turbine and by the removal of expenditures, such as fuel and maintenance costs, related to the running of the gas turbine engine.

In addition to carrying out tests, the blower was extensively used throughout the commissioning of the laboratory. Specifically, the blower was used to:

- check for proper assembly and operation of components;

- verify the correct installation and proper working conditions of the instrumentation;

- perform component calibration;

- select proper data acquisition system settings; and

- carry out shakedown tests of the various LabView programs developed for data reduction, monitoring, and storage purposes. 


\subsection{Gas Turbine Room}

The Gas Turbine Room with dimensions of $3.5 \mathrm{~m}(\sim 12 \mathrm{ft})$ by $5.2 \mathrm{~m}(\sim 17 \mathrm{ft})$ and a ceiling height of $6 \mathrm{~m}(\sim 20 \mathrm{ft})$ was the room devoted to the Allison 250-C20B gas turbine engine. The purpose of the gas turbine engine was to supply pressurized air, through a system of stainless steel pipes (A in Figure 7.1), to the microturbine combustor under investigation in the Combustion Room.

At the start of this research project the Allison 250-C20B was already installed in the Gas Turbine Room. In addition, a means by which to bleed pressurized air from the engine had also been previously addressed (Murphy, 2004). However, due to a damaged oil pump, the turbine engine was not in good working order and therefore, repair of the pump had to be undertaken before the engine could run. More significantly, to reduce testing costs, the Allison 250-C20B was modified by the author from its original turboshaft configuration to an auxiliary power unit (APU) configuration. This modification eliminated one person from the Control Room. Such an alteration decreased testing complexity by streamlining the operation of the laboratory and more importantly reduced experimental costs. The following sections, after giving a brief overview of the Allison 250-C20B engine, will report on the modifications, repair work and instrumentation done to the turbine engine.

\subsubsection{Allison 250-C20B Overview}

The Allison 250-C20B gas turbine engine used in the laboratory is a Rolls-Royce turboshaft engine.

The high power to low weight ratio and the reverse flow design of the Allison 250C20B engine makes it ideal for helicopter applications (Figure 7.2). The mechanically 
independent (or free) power turbine also favours this application since it permits the helicopter rotor to operate at constant speed (Figure 7.2). The helicopter rotor constant speed is achieved by changing the rotor blade pitch and by adjusting the engine power through controlling the amount of fuel burnt by the engine.

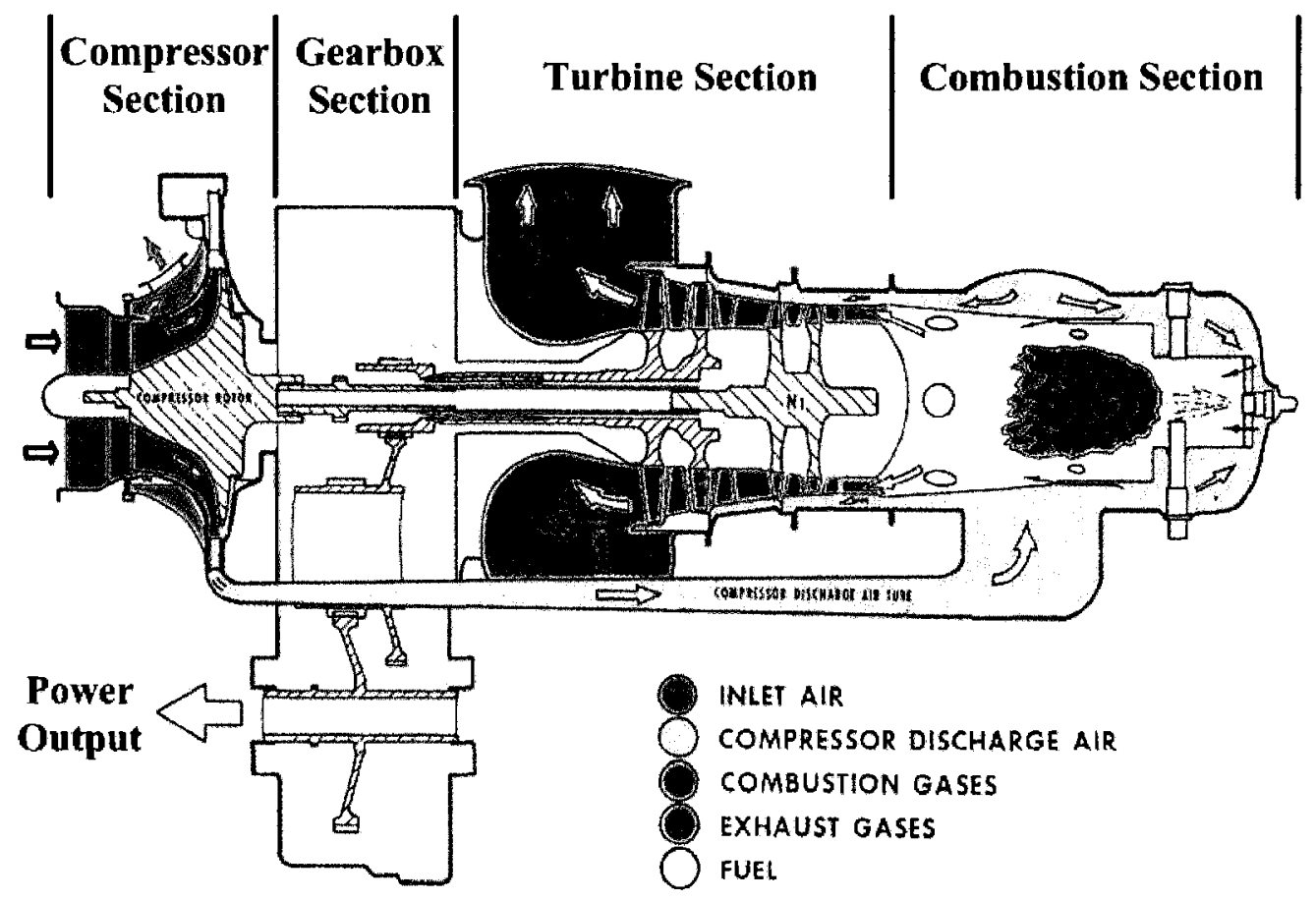

Figure 7.2 Allison 250-C20B configuration and air flow (Adapted from Anonymous, 2008)

As can be seen from Figure 7.2, the major components of the Allison 250-C20B engine are a compressor, which is composed of six axial compressor stages followed by one centrifugal stage, a single combustor, a two-stage gas producer turbine (high pressure turbine) and a two-stage power turbine (low pressure turbine) which supplies power to the helicopter rotor through a gearbox (Allison Engine Company, 1999). In this twinshaft arrangement, the high pressure turbine drives the compressor through one shaft while on the second shaft, the power turbine transmits the engine power to the helicopter rotor through a gearbox. 


\subsubsection{Allison 250-C20B Air Flow Path}

Figure 7.2 and Figure 7.3 show the air flow path of the Allison 250-C20B engine.

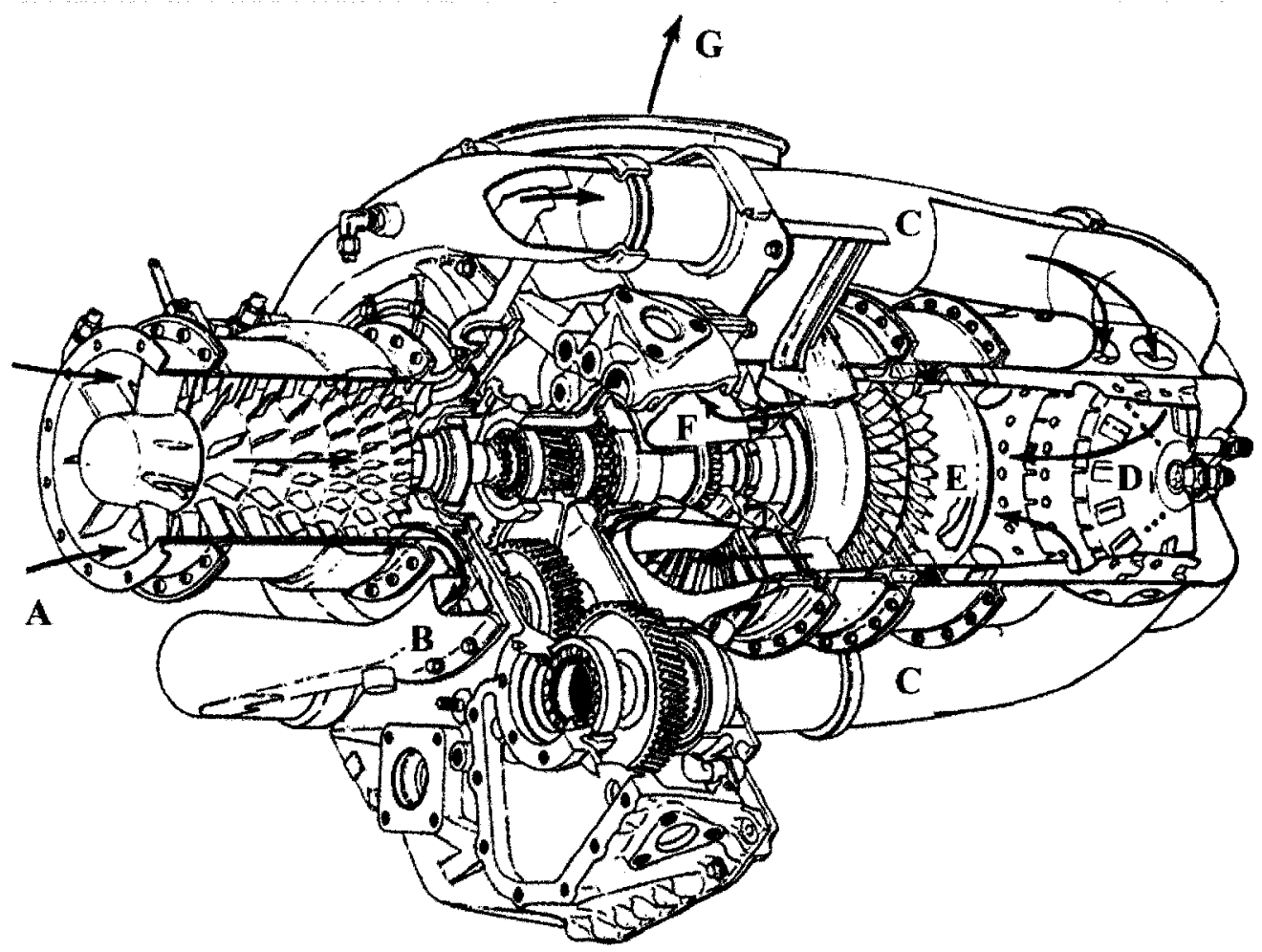

Figure 7.3 Allison 250-C20B isometric view and air flow path (Adapted from Allison

\section{Engine Company, 1999)}

In the Allison 250-C20B, as seen in Figure 7.3, the air enters the engine through the intake (A) and is pressurized by the compressor. From the compressor, it is discharged via a scroll type diffuser (B) into two ducts (C) with a pressure ratio of 7.1:1 (Allison Engine Company, 1999). The ducted and pressurized air then turns 180 degrees to enter the combustion section (D). The combustion section is made up of a combustion case and liner. The air enters the single combustion liner through a series of holes in the liner aft end. It is then mixed with fuel which is sprayed via a fuel nozzle and ignited by a spark igniter. The combustion products then leave the combustor to enter the turbine section (E) 
where they are expanded close to atmospheric pressure $(F)$ after which they are expelled into the atmosphere via two exhaust manifolds (G) (Allison Engine Company, 1999).

\subsubsection{Allison 250-C20B Engine Modifications}

As previously mentioned, before the engine could be run, a cracked shaft in the oil pump had to be repaired. Furthermore, a major engine modification that would greatly reduce testing costs and experimental complexity was also undertaken. This modification was to change the engine configuration from a turboshaft engine to an APU through the removal of the power turbine.

Since the operating principles of a turboshaft engine were previously discussed, only the auxiliary power unit (APU) concept will be covered here. An APU, by definition, is a device on a vehicle whose purpose is to provide energy for functions other than propulsion (Gunstone, 2004). For example, in large commercial aircrafts, the APU is a relatively small gas turbine that starts the aircraft main engines, through the use of compressed air, and provides electricity, hydraulic pressure and air conditioning while the aircraft is on the ground.

In the laboratory, the original turboshaft engine configuration had to be carefully aligned with and coupled to a hydraulic dynamometer (Figure 7.4) so that the output power produced by the engine could be safely dissipated. The removal of the Allison 250-C20B power turbine, which transformed the turboshaft engine into an APU, made the hydraulic dynamometer and the person controlling the equipment no longer necessary. Hence, the modification reduced testing costs by eliminating one person from the Control Room and decreased testing complexity by streamlining the operation of the laboratory. 


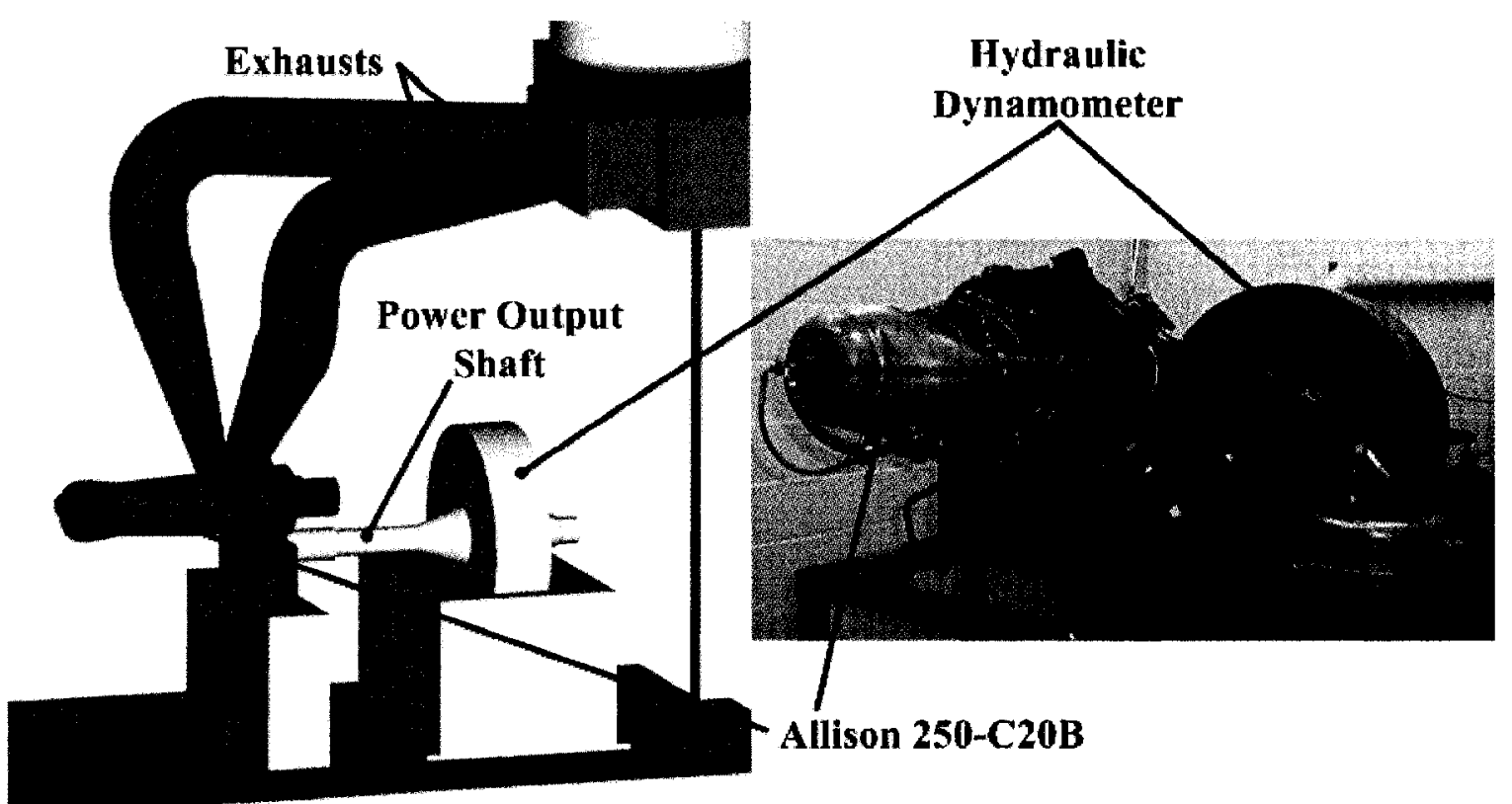

Figure 7.4 Allison 250-C20B and dynamometer

The Emissions Research and Measurement Department, where the combustion laboratory is located, routinely uses dynamometers to provide simulated road loading conditions for internal combustion engines so that detailed investigations into combustion emissions can be carried out. However, the scope of the hydraulic dynamometer used in this research project was neither to simulate engine loadings nor to measure torque and rotational speed from which power produced by the Allison 250-C20B engine could be calculated. The hydraulic dynamometer was used to prevent the free turbine from overspeeding. The power dissipation process was carried out using the hydraulic dynamometer as a water brake absorber. Specifically, water was added within the dynamometer housing until the turboshaft engine was held at a steady rotational speed against the load. As the turboshaft power settings were changed, the hydraulic dynamometer settings were also adjusted to compensate and to keep constant the new rotational speed of the power turbine shaft. This process involved the use of two people one person to control and monitor the Allison 250-C20B engine and the second person to 
control and monitor the hydraulic dynamometer. With the removal of the power turbine, therefore, the need to control the power shaft rotational speed was eliminated since the shaft was now stationary. Therefore, the dynamometer and its operator became no longer necessary.

Not to compromise the engine air flow path and structural integrity, the original twostage power turbine wheels were substituted with two (same part numbers) modified scrap turbine wheels. A set of scrap turbine wheels were supplied from Magellan Aerospace Corporation ${ }^{10}$. With the scrap turbine wheels on hand and with the help of the engine maintenance manual, the low pressure turbine module, housing the two-stage power turbine wheels, was disassembled from the rest of the engine (Figure 7.5).

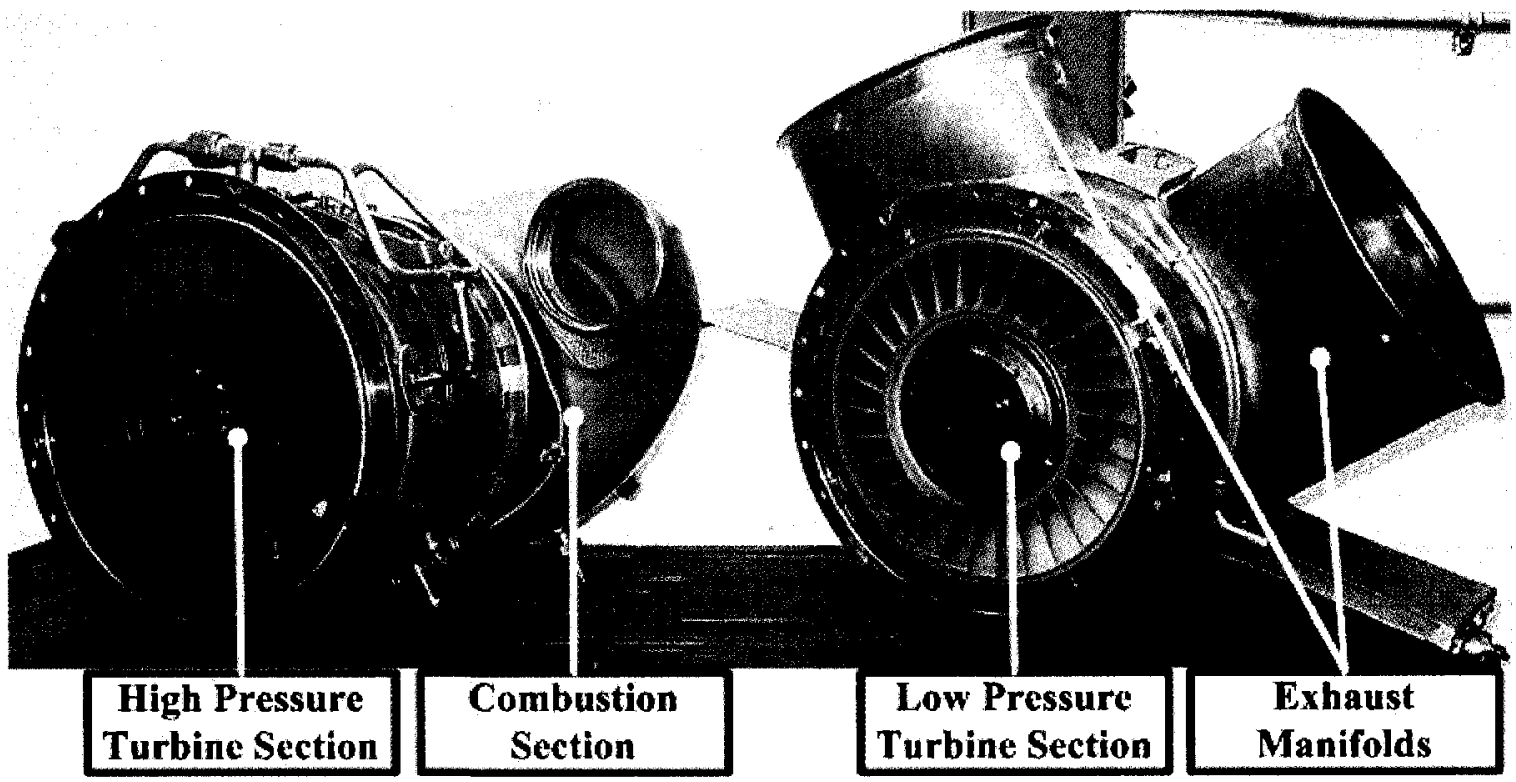

Figure 7.5 Partial disassembly of Allison 250-C20B engine

Tools were designed and manufactured so that complete disassembly of the various components making up the low pressure turbine section could be undertaken. An example of such a tool can be seen in Figure 7.6.

\footnotetext{
${ }^{10}$ Magellan Aerospace Corporation, 3160 Derry Road East, Mississauga, Ontario L4T 1A9, Canada
} 


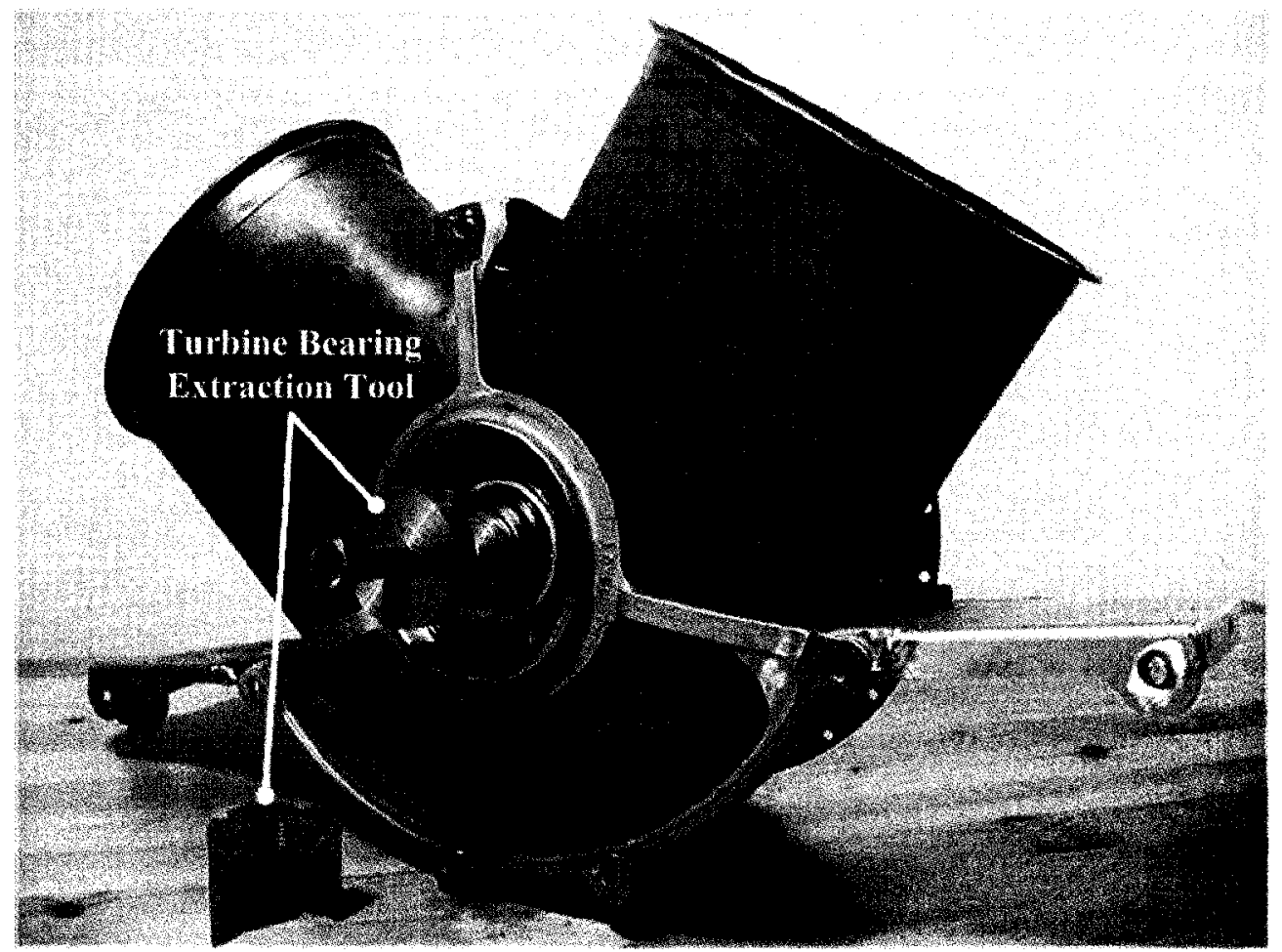

Figure 7.6 Example of tool used for engine disassembly

In addition to the creation of tools, a photo documentation process was initiated to record the modification progress.

Figure 7.7 shows one of the two scrap turbine wheels before and after modifications.
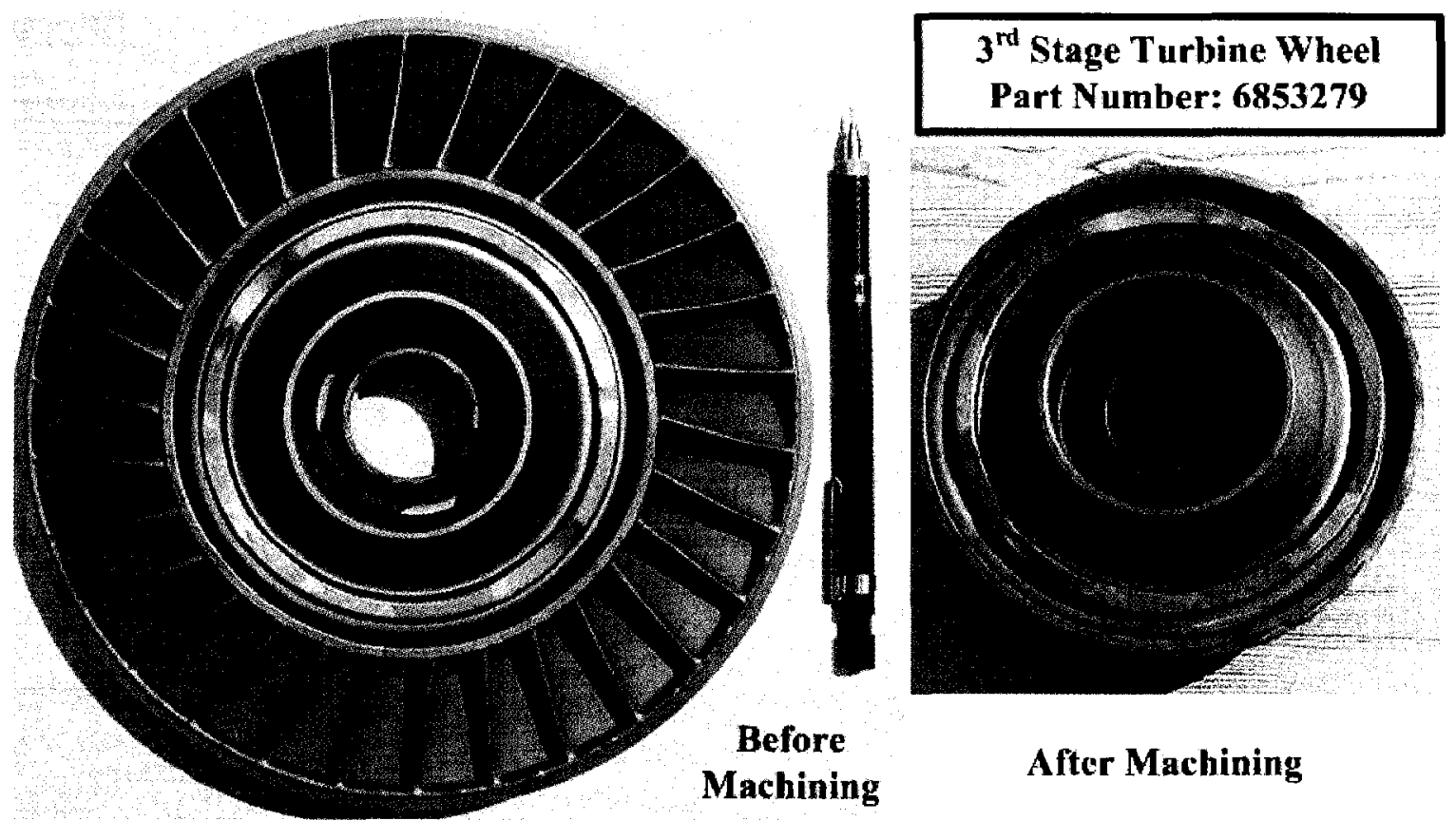

After Machining

Figure 7.7 Third stage low pressure turbine wheel before and after machining 
As can be seen by the exploded view of the low pressure turbine section (Figure 7.8), to retain the engine configuration and air flow path, the turbine disks were left untouched and only the turbine blades and shrouds were removed. The machining process was carried out, first by cutting the blades at their roots using an angle grinder and then by stone grinding the left over material. Since, without blades, the turbine wheels could no longer rotate, balancing of the disks was not necessary.

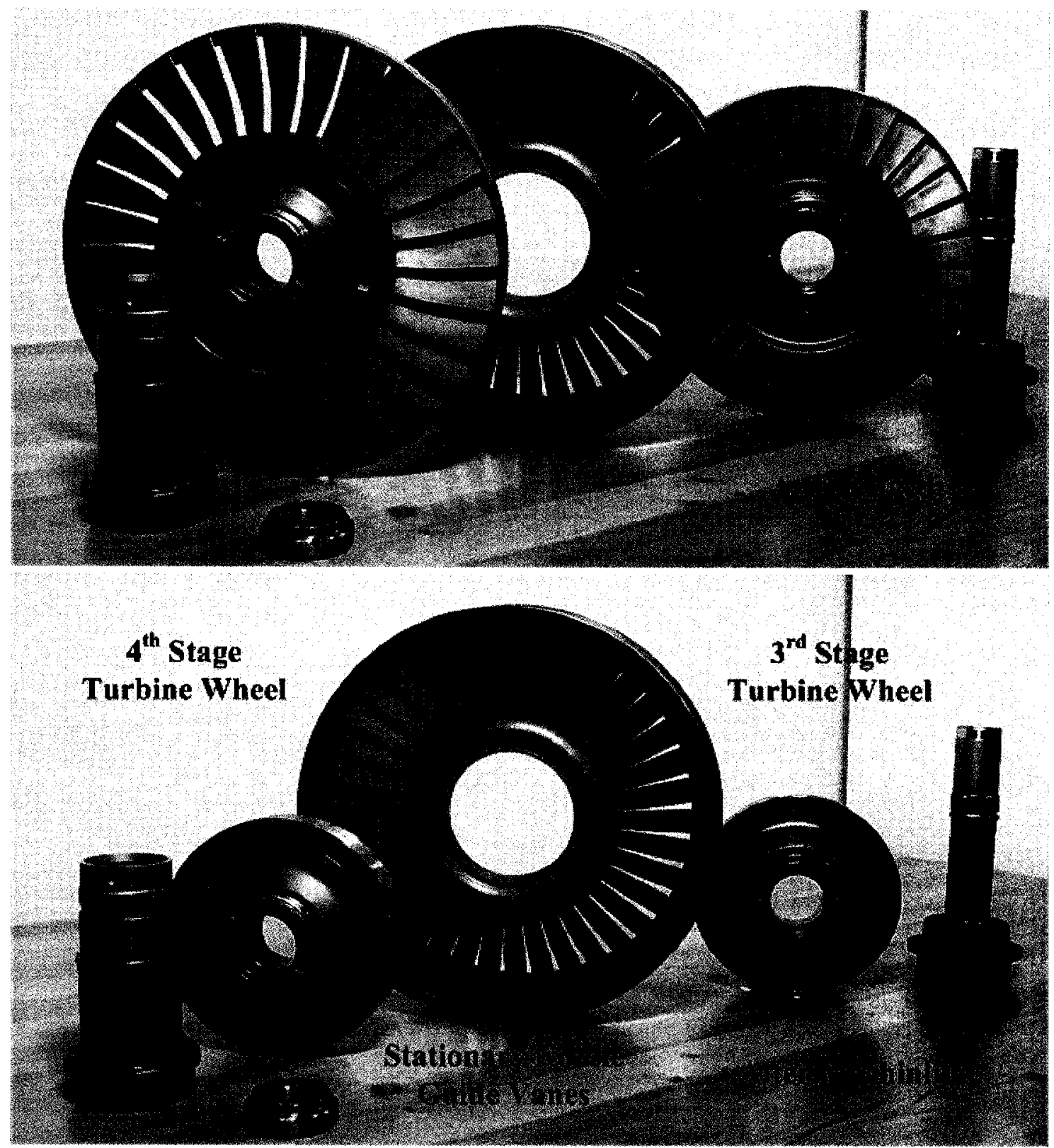

Figure 7.8 Exploded view of low pressure turbine section 
Once the modifications were completed, the reassembly of the low pressure turbine section was undertaken (Figure 7.9). With a new shaft in the oil pump, the engine was then reassembled (Figure 7.10 and Figure 7.11 respectively). Since the dynamometer was no longer of use, it was removed from the test cell.

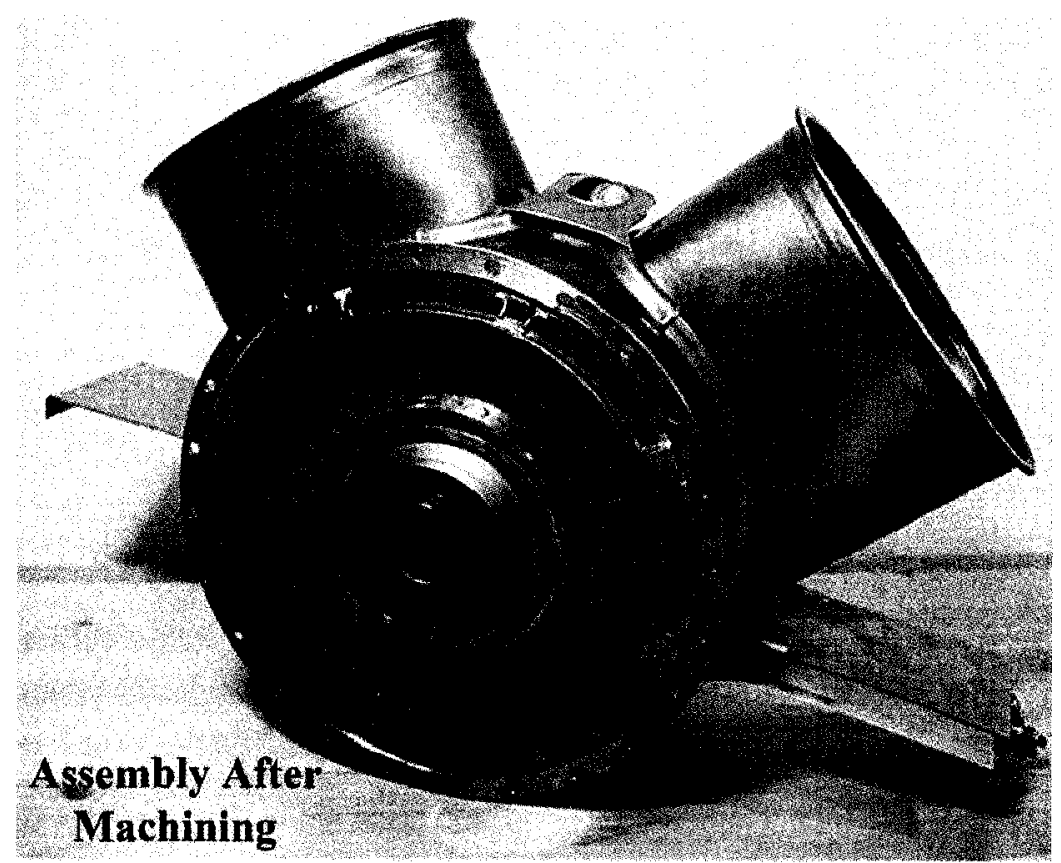

Figure 7.9 Low pressure turbine section reassembly

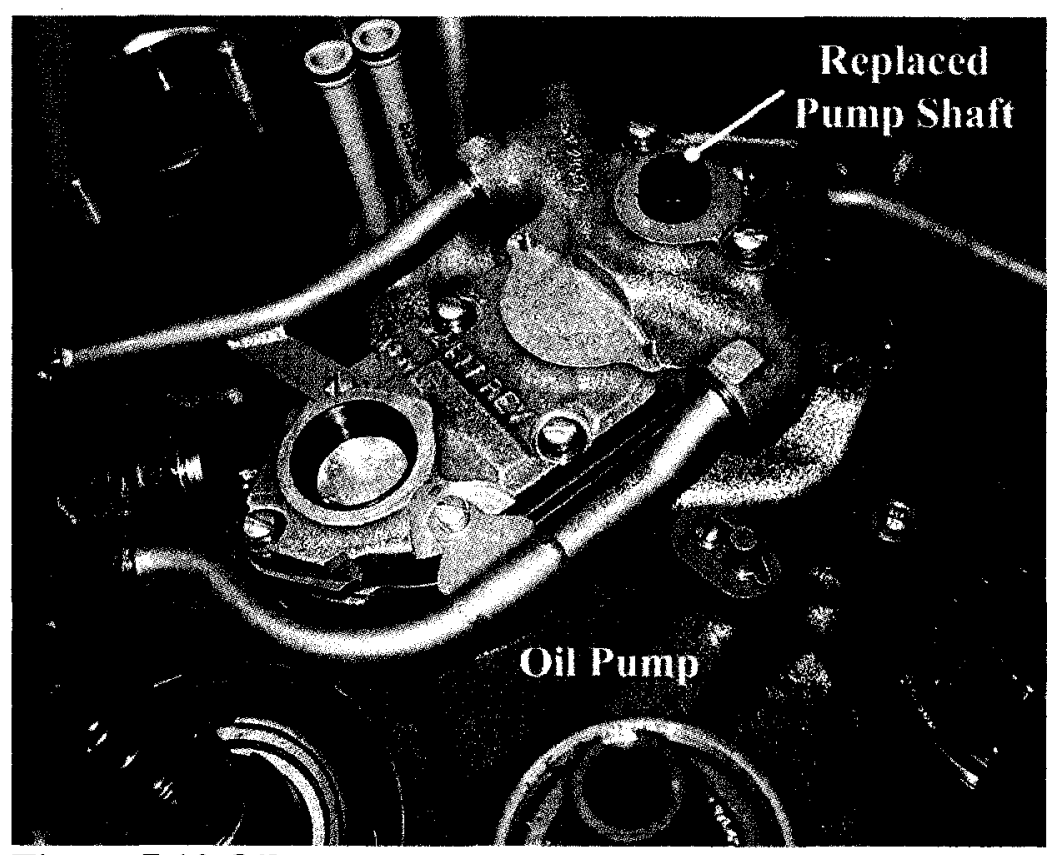

Figure 7.10 Oil pump assembly 


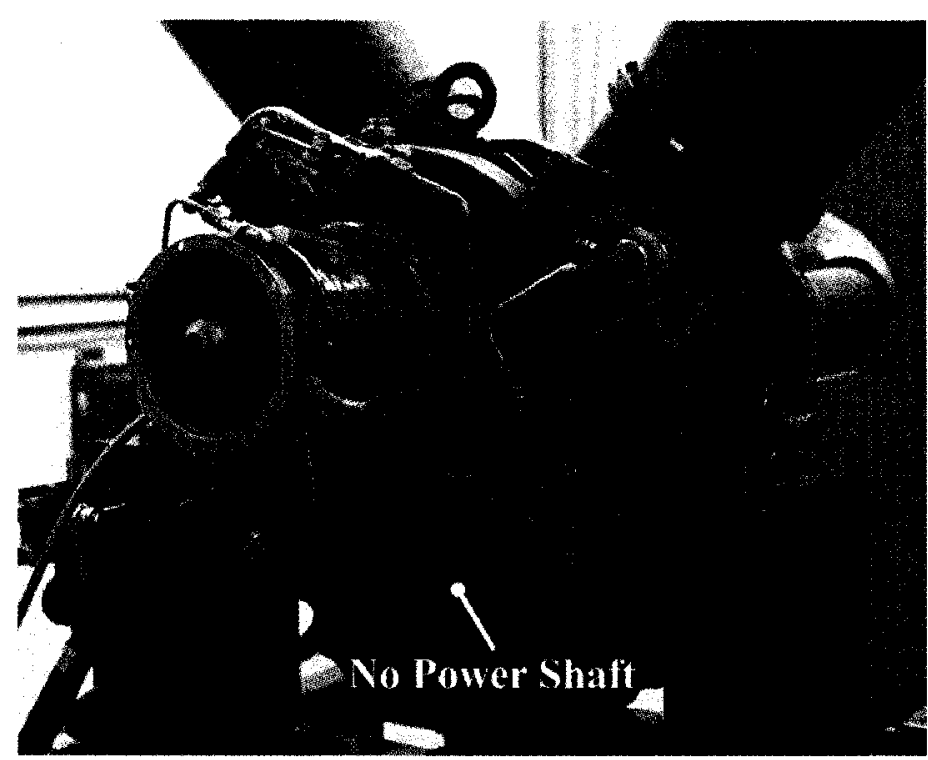

Figure 7.11 Allison 250-C20B final assembly after modification

Another fundamental engine modification was the inclusion of a bleed system. This work came from previous efforts carried out by Murphy (2004). The concepts behind this system will briefly be introduced below. For detailed information, the above reference should be consulted.

The bleed scheme used one of the two compressor discharge air tubes, which run between the compressor and combustor (Figure 7.12), to accomplish the design goal.

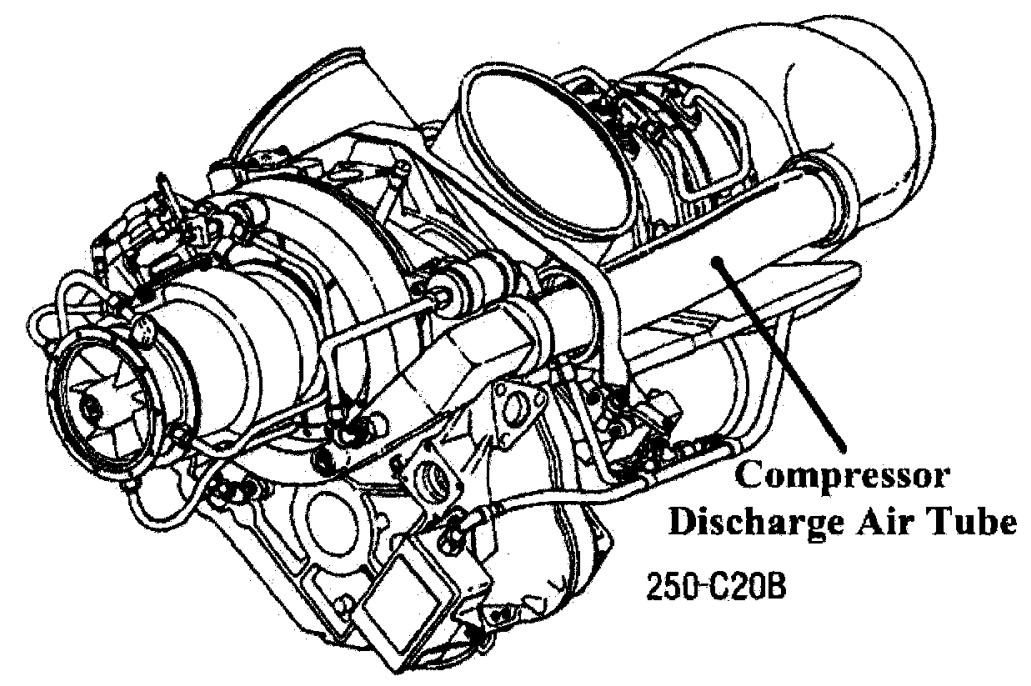

Figure 7.12 Allison 250-C20B discharge air tube (Adapted from Allison Engine Company, 1999) 
Three holes were made in the right discharge tube and a chamber, made of aluminum, was fastened around the duct enclosing the three holes (Figure 7.13). To ensure that there were no air leaks out of the bleed chamber, room temperature vulcanizing (RTV) material was used to make gaskets. These custom-fitted gaskets were then placed around all mating surfaces. Furthermore, an o-ring was used to stop air leakages where the bleed chamber flange mates with the stainless steel pipe that routes the compressed air to the Combustion Room. The bleed system was designed to permit for roughly one third of the engine mass flow rate $(0.5 \mathrm{~kg} / \mathrm{s}$ or $1.1 \mathrm{lb} / \mathrm{sec})$ to be bled (Murphy, 2004). The bled air would have an approximate pressure of 7 bar (100 psi) (Murphy, 2004).

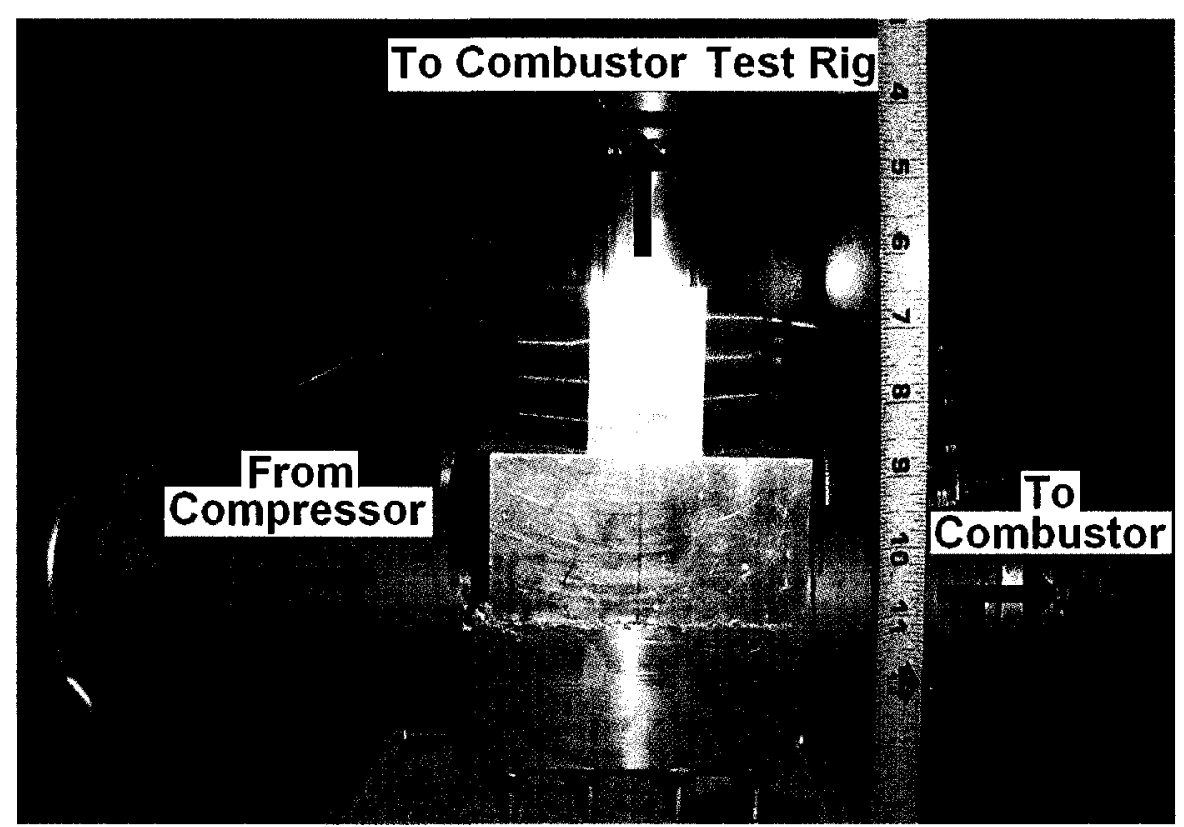

Figure 7.13 Air bleed system assembly (Murphy, 2004)

To improve engine performance, another adaptation to the gas turbine engine was carried out in this research project. A metering bellmouth was designed, constructed and installed to improve flow quality into the compressor and to accurately measure air mass flow rates (Section 7.2.4 for details) into the engine. The bellmouth design, consisting of an elliptical inlet followed by a cylindrical throat, was taken from the ASME long-radius 
nozzle guidelines provided by Blevins (1984). The metering bellmouth geometry and its dimensions can be seen in Figure 7.14.

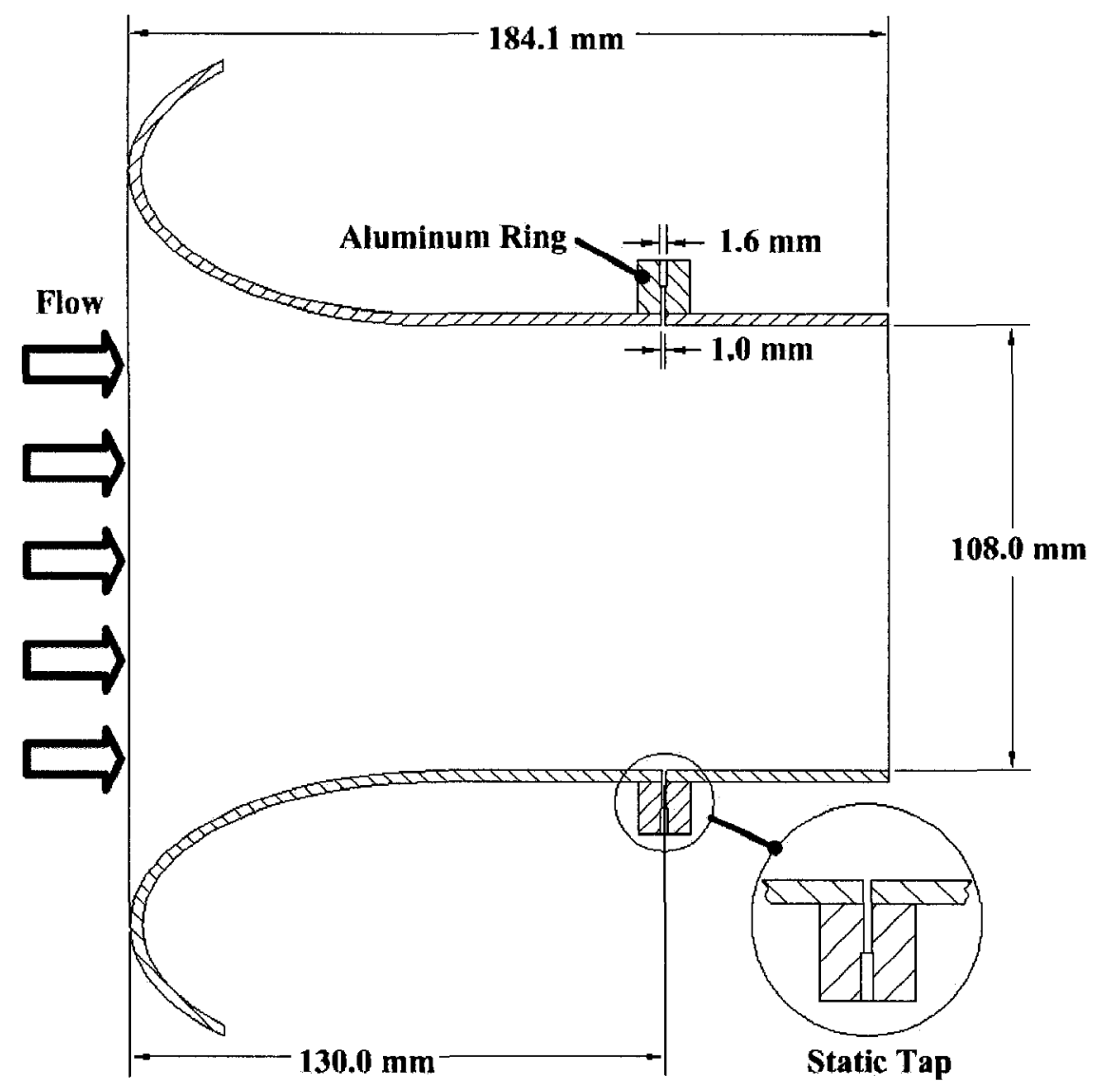

Figure 7.14 Metering bellmouth

The bellmouth was manufactured using a vacuum forming process which was carried out in the Industrial Designs Laboratory at Carleton University. In the vacuum forming process, a thermoplastic sheet was heated and stretched onto a previously machined mold which represented the negative geometry of the bellmouth (Figure 7.15). The stretched sheet was held against the mold until the thermoplastic completely cooled. This clinging process was achieved by creating a vacuum between the mold surface and the sheet via strategically located holes. The mold, which was made of previously stacked and glued medium-density fiberboards (MDF), was machined having a longer cylindrical throat than the original design. This was done to ensure safe removal of extra material plugging 
the bellmouth outlet and to include a $45^{\circ}$ draft angle to simplify the release of the formed bellmouth from the mold.

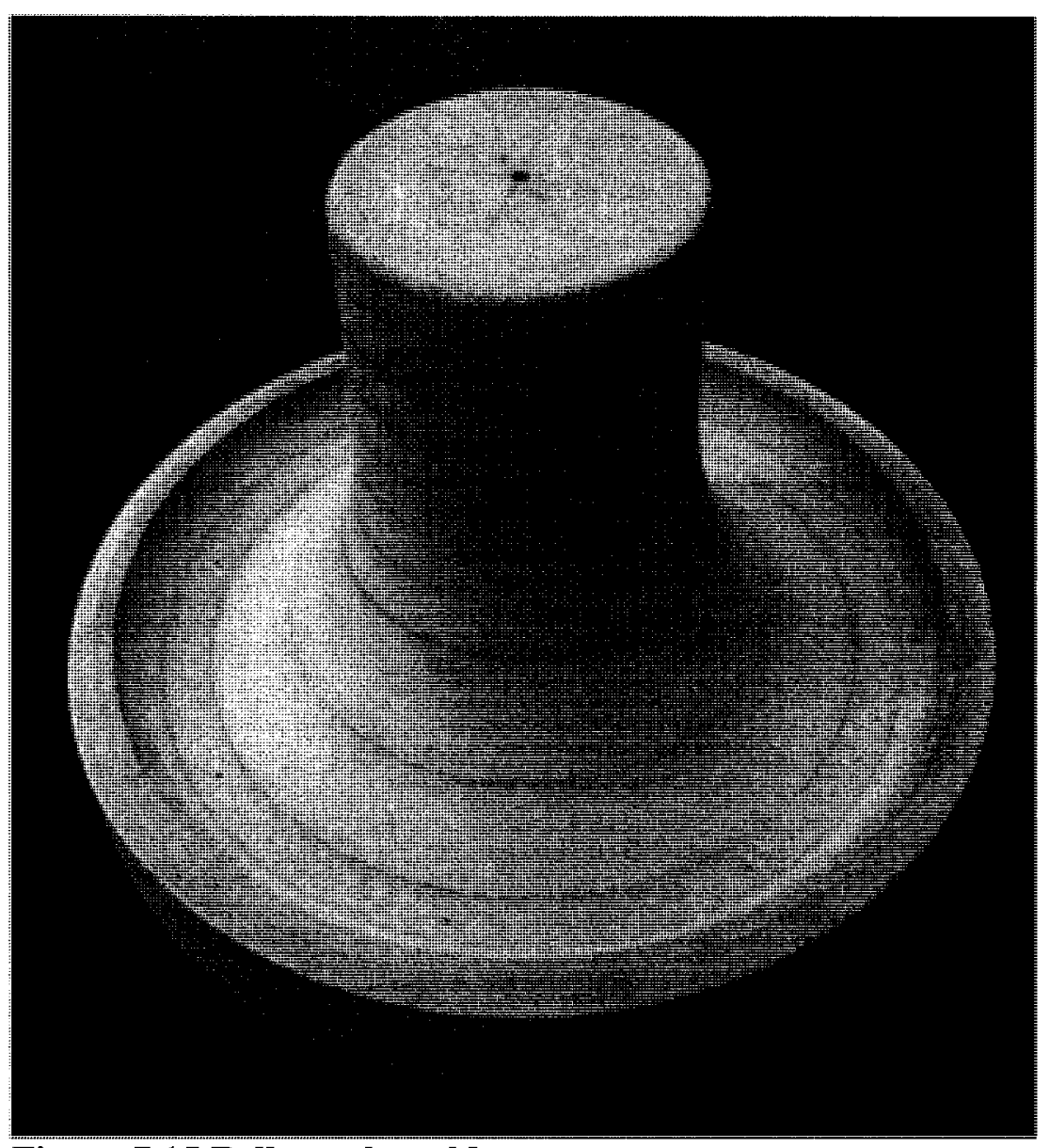

Figure 7.15 Bellmouth mold

The final product was a smooth and structurally sound metering bellmouth which had to be instrumented and then installed onto the compressor inlet as can be seen in Figure 7.16 .

After having completed the metering bellmouth installation, a protective screen ( $0.6 \mathrm{~m}$ by $0.6 \mathrm{~m}$ and $0.3 \mathrm{~m}$ deep) of $6 \mathrm{~mm}$ wire mesh was designed, manufactured and assembled around the engine bellmouth to prevent foreign objects from entering and damaging the engine (Figure 7.16) while it was running. 


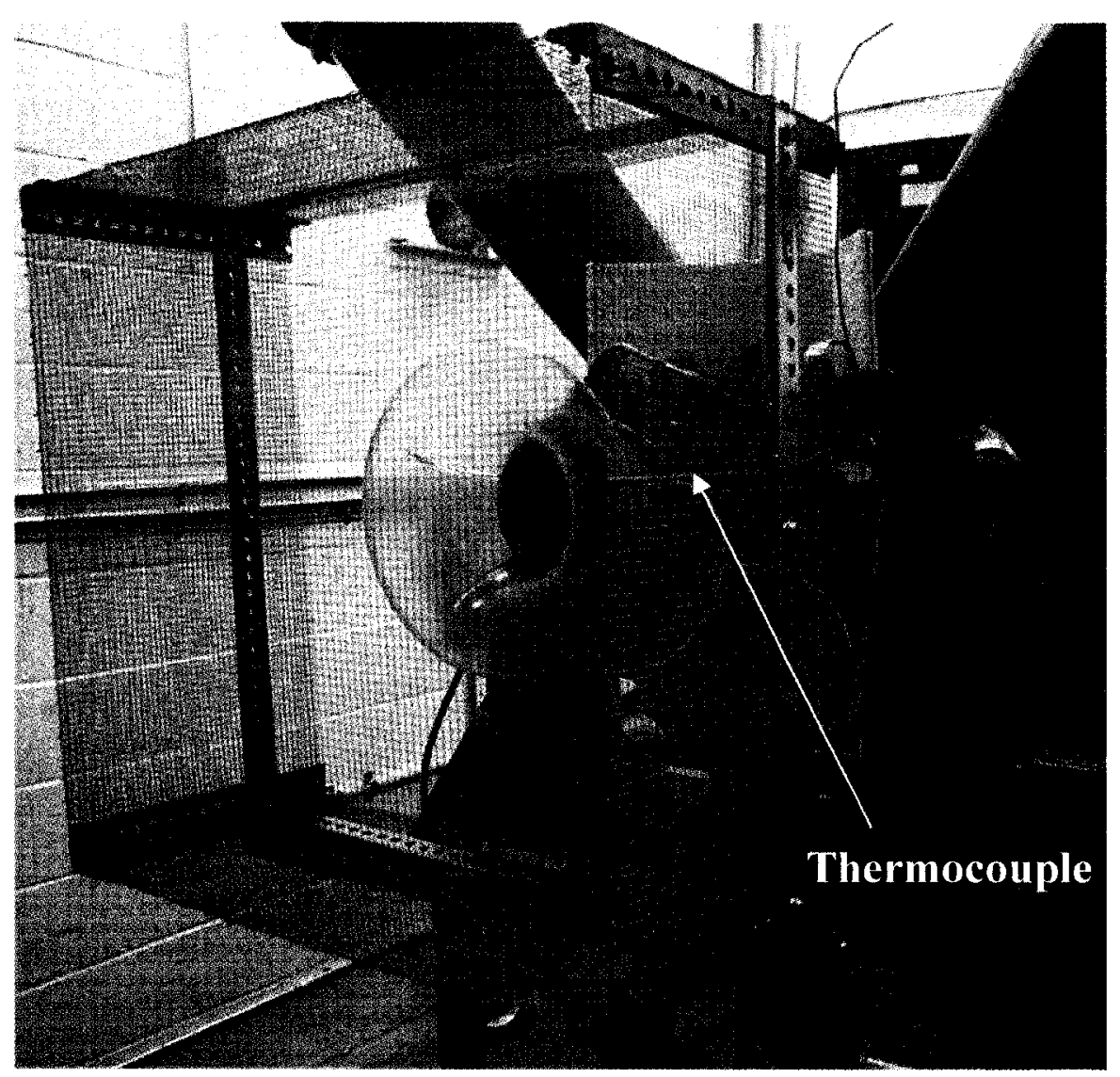

Figure 7.16 Inlet protective screen

For safety reasons, the last modification performed on the Allison 250-C20B engine was the addition of a fail-safe mechanism. The purpose of the fail-safe mechanism was to bring the running gas turbine down to idle conditions in case of engine control loss due to failure of the hydraulic control system, which will be discussed below.

In the gas turbine combustion research laboratory, the Allison 250-C20B engine is controlled by a hydraulic system which starts in the Control Room, spans across the Combustion Room and finishes in the Gas Turbine Room. The hydraulic control system, which regulates the amount of fuel injected into the Allison 250-C20B, is composed of a throttle, in the Control Room, and a hydraulic actuator, in the Gas Turbine Room. These two components are linked by stainless steel tubings and tube fittings to form a completely closed loop system which is filled with hydraulic oil. A throttle movement in 
the Control Room, therefore, makes the hydraulic actuator in the Gas Turbine Room move. This actuator, which is mechanically linked via a rod to the Allison 250-C20B fuel control/governor system, in turn delivers more or less fuel into the gas turbine combustor. In case of hydraulic oil loss, due to the breakage of any of the components (i.e., throttle, hydraulic actuator, tubings or tube fittings) making up the hydraulic control system, the Allison 250-C20B would no longer be able to be remotely controlled, creating a dangerous situation.

Adding an extension spring to the hydraulic control system is a way to evade the above-mentioned potential problem. Once incorporated into the system the spring is under a small load (spring almost unstretched) at idle engine conditions. As the engine is brought to operating conditions, other than idle, the spring, which is fixed at one end and fastened to the fuel control/governor arm at the other end, stretches, increasing the potential energy stored within it. In case of hydraulic control system failure (i.e., hydraulic oil loss and therefore, pressure loss in the control system) the potential energy stored by the spring would then be released, returning the spring to its original configuration. The contraction of the spring would bring the fuel control/governor arm back to its idle position, thus, reducing the amount of fuel injected into the Allison 250C20B combustor. Once at idle conditions, the gas turbine engine can be safely shut down and the hydraulic control system failure can be addressed. Figure 7.17 shows various views of the fail-safe mechanism. 


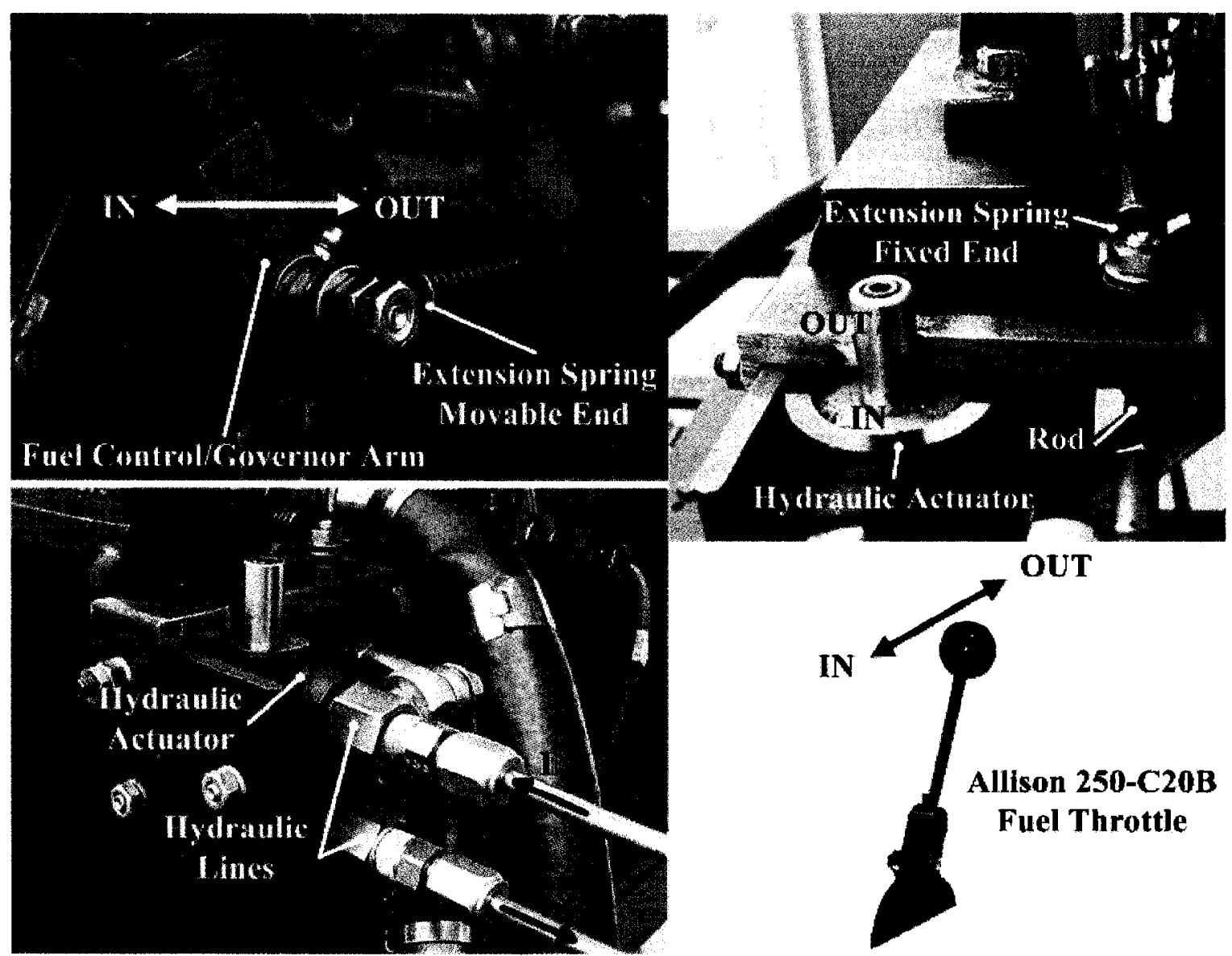

Figure 7.17 Fail-safe mechanism

\subsubsection{Allison 250-C20B Instrumentation}

In addition to the already existing gas turbine instrumentation, which is used to monitor the rotational speed of the engine, the oil pressure and temperature and the interstage turbine temperature (ITT) (which, with the removal of the power turbine, is now the exhaust gas temperature) a means by which to measure the mass flow rate, and vibrations of the engine was also incorporated.

The mass flow rate of the engine was estimated using the previously discussed metering bellmouth and the Bernoulli equation, explained below. 


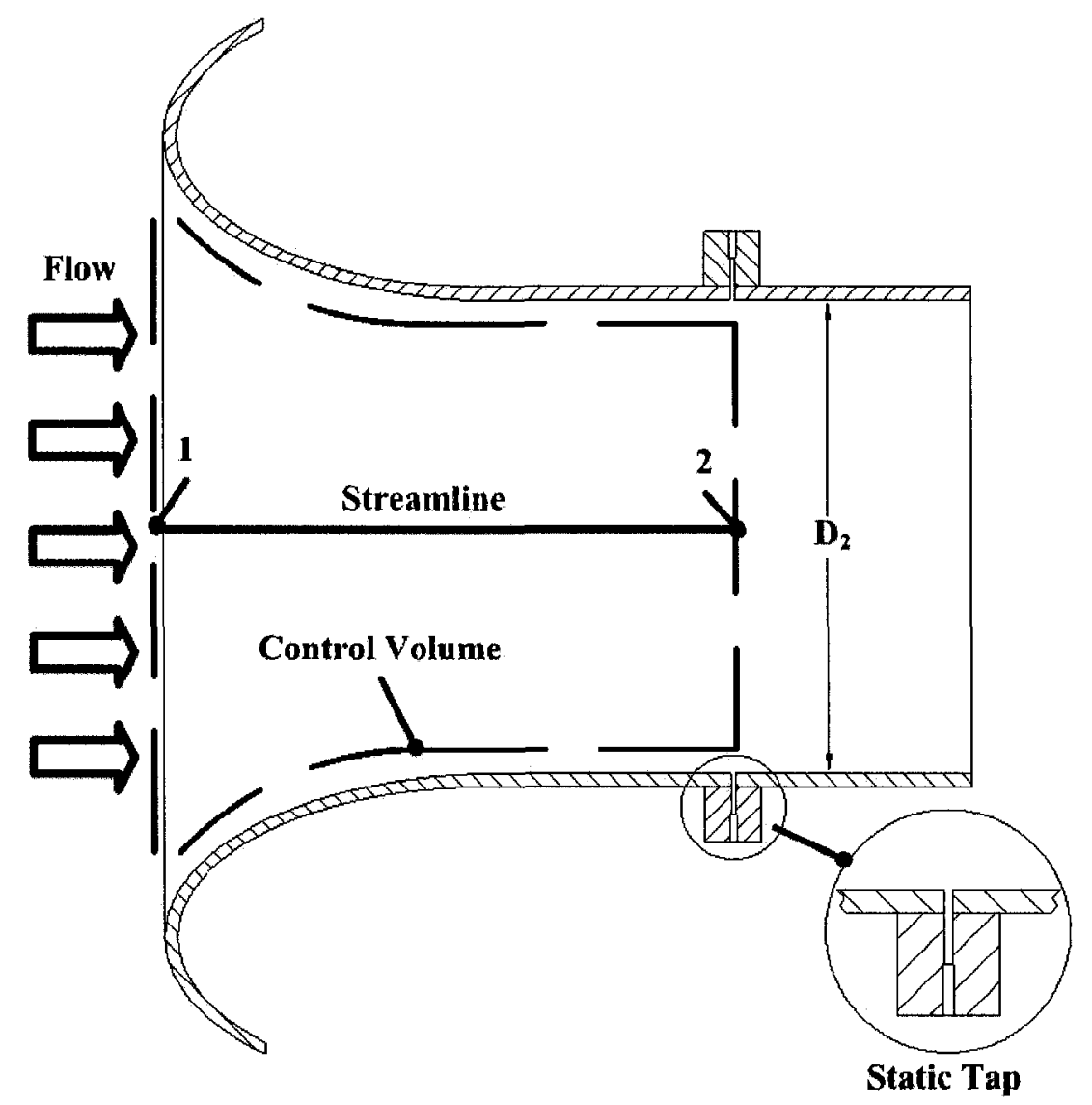

Figure 7.18 Metering bellmouth principle

Assuming a steady state flow which is incompressible (Mach number, $\mathrm{M} \leq 0.3$ ) and frictionless, the Bernoulli Equation (7.1) can be applied to any two points on a streamline (Figure 7.18) (White, 1999).

$$
\frac{p_{1}}{\rho}+\frac{V_{1}^{2}}{2}+g z_{1}=\frac{p_{2}}{\rho}+\frac{V_{2}^{2}}{2}+g z_{2}
$$

If point 1 on the streamline is taken far upstream of the bellmouth where the flow is motionless $\left(V_{1}=0\right)$ and given that there are no streamline elevation changes $\left(\mathrm{z}_{1}=\mathrm{z}_{2}\right)$, the Bernoulli equation can be rewritten as:

$$
p_{1}=p_{2}+\frac{V_{2}^{2}}{2}
$$


where $p_{1}=p_{a t m}$

Hence, by measuring the atmospheric pressure $\left(p_{a t m}\right)$ and the static pressure inside the bellmouth $\left(p_{2}\right)$, the velocity $\left(V_{2}\right)$ can be calculated.

Once the air velocity inside the bellmouth is obtained, the engine mass flow rate can be estimated using the following equation:

$\dot{m}_{2}=\rho V_{2} A_{2}$

With $V_{2}$ obtained and $A_{2}$ calculated using the bellmouth diameter at the wall taps location, the only factor missing in Equation (7.3) is the air density $(\rho)$. Assuming that air behaves as an ideal gas, the density can be calculated as,

$\rho=\frac{p}{R_{a} T}$

where $p$ is the air atmospheric pressure $\left(p_{a t m}\right)$

$T$ is the air temperature

$R_{a}$ is the air gas constant

As can be concluded from the above theory, the three experimental measurements needed to estimate the gas turbine mass flow rate are the atmospheric pressure, the static pressure at the bellmouth throat and the air temperature entering the engine.

The Gas Turbine Room atmospheric pressure was measured by a pressure transducer whose company and model number are Viatran 218. The range of this absolute pressure transducer, shown in Figure 7.25, varies between $0 \mathrm{~Pa}$ to $103.42 \mathrm{kPa}$ ( 0 psi to $15.0 \mathrm{psia}$ ) with a corresponding output signal of 0 VDC to 5 VDC. 
Experimentally, the static pressure can be measured using wall taps whose design is shown in Figure 7.18. Static pressure is a difficult measurement to make. Therefore, general guidelines are given for machining wall taps so that measurement accuracy can be maximized. The three recommended practices given by Saravanamuttoo (1990) for machining wall taps, are as follows:

- the wall tap hole(s) must be between $1.0 \mathrm{~mm}$ and $1.2 \mathrm{~mm}$;

- the hole(s) has to be drilled perfectly normal to the wall where the pressure is to be measured; and

- the hole(s) edges must be perfectly square and free of any burrs (if they exist) produced by the drilling process.

Closely following the above recommendations will ensure a minimum of disturbance to the flow passing over the wall tap(s), thus, giving more accurate measurements.

To make a better estimate of the static pressure, the Allison 250-C20B metering bellmouth was instrumented with four wall taps, circumferentially spaced at $90^{\circ}$ intervals. To reduce instrumentation costs as well as data acquisition times, the four wall taps were connected, via Teflon tubings, to an averaging manifold, which in turn was connected, through a single Teflon tubing, to a second pressure transducer present in the engine test cell, as shown schematically in Figure 7.19. The Teflon tubing, purchased from Scanivalve ${ }^{11}$, had a $1.37 \mathrm{~mm}(0.054 \mathrm{in})$ inner diameter and a $2.18 \mathrm{~mm}(0.086 \mathrm{in})$ outer diameter with a recommended maximum working pressure of $3450 \mathrm{kPa}(500 \mathrm{psi})$ and a maximum working temperature of $260^{\circ} \mathrm{C}$. The pressure transducer used to measure the

${ }^{11}$ Technel Engineering Inc., 60 Marycroft Ave. Unit 2, Woodbridge, Ontario L4L 5Y5, Canada 
bellmouth static pressure was a PX243A, purchased from Omega Enginnering ${ }^{12}$ (Figure 7.25). The pressure range measured by this instrument varied within a gauge pressure of $\pm 17.23 \mathrm{kPa}( \pm 2.5 \mathrm{psi})$ and the transducer analog output (1 to $6 \mathrm{VDC})$ was temperature compensated.

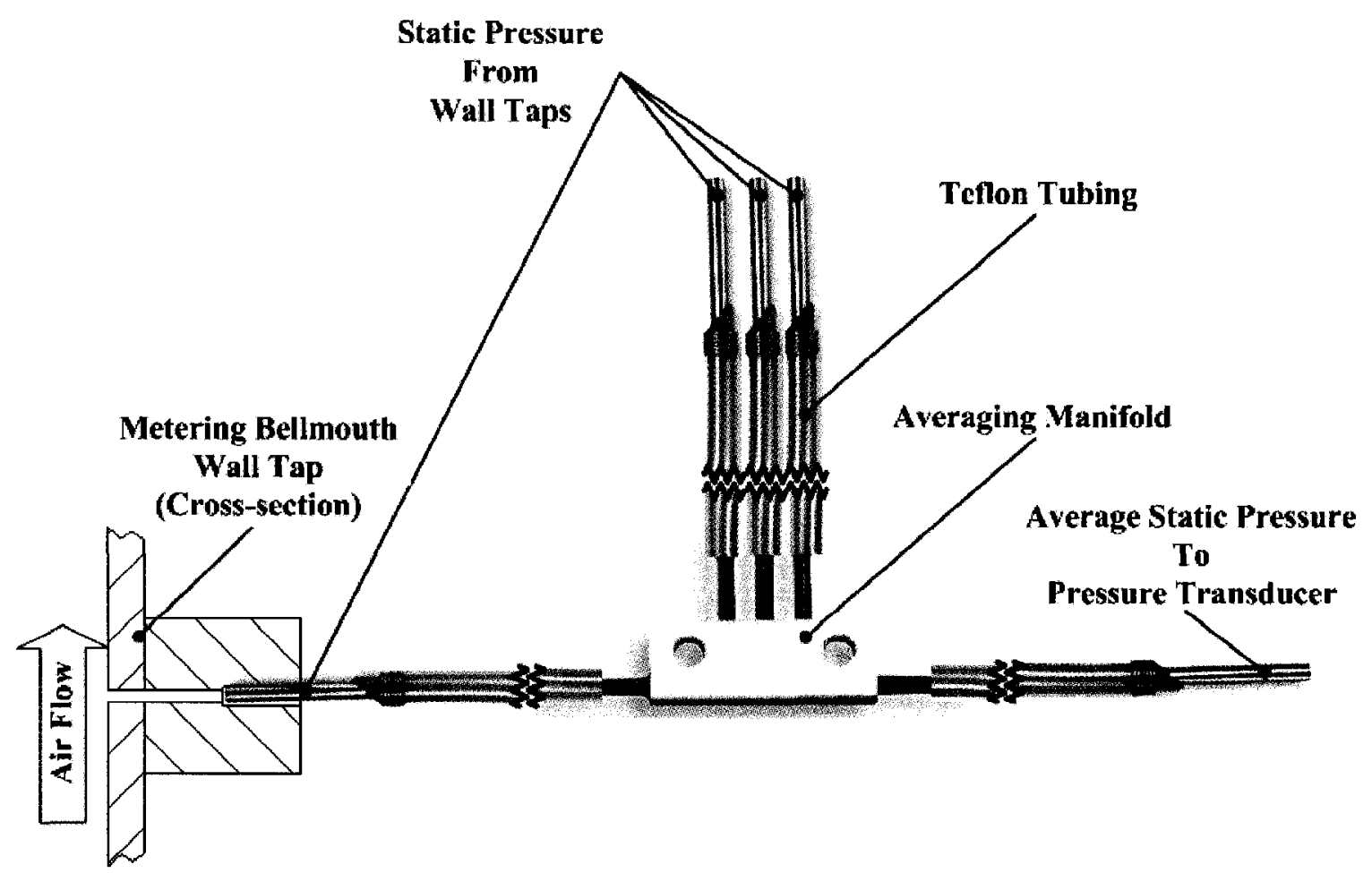

\section{Figure 7.19 Averaging manifold}

To estimate the air density to be used in Equation (7.4), a means by which to measure temperature was needed. The most common gas temperature sensor used when instrumenting gas turbine engines are thermocouples (Saravanamuttoo, 1990). Thermocouples, in their simplest form, consist of two wires made of different metals and joined at one end as shown in Figure 7.20.

\footnotetext{
${ }^{12}$ Omega Engineering 976 Bergar, Laval (Quebec) H7L 5A1, Canada
} 


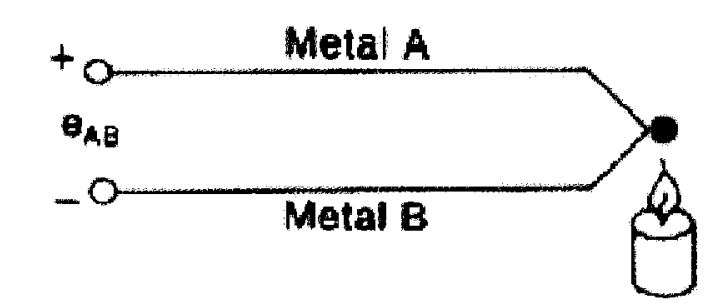

\section{$\mathrm{e}_{\mathrm{AB}}=$ SEEBECK VOLTAGE}

\section{Figure 7.20 Thermocouple working principle (Omega Engineering, 2004)}

With a change in temperature, the dissimilar metals produce a continuous current which flows in the thermoelectric circuit. The change in electromotive force (emf) between the two metal ends can be read by a voltmeter. Through mathematical manipulations, (Omega Engineering, 2004) the millivoltage is then transformed into engineering units of temperature such as ${ }^{\circ} \mathrm{C}, \mathrm{K},{ }^{\circ} \mathrm{F}$, or ${ }^{\circ} \mathrm{R}$.

For this research project, from the many types of thermocouples available, the type $\mathrm{K}$ thermocouple was chosen to be used throughout the gas turbine combustion research laboratory. The type $\mathrm{K}$ thermocouple was selected because of its operating temperature range which is from $-270^{\circ} \mathrm{C}$ to $1372^{\circ} \mathrm{C}$ and because of its lower cost when compared to other thermocouple types used in high temperature applications. In the type $\mathrm{K}$ thermocouple, the two metals making up the wires of the sensor are nickel-chromium $(+)$, also known as Chromel, and nickel-aluminun (-), also referred to as Alumel (Figure 7.21). The sheath metal protecting the wires was chosen to be stainless steel (316) for the thermocouples measuring temperatures upstream of the combustor and for the Allison 250-C20B inlet and Hastelloy for the thermocouples measuring the liner wall temperature and the exhaust gasses from the microturbine combustor and from the Allison 250-C20B. 


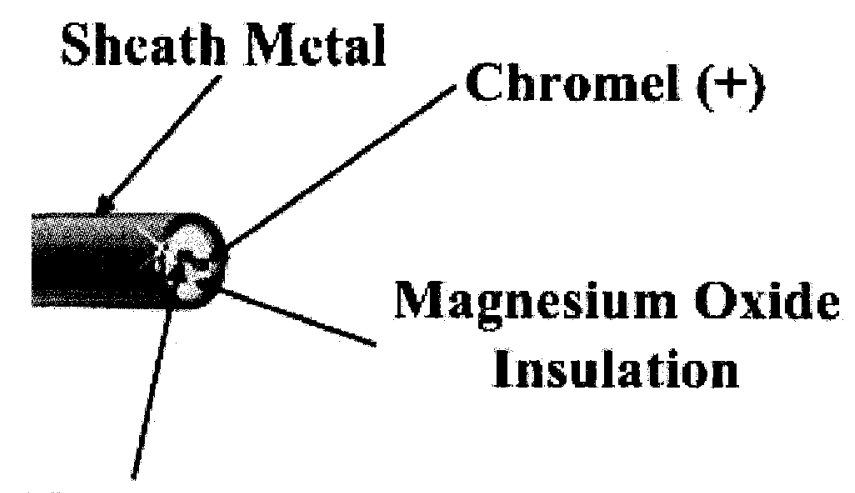

Alumel (-)

Figure 7.21 Type $K$ thermocouple nomenclature (Adapted from Omega Engineering, 2004)

After having selected the type of gas temperature sensor to be used, the engine was instrumented with two type $\mathrm{K}$ thermocouples. One thermocouple was placed at the bellmouth inlet, as is shown in Figure 7.16, and a second thermocouple was inserted into the exhaust manifold. The inlet thermocouple measured the air temperature entering the engine, needed for estimating the air density. The second thermocouple, measuring the exhaust gas temperature, was a redundant measurement since, as previously mentioned, the engine manufacturer had already provided a means by which to measure this hot gas temperature. However, having two sensors measuring the exhaust gas temperature permitted both people in the Control Room to monitor this very critical engine operating parameter so that, in case of emergency, reaction time delays or confusion could be minimized.

Since the engine configuration had been changed, a piezoelectric accelerometer was also installed on the Allison 250-C20B to see if the engine vibration signature (i.e., the engine natural frequencies) had been altered.

The piezoelectric accelerometer is a sensor that produces an electrical signal proportional to acceleration. Specifically, the accelerometer is composed of a 
piezoelectric crystal element and an attached mass (Figure 7.22). As the engine vibrates relative to its surroundings, the mass exerts an inertial force on the piezoelectric crystal (Omega Engineering, 2000). The force produces a proportional electrical charge $(\mathrm{V}=\mathrm{e}$ in Figure 7.22) on the crystal which is then mathematically manipulated to display units of acceleration (g). The accelerometer, purchased from Omega Engineering, was an ACC101 (Figure 7.22). The output of this accelerometer is $100 \mathrm{mV}$ per gravitational acceleration (g) with a maximum operating range of $\pm 80 \mathrm{~g}$.
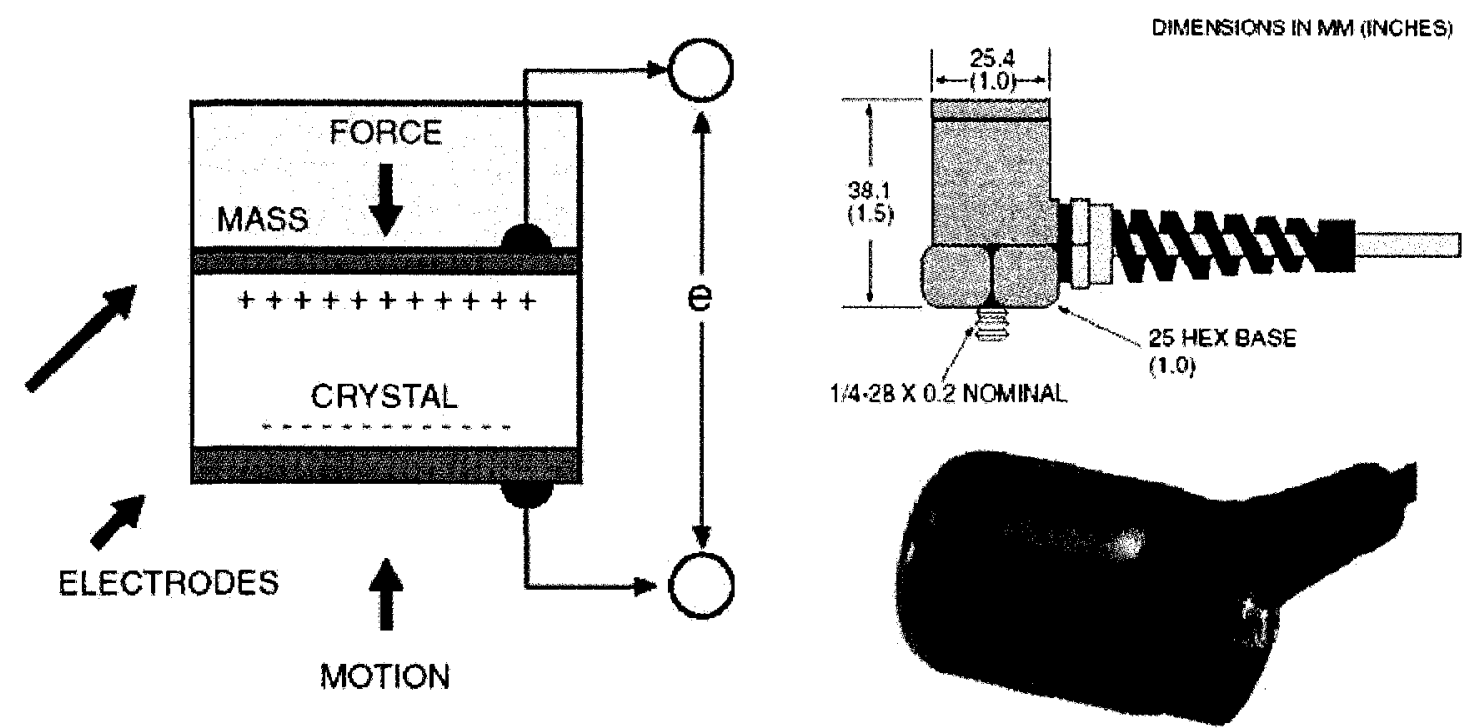

Figure 7.22 Accelerometer working principle and actual ACC101 accelerometer (Adapted from Omega Engineering, 2000)

The Allison 250-C20B accelerometer installation points were suggested by the engine manufacturer. Figure 7.23 shows such installation points. 


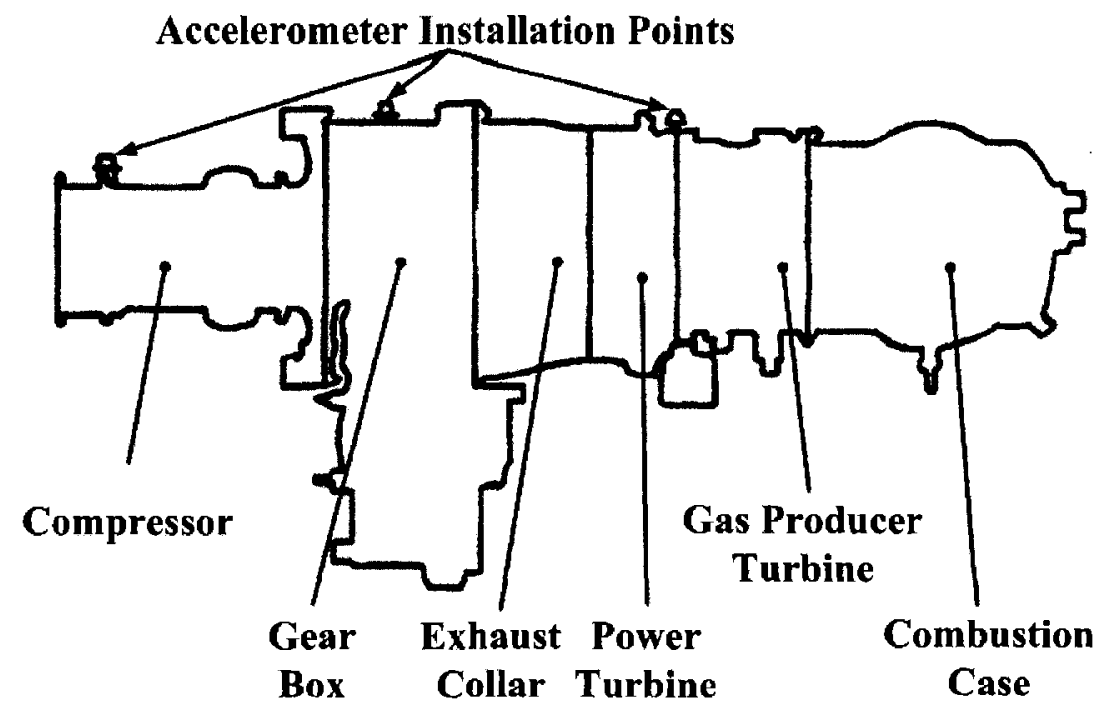

Figure 7.23 Accelerometer installation points (Adapted from Allison Engine Company, 1999)

Initially, the accelerometer and a protective temperature shield were mounted on the gearbox, as shown in Figure 7.24. Later, due to high temperatures experienced by the instrument, the accelerometer was moved and mounted onto the compressor casing where cooler temperatures were seen by the sensor.

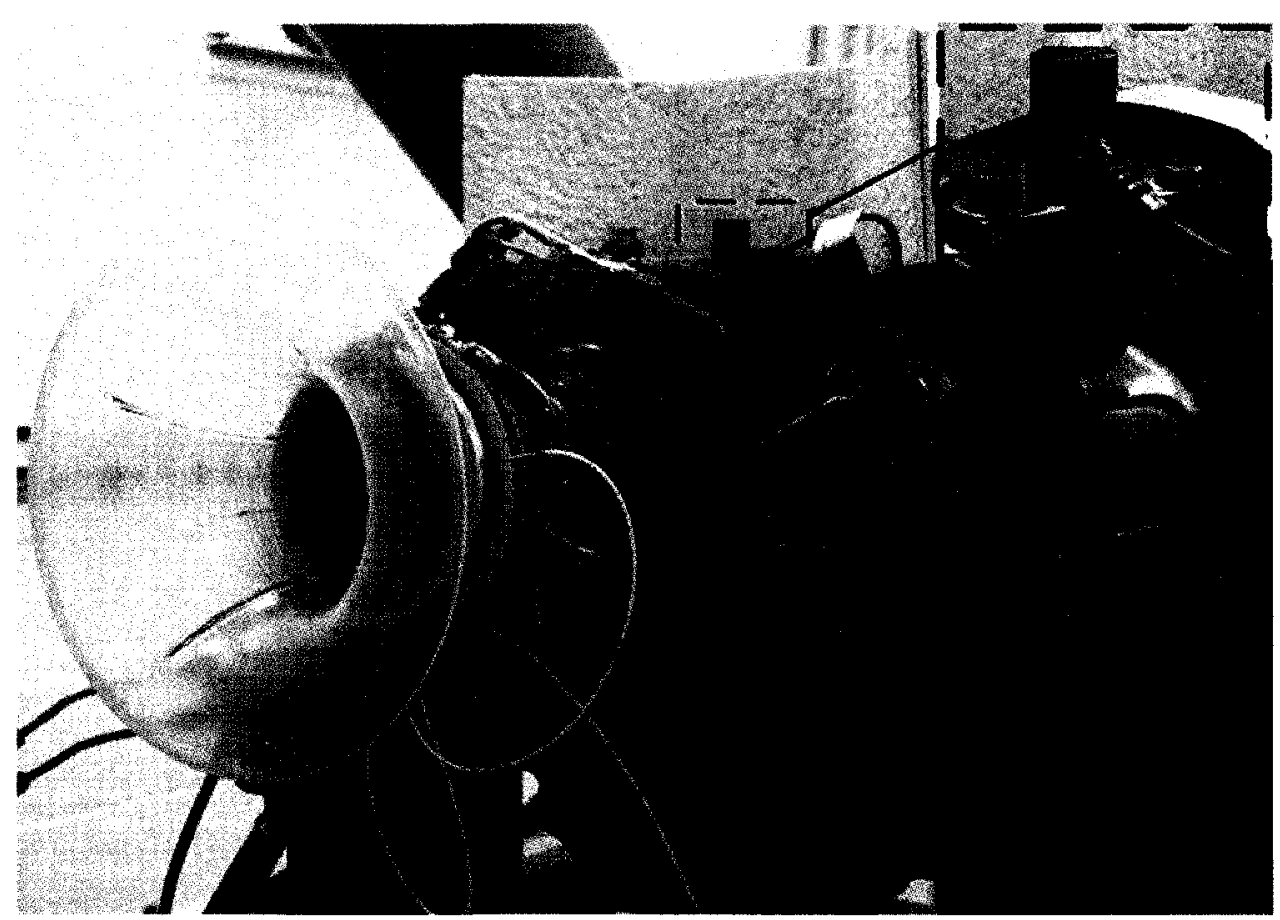

Figure 7.24 Gearbox accelerometer installation 
The pressure traducers used in the engine test cell were mounted within an enclosure for extra protection (Figure 7.25). All the pressure, temperature, and vibration measurements taken from the Allison 250-C20B were routed from the enclosure to the data acquisition system in the Combustion Room. From there, the acquired measurements were then directed to the Control Room where they were transformed from nonengineering units (VDC, $\mathrm{mVDC}$ ) into engineering units $\left(\mathrm{Pa},{ }^{\circ} \mathrm{C}\right.$ and $\mathrm{g}$ ) for monitoring and storage purposes.

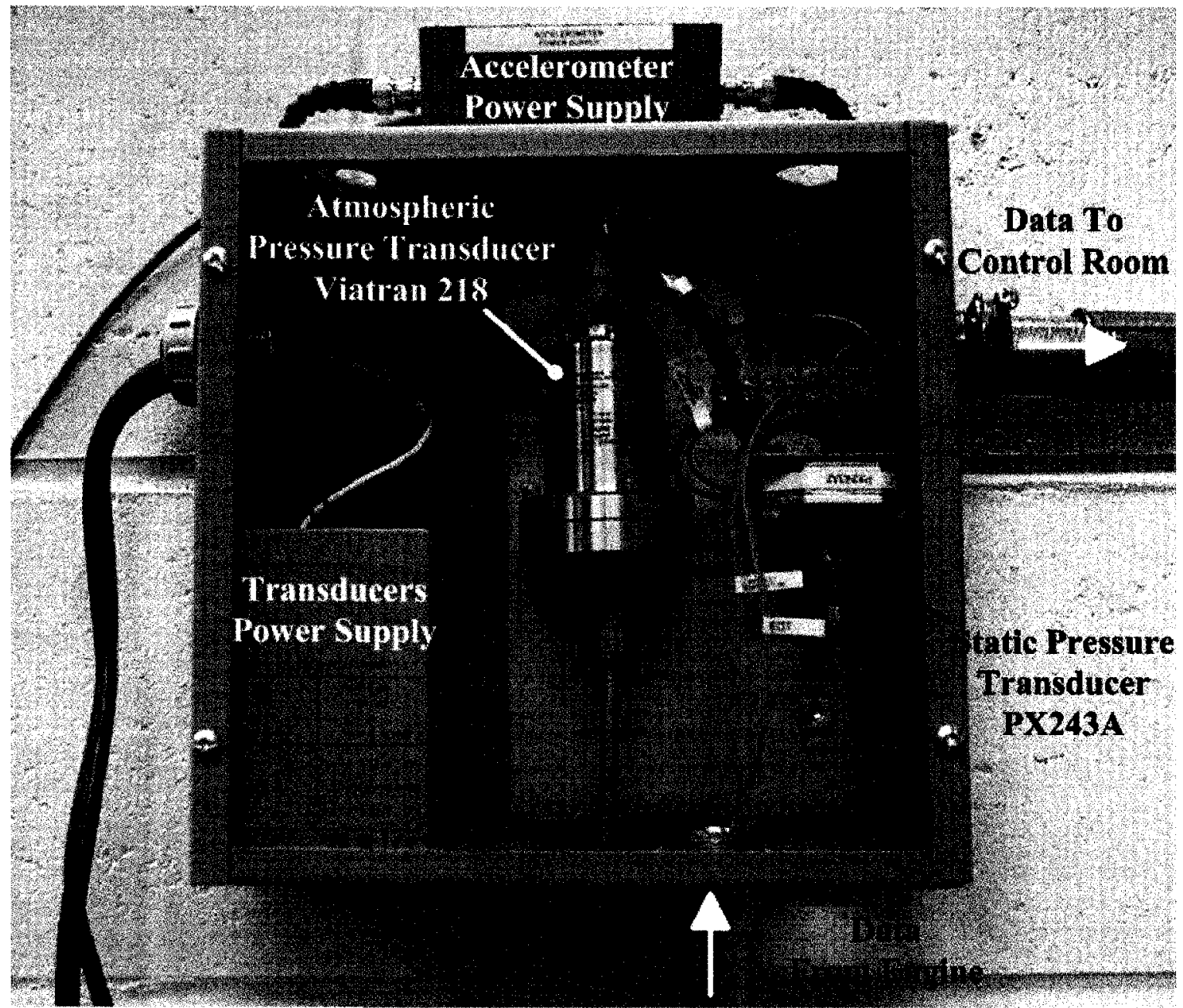

Figure 7.25 Test cell instrumentation 


\subsection{Combustion Room}

The Combustion Room (2 in Figure 7.26) is an L shaped area, with lengths of $8.5 \mathrm{~m}$ $(28 \mathrm{ft})$ by $7.6 \mathrm{~m}(25 \mathrm{ft})$ and a distance between walls of $3.3 \mathrm{~m}(11 \mathrm{ft})$. This room, in addition to housing the atmospheric blower (system $\mathrm{C}$ in Figure 7.26), is where the microturbine combustor under investigation is located. The following sections will describe the design, construction and instrumentation of the apparatuses present in this room, namely, the air delivery system (system A in Figure 7.26) and the fuel delivery system (system B in Figure 7.26).

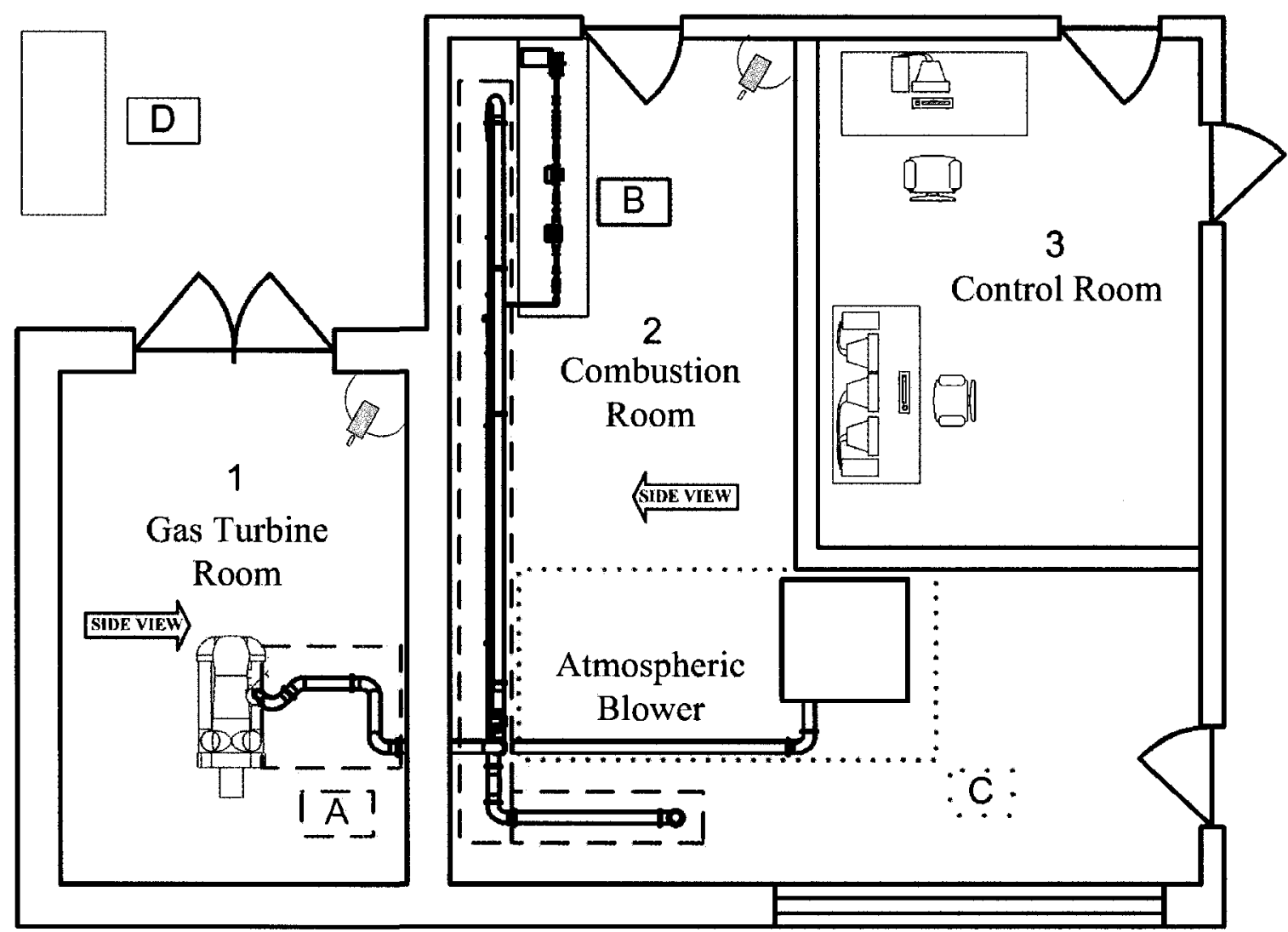

Figure 7.26 Gas turbine combustion research laboratory layout 


\subsubsection{High Pressure Air Delivery System}

The air delivery system, as previously mentioned, can be either coupled to the Allison 250-C20B engine to deliver air flow rates at high pressures to the microturbine combustor or connected to an atmospheric blower to deliver air flow rates at atmospheric pressure to the microturbine combustor. In addition to directing air, the air delivery system was designed with instrumentation considerations in mind so that the aerodynamic and combustion performance of the combustor could be assessed.

The following sections will first present the air delivery system layout, its dimensions and the chosen material for the apparatus. Secondly, the air flow path of the system and the components making up the rig will be described. Lastly, the system instrumentation will be addressed. Section 7.3.6 will finally elaborate on the minor changes needed to convert the air delivery system from a high pressure to atmospheric pressure configuration as well as give the atmospheric blower specifications.

\subsubsection{Air Delivery System Design and Flow}

Constraints given by ERMD, recommendations given by Murphy's work (2004) and different thesis objectives, from those of Murphy prompted redesigning the research laboratory. The research laboratory design incorporated, as much as possible, components that had been previously purchased by Murphy.

The air delivery layout in the high pressure configuration stretches between two rooms, namely, the Gas Turbine Room and the Combustion Room. The top view of this system can be seen in Figure 7.26 (system labelled A). The side views of the air delivery system can be seen in Figure 7.27 and Figure 7.28. Figure 7.27 shows the side view of 
the air delivery system coupled to the Allison 250-C20B engine. Figure 7.28 shows the side view of the air delivery system found in the Combustion Room.

The air delivery system dimensions, reported below, will be given in imperial units since this is the dominant system used when dealing with piping and pipelines. A table with piping dimension details and unit conversions can be found in Appendix D.

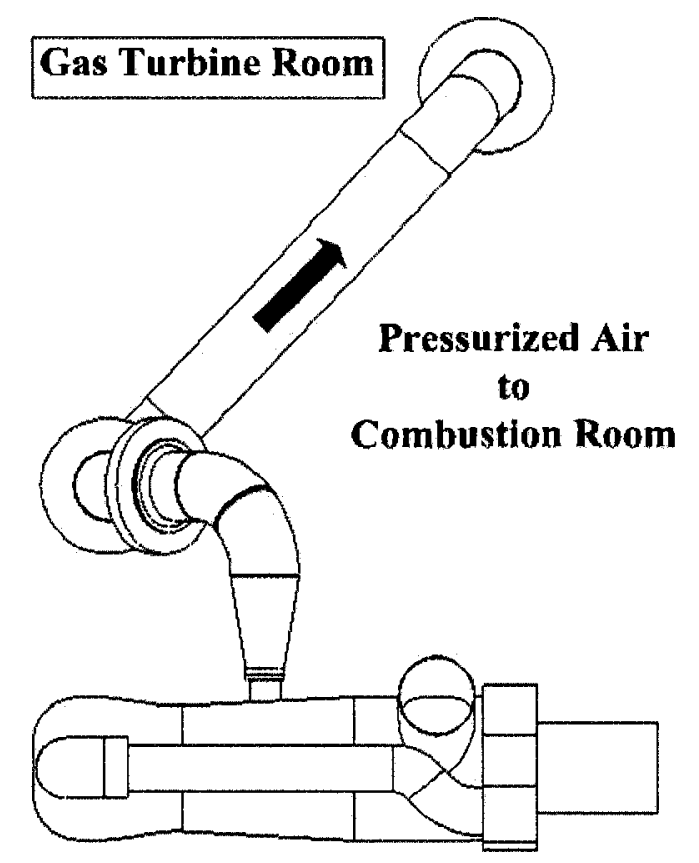

Figure 7.27 Air delivery system layout in Gas Turbine Room

\section{Combustion Room}

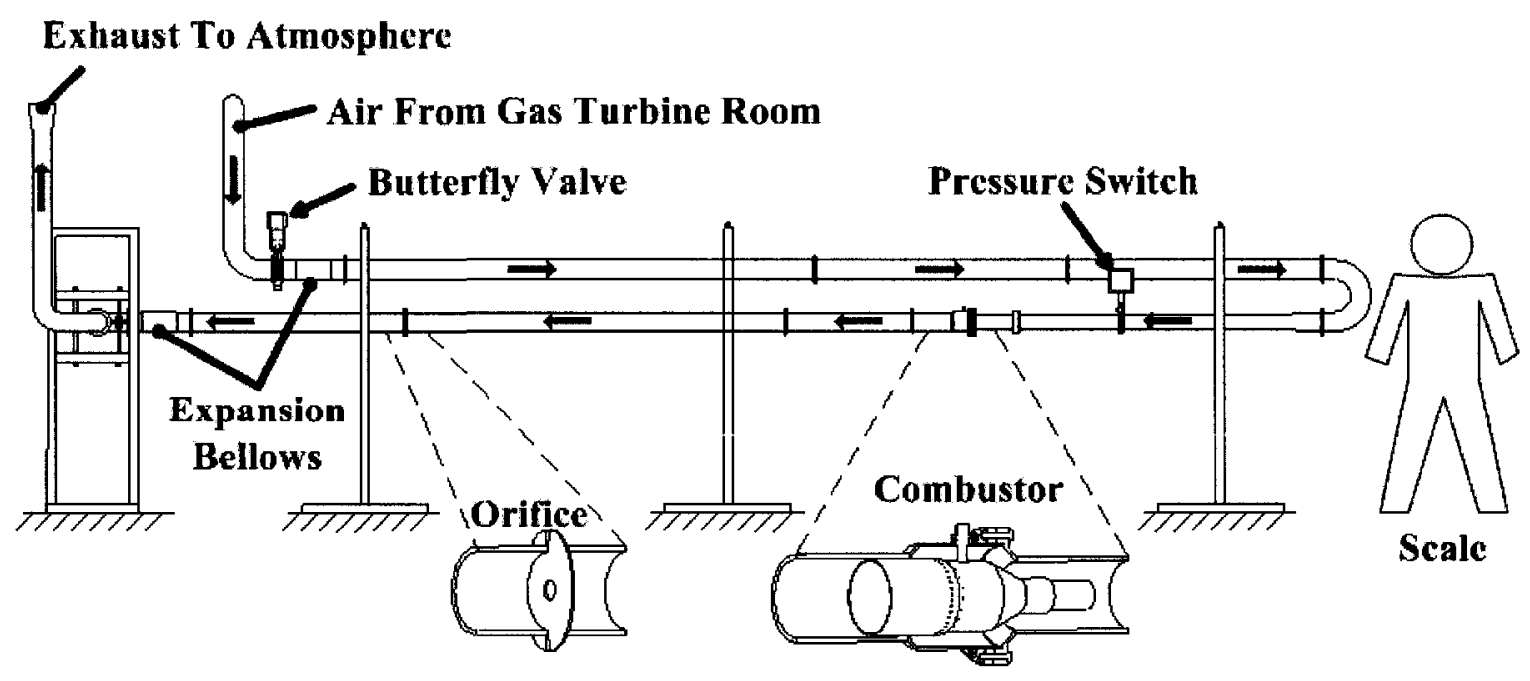

Figure 7.28 Air delivery system layout in Combustion Room 
In the high pressure configuration, air is bled from the Allison 250-C20B engine through the bleed chamber as outlined in Section 7.2.3. The air exiting the bleed chamber, which has an outlet internal diameter of 2 inches, is then expanded through a 6 inch long conical diffuser to enter a pipe with a nominal diameter of 4 inches. Via a series of pipe bends (pipes having a 4 in nominal diameter), the flow enters the Combustion Room. In the Combustion Room, the air passes through a butterfly valve followed by an expansion bellow. The air flow then travels inside a straight 4 inch diameter pipe for 223 inches before it is turned $180^{\circ}$. Downstream of the $180^{\circ}$ elbow ( 4 inches in diameter), the air enters a 5 inch long conical contraction which reduces the nominal pipe diameter from 4 inches to 3 inches which equals the combustor casing inlet diameter. The air flows into the combustor and then the combustion products then exit the 3.5 inch casing outlet diameter, travelling 24 inches before entering a conical diffuser. The 6 inch long conical diffuser expands the exhaust gasses from a 3.5 inch inlet diameter to a 4 inch outlet diameter. These hot gasses then travel inside a 4 inch diameter straight pipe for 90 inches before encountering a metering orifice plate. Fifty-two inches downstream of the orifice plate, the hot gasses then enter a second expansion bellow after which, through a series of pipe bends (pipes having a 4 in nominal diameter), they are expelled into the atmosphere.

The pipe sizes making up the air delivery system were chosen to minimize pressure losses, to match the combustor casing dimensions and to have the same pipe diameters as the pipes previously acquired by Murphy so that laboratory construction costs could be reduced. The elbows used in the air delivery system are long radius elbows which permit smoother flow transitions and therefore, lower pressure losses. 
The pressure losses of the air delivery system were estimated by the creation of two Mathcad programs. The first program (details given in Section 7.3.3) could thermodynamically model the Allison 250-C20B gas turbine engine. The second program used the thermodynamic outputs, calculated by the first program, to estimate the air delivery system pressure drop. For detailed information on how to estimate pressure losses in pipe and duct flows, please refer to Blevins (1984) and White (1999).

Using the first program, with the engine operating at $100 \%$ rotational speed, the air mass flow rate bled by the engine was estimated to be $0.5 \mathrm{~kg} / \mathrm{s}$ (Murphy, 2004). The bled air would have a pressure of 7.1 bar (Allison Engine Company, 1999) and a temperature of $645 \mathrm{~K}$ (calculated by program). Using these air properties as input for the second program, the pipe system pressure loss could be estimated as described below.

The air velocities and Reynolds numbers inside the various pipe diameters were calculated. Since the Reynolds numbers were found to be above $4000\left(\operatorname{Re}>1.8 \times 10^{5}\right)$, the flow within the pipes was determined to be turbulent. Using a stainless steel pipe roughness $(\varepsilon)$ of $0.002 \mathrm{~mm}$ (White, 1999), the turbulent friction factors $(f)$ throughout the system were calculated as,

$$
f=\left[1.14-2 \log _{10}\left(\frac{\varepsilon}{D_{p i p e}}+\frac{21.25}{R e_{p i p e}^{0.9}}\right)\right]^{-2}
$$

The pressure drop caused by friction was then estimated using the Darc-Weisbach formula shown below.

$$
\Delta P=\frac{\rho_{a} V_{\text {pipe }}^{2}}{2} \frac{f L_{\text {pipe }}}{D_{\text {pipe }}}
$$

where $\Delta P$ is the pipe pressure drop 
$D_{p i p e}$ is the pipe inner diameter

$L_{\text {pipe }}$ is the pipe length

$V_{\text {pipe }}$ is the average flow velocity over the pipe cross section

$\rho_{a}$ is the air density

$f$ is the turbulent friction factor

Next, the program calculated the non-recoverable loss coefficients of the various parts making up the air delivery system, such as the butterfly valve, gradual expansions, gradual contractions (conical pipes), and the many bends. Only the non-recoverable loss coefficient calculations for the butterfly valve will be shown below. The remaining calculated non-recoverable coefficients are presented in Table 7.1. The formulas to calculate the tabulated non-recoverable coefficients can be found in Blevins (1984).

The process to calculate the butterfly valve non-recoverable coefficient started by digitizing the company provided performance curve of the Jamesbury $815 \mathrm{~W}$ butterfly valve (Figure 7.29). Figure 7.29 shows the flow coefficient as the butterfly valve aperture goes from fully closed $(0 \%)$ to fully open $(100 \%)$. To convert the flow coefficient $\left(C_{v}\right)$ into the non-recoverable loss coefficient $\left(K_{\text {valve }}\right)$, the following equation was used (Jamesbury, 2003):

$K_{\text {valve }}=0.8569 C_{v}$

where $K_{\text {valve }}$ is the butterfly valve non-recoverable loss coefficient

$C_{v}$ is the butterfly valve flow coefficient 


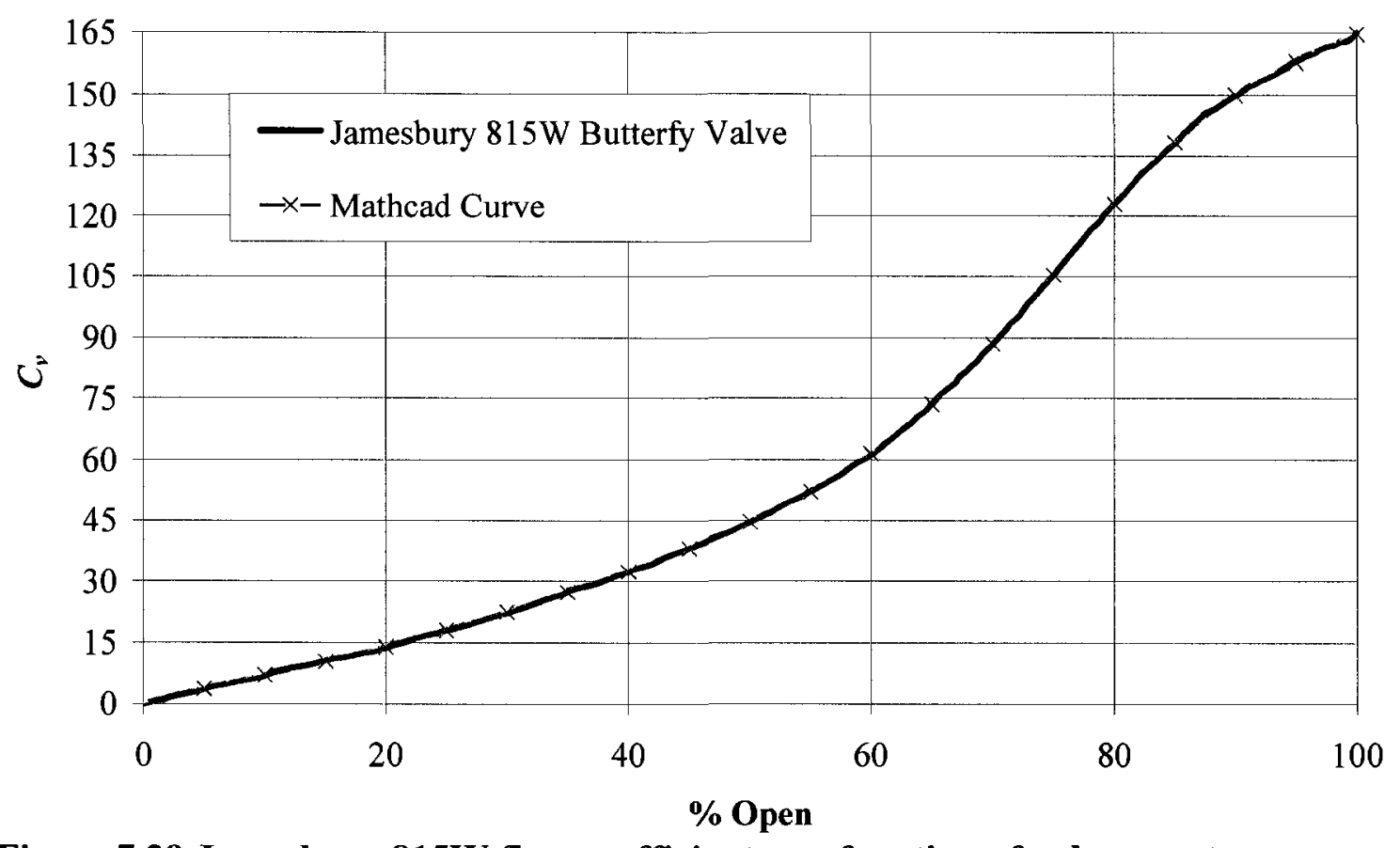

Figure 7.29 Jamesbury $815 \mathrm{~W}$ flow coefficient as a function of valve aperture

Finally, the pressure drop caused by the butterfly valve was calculated as,

$\Delta P=\frac{\rho_{a} V_{\text {valve }}^{2}}{2} K_{\text {valve }}$

Equation (7.8) can be used to estimate the pressure losses created by the gradual expansions, gradual contractions and many bends present in the air delivery system. However, the non-recoverable loss coefficient and air velocity used in the above formula should reflect the component being analyzed. The following table shows the calculated results for the non-recoverable loss coefficient of the aforementioned components. The total pressure drop in the air delivery system, from bleed to orifice plate, was the mathematical addition of the pressure drops across each of the components and the pressure losses due to friction. Therefore, the total pressure drop in the air delivery system was estimated to be $2700 \mathrm{~Pa}$ ( $3.8 \mathrm{psi})$. This value, calculated with a fully open butterfly valve, also included a $3 \%$ pressure drop across the combustor. 
Table 7.1 Air delivery system non-recoverable coefficients

\begin{tabular}{|c|c|c|}
\hline Component Description & Component Amount & $\begin{array}{c}\text { Non-recoverable Coefficient } \\
(K)\end{array}$ \\
\hline Butterfly Valve & 1 & 2.6 \\
\hline Conical Contraction & 1 & 0.03 \\
\hline Conical Expansion & 2 & 0.07 \\
\hline $45^{\circ}$ Bend & 1 & 0.14 \\
\hline $90^{\circ}$ Bend & 5 & 0.21 \\
\hline $180^{\circ}$ Bend & 1 & 0.28 \\
\hline
\end{tabular}

The overall length of the air delivery system resulted from guidelines which ensure that the air flow is fully developed before pressure measurements can be taken. Major flow disturbances created by elbows present in the air delivery system design produce secondary and swirling flows within the pipe system (Figure 7.30). For air flow pressure measurements to be repeatable during testing, the flow within the pipes has to be fully developed (Figure 7.30). Therefore, a sufficient length of straight pipes has to be present downstream of these disturbances. Blevins (1984) suggests a minimum of 10 straight pipe diameters upstream of any pressure instrumentation. When considering the metering orifice plate, Blevins suggests 20 diameters of straight pipe upstream of the orifice and four diameters of straight pipe downstream of the orifice. These guidelines were followed in the design of the air delivery system resulting in a total rig length of $7.7 \mathrm{~m}(25.2 \mathrm{ft})$ as shown in Figure 7.31. 


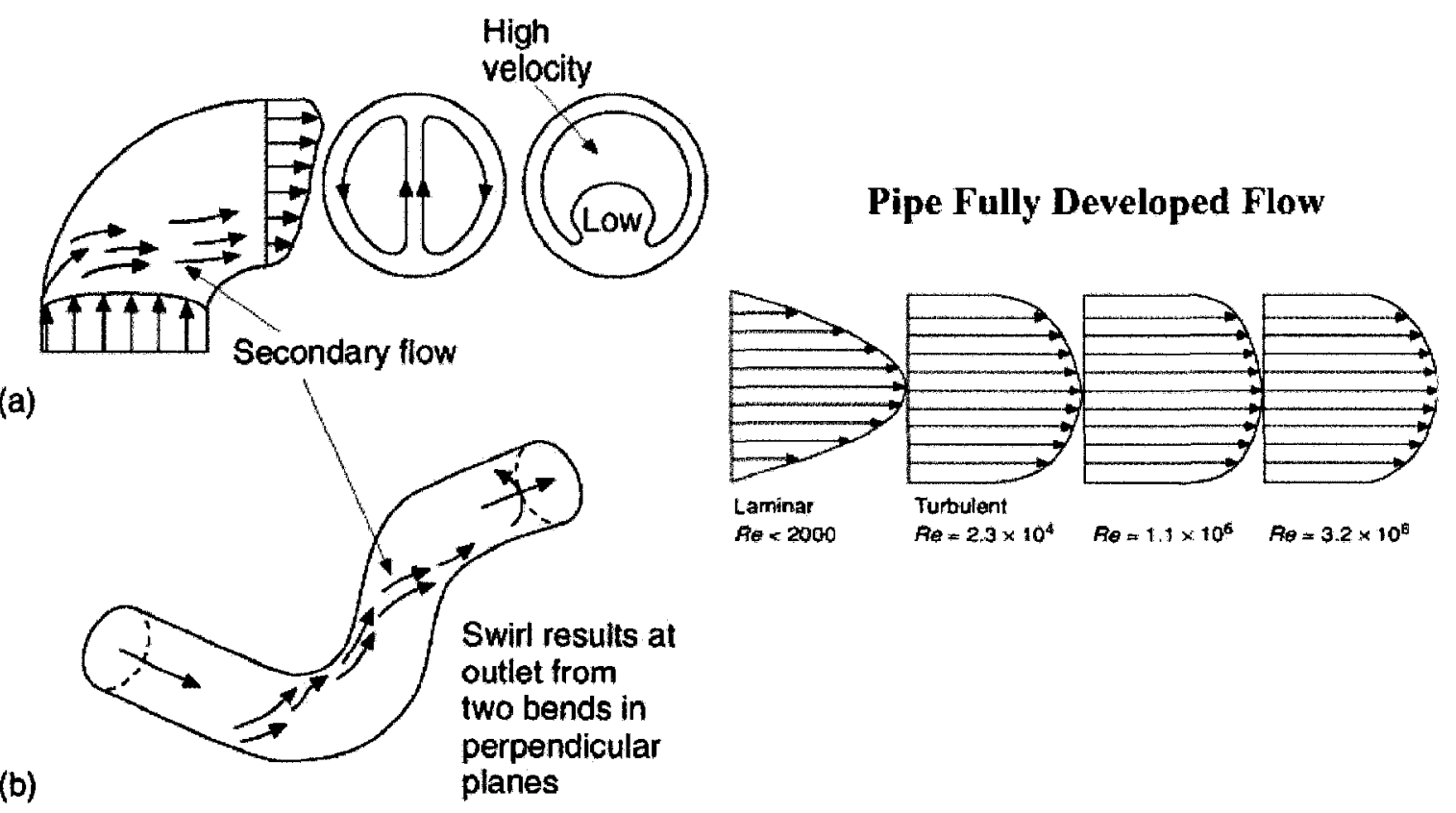

Figure 7.30 Pipe flows (Baker, 2003)

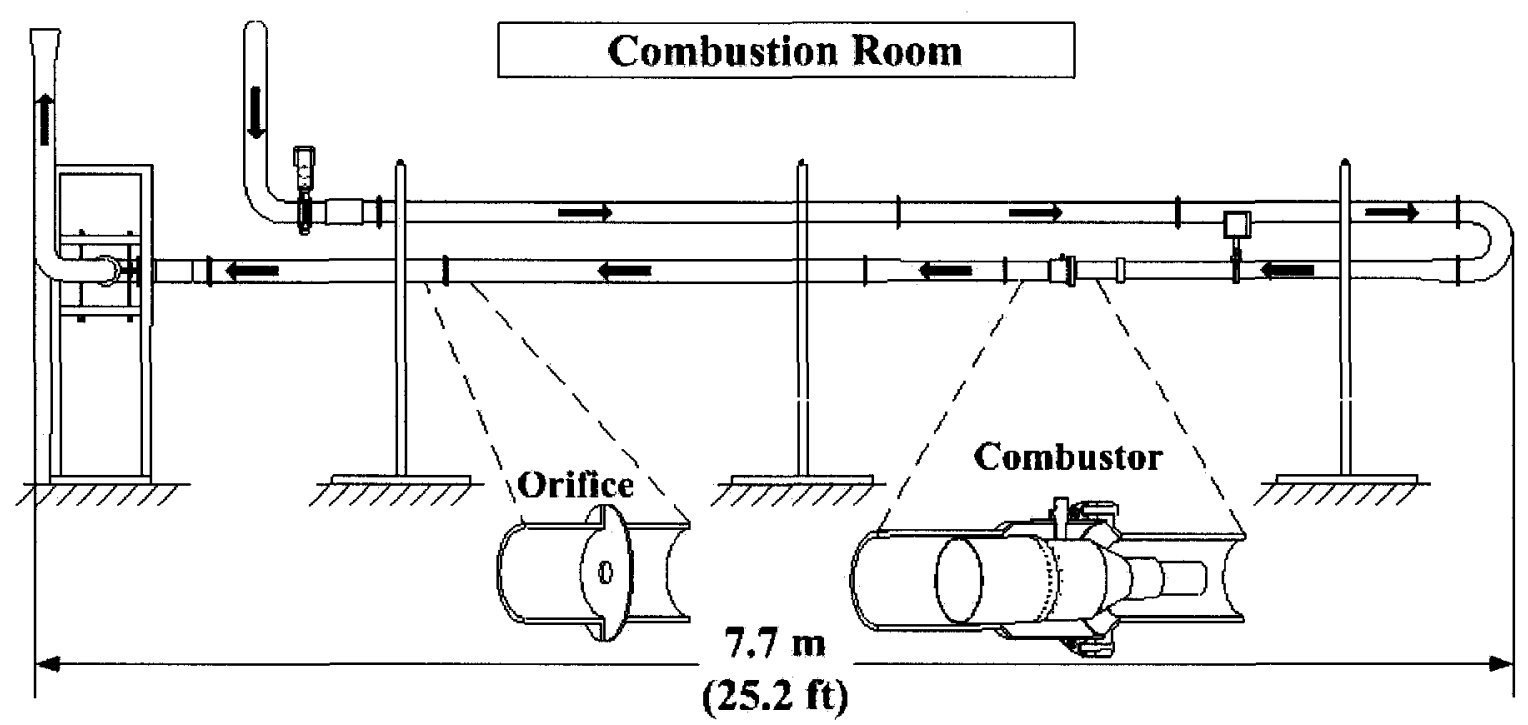

Figure 7.31 Air delivery system total length

The material selected for the pipes making up the air delivery system was stainless steel with a $316 \mathrm{~L}$ grade. This material was found to be a good compromise between cost and performance since, as previously mentioned, $316 \mathrm{~L}$ grades can be used up to $1200 \mathrm{~K}$ 
$\left(925^{\circ} \mathrm{C}\right)$ for continuous temperature operations and up to $1140 \mathrm{~K}\left(870^{\circ} \mathrm{C}\right)$ for intermitted temperature operations (Bhadeshia and Honeycombe, 2006).

The pipe thicknesses were chosen according to guidelines given in the Process Piping ASME B31.3 (2002) code and in the engineering standards manual from the Los Alamos National Laboratory (LANL, 2005). Figure 7.32 summarizes, in a graphical manner, the maximum allowable operating conditions for non-threaded stainless steel (316L) pipes having a schedule $40 \mathrm{~S}$ for wall thickness (for data please refer to Appendix E).

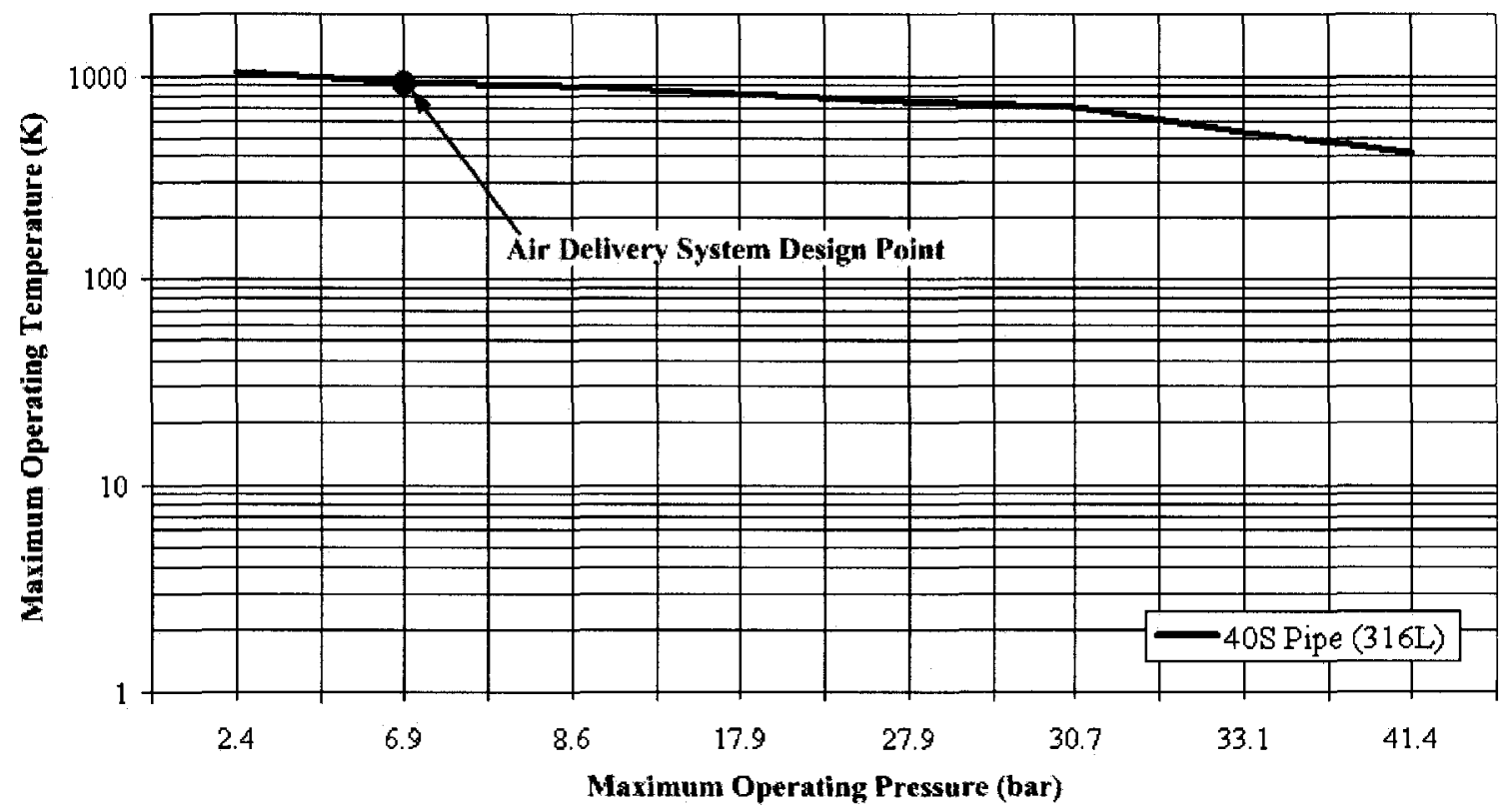

Figure 7.32 Maximum operating conditions of sch. 40S stainless steel (316L) pipes

Therefore, from the guidelines given by the aforementioned references, the decision was made to have a $40 \mathrm{~S}$ schedule for the wall thickness for all the pipes. Furthermore, the maximum allowable operating temperature and pressure of the air delivery system were established to be $900 \mathrm{~K}$ and 6.9 bar respectively.

To absorb thermal expansion two bellow-type expansion joints were used in the air delivery system. These bellows, made of corrugated stainless steel (316), had been purchased during Murphy's work. The main attraction of this type of expansion joint, 
when compared to slip joints, is that they do not have leakage problems and they do not require periodic maintenance. One bellow was installed downstream of the butterfly valve and the second bellow was installed downstream of the orifice plate.

The design of the air delivery system was envisioned to be modular so that it could be easily installed and adapted for future research projects. For these reasons, the system was made up of various pipe sections which were fastened together via slip-on flanges. Figure 7.33 shows an example of a pipe section whose ends are composed of stub ends and slip on flanges. The stub ends were joined at each end of the pipe section using GTAW as the welding process.

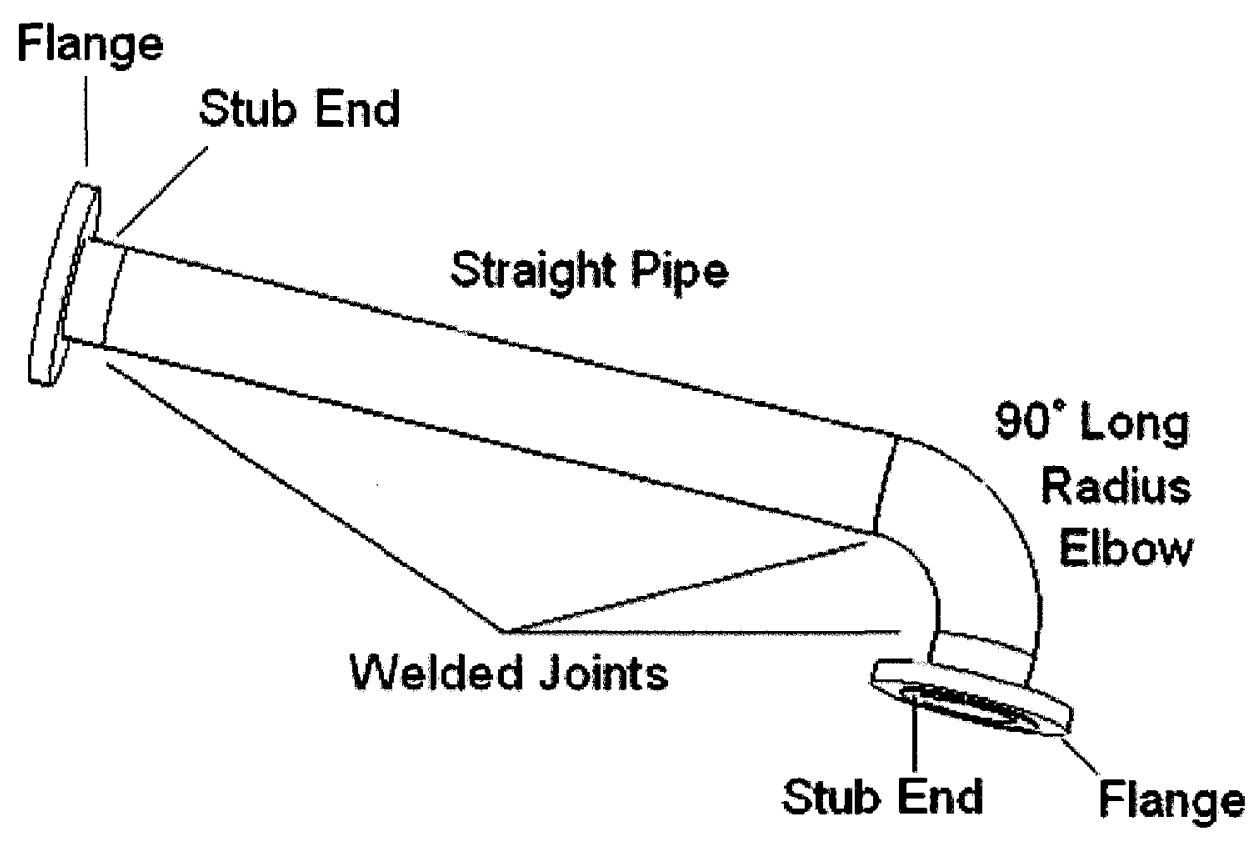

Figure 7.33 Example of pipe section

The welding process, joining the various pipe segments (i.e., pipes, elbows, contractions, expansions and stub ends), followed guidelines given by the American Welding Society (AWS D14.6, 2005, AWS C5.5-80). In particular, a bevel (see detail in Figure 7.34), if not already existing, was machined on all the surfaces of the components to be butt welded. Machining bevels ensured that full weld penetration could be achieved. 
Figure 7.34 shows one of the many welding drawings given to FullFusion Welding which carried out the pipe welding process. For clarification of welding symbols, please refer to the following standard AWS A2.4-98 (AWS A2.4, 1998).

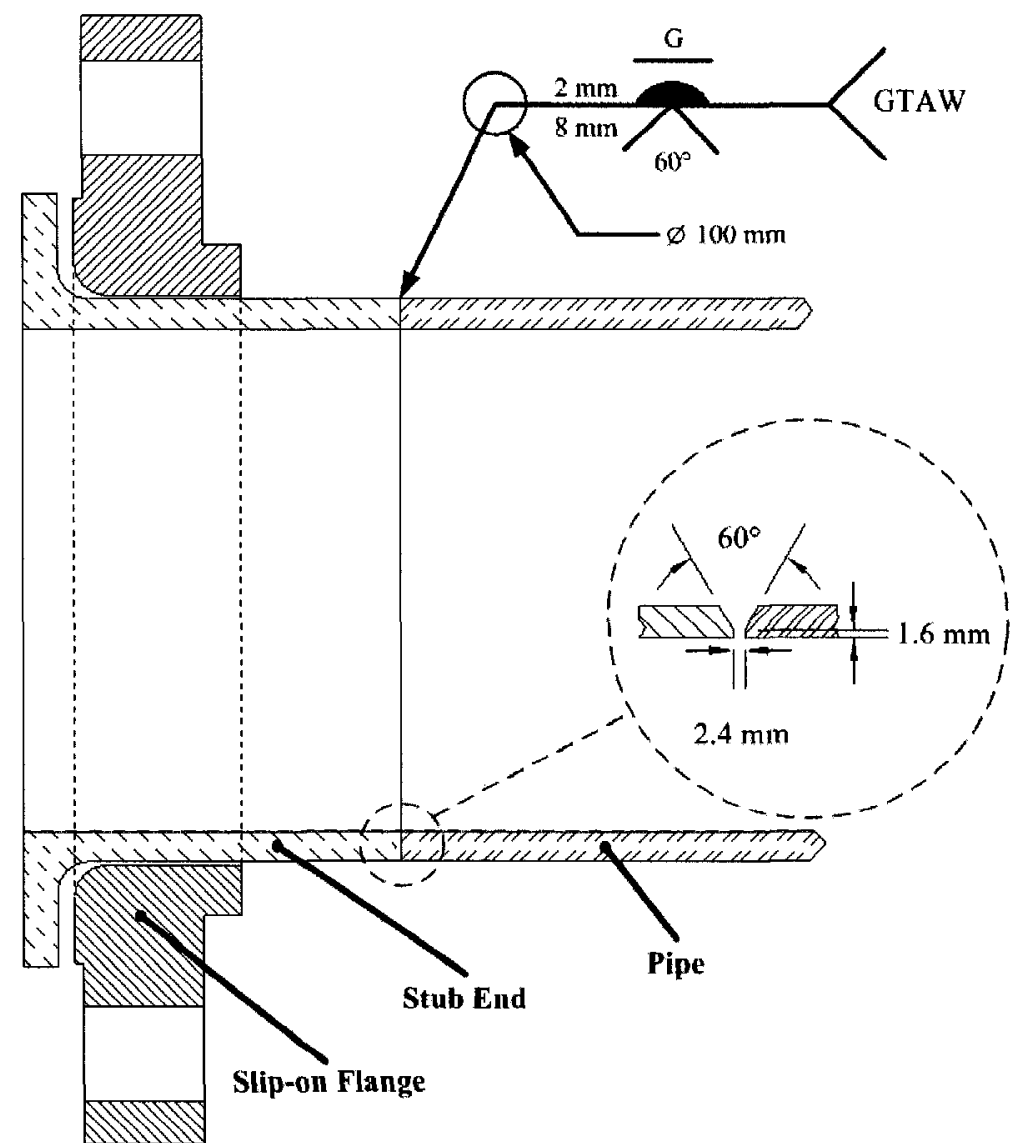

\section{Figure 7.34 Example of pipe welding}

Once the joining process was completed, the pipe sections could then be fastened together via the slip on flanges and the use of bolts and nuts. The selection of the bolts and nuts took into consideration the high pressure and high temperature of the air delivery system. To reduce laboratory construction costs, two types of bolt and nut material were used. Upstream of the combustor, the cooler operating temperatures permitted to use of medium-carbon, grade 7 type bolts and nuts. Downstream of the combustor austenitic chromium nickel 18/8 steel type (stainless steel) bolts and nuts were used because of their higher temperature applications $\left(848 \mathrm{~K} ; 575^{\circ} \mathrm{C}\right)$. All the bolts and 
nuts had a $15.9 \mathrm{~mm}(5 / 8 \mathrm{in})$ diameter and had fine threads since, as can be seen in Figure 7.35 , fine threads have higher breaking loads than coarse threads.

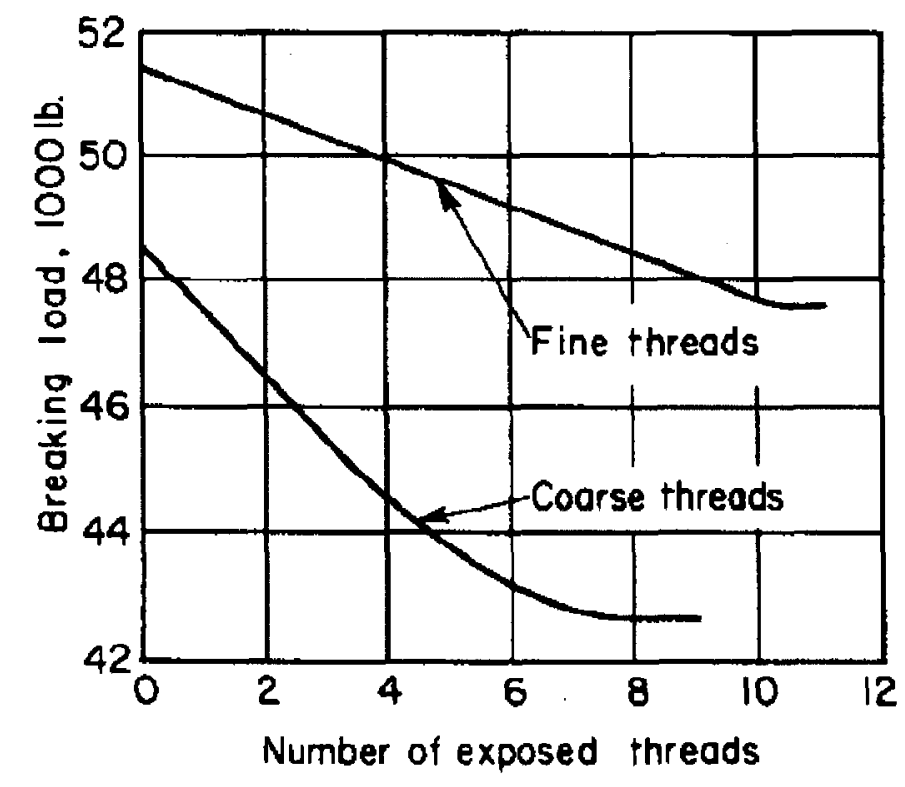

Figure 7.35 Breaking load of fine versus coarse threads (Nayyar, 2000)

Torquing of the slip-on flanges was done in multiple passes and performed in a cross pattern to reduce warping of the flanges and crushing of the gaskets. Stainless steel (grade 316) washers, to distribute the load produced by the fastening process, were used in all the slip-on assemblies.

The gasket material, used to prevent air leakage between the mating stub ends, was a vitreous aluminosilicate refractory ceramic paper, $6.4 \mathrm{~mm}$ thick, which was purchased from Hydro Silica Gaskets ${ }^{13}$. The high temperature ceramic paper gaskets compressed as the slip on flanges were fastened together, resulting in gas-tight seals.

Completely assembled, the air delivery system weight was estimated to be approximately $450 \mathrm{~kg}(\sim 1000 \mathrm{lbs})$, thus, support structures were required. A simplified force analysis led to the design and construction of five frames made out of square

${ }^{13}$ Hydro Silica Gasket Ltd., 1211 Newmarket St., Ottawa, Ontario K1B 3V1, Canada 
tubing. The $5 \mathrm{~cm}(2 \mathrm{in})$ square tubing, made of mild steel, had a wall thickness of $3 \mathrm{~mm}$ (1/8 in). The tubing was cut and welded to its final geometry as seen in Figure 7.36. The pipes were supported by riser clamps whose height could be adjusted through turning stainless steel nuts fastened onto $1.35 \mathrm{~cm}(0.5 \mathrm{in})$ stainless steel threaded rods. The number of frames used to support the air delivery structure was guided by information found in literature (Nayyar, 2000) and by introducing a safety factor to take into consideration the high temperature application.
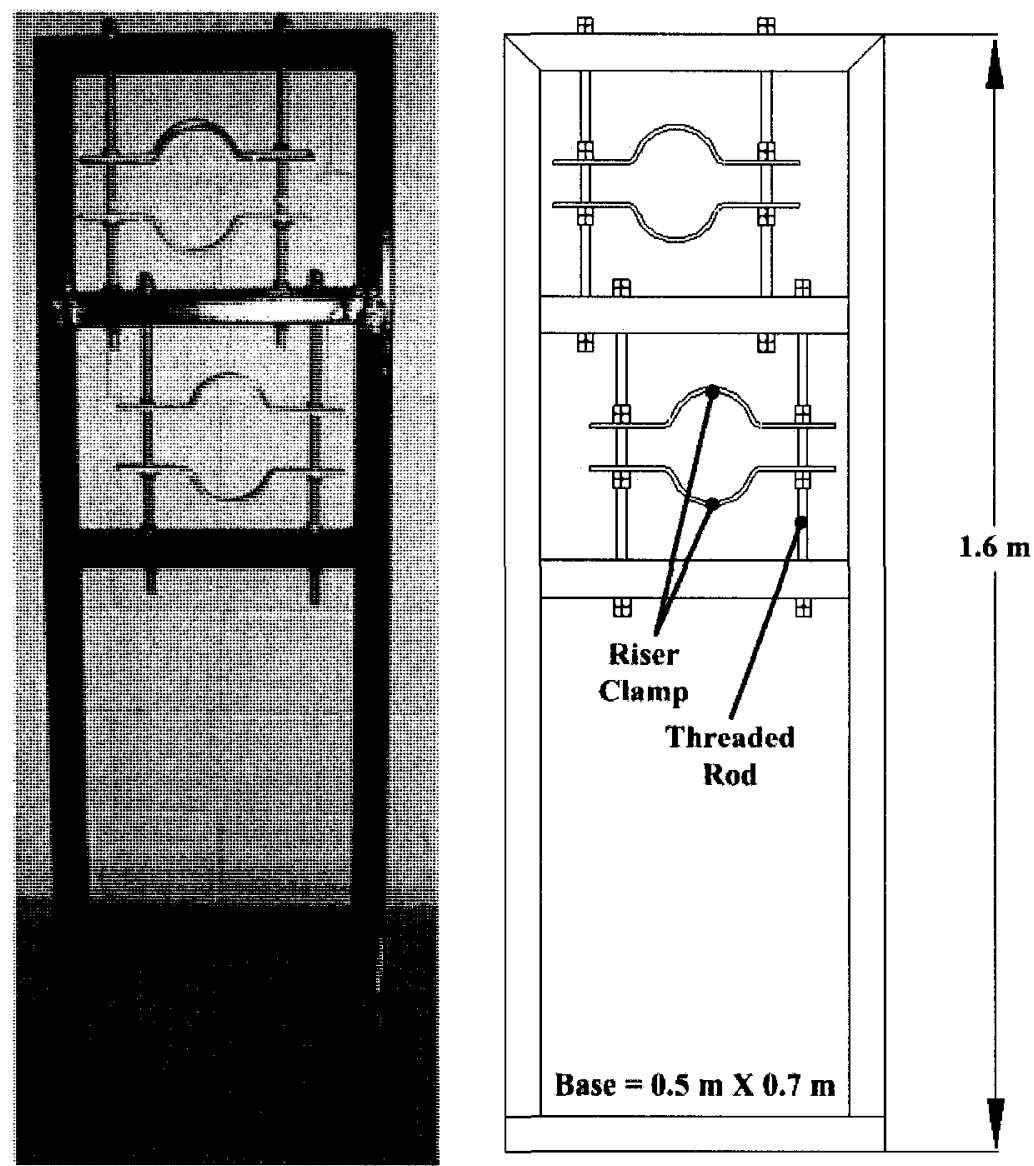

Figure 7.36 Supporting frame

\subsubsection{Air Delivery System Components}

The component that controls the amount of air that can be bled from the Allison 250C20B is the Jamesbury $815 \mathrm{~W}$ butterfly valve shown in Figure 7.37 . The butterfly valve, 
which had been purchased during Murphy's work, was originally manually controlled. The actuation mode was updated to be electrically operated so that the butterfly valve could be remotely handled from the Control Room.

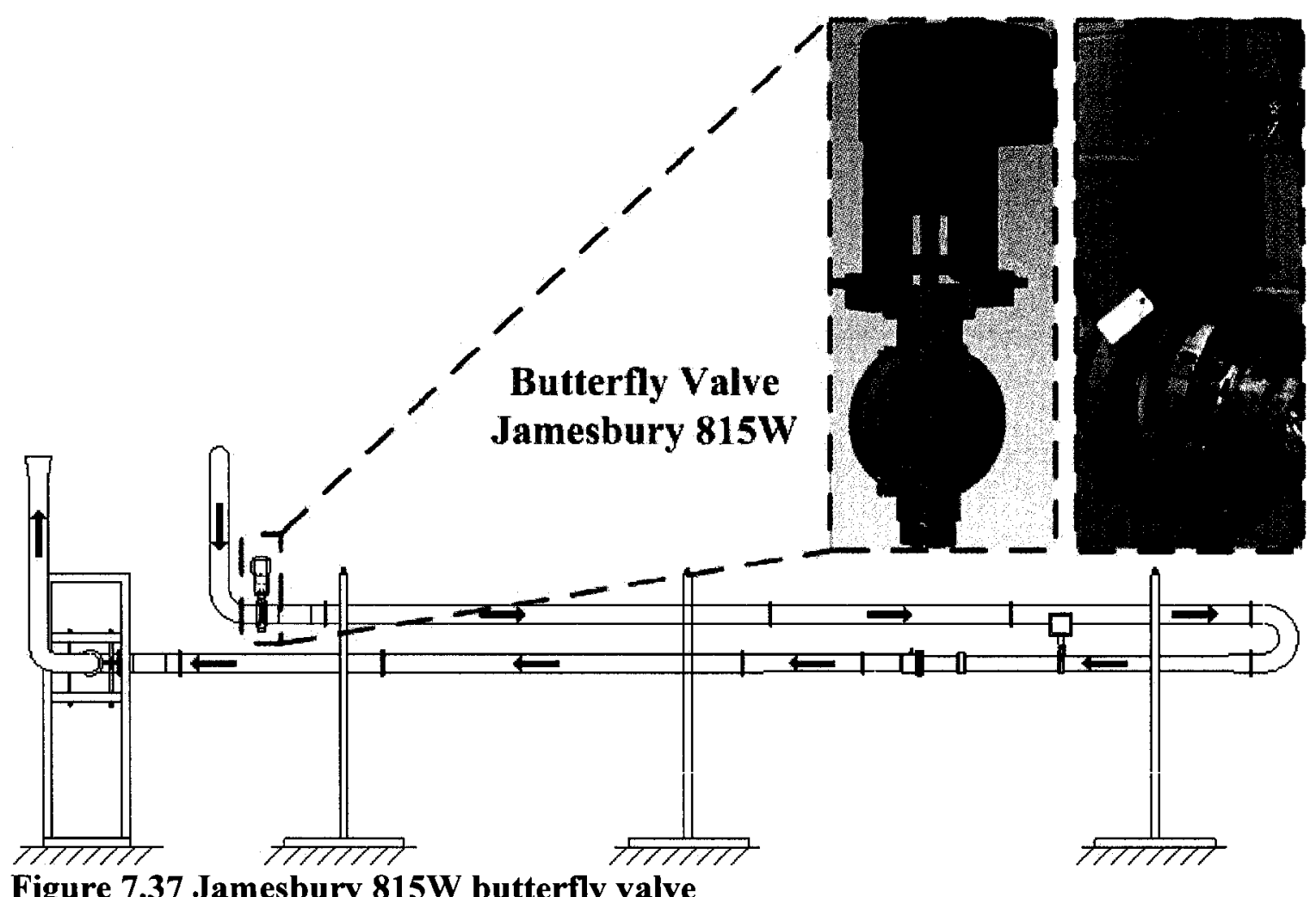

Figure 7.37 Jamesbury $815 \mathrm{~W}$ butterfly valve

With the butterfly valve fully open, the component that constrained the maximum amount of air bled from the engine was the orifice plate hole diameter. The orifice plate material was Hastelloy $\mathrm{X}$ and the plate geometry (Figure 7.38) was cut out of a piece of sheet $1.6 \mathrm{~mm}(1 / 16 \mathrm{in})$ thick. The machining process used to fabricate the orifice plate was abrasive water jet cutting performed by Hydrotech Cutting ${ }^{14}$. The estimation of the orifice hole diameter required some reverse engineering work which is presented next.

\footnotetext{
${ }^{14}$ Hydrotech Cutting Inc., 75 Bongard Av., Nepean, Ontario K2E 6V2, Canada
} 


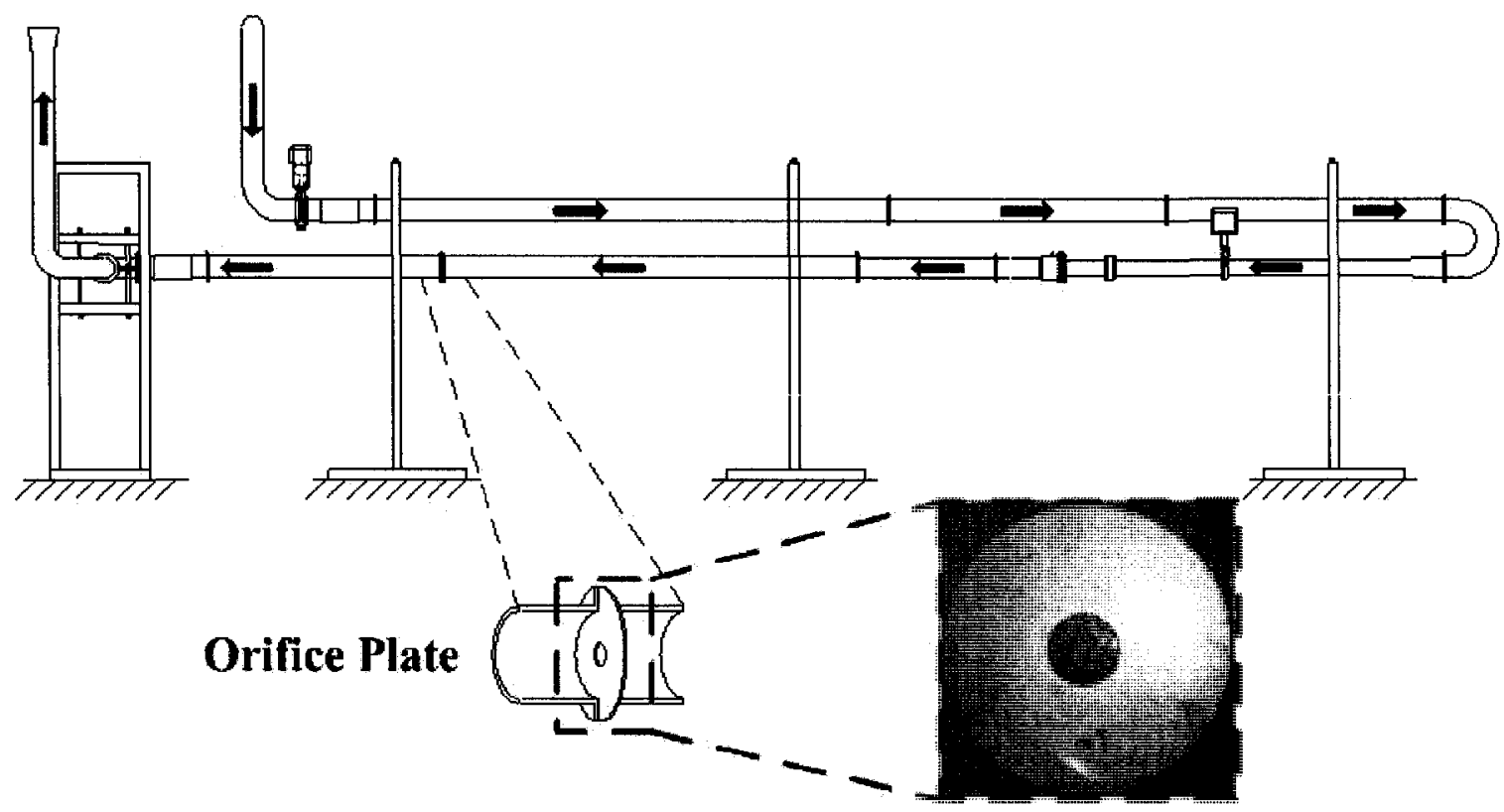

\section{Figure 7.38 Orifice plate}

The orifice hole diameter had to be sized in such a way that the maximum amount of air mass flow rate bled from the Allison 250-C20B would not cause the interstage turbine temperature (ITT) to exceed its limit. For the engine model this maximum allowable ITT was $1083 \mathrm{~K}\left(810^{\circ} \mathrm{C}\right)$ (Allison Engine Company, 1999). There is a relationship between the amount of air bled from the engine and the engine ITT which, with the removal of the power turbine, is now the EGT. As air is bled downstream of the compressor, a work unbalance between the shaft coupled compressor and the turbine is created, where the compressor work is higher than that of the turbine. To compensate for this work unbalance, more fuel is injected into the combustor. The combustion process transforms the chemical energy of the reactants into kinetic energy which is then changed into work by the turbine until equilibrium is once again reached. The injection of more fuel into the combustor to compensate for the work unbalance translates into higher gas temperatures and, if not careful, the maximum allowable EGT can easily be exceeded. Therefore, a Mathcad program was created to size more precisely the orifice hole diameter so that 
when the butterfly valve was fully open, the amount of air bled from the Allison 250C20B would, therefore, be limited..

The program, whose algorithm is presented in Figure 7.39 , modeled a simple gas turbine thermodynamic cycle and used the outputs to size the orifice plate hole. The program was based on theory found in Saravanamuttoo (2001) and Gauthier (2005).

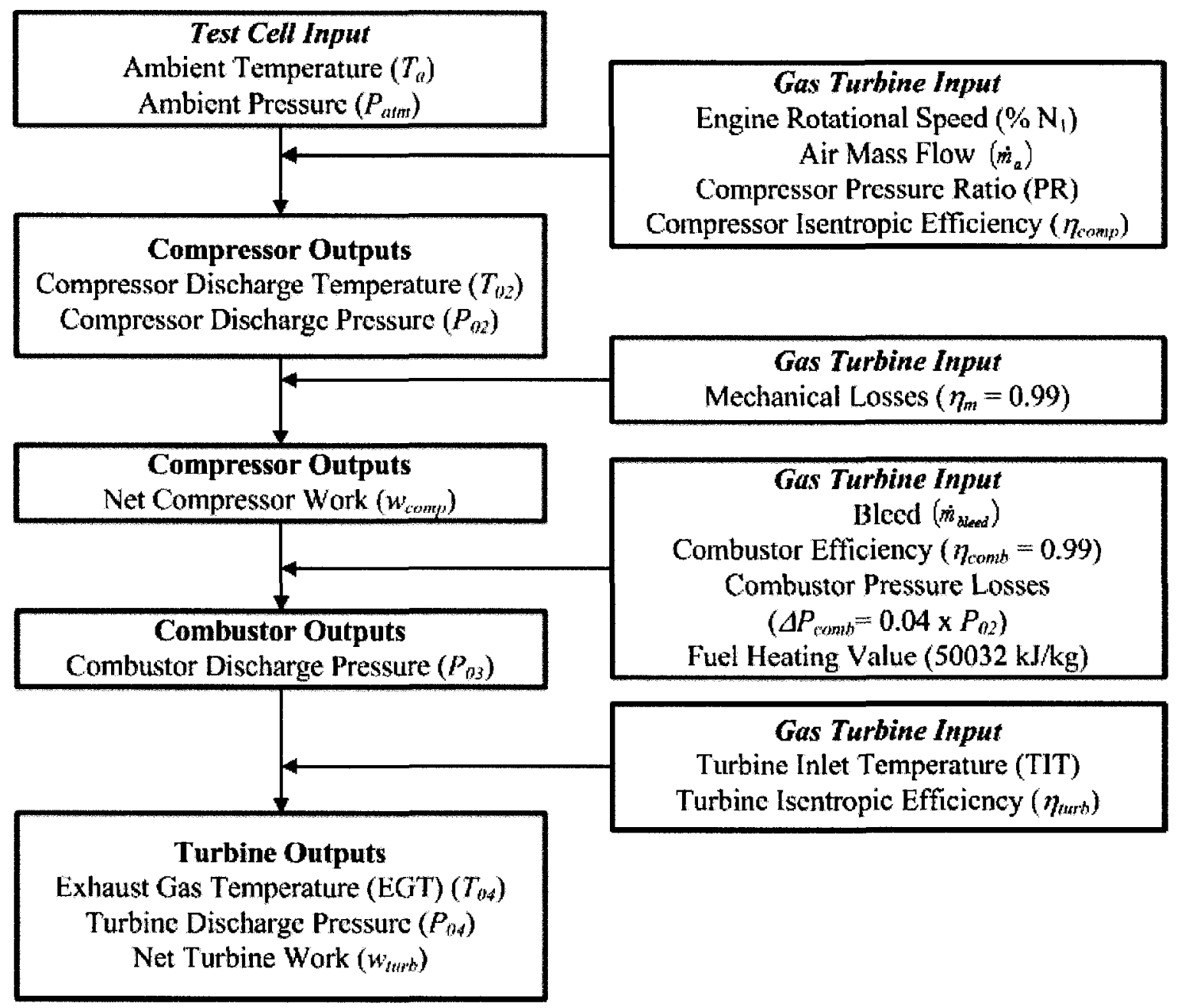

Figure 7.39 Program algorithm for simple gas turbine thermodynamic cycle

Due to lack of Allison 250-C20B engine performance data, the program inputs used information found on a T-63-A-700 (Haas, 1996) gas turbine engine (Table 7.2), which is the military derivative of the 250 model. In particular, the developed Mathcad program assumed that these two engines had the same compressor $\left(\eta_{\text {comp }}\right)$ and turbine $\left(\eta_{\text {turb }}\right)$ 
isentropic efficiencies which varied depending on the engine rotational speed $\left(\mathrm{N}_{1}\right)$. The remaining program inputs, such as air mass flow rate $\left(\dot{m}_{a}\right)$ and pressure ratio (PR), were those of the Allison 250-C20B. The key program outputs, which permitted the sizing of the orifice hole diameter, were the compressor discharge pressure (CDP) and temperature (CDT) as well as the exhaust gas temperature (EGT). The program outputs, shown in Table 7.3, were verified against Haas (1996) and the commercially available software GasTurb 10 and were found in good agreement.

Table 7.2 Predicted thermodynamic performance of T63-A-700 (Haas, 1996)

\begin{tabular}{|c|c|c|c|c|c|c|c|c|}
\hline \multicolumn{9}{|c|}{ T63-A-700 } \\
\hline $\mathbf{N}_{\mathbf{1}} \mathbf{( \% )}$ & $\begin{array}{c}\dot{m}_{a} \\
\mathbf{( k g / s )}\end{array}$ & $\begin{array}{c}\text { Air Mass } \\
\text { Flow \% } \\
\text { (Total) }\end{array}$ & $\begin{array}{c}\boldsymbol{P}_{\text {atm }} \\
\mathbf{( b a r )}\end{array}$ & $\eta_{\text {comp }}$ & $\eta_{\text {turb }}$ & $\begin{array}{c}\text { CDP } \\
\text { (bar) }\end{array}$ & $\begin{array}{c}\text { CDT } \\
\mathbf{( K )}\end{array}$ & $\begin{array}{c}\text { EGT } \\
\mathbf{( K )}\end{array}$ \\
\hline 70.0 & 0.9 & 62.7 & 1.0 & 0.764 & 0.872 & 2.9 & 422 & 642 \\
\hline 75.0 & 1.0 & 66.9 & 1.0 & 0.772 & 0.879 & 3.4 & 442 & 673 \\
\hline 80.0 & 1.1 & 74.8 & 1.0 & 0.781 & 0.882 & 3.9 & 462 & 739 \\
\hline 85.0 & 1.1 & 78.8 & 1.0 & 0.786 & 0.881 & 4.5 & 481 & 780 \\
\hline 90.0 & 1.2 & 87.3 & 1.0 & 0.787 & 0.883 & 5.1 & 502 & 833 \\
\hline 95.0 & 1.3 & 94.4 & 1.0 & 0.771 & 0.883 & 5.7 & 526 & 902 \\
\hline 100.0 & 1.4 & 100.0 & 1.0 & 0.743 & 0.883 & 6.3 & 552 & 980 \\
\hline
\end{tabular}

Table 7.3 Calculated thermodynamic performance of Allison 250-C20B

\begin{tabular}{|c|c|c|c|c|c|c|c|c|}
\hline \multicolumn{7}{|c|}{ Allison 250-C20B } \\
\hline $\mathbf{N}_{\mathbf{1}} \mathbf{( \% )}$ & $\begin{array}{c}\dot{m}_{a} \\
\mathbf{( k g / s )}\end{array}$ & $\begin{array}{c}\text { Air Mass } \\
\text { Flow \% } \\
\text { (Total) }\end{array}$ & $\begin{array}{c}\boldsymbol{P}_{\text {atm }} \\
\text { (bar) }\end{array}$ & $\eta_{\text {comp }}$ & $\eta_{\text {turb }}$ & $\begin{array}{c}\text { CDP } \\
(\mathbf{b a r})\end{array}$ & $\begin{array}{c}\text { CDT } \\
(\mathbf{K})\end{array}$ & $\begin{array}{c}\text { EGT } \\
\mathbf{( K )}\end{array}$ \\
\hline 85.0 & 1.2 & 78.8 & 1.0 & 0.786 & 0.881 & 5.1 & 502 & 786 \\
\hline 90.0 & 1.4 & 87.3 & 1.0 & 0.787 & 0.883 & 5.8 & 524 & 838 \\
\hline 95.0 & 1.5 & 94.4 & 1.0 & 0.771 & 0.883 & 6.6 & 549 & 908 \\
\hline 100.0 & 1.6 & 100.0 & 1.0 & 0.743 & 0.883 & 7.1 & 576 & 987 \\
\hline
\end{tabular}

After having obtained confidence in the program outputs, a series of computer simulations were carried out. The purpose of the simulations was to estimate the maximum amount of air that could be safely bled from the engine before the EGT limit of 
$1083 \mathrm{~K}\left(810^{\circ} \mathrm{C}\right)$ was exceeded. The simulation results can be seen graphically in Figure 7.40 .

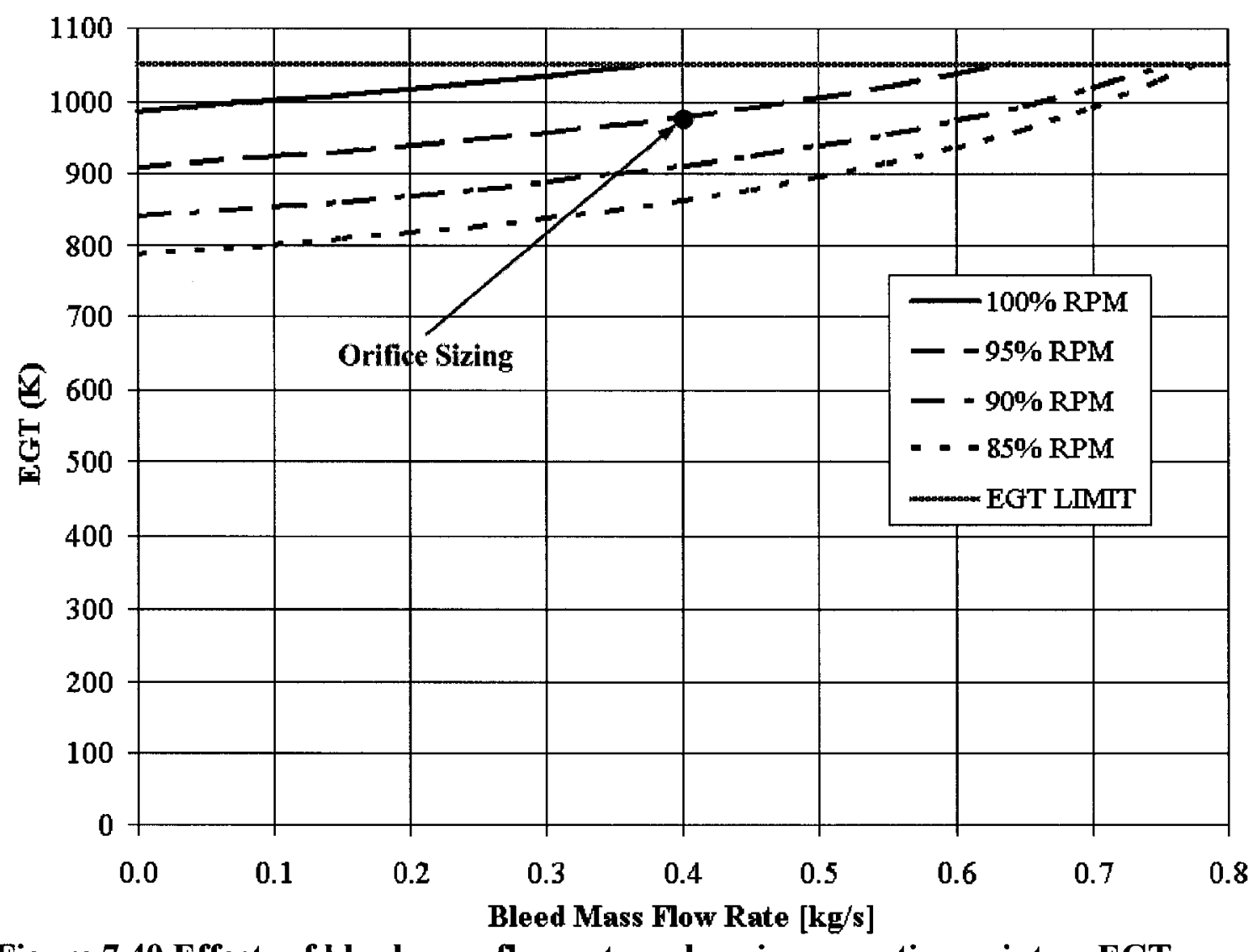

Figure 7.40 Effects of bleed mass flow rate and engine operating point on EGT

Figure 7.40 , shows that theoretically the maximum amount of air that can be safely bled from the Allison 250-C20B while running at full rotational speed is approximately $0.37 \frac{\mathrm{kg}}{\mathrm{s}}$. By reducing the engine rotational speed by $5 \%$, the amount of air that can be safely bled is approximately $0.63 \frac{\mathrm{kg}}{\mathrm{s}}$. With these results in mind a conservative approach for the orifice hole sizing was taken. Therefore, the orifice hole diameter was calculated with the engine operating at $95 \%$ of the full rotational speed and a maximum bleed mass flow rate of $0.40 \frac{\mathrm{kg}}{\mathrm{s}}$. 
Using theory found in Blevins (1984), the orifice hole diameter was calculated to be $19.0 \mathrm{~mm}(0.75 \mathrm{in})$. Taking into consideration that the orifice sizing was done using an analytical tool (Mathcad program), which is based on simplifying assumptions two more orifices with their holes slightly oversized when compared to the original design were manufactured. The two orifice hole diameters were $20.8 \mathrm{~mm}(0.82 \mathrm{in})$ and $22.9 \mathrm{~mm}(0.90$ in) respectively.

The last component making up the air delivery system is a pressure switch. The pressure switch in Figure 7.41 was purchased from Omega Engineering and its model number is PSW-108. The air delivery system was equipped with a pressure switch for safety reasons.

As the name implies, the pressure switch is a switch that senses pressure and that actuates an electrical signal by changing the position of the electrical contacts within the $15 \mathrm{amp}$, single pole, double throw switch (Figure 7.42). The pressure sensing mechanism (actuator) can be adjusted between 0.2 bar and 6.9 bar ( 3 psi to 100 psi) and the switch can be wired either "normally open" (i.e., no electrical current flowing through the switch) or "normally closed".

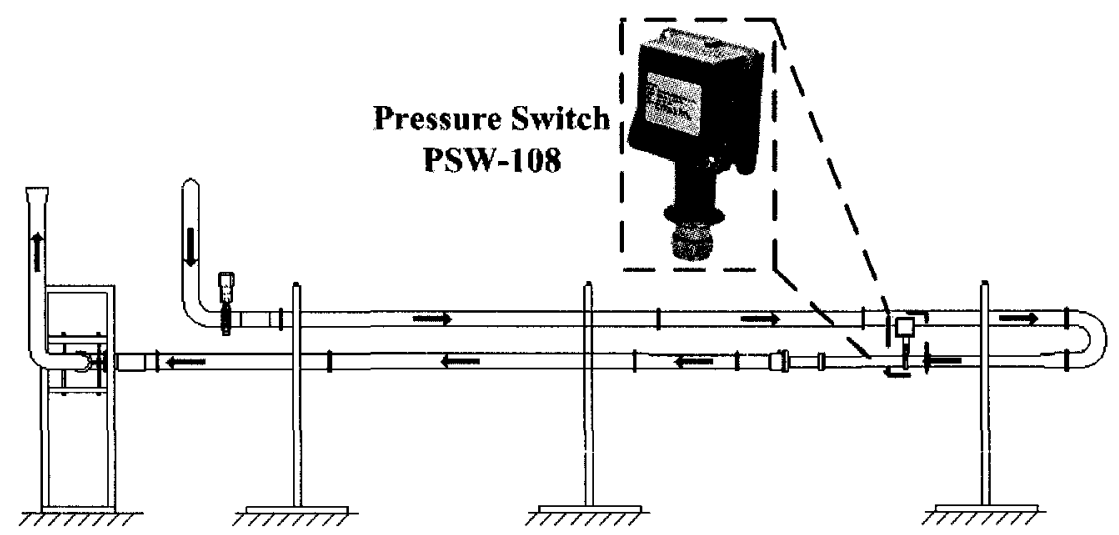

Figure 7.41 Pressure switch location in air delivery system (Adapted from Omega Engineering, 2000) 
In the gas turbine combustion research laboratory the pressure switch was mechanically connected to the air delivery system via a $6.4 \mathrm{~mm}(0.25 \mathrm{in})$ stainless steel tubing and was electrically linked, through wires, to the on/off solenoid valve (ASCO 8223G027) present in the fuel delivery system (valve details given in Section 7.3.7). The switch was wired in the normally open position and the pressure sensing mechanism was adjusted to actuate at pressures higher than 2 bar ( $30 \mathrm{psi})$. In other words, at pressures higher than 2 bar, the pressure sensing mechanism would change the position of the electrical contacts from open to closed, allowing current to reach the on/off solenoid valve in the fuel delivery system. In case of a sudden pressure loss in the air delivery system, due to an Allison 250-C20B malfunction for example, the pressure switch would automatically open, stopping the current from flowing to the on/off solenoid valve. The now de-energized on/off solenoid valve would automatically close, stopping the fuel flow into the microturbine combustor and therefore, impeding any further combustion process.

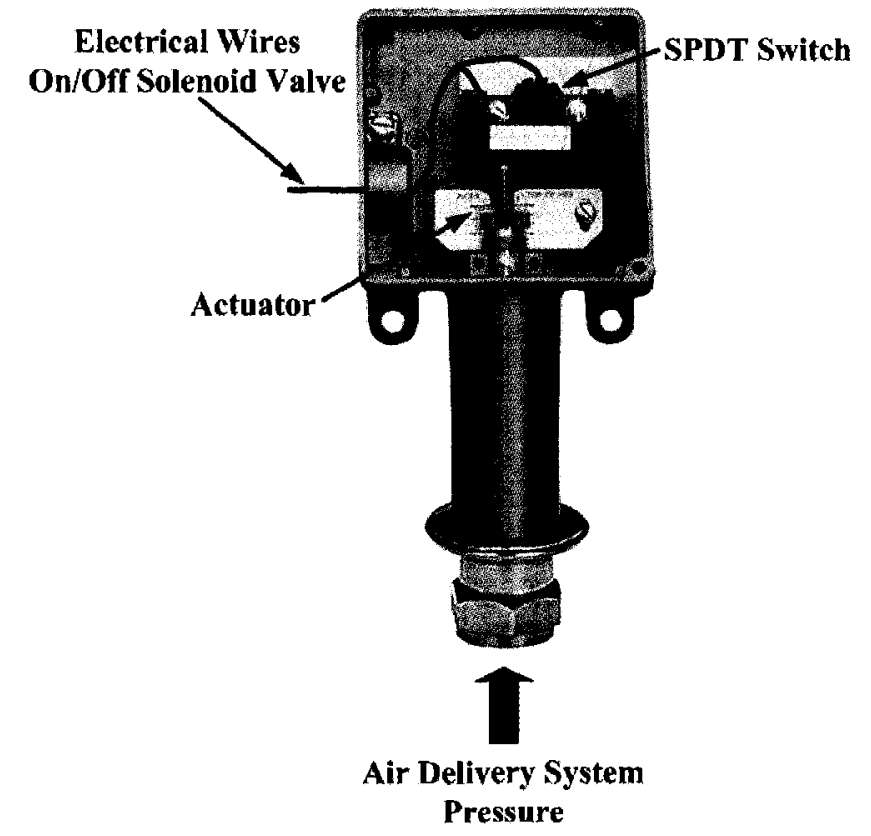

Figure 7.42 PSW-108 pressure switch details (Adapted from Omega Engineering, 2000) 


\subsubsection{Air Delivery System Instrumentation}

In the high pressure configuration, the air delivery system instrumentation was localized around the microturbine combustor and the orifice plate.

\subsubsection{Microturbine Combustor Instrumentation}

In general, combustor instrumentation should be selected so that the combustor pressure drop, combustion efficiency and combustor patter factor can be obtained via the acquisition of accurate experimental measurements. Furthermore, the instruments selected have to withstand the hostile temperature environments found downstream of the combustor. Lastly, due to large temperature gradients at the combustor outlet, numerous experimental measurements must be taken to obtain a comprehensive understanding of the hot gasses exiting the combustor. Thus, the instrumentation should be circumferentially and radially traversable so that a thorough set of measurements of the combustor outlet can be obtained.

In the laboratory, the microturbine combustor was equipped with pressure and temperature instrumentation so that all the above mentioned objectives could be met. Specifically, the instrumentation permitted measuring the total and static pressures as well as the gas temperatures upstream and downstream of the combustor. In addition, the liner walls were also instrumented with temperature sensors so that the material temperature could be acquired.

Due to the small cross-sectional areas of the microturbine flow paths, careful attention was given when choosing the dimensions of the instrumentation. In particular, the dimensions of the measuring sensors inserted into the flow path were such that a blockage factor below 5\%, as suggested by Saravanamuttoo (1990), was ensured. Other 
considerations taken into account, when choosing the suitable instrumentation, were: cost, ease of manufacturing and ease of installation.

At the combustor inlet, the total pressure was measured by a pitot rake designed and constructed by the author. The function of the rake was to bring the local flow (i.e., flow interfering with the rake) to a zero velocity so that the air total pressure could be measured. The rake, shown in Figure 7.43, was made up of 13 Inconel tubes with inner and outer diameters of $1.0 \mathrm{~mm}(0.04 \mathrm{in})$ and $1.6 \mathrm{~mm}(1 / 16 \mathrm{in})$ respectively. The $305 \mathrm{~mm}$ (12 in) long tubings (model number INC-116-12OPEN) were purchased from Omega Engineering. The tubings were bent into an $\mathrm{L}$ shape with a corner radius of $10 \mathrm{~mm}$. The rake was then formed by placing the tubings $1.6 \mathrm{~mm}$ apart and soldering them together. Figure 7.43 shows the final product. The proper alignment of the rake with respect to the air flow inside the pipe was ensured by designing and constructing the assembly mechanism shown in Figure 7.44.

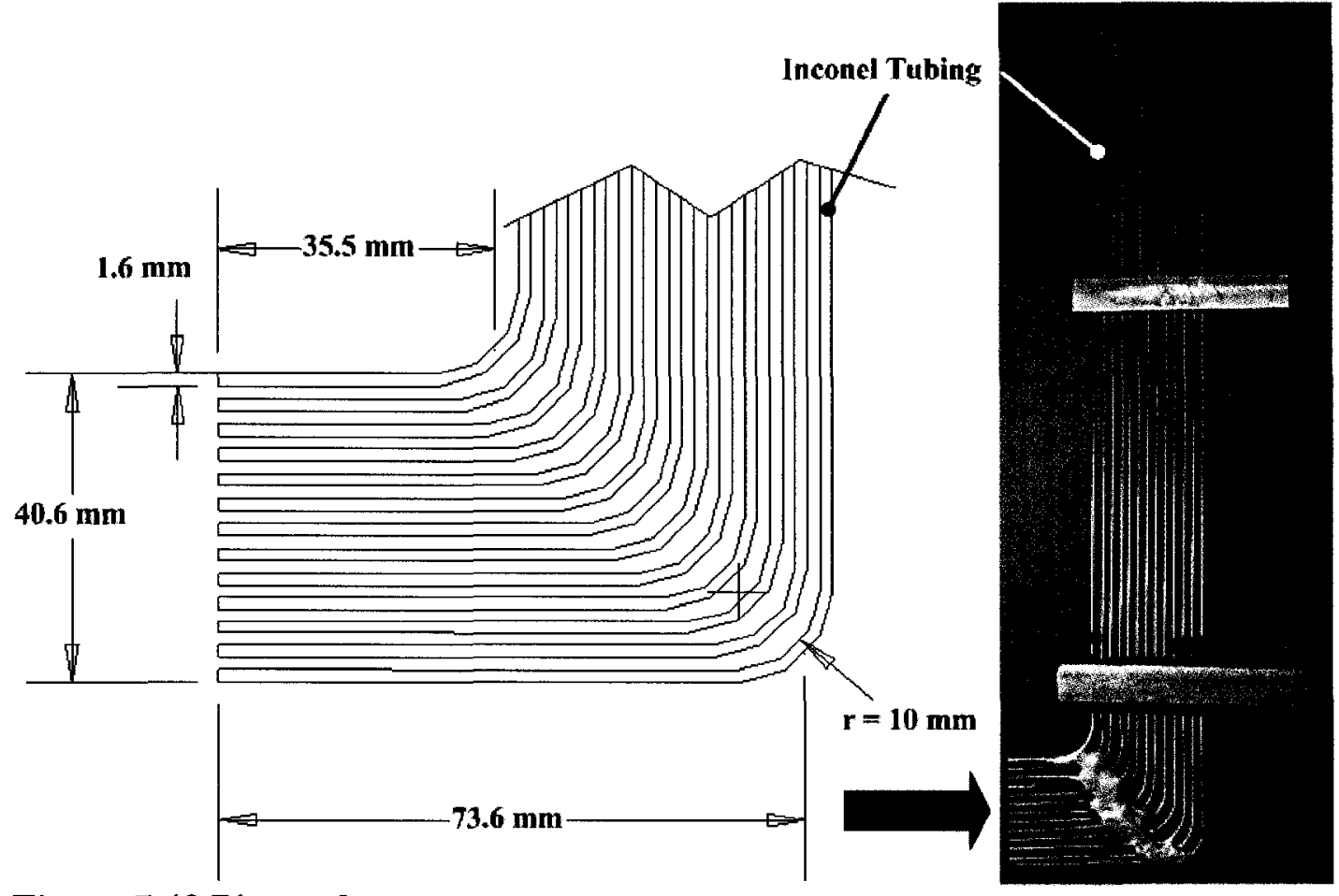

Figure 7.43 Pitot rake 

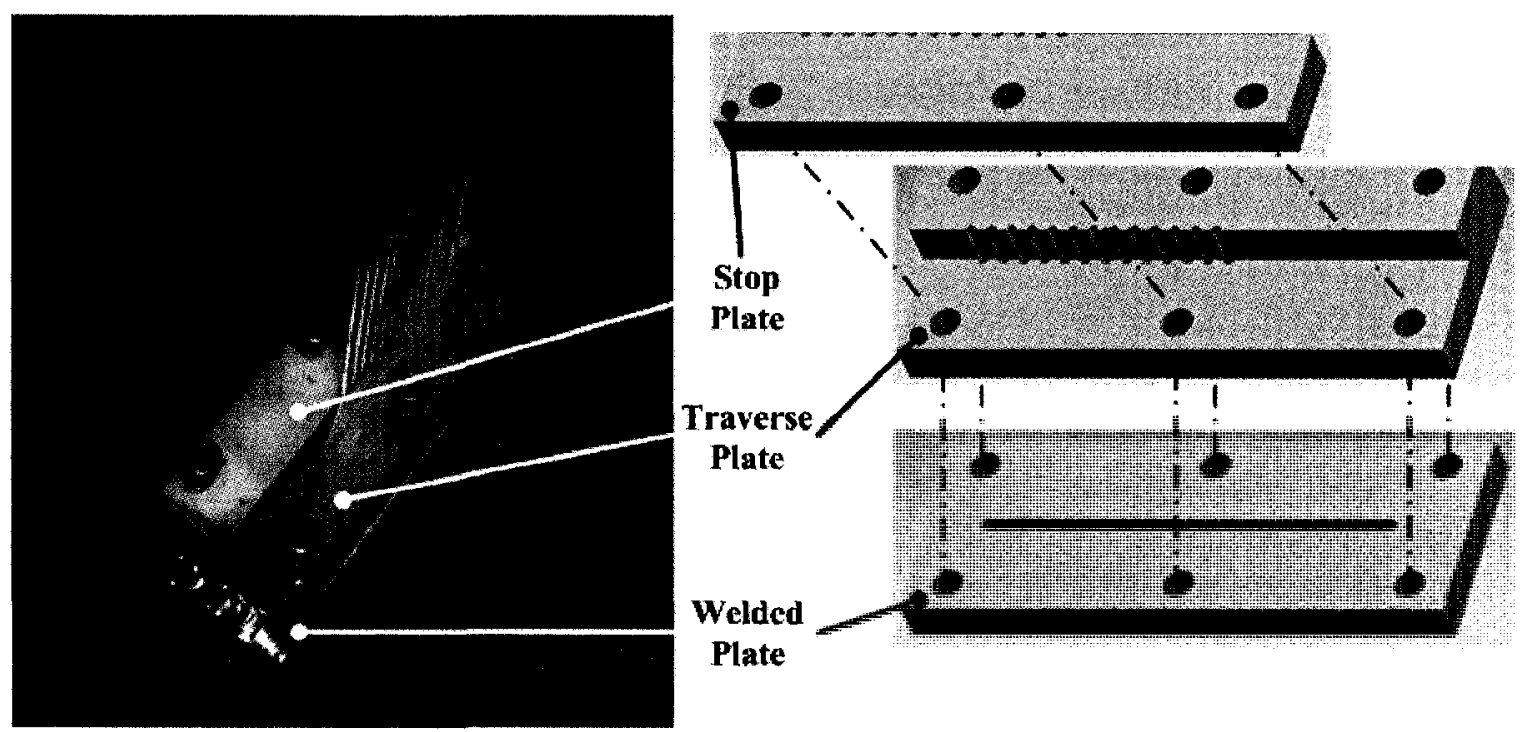

Figure 7.44 Pitot rake assembly

The location of the rake with respect to the inlet of the microturbine combustor can be seen in Figure 7.45. The figure also shows the location of the wall taps. To ensure that the static pressure measurements were not influenced by the pitot rake, the wall taps were located $150 \mathrm{~mm}(6 \mathrm{in})$ upstream of the rake.

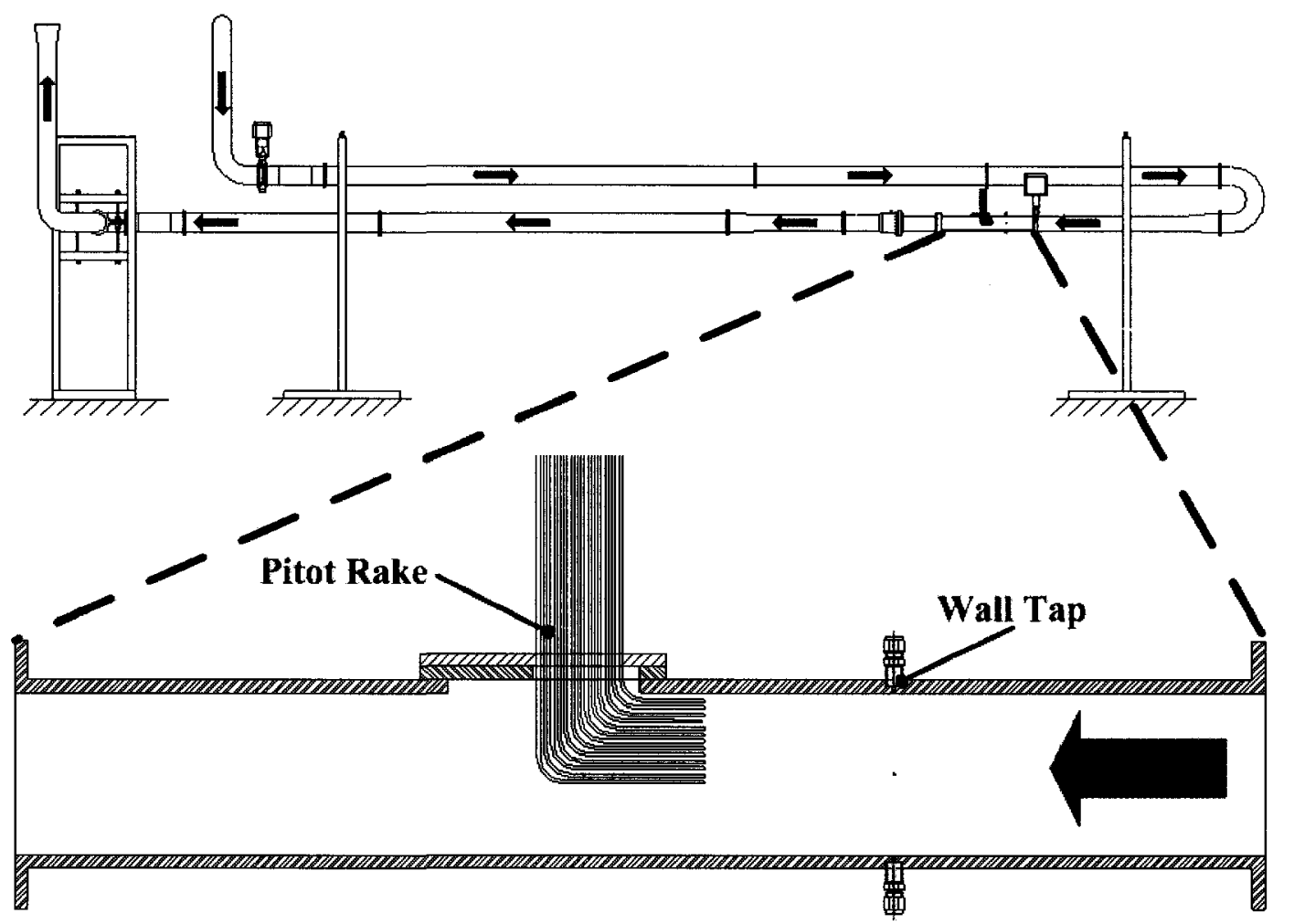

Figure 7.45 Instrumentation upstream of microturbine combustor 
The wall taps were manufactured by the author using the guidelines reported in Section 7.2.4. The wall tap manufacturing process was carried out by first drilling the 1.0 $\mathrm{mm}$ hole, normal to the pipe wall, and by then GTAW welding a modified tube fitting (MNPT threads removed) onto the pipe outer wall (Figure 7.46).

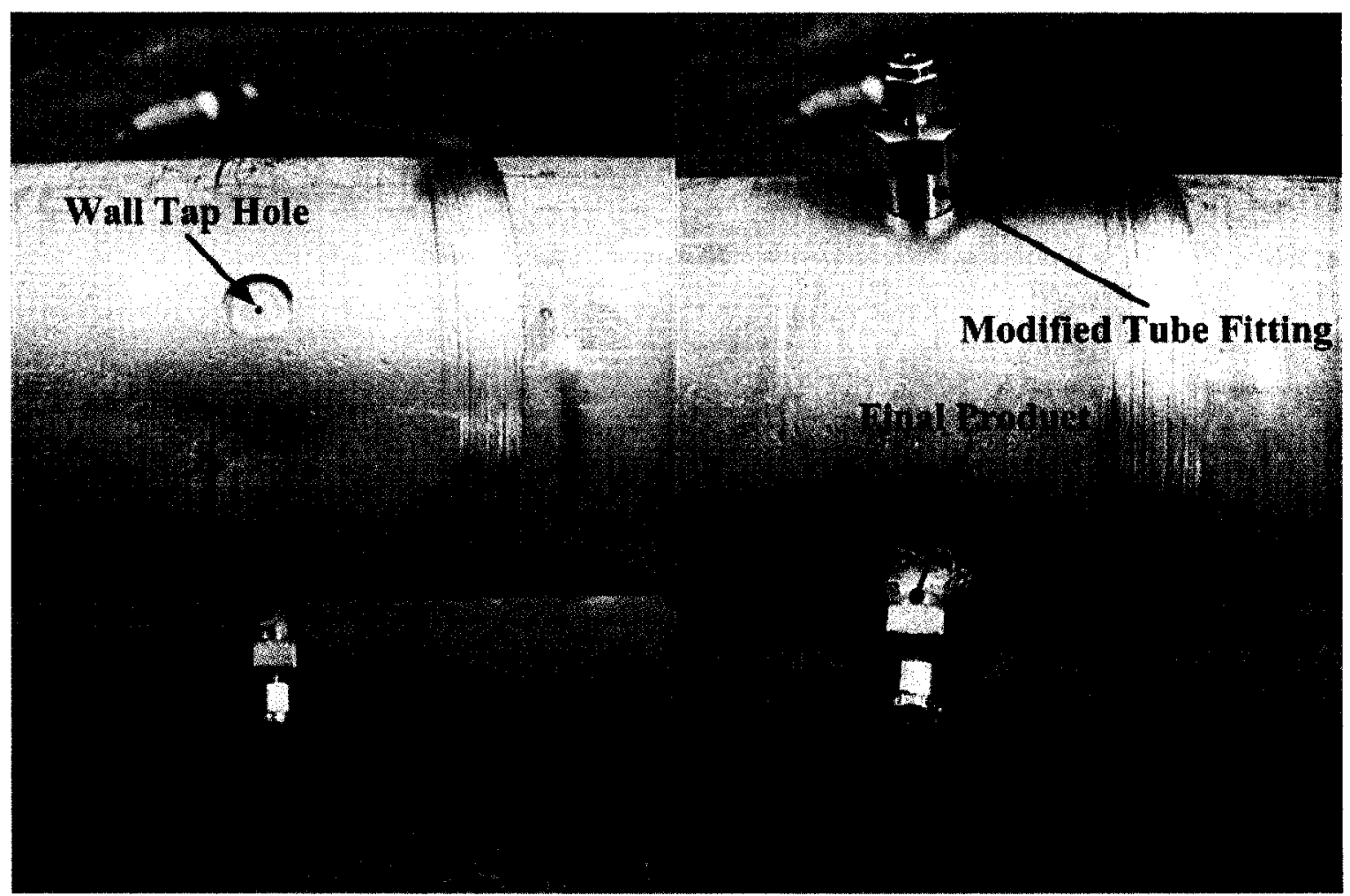

Figure 7.46 Wall tap manufacturing process

The last instrument found upstream of the combustor was a type $\mathrm{K}$ thermocouple. The thermocouple, which was inserted inside one of the rake's pitot tubes (Figure 7.47), measured the air temperature entering the microturbine combustor. 


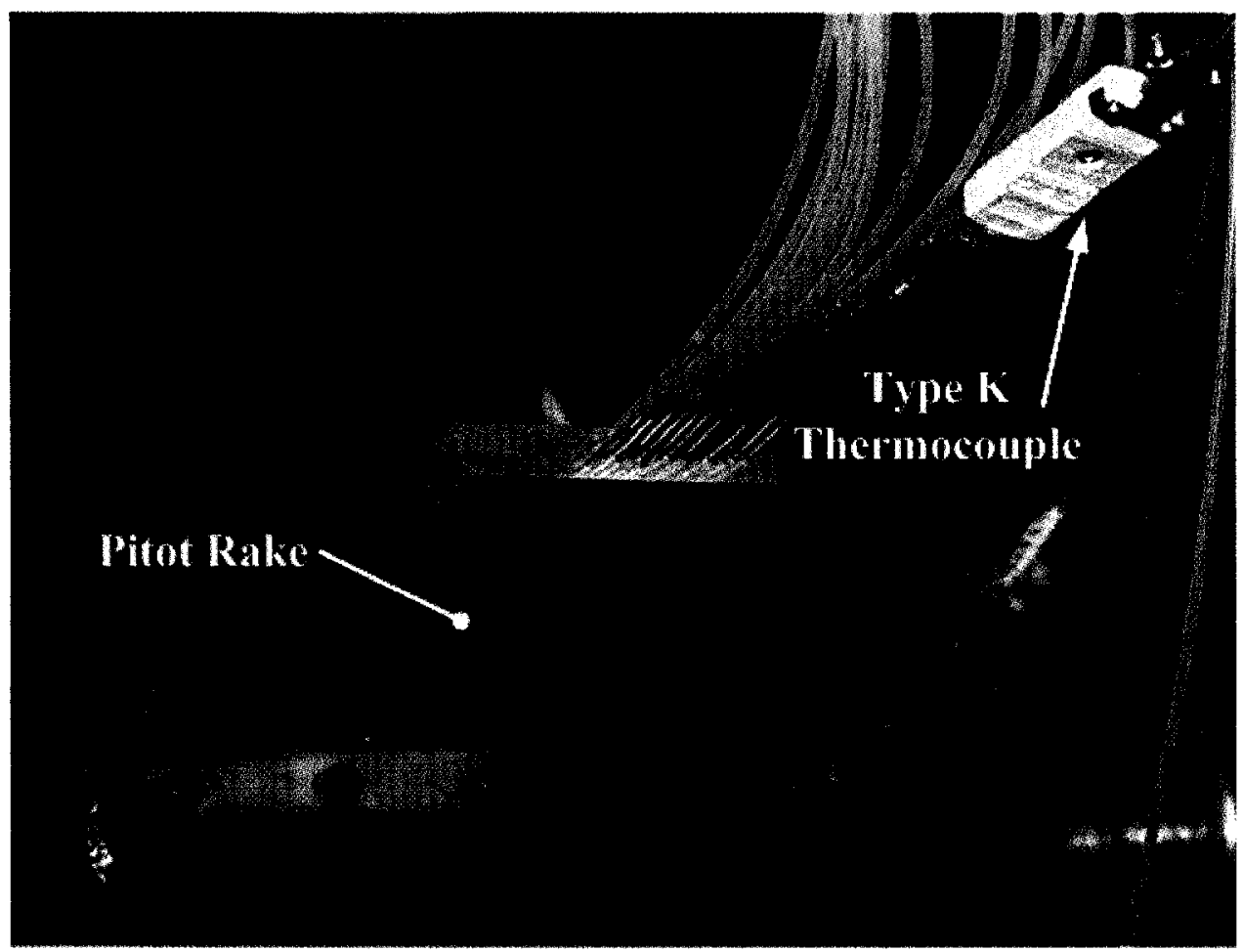

\section{Figure 7.47 Microturbine air inlet temperature thermocouple}

The measurements conducted at the combustor outlet were the total and static pressures and the exhaust gas temperature. The instrumentation used to carry out these measurements was selected to sustain high temperatures while keeping the blockage factor below $5 \%$.

In addition to being small, the total pressure probe chosen had to be insensitive to angles of attack (i.e., flow directions) since the exhaust gas flow exiting the combustor could approach the probe from many different directions. The pitot probe selected, to measure the total pressure downstream of the combustor, had a Kiel type head. The details of the probe (model KBC-8-W), purchased from United Sensor Corporation ${ }^{15}$, can be seen in Figure 7.48. The advantage of this particular probe head design was the insensitivity to flow direction. The Kiel probe calibration curves presented in Figure 7.49

\footnotetext{
${ }^{15}$ United Sensor Corporation, 3 Northern Boulevard, Amherst, NH 03031-2329 U.S.A
} 
show the sensor insensitivity to flow direction. Figure 7.49 shows that the purchased probe can measure the total pressure of flows approaching at yaw and pitch angles ranging between $\pm 55^{\circ}$ and $\pm 50^{\circ}$ respectively. The probe insensitivity to flow directions is achieved due to its outer tube which realigns the streamtube with the centerline of the probe with minimal total pressure loss (Ower and Pankhurst, 1977). The inner tube then measures the total pressure.
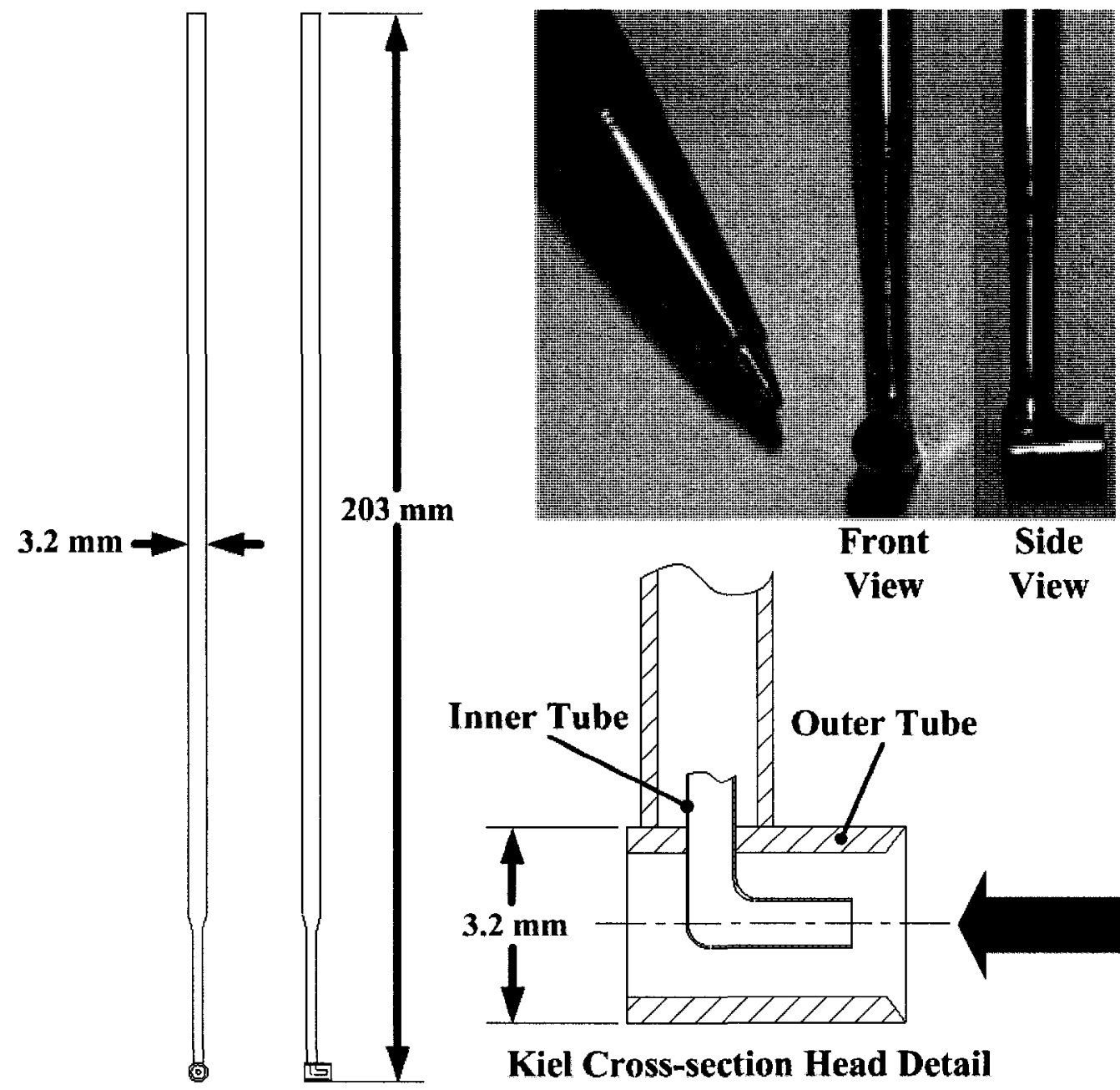

Figure 7.48 Kiel probe design

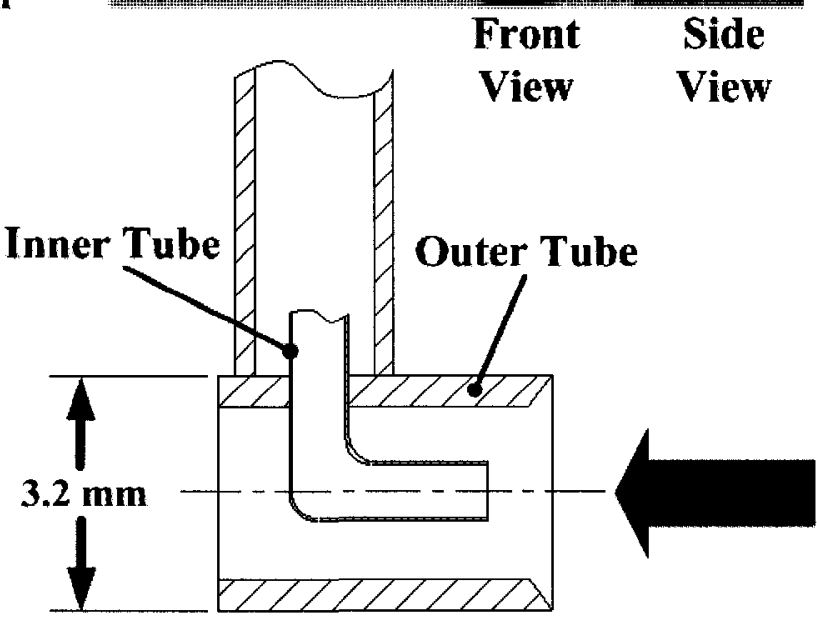

Kiel Cross-section Head Detail 

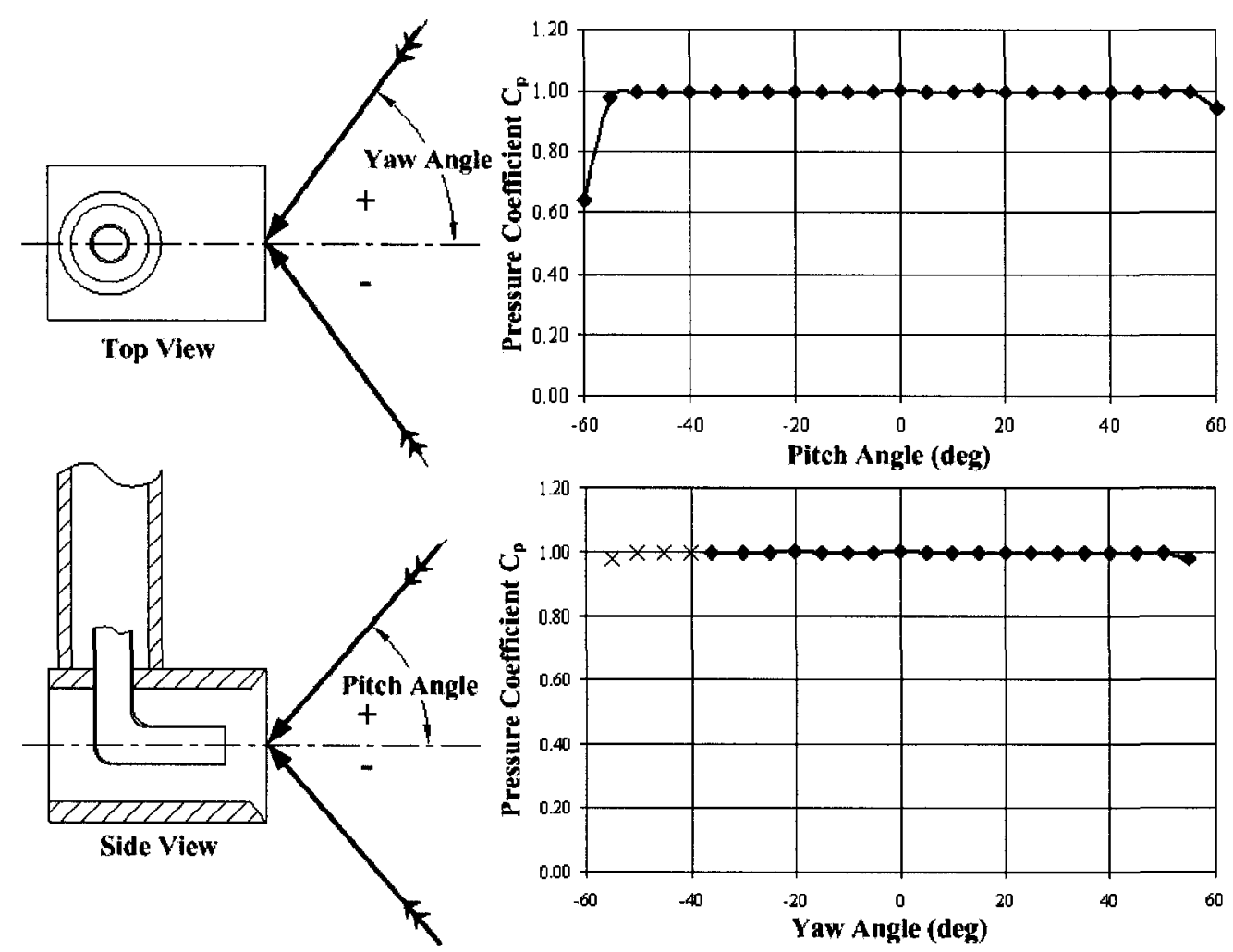

Figure 7.49 Kiel probe flow angles

The purchased Kiel probe can be used up to $1366 \mathrm{~K}$ temperatures (United Sensor, 2005). The suitability of the probe selection was further confirmed when reviewing work from Haas (1996) who purchased, from United Sensor Corporation, the same type of Kiel probe. In Haas' work, as it was for this research project, the Kiel probe was placed downstream of a gas turbine combustor (Allison T63-A-700, military derivative of Allison 250 model) and the total pressure at the turbine inlet was successfully measured.

The static pressure downstream of the microturbine combustor was measured using four wall taps. The guidelines and actual manufacturing technique used to fabricate the wall taps has previously been addressed in this section. Figure 7.50 shows the placement of the Kiel probe and wall taps with respect to the microturbine combustor. Specifically, the wall taps were located $230 \mathrm{~mm}(9 \mathrm{in})$ from the combustor casing outlet and the Kiel probe was inserted $38 \mathrm{~mm}$ (1.5 in) downstream of the wall taps. 


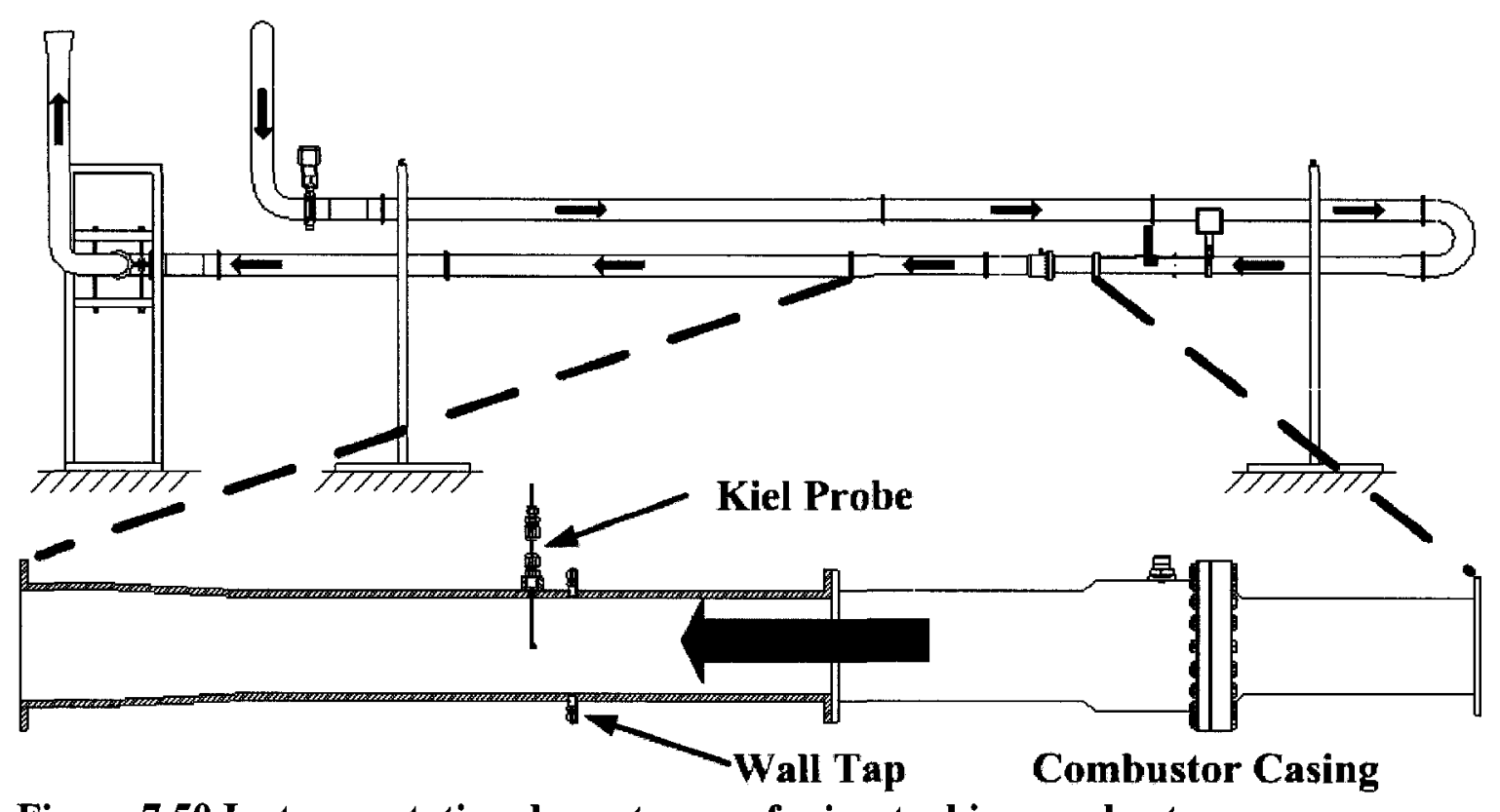

Figure 7.50 Instrumentation downstream of microturbine combustor

The temperature of the exhaust gasses exiting the microturbine combustor was measured by a type $\mathrm{K}$ thermocouple. To minimize radiation, conduction and convection measurement errors (Saravanamuttoo, 1990), the thermocouple was placed within a ceramic protection tube. The protection tube (model PTRA-11618-12), purchased from Omega Engineering, had an outer diameter of $3.1 \mathrm{~mm}(1 / 8 \mathrm{in})$, an inner diameter of 1.6 $\mathrm{mm}(1 / 16)$ and a length of $305 \mathrm{~mm}$ (12 in). The protection tube material was pure alumina ceramic $\left(\mathrm{Al}_{2} \mathrm{O}_{3}\right)$. Two small holes had to be machined onto the protection tube so that the exhaust gasses could interact with the thermocouple. The grinding process, used to create the holes in the protection tube, was a difficult process due to the hardness and brittleness of the $\mathrm{Al}_{2} \mathrm{O}_{3}$ material. The final product with some key details can be seen in Figure 7.51. 


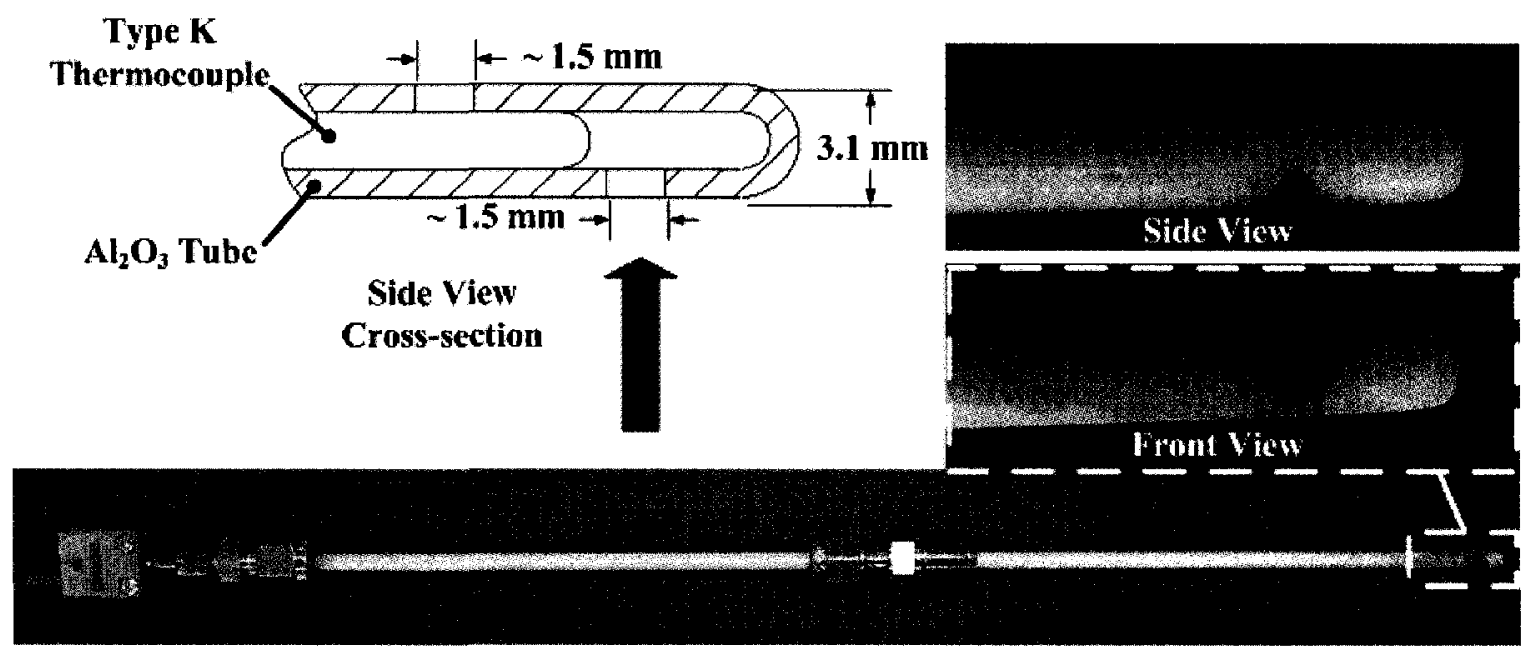

Figure 7.51 Thermocouple assembly for measuring combustor outlet temperature

After having completed the thermocouple assembly, the sensor was inserted $305 \mathrm{~mm}$ (12 in) downstream of the combustor outlet. The insertion point of the temperature sensor was positioned in such a way to minimize disruption to total and static pressure measurements occurring downstream. In other words, the sensor insertion point was not in line with any of the pressure sensors located downstream. This can be seen in Figure 7.52 .

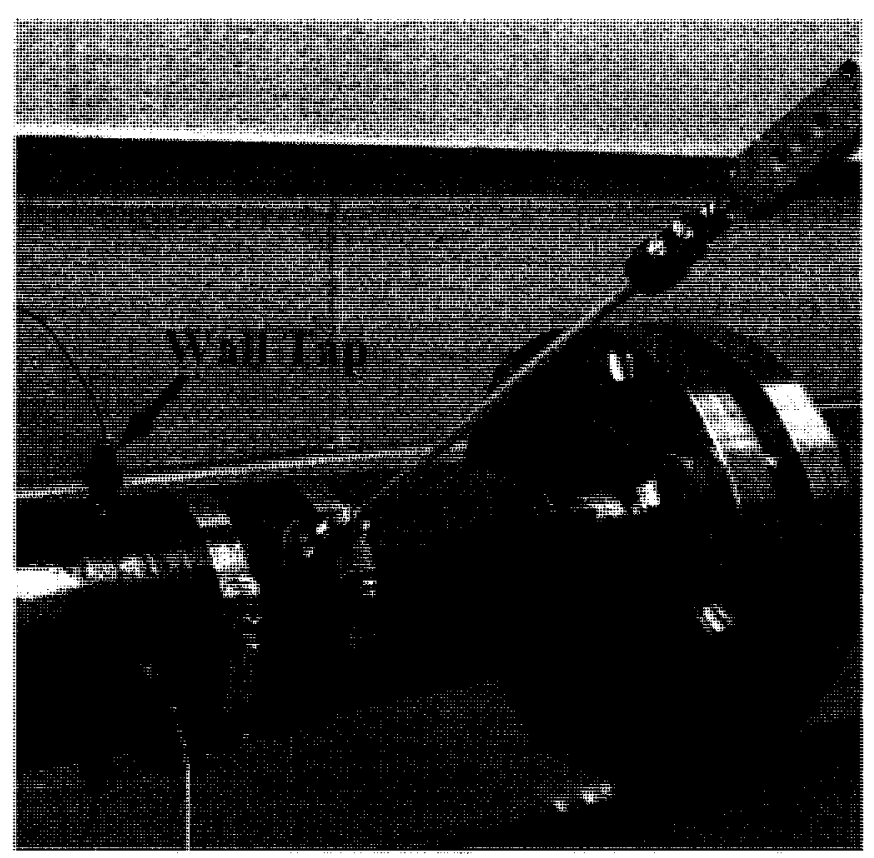

Figure 7.52 Temperature sensor insertion point 
The traverse mechanism for both the Kiel probe and the temperature sensor was accounted for by using tube fittings as the support structure. At this point, the traverse mechanisms can only be operated manually. Creating a means by which remote actuation can be achieved should be addressed in the future.

To asses the cooling performance of the liner, as well as to provide test data that could be used for validation purposes in future combustor modelling simulations, the liner walls were instrumented with a series of strategically placed thermocouples. Ten meters ( 33 feet) of sheathed, type $\mathrm{K}$ thermocouple wire, was purchased from Omega Engineering for the liner walls instrumentation. Hastelloy $\mathrm{X}$ was chosen for the sheath metal because of its resistance to high temperature and high temperature oxidation. One $\mathrm{mm}(0.04 \mathrm{in})$, smallest available size, was chosen to be the outer diameter of the thermocouple wire to minimize combustor flow disturbances.

Upon having received the thermocouple wire, 20 segments of various lengths were cut. The sheath metal at both ends of each thermocouple segment was then manually stripped to expose the enclosed thermocouple wires. The stripping process was carried out through the use of a commercially available tool retailed by Omega Engineering (Figure 7.53).

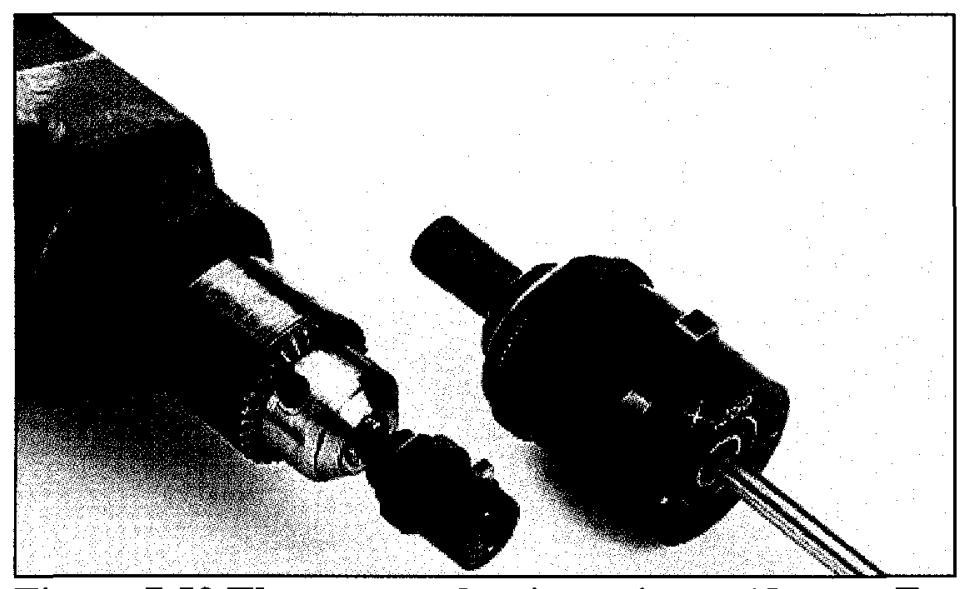

Figure 7.53 Thermocouple wire stripper (Omega Engineering, 2004) 
The alloys of the two wires contained within the type $\mathrm{K}$ thermocouple are nickelchromium $(+)$, also known as Chromel and nickel-aluminun $(-)$, also referred to as Alumel (Figure 7.54).

\section{Sheath Metal}

\section{(Hastelloy X)}

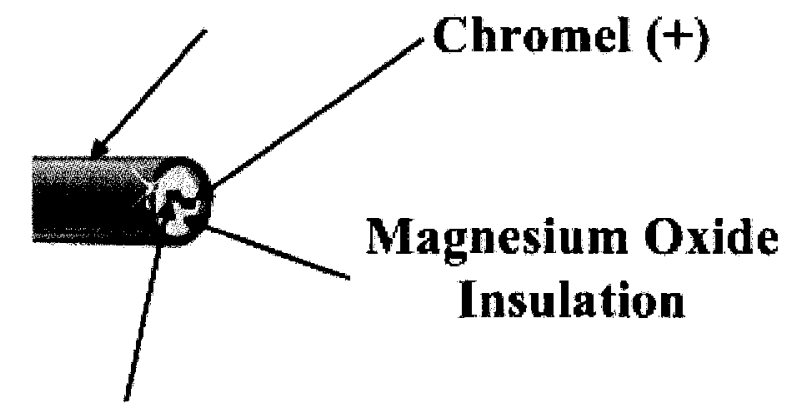

\section{Alumel (-)}

Figure 7.54 Type $K$ thermocouple nomenclature (Adapted from Omega Engineering, 2004)

At one end of the thermocouple wire segment, the two wires were joined together and spot welded to the liner wall. At the other end of the segment, the two wires (each the thickness of a hair) were carefully connected to a miniature female connector as shown in Figure 7.55 .

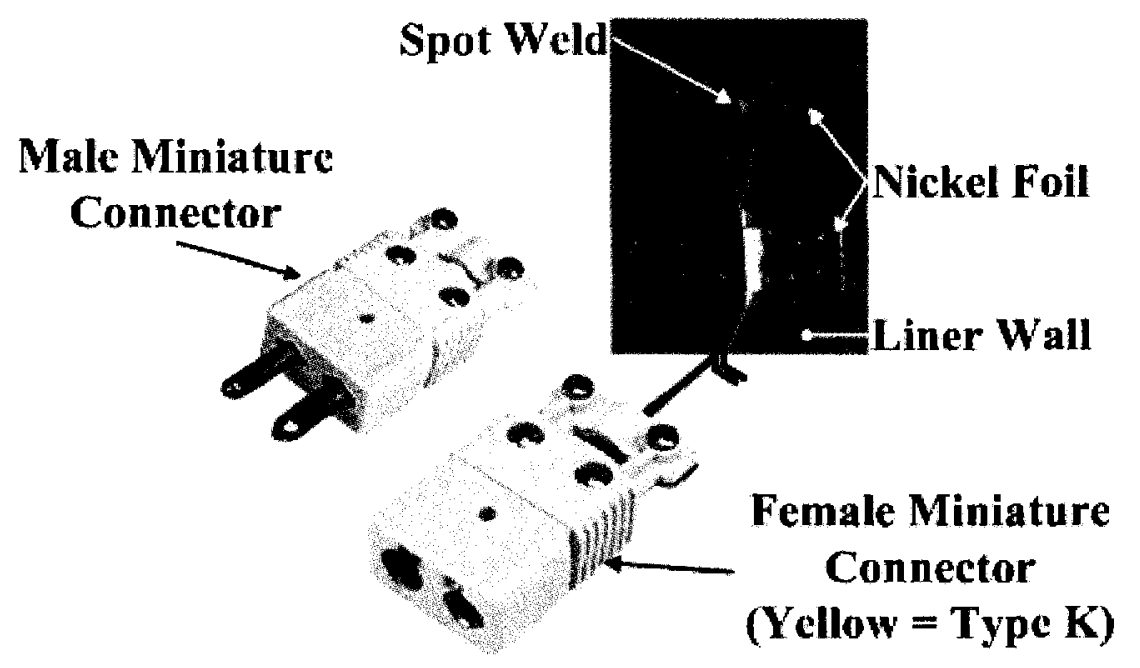

Figure 7.55 Thermocouple connectors (Adapted from Omega Engineering, 2004) 
As shown in Figure 7.56, the exposed thermocouple wires have fixed references. In other words, one wire is positive (Chromel) while the other is negative (Alumel). An important part of the connection process of the wires and female connector was to carefully assess which wire was negative and which was positive and then to fasten them to their correct places within the connector. To determine the proper reference of these extremely small wires, the magnetic properties of the Alumel wire were relied upon. Hence, with the use of a magnet, the distinction between the two wires was obtained and correct installation within the female connector was carried out.

Since no CFD modelling on the combustor was carried out, the locations for the thermocouples were chosen according to engineering judgement. The number of thermocouples used was decided by the number of available channels in the data acquisition system. Therefore, the total number of temperature sensors used in the liner wall instrumentation was 20 . Given the limited amount of temperature sensors, eight thermocouples were used to acquire the axial temperature distribution along the liner wall and the remaining 12 thermocouples were spaced out over other wall locations so that a comprehensive liner wall temperature distribution could be obtained (Figure 7.56).

To reduce the possibility of thermocouple detachment from the liner wall during testing, a $0.03 \mathrm{~mm}(0.001 \mathrm{in})$ thick nickel foil was purchased and cut into small strips which were then spot welded along the thermocouple lengths. The nickel foil was purchased from McMaster-Carr ${ }^{16}$. As can be seen from Figure 7.56 and Figure 7.57, the thermocouple wires were bent approximately normal to the liner centre axis. This permitted for the spot welds to follow the temperature induced thermal expansion and

\footnotetext{
${ }^{16}$ McMaster-Carr, 200 New Canton Way, Robbinsville, NJ 08691-2343, U.S.A
} 
contraction experienced by the liner during testing. The final liner wall instrumentation, showing the thermocouple locations and spot weld details, can be seen in Figure 7.56 and Figure 7.57.

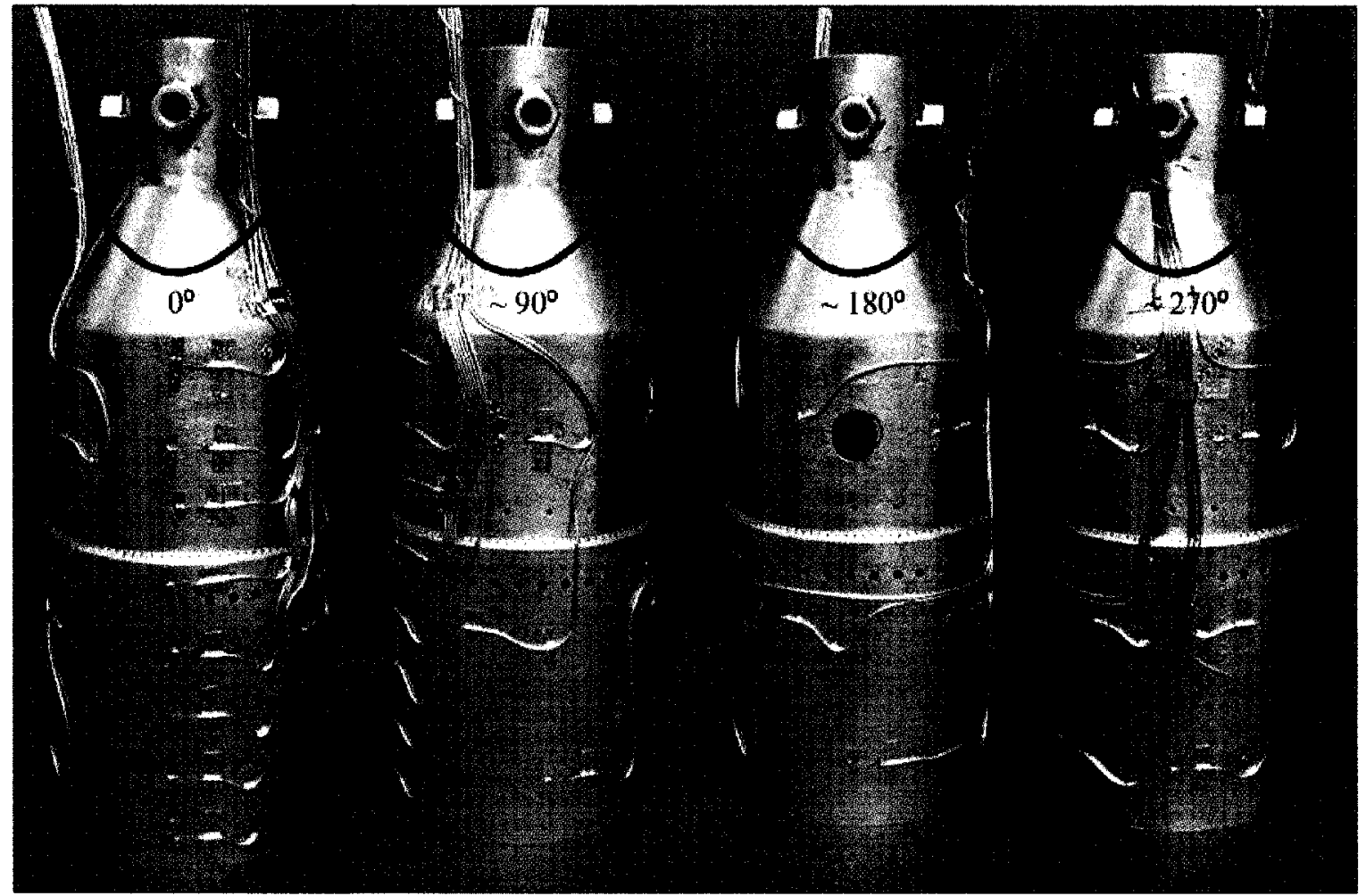

Figure 7.56 Views of liner instrumentation through a $270^{\circ}$ rotation

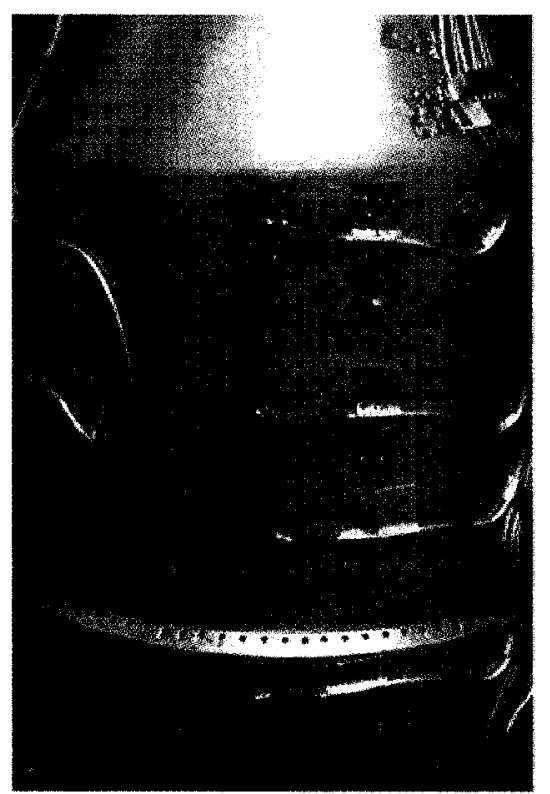

Figure 7.57 Thermocouples spot welds detailed view 


\subsubsection{Orifice Instrumentation}

The thin square-edged orifice plate introduced in Section 7.3.3 was used to measure the amount of air bled from the Allison 250-C20B engine, thus quantifying the amount of air entering the microturbine combustor. The orifice plate measuring technique relies on the large drop in static pressure experienced by the flow when it travels from the full pipe diameter to the smaller hole in the orifice plate. This static pressure difference can be measured by strategically located wall taps. There are three wall tap designs that measure the mass flow rate accurately-namely, flange taps, vena contracta tap and 1-D and $\frac{1}{2}-\mathrm{D}$ taps. The author selected the last type of design where, as can be deduced from the name, this design uses one or more wall taps at 1 diameter upstream of the orifice and one or more wall taps at $\frac{1}{2}$ diameter downstream of the orifice. Furthermore, as mentioned before, a straight pipe span of 20 diameters upstream and 10 diameters downstream of the orifice are needed to ensure accurate flow measurements.

The orifice plate in the air delivery system was instrumented with four wall taps upstream and four wall taps downstream. Once again, the guidelines and manufacturing techniques followed to fabricate the orifice wall taps are those that have been previously described in Sections 7.2.4 and 7.3.4.1. Figure 7.58 shows the orifice plate measuring principle. Figure 7.59 shows the wall taps upstream of the orifice plate. 


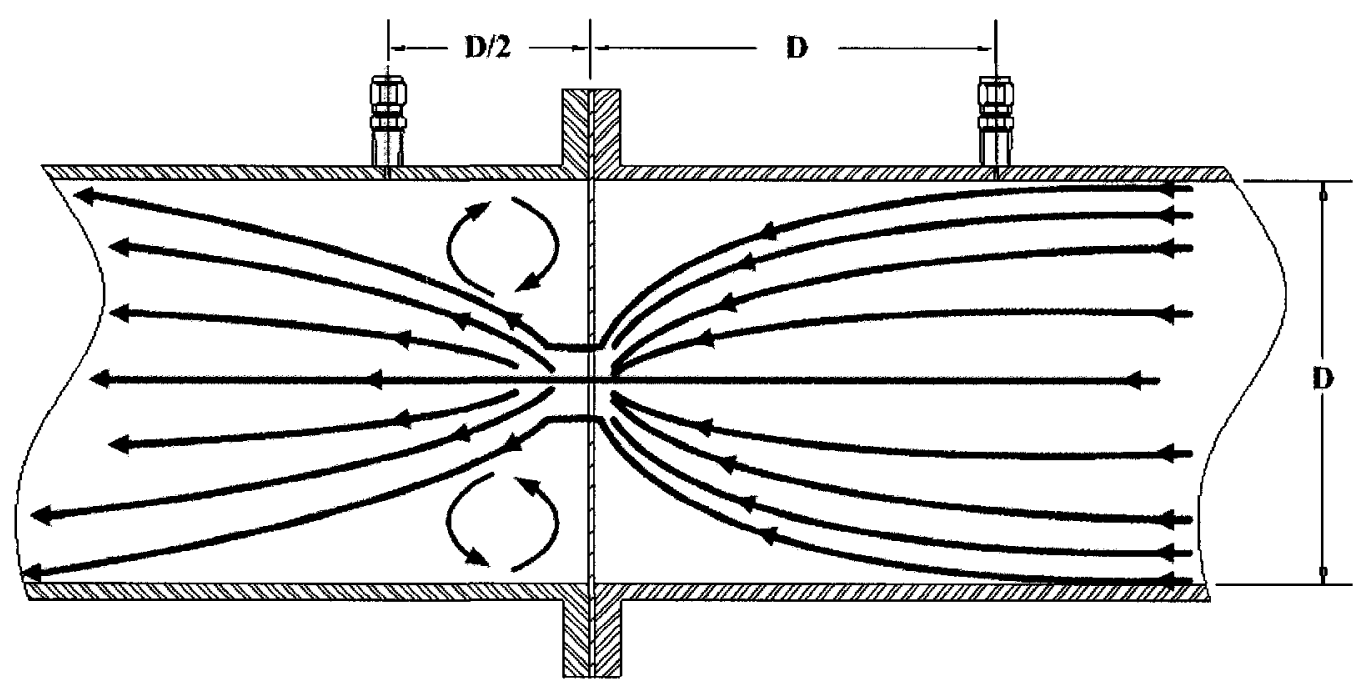

Figure 7.58 Orifice plate with 1-D and $\frac{1}{2}-D$ wall taps

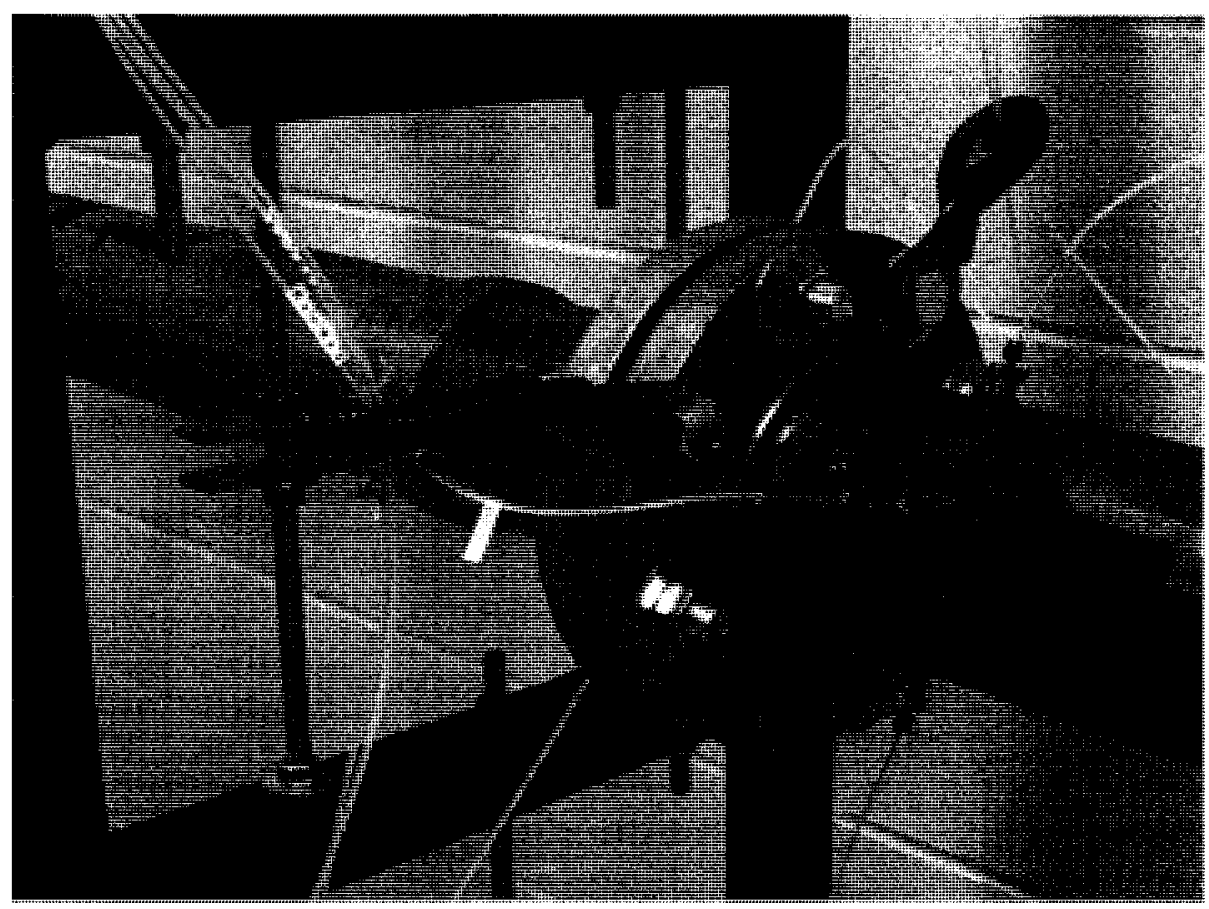

\section{Figure 7.59 Orifice plate wall taps (upstream)}

The welded tube fittings used in the wall taps and a detachable tube fitting at the Kiel probe outlet were utilized to couple the pressure sensors to the pressure transducers. Specifically, these fittings were coupled to Inconel tubings, which in turn were linked to the pressure transducers via Teflon tubings. The purpose of the Inconel tubings, which had the same specifications as those used for the pitot rake, was two-fold. The Inconel 
tubing's sturdy construction permitted for a structurally sound and gas-tight connection between the Inconel tube and the fitting, and between the Inconel and Teflon tubings. The Inconel tubings also allowed for heat to be transferred to the surroundings so that the Teflon tubing maximum operating temperature was not exceeded. This was particularly important downstream of the combustor where the pressure sensors would be operating in high temperature environments. Thus, for enough heat to be transferred to the surroundings, Inconel tube lengths of $305 \mathrm{~mm}$ (12 in) were used for the pressure sensors located downstream of the combustor.

The Teflon tubing and pitot rake coupling mechanism took advantage of the sensor design. Since the pitot rake was already made up of Inconel tubings, the Teflon tubings were adhered, using epoxy, directly to the pitot rake tube outlets. Figure 7.60 shows examples of a wall tap and of the pitot rake tubing coupling mechanisms. The other ends of the Teflon tubings, whose specifications were given in Section 7.2.4, were then connected to pressure transducers.

Using a pressure scanner, the minimum amount of pressure transducers that could be used to measure all the pressures along the air delivery system was determined to be two. Two pressure transducers were needed due to high pressure differences upstream and downstream of the orifice plate. In other words, one transducer was needed to measure high pressures upstream of the orifice (up to 7 bar) and the other transducer was needed to measure the static pressures (slightly above 1 bar) downstream of the orifice. 


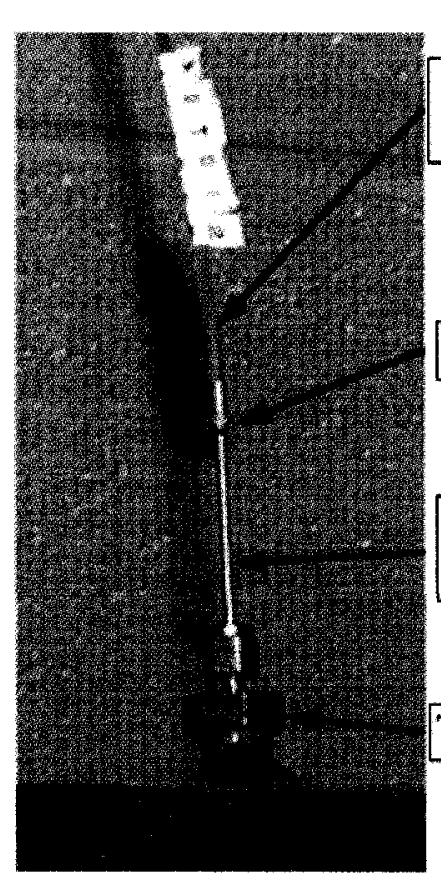

Wall Tap

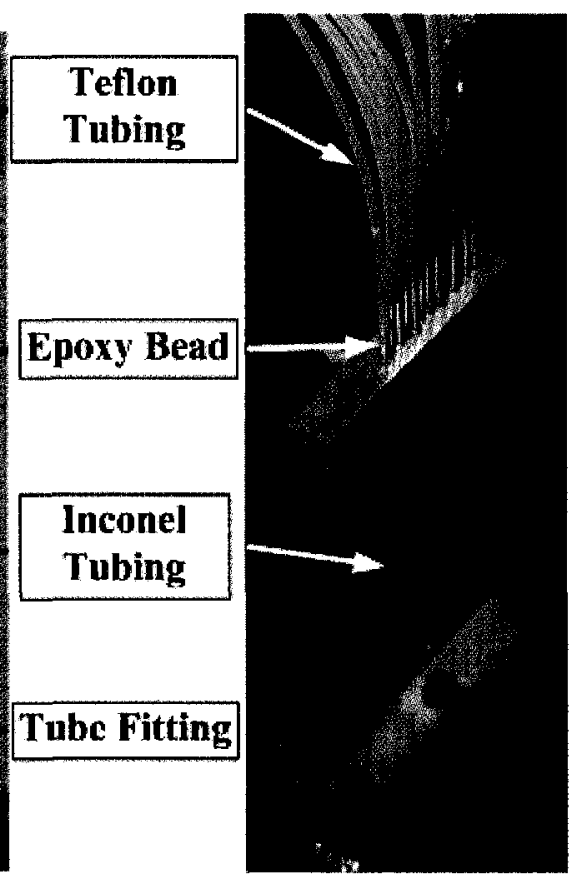

Pitot Rake

Figure 7.60 Wall tap and pitot rake pressure lines

The apparatus that minimized the number of pressure transducers used in the air delivery system was a Scanivalve pressure scanner coupled with a solenoid controller, as can be seen in Figure 7.61.

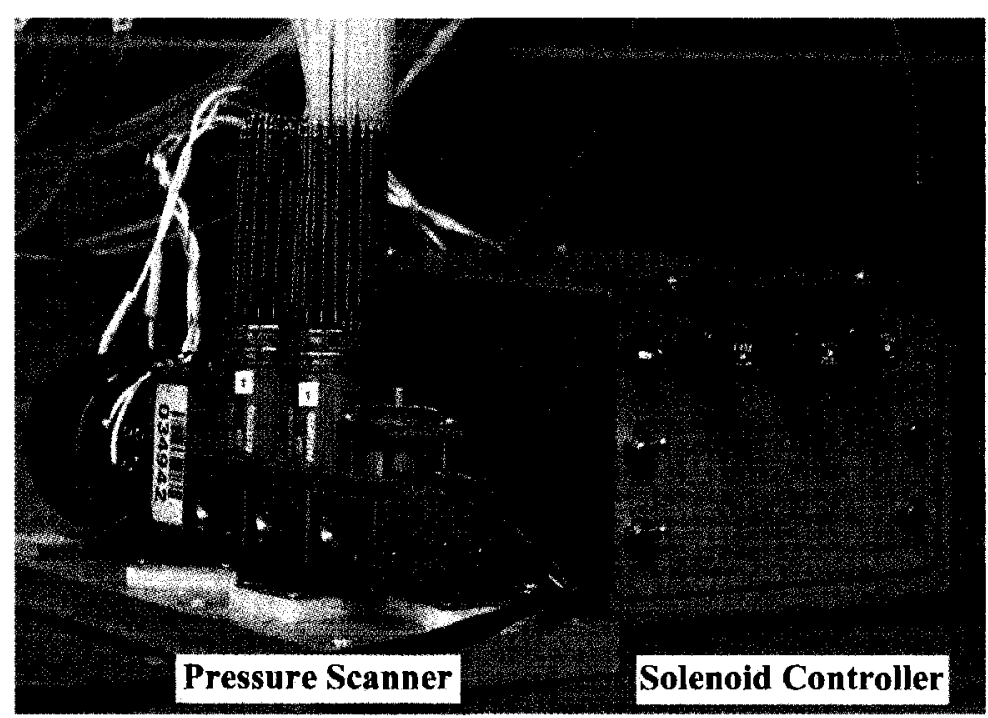

Figure 7.61 Scanivalve pressure scanner and solenoid controller

In general, the pressure scanner design permitted multiple inlet pressure lines to be connected to a single outlet pressure line. The stepping mechanism present in the pressure 
scanner allowed one pressure line at the time to be open. Therefore, multiple sensor locations could be scanned with only a single transducer measuring the various scanned pressures.

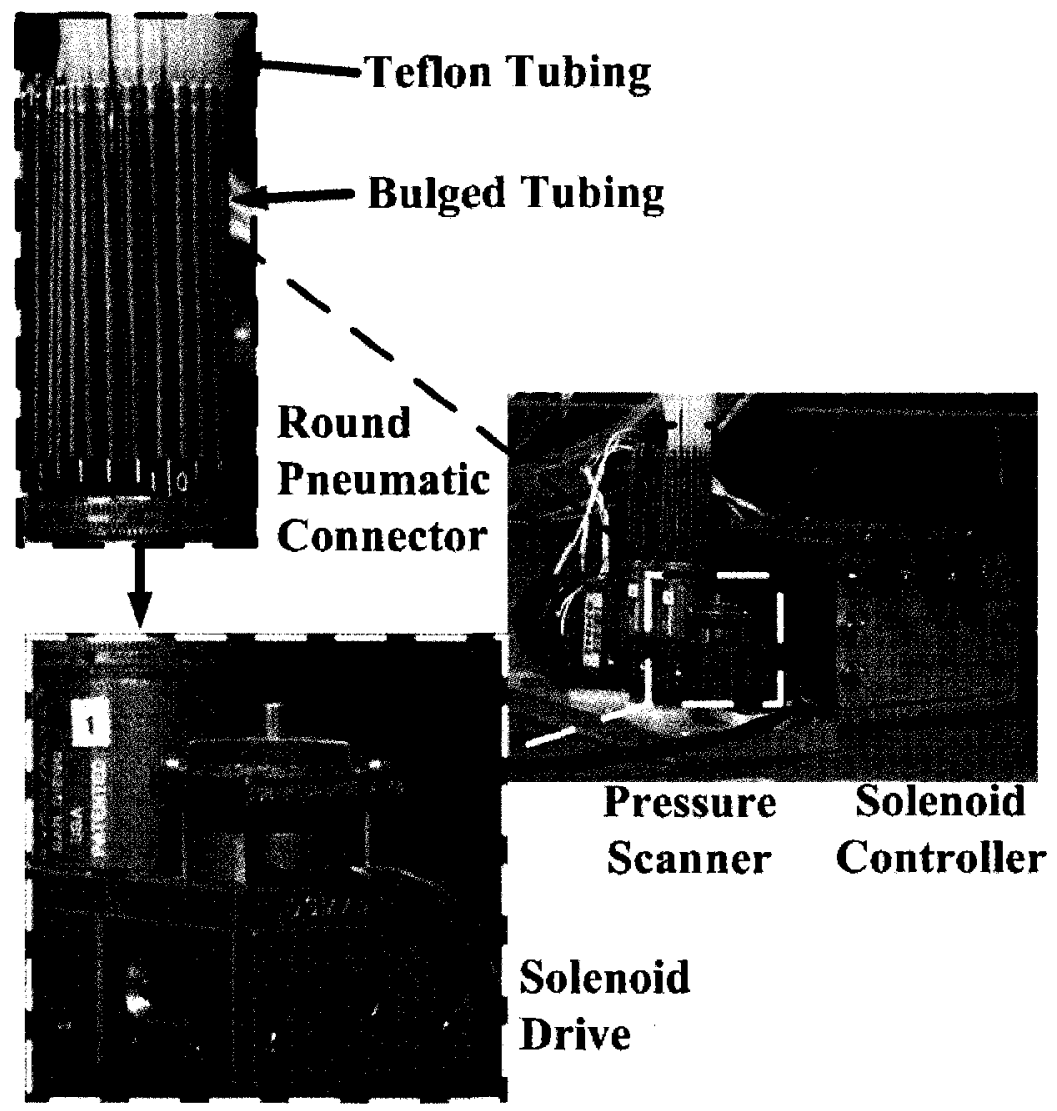

Figure 7.62 Pressure scanner components

The inlet pressure lines (Teflon tubings) coming from the various sensors located throughout the air delivery system were inserted onto the bulged tubings present in the round pneumatic connector (Figure 7.62). The pneumatic connector was then screwed onto the main body of the pressure scanner namely, the solenoid drive (Figure 7.62). A flat gasket was inserted between the pneumatic connector and the solenoid drive mating surfaces for sealing purposes, thus, ensuring that each pressure tubing was isolated from the other. The solenoid drive, which could be directly or remotely operated, was electrically triggered via push button switches, present in the Control Room, or directly 
via a solenoid controller. The switches permitted either to step from one pressure tube to the next or to return to the home position. Therefore, after completing a pressure scan of the entire air delivery system, the solenoid drive could then be brought back to the home position by pushing the home button once.

Shakedown tests of the pressure scanning system revealed that instead of monitoring critical combustion test parameters, such as liner wall temperatures, too much time was spent on scanning and monitoring the 29 pressure values acquired along the air delivery system. Therefore, a total of six pressure transducers were used instead. Thus, the pressure lines sensing the static pressures along the air delivery system were disconnected from the pressure scanner. At each static pressure location, four wall taps were used to better estimate the static pressure. The four wall taps, for each static pressure measurement location, were then averaged using the same type of manifold previously described and shown in Figure 7.19. The average static pressures were then measured by four independent pressure transducers. The pressure lines of the pitot rake were left connected to the pressure scanner and by stepping from one port to the next, the 12 total pressures experienced by the probe were measured by a fifth pressure transducer . The sixth and final transducer was that measuring the total pressure of the Kiel probe.

The transducers used to measure pressures upstream of the orifice plate were of type PX243 and were purchased from Omega Engineering. This type of transducer can measure gauge pressures between 0 bar and 6.9 bar ( 0 psig to 100 psig). The static pressure downstream of the orifice plate was measured by the same transducer model but with a gauge pressure ranging between \pm 0.17 bar gauge $( \pm 2.5 \mathrm{psig})$. The transducer analog outputs (1 to 6 VDC) were temperature compensated between $-18^{\circ} \mathrm{C}$ and $63^{\circ} \mathrm{C}$. 


\subsubsection{Data Acquisition System}

The analog outputs produced by all the pressure and temperature sensors making up the gas turbine combustion research laboratory were acquired by a Keithley 2700 data acquisition system (DAQ) through two cards having 20 input channels each (Figure 7.63). The acquisition system, located in the Combustion Room, then converted the analog measurements into digital signals which were then sent via wire to a desktop computer located in the Control Room.

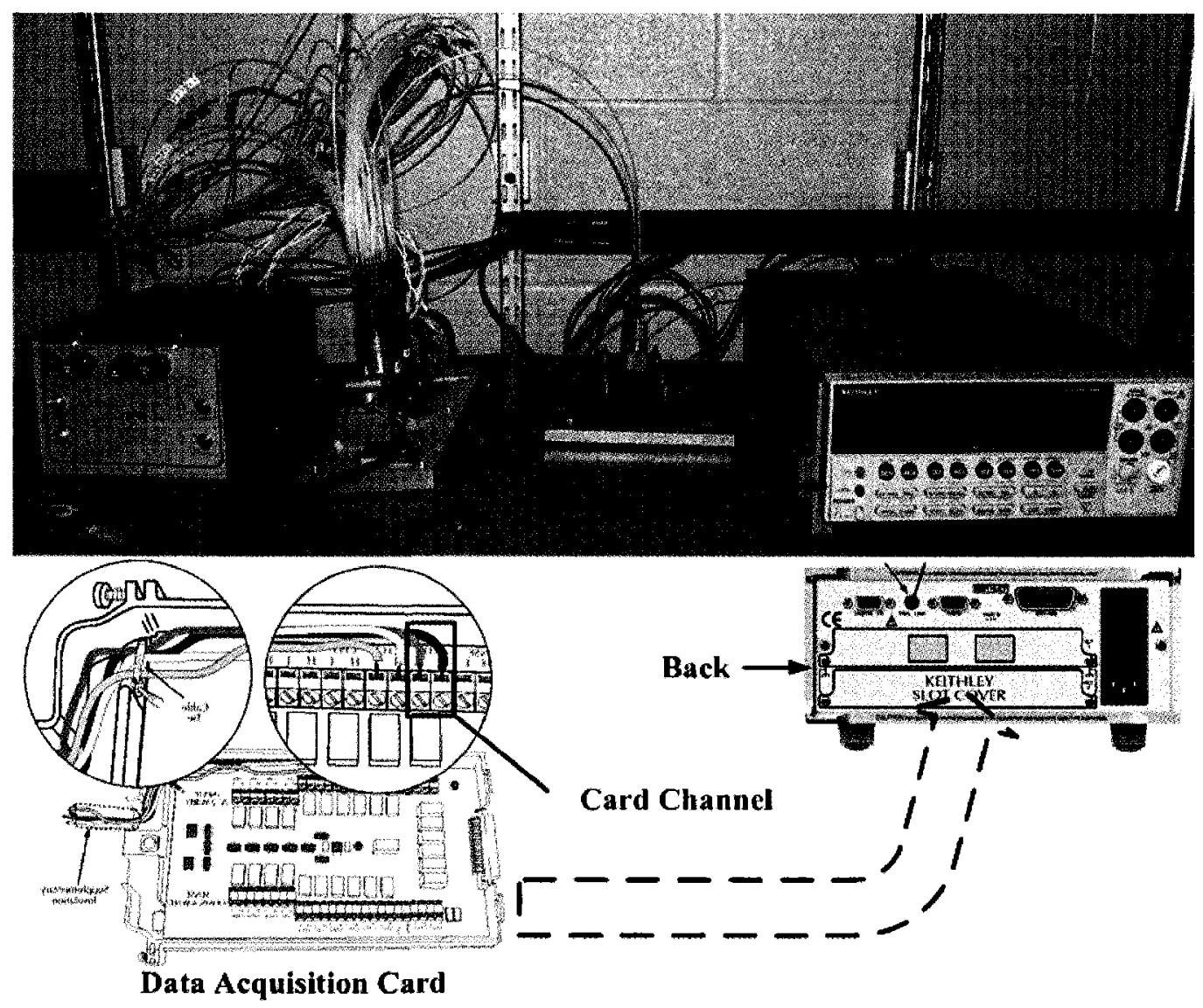

Figure 7.63 Keithley 2700 data acquisition system

LabView programs created by the author manipulated these digital signals from nonengineering units (VDC, mVDC) to units that could readily be interpreted, such as bar for pressures and Kelvin for temperatures. In addition to displaying the data for monitoring purposes, the computer was also used to store the measurements. 
Due to the large amount of temperature and pressure sensors used in the air delivery system more precisely, 22 thermocouples and 29 pressure ports, a measurement identification technique suggested by Saravanamuttoo (1990) was adopted. The thermocouple extension wires and pressure lines were identified with tags as follows:

Measured Parameter

Microturbine Station

Sensor Station

Angular Position

Sensor Number
$\mathrm{P}, \mathrm{S}, \mathrm{T}$

3,4

$0,1,2 \ldots \ldots \ldots . . .99$

A, B, C, ,.......

$01,02,03 \ldots \ldots . . .99$

On the identification tags the $\mathrm{P}$ indicated total pressure, the $\mathrm{S}$ indicated static pressure and the temperature was indicated with a $\mathrm{T}$. All the measurements taken upstream of the microturbine combustor inlet were indicated by the number 3 whereas the measurements downstream of the combustor were labelled with $4 \mathrm{~s}$. The sensor stations along the air delivery system were labelled sequentially starting from the number 0 . The angular positions of the sensors were determined by viewing the air delivery system cross section from the upstream to the downstream direction. The pipe angles were divided into segments of $15^{\circ}$ increments as shown in Table 7.4.

Table 7.4 Angular location of sensor

\begin{tabular}{|c|c|c|c|}
\hline $0^{\circ} \leq \mathrm{A}<15^{\circ}$ & $90^{\circ} \leq \mathrm{G}<105^{\circ}$ & $180^{\circ} \leq \mathrm{M}<195^{\circ}$ & $270^{\circ} \leq \mathrm{T}<285^{\circ}$ \\
\hline $15^{\circ} \leq \mathrm{B}<30^{\circ}$ & $105^{\circ} \leq \mathrm{H}<120^{\circ}$ & $195^{\circ} \leq \mathrm{N}<210^{\circ}$ & $285^{\circ} \leq \mathrm{U}<300^{\circ}$ \\
\hline $30^{\circ} \leq \mathrm{C}<45^{\circ}$ & $120^{\circ} \leq \mathrm{I}<135^{\circ}$ & $210^{\circ} \leq \mathrm{P}<225^{\circ}$ & $300^{\circ} \leq \mathrm{V}<315^{\circ}$ \\
\hline $45^{\circ} \leq \mathrm{D}<60^{\circ}$ & $135^{\circ} \leq \mathrm{J}<150^{\circ}$ & $225^{\circ} \leq \mathrm{Q}<240^{\circ}$ & $315^{\circ} \leq \mathrm{W}<330^{\circ}$ \\
\hline $60^{\circ} \leq \mathrm{E}<75^{\circ}$ & $150^{\circ} \leq \mathrm{K}<165^{\circ}$ & $240^{\circ} \leq \mathrm{R}<255^{\circ}$ & $330^{\circ} \leq \mathrm{X}<345^{\circ}$ \\
\hline $75^{\circ} \leq \mathrm{F}<90^{\circ}$ & $165^{\circ} \leq \mathrm{L}<180^{\circ}$ & $255^{\circ} \leq \mathrm{S}<270^{\circ}$ & $345^{\circ} \leq \mathrm{Y}<360^{\circ}$ \\
\hline
\end{tabular}


Finally, if more than one sensor was used at the same measurement location the instrument lines were sequentially numbered. This was the case for the pitot rake in which each tube was numbered sequentially in ascending order towards the mounting flange. Figure 7.64 gives a graphical example of the labelling system for the instrumentation upstream of the microturbine combustor.

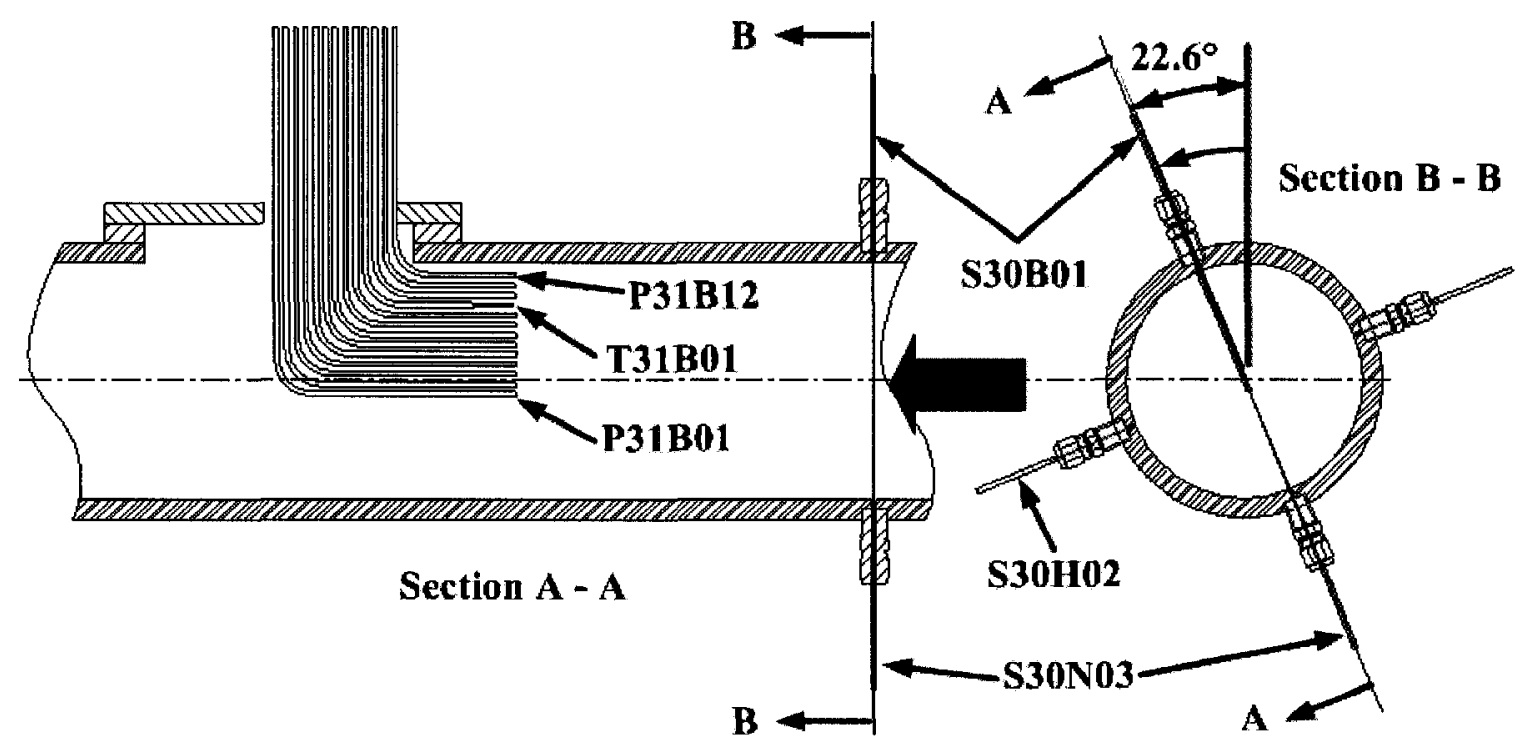

Figure 7.64 Measurements identification

Lastly, the air delivery system was also equipped with an access port downstream of the combustor outlet so that a probe could be inserted to sample the exhaust gasses. The results of the samples could then measure the efficiency of the microturbine combustion and the amount of pollutants produced by the combustion process. This part of the test would use equipment belonging to ERMD.

\subsubsection{Atmospheric Pressure Air Delivery System}

The air delivery layout, in the atmospheric pressure configuration, resided within the Combustion Room as shown in Figure 7.65. The bleed pipe coming from the Gas Turbine Room and protruding into the Combustion Room had to be disconnected so that the 
atmospheric blower (Spencer Turbine Company, model 30104A3) could be coupled to the air delivery system using a rubber hose and two $90^{\circ}$ long radius elbows, as seen in Figure 7.66.

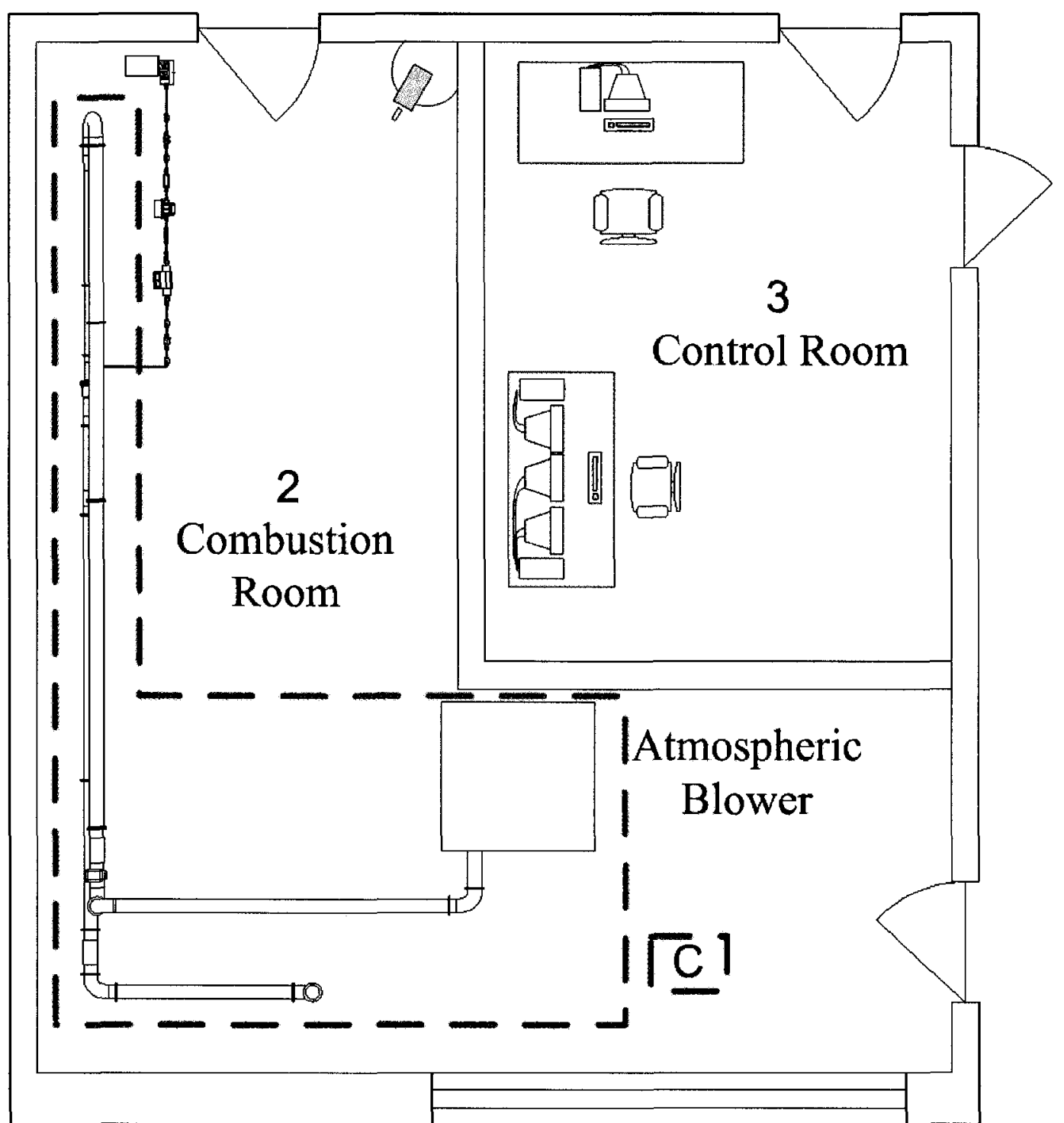

Figure 7.65 Layout top view of atmospheric pressure air delivery system 


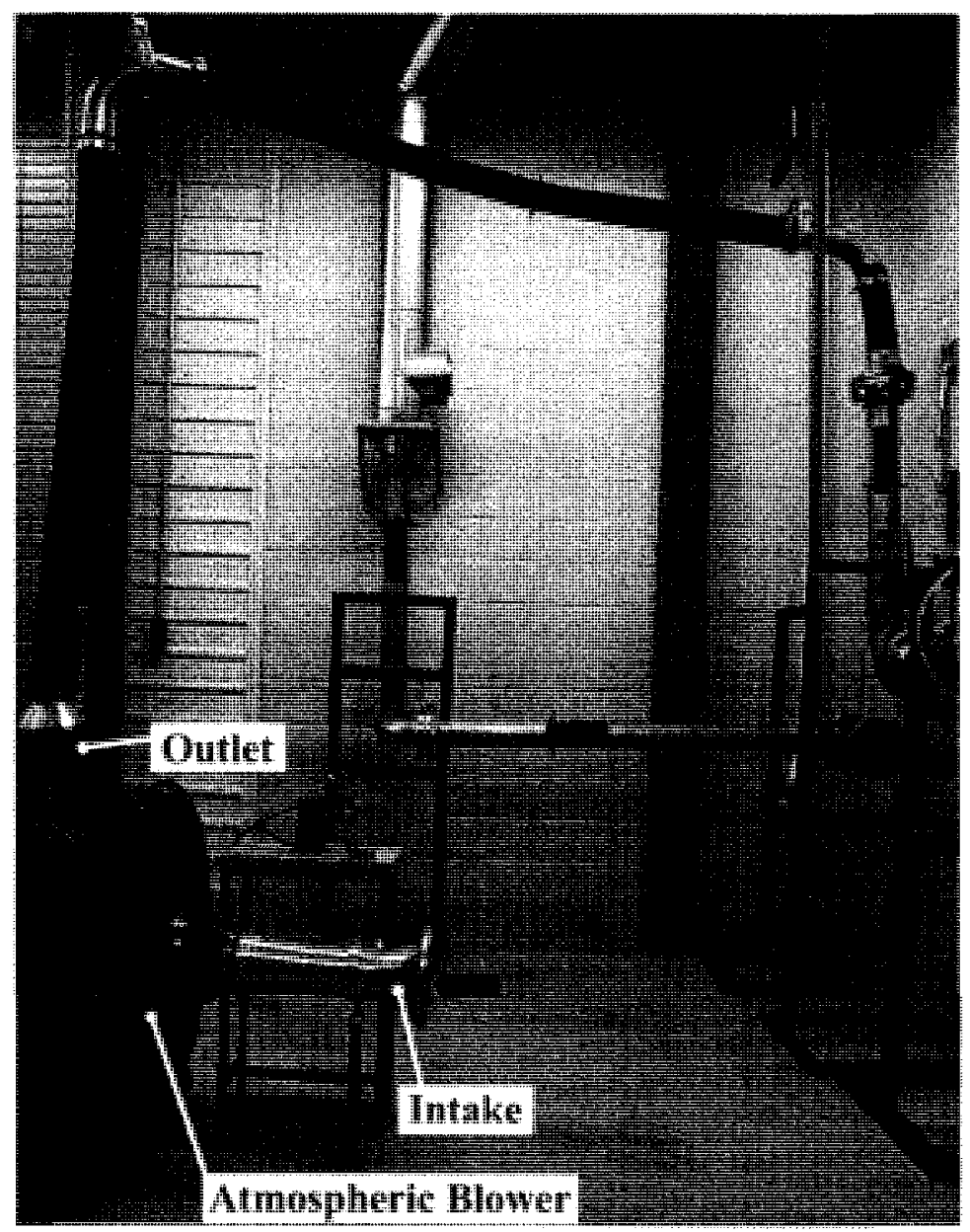

\section{Figure 7.66 Atmospheric configuration set-up}

The blower (Figure 7.67) could deliver volumetric flow rates up to $0.67 \frac{\mathrm{m}^{3}}{\mathrm{~s}}$ with a pressure slightly above atmospheric (1.12 bar). The blower performance curve was used to size the rubber hose which would couple the blower to the air delivery system. More specifically, a parametric study was conducted to calculate the pressure drop sustained by the coupling system as a function of the hose diameter to be used at the blower outlet. Figure 7.68 shows the blower performance curve and the pressure drops sustained for different hose diameters. The small difference in pressure losses between hoses having diameters of $102 \mathrm{~mm}$ and $152 \mathrm{~mm}$ (4 in and 6 in) did not justify the price difference between the diameters. Therefore, a rubber hose having smooth internal walls with an 
internal diameter of $102 \mathrm{~mm}$ ( 4 in) was deemed to be an acceptable compromise between system pressure drop and cost.
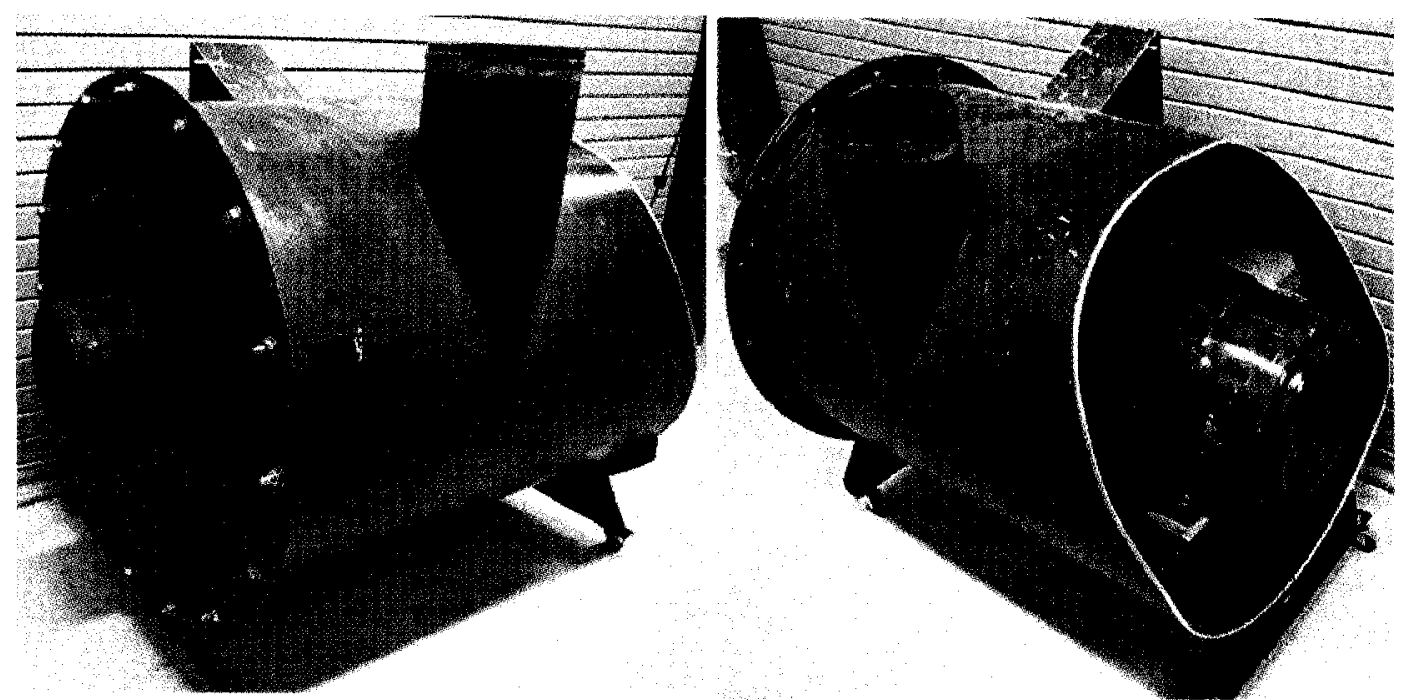

Figure 7.67 Spencer Turbine Company blower model 30104A3

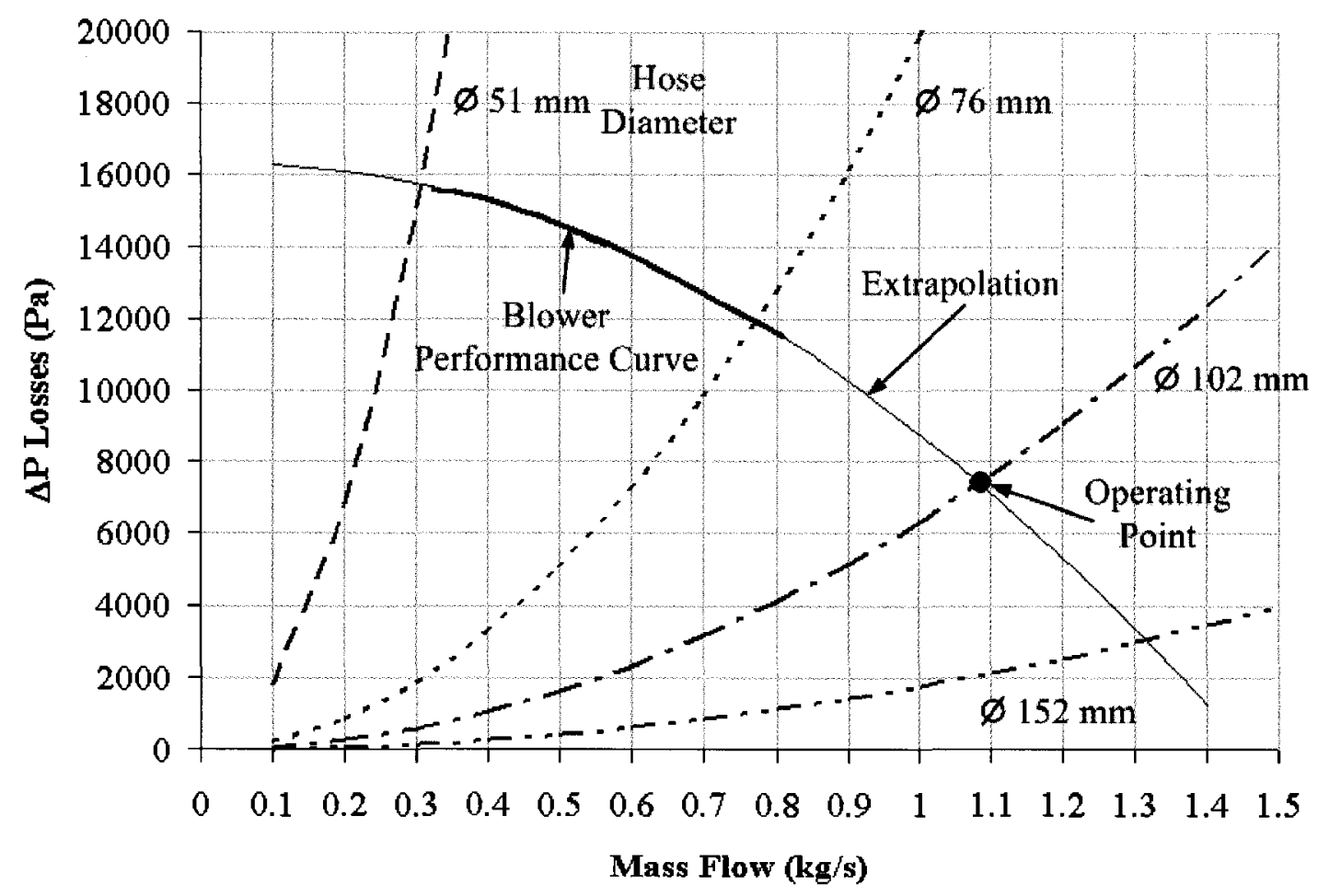

Figure 7.68 Blower performance curve and hose pressure losses

The air delivery system configuration downstream of the blower hose was exactly the same as that for the high pressure configuration as shown in Figure 7.69 and Figure 7.70. 


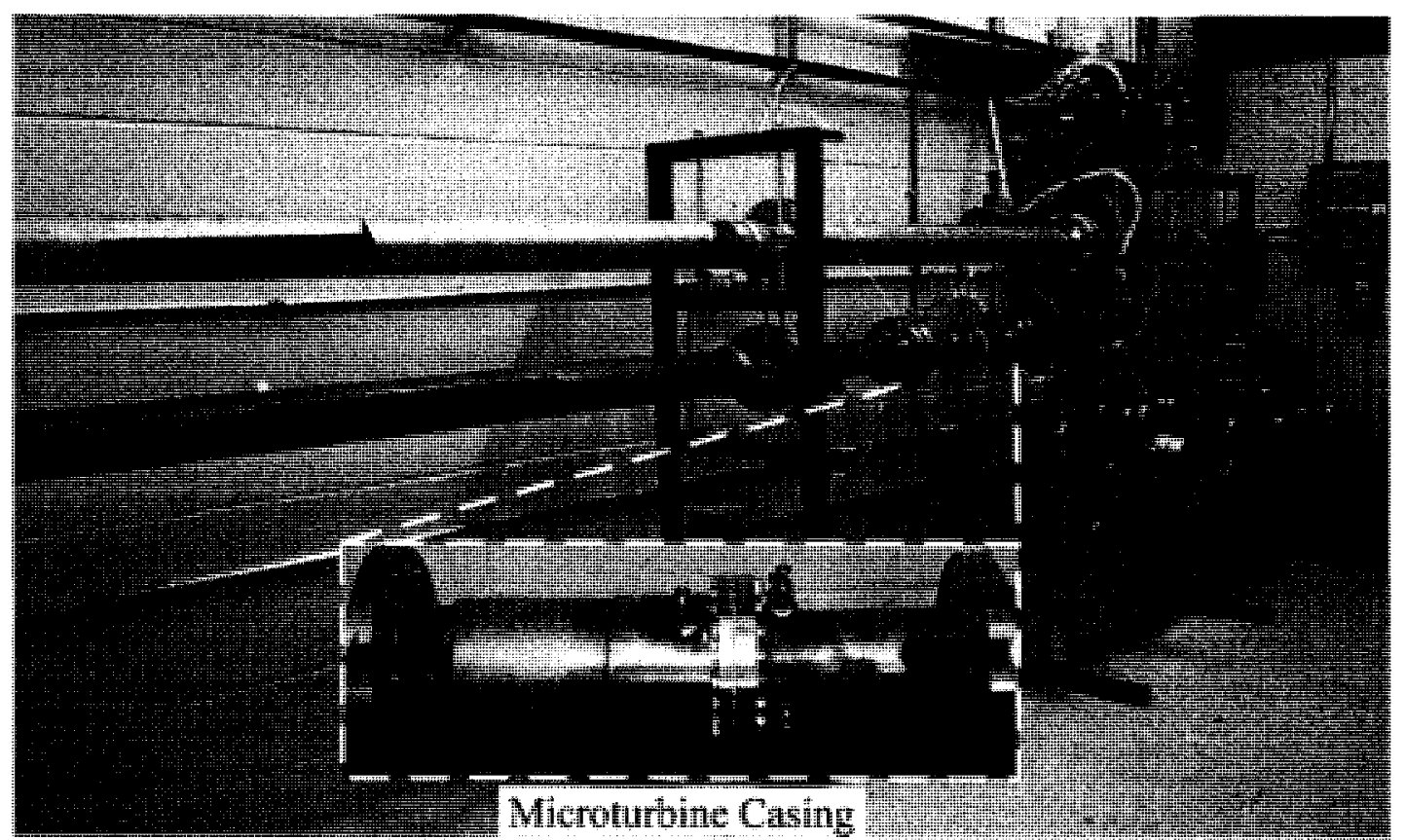

Figure 7.69 Atmospheric and high pressure configurations of air delivery system

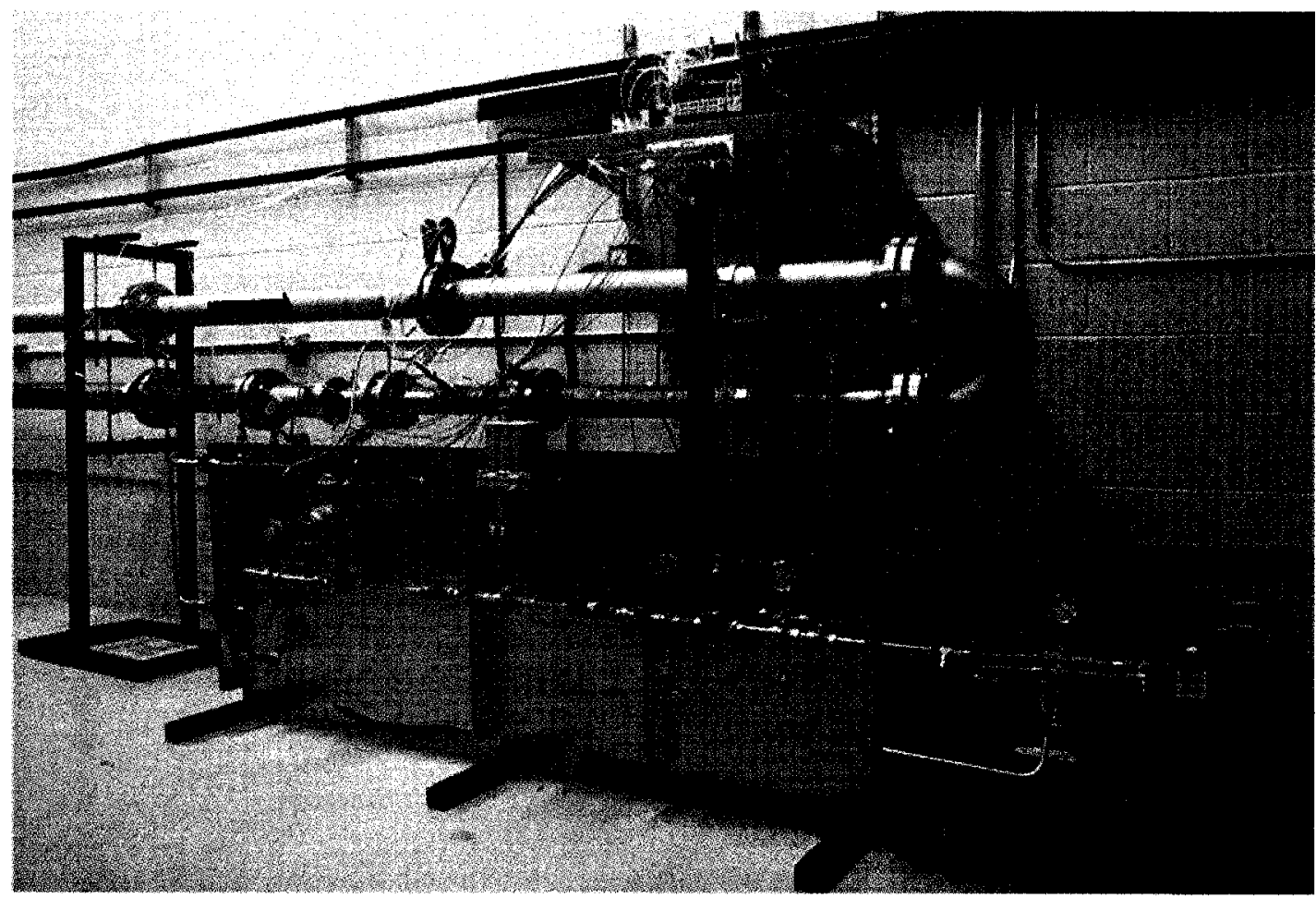

Figure 7.70 Close-up of air and fuel delivery systems

As mentioned in Section 7.1, one of the objectives of the atmospheric set-up was to determine the discharge coefficients of the dilution and cooling holes present in the combustor liner under investigation. As part of the commissioning of the laboratory, trial 
tests for determining liner hole discharge coefficients were, therefore, carried out. By performing these tests, possible unforeseen problems could be identified and resolved.

From the conducted tests, minor modifications to the air delivery system configuration and instrumentation were needed to obtain the discharge coefficients of the holes present in the microturbine liner. Details on how to experimentally obtain the liner hole discharge coefficients and on the needed air delivery system modifications are discussed below.

The liner hole discharge coefficients can be calculated using Equation (4.90) repeated here for convenience.

$\dot{m}_{h}=C_{d} A_{h}\left[2 \rho_{3}\left(P_{3}-p_{j}\right)\right]^{0.5}$

The discharge coefficient $\left(C_{d}\right)$ of an opening with an area $A_{h}$ can be obtained experimentally by measuring the total pressure $\left(P_{3}\right)$ upstream of the hole, the static pressure $\left(p_{j}\right)$ downstream of the hole, the air temperature (for calculating the air density, $\left.\rho_{3}\right)$ and the air mass flow rate $\left(\dot{m}_{h}\right)$ through the hole. Thus, to carry out these measurements, the only flow path allowed through the liner is that entering the hole(s) under investigation.

Since the microturbine combustor has a large number of very small holes, tests on a set of holes rather than a single hole were carried out. For example, to test and calculate the discharge coefficients of the dome cooling holes (16 holes with $0.8 \mathrm{~mm}$ diameter each), all other liner openings had to be sealed. This was done using aluminum tape and a product called Tac'N Stick produced by Ross. The latter product, which is a reusable adhesive, was found to be ideal for this application. In particular, the moisture retention 
of the product made it very easy to mould around the cooling rings and as easy to remove after testing, as can be seen in Figure 7.71.

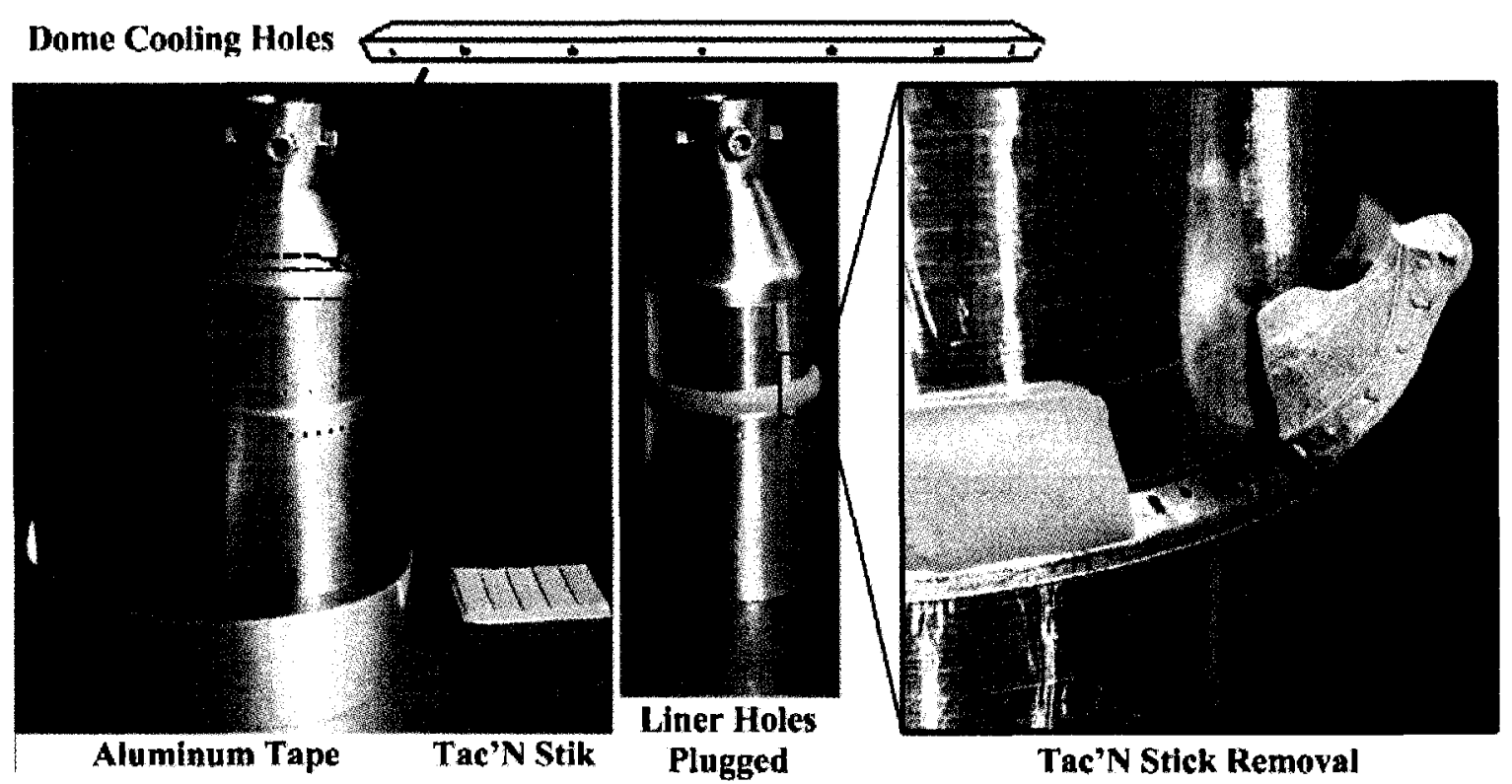

Figure 7.71 Liner preparation for discharge coefficient type tests

After having assembled the liner inside the casing, the annulus area (i.e., area constrained by the casing inner wall and the liner outer wall) was also plugged so that all the air mass flow entering the combustor would only travel through the dome cooling holes.

During testing, the total pressure $\left(P_{3}\right)$ upstream of the dome holes was sensed by the pitot rake and measured by a PX243 transducer ( \pm 0.17 bar gauge; \pm 2.5 psig). The static pressure $\left(p_{j}\right)$ downstream of the dome holes was sensed by the wall taps at the outlet of the combustor and measured by a second PX243 transducer ( \pm 0.17 bar gauge; \pm 2.5 psig). The air temperature was measured by the pitot rake thermocouple. The air mass flow rate $\left(\dot{m}_{h}\right)$ through the holes, however, was so small that it could not be measured by 
the orifice plate. To solve this problem, the orifice plate was replaced by a laminar flow element.

A laminar flow element, patented and manufactured by Meriam Instrument Corporation ${ }^{17}$, is designed to produce a pressure differential directly proportional to the flow rate. More specifically, laminar flow elements (LFE), permits the measurement of flow rates using the capillary flow principle.

A LFE contains a matrix that is either made from individual stainless steel tubes or windings of stainless steel foil. These tubes are long enough, relative to their inside diameter, to cause laminar flow to occur inside each tube. The result is a near linear relationship between the differential pressure across the tubes and the flow rate entering the LFE as shown by the equation below (Fox and McDonald, 1994):

$$
Q=\frac{\pi \Delta p D^{4}}{128 \mu L}
$$

where $\Delta p$ is the static pressure drop across the tube, $\mathrm{Pa}$

$D$ is the tube diameter, $\mathrm{m}$

$\mu$ is the fluid dynamic viscosity, $\frac{\mathrm{kg}}{\mathrm{ms}}$

$L$ is the tube length, $\mathrm{m}$

As can be seen from Equation (7.9), the relationship between the pressure drop and the flow rate for laminar flows depends on the fluid dynamic viscosity $(\mu)$ which is a function of temperature. Therefore, the fluid temperature must be known to obtain accurate metering when using LFE.

${ }^{17}$ SRP Control Systems Ltd., 19-5155 Specturm Way, Mississauga, Ontario L4W 5A1, Canada 
During the discharge coefficients tests, the LFE replaced the orifice plate as shown in Figure 7.72 .

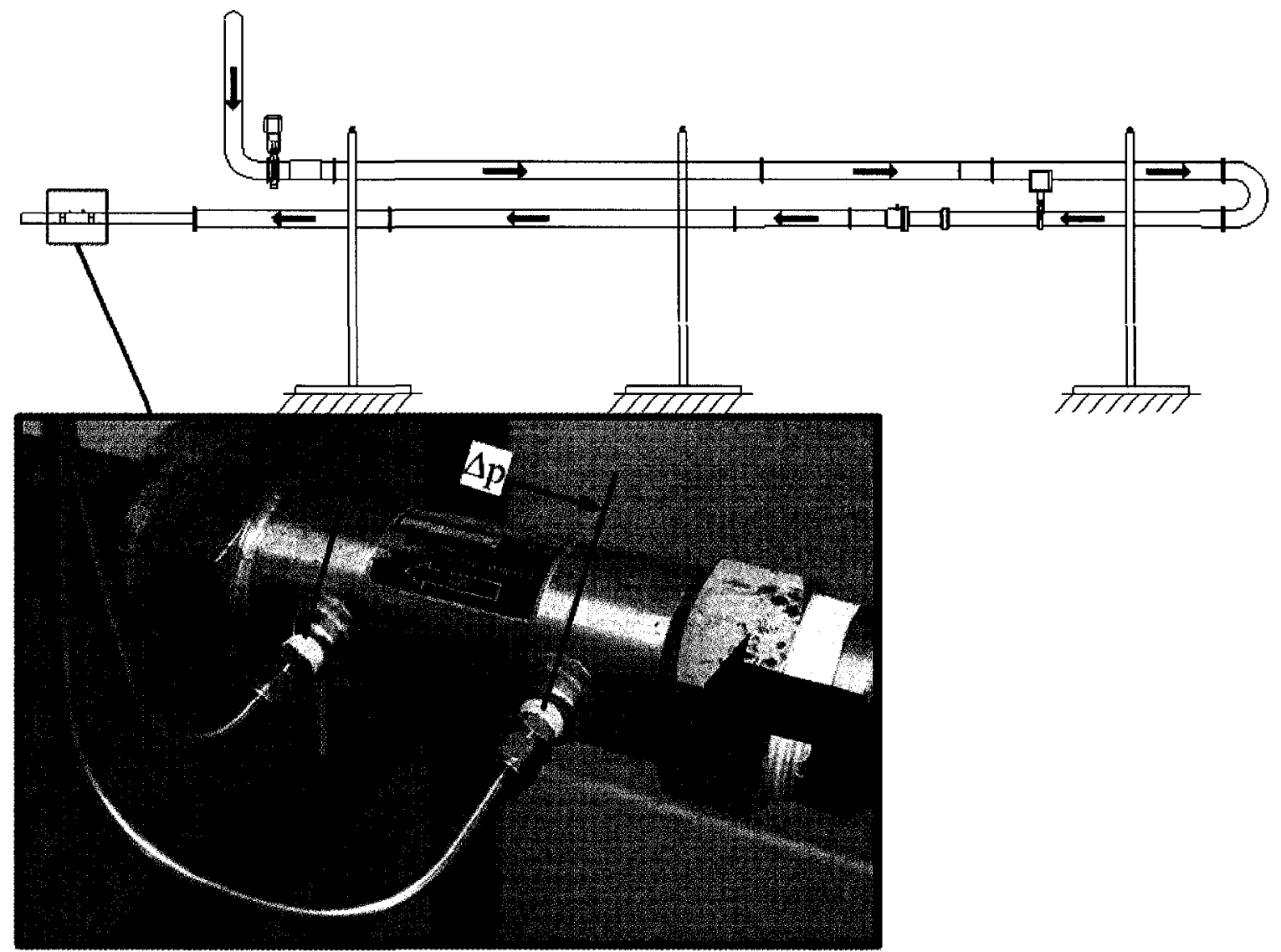

Figure 7.72 Laminar flow element assembly

To have a fully developed flow entering the LFE, a pipe, having a $51 \mathrm{~mm}$ ( 2 in) nominal diameter and a length of $635 \mathrm{~mm}$ (26 in), was inserted upstream of the LFE.

The LFE (model 50MW20-1 or 50MW20-2) was instrumented to measure the static pressure difference across the matrix as well as the absolute pressure and temperature of the air entering the sensor. Figure 7.73 shows the instrumentation schematic. 


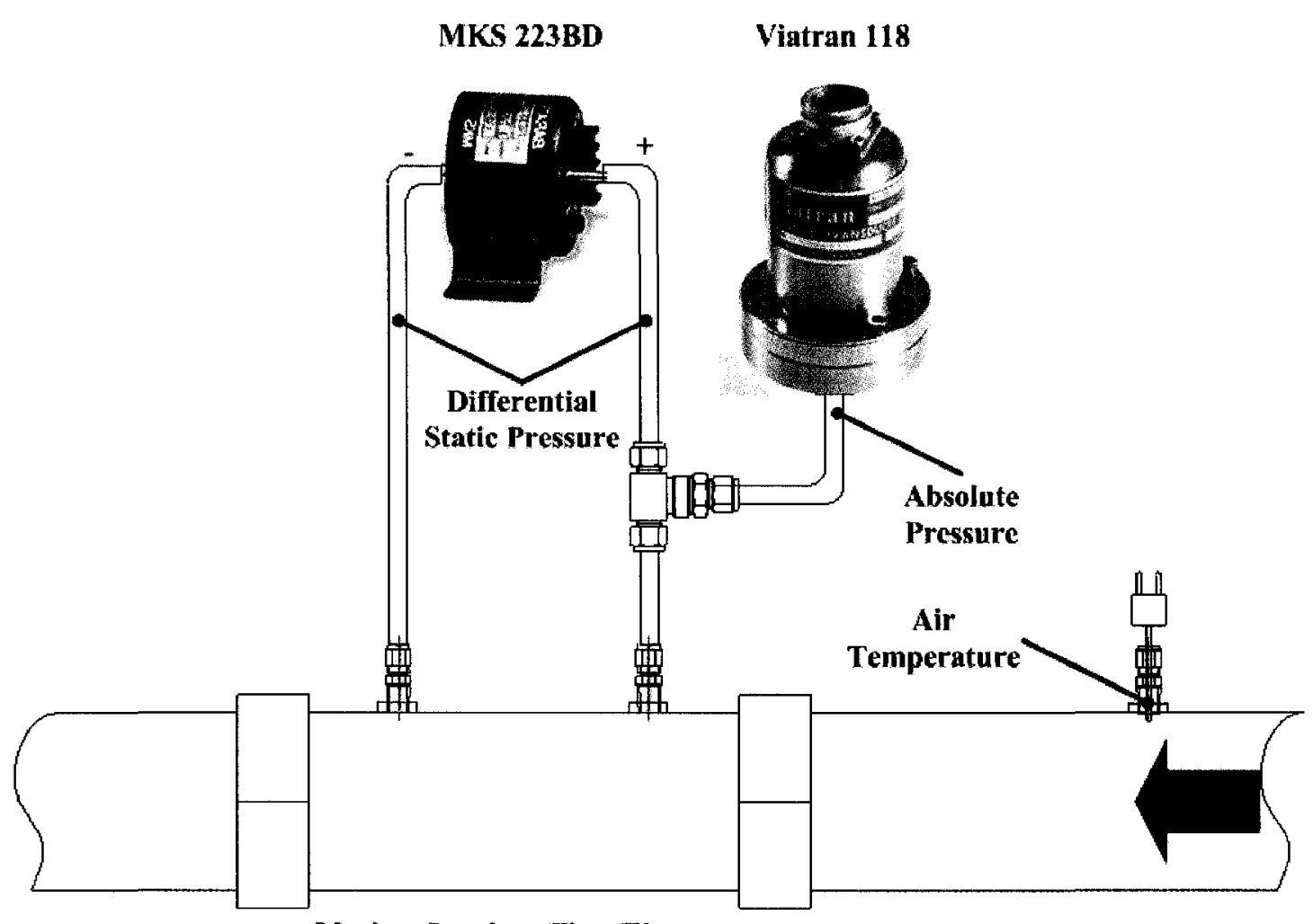

Meriam Laminar Flow Element

Figure 7.73 Laminar flow element instrumentation

The absolute pressure of the air was measured via a Viatran 118 transducer. The range of this absolute pressure transducer, shown in Figure 7.73, varies between 0 bar and 1.034 bar ( 0 psi to 15.0 psia) with a corresponding output signal between $0 \mathrm{mVDC}$ and $100 \mathrm{mVDC}$. The measurements of the absolute pressure and temperature of the air (type $\mathrm{K}$ thermocouple upstream of the LFE) permitted the air density entering the LFE to be determined. The pressure loss across the LFE matrix was measured using a differential pressure transducer whose brand and model were MKS 223BD-0010. The pressure range of this pressure was between 0 inch $\mathrm{H}_{2} \mathrm{O}$ and 10 inch $\mathrm{H}_{2} \mathrm{O}(0$ bar and 0.025 bar) with a 0 VDC to 5 VDC analog output.

The laminar flow element used during testing for cooling hole discharge coefficients (i.e., dome, primary zone and dilution zone cooling holes) was a LFE model 50MW20-1. 
This LFE could measure mass flow rates up to $0.25 \frac{\mathrm{kg}}{\mathrm{min}}$. The higher flow rates through the primary and dilution holes were measured using a LFE model 50MW20-2. The maximum mass flow rate that this instrument could measure was $1.36 \frac{\mathrm{kg}}{\mathrm{min}}$.

\subsubsection{Fuel Delivery System}

The other apparatus that can be found in the Combustion Room is the fuel delivery system (B in Figure 7.74). The fuel delivery system was designed to deliver liquid fuels to gauge pressures up to $34.5 \mathrm{bar}(500 \mathrm{psig})$ and flow rates up to $4.2 \frac{1}{\mathrm{~min}}$. This system, designed and constructed by the author, took advantage of, as much as possible, components which had been purchased during Murphy's work (2004). The components of the fuel delivery system can be seen in Figure 7.75.

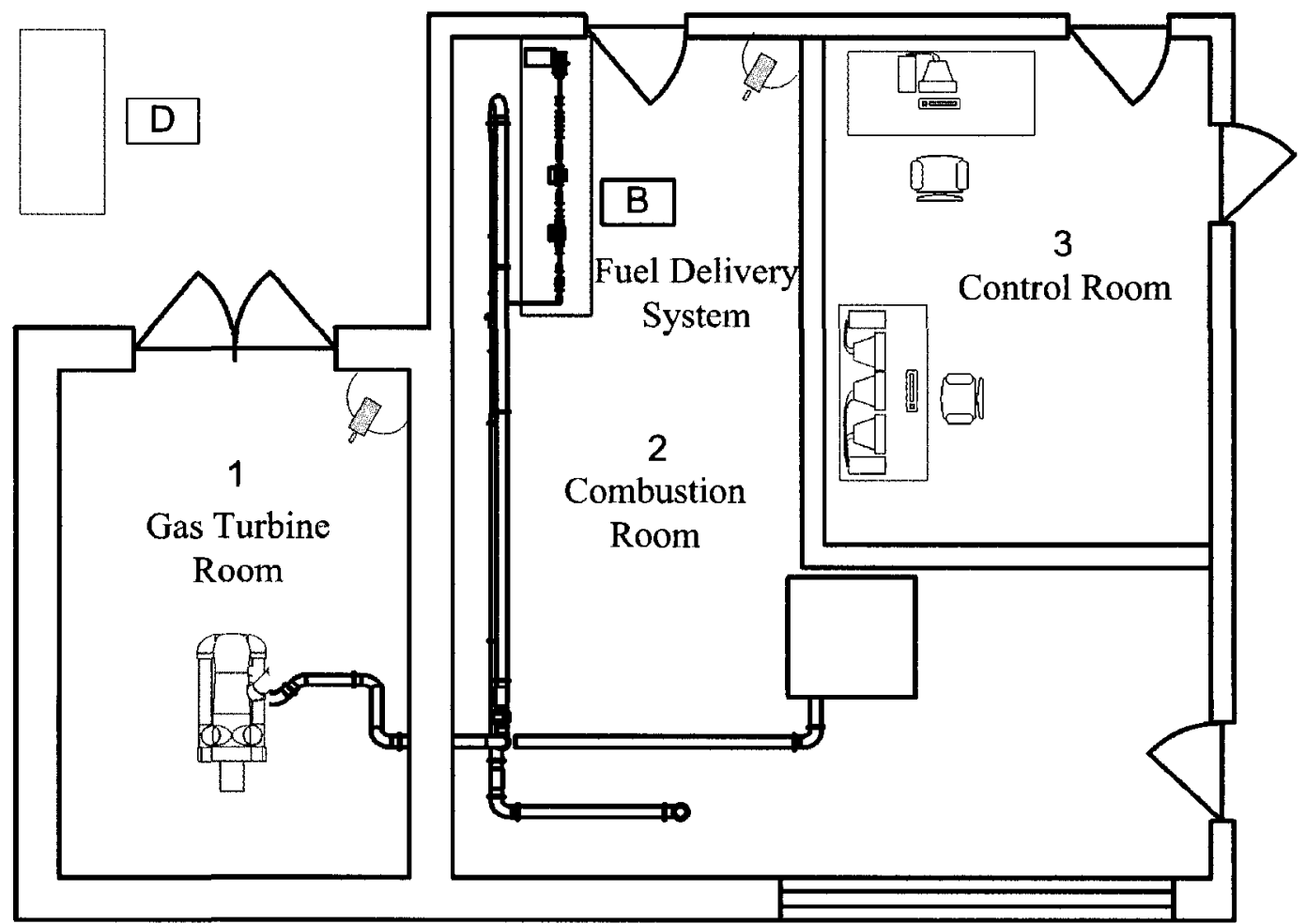

Figure 7.74 Fuel delivery system layout top view 


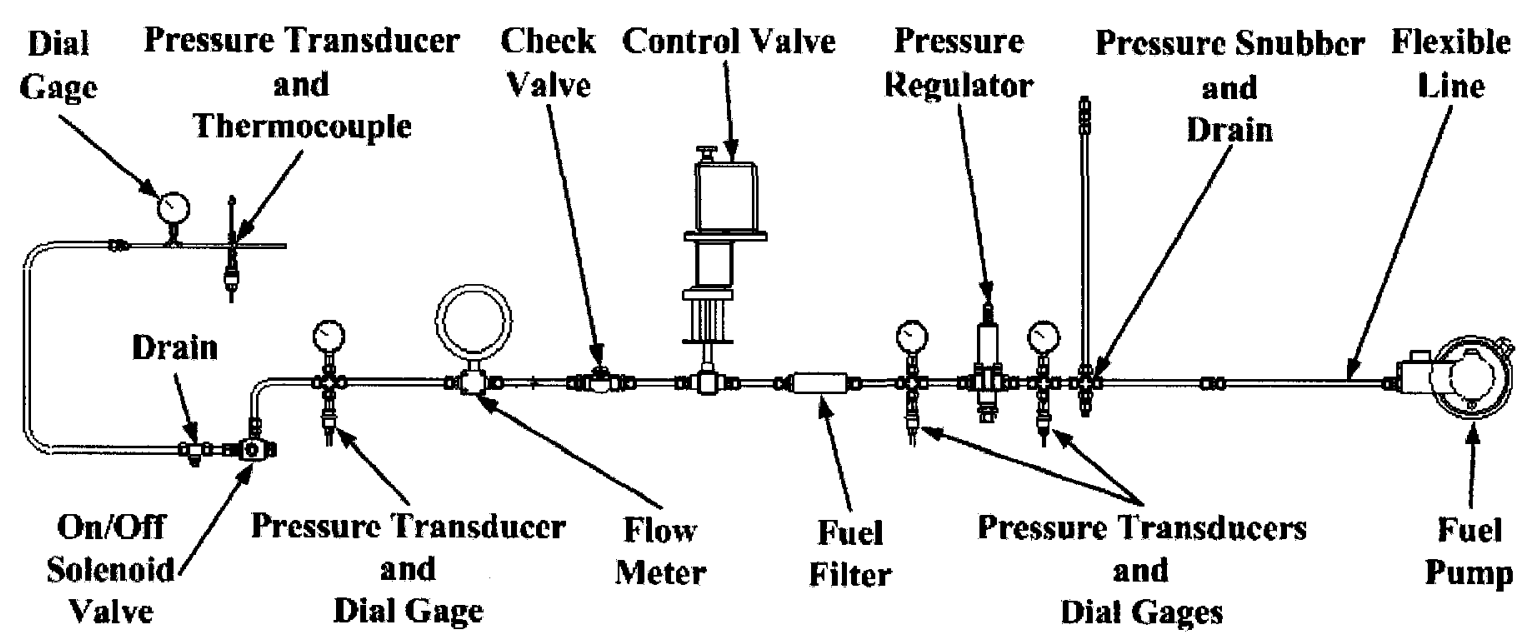

Figure 7.75 Fuel delivery system components

The fuel to be used in future microturbine combustion tests is No. 2 diesel with low sulphur content. This is the same fuel that is used by the Allison 250-C20B engine present in the research laboratory. Particularly, both the gas turbine engine and the microturbine combustor acquire the fuel from the same 200 litre barrel stored in an explosion proof cabinet located outside the Gas Turbine Room (D in Figure 7.74). The fuel lines (stainless steel tubes with an outside diameter of $12.7 \mathrm{~mm}$ and $1.25 \mathrm{~mm}$ wall thickness) running from the barrel to the Allison 250-C20B fuel pump and to the pump residing in the Combustion Room were always kept full of fuel using a priming pump.

The fuel delivery system found in the Combustion Room can be seen in Figure 7.75. All the component materials making up the system were selected to be compatible with alternative fuels, such as pyrolytic oil. This was done so that such fuels could be used by possible future research projects. Specifically, the wetted parts materials of the components making up the fuel delivery system were stainless steel, brass and Teflon.

The fuel delivery system used stainless steel tubings $(12.7 \mathrm{~mm}$ outer diameter and $1.25 \mathrm{~mm}$ wall thickness) and tube fittings to connect the various parts together. The 
maximum working pressure of the stainless steel tubings is 220 bar at $311 \mathrm{~K}$ (Swagelok, 2003).

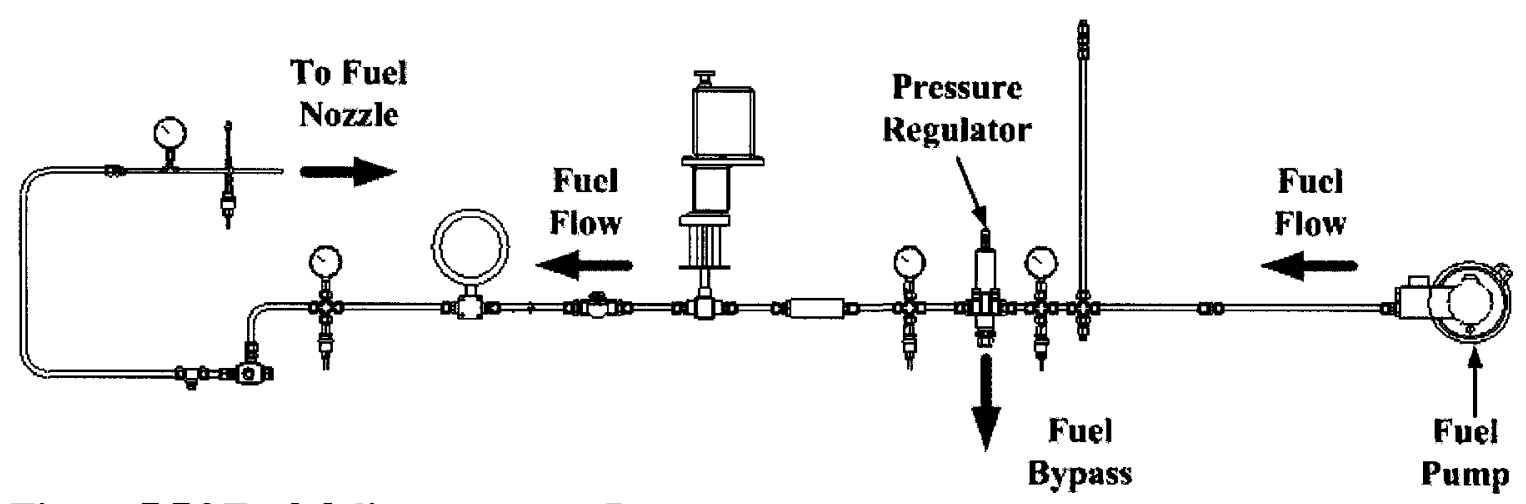

Figure 7.76 Fuel delivery system flow

Figure 7.76 shows the fuel flow path of the fuel delivery system. The first component in the path is the fuel pump head. The fuel pump head is a Hydra-Cell M03B which is coupled to a $0.75 \mathrm{~kW}(1.0 \mathrm{hp})$ electric motor. This diaphragm pump can deliver a maximum flow rate of $4.2 \frac{1}{\min }(1.1 \mathrm{gpm})$ at an $83 \mathrm{bar}(1200 \mathrm{psig})$ gauge pressure.

Downstream of the pump, a polytetrafluoroethylene (PTFE) lined, stainless steel braided hose was installed to isolate the fuel delivery system from vibrations created by the fuel pump. The maximum working pressure and temperature of the braided hose are 206 bar and $503 \mathrm{~K}$ respectively.

To reduce pressure pulses created by the diaphragm pump, a $500 \mathrm{~mm}$ long piece of tubing (same tubing material and diameter as described above) was inserted downstream of the braided hose. The vertical installation and the long length of the tubing permit it to be partially filled with air. The air volume within the tubing functions as a pulsation dampener by contracting and expanding as a result of the pressure pulses created by the 
diaphragm fuel pump during its operation. By absorbing the pulsations, the lives of the components and instrumentation downstream of the pump are extended.

To monitor the pressure along the fuel delivery system, four pressure transducers and four dial gauges were installed along the fuel line. The locations of the transducers were selected to monitor possible malfunctions of critical components, such as the control valve, or obstructions in the fuel line. The last pressure transducer located before the fuel enters the microturbine combustor, was used to monitor the pressure at which the fuel was injected into the combustor premixer. The model of the pressure transducers used in the system was PX481A (Omega Engineering), having a temperature compensated analog output between 1 VDC and 5 VDC. Specifically, the pressure transducer just downstream of the pump has a gauge pressure range between 0 bar and 69 bar ( 0 psig to $1000 \mathrm{psig}$ ) whereas all the other pressure transducers have a gauge pressure range between 0 bar and 34.5 bar ( 0 psig to $500 \mathrm{psig})$. The dial gauges, with the same pressure range as that given for the transducers, permitted to acquire and to inspect pressures visually. The dial gauges proved to be very helpful during initial construction of the fuel delivery system.

The purpose of the pressure regulator, as the name implies, was to regulate the fuel delivery system pressure. The key components of the Hydra-Cell C62 valve (pressure regulator), as seen in the exploded view (Figure 7.77), are an adjusting bolt, a spring and a plunger. By torquing the bolt, the pressure regulator could be manually adjusted to open between a pressure range of 5.3 bar and 34.5 bar ( 75 psig to $500 \mathrm{psig}$ ). Therefore, if the pressure of the fuel entering the valve was higher than the set pressure exerted by the spring on the plunger, the plunger would lift up, allowing the fuel to bypass the system, 
thus, reducing the pressure in the system. The bypassed fuel would then return to the 200 litre barrel housed outside the turbine room.

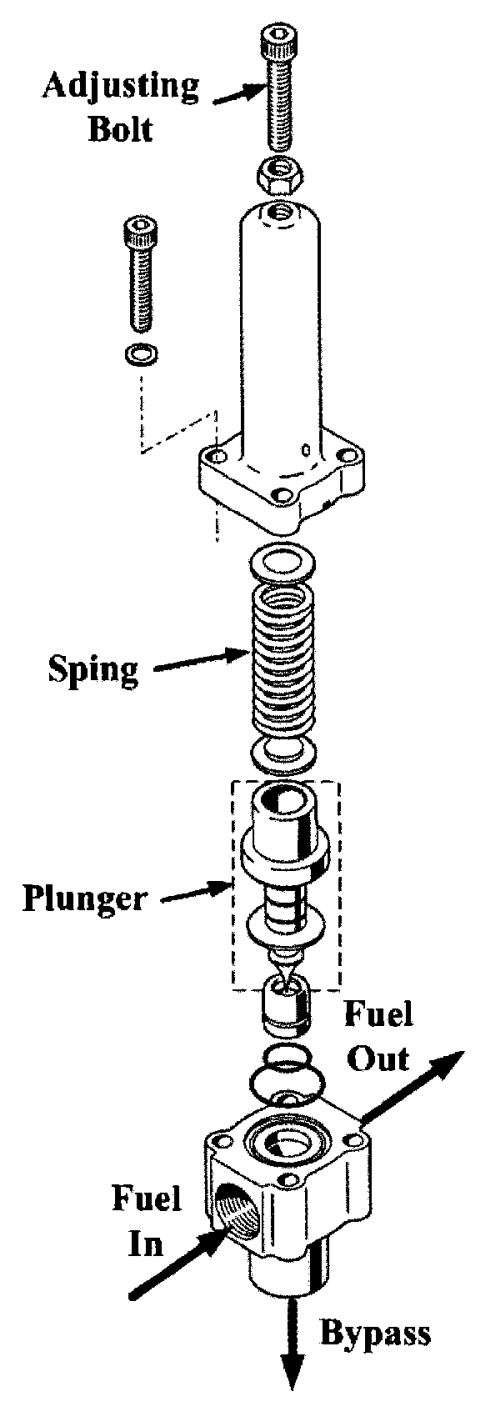

Figure 7.77 Hydra-Cell C62 pressure regulator valve (Adapted from Wanner, 2002)

The diesel fuel filter, located downstream of the pressure regulator, can block particles bigger than 74 microns, thus, preventing possible blockage of the fuel line and fuel nozzle. The brand and model number of the filter were Flow Ezy 6ILA-03-74 respectively. The maximum operating gauge pressure of the filter is $69 \mathrm{bar}$ (1000 psig).

To control the amount of fuel injected into the microturbine combustor, a fractional flow control valve was sized and purchased. The purchased control valve (Jordan, model: 
Mark 708MV-050-S6) has a $\mathrm{C}_{\mathrm{v}}$ value of 0.5 which permits a maximum fuel flow rate of $8.5 \frac{1}{\min }$ and a maximum gauge operating pressure of 69 bar $(1000 \mathrm{psig})$. One of the attractive features of this valve, other than it can be remotely controlled, is that the travel of the valve (i.e., valve opening) with respect to the input control voltage can be adjusted. For example, as received, the valve was set to the full operational range, that is, fully closed at an input signal of $0 \mathrm{VDC}$ and fully open $\left(8.5 \frac{1}{\mathrm{~min}}\right.$ maximum flow rate $)$ at 5 VDC. However, for the microturbine combustor operation, the opening span of the valve was adjusted so that, for a 5 VDC input signal, the valve would only permit for a maximum fuel flow rate of $1 \frac{1}{\min }$. The accuracy of the opening position $( \pm 0.051 \mathrm{~mm})$ combined with the adjustable control span permitted to accurately control the amount of fuel injected into the combustor. For safety reasons, the valve was wired so that upon loss of input signal, it would automatically close, thus stopping the fuel from being injected into the combustor.

Downstream of the fractional flow control valve, a self-actuating check valve assured that the fuel would only travel in one direction; towards the fuel nozzle.

The amount of fuel burned was measured by an FTB 502 low flow rate meter. The meter utilized a pelton wheel-like rotor whose motion is converted into analog output signals ranging between 0 VDC and 5 VDC. The maximum flow and operating pressure of the flow meter is $69 \mathrm{bar}$ (gauge) (1000 psig) and $0.94 \frac{1}{\min }$ respectively.

An ASCO 8223G027 on/off solenoid valve is the component that allows the fuel to enter the microturbine combustor. The valve, which is either open or closed, can quickly 
cut off the fuel flow to the combustor. This aspect was considered very important for reasons of possible emergency shut-downs. As mentioned in Section 7.3.3, the on/off solenoid valve was electrically wired to the pressure switch present in the air delivery system. In case of a sudden pressure loss in the air delivery system, the on/off solenoid valve would de-energize, stopping the fuel from flowing into the combustor. Another way to stop the fuel is to discontinue the current to the solenoid valve via an on/off electrical switch and/or by an emergency switch which are both located on the operating console in the Control Room. These redundant ways of de-energizing the on/off solenoid valve were deemed more than adequate to address any possible emergency scenarios.

Finally, before entering the microturbine combustor, the fuel pressure and temperature were measured by a PX481A transducer (gauge pressure range between 0 bar and 69 bar) and by a type $\mathrm{K}$ thermocouple.

A PTFE lined, stainless steel braided, hose connects the fuel delivery system to the fuel nozzle. The purpose of the hose is to isolate the fuel nozzle, and thus the combustor, from experiencing possible vibration created by the fuel delivery system.

Two drains were included in the design of the fuel delivery system to limit the amount of fuel spillage during disassembly of the apparatus. The drain downstream of the pump removes fuel up to the on/off solenoid valve. The second drain empties the pipes up to the fuel nozzle.

For mounting purposes and to better detect possible fuel leaks, the fuel delivery system was fastened to a frame with an aluminum plate backing. The complete fuel delivery system can be seen in Figure 7.78. 


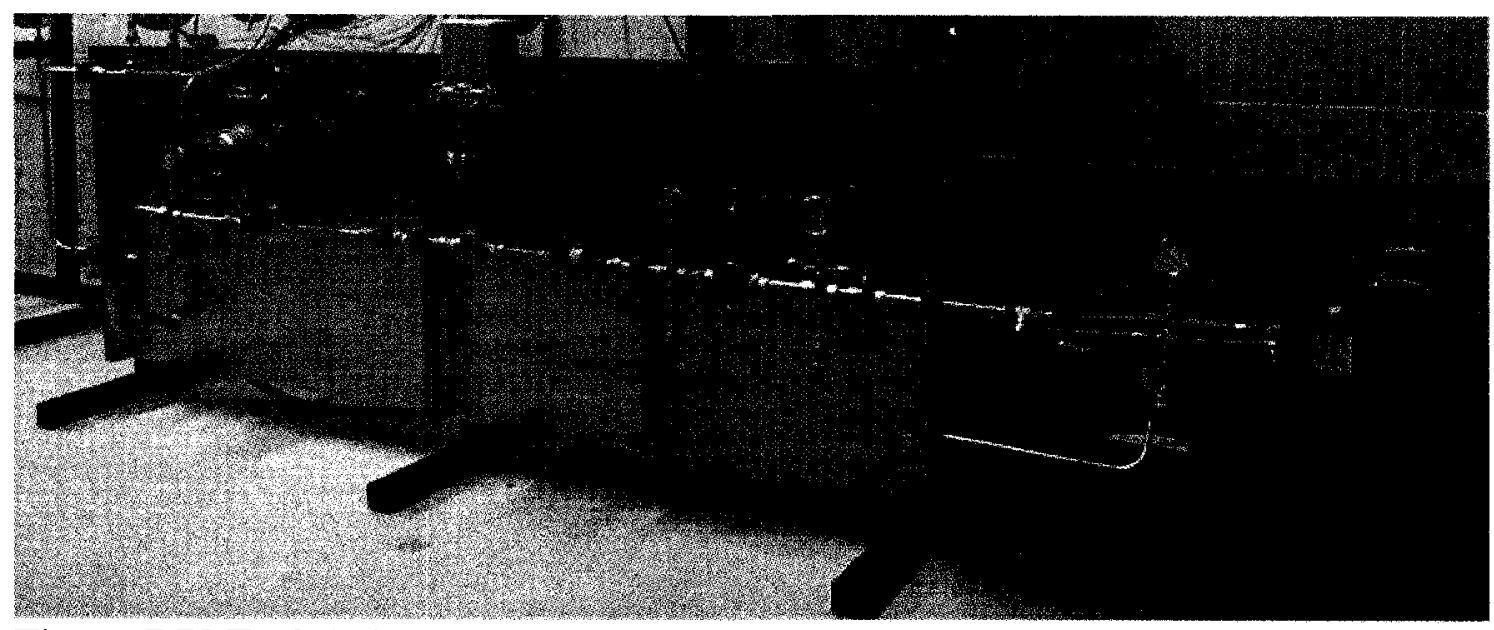

Figure 7.78 Fuel delivery systems close-up

\subsubsection{Control Room}

The last room of the constructed gas turbine combustion research laboratory is the Control Room. Within this room there are two controlling stations. One station for operating and monitoring the Allison 250-C20B gas turbine and a second station for controlling and monitoring the systems present in the Combustion Room and for acquiring all the experimental data. The Control Room layout can be seen in Figure 7.79.

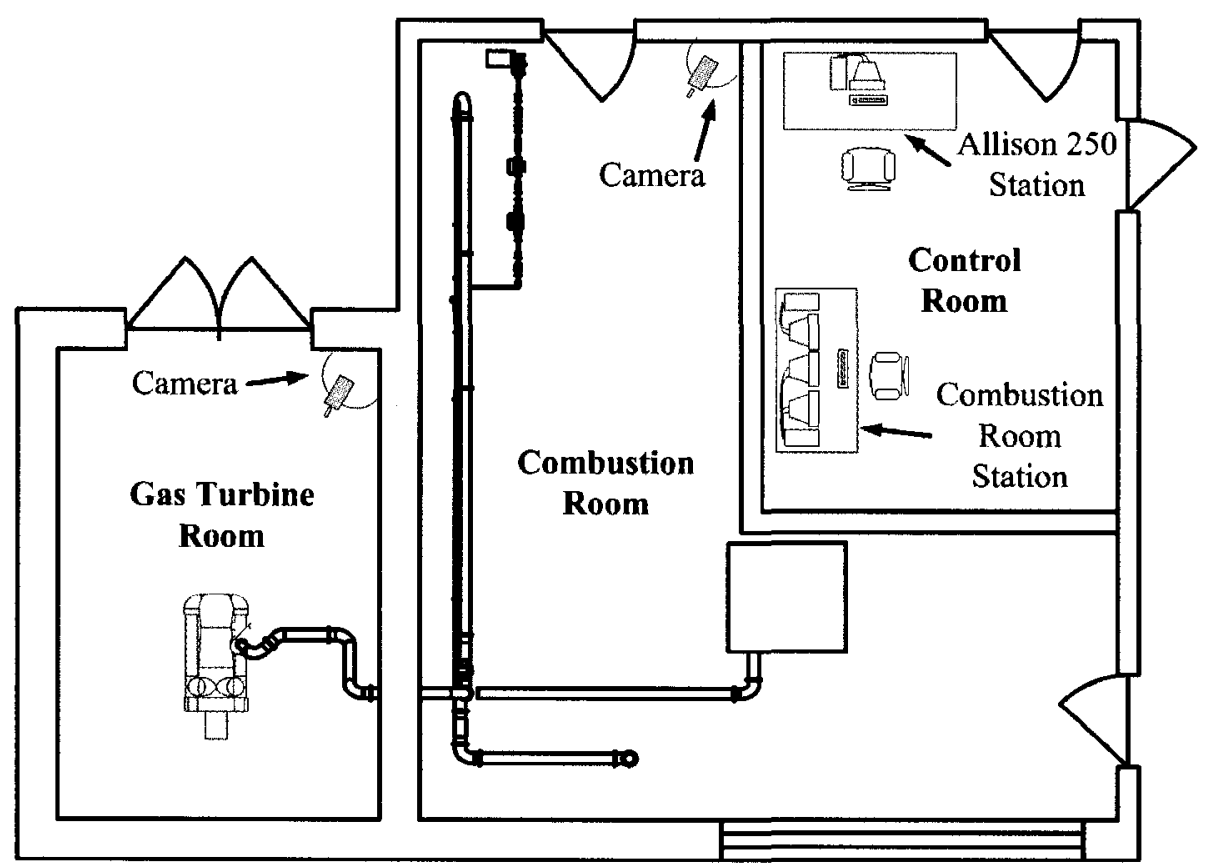

Figure 7.79 Control Room layout top view 
The Allison 250-C20B controlling and monitoring station was already in full working condition when construction of the research laboratory was begun and therefore, except for the introduction of the fail-safe mechanism (Section 7.2.3) no further work on it was needed.

As previously mentioned, the Allison $250-\mathrm{C} 20 \mathrm{~B}$ engine was controlled by a throttle on the station console which was hydraulically connected to the engine fuel control/governor. The fuel control/governor in turn regulated the amount of fuel injected into the Allison 250-C20B engine. A computer and data acquisition system was used to monitor critical engine parameters such as gas generator rotational speed $\left(\mathrm{N}_{1}\right)$, power turbine rotational speed $\left(\mathrm{N}_{2}\right)$, which is now zero due to the engine modification, inter turbine temperature, which is now the exhaust gas temperature due to the removal of the power turbine, oil pressure, oil temperature and finally, the Gas Turbine Room temperature.

A camera, located in the Gas Turbine Room (Figure 7.79), was connected to a television, located in the Control Room, so that additional information on the engine operating status could be gained. Thus, the main scope of this surveillance system was to detect engine operation anomalies such as fuel or oils leaks, smoke or fire. In case of an emergency, the fuel flow into the gas turbine engine could be cut by pressing an emergency switch. Figure 7.80 shows the Allison 250-C20B control and monitoring station. 


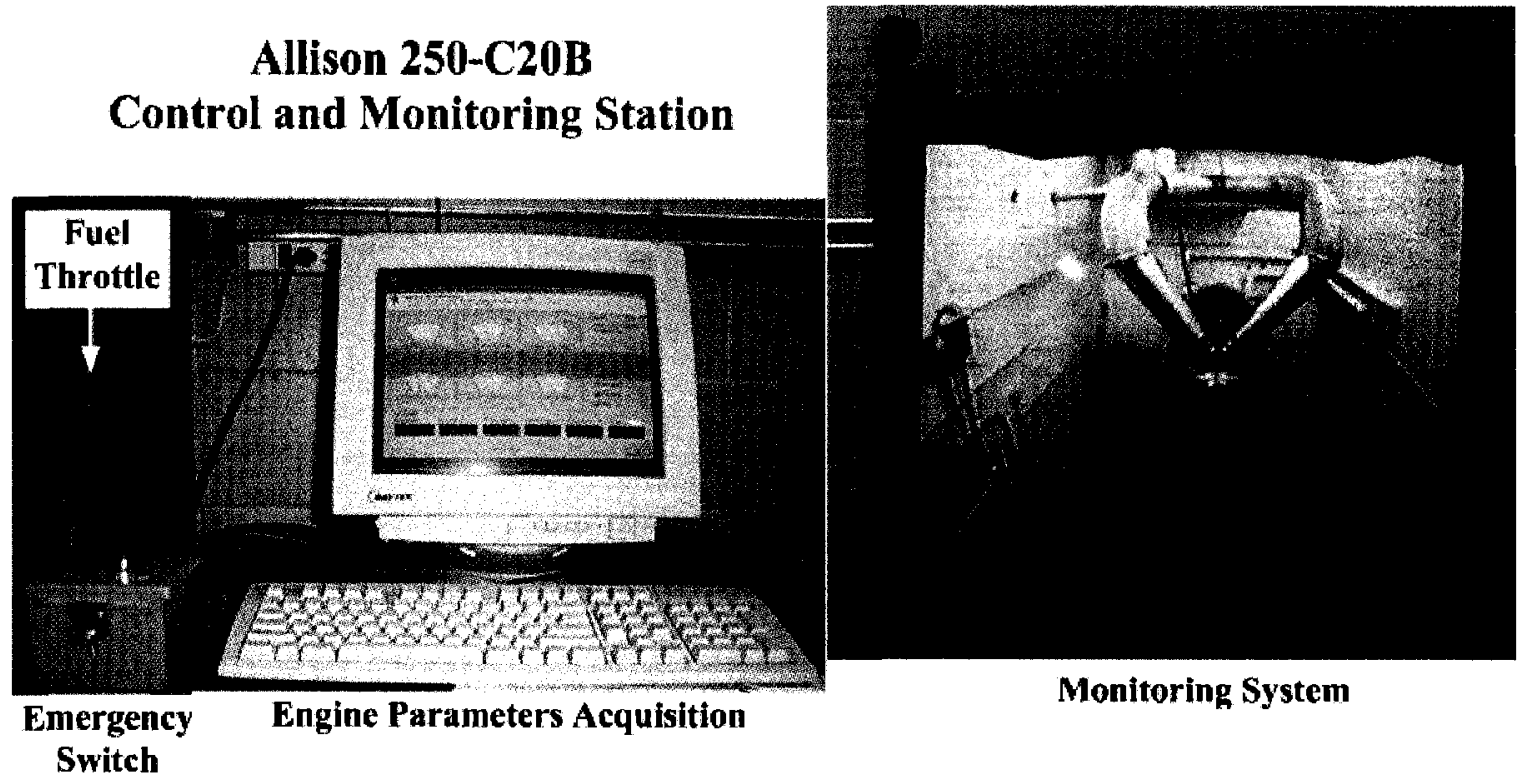

\section{Figure 7.80 Allison 250-C20B control and monitoring station}

The second operating station which acquired data from, controlled and monitored the systems present in the Combustion Room was inexistent at the start of the research project and therefore, became part of the thesis objectives.

The development of the Combustion Room operating station started with the design and construction of a console. This console had to be big enough to house all the equipment needed to control, to monitor and to acquire data from the systems present in the Combustion Room.

After having completed the construction of the console, the electrical wiring of the components making up the air and fuel delivery systems was undertaken. To comply with the EMRD laboratory standards, the electrical wiring was split into low and high voltage. All the high voltage ( $>110 \mathrm{VAC}$ ) equipment operated from the Control Room had to be activated using a low voltage line ( $24 \mathrm{VAC}$ ). This was achieved by placing a relay box inside the Combustion Room. Thus, all the electrical wires coming from the Control Room and entering the relay box used a 24 volt alternate current. The wires exiting the 
relay box and connecting to the various components making up the air and fuel delivery systems carried a high voltage alternating current (> 110 VAC). The use of low voltage in the operating station created a safer working environment. Furthermore, to minimize potential accidents or loss of equipment, all the electrical wires were carefully identified with labels. All the electrical circuits were also fitted with one time use fuses. In case of current surges or short circuits, the fuse filament would break, interrupting the flowing current and preventing harm from coming to either personnel or equipment.

Except for the fractional flow control valve, all the other components were operated using on/off switches (SPDT bat handle type switches). The on/off solenoid valve in the fuel delivery system was also wired to an emergency switch for quick reaction times in case of an emergency.

Indicator lights were installed throughout the operating console so that the operator could be aware of the status of the components (i.e., component either energized or deenergized).

To accurately control the amount of fuel flowing through the fractional flow control valve, a NI USB-6009 multifunction data acquisition system coupled to LabView was used. Using the NI USB-6009 and LabView, the input voltage (i.e., NI USB-6009 output voltage) experienced by the fractional flow control valve could be precisely controlled. In other words, through the use of a computer interface the fuel flow rate could be increased or decreased by accurately changing the NI USB-6009 output voltage. This output voltage could be adjusted by very small intervals $(0.1 \mathrm{~V})$ by simply typing or by using the mouse to obtain the desired voltage. This is shown schematically in Figure 7.81. 


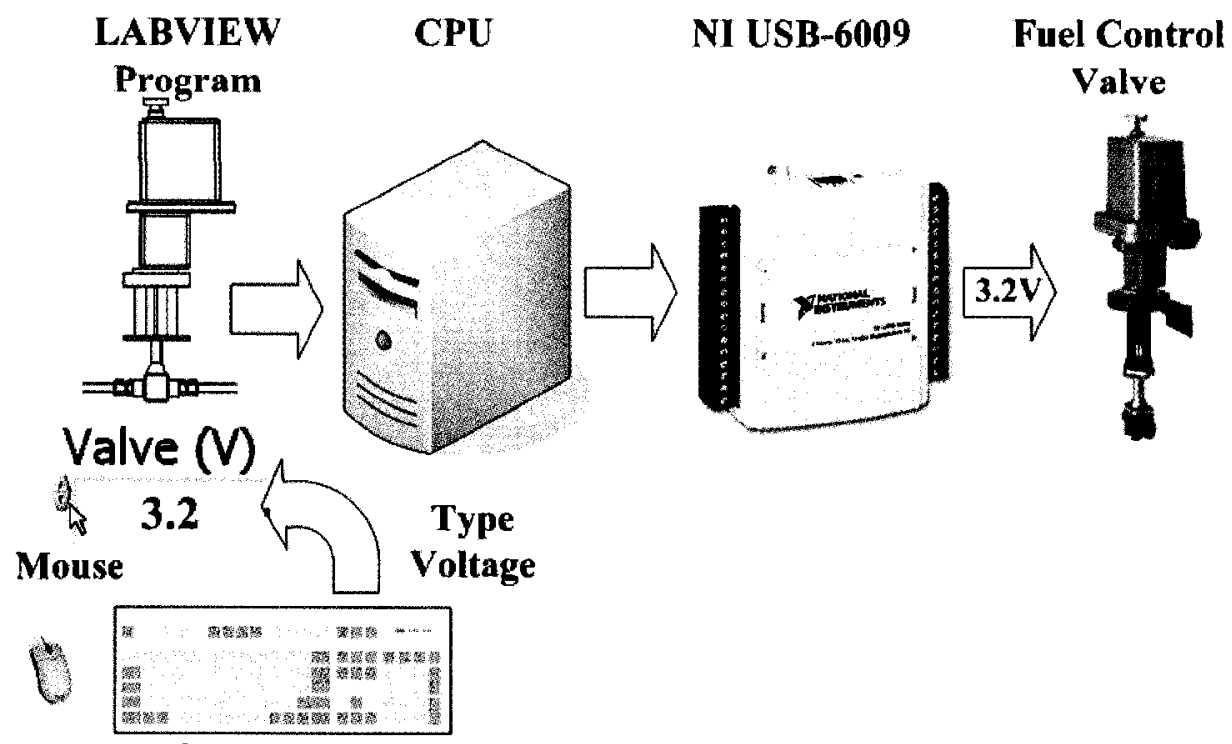

Figure 7.81 Fractional flow control valve actuation system

Figure 7.82 and Figure 7.83 show various views of the completed Combustion Room operating station. As can be seen from Figure 7.82, the operating console was equipped with two computers, one having two monitors (Figure 7.83). More specifically, one computer was used to survey the status of the systems present in the combustion room whereas the second computer was used to actuate the fuel control valve as well as to monitor, acquire and store data pertaining to the air and fuel delivery systems.

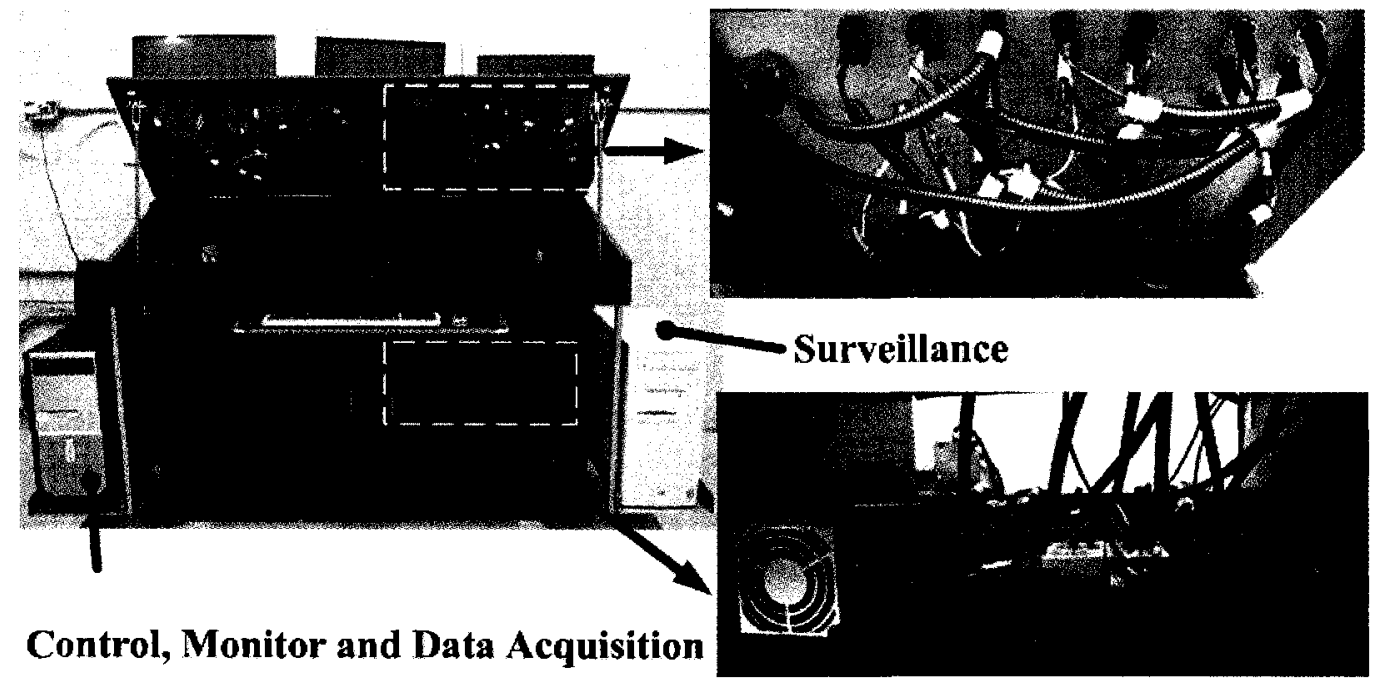

Figure 7.82 Operating console wiring details 


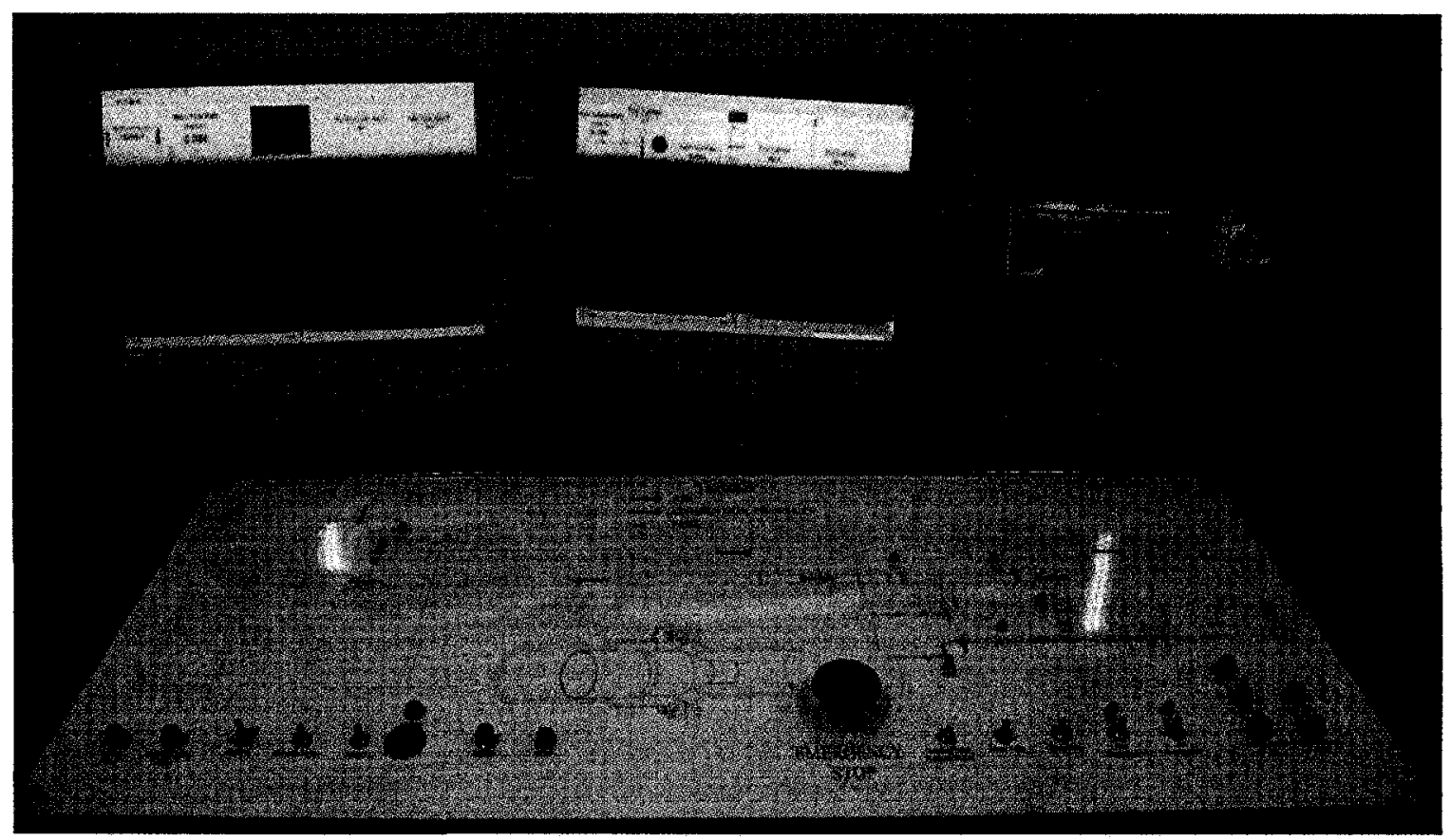

\section{Figure 7.83 Operating console top panel and monitors}

The visual surveillance of the components residing in the Combustion Room was achieved using a camera system coupled to a desktop computer. This monitoring system (X10 model VK77A) could pan and tilt the camera (Figure 7.84) so that the entire Combustion Room could be surveyed. In addition, the zooming capabilities of the camera permitted investigating in more detail potential problems. The video camera images were wirelessly transferred to the computer which, through the use of the software accompanying the camera, could record movies, take static pictures or program routine scans of the combustor room, to name a few of the many system capabilities. 


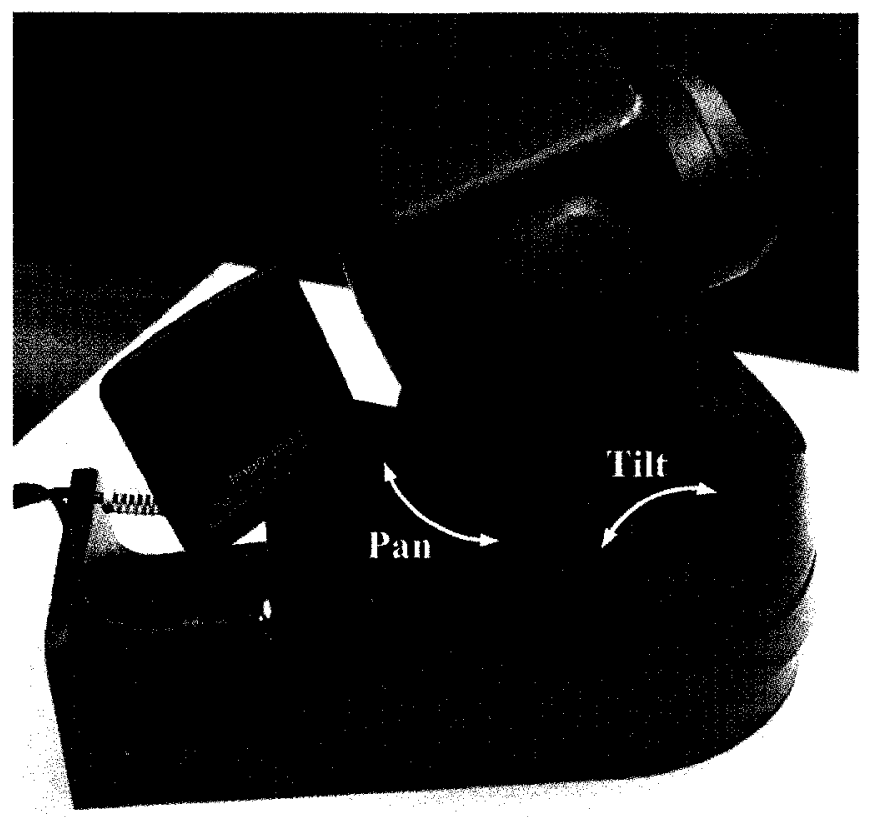

\section{Figure 7.84 Monitoring camera, model VK77A}

The other computer was used to control the flow control valve as well as to acquire, monitor and store all the experimental data produced by the air and fuel delivery systems.

As mentioned in Section 7.3.5, all the analog outputs produced by the instrumentations were collected by the Keithley 2700 DAQ system. Within the DAQ, the analog measurements were converted into digital signals which were then sent, through a cable, to the computer located in the Control Room.

Once in the computer the data was manipulated from non-engineering units (VDC and $\mathrm{mVDC}$ ) to units that could be readily understood such as bar for pressures and Kelvin for temperatures. The software used for data manipulation, display and storage was LabView. The LabView program, created by the author, was a compilation of many subroutines as shown in Figure 7.85. Figure 7.85 shows a fragment of the LabView program, and gives details on one of the many subroutines created. The subroutine, called Fuel 2.vi, was written for manipulating the data acquired by the transducer located just downstream of the fuel pump. During pump operation, the gauge pressure sensed by the 
transducer would be outputted as a voltage signal. This voltage signal would then be mathematically manipulated using coefficients that had been previously obtained from the transducer calibration process (see Chapter 8 for details). At the end of the mathematical manipulation, the voltage would then be transformed into a pressure measurement of imperial units (psig). Finally, through a conversion factor, the pressure would then be converted from imperial units to SI units (bar) for display and storage purposes. Before being displayed and stored, the measurement would enter a warning subroutine. If the measured pressure was higher than $62 \mathrm{bar}$, a red light and a warning sound would be triggered.

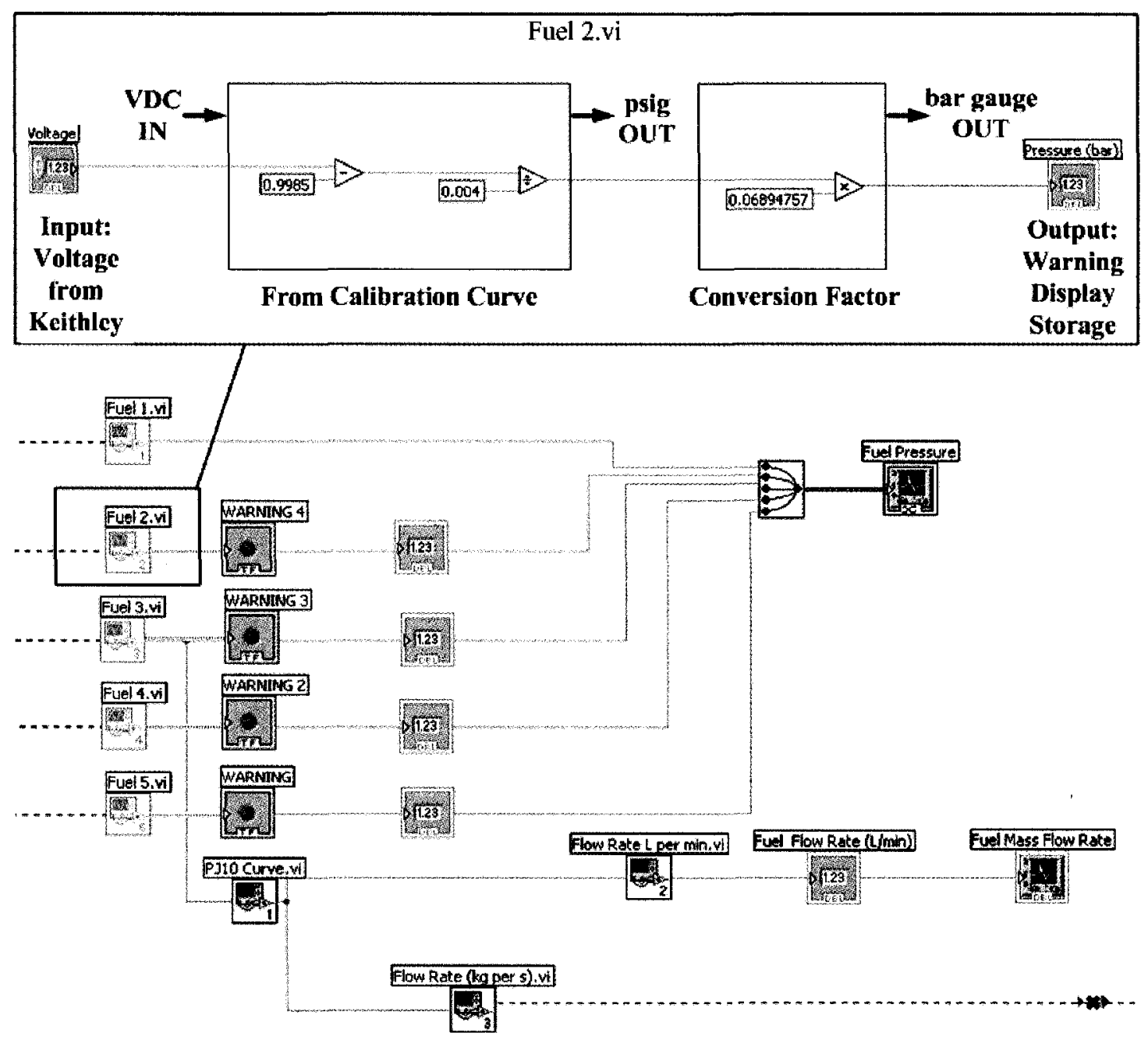

Figure 7.85 LabView program fragment with detailed transducer subroutine 
Figure 7.86 shows the graphical interfaces resulting from the program created using LabView. The interfaces were designed such that they could be displayed onto two monitors. One monitor focused on the air delivery system while the second monitor showed details on the fuel delivery system. As can be seen from the figure, the interfaces displayed critical testing parameters and tracked operating changes through real time graphs. Warning lights, coupled with sounds, were strategically located throughout the interface so that the operator could easily be alerted when operating limits were about to be exceeded.

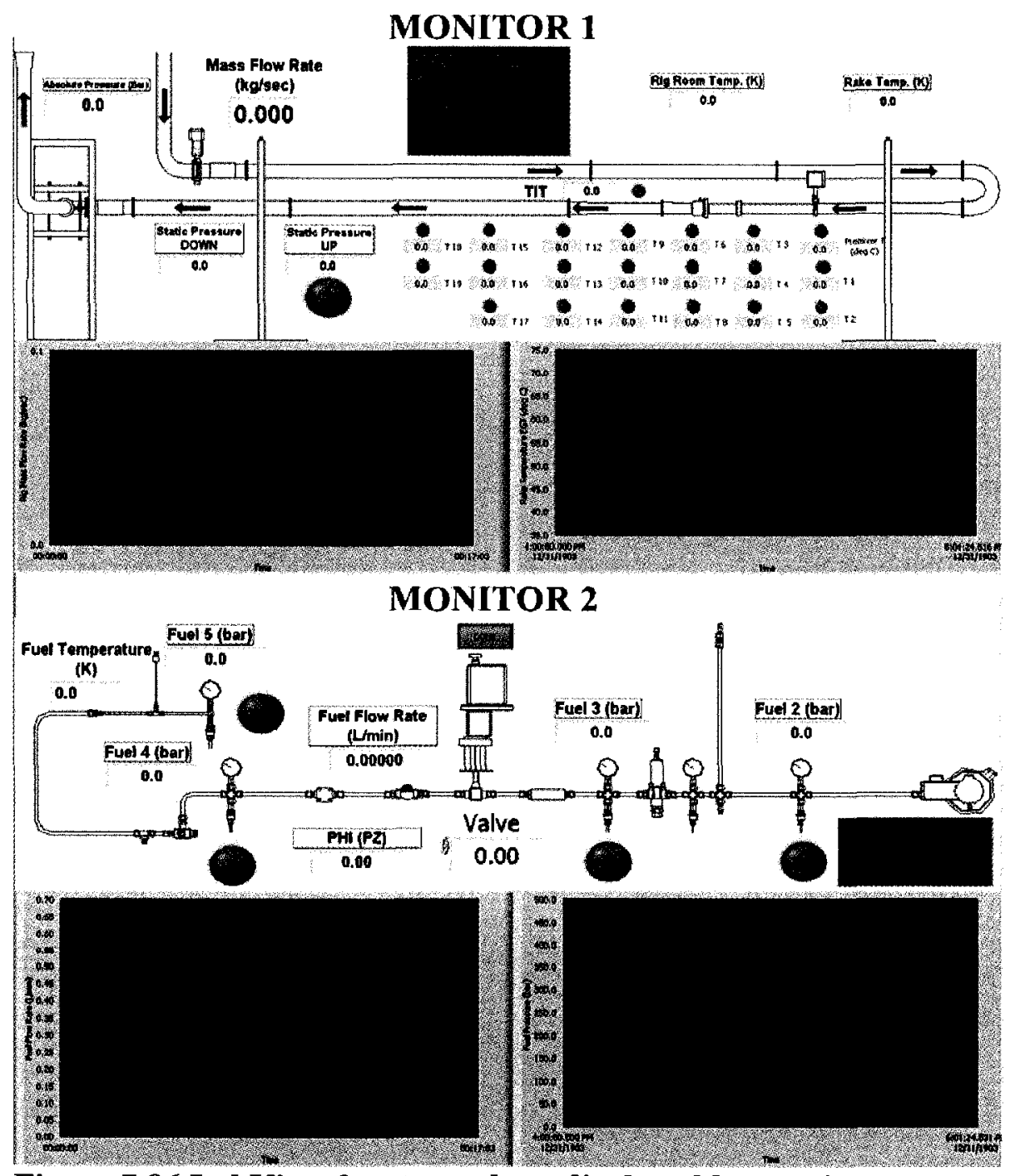

Figure 7.86 LabView front panels as displayed by monitors 


\section{INSTRUMENT CALIBRATION PROCESS AND SHAKEDOWN}

\section{TESTS}

All the instrumentation used in the gas turbine combustion research laboratory underwent a calibration process. This process verified the working condition of the instrumentation used in the laboratory as well as provided coefficients that were later used for manipulating instrument outputs from non-engineering units into units that could be readily understood.

Since the execution process for calibrating the various pressure transducers and thermocouples was the same only one example per type of instrument will be given next. Before describing the calibration process details, the fact that the transducers and thermocouples were calibrated in line should be mentioned. In other words, the junctions and wires used to link the instruments (i.e., pressure transducer or thermocouple) to the Keithley DAQ were the same as those used during testing, thus avoiding possible calibration discrepancies that could have otherwise occurred.

\subsection{Thermocouples Calibration}

Static calibration of the thermocouples was conducted using an Omega Engineering CL 122-2 block calibrator. This portable equipment, shown in Figure 8.1, calibrated all the thermocouples (except for the liner wall thermocouples) used throughout the laboratory. The temperature range of the $\mathrm{CL} 122-2$ is between $-30^{\circ} \mathrm{C}$ and $500^{\circ} \mathrm{C}$. 


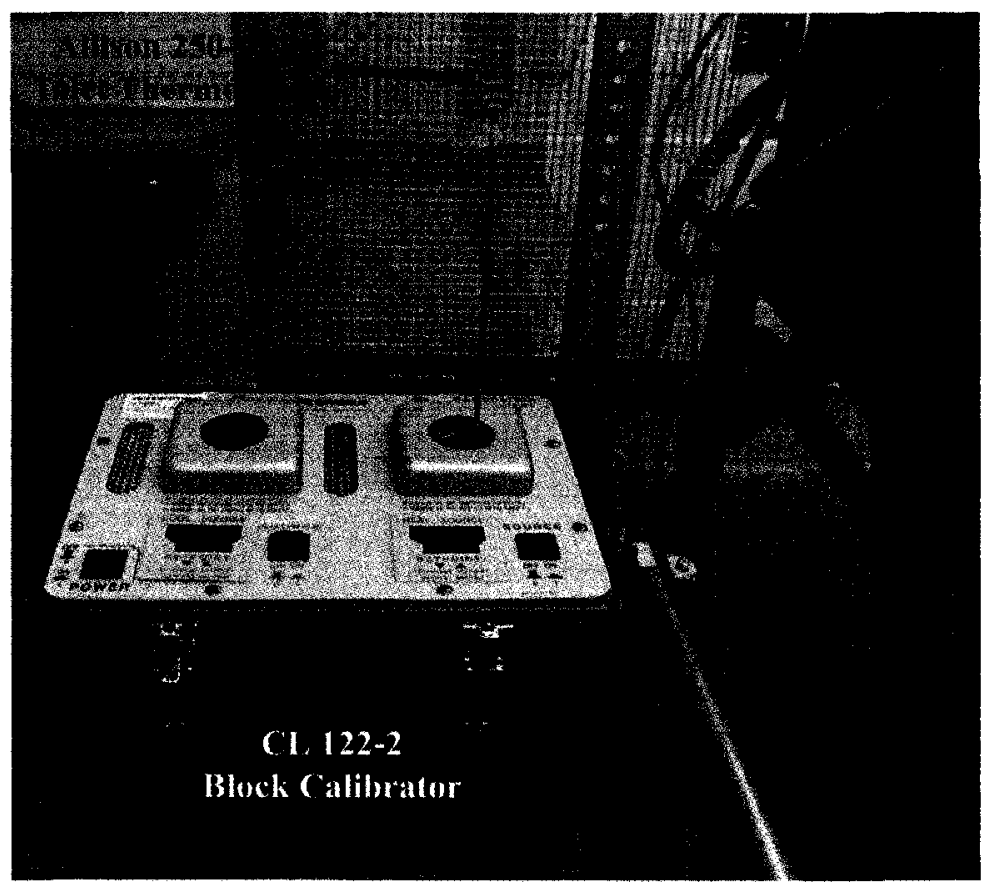

\section{Figure 8.1 CL 122-2 block calibrator and Allison 250-C20B inlet thermocouple}

The calibration process involved inserting the thermocouple under investigation into the block calibrator and comparing the setpoint temperature of the equipment to the temperature measured by the thermocouple. The setpoint temperature of the equipment could be incremented by $0.1^{\circ} \mathrm{C}$ steps. The setpoints were increased by $50^{\circ} \mathrm{C}$ intervals until the CL 122-2 upper range was reached. After having selected the setpoint, a 10 minute period was allowed so that the equipment could stabilize. With the block calibrator at equilibrium, a series of temperature measurements were taken. The process was then repeated at different temperature setpoints until the maximum temperature range of the CL122-2 was reached. Figure 8.2 shows the calibration curve for the thermocouple measuring the EGT exiting the Allison 250-C20B. 


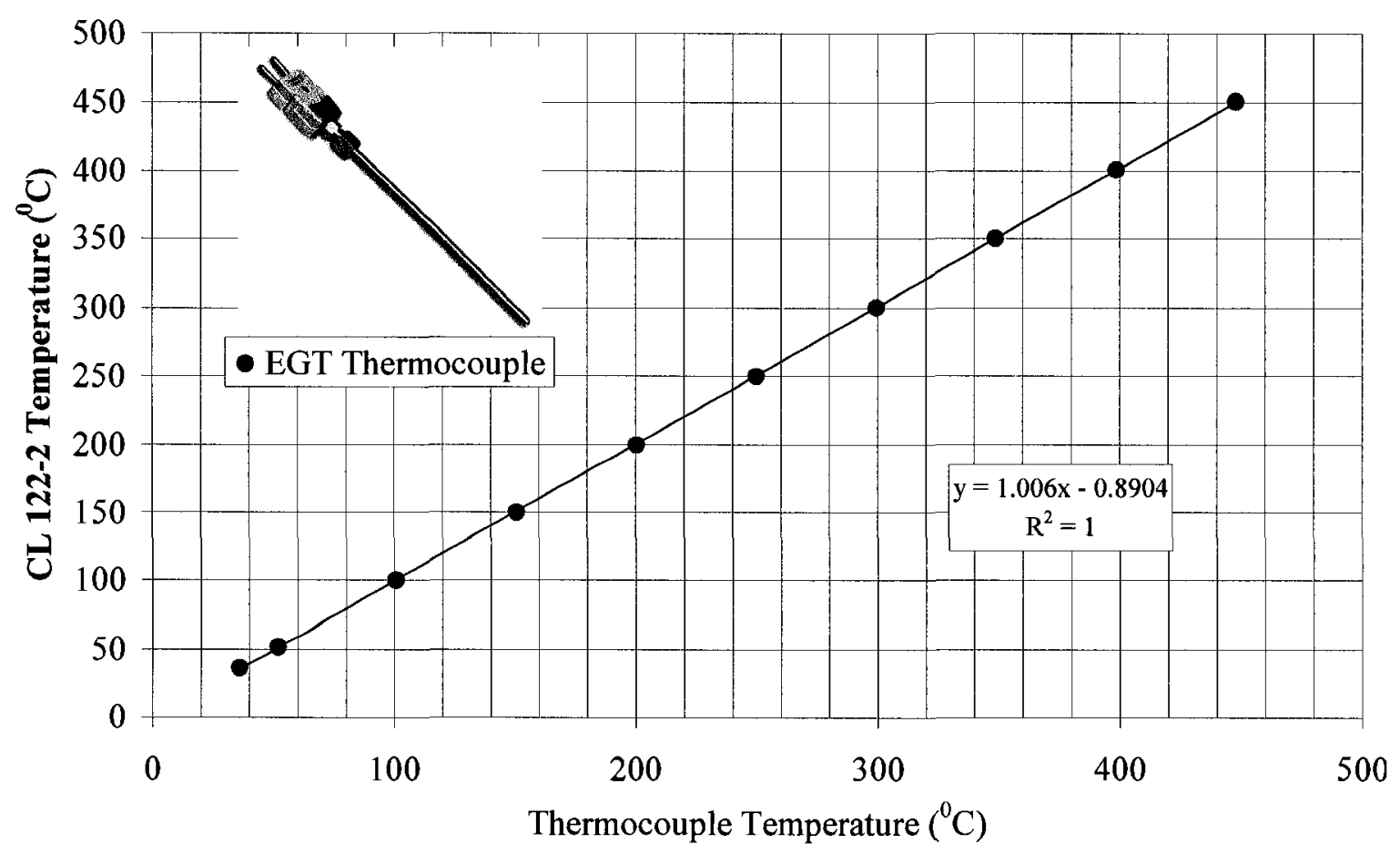

\section{Figure 8.2 EGT thermocouple calibration}

Figure 8.2 shows that 10 different setpoints were used to calibrate the EGT thermocouple. The coefficients given by the linear trendline were then used, in the LabView program to correct the temperature measurements. Except for the thermocouples spot welded onto the liner wall, similar calibration processes were repeated for all the remaining thermocouples used in the laboratory. The remaining calibration curves can be found in Appendix F.

\subsection{Pressure Transducers Calibration}

The pressure transducers were calibrated using a Druck DPI 605 pressure calibrator. The DPI 605 is a portable equipment designed to calibrate transducers and systems with gauge pressures ranging between $-14.7 \mathrm{psi}$ and $300 \mathrm{psi}$. To calibrate a pressure transducer, a Teflon tubing line and a tube fitting were used to couple the transducer to the calibrator pressure port, as shown in Figure 8.3. 


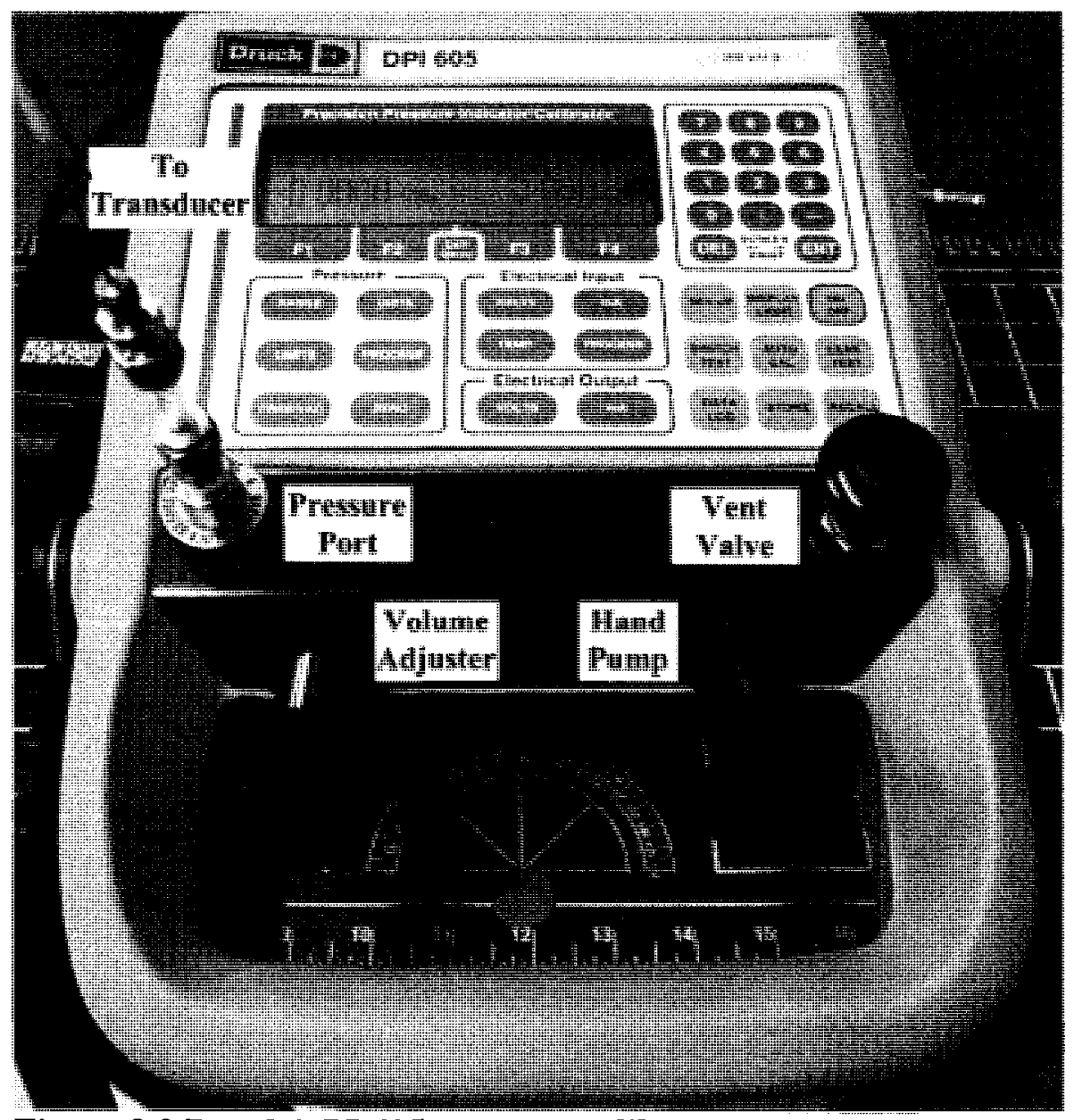

Figure 8.3 Druck DPI 605 pressure calibrator

To generate pressure or vacuum using the calibrator the volume adjuster was set to approximately half way. After a short stabilizing period ( 10 seconds), the DPI pressure display was zeroed. The instrument (DPI 605) was then set to either generate pressure or vacuum. After the zeroing process was completed, the vent valve was closed and by manually operating the hand pump, the approximate required pressure was achieved. Using the volume adjuster, the pressure sensed by the transducer was then fine-tuned. With the system stabilized, a set of pressure measurements were then acquired using the Keithley 2700. This process was repeated for the entire pressure transducer range. Upon having completed the transducer calibration, the pressure or vacuum built up in the 
system was released by opening the vent valve. The Teflon line was finally decoupled from the transducer which was then linked back to the sensing port.

The transducers used in the fuel delivery system had a higher pressure range when compared to the DPI 605. Thus, the limit pressure for the calibration of these transducers was set by the maximum operating pressure of the DPI 605 which was 300 psig. The possible measurement inaccuracy at pressures higher than 300 psig was deemed acceptable since the scope of the transducers used in the fuel delivery system was that of monitoring rather than accurately measuring performance.

Figure 8.4 shows calibration curves for the PX243A-1 pressure transducer. This particular pressure transducer was used, having the air delivery system in the atmospheric set-up configuration, to measure the gauge static pressure upstream of the microturbine combustor. As can be seen from the figure, 12 pressure points were used to calibrate the transducer. Furthermore, to monitor the performance of the transducer over time, multiple calibration tests were performed. In particular, Figure 8.4 shows that after almost 10 months of usage the transducer performance was still acceptable. The coefficients given by the most recent trendline were those used in the LabView program. 


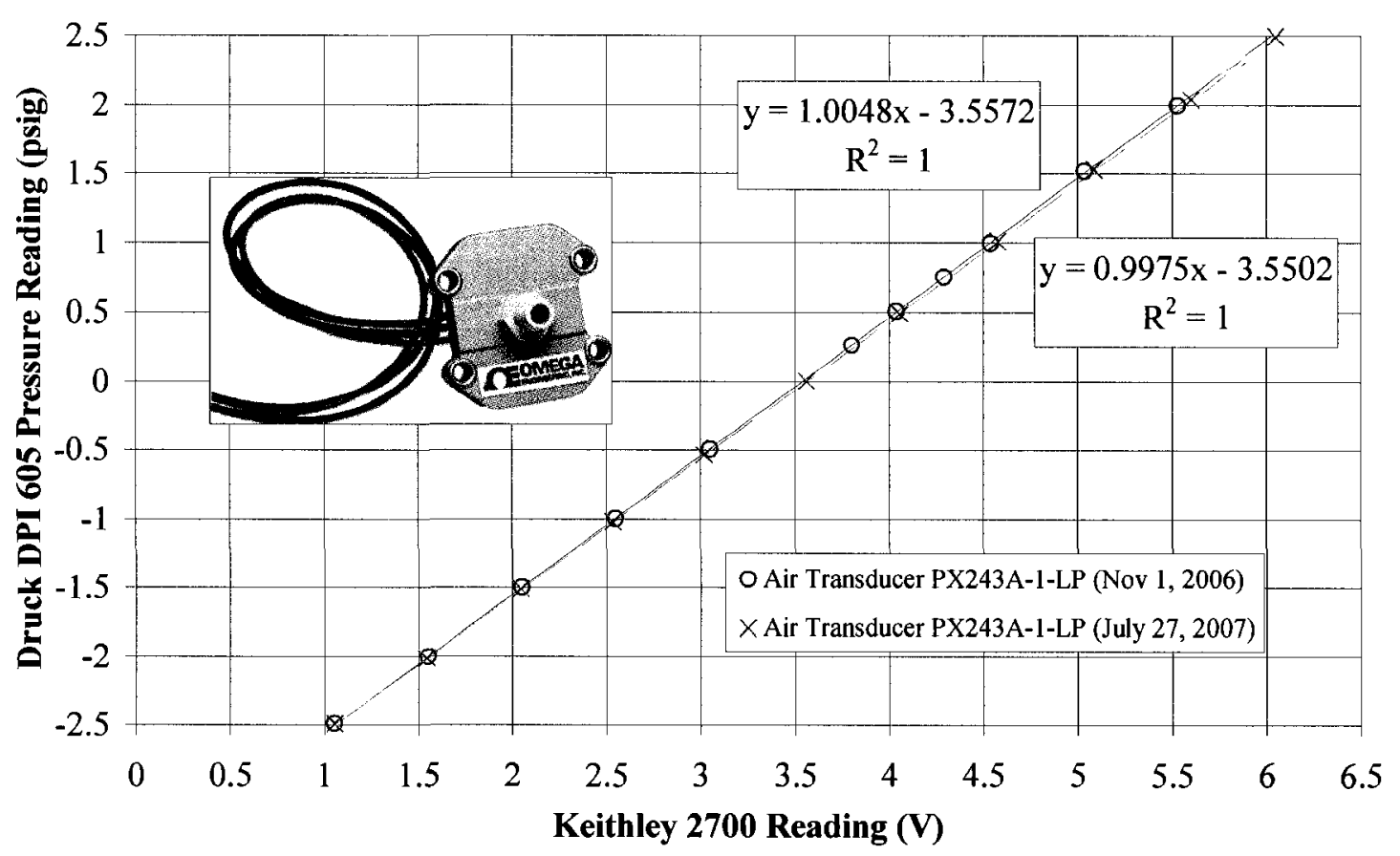

Figure 8.4 PX243A-1 pressure transducer calibration curves

\subsection{Pressure Probes Calibration}

The Kiel probe performance was also investigated to ensure that the claimed yaw and pitch insensitivities were actually achieved. A probe calibration apparatus (Mahallati, 2003) available at Carleton University was used to carry out this investigation. Figure 8.5 shows the apparatus schematic and the Kiel probe being mounted downstream of the inlet nozzle. The variation in the pitch and yaw turntable angles translated into angle changes in the probe pitch and yaw, while maintaining unchanged the Kiel probe head absolute position (i.e., position of Kiel probe head with respect to inlet nozzle). 


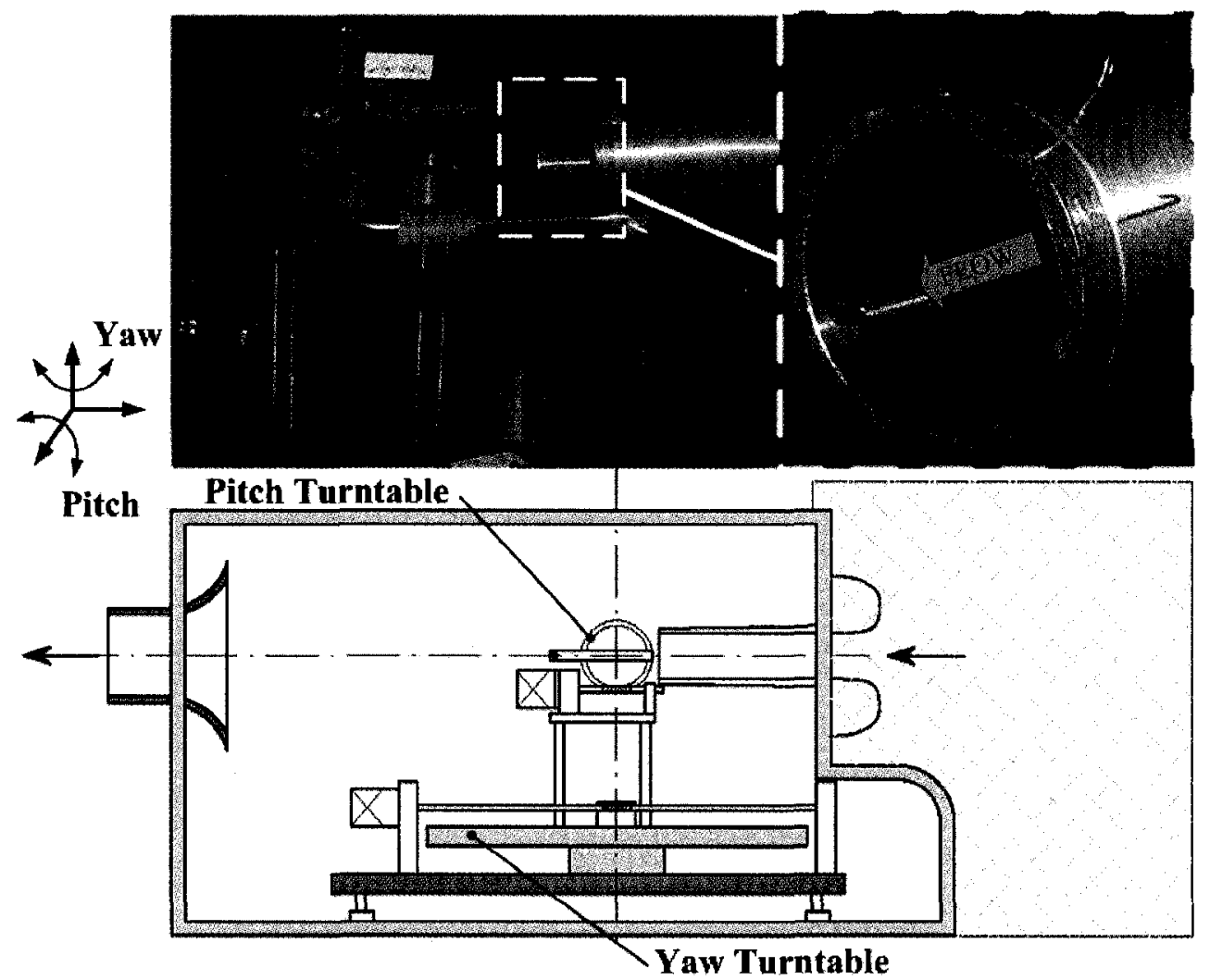

Figure 8.5 Kiel probe calibration rig (Adapted from Mahallati, 2003)

Figure 8.6 shows the pitch traverse results. As can be seen, the claimed pitch insensitivity to angles up to $\pm 55^{\circ}$ was confirmed (see Appendix F for yaw results).

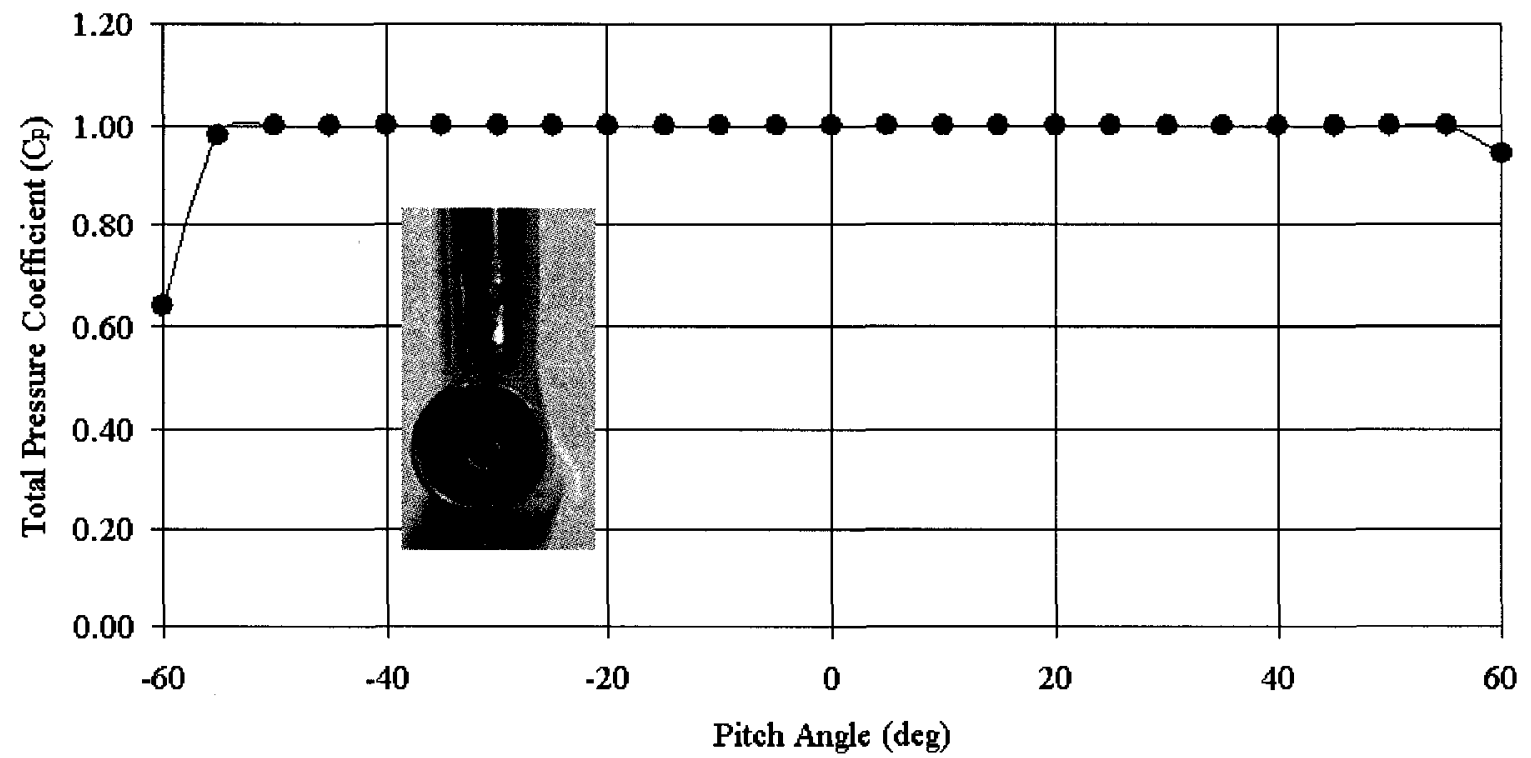

Figure 8.6 Effect of Kiel probe pitch angle on total pressure coefficient 
Where the total pressure coefficient was calculated using the following formula and the sensor locations can be seen in Figure 8.7 (Mahallati, 2003).

$$
C_{p}=\frac{P_{0}-P_{c 1}}{P_{c 1}-P_{c 2}}
$$

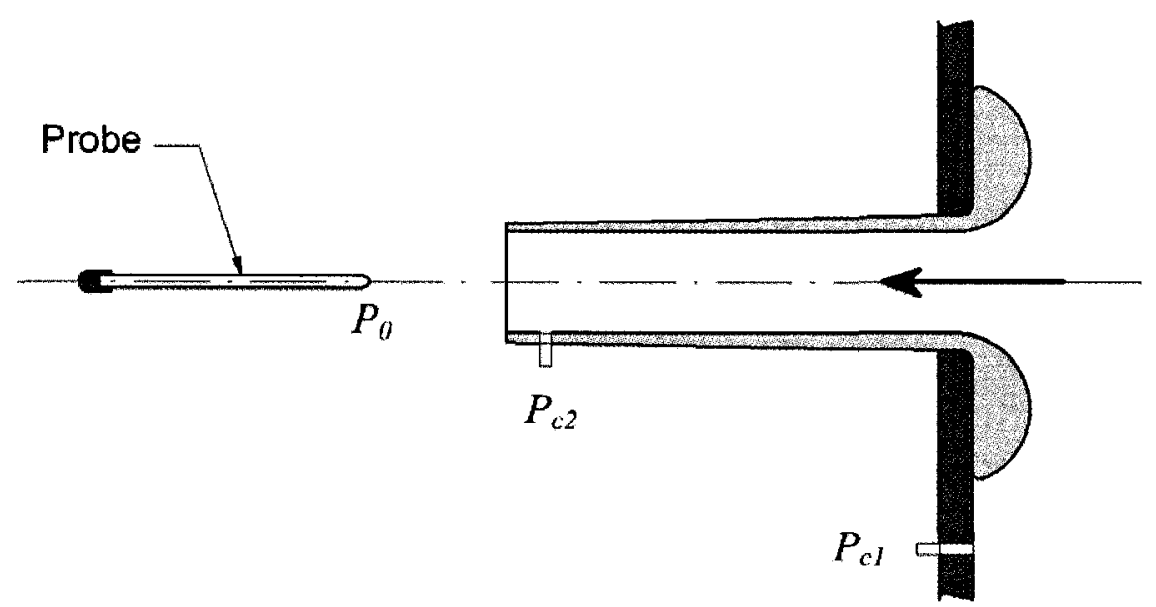

Figure 8.7 Calibration rig sensor location (Adapted from Mahallati, 2003)

An attempt to calibrate the pitot rake using the calibration apparatus mentioned above was also conducted. However, the rake could not fit within the apparatus and therefore calibration could not be conducted. The rake readings errors, due to effects of viscosity and wall proximity, were, thus, estimated using work carried out by MacMillan (Figure 8.8) and reported in Ower and Pankhurst (1977). Particularly, using curve A, a $0.1 \%$ correction factor was applied to the readings taken using the pitot rake. 


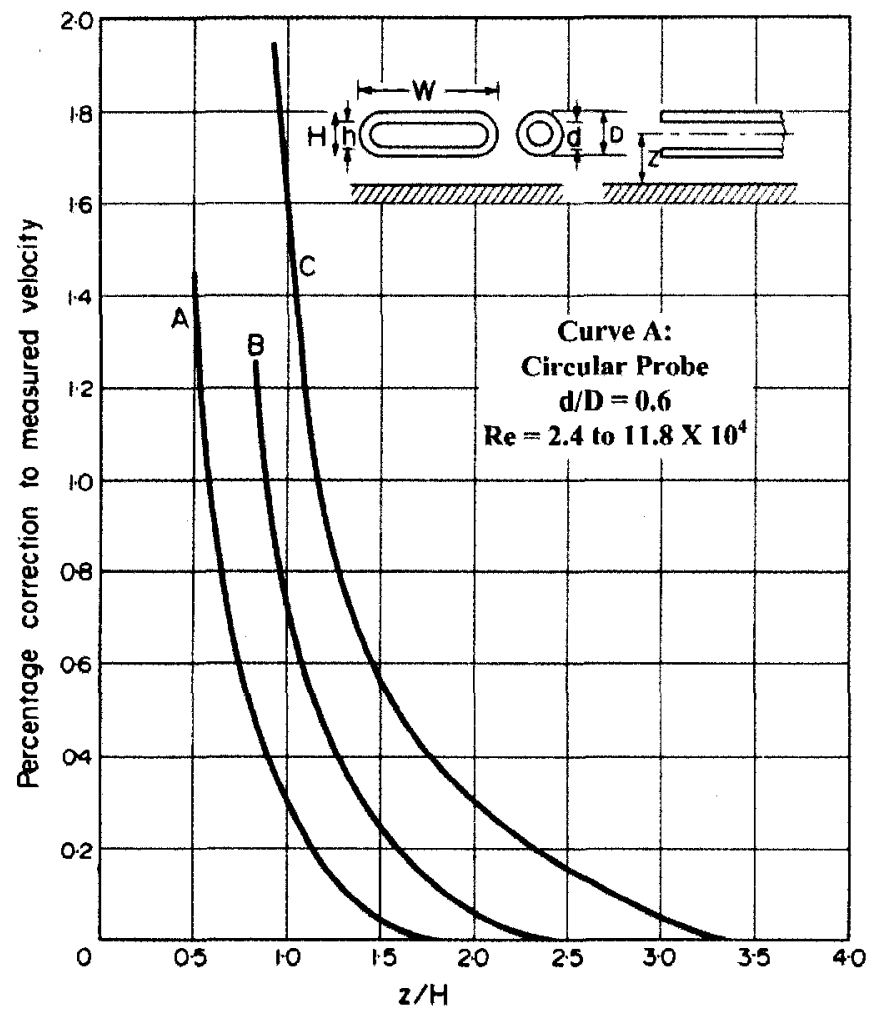

Figure 8.8 Viscosity and wall proximity correction for pitot tubes (Ower and Pankhurst, 1977)

\subsection{Orifice Calibration}

Evaluation of the orifice plate metering performance was also undertaken. The scope of this evaluation was to understand if the manufacturing process used to produce the orifice plate and the wall taps had been successful. The test was performed by inserting a metering bellmouth at the blower inlet (Figure 8.9) and then by comparing the flow rates measured by both methods. The orifice plate and wall taps manufacturing process was deemed successful and the maximum error was found to be $2 \%$. 


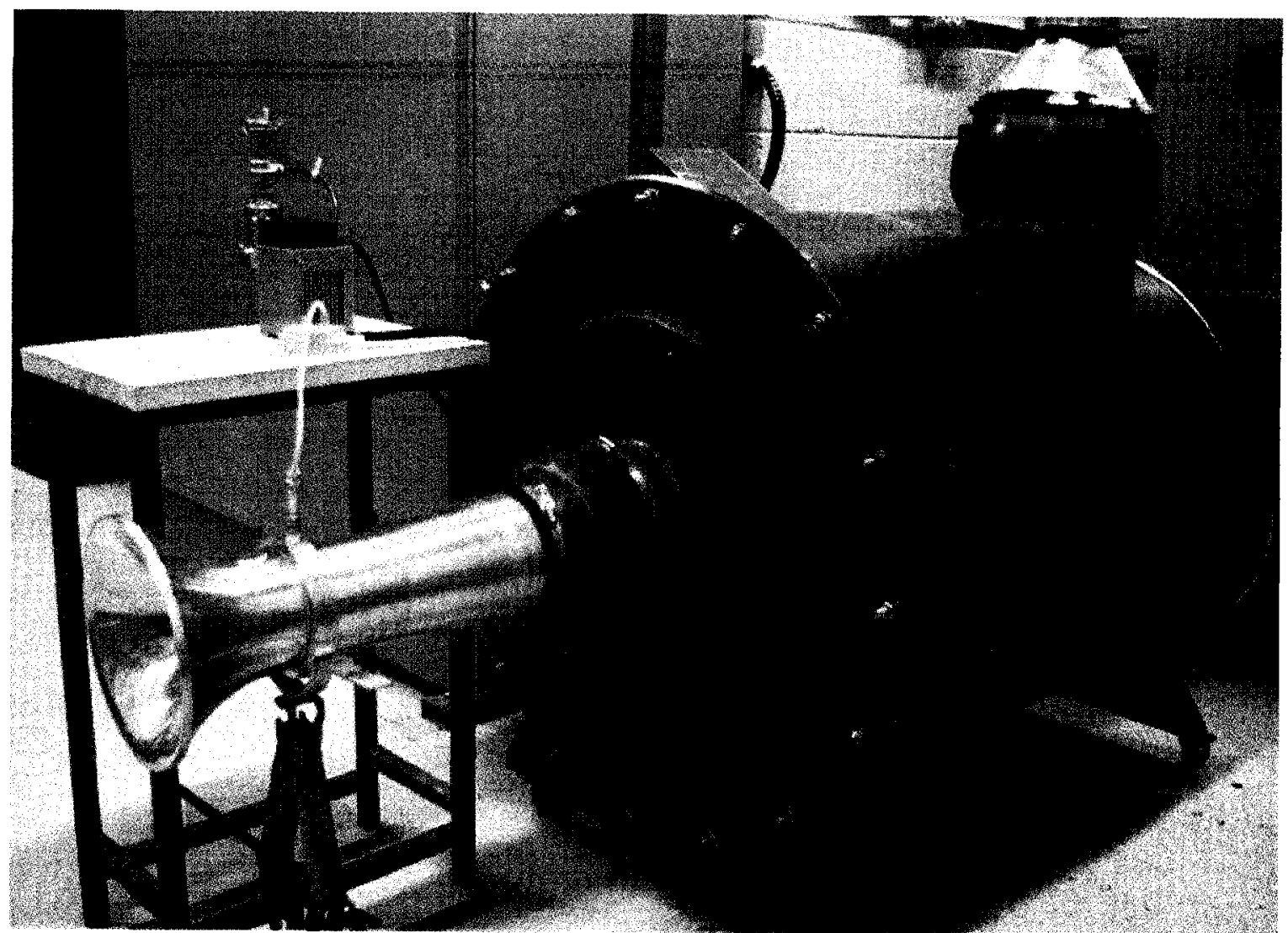

Figure 8.9 Atmospheric blower instrumented with metering bellmouth

\subsection{Shakedown Tests}

The successful construction and operation of the gas turbine combustion research laboratory required hundreds of hours of shakedown tests. The shakedown tests started at a component level. They then evolved into shakedown tests of individual systems (i.e., air delivery shakedown tests, fuel delivery shakedown tests and control/acquisition shakedown tests) and finally they reached their maximum complexity by testing the various systems working together. Of the many shakedown tests conducted, the following sections will only describe the most important ones. 


\subsubsection{Wall Tap Averaging}

As previously mentioned, to gain a better estimate of static pressures each sensing location was instrumented with four wall taps, circumferentially spaced at $90^{\circ}$ intervals. However, to reduce instrumentation costs, the number of pressure transducers used to measure the static pressures was minimized by introducing averaging manifolds. However, before this averaging process could be carried out, the static pressure measurements of each tap were ensured to be within $1 \%$ of each other. This guaranteed that the averaged static pressures were then meaningful measurements.

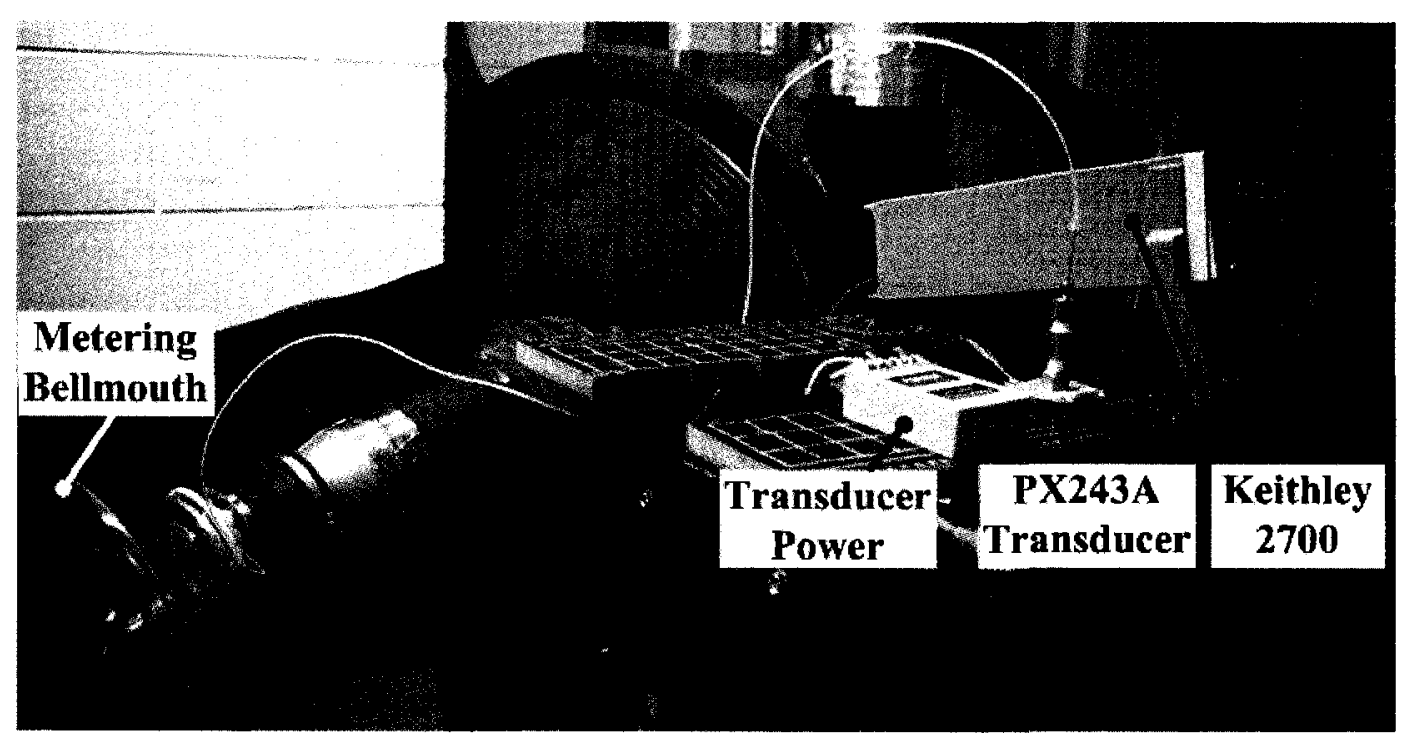

Figure 8.10 Performance assessment of metering bellmouth wall taps

An example of this type of shakedown test is shown in Figure 8.10 where the metering bellmouth wall taps were under investigation. With the bellmouth properly installed and the blower operating at steady state, a set of static pressure measurements, using a PX243A transducer and the Keithley 2700 DAQ, were taken for each wall tap present on the bellmouth. The results were then plotted to see if the readings were within $1 \%$ of each other (Figure 8.11). The success of the tests permitted the use of manifolds to average the static pressures sensed by the set of wall taps. This allowed therefore, to use 
only one pressure transducer while still ensuring a better static pressure measurement than in the case of having only one wall tap and one transducer.

The same type of test was carried out for all the wall taps present along the air delivery system. The outcome of these shakedown tests resulted in the usage of five pressure transducers instead of 20 to measure all the static pressures in the gas turbine combustion research laboratory.

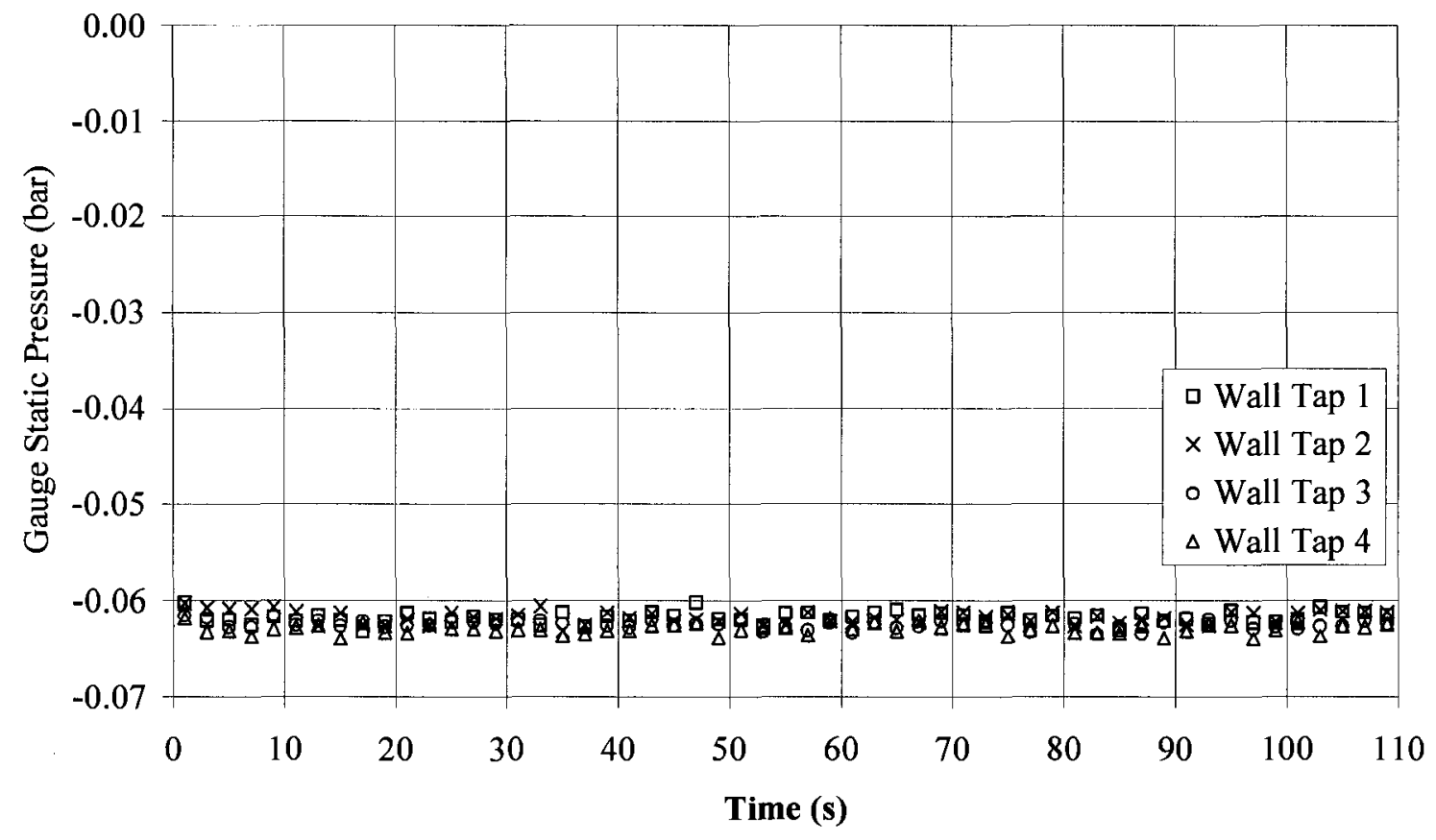

Figure 8.11 Performance assessment of metering bellmouth wall taps

\subsubsection{Leak Tests of Instrumentation Pressure Lines}

To ensure that the pressure lines, connecting the various sensors (i.e., wall taps, pitot rake, Kiel probe, etc.) to the transducers, were gas-tight, a series of pressure leak shakedown tests were conducted. These shakedown tests were carried out using a Druck DPI 603 pressure calibrator. Each pressure line, in its final configuration, was detached from the sensor. The line was then connected to the DPI 603 pressure calibrator which, through a manual pump, put pressure in the line. The drop in pressure of the line was 
monitored over a span of time (Figure 8.12). More specifically, the leak tests were conducted by pressurizing the lines to a gauge pressure of 6.9 bar (100 psig) and monitoring the pressure drop over 3 minutes. If a pressure drop was detected, the line junctions were investigated using Snoop, a liquid leak detector produced by Swagelok. Snoop was applied on the external surfaces of the joints and a leak wad detected if bubbles were formed. The leaky joint(s) was then addressed and the problem corrected. The leak tests were repeated until no pressure drop or minimal leak (less than 0.0035 bar; $0.05 \mathrm{psi}$ ) was recorded in the line under investigation.

Of all the tests conducted, the most problematic one was that of the static tap S30B01. A gauge pressure drop of 0.18 bar ( $2.6 \mathrm{psig}$ ) per minute was recorded on this particular sensor line (Figure 8.12). Through many tests, the problem was identified to be a defective gasket in the Scanivalve pressure scanner. Replacement of the gasket reduced the pressure drop to 0.0017 bar ( $0.025 \mathrm{psig})$ per minute which was deemed acceptable.

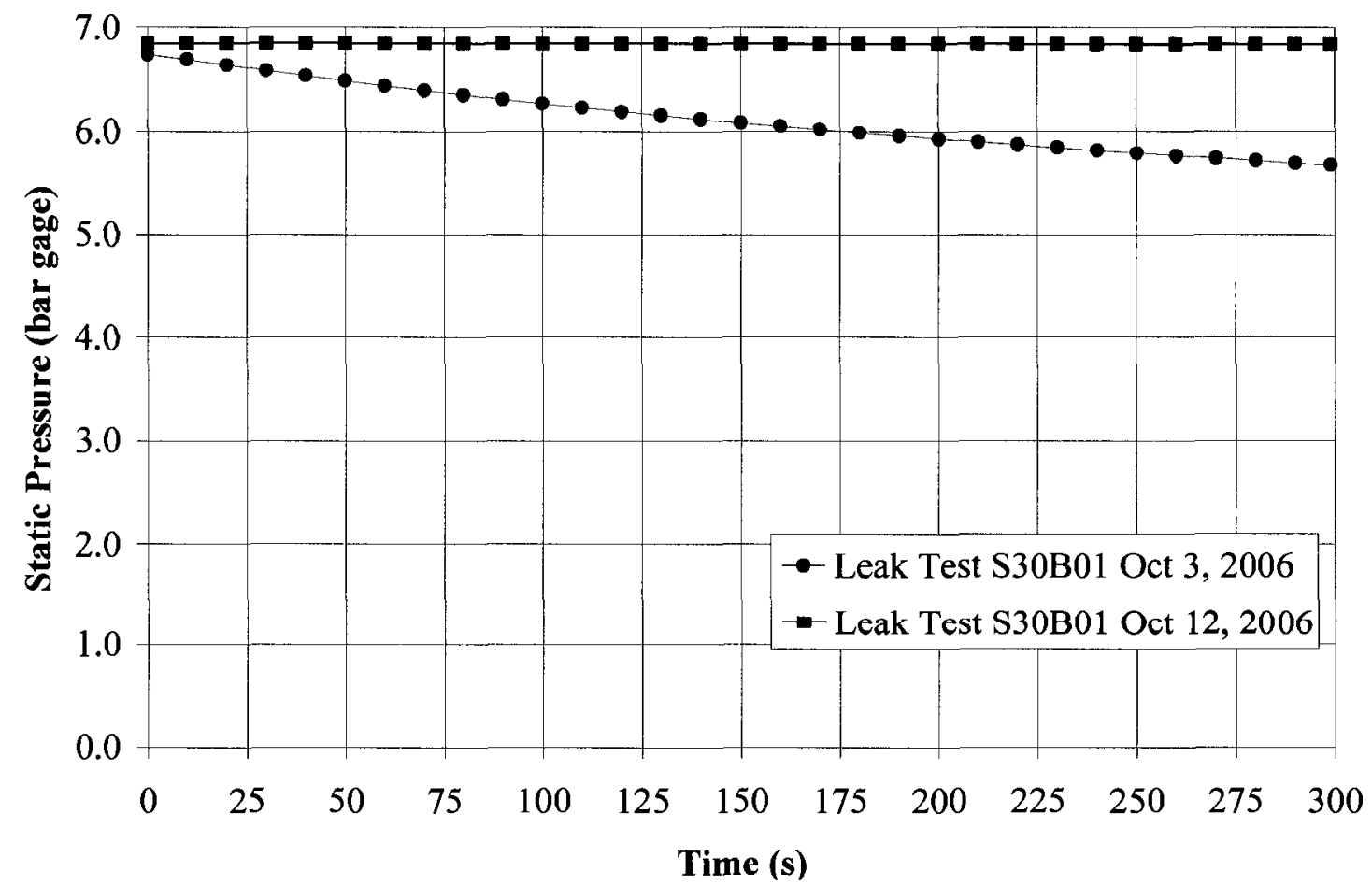

Figure 8.12 Pressure leak test for S30B01 pressure line 
After having completed the pressure leak tests, the pressure lines were then reconnected to their respective pressure sensing ports or pitot tubes.

\subsubsection{Air Delivery System Pressure Leak Tests}

With the pressure lines reinstalled, the whole air delivery system was pressurized to a gauge pressure of approximately $6.9 \mathrm{bar}(100 \mathrm{psig})$. The scope of the test was to inspect the whole air delivery system for gas leaks. Particular attention was given to the welds, used to join the various pipe segments together, to mounting structures, used for the instrumentation (i.e., wall taps welds, Kiel probe traverse mechanism, etc.) and to pipe end mating surfaces.

The test was carried out by pressurizing the air delivery system starting at the bleed pipe and ending at the exhaust stack. As can be seen in Figure 8.13, a pressure regulator was installed at the inlet of the bleed pipe so that compressed air could be safely introduced into the sealed air delivery system. To seal the air delivery system, a plate was inserted and fastened between the mating surfaces of two pipes just upstream of the exhaust stack (Figure 8.14). With the air delivery system pressurized, a careful visual inspection, using Snoop, was conducted. All the pipe welds and instrumentation mounting systems were deemed gas-tight. Minor leaks were found between pipe mating surfaces. These problematic leaks were addressed by replacing the existing gaskets with new and improved ones. 


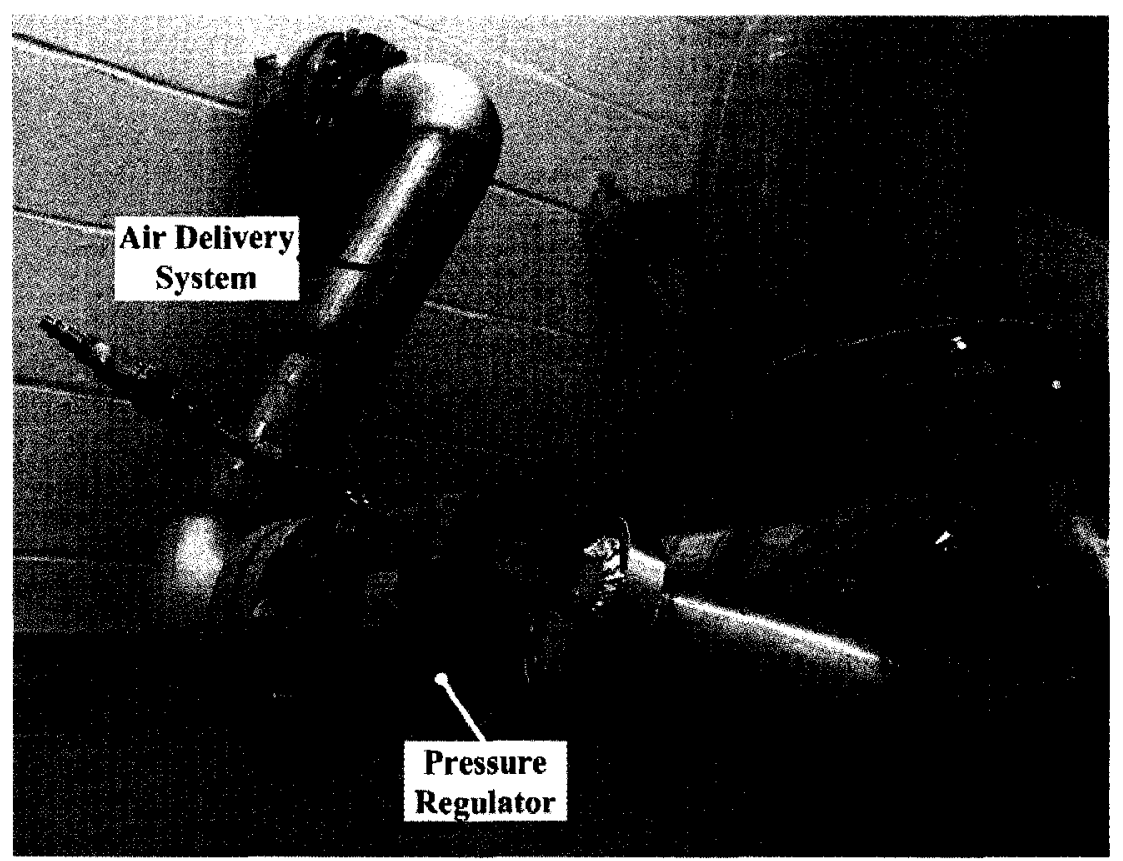

Figure 8.13 Pressure leak test for air delivery system; pressure regulator details

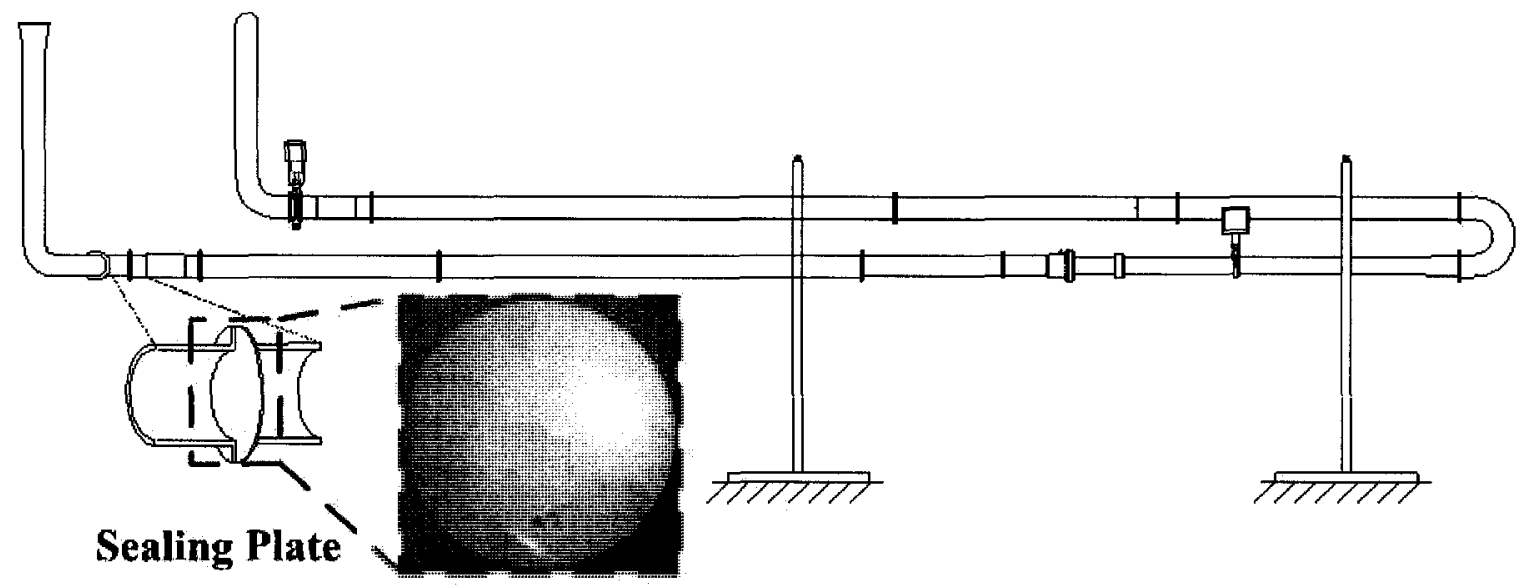

Figure 8.14 Pressure leak test for air delivery system; sealing plate details

\subsubsection{Air Delivery System Shakedown Tests}

The next set of shakedown tests were conducted with the air delivery system in the atmospheric configuration. In these tests the blower was used as a source of air flow so that the instrumentation, data acquisition system and LabView programs could be investigated and problems could be addressed. 
For the tests, the total pressure profiles upstream and downstream of the combustor were examined to understand if the pitot rake had been properly manufactured and to comprehend if the traverse mechanism used for the Kiel probe was adequate. The test results concluded that no modifications were needed to be done to the total pressure sensors.

These shakedown tests were also able to inspect the acquisition rate of the Keithley 2700. Findings showed that, in the factory settings, the Keithley 2700 would take almost 6 seconds for a complete scan of the experimental measurements (i.e., the acquisition of 12 pressures and 26 temperatures). This was deemed too long since combustion is a very fast process. By reprogramming the settings of the Keithley 2700 , the acquisition time was reduced, for a complete scan (i.e., 38 channels), to a minimum of 2 seconds. This acquisition time could be further minimized if only critical measurements were gathered. Therefore, for future microturbine experiments, aerodynamic tests should be split from combustion tests so that only critical measurements are taken. Furthermore, the combustion tests could be divided so that the liner cooling performance is addressed first, the pattern factor next and lastly the combustion performance can be evaluated.

The shakedown tests were also able to debug the LabView programs created for data monitoring and storage purposes and for arranging the displayed measurements in such a way that could be easily viewed by the operator. The minor programming problems encountered were addressed and the displayed measurements and warning lights were arranged so that they could be easily seen. 
Finally, these shakedown tests, also evaluated the successful effectiveness of warning sounds, produced by a set of speakers, as simulated data measurements approached the air delivery system pressure and temperature operational limits.

\subsubsection{Repeatability Shakedown Tests}

A series of repeatability tests, with the air delivery system in the atmospheric configuration, were conducted to understand if experiment conditions could be duplicated. In particular, these series of tests focused on the investigation of the discharge coefficients of the dilution holes. A total of 30 experiments over the span of 3 days were carried out.

All the liner holes, except for the dilution holes, were plugged using the procedure given in Section 7.3.6. After having assembled together the liner and casing, the annulus area was also plugged. With the LFE model 50MW20-2 in place, a series of pressure and temperature measurements were taken so that discharge coefficients of the dilution holes could be calculated. After having completed an experimental run, the combustor was removed from the air delivery system and a visual inspection of all the plugs was conducted before reassembly was initiated. With the reassembly completed, another set of measurements were taken. This process was carried out for a total of 18 times while maintaining the same test conditions (i.e., butterfly valve angle unchanged).

The remaining 12 tests investigated the effects of start-up and shut-down procedures on the acquired data. For these types of tests the combustor was left untouched and 12 start-up/shut-down procedures were carried out over the span of two days.

The test procedure was as follows:

- Blower start-up 
- 10 minute stabilization time

- Open butterfly valve

- Acquire data

- Close butterfly valve

- Blower shut-down

From the experimental results (Figure 8.15), the conclusion was that test conditions could be duplicated. However, when comparing the experimental results $\left(C_{d}=0.595\right)$ with results given by the empirical correlation (Equation (4.93) solved using test conditions; $\mathrm{C}_{\mathrm{d}}=0.625$ ) a $4.8 \%$ maximum error was calculated. Therefore, it was concluded that the pitot rake should be calibrated so that the percentage correction to measured velocity can be better estimated.

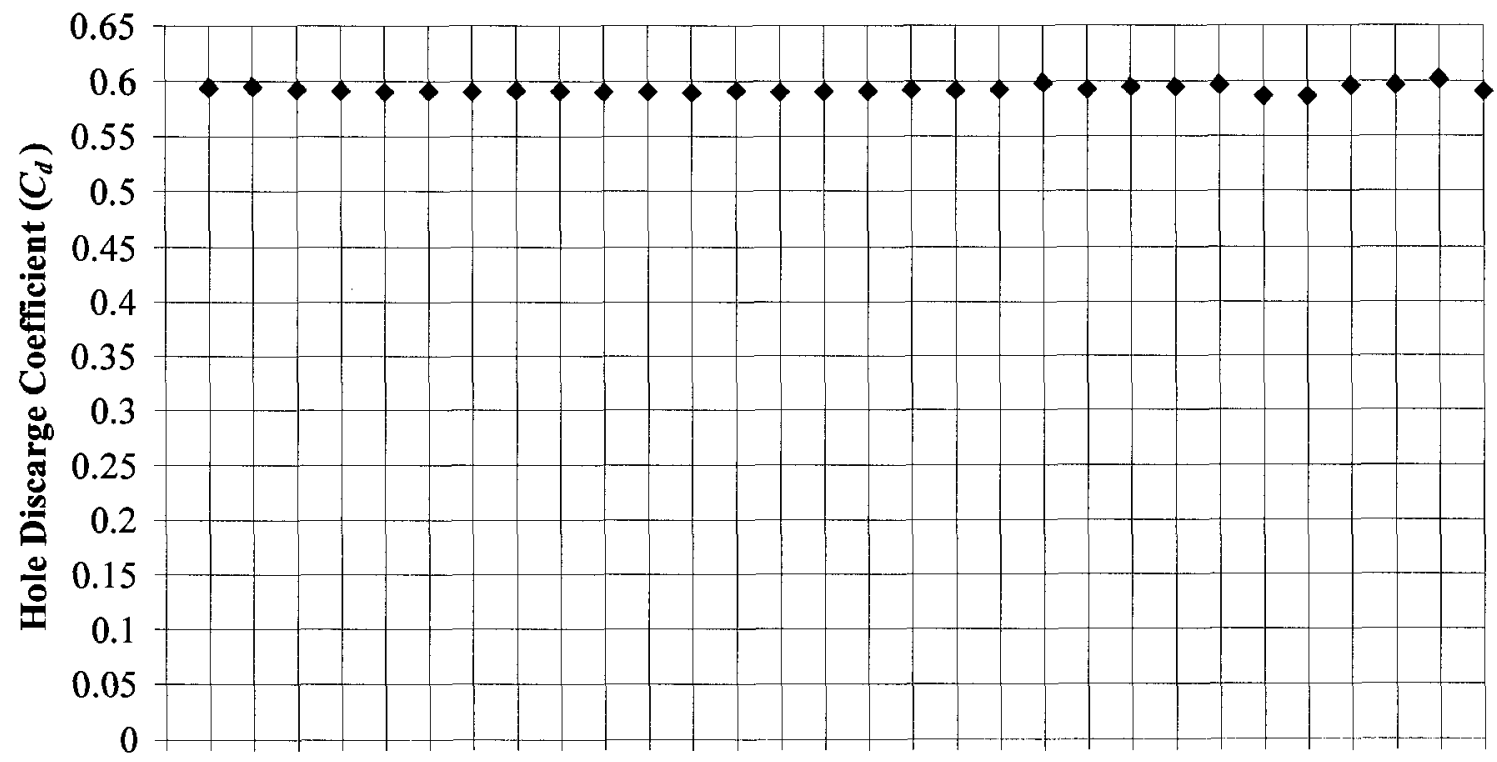

$\begin{array}{llllllllllll}0 & 1 & 2 & 3 & 4 & 5 & 6 & 7 & 8 & 9 & 1011 & 12131415161718192021222324252627282930\end{array}$ Test Number

Figure 8.15 Repeatability tests 


\subsubsection{Fuel Delivery System Shakedown Tests}

The fuel delivery system was extensively tested using water. Once confidence in the system was obtained, further tests using diesel fuel were conducted. The scope of the shakedown tests using water was to evaluate the performance of the components making up the fuel delivery system. The scope of the tests performed using diesel fuel was to gain further knowledge on the performance of the fuel nozzles and to confirm the accurate calibration of the purchased FTB 502 low flow rate meter.

The results of the many shakedown tests carried out using water showed that the fuel delivery system was satisfactory. In particular, the fuel delivery system could be operated remotely and its performance was found to be very reliable even under emergency situations.

The tests also showed that the liquid flow rate could be accurately metered using the fractional flow control valve and that the pressure regulator permitted gauge pressures of up to 32.5 bar (471 psig) at the nozzle tip to be reached.

The ASCO $8223 \mathrm{G} 027$ on/off solenoid valve was carefully investigated since this was the component that would stop the fuel from entering the combustor in case of an emergency. As described before, the valve was electrically connected to a pressure switch sensing the air delivery system operating pressure. In case of sudden pressure loss in the air delivery system, the on/off solenoid valve was de-energized and fuel was stopped from flowing into the combustor. This type of scenario was simulated by coupling the pressure switch to the Druck 605 calibrator. The air delivery operating pressure sensed by the switch was simulated by the Druck 605 with which the sudden loss of pressure was achieved by opening the vent valve. The investigation of the fuel delivery response to the 
loss of pressure was successful. The sudden pressure loss de-energized the on/off valve which in turn stopped the liquid flow.

A series of shakedown tests, investigating the emergency shut-down procedure, led to a modification in the electrical wiring of the emergency switch. Originally, when pressing the emergency button, current was cut to the on/off solenoid valve while the fuel pump was still in operation. This sudden pressing of the emergency switch caused a pressure spike in the fuel delivery system which was experienced by all the components downstream of the solenoid valve. This was deemed unacceptable since pressure spikes would reduce the lives of the fuel delivery components, especially the instrumentation (even though a pressure snubber was mounted on each transducer). As a result of these tests, the emergency stop button was rewired to cut current to both the on/off solenoid valve and the fuel pump. This rectification not only extended the lives of the components making up the fuel delivery system but also addressed the possibility of a fuel line breakage.

Using a bucket, scale and stop watch, the mass flow rates of the purchased fuel nozzles were investigated. The results were then compared with the performance curves of the nozzles given by the manufacturer. The outcome of the tests proved that the nozzle performances were actually met and that the testing method used (i.e., bucket, scale and stop watch) was suitable. Figure 8.16 shows test results for the PJ12 nozzle. Particularly, when looking at Figure 8.16 it can be seen that the nozzle modification process (i.e., machining and welding) did not alter the performance of the nozzle. 


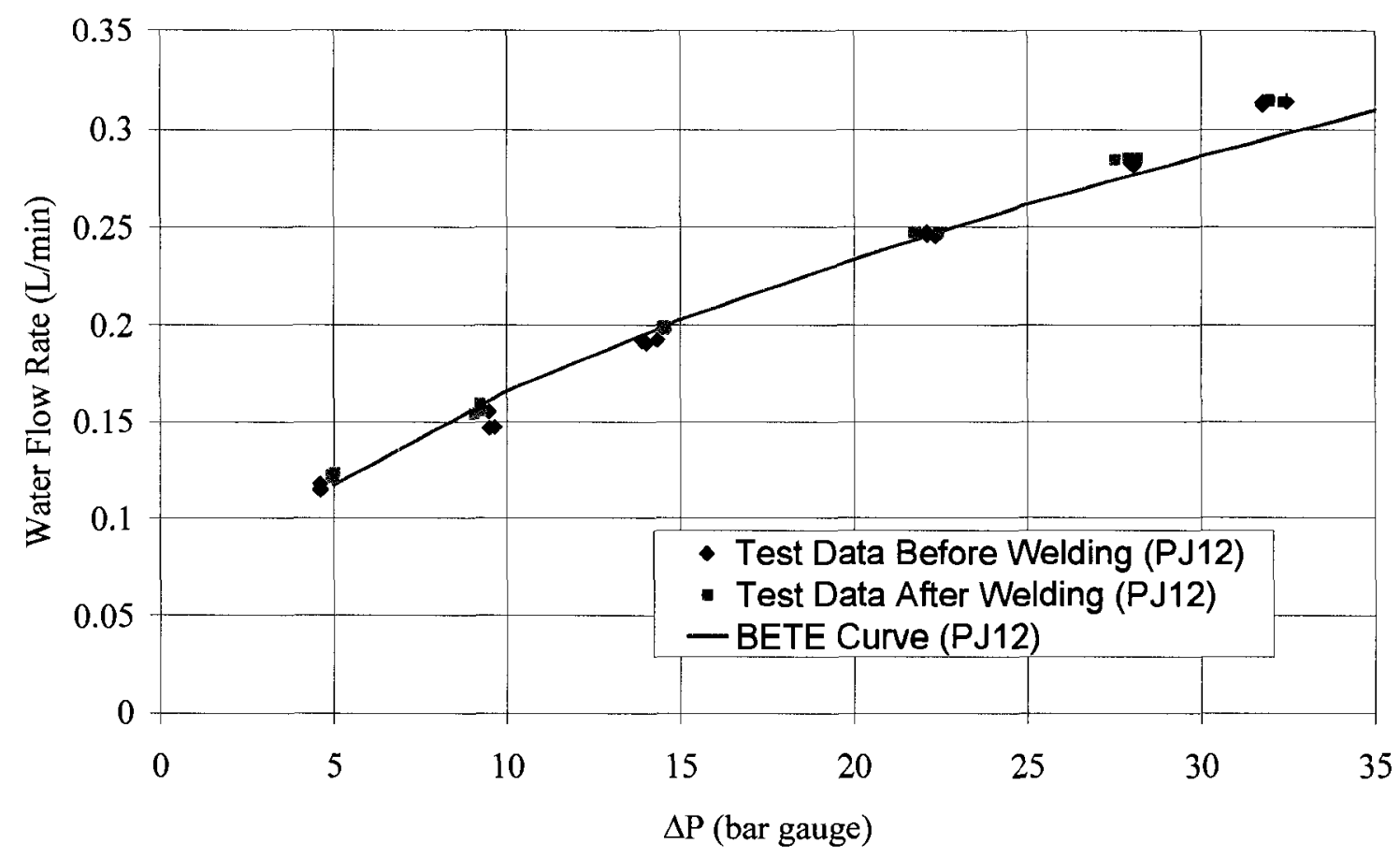

Figure 8.16 Effect of differential pressure across PJ12 nozzle on water flow rate

With confidence gained in the fuel delivery system, diesel was then used to further investigate fuel nozzle performance and to evaluate the working condition of the newly purchased FTB 502 low flow rate meter.

The series of shakedown tests using diesel fuel showed a large discrepancy between the mass flow rates measured by the author, using the bucket, scale and stop watch method, and the mass flow rates measured by the FTB 502 and acquired by the Keithley 2700 Figure 8.17. Since the installation of the flow meter followed guidelines given by the company (Omega Engineering) it was concluded that the flow meter had to be recalibrated. To continue with the laboratory shakedown tests, the decision to measure the fuel mass flow rate by creating a LabView subroutine rather than using the FTB 502 meter was made. The LabView subroutine calculated the diesel fuel mass flow rate using the empirical correlation (Figure 8.17) obtained from the nozzle shakedown tests. 


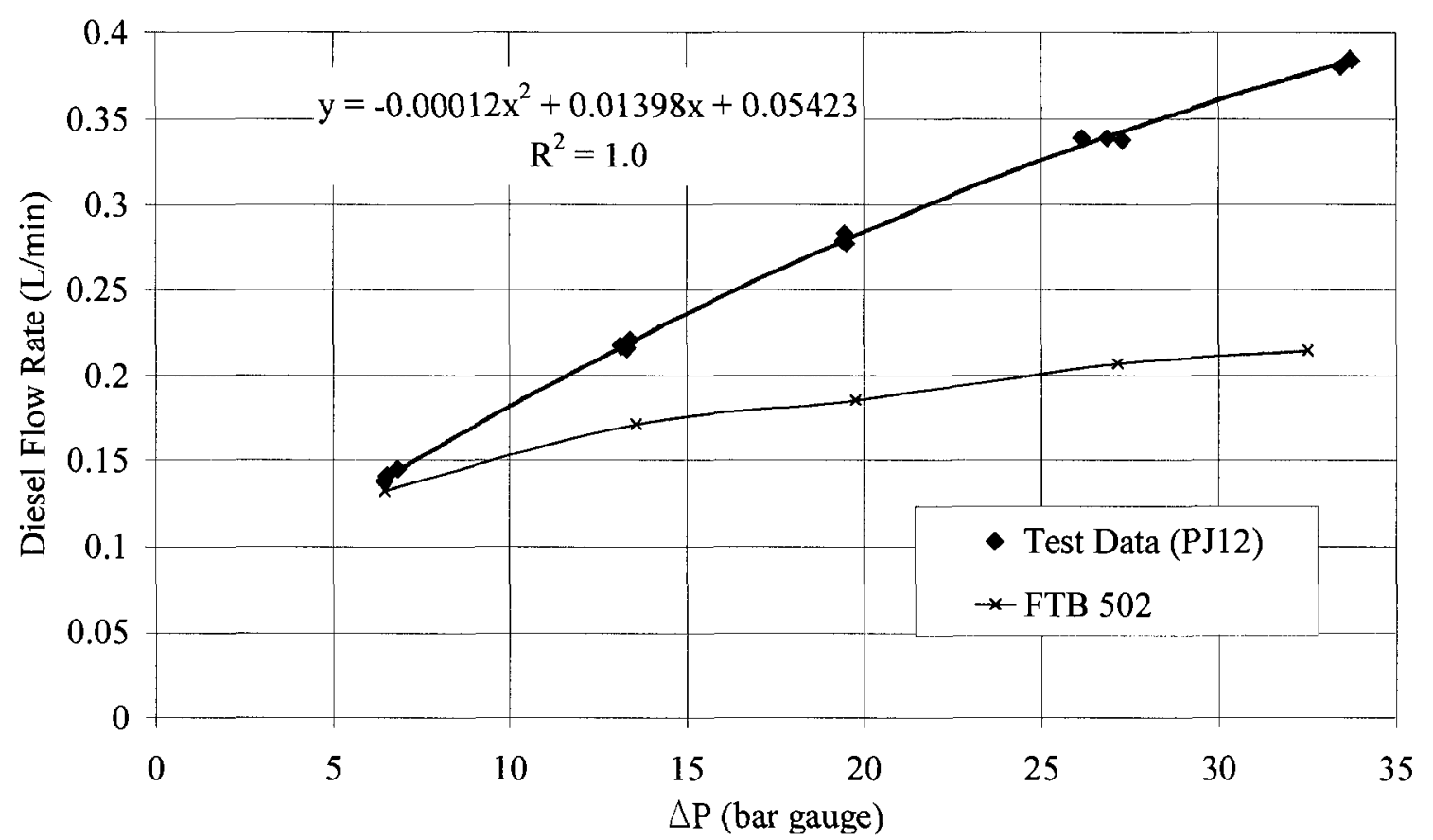

Figure 8.17 Effect of differential pressure across PJ12 nozzle on diesel flow rate

\subsubsection{Allison 250-C20B Shakedown Tests}

A series of shakedown tests were conducted on the Allison 250-C20B to evaluate its performance after having changed the engine configuration from the original turboshaft design to the modified APU design. In these shakedown tests the bleed duct was not installed on the engine so that unforeseen problems could be minimize and focus could be strictly given to the change in engine configuration. The primary objectives of the shakedown tests were to prove the effectiveness of the major engine modification, to ensure that the modified engine was still operating within vibration limits and to fine tune a start-up/shut-down procedure compiled by the author (Appendix G).

A series of three tests were conducted using the following sequence:

- Allison 250-C20B start-up

- 2 minute dwell time at idle 
- Increase, at $5 \%$ intervals, the engine operating point from idle to $100 \%$ $N_{1}$, where $N_{1}$ is the rotational speed of the gas generator

- Decrease the engine operating point from $100 \% \mathrm{~N}_{1}$ to idle

- 2 minute dwell time at idle

- Allison 250-C20B shut-down

The series of tests conducted were deemed successful. The monitored rotational speed of the power turbine $\left(\mathrm{N}_{2}\right)$ was found to be $0 \%$ which indicated that the power turbine shaft was not rotating, thus signifying that the engine modification was successful.

The vibrations of the Allison 250-C20B were recorded throughout the engine operating range and were found within the maximum allowed limits. The maximum average engine accelerations occurred when the engine was operating between $90 \%$ and $100 \%$ of the maximum gas generator rotational speed $\left(\mathrm{N}_{1}\right)$. At these operating points, the maximum average accelerations recorded was $4.8 \mathrm{~g}$ (manufacturer limit $19 \mathrm{~g}$; Allison Engine Company, 1999). 


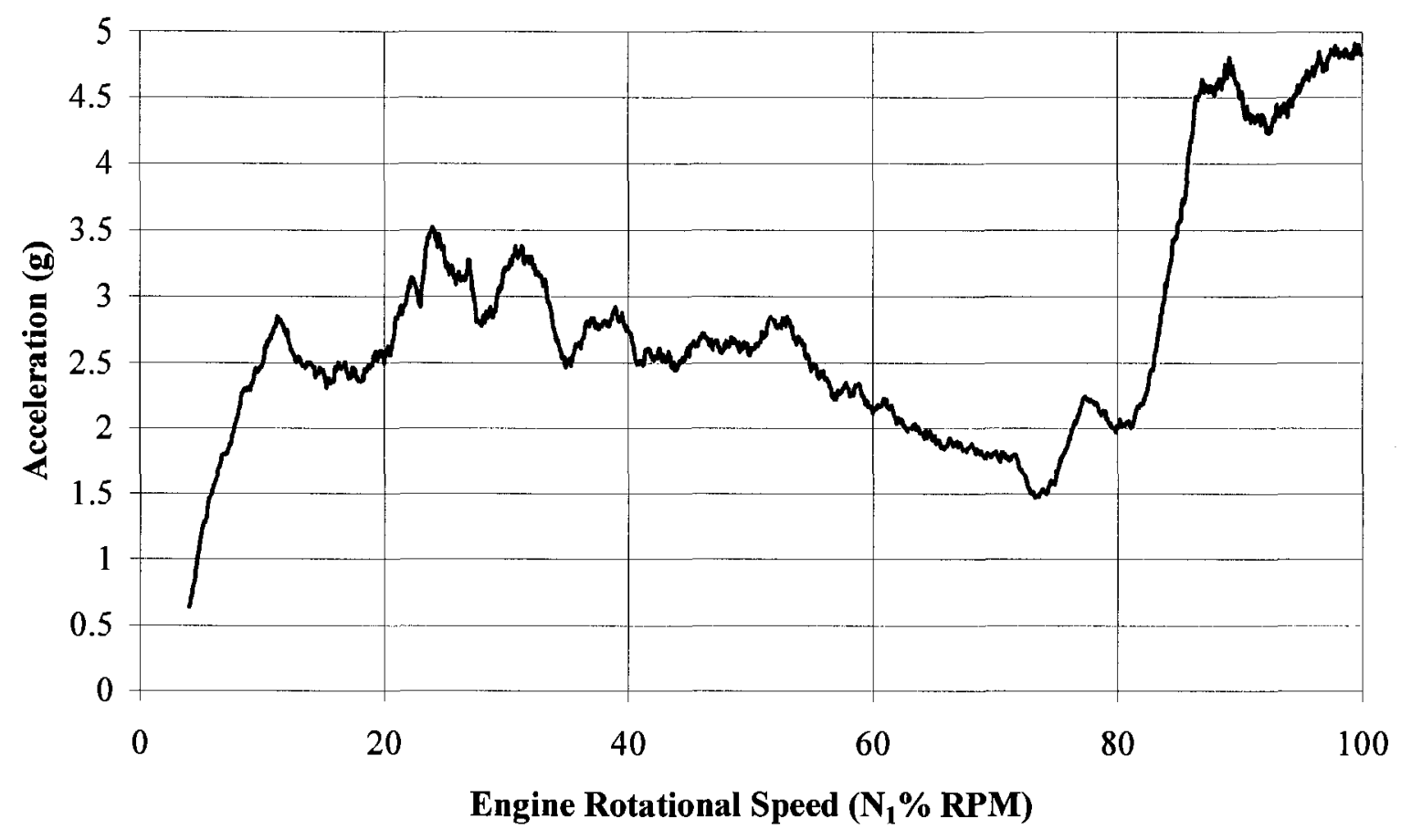

Figure 8.18 Effect of gas generator rotational speed on Allison 250-C20B vibrations

As a result of the conducted shakedown tests, changes to the Allison 250-C20B startup/shut-down operating procedure were made (Appendix G). An example of the changes made was to include overlooked details, such as to manually spin the compressor before start-up to ensure free rotation of the turbomachinery.

\subsubsection{Bleed Shakedown Tests}

After having conducted the above mentioned tests, which increased confidence in the new APU configuration of the Allison 250-C20B, a series of shakedown tests were performed to analyze the engine performance as air was bled downstream of the engine compressor. Therefore, the test objectives were to analyze the performance of the engine in the bleed configuration, to verify that the orifice sizing was adequate and to measure the amount of air that could be safely bled from the engine before the EGT limit was exceeded. 
These shakedown tests unfortunately revealed an unforeseen problem that, due to time constraints, will have to be addressed in the future. Two bleed shakedown tests were carried out. During these tests, compressed air was successfully bled from the engine, but only for a time span of 2 minutes (Figure 8.19). The unforeseen problem was the rapid rise in air temperature in the Gas Turbine Room due to the Allison 250-C20B's oversized exhaust manifolds (Figure 8.20). The high test cell temperature not only decreases the gas turbine performance, due to the decrease in air density, but could also lead to a greater problem like the activation of the fire detection system. Especially, since the exhausts manifolds are in close proximity to the fire detection system. The cold water sprayed by the sprinklers and the hot engine would then lead to thermal gradients of such high magnitudes that, in the worst-case scenario, could make the engine inoperable.

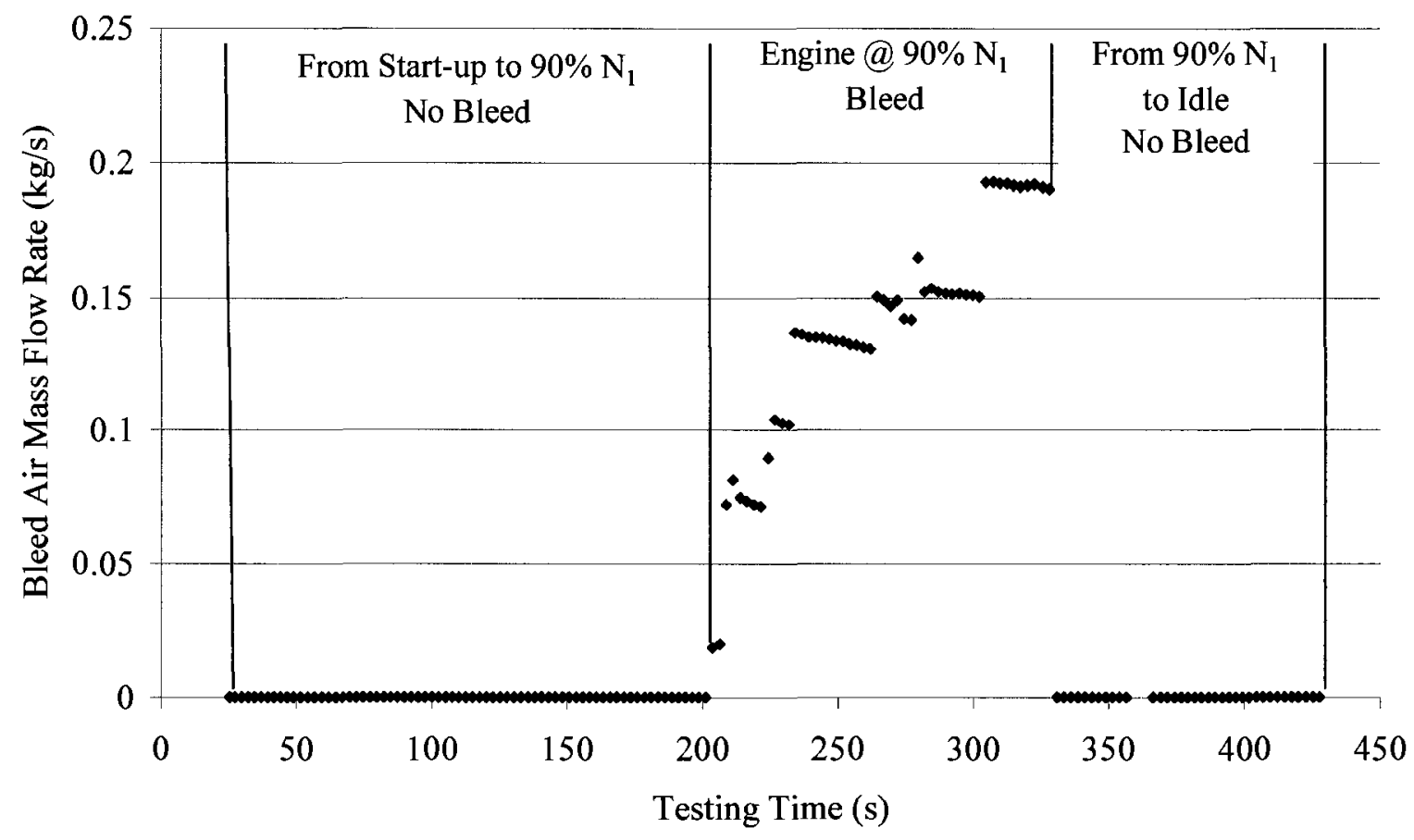

Figure 8.19 Allison 250-C20B bleed shakedown test 


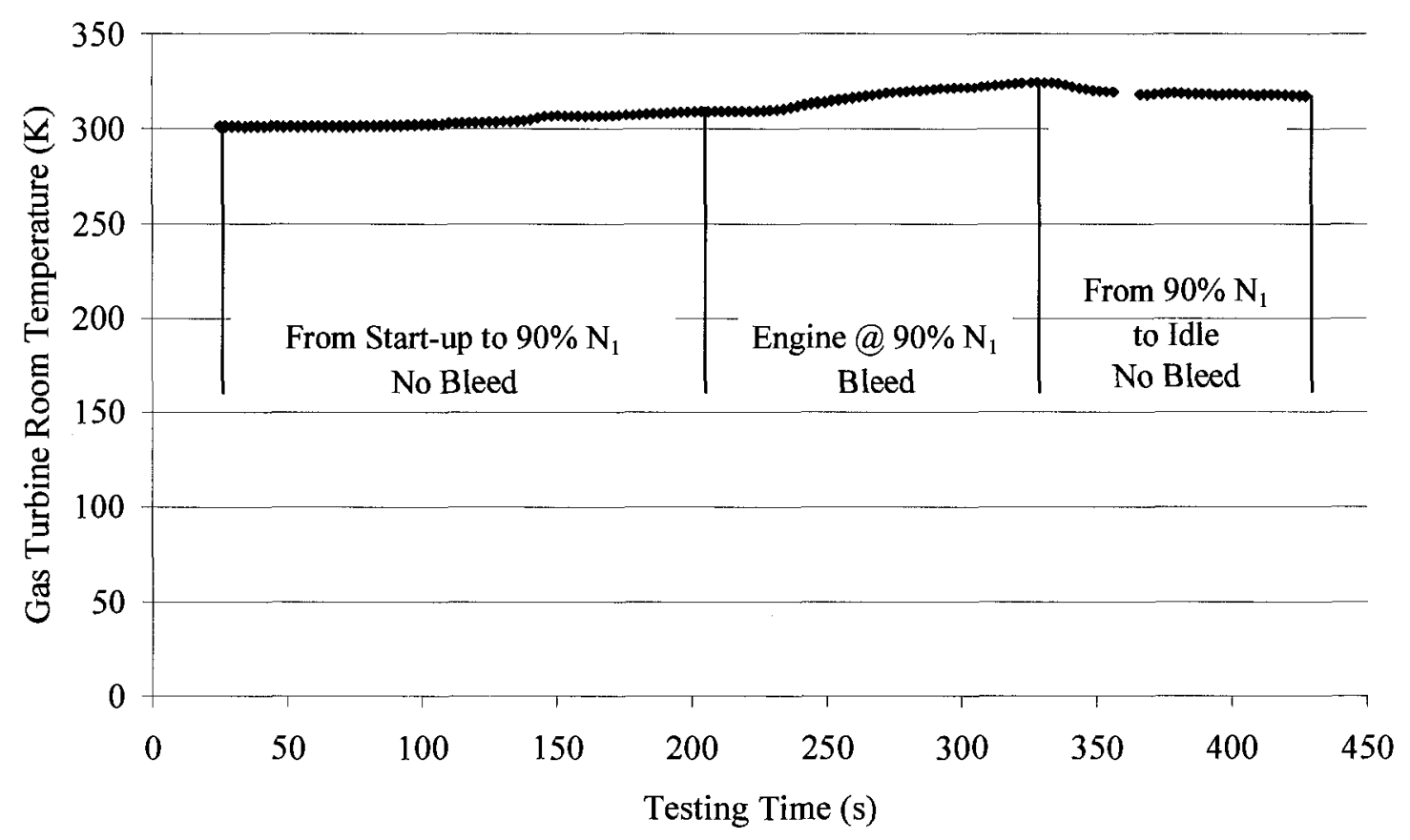

Figure 8.20 Effect of testing time on Gas Turbine Room temperature

During the first shakedown test, bleeding air from the engine caused the EGT to be pushed close to its limit (1083 K; Allison Engine Company, 1999) (Figure 8.21). The large surface area of the exhausts manifolds, which were sized to accommodate gas turbine engines up to $1 \mathrm{MW}$ power output, radiated a large amount of heat to the surrounding air. In fact, the Gas Turbine Room temperature rose from $308.7 \mathrm{~K}$ to $324.6 \mathrm{~K}$ $\left(35.6^{\circ} \mathrm{C}\right.$ to $51.5^{\circ} \mathrm{C}$ ) in 2 minutes (Figure 8.20 ). Because of this, the amount of air bled from the engine was quickly reduced to $0 \frac{\mathrm{kg}}{\mathrm{s}}$ and the Allison 250-C20B engine was brought down to idle. After a 2 minutes dwell time at idle the test was terminated by shutting down the engine. 


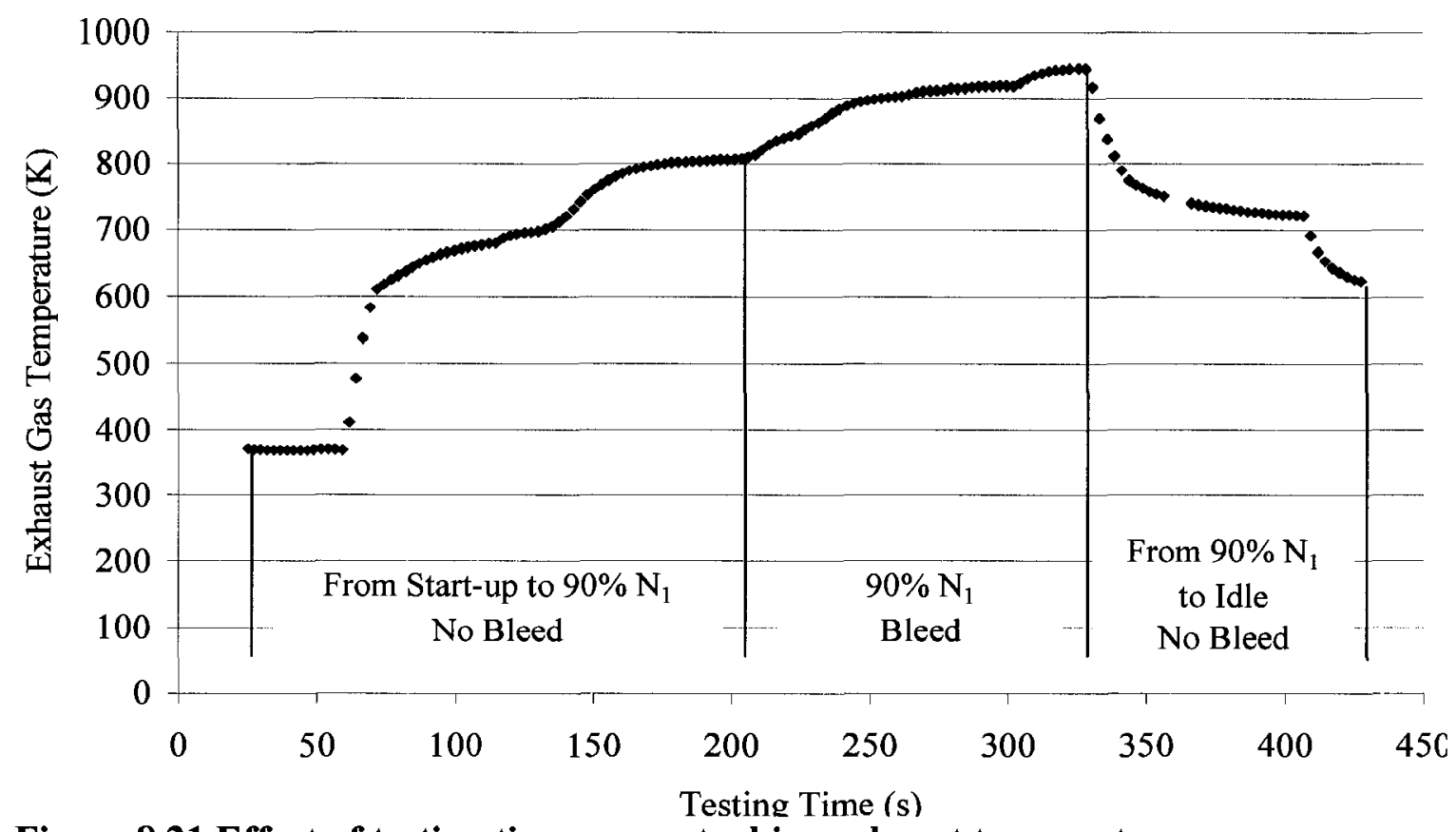

Figure 8.21 Effect of testing time on gas turbine exhaust temperature

To solve this unforeseen problem in a timely fashion, the exhaust manifolds were wrapped with vitreous aluminosilicate refractory ceramic paper. This material, which had been previously used to make gaskets for the pipe mating surfaces of the air delivery system, was readily available from Hydro Silica Gaskets and has very good insulation properties. Furthermore, the $6.4 \mathrm{~mm}$ paper could be easily cut and molded around the Allison 250-C20B exhaust manifolds. Once the exhaust manifolds were insulated testing was resumed.

Unfortunately, the second bleed test did not prove to be any more successful. The heat transfer between the exhausts and the surrounding air was reduced, however, the gas analyzer present in the test cell was set off by the smoke produced by the ceramic paper as result of the high temperatures to which it was exposed.

From the outcomes of the tests, a better, but more timely, solution is needed before further testing can be resumed. The problem encountered could be easily solved with 
proper exhaust manifolds insulation. By applying ceramic coatings on both the inner and outer surfaces of the exhaust manifolds, the amount of heat transferred to the surroundings could be greatly reduced. If, however, the coating application is not sufficient, the use of custom made high temperature blankets, such as the ones produced by companies like Worbo Incorporated (Peterborough, Canada) or Superior Energies Incorporated (Groves, USA), could further minimize or even eliminate the heat transfer to the surroundings. Because of time constraints and long lead times for applying ceramic coatings and/or high temperature blankets, the above solutions had to be regarded as recommendations for future work. 


\section{CONCLUSIONS AND RECOMMENDATIONS}

The following conclusions and recommendations are based on the research work which has been reported in the previous chapters. Specifically, with respect to the objectives outlined in Section 1.3, as well as the results discussed in Chapters 5 and 8 the following conclusions and recommendations can be drawn.

\subsection{Conclusions}

A design methodology, based on empirical and semi-empirical correlations, was developed to preliminary design conventional and lean premixed combustors which use either liquid or gaseous fuels. The use of this methodology is a starting point for any future design refining processes whether through using computer models, like CFD or CMR, or through experimentation.

Using the developed design methodology, a lean premixed, prevaporized microturbine combustor was designed and then manufactured. Even though the small size of the combustor created some fabrication difficulties, the final product was successfully completed through careful selection of manufacturing techniques.

A gas turbine combustion research laboratory was also designed and constructed. The commissioned gas turbine combustion research laboratory was demonstrated to be functional through hundreds of hours of shakedown tests. In general, the research laboratory was designed so that tests independent from combustor operating points could be carried out in an atmospheric environment, thus allowing development costs to be minimized. High pressure combustion tests could be carried out using compressed air which is bled from an Allison 250-C20B gas turbine engine. 
The following conclusions can be drawn for the constructed gas turbine combustion research laboratory:

- An Allison 250-C20B gas turbine engine was successfully modified from its original turboshaft design to an APU configuration through the removal of the power turbine.

- The Allison 250-C20B modification resulted in the elimination of a hydraulic dynamometer and its operator. Therefore, reducing future testing costs.

- The Allison 250-C20B gas turbine engine was equipped with additional instrumentation for better monitoring purposes.

- Through a fail-safe mechanism the Allison 250-C20B could automatically return to its idle operating condition in case of loss of control.

- Compressed air was successfully bled downstream of the Allison 250-C20B compressor. However, the engine exhaust manifolds will have to be properly insulated before any prolonged testing times can be carried out.

- An air delivery system was successfully designed and constructed. It could also be remotely operated and monitored under high and low pressure testing conditions.

- The air delivery system and microturbine combustor were successfully instrumented so that the combustor performance can be evaluated in the future.

- A liquid fuel delivery system was successfully designed and constructed. It could also be remotely operated and monitored. 
- The fuel delivery system reliability and response to possible emergency scenarios was extensively investigated and deemed more than acceptable.

- An operating station was successfully designed and constructed. The operating station allowed controlling the air and fuel delivery systems from a safe and remote environment.

In conclusion, the developed gas turbine combustion research laboratory has the potential to be a valuable tool for gas turbine combustion research. The careful selection of the materials used in the gas turbine combustion research laboratory also allows alternative fuels combustion research to be possible. Furthermore, the modular design of the laboratory not only allows it to be easily adapted to future combustor designs, but also permits it to test gas turbine hot section component materials and coatings.

\subsection{Recommendations}

As a result of the work conducted in this thesis, the main recommendations are:

- The developed design methodology should be regularly updated to include new empirical and semi-empirical correlations resulting from innovative research.

- The insulation of the Allison 250-C20B exhaust manifolds should be addressed before any more bleed tests are attempted.

- More bleed tests are needed to better evaluate the performance of the Allison 250-C20B and the air delivery system.

- The pitot rake should be calibrated. 
- The performance of FTB 502 low flow rate meter, purchased from Omega Engineering, should be further investigated and possibly sent back to the company for recalibration.

- The time needed to acquire all the data produced by the gas turbine combustion research laboratory could be further reduced by using a recently received DSA3217 Scanivalve pressure module. This pressure module, which can measure up to 18 pressures, could be used in combination with the Keithley 2700. This, however, would require modifying the LabView programs to reflect the changes.

- A remotely controlled traverse mechanism should be designed and constructed for both the Kiel probe and the thermocouple measuring the microturbine combustor outlet gas temperatures.

- The first combustion tests should be very conservative and done to assess the structural performance of the air delivery system and its instrumentation. Furthermore, these tests should give information on the effects of the radiative heat on the Combustion Room temperature. Corrective measures should be taken if needed.

- Tests should be conducted to assess the performance of the developed and constructed microturbine combustor. 


\section{REFERENCES}

Abramovich, G.N., 1962. Theory of Turbulent Jets. Cambridge, MA: MIT Press

Allaire, D., 2006. A Physics-Based Emissions Model for Aircraft Gas Turbine Combustors. M.Sc. Thesis, Massachusetts Institute of Technology, Cambridge, USA.

Allison Engine Company, 1999. Model 250-C20, -C20B, -C20F, -C20J, -C20W, C20S Operation and Maintenance Manual Publication No. 10W2. Sixth Edition, Third Revision.

Allison Engine Company, 1999. Model 250-C20, -C20B, -C20F, -C20J, -C20W, C20S Engine Illustrated Parts Catalogue Publication No. 10W4. Thirteenth Edition, Second Revision.

Anderson, J.D., 1995. Computational Fluid Dynamics the Basics with Application. New York: McGraw-Hill.

Anonymous, 2008. Helicopter Flight Information. Accessed: February 7, 2008. http://helicopterflight.net/engine1.jpg

ASME B31.3, 2002. Process Piping ASME Code for Pressure Piping, B31. New York: ASME.

Assanis, D.N., Filipi, Z.S., Fiveland, S.B., Symiris, M., 2003. A Predictive Ignition Delay Correlation Under Steady-State and Transient Operation of a Direct Injection Diesel Engine. Transaction of the ASME, 125 (April), 450-457

AWS A2.4-98, 1998. Standard Symbols for Welding, Brazing, and Nondestructive Examination. Miami, Fl: AWS.

AWS C5.5-80, 1980. Recommended Practices for Gas Tungsten Arc Welding. Miami, Fl: AWS.

AWS D14.6, 2005. Specification for Welding of Rotating Elements of Equipment. Miami, Fl: AWS.

Baker, R.C., 2003. Introductory Guide to Flow Measurement, (ASME Edition). New York: ASME Press.

Ballal, D.R., Lefebvre, A.H., 1972. A Proposed Method for Calculating Film-Coole Wall Temperatures in Gas Turbine Combustion Chambers. ASME Paper 72-WA/HT-24

Ballal, D.R., Lefebvre, A.H., 1981. Some Fundamental Aspects of Flame Stabilization. Pages 48.1-48.8 of: Fifth International Symposium on Airbreathing Engines. 
Beer, J.M., Chigier, N.A., 1983. Combustion Aerodynamics. Malabar, Fl: Krieger

BETE, 2007. Accessed: January 11, 2007. PJ - Smallest Physical Size, Impingement Fog, Atomizing. http://www.bete.com/products/pj.html

Bhadeshia, H.K.D.H., Honeycombe, R.W.K., 2006. Steel - Microstructure and Properties. Third Edition. Oxford, UK: Butterworth - Heinemann.

Blevins, R.D., 1984. Applied Fluid Dynamics Handbook. New York: Van Nostrand Reinhold Company.

Boyce, M.P., 2006. Gas Turbine Engineering Handbook. Third Edition. Burlington, MA: Gulf Professional Publishing.

Campbell, F.C. 2006. Manufacturing Technology for Aerospace Structural Materials. San Diego, CA: Elsevier Science and Technology Books.

Çengel, Y.A., 1997. Introduction to Thermodynamics and Heat Transfer. New York: McGraw-Hill

Charest, M.R.J., 2005. Design Methodology for a Lean Premixed Prevaporized Can Combustor. M.Sc. Thesis, Carleton University, Ottawa, Canada.

Chok, N.N., 2003. CFD Simulation of a Gas Turbine Combustor. M.Sc. Thesis, Carleton University, Ottawa, Canada.

Cumpsty, N., 2003. Jet Propulsion. Second Edition. Cambridge, UK: Cambridge University Press.

Derr, W.S., Mellor, A.M., 1990. Recent Developments. Chapter 5 of: Mellor, A.M. (ed), Design of Modern Turbine Combustors. New York: Academic Press.

Davis, J.R., (ed), 2000. Nickel, Cobalt, and Their Alloys. Materials Park, OH: ASM International.

Dodds, W.J., and Bahr, D.W., 1990. Combustion System Design. Chapter 4 of: Mellor, A.M. (ed), Design of Modern Turbine Combustors. New York: Academic Press.

Elkotb, M.M., 1982. Fuel Atomization for Spray Modeling. Progress in Energy and Combustion Science, 8 (1), 61-91

FLUENT Inc., 1998. Fluent 5 Documentation. 10 Cavendish Court, Lebanon, NH 03766

Fox, R.W., McDonald, A.T., 1994. Introduction to Fluid Mechanics. Second Edition. New York: John Wiley \& Sons, Inc. 
Fox, R.O., 2003. Computational Models for Turbulent Reacting Flows. Cambridge, UK: Cambridge University Press

Freeman, B.C., 1965. Discharge Coefficients of Combustion Chamber Dilution Holes. M.Sc. Thesis, College of Aeronautics, Cranfield, England

Gauthier, J.E.D., 2005. Gas Turbine Combustion. Carleton University, Ottawa. Lecture Notes for MECH 5400

Gauthier, J.E.D., Bardon, M.F., Rao, V.K., 1996. General Flame Propagation Model for Fuel Droplet, Particle and Vapour Mixtures in Air. Journal of the Institute of Energy, 69 (June), 59-67.

Gauthier, J.E.D., 2005. Gas Turbines. Carleton University, Ottawa. Lecture Notes for MECH 5402.

Gauthier, J.E.D., 2007. Gas Turbine Combustion. Carleton University, Ottawa. Lecture Notes for MECH 5400

Gülder, Ö.L., 1986. Flame Temperature Estimation of Conventional and Future Fuel Jets. Transaction of the ASME, 108, 376-380

Gunstone, B., (ed), 2004. The Cambridge Aerospace Dictionary. Cambridge, UK: Cambridge University Press.

Haas, D.W., 1996. The Instrumentation Design and Control of a T63-A-700 Gas Turbine Engine. M.Sc. Thesis, Naval Postgraduate School, Monterey, California.

Hallett, W.L.H., 2003. Combustion in Diffusion Systems. University of Ottawa, Ottawa, Lecture Notes for MCG 5192.

Hansen, G.A., Douglass, R.W., Zardecki, A., 2005. Mesh Enhancement-Selected Elliptic Methods Foundation and Applications. London: Imperial College Press

Hewitt, G.F., Vassilicos, J.C., 2005. Prediction of Turbulent Flow. Cambridge, UK: Cambridge University Press

Jamesbury, 2003. Series 815 ANSI Class 150 and Series 830 ANSI Class 300 WaferSphere ${ }^{\circledR}$ High performance Butterfly Valves. Shrewsbury, Ma: Metso Automation.

Jiang, L.Y., Campbell, I., 2005. Turbulence Modeling in a Modern Combustor. ASME Paper GT2005-68403 
Jiang, L.Y., Campbell, I., 2007. Reynolds Analog in Combustor Modeling. ASME Paper GT2007-27017

Kaddah, K.S., 1964. Discharge Coefficients and Jet Deflection Angles for Combustor Liner Air Entry Holes. M. Sc. Thesis, College of Aeronautics, Cranfield, England

Kee, R. J., Rupley, F. M., Miller, J. A., Coltrin, M. E., Grcar, J. F., Meeks, E., Moffat, H. K., Lutz, A. E., Dixon-Lewis, G., Smooke, M. D., Warnatz, J., Evans, G. H., Larson R. S., Mitchell, R. E., Petzold, L. R., Reynolds, W. C., Caracotsios, M., Stewart, W. E., Glarborg, P., Wang, C., McLellan, C. L., Adigun, O., Houf, W. G., Chou, C. P., Miller, S. F., Ho, P., Young, P. D., Young, D. J., Hodgson, D. W., Petrova, M. V., Puduppakkam, K. V., 2006. Chemkin Release 4.1, San Diego, CA: Reaction Design.

Kilik, E., 1976. The Influence of Swirler Design Parameters on the Aerodynamics of the Downstream Recirculation Region. Ph.D. Thesis, School of Mechanical Engineering, Cranfield Institute of Technology.

Klein, A., 1995. Characteristics of Combustor Diffusers. Progress in Aerospace Science, 31(3), 171-271.

Kolanowsky, B. F., 2004. Guide to Microturbines. Lilburn, GA: Fairmont Press Inc.

Kretschmer, D. 2000. Le Foyer de la Turbine à Gaz. Laval University, Quebec City. Lecture Notes for GMC-65435.

Kurzke, J., 2005. GasTurb 10. Max Feldbaurer Weg 5, 85221, Dachau, Germany

LANL, 2005. Process Piping Guide. Accessed: October 11, 2005. http://library.lanl.gov/infores/stand/

Lefebvre, A.H. 1999. Gas Turbine Combustion. Second Edition. London: Taylor \& Francis.

Mahallati, A., 2003. Aerodynamics of a Low-Pressure Turbine Airfoil Under Steady and Periodically Unsteady Conditions. Ph.D. Thesis, Carleton University, Ottawa, Canada.

Matthews, C., 2005. ASME Engineer's Data Book. Second Edition. New York: ASME Press.

Mattingly, J.D., Heiser, W.H., Pratt, D.T. 2002. Aircraft Engine Design. Second Edition. Reston, VA: AIAA Education Series

Mellor, A.M., (ed), 1990. Design of Modern Turbine Combustors. London: Academic Press 
Mongia, H.C., 2003. Data Reduction Analysis (DRA) fir Emissions and Lean Blowout Part 1: Mostly Empirical Analysis (MEA). AIAA Paper 2003-0822

Murphy, C.M., 2004. Design and Construction of a Gas Turbine Combustor Test Rig for Alternative Fuel Testing. M.Sc. Thesis, Carleton University, Ottawa, Canada.

Nayyar, M.L., 2000. Piping Handbook. New York: McGraw-Hill

Nukiyama, S., Tanasawa, Y., 1939. Experiments on the Atomization of Liquids in an Airstream. Transaction of the ASME, 5, 68-75

Olikara, C., Borman, G.L., 1975. A Computer Program for Calculating Properties of Equilibrium Combustion Products with Some Applications to I. C. Engines. SAE Paper 750468

Omega Engineering, 2004. The Temperature Measurement Handbook and Encyclopedia. Volume MMV

Omega Engineering, 2000. The Pressure, Strain and Force Handbook and Encyclopedia. Volume MM.

Ower, E., Pankhurst R.C., 1977. The Measurement of Air Flow. Fifth edition. New York: Pergamon Press.

Peters, J.E., Hammond, D.C., 1990. Combustion System Design. Chapter 1 of: Mellor, A.M. (ed), Introduction to Combustion for Gas Turbines. New York: Academic Press.

Poeshl, G., Runhkamp, W., Pfost, H., 1994. Combustion with Low Pollutant Emissions of Liquid Fuels in Gas Turbines by Premixing and Prevaporization. ASME Paper 94GT-443

Poinsot, T., Veynante, D., 2001. Theoretical and Numerical Combustion. Philadelphia: R.T. Edwards, Inc.

Ranz, W.E., Marshall, W.R., 1952. Evaporation from Drops. Parts I \& II. Chemical Engineering Program, 48, 141-146; 173-180.

Reed, R.C., 2006. The Superalloys Fundamentals and Applications. Cambridge, UK: Cambridge University Press

Rizk, N.K., Chin, J.S., Marshall, A.W., Razdan, M.K., 2002. Prediction of NOx Formation Under Combined Droplet and Partially Premixed Reaction of Diffusion Flame Combustors. Journal of Engineering for Gas Turbines and Power, 124 (July), 31-38. 
Rolls-Royce plc., 1996. The Jet Engine. Fifth Edition. Derby: The Technical Publications Department Rolls-Royce plc.

Rolls-Royce plc., 2004. Model 250. Accessed: December 11, 2007. http://www.rolls-royce.com/civil_aerospace/products/regional/model250/description.jsp

Rosin, P., Rammler, E., 1933. The Laws Governing the Fineness of Powder Coal. Journal of Institute of Fuel, 7 (31), 29-36

Russo, C., Mori, G., Parente, J., 2007. Micro Gas Turbine Combustor Emissions Evaluation Using the Chemical Reactor Modelling Approach. ASME Paper GT200727687.

Saravanamuttoo, H.I.H., (ed), 1990. Recommended Practices for Measurement of Gas Path Pressures and Temperatures for Performance Assessment of Aircraft Turbine Engines and Components. AGARD Advisory Report No. 245

Saravanamuttoo, H.I.H., Rogers, G.F.C., Cohen, H. 2001. Gas Turbine Theory. Fifth Edition. New York: Prentice Hall.

Sawyer, J.W., (ed), 1985. Sawyer's Gas Turbine Engineering Handbook. Third Edition. Norwalk, CT: Turbomachinery International Publications.

Schneider, E., Sadiki, A., Maltsev, A., Janicka, J., 2007. Numerical Study of the Precessing Vortex Core in a Confined Partially Premixed Swirl Combustion System. ASME Paper GT2007-27272.

Smith, P., Zappe R.W., 2004. Valve Selection Handbook - Engineering Fundamentals for Selecting the Right Valve Design for Every Flow Application. Fifth Edition. New York: Gulf Professional Publishing.

Spincraft, 2007. What is metal spinning? Accessed: December 10, 2007. www.spincraft.net/metalspin.htm

Swagelok, 2003. Tubing Data. Miami: Swagelok Company

Taylor, J.R., 1978. Experimental Clean Combustor Program - Phase III, Turbulence Measurement Addendum. NASA CR-135422

Tsague, L., Tatieste, T.T., Ngundam, J., Tsogo, J., 2007. Prediction of Emissions in Turbojet Engines Exhausts: Relationship between Nitrogen Oxides Emission Index $\left(\mathrm{EI}_{\mathrm{NOx}}\right)$ and the Operational Parameters. Aerospace Science and Technology, 11 (2007), 459-463.

Tschaetsch, H., 2006. Metal Forming Practice Processes - Machines - Tools. New York: Springer 
Turns, S.R., 2000. An Introduction to Combustion: Concepts and Applications. Second Edition. New York: McGraw-Hill.

United Sensors, 2005. Kiel Probes General Information. Accessed: May 10, 2005 http://www.unitedsensorcorp.com/kiel.html

Wanner Engineering, 2002. Instruction Manual Installation - Operation Parts - Service Models: C-62-A; C-62-D. Minneapolis: Wanner Engineering, Inc.

Weman, K., 2003. Welding Process Handbook. New York: CRC Press.

White, F.M., 1999. Fluid Mechanics. Fourth Edition. New York: McGraw-Hill.

Winterfeld, G., Eickhoff, H.E., Depooter, K., 1990. Combustion System Design. Chapter 3 of: Mellor, A.M. (ed), Design of Modern Turbine Combustors. New York: Academic Press. 
APPENDIX A : EXAMPLE OF MICROTURBINE COMBUSTOR TECHNICAL DRAWING 


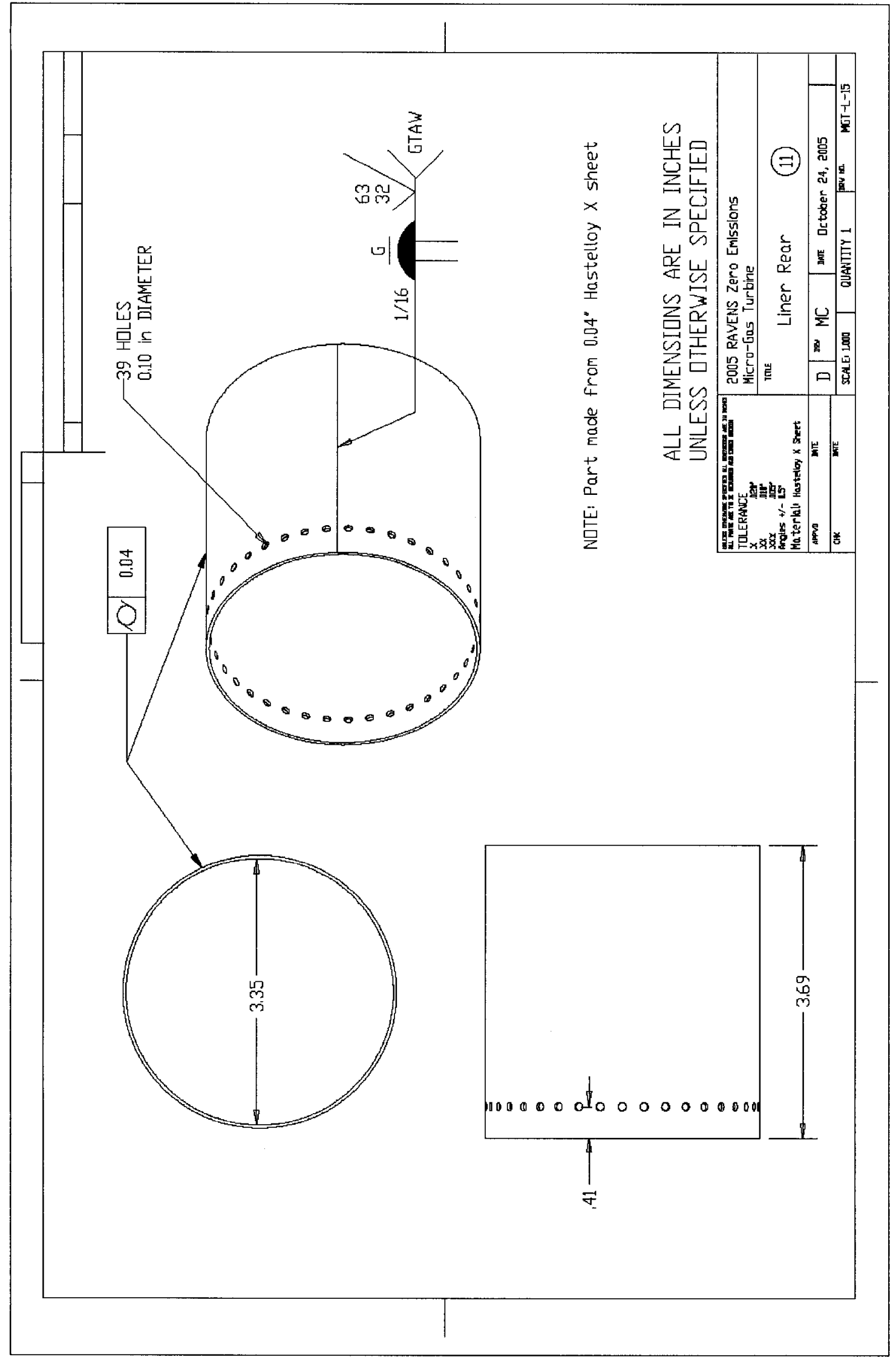


APPENDIX B : MATERIALS PROPERTIES 


\section{Hastelloy X}

\section{TYPICAL PHYSICAL PROPERTIES}

Temperature, ${ }^{\circ} \mathrm{F}$ British Units Temperature, ${ }^{\circ} \mathrm{C}$ Metric Units

\begin{tabular}{|c|c|c|c|c|}
\hline Density & 72 & $0.297 \mathrm{lb} / \mathrm{in}^{3}$ & 22 & $8.22 \mathrm{~g} / \mathrm{cm}^{3}$ \\
\hline Melting Range & $2300-2470$ & & $1260-1355$ & \\
\hline Electrical Resistivity & 72 & $\begin{array}{r}46.6 \text { microhm-in. } \\
\text { (712 ohms per cir. mil-ft.) }\end{array}$ & 22 & $1.18 \mathrm{microhm}-\mathrm{cm}$ \\
\hline \multirow[t]{7}{*}{ Thermal Conductivity } & 70 & 63 Btu-in. $/ \mathrm{ft}^{2}$ hr.- $\mathrm{F}$ & 21 & $9.1 \mathrm{~W} / \mathrm{m}-\mathrm{K}$ \\
\hline & 200 & 76 Btumin. $/ \mathrm{ft}^{2}{ }^{2} \mathrm{hr} .{ }^{\circ} \mathrm{F}$ & 93 & $11.0 \mathrm{~W} / \mathrm{m}-\mathrm{K}$ \\
\hline & 500 & 98 Btu-in. fft. $^{2}$ hr. $-{ }^{\circ} \mathrm{F}$ & 200 & $14.1 \mathrm{~W} / \mathrm{m}-\mathrm{K}$ \\
\hline & 1100 & $1448 t u-i n . / \mathrm{ft}^{2} \mathrm{hr} .{ }^{\circ} \mathrm{F}$ & 593 & $20.8 \mathrm{~W} / \mathrm{m}-\mathrm{K}$ \\
\hline & 1300 & 159 Btu-in. $/ \mathrm{ft}^{2} \mathrm{hr} .{ }^{\circ} \mathrm{F}$ & 704 & $22.9 \mathrm{~W} / \mathrm{m}-\mathrm{K}$ \\
\hline & 1500 & 174 Btu-in./ft. ${ }^{2}$ hr. ${ }^{\circ} \mathrm{F}$ & 816 & $25.1 \mathrm{~W} / \mathrm{m}-\mathrm{K}$ \\
\hline & 1700 & $189 \mathrm{Btu}-\mathrm{in} . / \mathrm{ft}^{2} \mathrm{hr} \cdot{ }^{\circ} \mathrm{F}$ & 927 & $27.2 \mathrm{~W} / \mathrm{m}-\mathrm{K}$ \\
\hline \multirow[t]{11}{*}{ Specific Heat } & Room & $0.116 \mathrm{Btu} / \mathrm{lb} . \mathrm{-}^{\circ} \mathrm{F}$ & Room & $486 \mathrm{~J} / \mathrm{Kg}-\mathrm{K}$ \\
\hline & 200 & $0.117 \mathrm{Btu} / \mathrm{lb} . .^{\circ} \mathrm{F}$ & 93 & $490 \mathrm{~J} / \mathrm{Kg}-\mathrm{K}$ \\
\hline & 400 & 0.118 Btu/lb. $=\mathrm{F}$ & 204 & $494 \mathrm{~J} / \mathrm{Kg}-\mathrm{K}$ \\
\hline & 600 & 0.119 Btu/lb. ${ }^{\circ} \mathrm{F}$ & 316 & $498 \mathrm{~J} / \mathrm{Kg}-\mathrm{K}$ \\
\hline & 800 & 0.123 Btu/lb. ${ }^{\circ} \mathrm{F}$ & 427 & $515 \mathrm{~J} / \mathrm{Kg}-\mathrm{K}$ \\
\hline & 1000 & $0.130 \mathrm{Btu} / \mathrm{lb} .-^{\circ} \mathrm{F}$ & 538 & $544 \mathrm{~J} / \mathrm{Kg}-\mathrm{K}$ \\
\hline & 1200 & $0.139 \mathrm{Btu} / \mathrm{lb} .{ }^{\circ} \mathrm{F}$ & 649 & $582 \mathrm{~J} / \mathrm{Kg}-\mathrm{K}$ \\
\hline & 1400 & $0.151 \mathrm{Btu} / \mathrm{lb} .-^{\circ} \mathrm{F}$ & 760 & $632 \mathrm{~J} / \mathrm{Kg}-\mathrm{K}$ \\
\hline & 1600 & 0.167 Btu/lb. ${ }^{\circ} \mathrm{F}$ & 871 & $699 \mathrm{~J} / \mathrm{Kg}-\mathrm{K}$ \\
\hline & 1800 & $0.186 \mathrm{Btu} / \mathrm{lb} . \mathrm{m}^{\circ} \mathrm{F}$ & 982 & $799 \mathrm{~J} / \mathrm{Kg}-\mathrm{K}$ \\
\hline & 2000 & 0.205 Btu/lb. $-{ }^{\circ} \mathrm{F}$ & 1093 & $858 \mathrm{~J} / \mathrm{Kg}-\mathrm{K}$ \\
\hline \multirow{7}{*}{$\begin{array}{l}\text { Mean Coefficient of } \\
\text { Thermal Expansion }\end{array}$} & $79-200$ & 7.7 microinches $/$ in. $-{ }^{\circ} \mathrm{F}$ & $26-93$ & $13.910^{-6} \mathrm{~m} / \mathrm{m}-{ }^{\circ} \mathrm{C}$ \\
\hline & $79-1000$ & 8.4 microinches/in. ${ }^{\circ} \mathrm{F}$ & $26-538$ & $15.110^{-6} \mathrm{~m} / \mathrm{m}-{ }^{\circ} \mathrm{C}$ \\
\hline & $79-1200$ & 8.6 microinches $/$ in. ${ }^{\circ} \mathrm{F}$ & $26-649$ & $15.510^{-6} \mathrm{~m} / \mathrm{m}-^{\circ} \mathrm{C}$ \\
\hline & $79-1350$ & 8.8 microinches/in.- ${ }^{\circ} \mathrm{F}$ & $26-732$ & $15.810^{-8} \mathrm{~m} / \mathrm{m}={ }^{\circ} \mathrm{C}$ \\
\hline & 79.1500 & 8.9 microinches $/ \mathrm{in} .{ }^{\circ} \mathrm{F}$ & $26-816$ & $16.010^{-6} \mathrm{~m} / \mathrm{m}-{ }^{\circ} \mathrm{C}$ \\
\hline & $79-1650$ & 9.1 microinches $/$ in. ${ }^{\circ} \mathrm{F}$ & $26-899$ & $16.410^{-6} \mathrm{~m} / \mathrm{m}-{ }^{\circ} \mathrm{C}$ \\
\hline & $79-1800$ & 9.2 microinches/in.- ${ }^{\circ} \mathrm{F}$ & $26-982$ & $16.610^{-6} \mathrm{~m} / \mathrm{m}-{ }^{\circ} \mathrm{C}$ \\
\hline Poisson's & -108 & 0.328 & -78 & 0.328 \\
\hline Ratio & 72 & 0.320 & 22 & 0.320 \\
\hline $\begin{array}{l}\text { Magnetic } \\
\text { Permeability }\end{array}$ & Room & & at 200 oers & $5,900 \mathrm{~A} / \mathrm{m})$ \\
\hline
\end{tabular}




\section{Stainless Steel 316L}

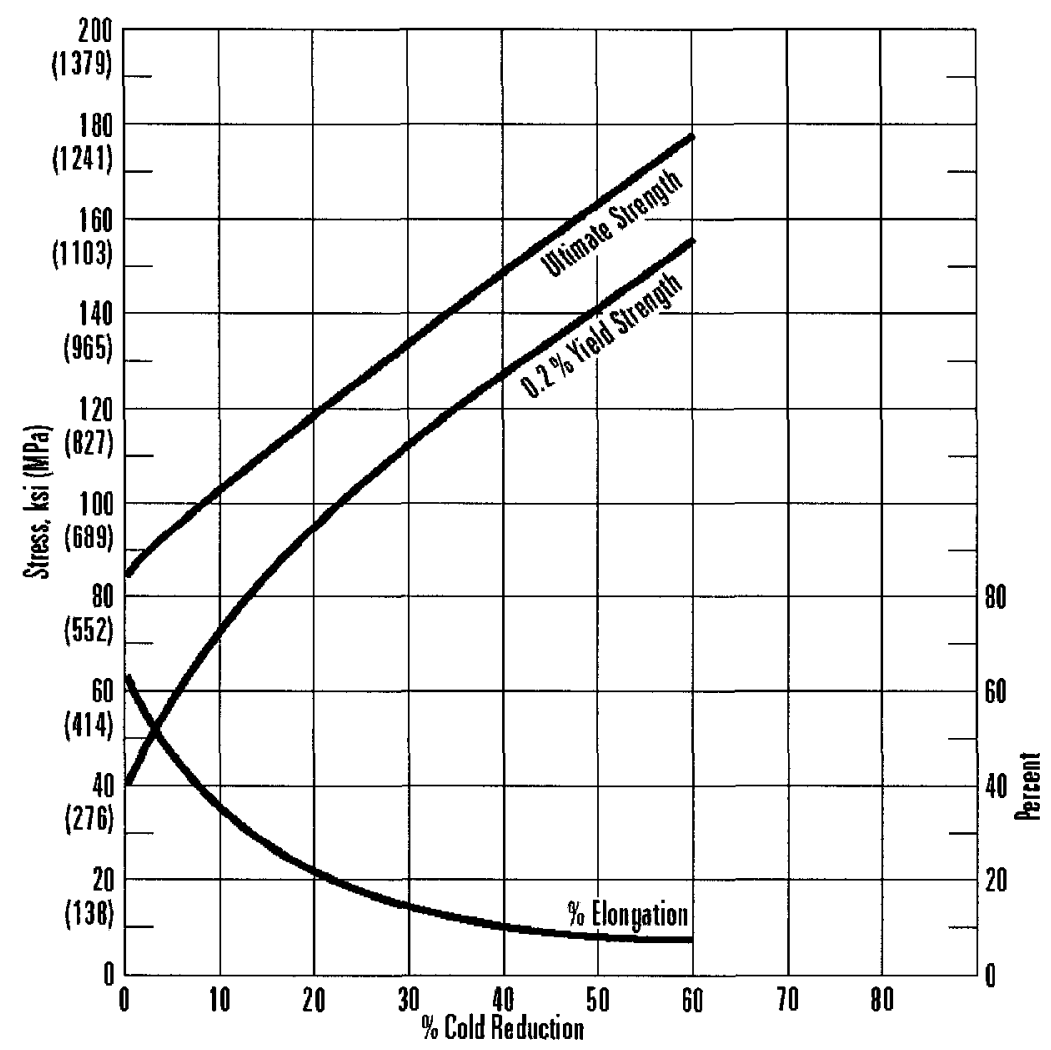

Physical Properties

Density, $0.29 \mathrm{lbs} / \mathrm{in}^{3}$

\section{$7.99 \mathrm{~g} / \mathrm{cm}^{3}$}

Electrical Resistivity, microhm-in (microhm-cm) $68^{\circ} \mathrm{F}\left(20^{\circ} \mathrm{C}\right)-29.4(74)$

Specific Heat, BTU//b/F $(\mathrm{kJ} / \mathrm{kg} \cdot \mathrm{K})$ 32 - $212^{\circ} \mathrm{F}\left(0-100^{\circ} \mathrm{C}\right)-0.12(0.50)$

Thermal Conductivity, BTU/hr/ft/ $/ \mathrm{tt} /{ }^{\circ} \mathrm{F}(\mathrm{W} / \mathrm{m} \cdot \mathrm{K})$ at $212^{\circ} \mathrm{F}\left(100^{\circ} \mathrm{C}\right)-9.4(16.2)$ at $932^{\circ} \mathrm{F}\left(500^{\circ} \mathrm{C}\right)-12.4(21.4)$

Mean Coefficient of Thermal Expansion, $\mathrm{in} / \mathrm{in} /{ }^{\circ} \mathrm{F}(\mu \mathrm{m} / \mathrm{m} \cdot \mathrm{K})$

32- $212^{\circ} \mathrm{F}\left(0-100^{\circ} \mathrm{C}\right)-8.9 \times 10^{-6}(16.0)$

32- $600^{\circ} \mathrm{F}\left(0-315^{\circ} \mathrm{C}\right)-9.0 \times 10^{-6}(16.2)$

32 - $1000^{\circ} \mathrm{F}\left(0-538^{\circ} \mathrm{C}\right)-9.7 \times 10^{-6}(17.5)$

32 - $1200^{\circ} \mathrm{F}\left(0-649^{\circ} \mathrm{C}\right)-10.3 \times 10^{-6}(18.5)$

32 - $1500^{\circ} \mathrm{F}\left(0-871^{\circ} \mathrm{C}\right)-11.1 \times 10^{-6}(19.9)$
Modulus of Elasticity, ksi (MPa) $28.0 \times 10^{3}\left(193 \times 10^{3}\right)$ in tension $11.2 \times 10^{3}\left(77 \times 10^{3}\right)$ in torsion

Magnetic Permeability, $\mathrm{H}=200$ Oersteds Annealed - 1.02 max.

Melting Range, ${ }^{\circ}\left({ }^{\circ} \mathrm{C}\right)-2500-2550$ (1371 - 1399) 


\section{APPENDIX C : BETE PJ MODEL INFORMATION}

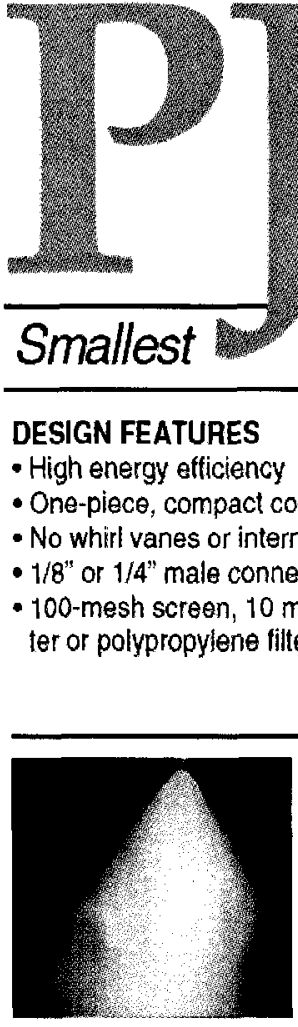

Fog

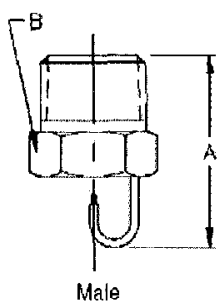

Male

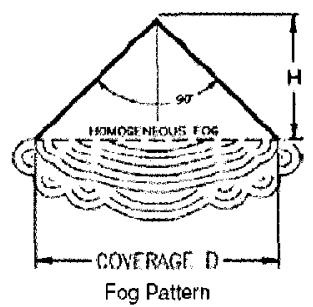

Fog Pattern

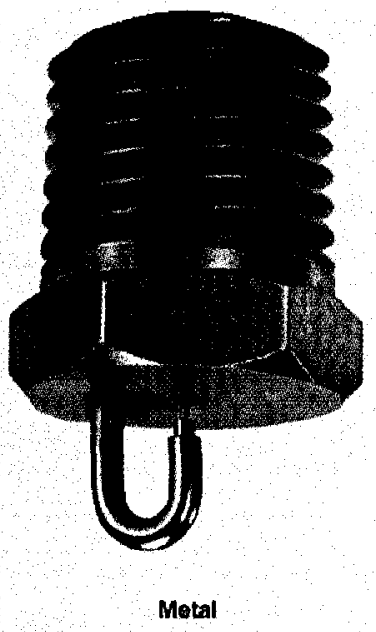

operate nozzle at or above 4 bar

Flow rates: $0.043105 .341 / \mathrm{min}$

SPRAY CHARACTERISTICS

- Finest fog of any direct pressure nozzle

- Produces high percentage of droplets under 50 microns

Spray pattern: Cone-shaped Fog

Spray angle: $90^{\circ}$. For best $90^{\circ}$ pattern

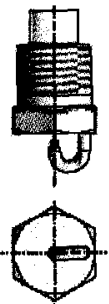

PJ with polypropylene filter 


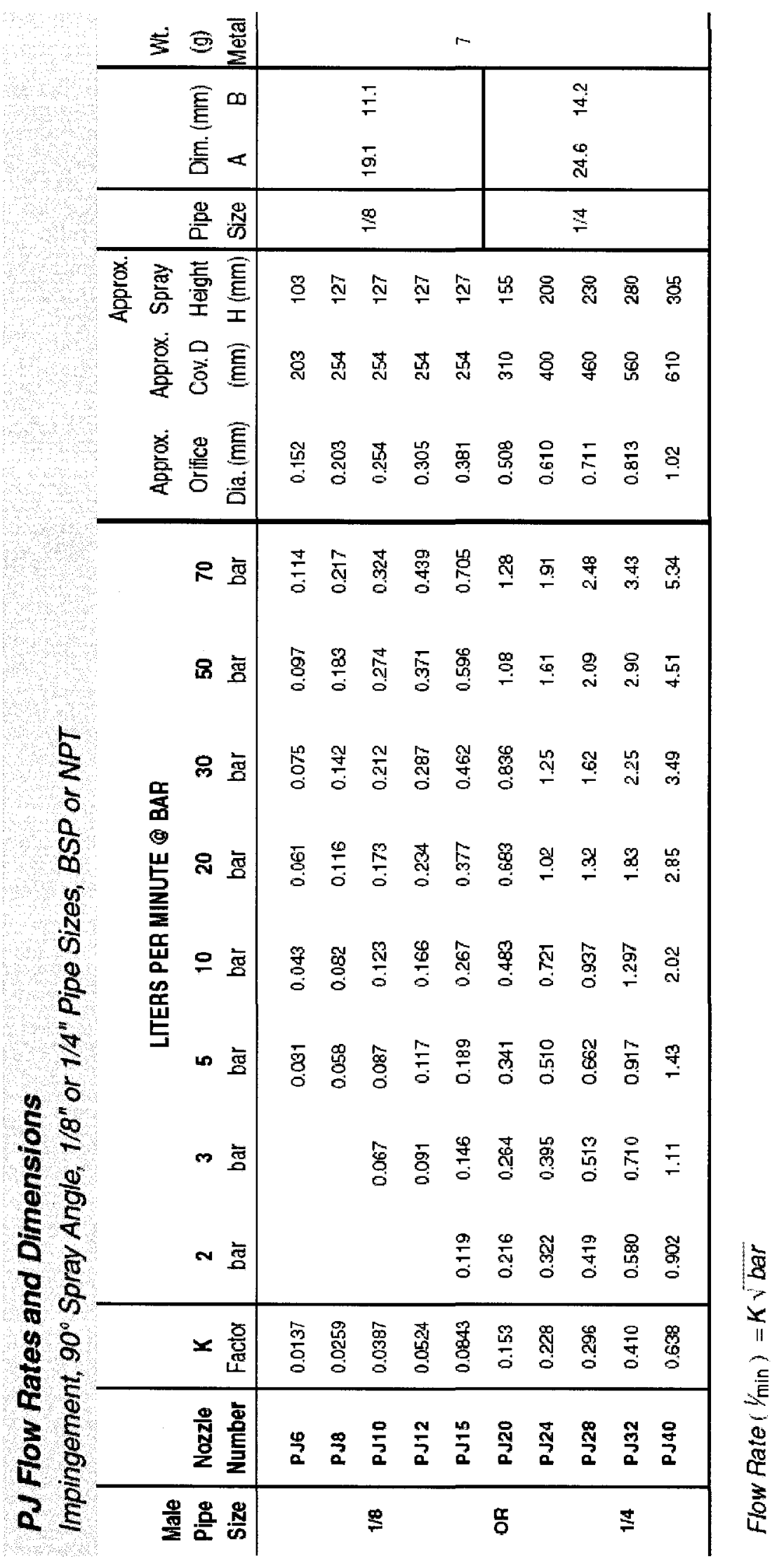




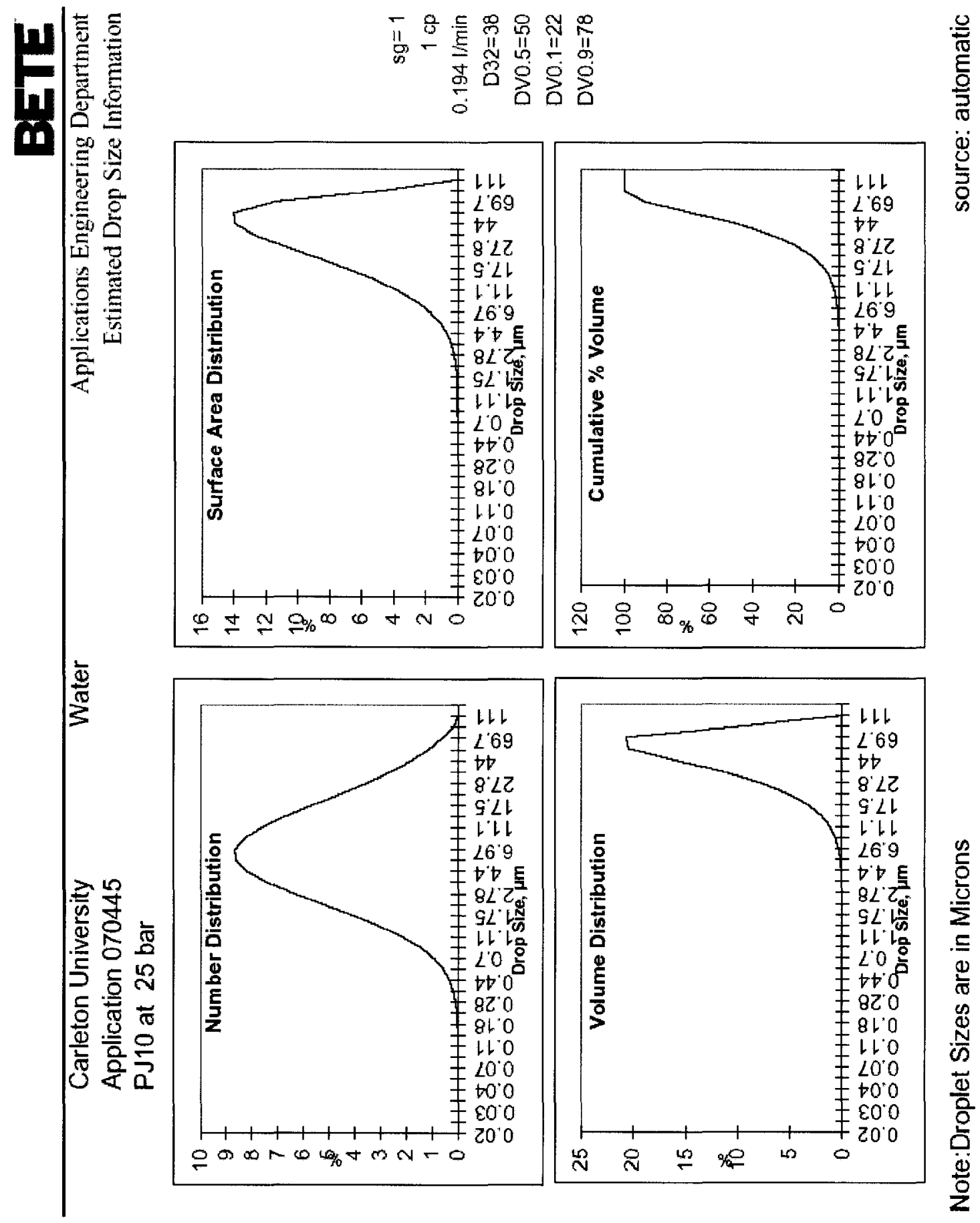




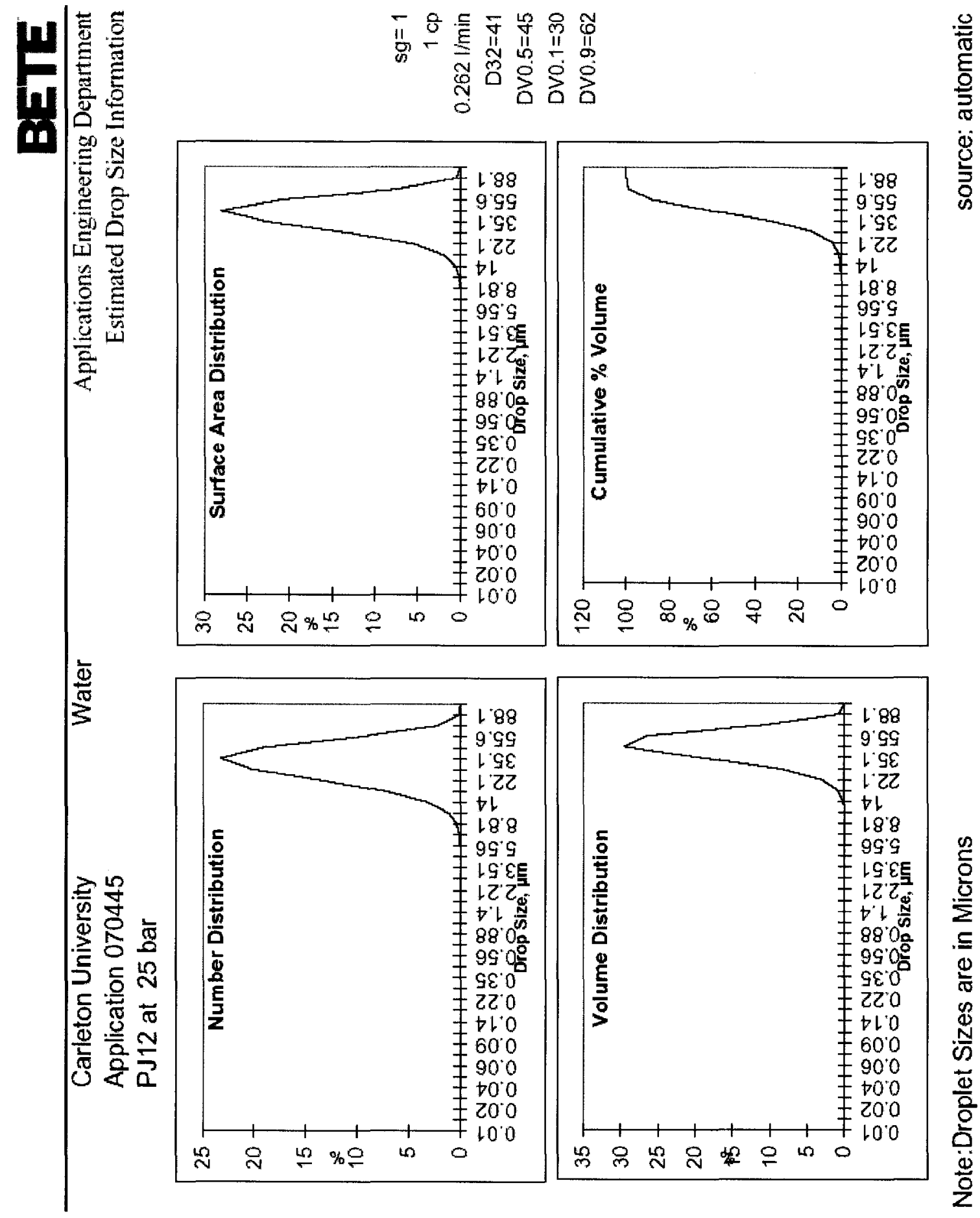



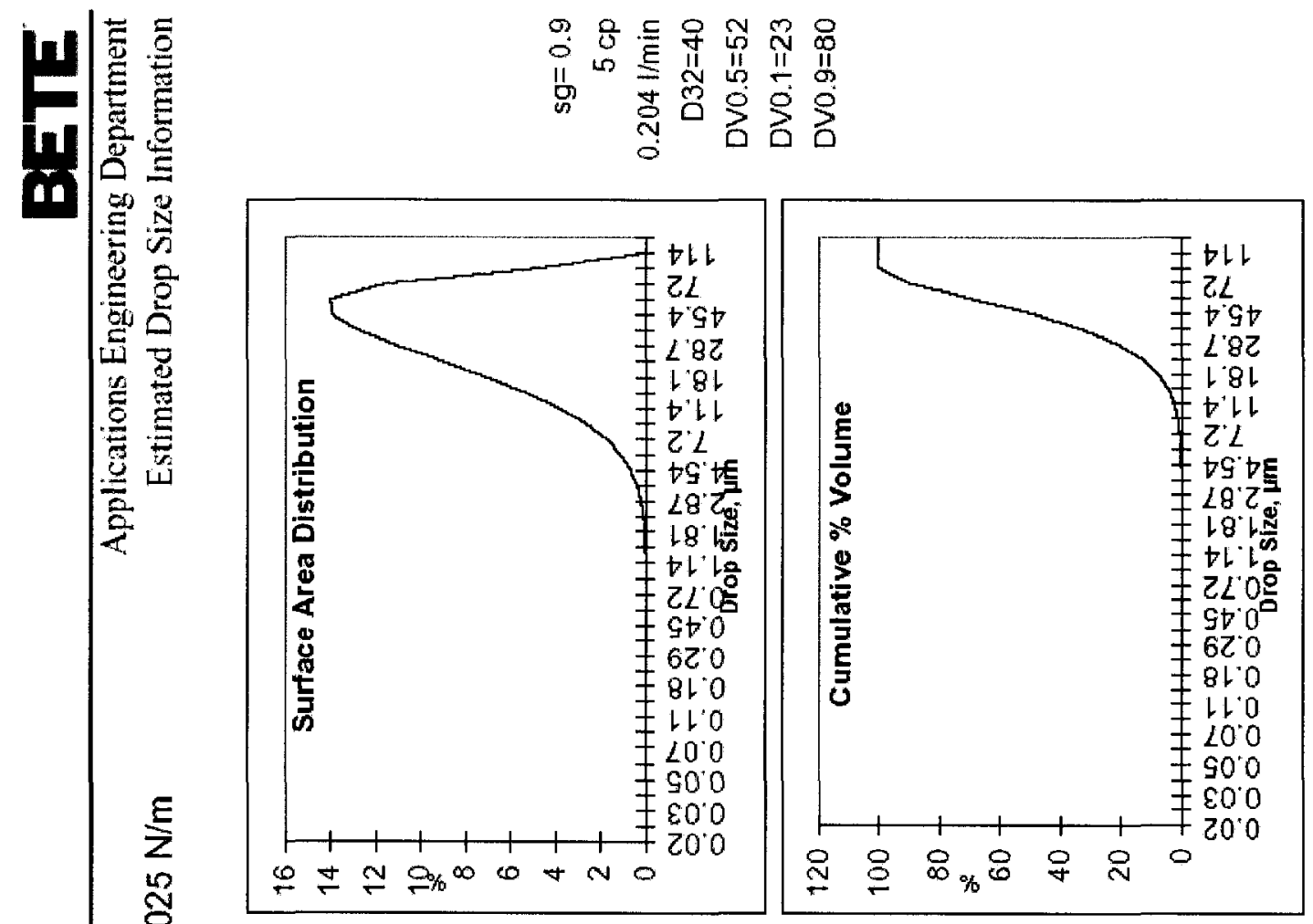

ঠ్

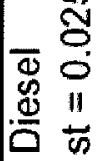
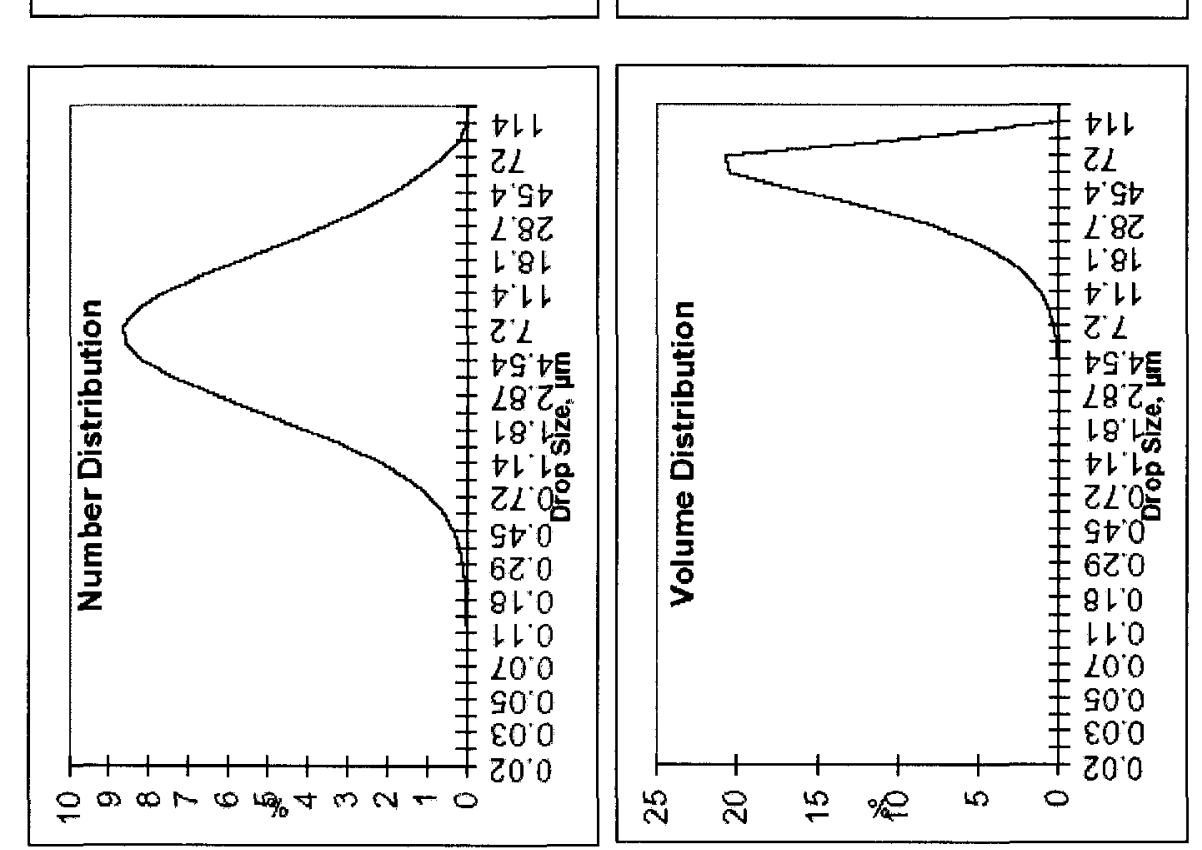

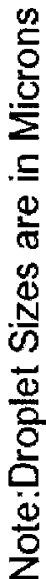




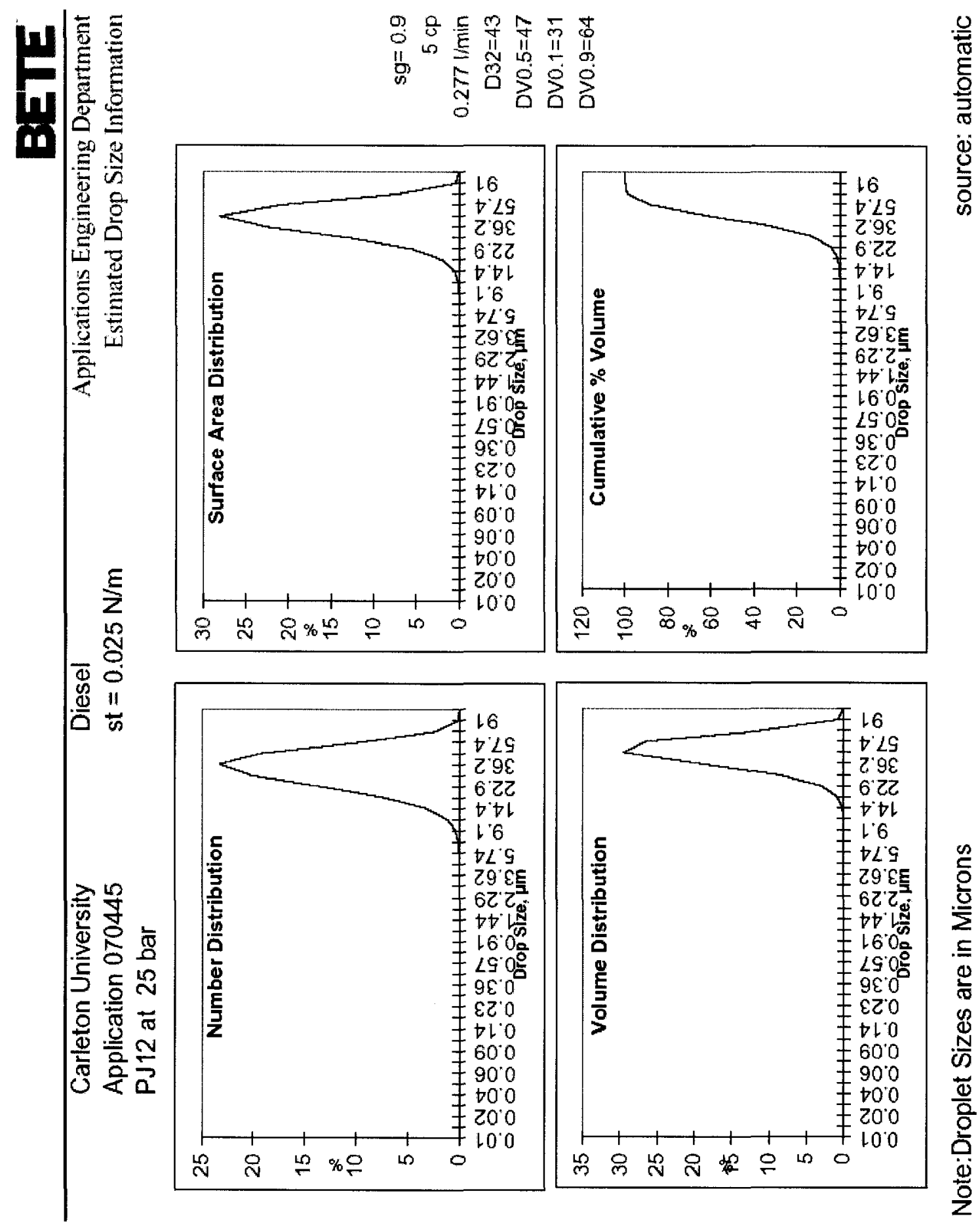




\section{APPENDIX D : STAINLESS STEEL PIPE DIAMETERS}

\begin{tabular}{|c|c|c|c|c|c|}
\hline \multirow{2}{*}{$\begin{array}{c}\text { nominal pipe size outside } \\
\text { diameter } \\
\text { in }\end{array}$} & \multicolumn{3}{|c|}{ schedule } & \multirow{2}{*}{$\begin{array}{c}\text { wall thick-ness } \\
\text { in } \\
\text { mm }\end{array}$} & \multirow{2}{*}{$\begin{array}{c}\text { inside diameter } \\
\text { in } \\
\mathbf{m m} \\
\end{array}$} \\
\hline & $\mathbf{a}$ & b & c & & \\
\hline \multirow{6}{*}{$\begin{array}{c}2 \\
2.375 \\
\mathbf{6 0 . 3 2 5}\end{array}$} & \multirow{2}{*}{ "-" } & \multirow{2}{*}{ "-" } & \multirow{2}{*}{$10 S$} & 0.154 & 2.067 \\
\hline & & & & 3.912 & 52.502 \\
\hline & \multirow{2}{*}{40} & \multirow{2}{*}{ Std } & \multirow{2}{*}{$40 \mathrm{~S}$} & 0.218 & 1.939 \\
\hline & & & & 5.537 & 49.251 \\
\hline & \multirow{2}{*}{80} & \multirow{2}{*}{$\mathrm{XS}$} & \multirow{2}{*}{$80 \mathrm{~S}$} & 0.343 & 1.689 \\
\hline & & & & 8.712 & 42.901 \\
\hline \multirow{6}{*}{$\begin{array}{c}21 / 2 \\
2.875 \\
\mathbf{7 3 . 0 2 5}\end{array}$} & \multirow[t]{2}{*}{ "-" } & \multirow[t]{2}{*}{ "_" } & \multirow{2}{*}{$10 S$} & 0.12 & 2.635 \\
\hline & & & & 3.048 & 66.929 \\
\hline & \multirow{2}{*}{40} & \multirow{2}{*}{ Std } & \multirow{2}{*}{$40 S$} & 0.203 & 2.469 \\
\hline & & & & 5.156 & 62.713 \\
\hline & \multirow{2}{*}{80} & \multirow{2}{*}{ XS } & \multirow{2}{*}{$80 \mathrm{~S}$} & 0.276 & 2.323 \\
\hline & & & & 7.010 & 59.004 \\
\hline & "_" & "n" & $10 \mathrm{~S}$ & 0.12 & 3.26 \\
\hline & $=$ & & IOS & 3.048 & 82.804 \\
\hline 3.5 & 40 & Std & $40 \mathrm{~S}$ & 0.216 & 3.068 \\
\hline & 40 & sid & SUS & 5.486 & 77.927 \\
\hline & 80 & XS & $80 \mathrm{~S}$ & 0.3 & 2.9 \\
\hline & 00 & AS & ous & 7.620 & 73.660 \\
\hline & " " & " " & $10 \mathrm{~s}$ & 0.188 & 4.124 \\
\hline $31 / 2$ & $="$ & $-\cdots$ & IOS & 4.775 & 104.750 \\
\hline 4 & 40 & Std & $40 \mathrm{~S}$ & 0.226 & 3.548 \\
\hline 101.6 & 40 & Did & SUS & 5.740 & 90.119 \\
\hline & 80 & XS & $80 \mathrm{~S}$ & 0.318 & 3.364 \\
\hline & 00 & As & ous & 8.077 & 85.446 \\
\hline & " " & " & $10 \mathrm{~s}$ & 0.12 & 4.26 \\
\hline 4 & - & - & IOS & 3.048 & 108.204 \\
\hline 4.5 & 40 & Std & $40 S$ & 0.237 & 4.026 \\
\hline 114.3 & 40 & sud & Sטי & 6.020 & 102.260 \\
\hline & 80 & XS & 805 & 0.337 & 3.826 \\
\hline & 00 & As & ous & 8.560 & 97.180 \\
\hline & "_" & "_" & $10 \mathrm{~S}$ & 0.134 & 5.295 \\
\hline 5 & " & -1 & IOS & 3.404 & 134.493 \\
\hline 5.563 & 40 & Std & $40 \mathrm{~S}$ & 0.258 & 6.047 \\
\hline 141.300 & & & & 6.553 & $\mathbf{1 5 3 . 5 9 4}$ \\
\hline & 80 & XS & $80 \mathrm{~S}$ & 0.375 & 4.813 \\
\hline & 80 & AS & 800 & 9.525 & 122.250 \\
\hline & "_" & "-" & $10 \mathrm{~S}$ & 0.219 & 6.187 \\
\hline 6 & & & I0S & 5.563 & 157.150 \\
\hline 6.525 & 40 & Std & $40 \mathrm{~S}$ & 0.28 & 6.065 \\
\hline 165.735 & 40 & sid & 4013 & 7.112 & 154.051 \\
\hline & 80 & $\mathrm{XS}$ & $80 \mathrm{~S}$ & 0.432 & 5.761 \\
\hline & 80 & $\Lambda \mathrm{S}$ & OUD & 10.973 & 146.329 \\
\hline
\end{tabular}




\section{APPENDIX E : PIPING GUIDE ASME B31.3}

LANL Engineering Standards Manual OST220-03-01-ESM

Chapter 6, Mechanical Section D20 App A, ASME B31.3 Piping Guide - Appendix A

Piping Specification 211
Date: November 29,2004

General Notes

Refer to General Notes 1-12, 16, 19

\section{Allomagle Pipe Materials}

\begin{tabular}{|l|l|l|l|l|l|l|}
\hline Component & Size & Rating & Standard & Materlal & Materlal Grade & Additlonal Requinements \\
\hline Piping & $1 / 4-12$ & Schedule Tabtes & ASME B36.19 & ASTM A312 & TP 316L & Seamless \\
\hline
\end{tabular}

Required Schedules for Non-Threaded Pipe

\begin{tabular}{|c|c|c|c|c|c|c|c|c|c|c|c|c|c|c|c|}
\hline $\begin{array}{c}\text { P. } \\
\text { Spec }\end{array}$ & $\begin{array}{c}\text { Corrosion } \\
\text { Allowance }\end{array}$ & Pipe Size & $1 / 4$ & $1 / 2$ & $\%$ & 1 & $1 \%$ & 2 & $2 \%$ & 3 & 4 & 6 & 8 & 10 & 12 \\
\hline A & 0.00 & Schedule & $10 S$ & $10 S$ & $10 S$ & $10 S$ & $10 S$ & $10 S$ & $10 S$ & $10 S$ & $10 S$ & $40 S$ & $40 S$ & $40 S$ & $40 S$ \\
\hline B & 0.03 & Schedule & $10 S$ & $10 S$ & $10 S$ & $10 S$ & $10 S$ & $10 S$ & $10 S$ & $40 S$ & $40 S$ & $40 S$ & $40 S$ & $40 S$ & $40 S$ \\
\hline
\end{tabular}

\section{Required Schedules for Threaded Pipe}

\begin{tabular}{|c|c|c|c|c|c|c|c|c|c|c|c|c|}
\hline $\begin{array}{c}\text { P. } \\
\text { Spec }\end{array}$ & $\begin{array}{c}\text { Corrosion } \\
\text { Allowance }\end{array}$ & Pipe Size & $1 / 4$ & $1 / 2$ & $3 / 4$ & 1 & $11 / 2$ & 2 & $21 / 2$ & 3 & 4 & 6 \\
\hline A & 0.00 & Schedule & $40 S$ & $40 S$ & $40 S$ & $40 S$ & $40 S$ & $40 S$ & $40 S$ & $40 S$ & $40 S$ & $40 S$ \\
\hline B & 0.03 & Schedule & $80 S$ & $80 S$ & $80 S$ & $80 S$ & $80 S$ & $80 S$ & $80 S$ & $80 S$ & $80 S$ & $80 S$ \\
\hline
\end{tabular}

\section{Fitmmas}

\begin{tabular}{|l|l|l|l|l|l|l|}
\hline Component & Size & Rating & Standard & Material & Material Grade & Addiltional Requirements \\
\hline Threaded Fittings & $1 / 4-4$ & $2000 \#$ & ASME B16.11 & ASTM A182 & F316/F316L & Onily for fit up to threaded components \\
\hline Socket-Wheld Fittings & $1 / 4-2$ & $3000 *$ & ASME B16.11 & ASTM A182 & F316L & \\
\hline Buttweld Fititings & $1 / 2-12$ & Schedule Tabies & ASME B16.9 & ASTM A403 & WP316L & \\
\hline Buttweld Fittings & $1 / 2-12$ & Schedule Tables & ASME B16.28 & ASTM A403 & WP316L & \\
\hline
\end{tabular}

\section{Flanges}

\begin{tabular}{|l|l|l|l|l|l|l|}
\hline Component & Size & Rating & Standard & Material & Material Grade & Additional Requirements \\
\hline Socket-Weld Flange & $1 / 2-2$ & See note 19 & ASME B16.5 & ASTM A182 & See note 19 & \\
\hline Thicaded Flanges & $1 / 2-6$ & Soe note 19 & ASME B16.5 & ASTMA182 & See note 19 & \\
\hline Weldneck Flange & $1 / 2-12$ & See note 19 & ASME B16.5 & ASTM A182 & See note 19 & \\
\hline Slip-an Flange & $1 / 2-12$ & See note 19 & ASME B16.5 & ASTM A182 & See note 19 & \\
\hline Blind Flange & $1 / 2-12$ & See note 19 & ASME B16.5 & ASTM A182 & See note 19 & \\
\hline Backup Flange & $1 / 2-12$ & See note 19 & ASME B16.5 & ASTM A105 & NiA & \\
\hline
\end{tabular}

\section{MEchanical Fasteners}

\begin{tabular}{|l|l|l|l|l|l|}
\hline Component & Stze & Standard & Material & Material Grade & Additionai Requirements \\
\hline Fasteners & $1 / 2-8 / 4$ & ASME B18.2.1 & ASTM A193 & B8 Cl 2-HH & Limiled to 1000"F, See General Nate 10. \\
\hline Nuts & $1 / 2-8 / 6$ & ASME B18.2.2 & ASTM A194 & BF-HH & Limited to 1000"F \\
\hline
\end{tabular}


APPENDIX F : INSTRUMENT CALIBRATION CURVES 


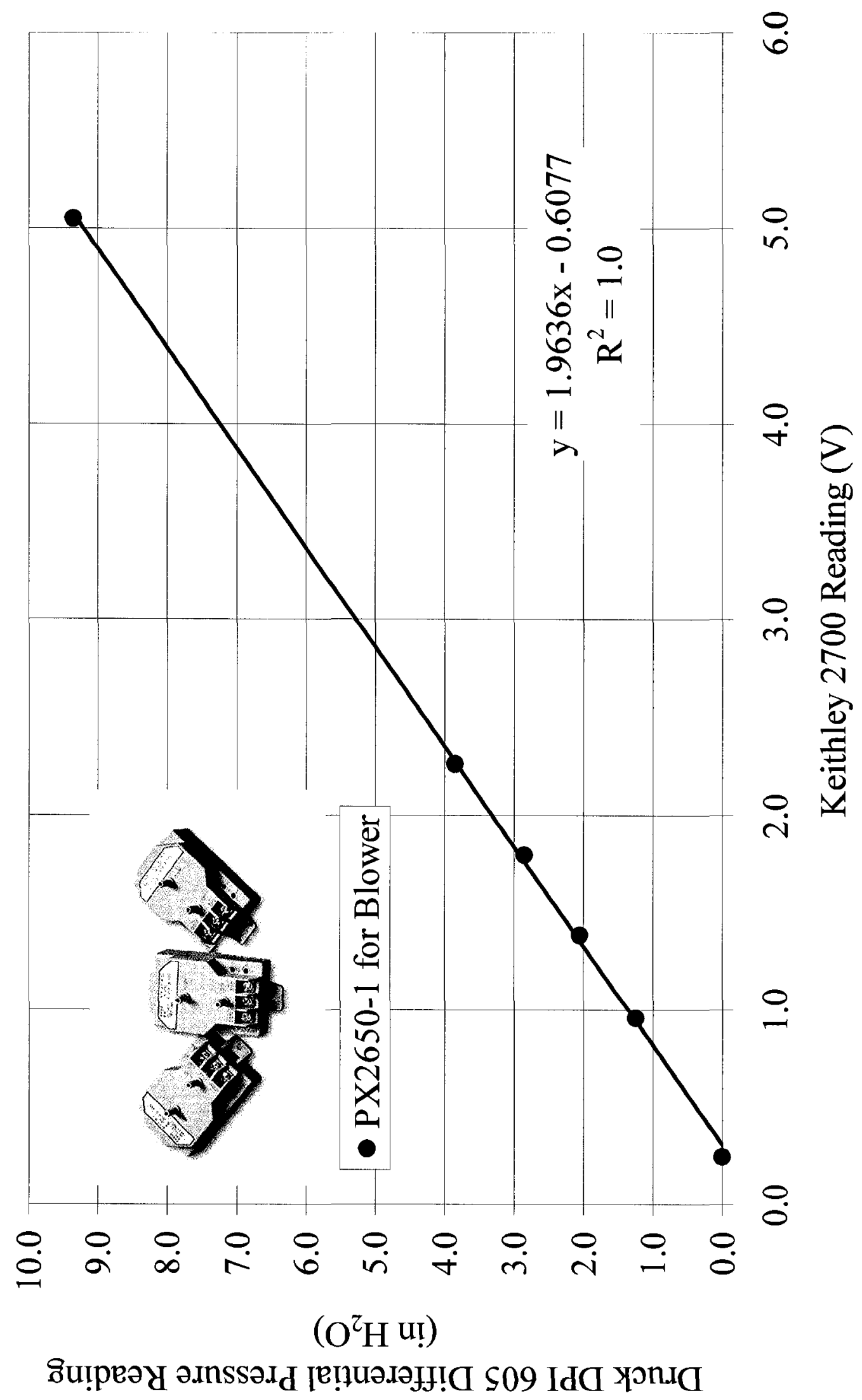




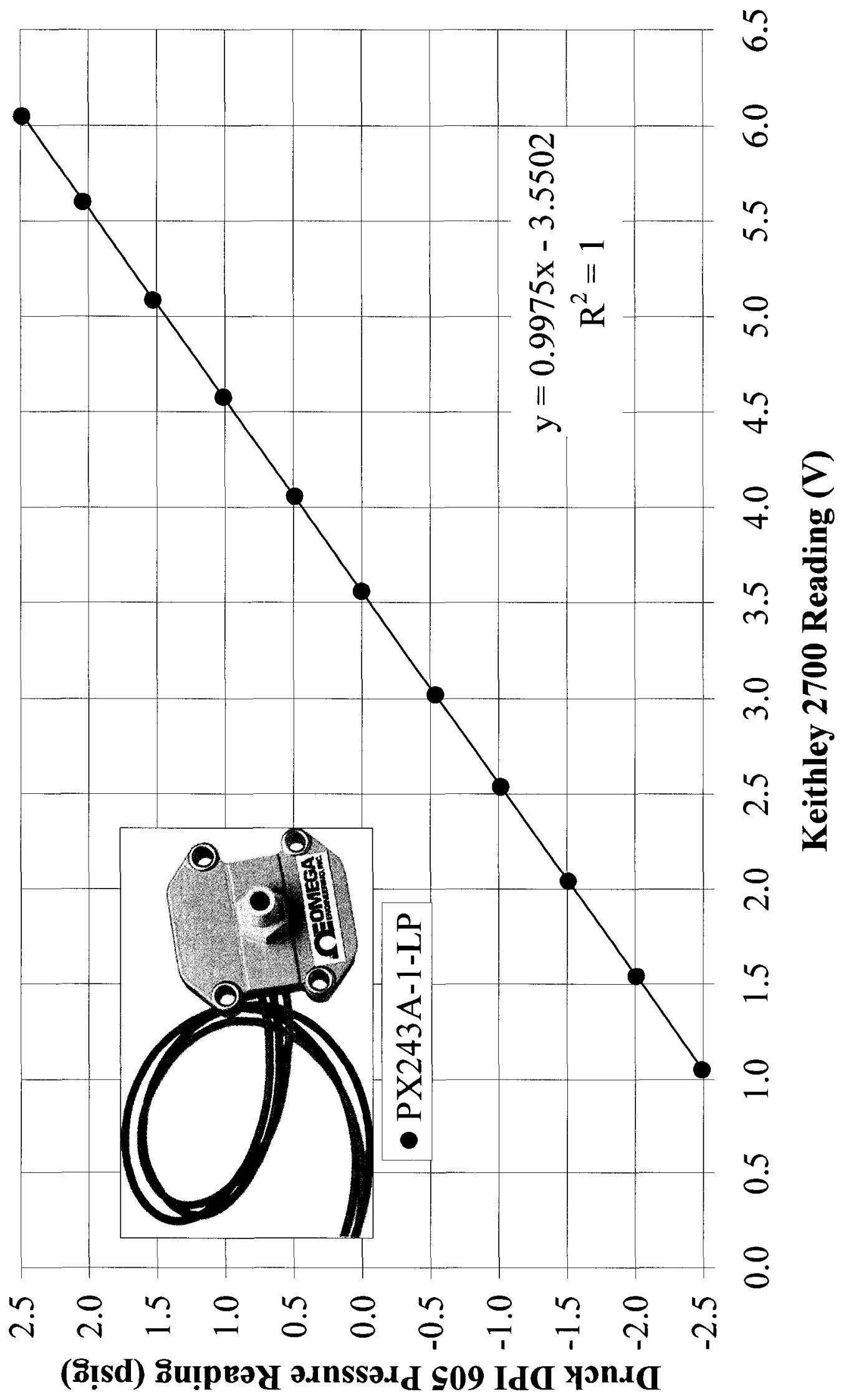




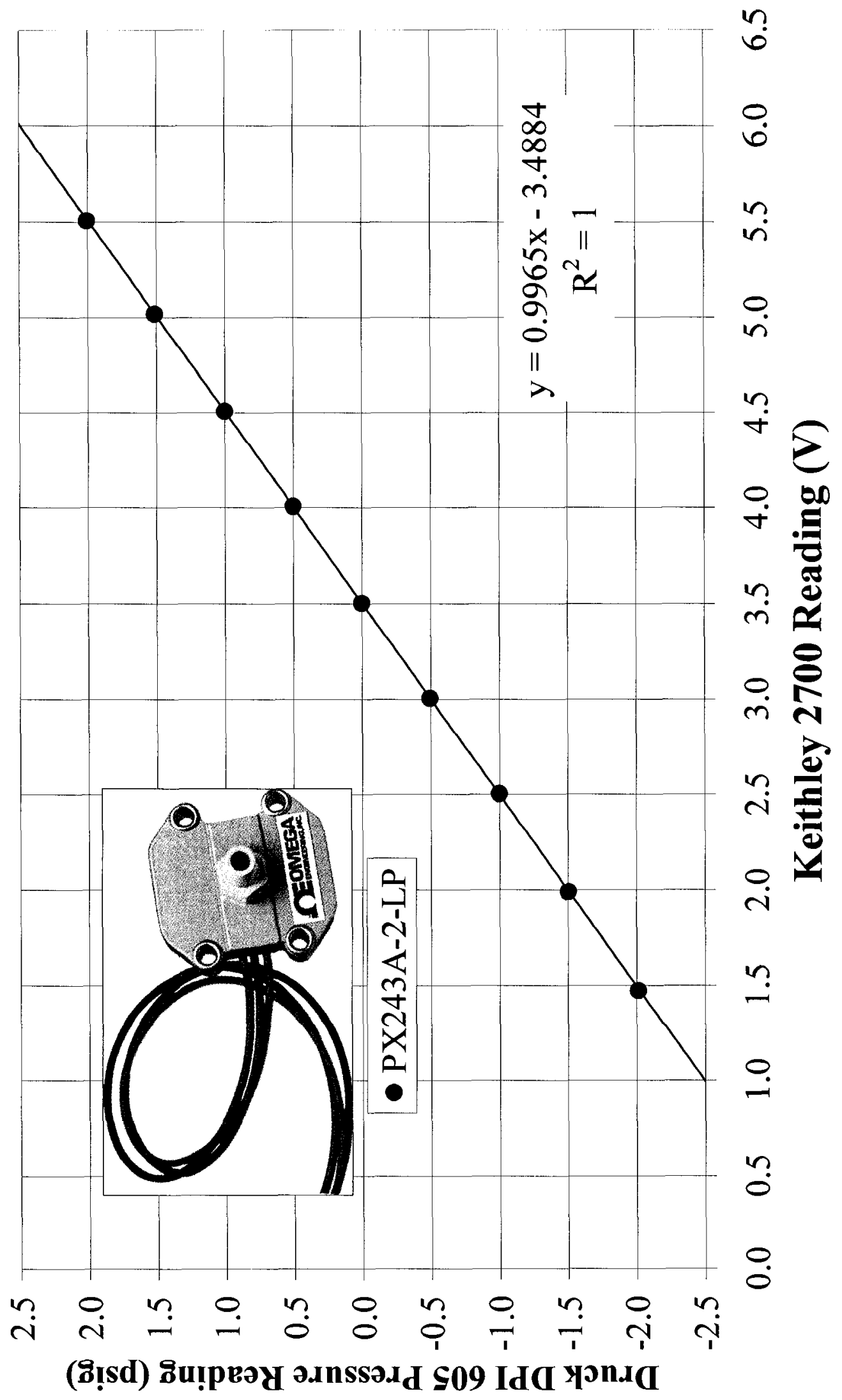




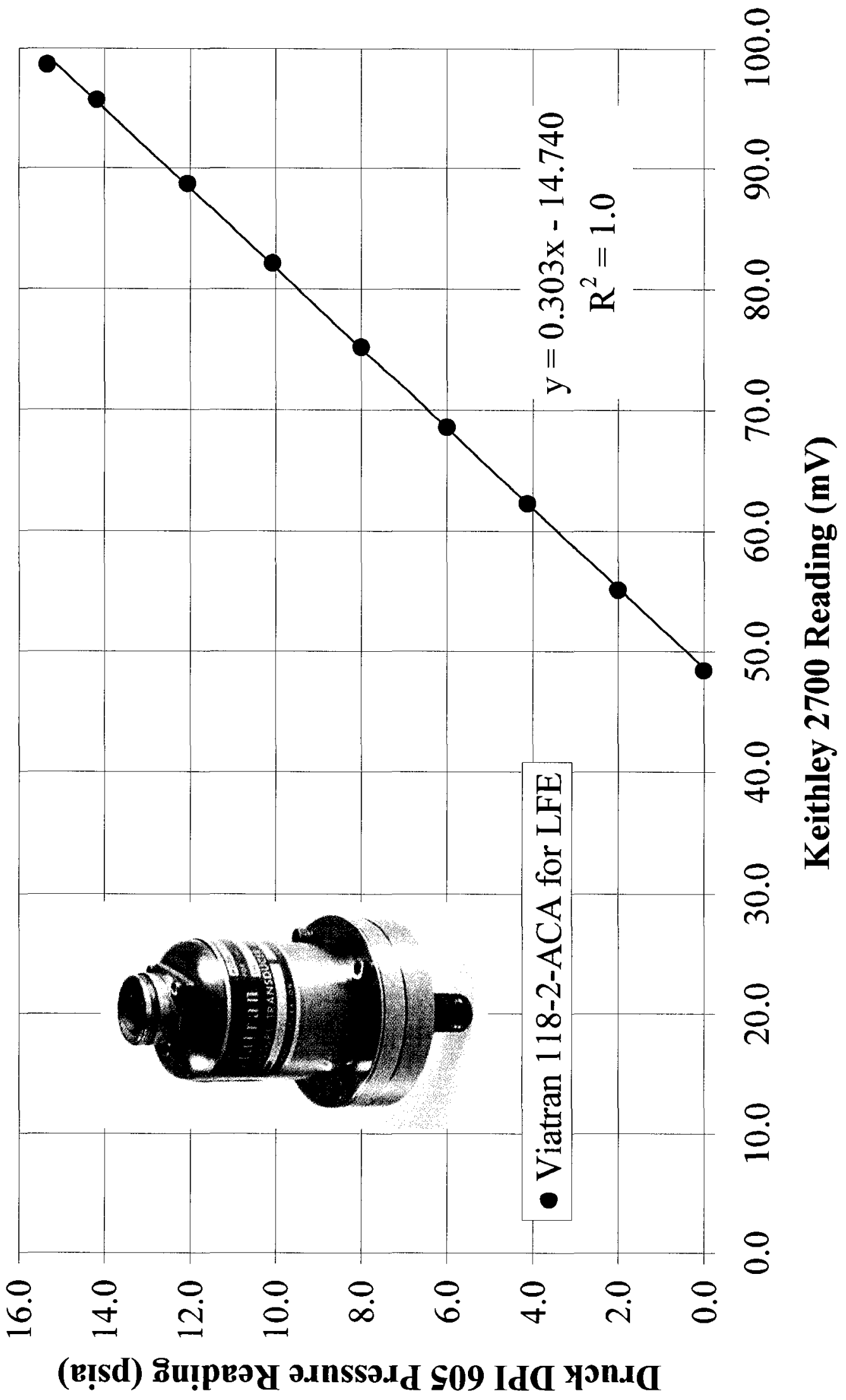




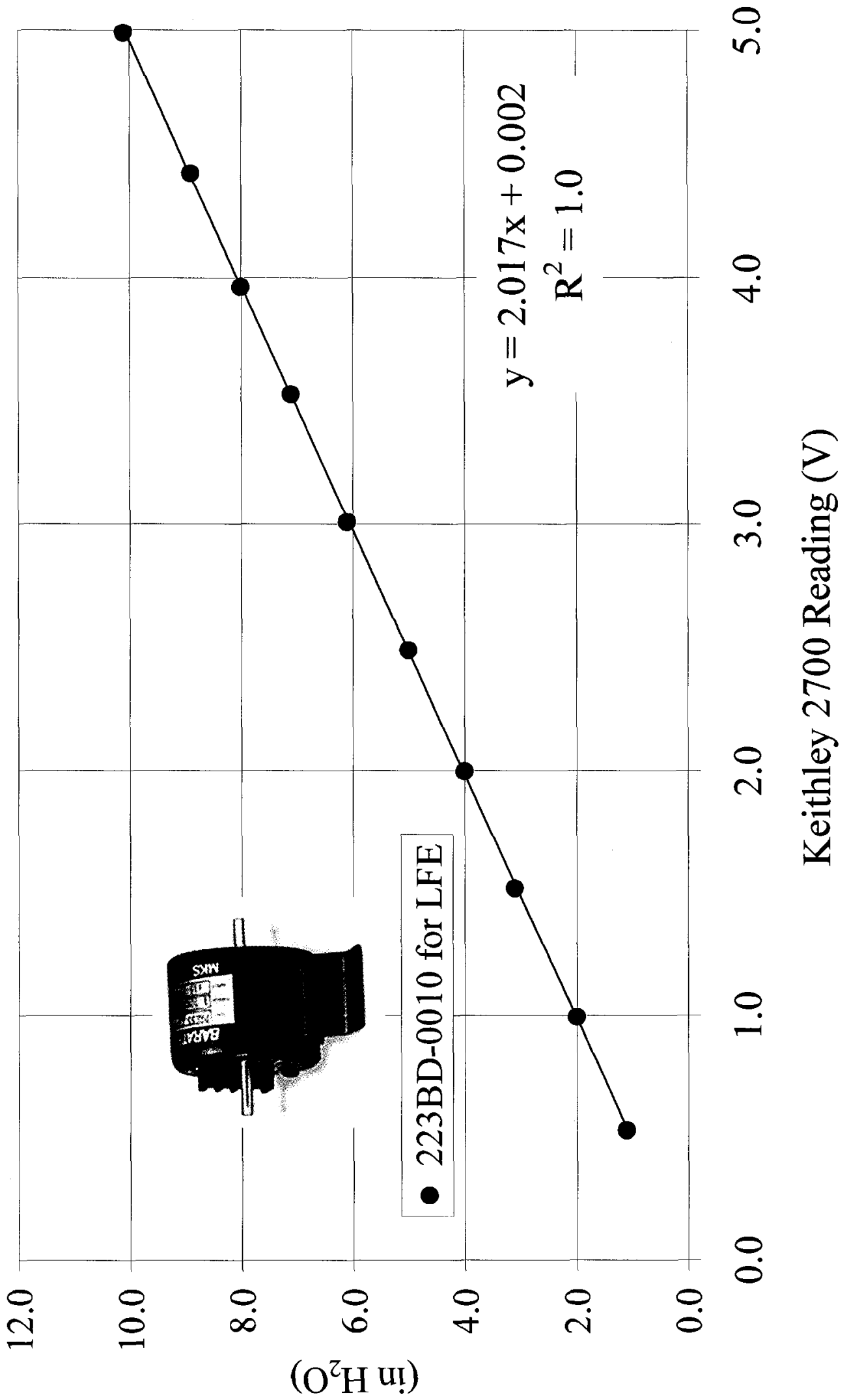

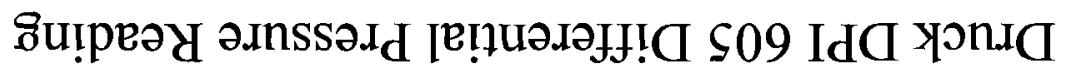




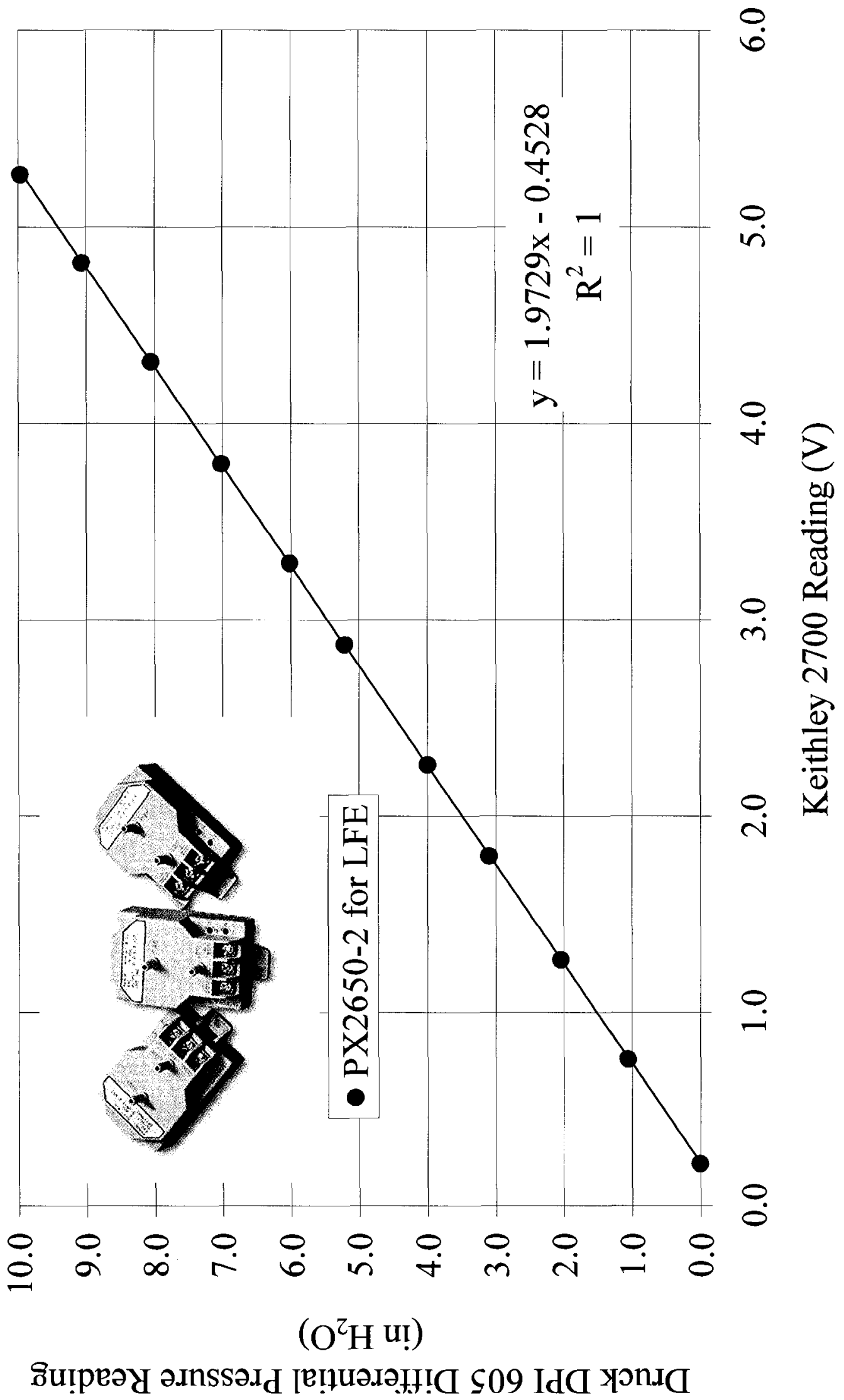




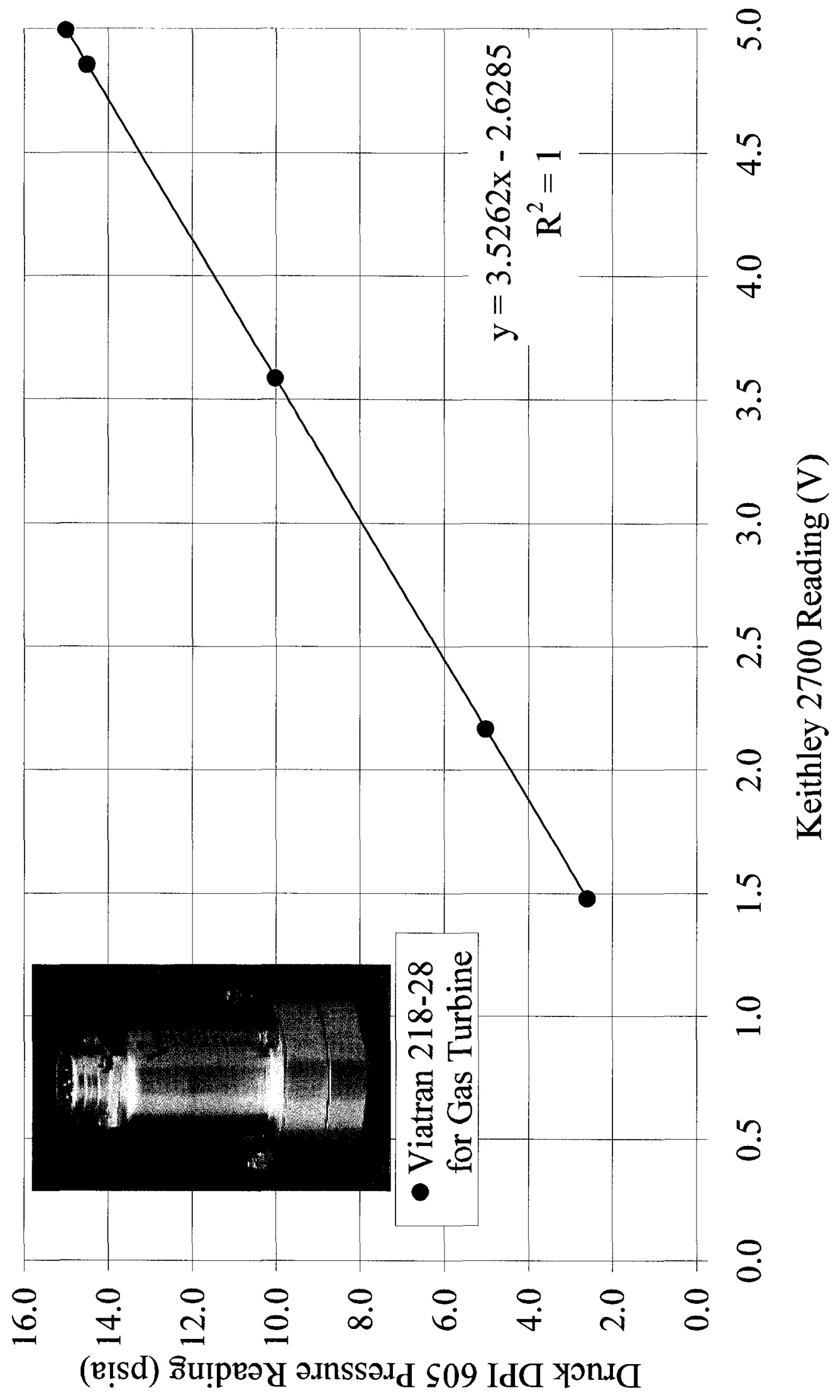




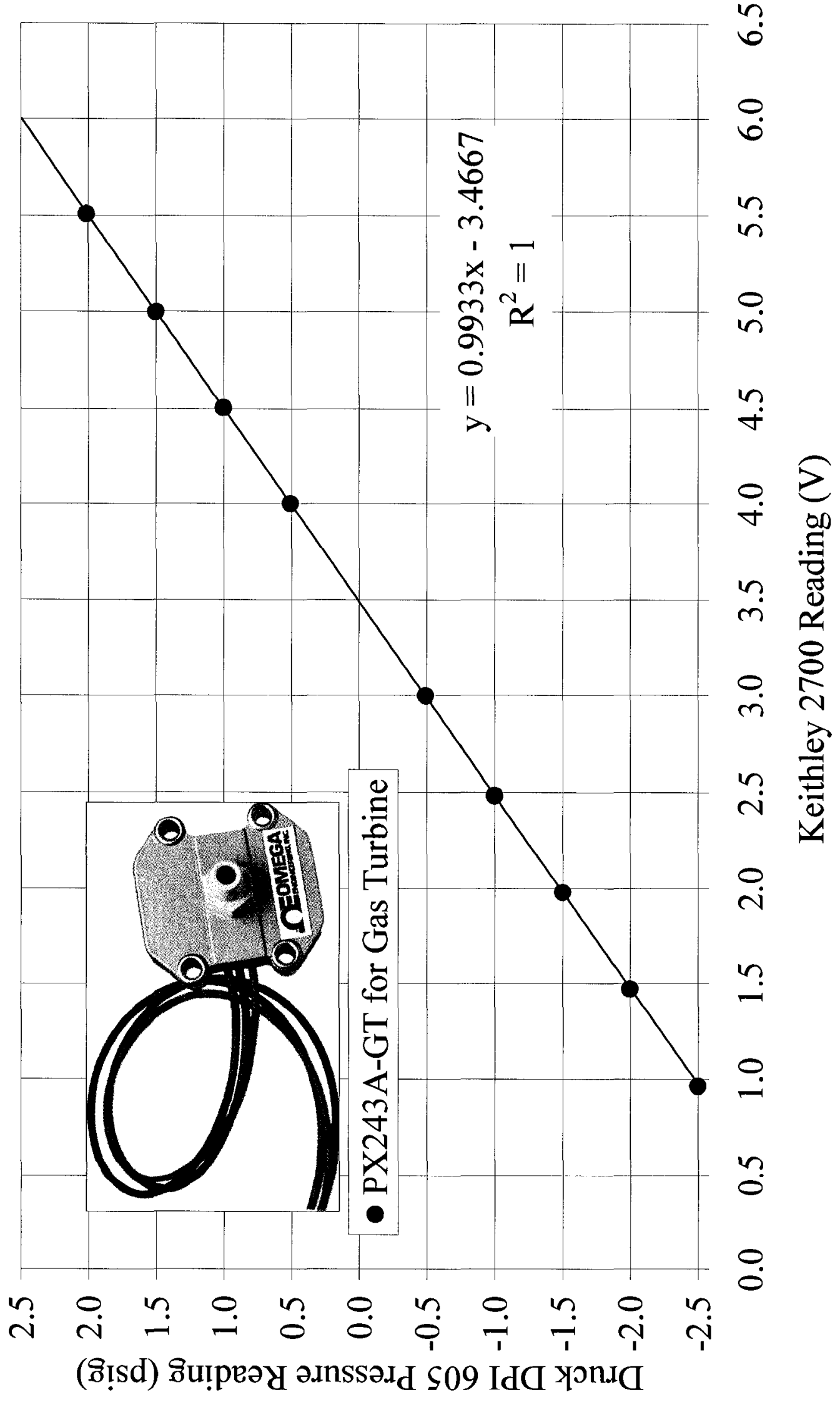




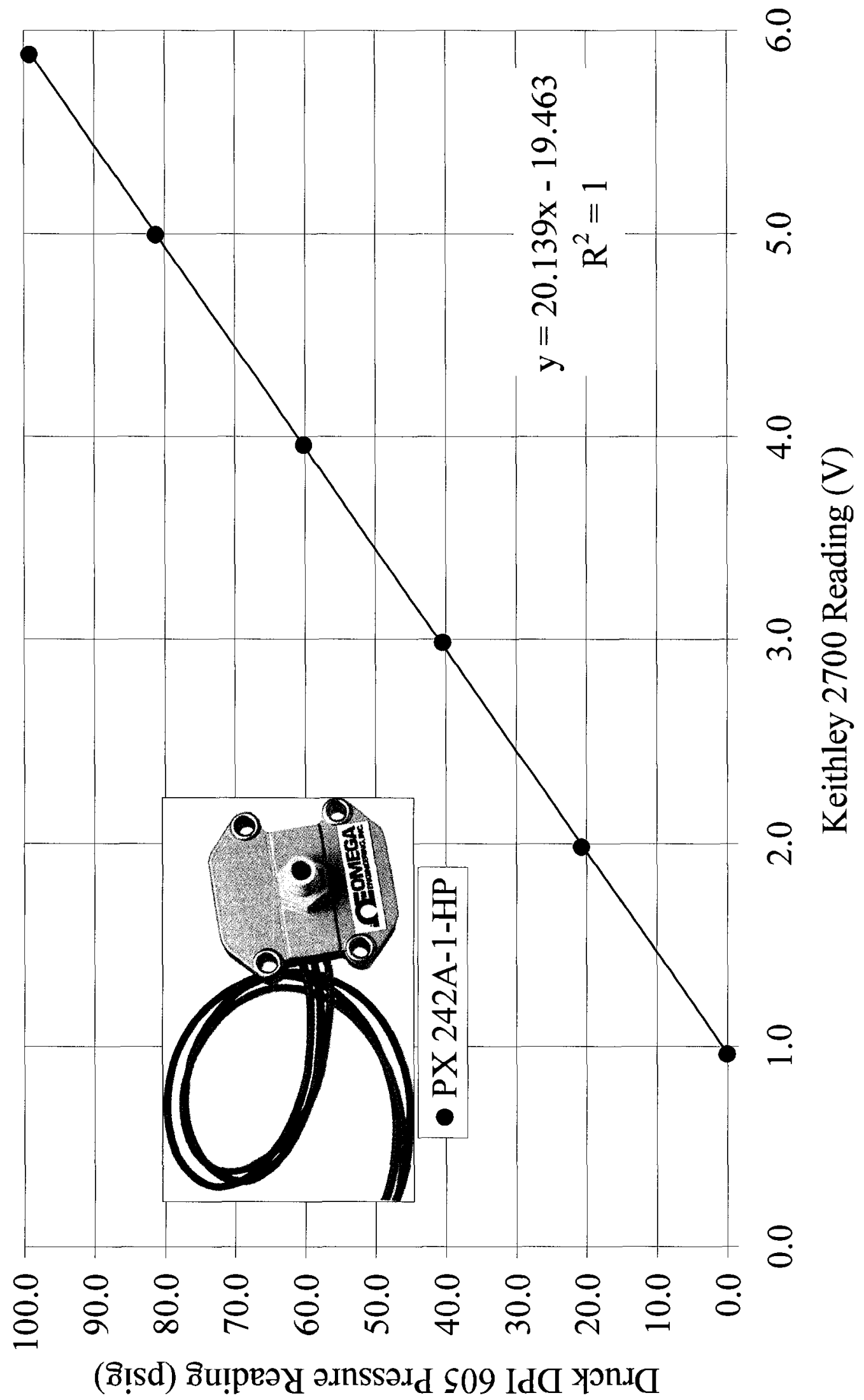




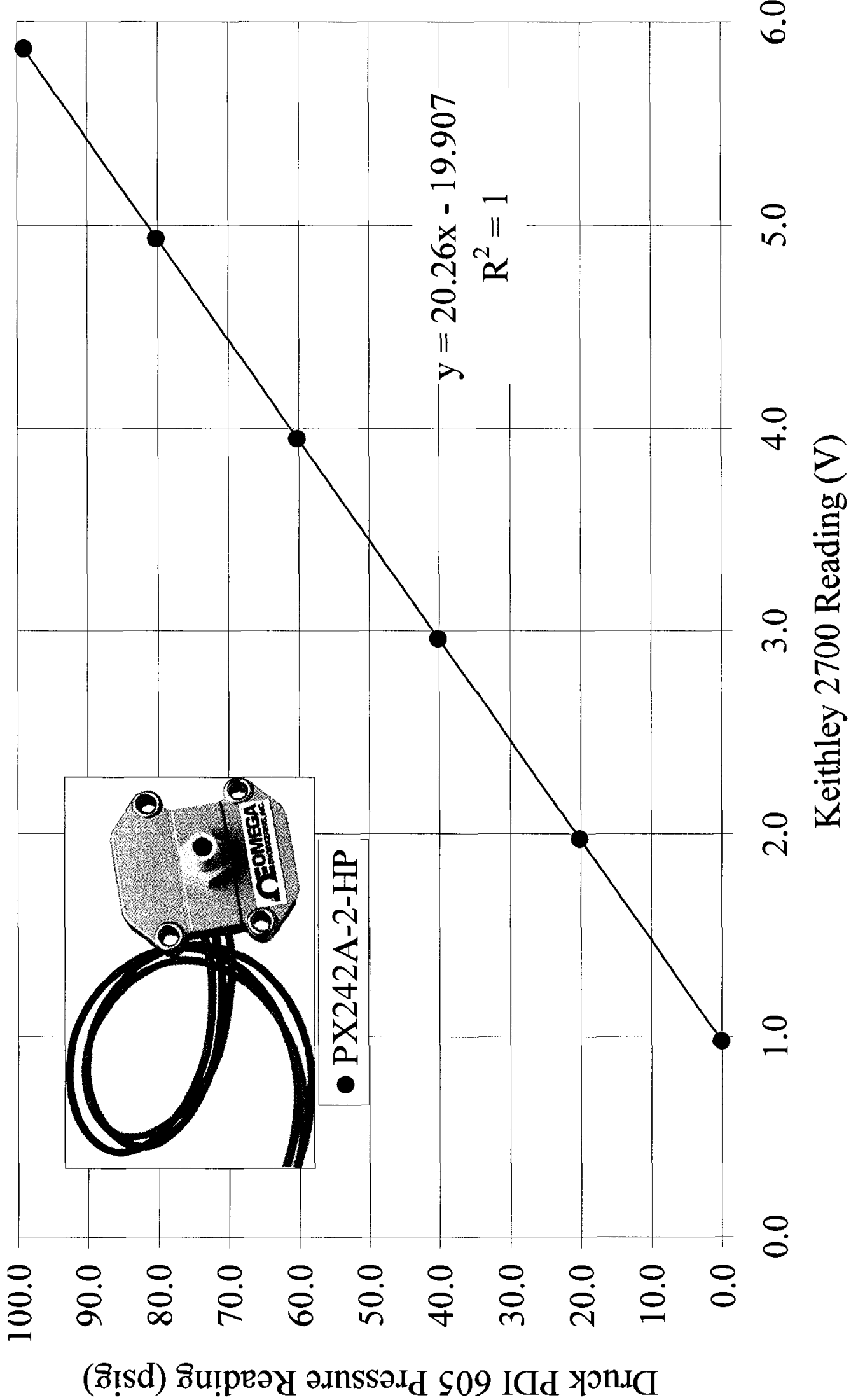




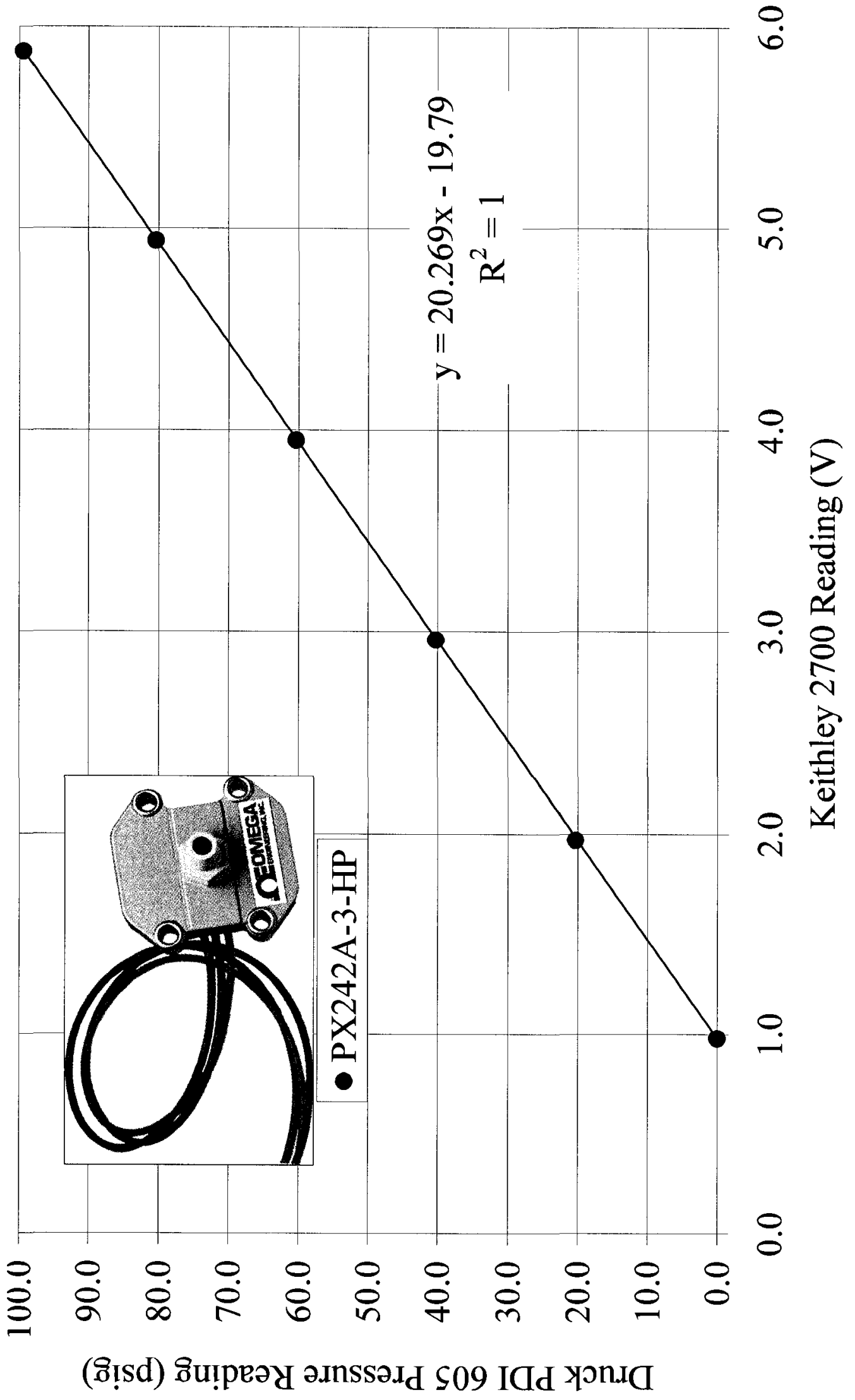




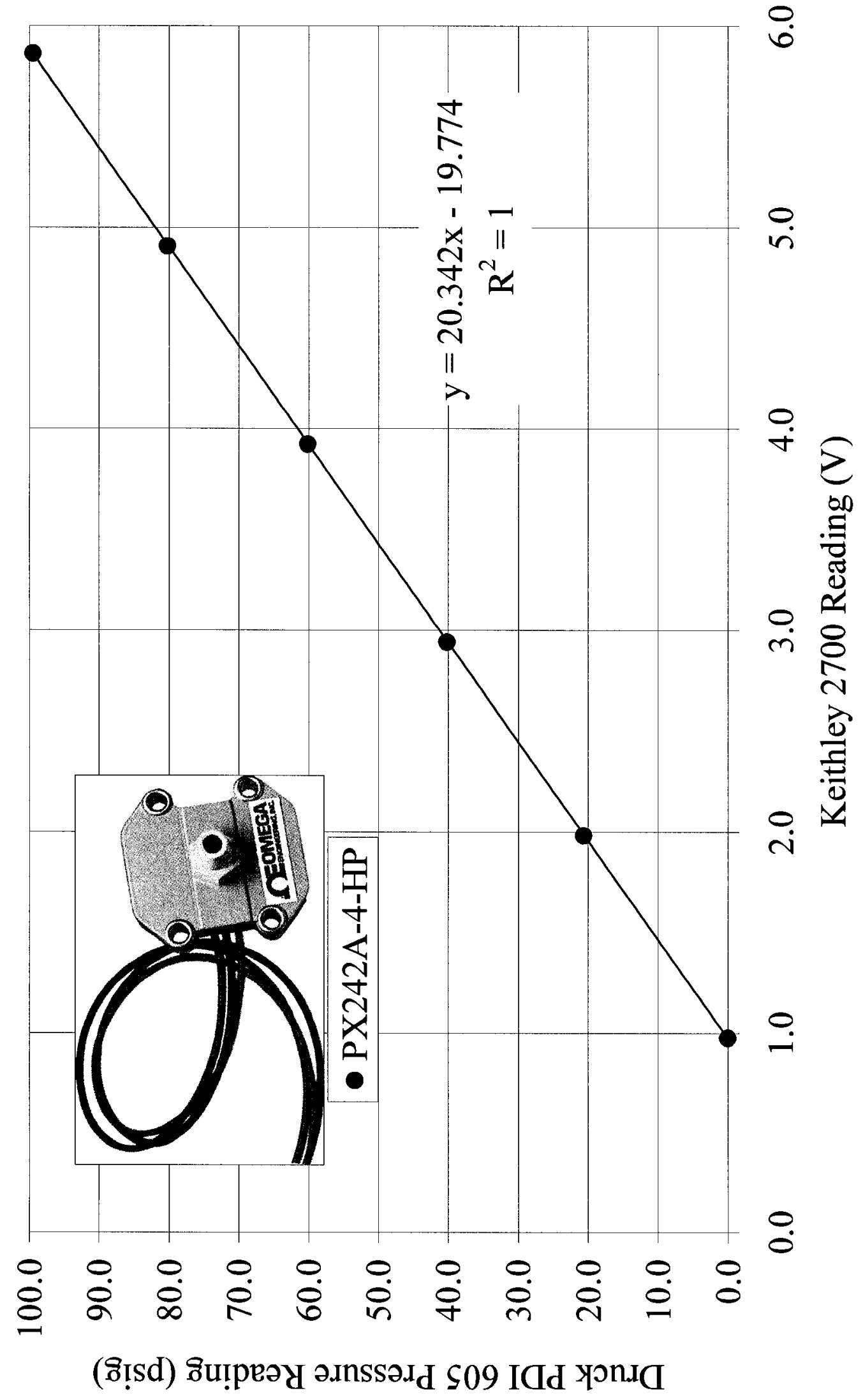




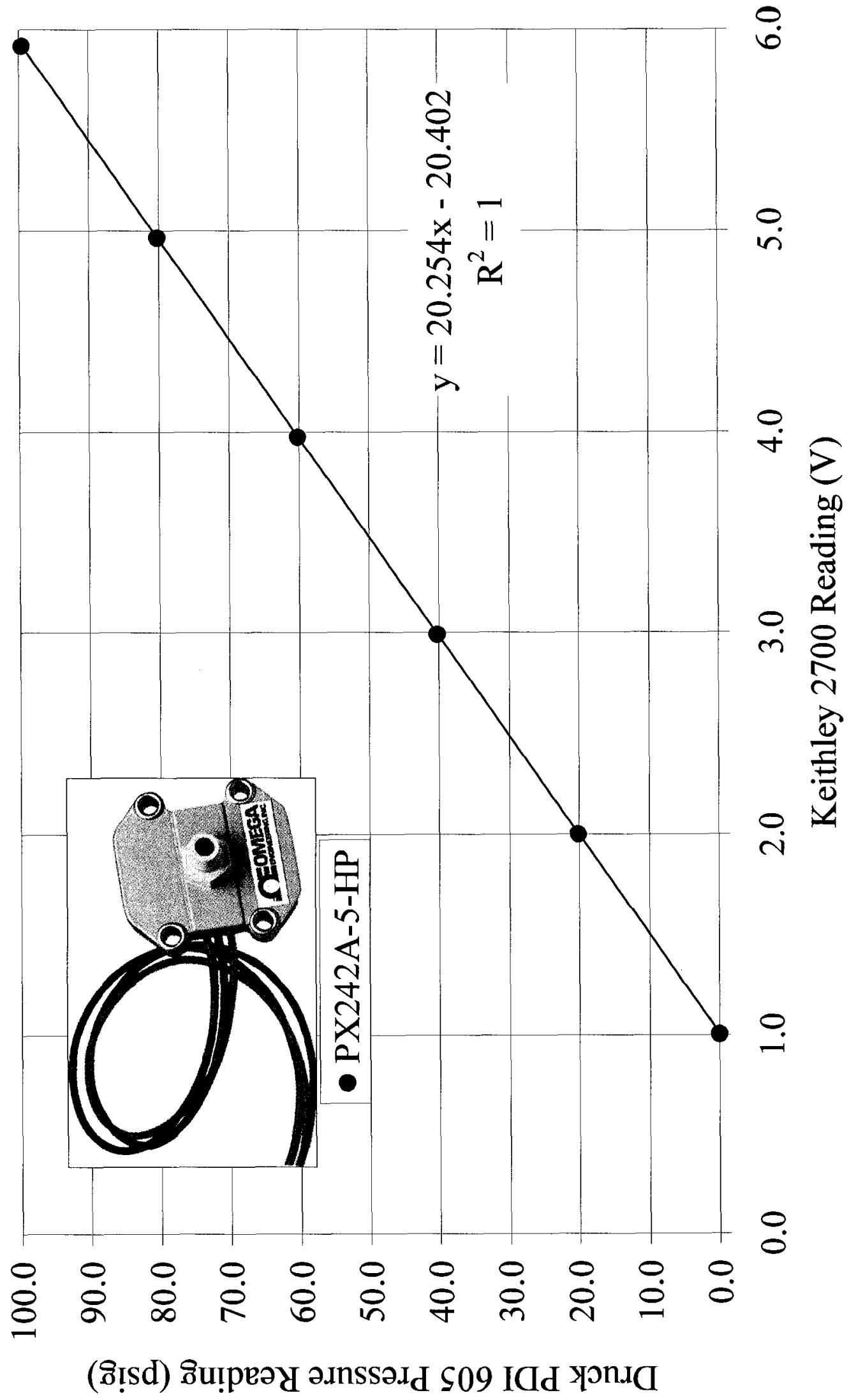




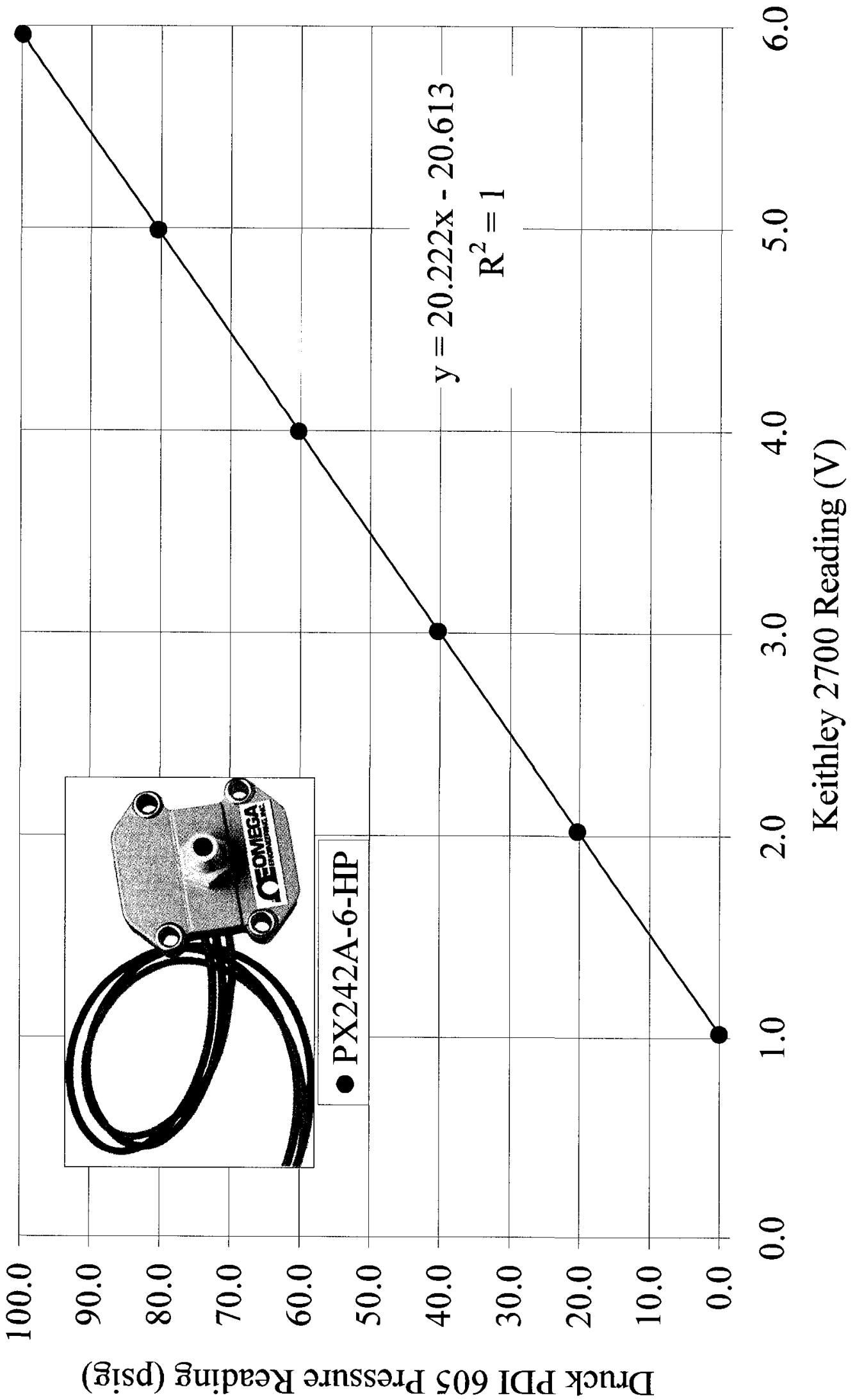




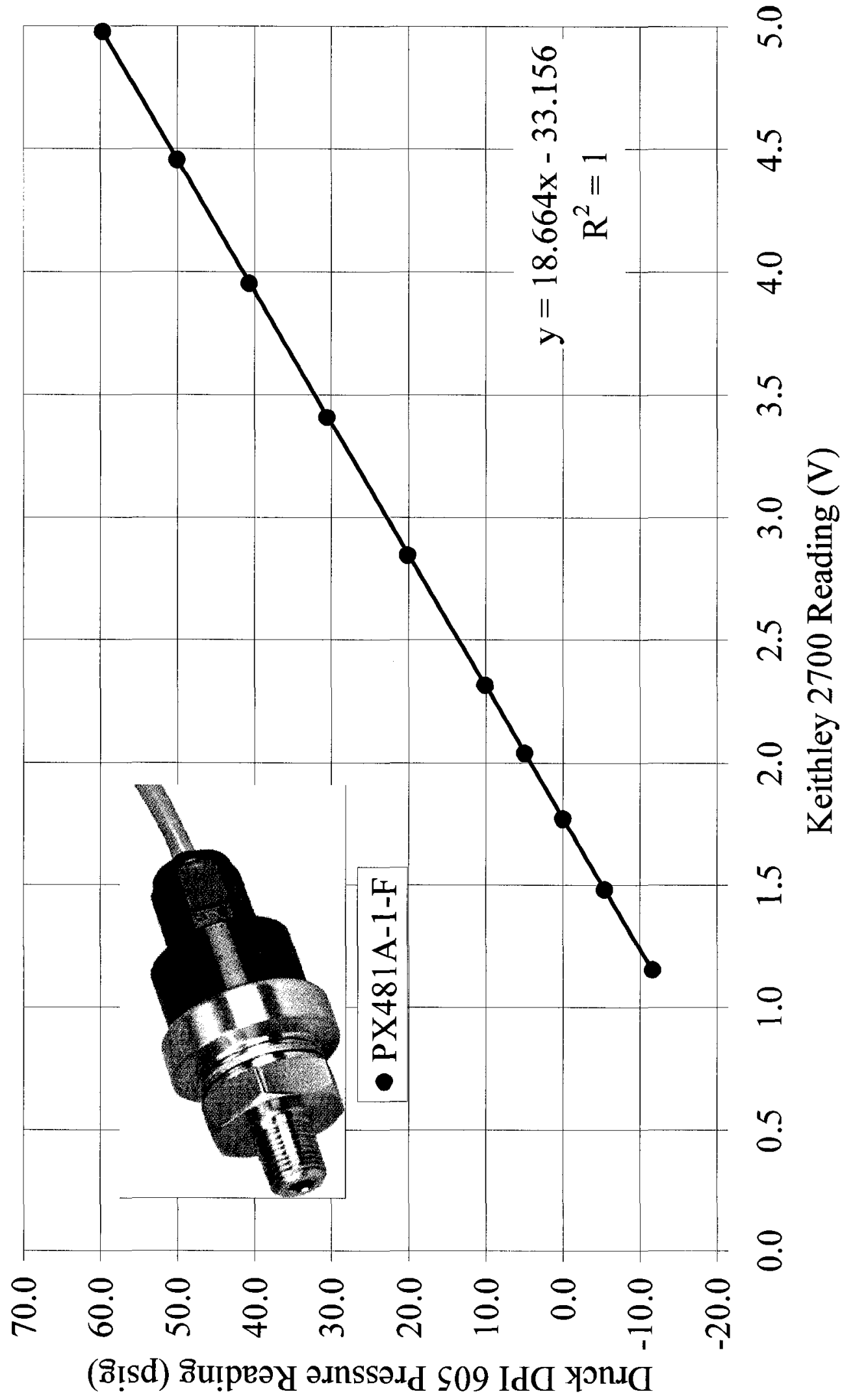




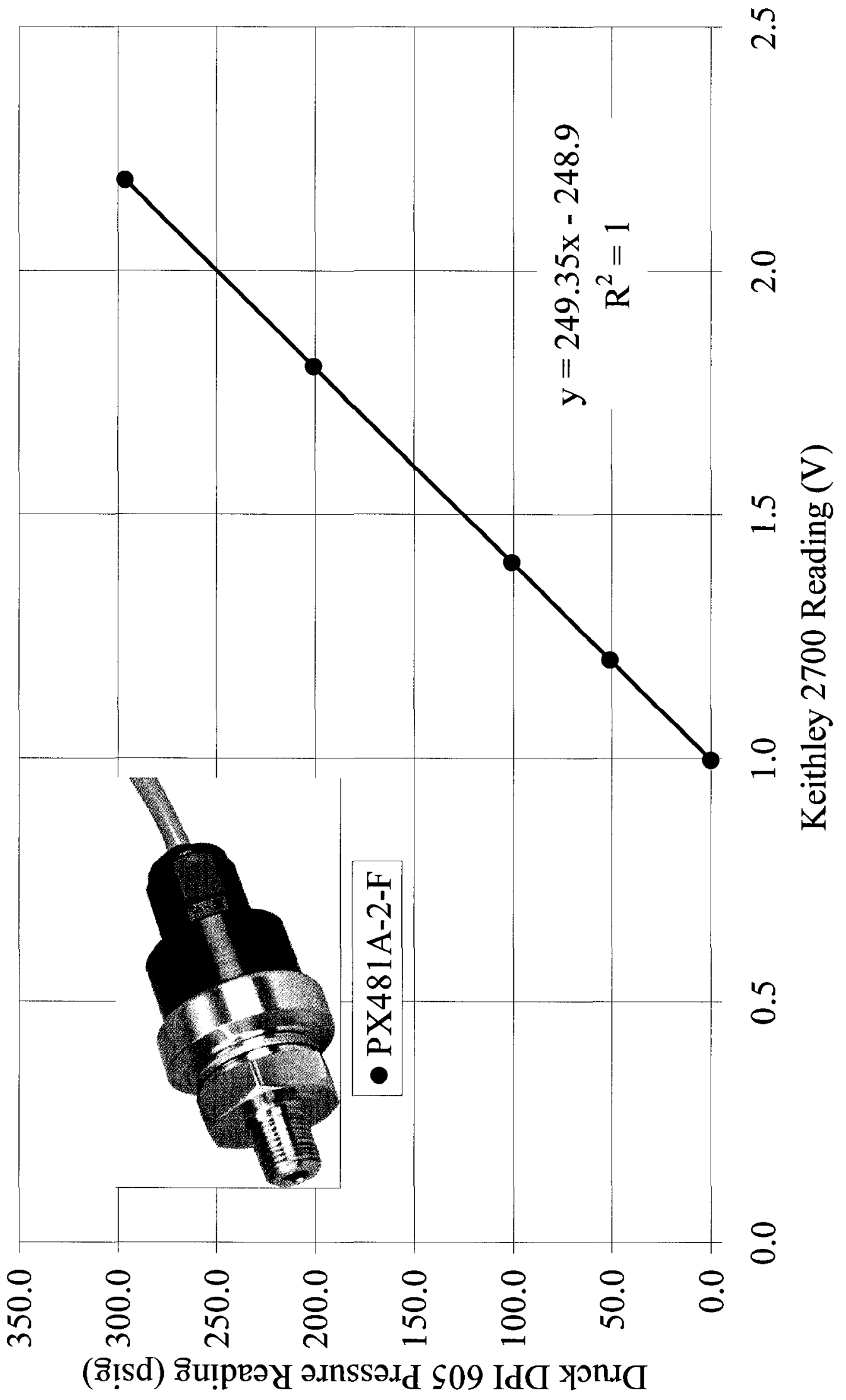


335

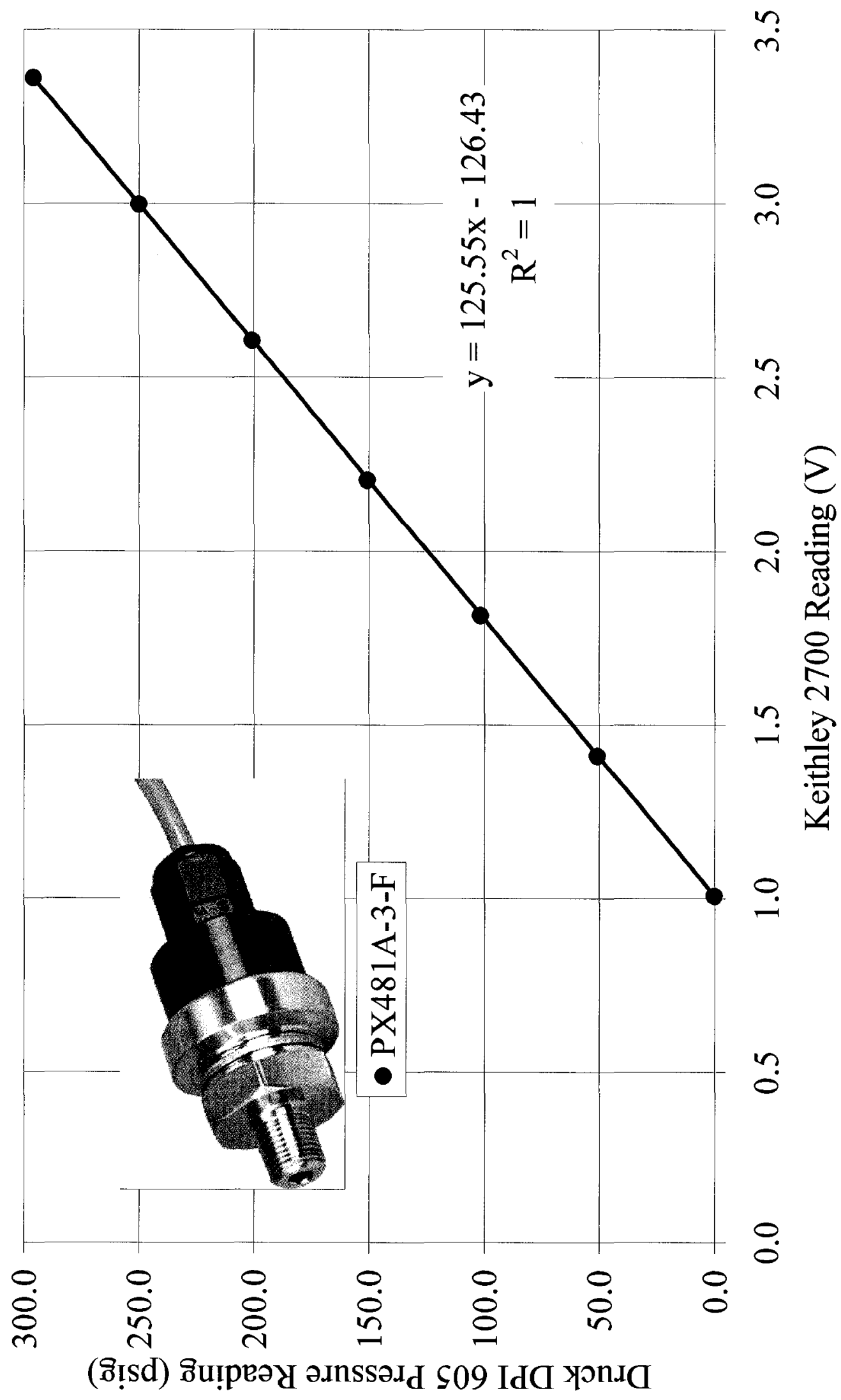




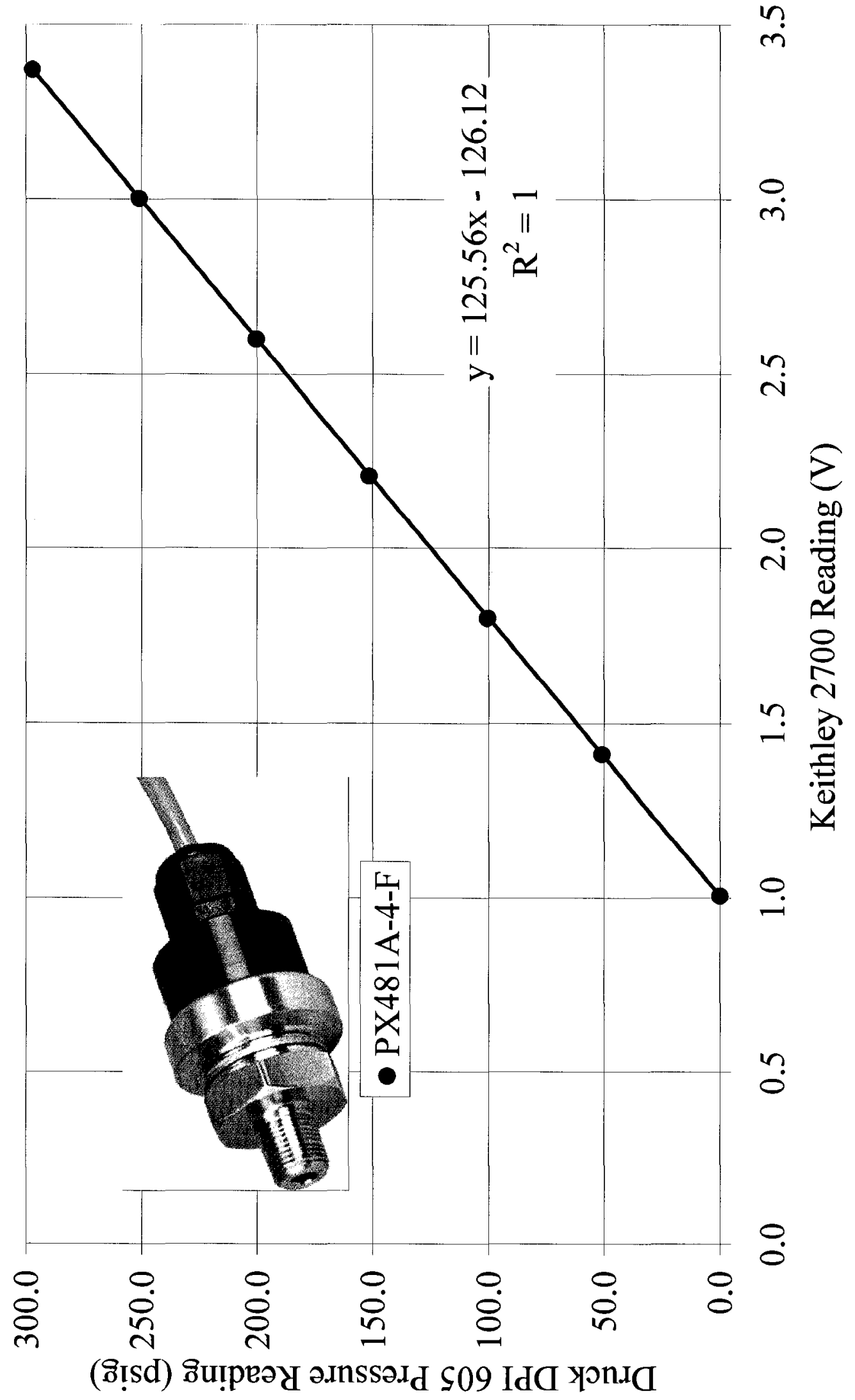




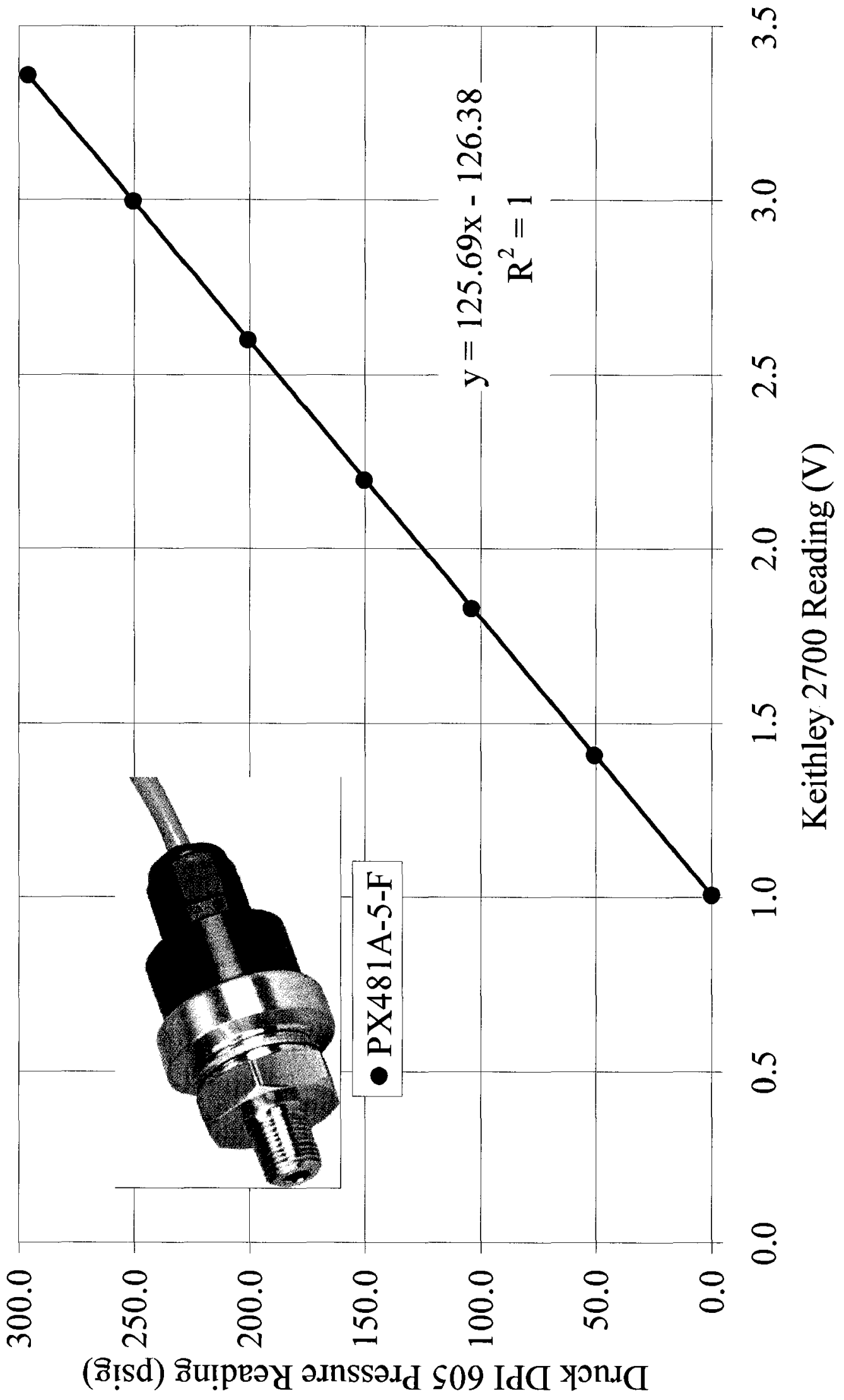




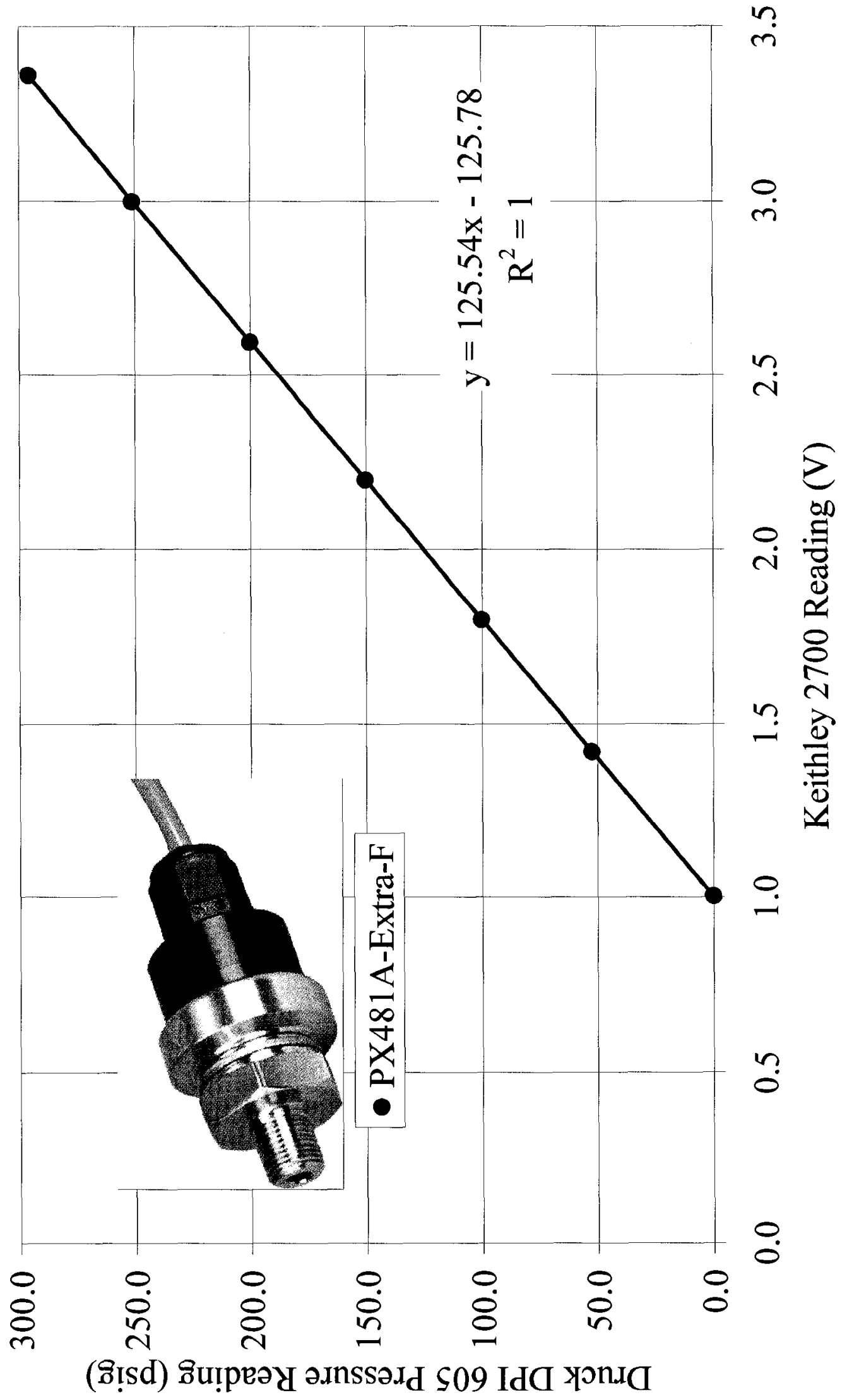




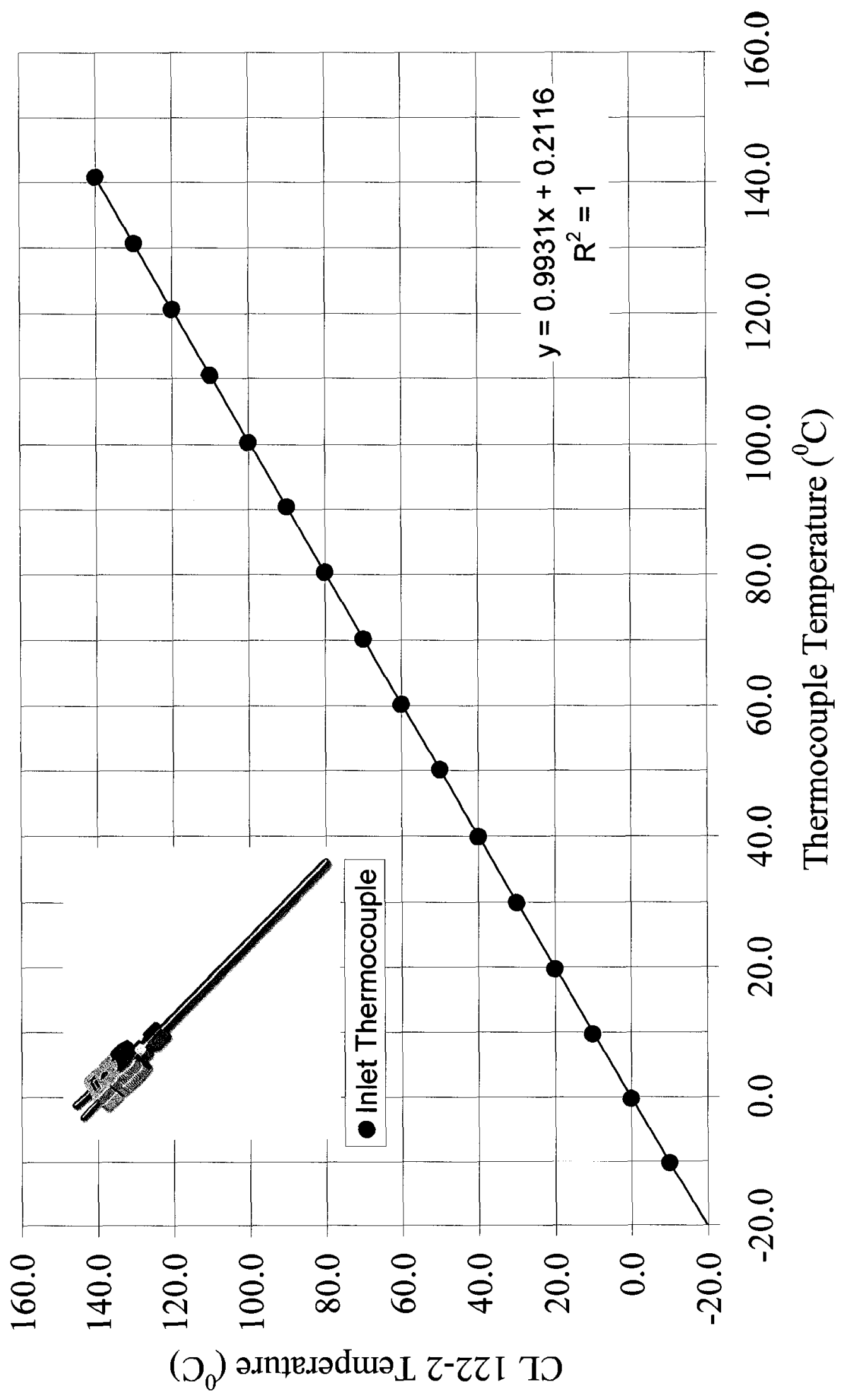




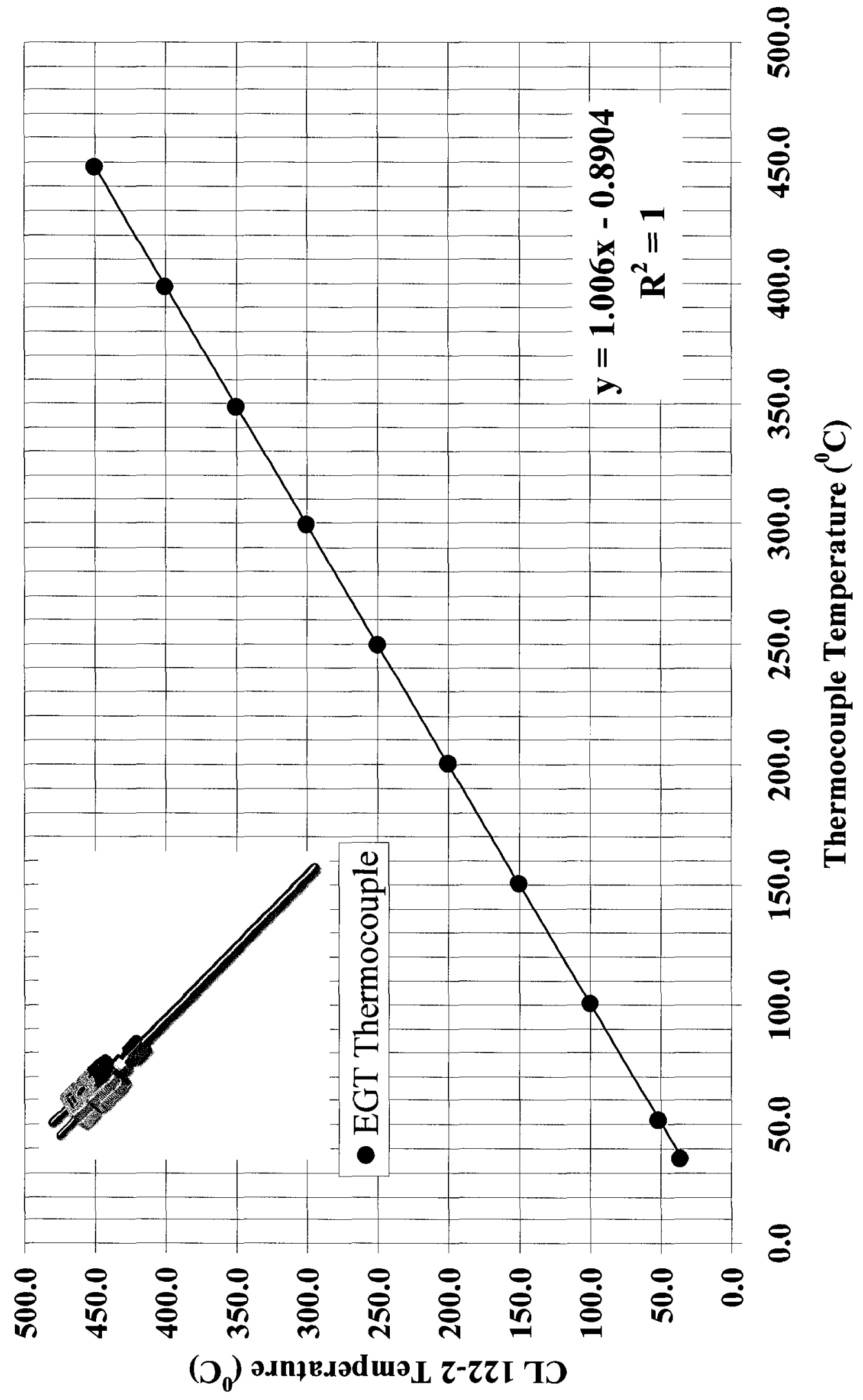




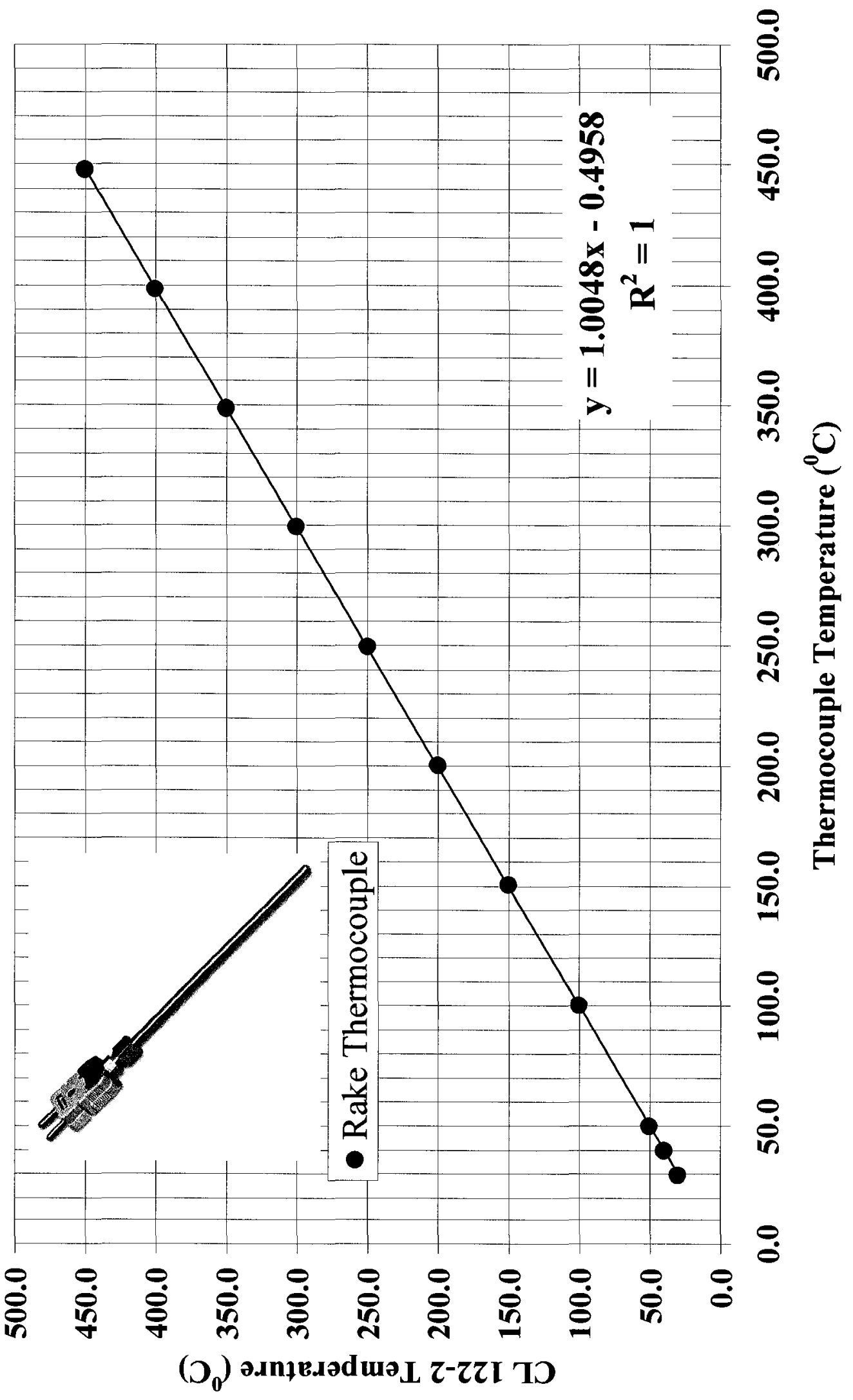




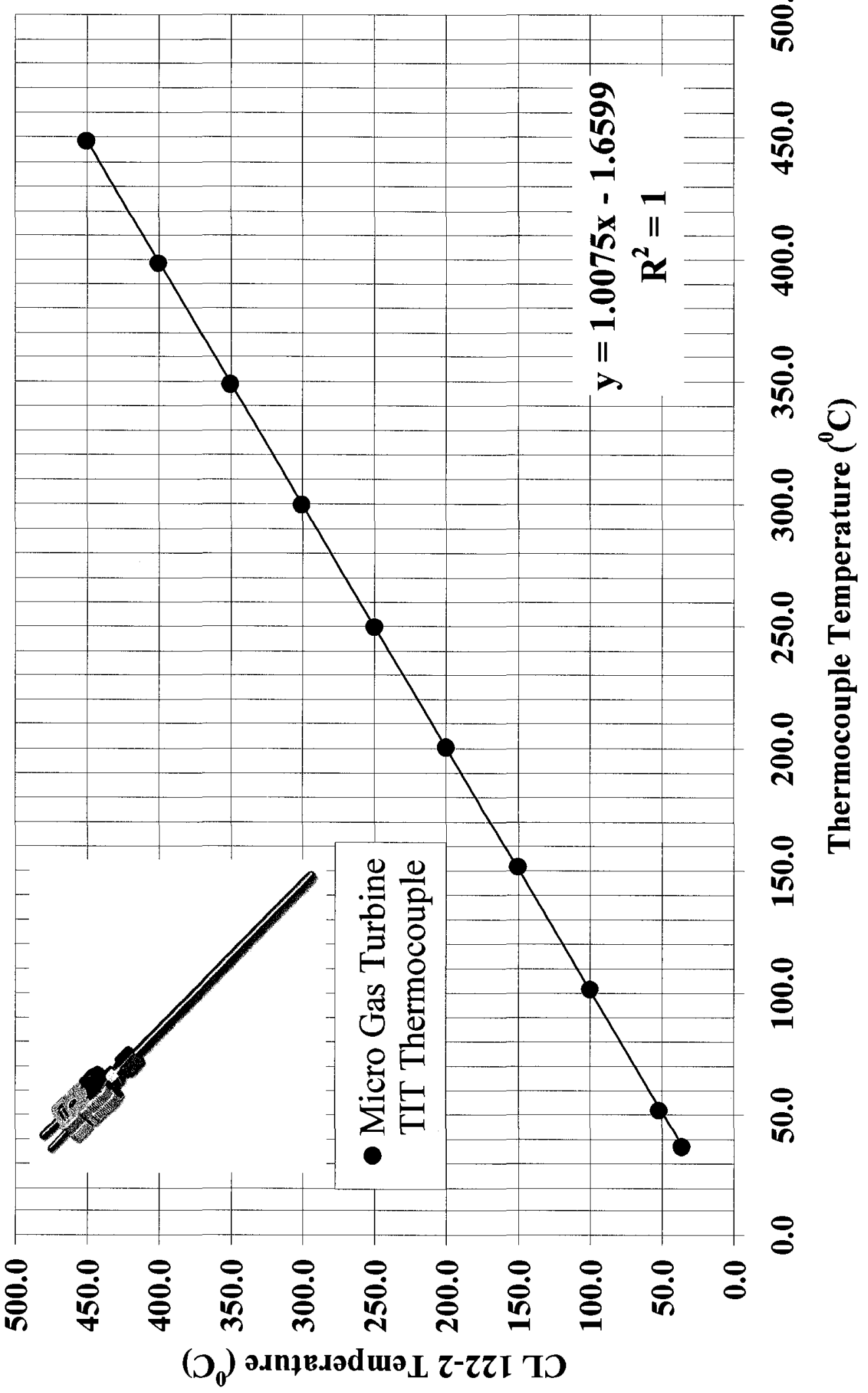




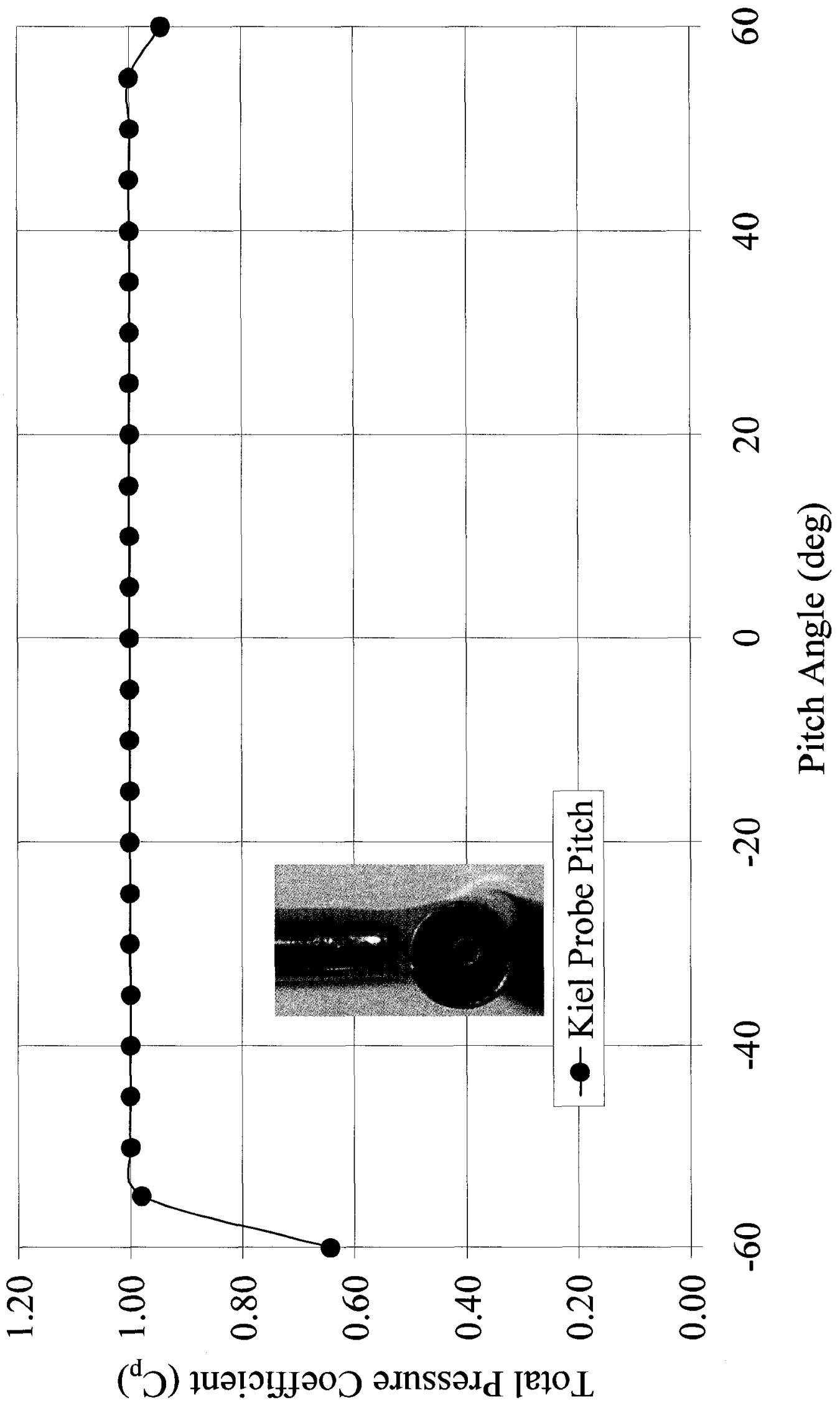




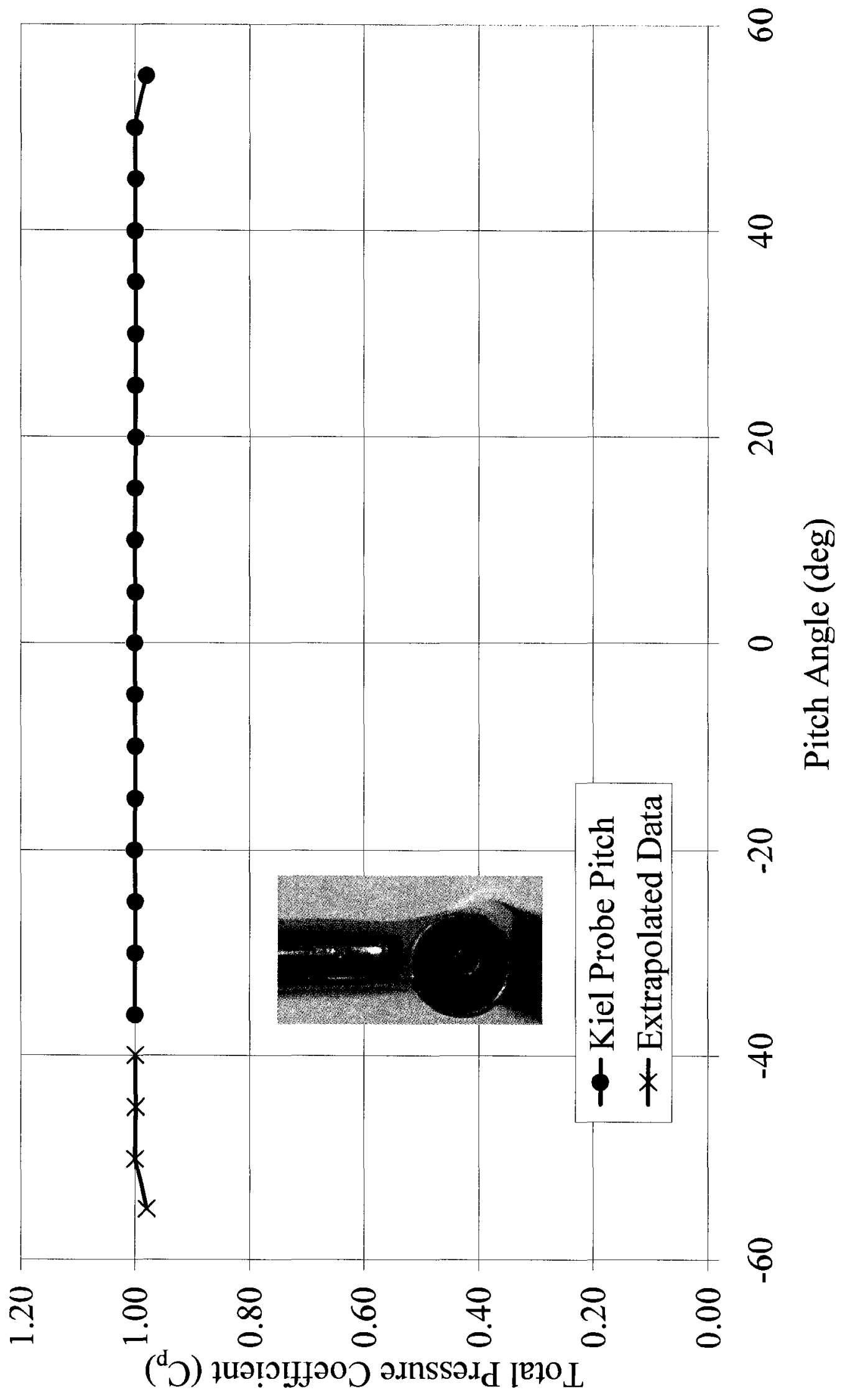




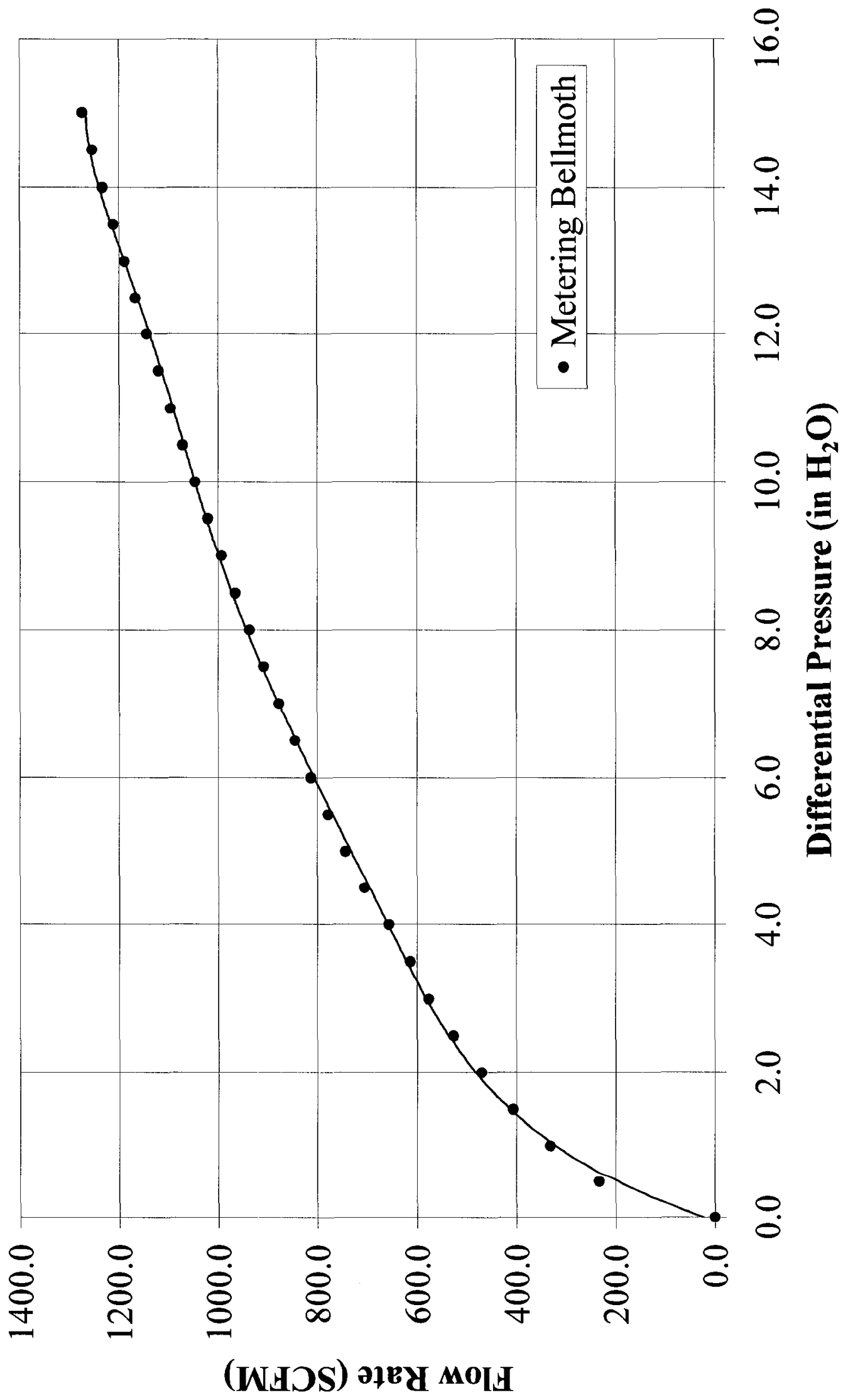




\section{APPENDIX G : ALLISON 250-C20B LIMITS AND OPERATING PROCEDURE}

\section{Engine Ratings}

Design Speed Gas Producer

Maximum measured gas temperature (TOT)

Maximum oil consumption
$100 \%(50,970 \mathrm{rpm})$

$810^{\circ} \mathrm{C}\left(1490^{\circ} \mathrm{F}\right)$

$0.05 \mathrm{US}$ gallons/hr or $1 \mathrm{qt}$ in 5 hours

\section{Performance Ratings}

\begin{tabular}{|c|c|c|c|}
\hline Rating & $\begin{array}{c}\text { Estimated Gas } \\
\text { Producer }(\mathbf{r p m})\end{array}$ & $\begin{array}{c}\text { Fuel Flow } \\
(\mathbf{l b} / \mathbf{h r})\end{array}$ & $\begin{array}{c}\text { Measured Gas Temp. } \\
\mathbf{(} \mathbf{C} \mathbf{C})\end{array}$ \\
\hline Takeoff $(5$ min) & 53,000 & 273 & 810 \\
\hline Normal Cruise & 51,200 & 273 & 738 \\
\hline Ground Idle & 33,000 & 70 & $372-468$ \\
\hline
\end{tabular}

\section{Engine Speed}

If any of the following limits are exceeded send designated engine components to repair/overhaul. RECORD EXTENT OF OVERSPEED IN LOG BOOK.

\begin{tabular}{|c|c|}
\hline \multicolumn{2}{|c|}{$\mathbf{N}_{\mathbf{1}}$ (Gas Producer) } \\
\hline LIMIT & COMPONENT \\
\hline $105 \%-$ max. continuous & None \\
\hline $105-106 \%--15 \mathrm{sec}$ max & None \\
\hline $105-106 \%--$ over $15 \mathrm{sec}$ & Turbine and Compressor \\
\hline Over $106 \%-$ NOT ALLOWED & Turbine and Compressor \\
\hline
\end{tabular}


Engine Temperature

WARNING: HOT STARTS OR AFTERFIRES AFTER SHUTDOWN WILL CAUSE TURBINE BLADE AND WHEEL DAMAGE, WHICH CAN RESULT IN ENGINE FAILURE.

\begin{tabular}{|c|c|c|}
\hline \multicolumn{3}{|c|}{ Measured Gas Temperature Limits (TOT) - 250-C20B } \\
\hline Temperature Range $\left({ }^{\circ} \mathrm{C}\right)$ & Time & Maintenance Action \\
\hline \multicolumn{3}{|c|}{ STEADY STATE } \\
\hline 810 & Takeoff $(5 \mathrm{~min})$ & $\begin{array}{l}\text { If time or temperature } \\
\text { exceeded inspect turbine }\end{array}$ \\
\hline 738 & Normal cruise and below & None \\
\hline \multicolumn{3}{|c|}{ DURING STARTING AND SHUTDOWN } \\
\hline Up to 810 & No limit & None \\
\hline $810-927$ & $10 \sec \max$ & Inspect Turbine \\
\hline $927-999$ & Not Allowed & Inspect Turbine \\
\hline Over 999 & Not Allowed & $\begin{array}{l}\text { Remove turbine for heavy } \\
\text { maintenance or overhaul }\end{array}$ \\
\hline \multicolumn{3}{|c|}{ DURING POWER TRANSIENT } \\
\hline Up to 779 & No limit & None \\
\hline $779-810$ & Until stabilized $(5 \min \max )$ & None \\
\hline $810-843$ & $0-6 \mathrm{sec}$ & None \\
\hline $810-843$ & $6-12 \mathrm{sec}$ & \multirow{2}{*}{$\begin{array}{l}\text { Max of } 3 \text { occurrences per } \\
\text { life of each turbine wheel }\end{array}$} \\
\hline $810-843$ & Over $12 \mathrm{sec}$ & \\
\hline $843-927$ & Not allowed & Inspect Turbine \\
\hline Over 927 & Not Allowed & $\begin{array}{l}\text { Remove turbine for heavy } \\
\text { maintenance or overhaul }\end{array}$ \\
\hline
\end{tabular}

\section{Oil Pressure and Temperature}

$94.2 \% \mathrm{~N} 1$ speed and above

78.5 to $94.2 \% \mathrm{~N} 1$ speed

Below 78.5\% N1 speed

During Start

Minimum Temperature

Maximum Temperature
$115-130$ psig

$90-130$ psig

$50-130$ psig

a positive indication must be obtained when $59 \%$ (idle is reached)

$-40^{\circ} \mathrm{C}$

$107^{\circ} \mathrm{C}$ 


\section{Pre-Start-up Inspections}

Before operating engine, open test cell air inlet

$>$ Before operating engine, check test cell for foreign objects

Before operating engine, check the engine air inlet for foreign objects

Before operating engine, manually spin compressor to ensure free rotation

Before operating engine, check oil level

Before operating engine, check fuel level

$>$ Before operating engine, check throttle operating range and response

$>$ Before operating engine, turn on oil cooler

Before operating engine, perform manual start (no ignition) from within test cell to ensure proper working order of engine

Before operating engine, remove exhaust cap

\section{Operating Procedures}

The following procedure is applicable to either the CECO or the Bendix control system

\section{$\underline{\text { STARTING MODE }}$}

a) Position the throttle at FUEL OFF

b) Turn on switches required to provide fuel to the engine

CAUTION: DURING A START THE THROTTLE MUST NEVER BE ADVANCED OUT OF THE FUEL OFF POSITION UNTIL AFTER THE STARTER AND IGNITION EXCITER HAVE BEEN ENERGIZED AND THE DESIRED CRANCKING SPEED HAS BEEN ATTAINED. TO DO SO MIGHT RESULT IN AN EXPLOSIVE LIGHTOFF OR AN OVERTEMPERATURE START.

AN ENGINE FIRE (WITH THE RESULTANT FLAME EMANATING FROM THE TAILPIPE) CAN OCCUR DURING START IF THE COMBUSTION CHAMBER BECOMES OVERLOADED WITH FUEL BEFORE IGNITION TAKES PLACE. TO EXTIGUISH THE FIRE, CONTINUE TO MOTOR THE ENGINE USING THE STARTER WITH THE THROTTLE FULLY CLOSED AND THE MAIN FUEL SWITCH OFF. 
MONITOR OIL PRESSURE DURING START. DAMAGE TO ROTOR BEARINGS CAN RESULT IF A POSITIVE INDICATION OF OIL PRESSURE IS NOT OBTAINED BY THE TIME THE IDLE SPEED IS REACHED.

c) Residual TOT should be no more than $150^{\circ} \mathrm{C}$ when lightoff is attempted.

(Residual TOT can be easily reduced to or below $150^{\circ} \mathrm{C}$ by motoring engine with the starter.)

d) Energize the starter motor and ignition exciter.

e) As $\mathrm{N}_{1} \mathrm{rpm}$ accelerates through $12-15 \% \mathrm{~N}_{1}$, move the throttle to the IDLE detent to begin fuel flow.

NOTE: Do not wait for $\mathrm{N}_{1}$ peak out. Introduce fuel immediately upon reaching desired $N_{1}$ speed. Delay in moving the throttle to idle detent may diminish battery capacity early in the start cycle.

CAUTION: A START SHOULD NOT BE ATTEMPETED AT $\mathrm{N}_{1}$ SPEEDS BELOW 12\%. STARTING AT $\mathrm{N}_{1}$ SPEEDS LESS THAN 12\% INCREASES THE POSSIBILITY OF EXCEEDING ENGINE TEMPERATURE LIMITS.

FOR ENGINE INCORPORATING LOW ENERGY EXCITERS, OPERATING TIME LIMITS ARE AS FOLLOWS: 2 MINUTES ON, 3 MINUTES OFF; 2 MINUTES ON, 23 MIUTES OFF. HIGH ENERGY IGNITION EXCITERS ARE QUALIFIED FOR CONTINUOS DUTY OPERATION. HOWEVER, USE OF THE IGNITION SYSTEM ON A CONTINUOS BASIS IS NOT RECCOMENDED BACAUSE OF DEGRADATION OF THE SPARK IGNITER.

f) De-energize the starter and ignition when $58 \% \mathrm{~N}_{1}$ speed is reached. The start is completed when a stabilized $\mathrm{N}_{1}$ speed of $59-65 \%$ is reached. Completion of the start normally occurs 25 to 60 seconds after starter engagement. A positive indication of oil pressure must be obtained by this point in the start. If it is not, shut down the engine and check to be sure that oil is available at the power and accessory gearbox inlet. Monitor the measured gas temperature; do not exceed limits given in above table.

If the start is aborted turn the throttle to FUEL OFF and motor the engine for 10 seconds without ignition

\section{$\underline{\text { RESTART }}$}

a) Emergency Restart:

When immediate power restoration is required, make an emergency restart by energizing the starter within 10 seconds after power loss occurs. 
NOTE: $\quad \mathrm{N}_{1}$ will not decrease below minimum starting speed within 10 seconds because of rotational inertia plus possible ram effect. The throttle can be left in the open position since fuel flow during the start will be on the normal acceleration schedule.

CAUTION: DUE TO THERMAL CHANGES WITHIN THE TURBINE, THA GAS PRODUCER SECTION OF THE ENGINE MAY LOCK UP AFTER AN "INFLIGHT" SHUTDOWN. THIS IS A TEMPORARY CONDITION WHICH EXISTS AFTER THE ENGINE HAS BEEN SHUT DOWN FOR APPROXIMATELY ONE MINUTE AND WHICH MAY CONTINUE FOR UP TO TEN MINUTES FOLLOWING THE SHUTDOWN. THEREFORE, EXCEPT DURING AN EMERGENCY, AIR START SHOULD NOT BE ATTEMPTED DURING THE TIME PERIOD BETWEEN ONE MINUTE AFTER SHUTDOWN AND TEN MINUTES AFTER SHUTDOWN.

b) Normal Restart:

Make normal restart as follows:

a. With the throttle in FUEL OFF, energize the starter and ignition exciter.

b. At the desired $\mathrm{N}_{1}$ speed position the throttle in the full open position. Use the following guide to determine desired $\mathrm{N}_{1}$ starting speed versus outside air temperature.

$15 \% \mathrm{~N}_{1}$ rpm above $7^{\circ} \mathrm{C}$ $13 \% \mathrm{~N}_{1}$ rpm minus 18 to plus $7{ }^{\circ} \mathrm{C}$ $12 \% \mathrm{~N}_{1} \mathrm{rpm}$ below minus $18^{\circ} \mathrm{C}$

c. De-energize the starter at $58 \% \mathrm{~N}_{1}$ speed.

ENGINE STOPPING

WARNING: OVERTEMPERATURE STARTS OR AFTERFIRES AFTER SHUTDOWN WILL CAUSE CRACK IN THE TURBINE FIRST-STAGE WHEEL RIM. THESE CRACKS CAN EVENTUALLY CAUSE A SECTION OF THE WHEEL TO BREAK OFF, CAUSING TURBINE IMBALANCE AND ENGINE FAILURE.

CAUTION: FOR THE ULTIMATE SAFETY OF ALL PERSONNEL WHO COME IN CLOSE PROXIMITY WITH THE ENGINE IN THE FUTURE, IT IS THE RESPONSIBILITY OF THE PERSON(S) OPERATING THE ENGINE TO RECORD AND TAKE RECOMMENDED CORRECTIVE ACTION WHEN OVERTEMPERATURE OCCURS. 
a) Normal Shutdown

a. Position the throttle to the IDLE position

CAUTION: IDLE DWELL TIME PRIOR TO SHUT DOWN IS IMPORTANT TO PREVENT HARMFUL ACCUMULATION OF CARBON IN THE ENGINE WHICH CAN RESULT IN ENGINE FAILURE.

b. Maintain the engine at $59-65 \% \mathrm{~N}_{1}$ speed for a minimum of two minutes prior to shutdown.

NOTE: TOT at Ground Idle may be higher than those experienced at higher throttle settings.

c. Position throttle in FUEL OFF. Monitor TOT until $N_{1}$ rotation has stopped.

d. Turn off all engine switches.

CAUTION: AN ENGINE FIRE (RECOGNIZED BY A RAPID INCREASE IN TOT) CAN OCCUR DURING SHUTDOWN IF FUEL CUTOFF IS NOT COMPLETE. IF A SHUTDOWN FIRE OCCCURS, IMMEDIATELY ENGAGE THE STARTER AND MOTOR THE ENGINE TO MINIMIZE THE TEMPERATURE ENCOUNTERED. TO EXTINGUISH THE FIRE, CONTINUE TO MOTOR THE ENGINE USING THE STARTER WITH THE THROTTLE FULLY CLOSED AND THE MAIN FUEL SWITCH OFF. THE TEMPERATURE LIMITATIONS AND MAINTENANCE ACTION GIVEN PREVIUSLY MUST BE OBSERVED.

e. Monitor instrumentation to ensure that shutdown has occurred. To ensure throttle cutoff, hold in the closed position until $\mathrm{N}_{1}$ speed is zero and TOT has stabilized. 